\title{
Anaphoric Dependencies in Spanish and European Portuguese A Minimalist Analysis
}

Anja Weingart

Göttingen 2020 



\title{
Anaphoric Dependencies in Spanish and European Portuguese: A Minimalist Analysis
}

\author{
Dissertation \\ zur Erlangung des philosophischen Doktorgrades \\ an der Philosophischen Fakultät der \\ Georg-August-Universität Göttingen
}

\author{
vorgelegt von \\ Anja Weingart \\ aus München
}

Göttingen 2020 



\section{Table of Contents}

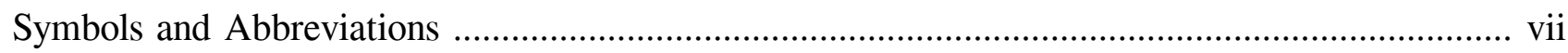

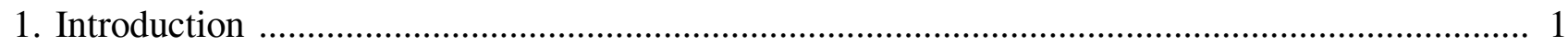

1.1 Binding Theory: Le roi est mort, vive le roi ! .................................................................. 2

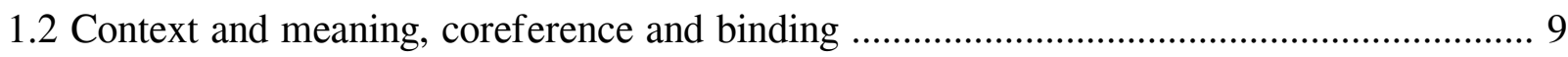

1.3 Basic theoretical assumptions: the probe-goal framework ............................................. 14

1.4 The Ibero-Romance perspective: topic and structure ................................................. 18

2. Basic syntax of pronouns in Spanish and European Portuguese ............................................ 23

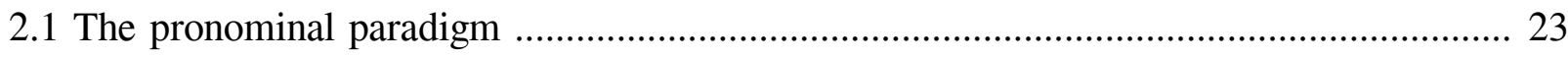

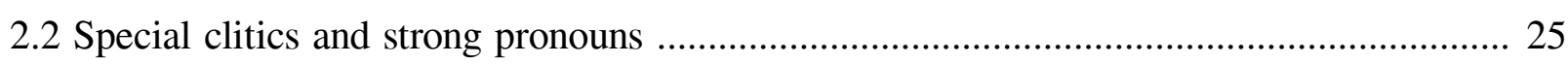

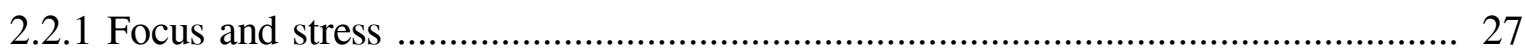

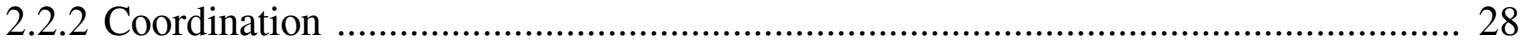

2.2.3 Clitic clusters and the Person-Case Constraint ............................................... 29

2.2.4 Clitic placement: proclisis and enclisis ......................................................... 32

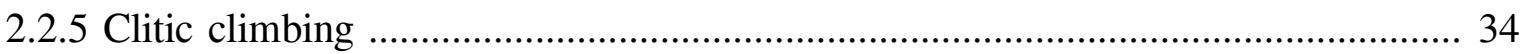

2.2.6 Clitic doubling and object marking …............................................................ 35

2.2.7 Approaches to clitic syntax in a nutshell ........................................................... 43

2.3 Reflexive and non-reflexive uses of the clitic se ......................................................... 44

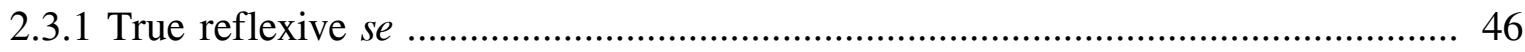

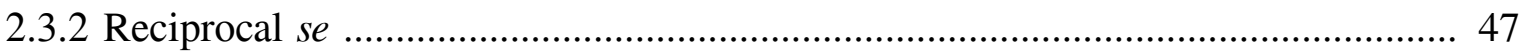

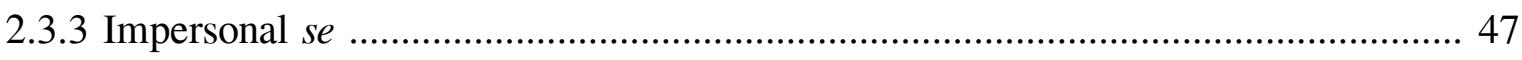

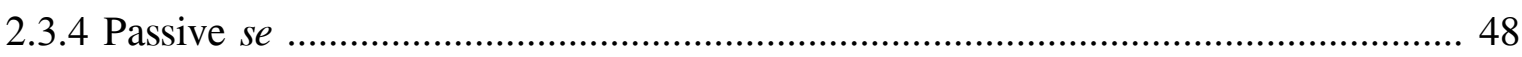

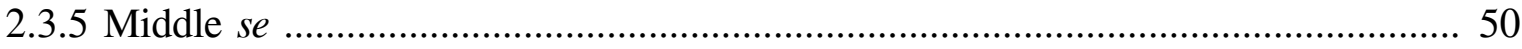

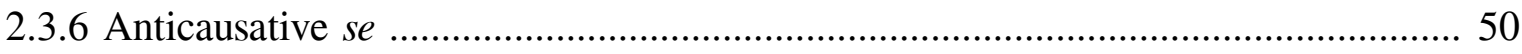

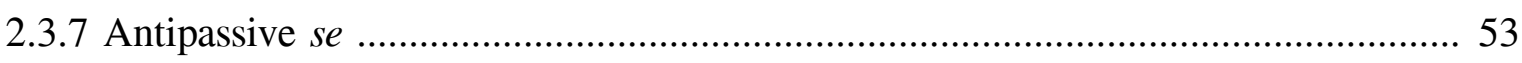

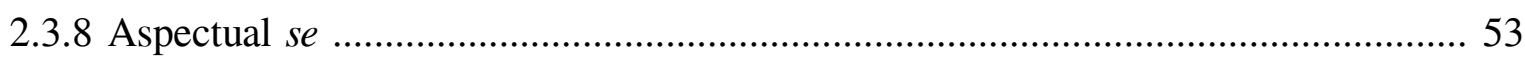

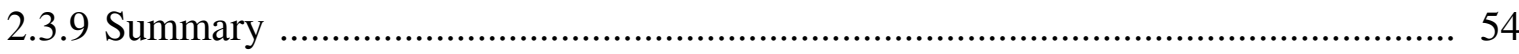

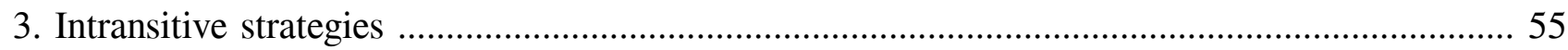

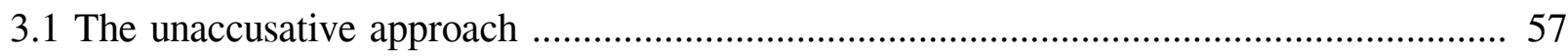

3.1.1 Parallels between passive, unaccusative, and reflexive predicates ....................... 57

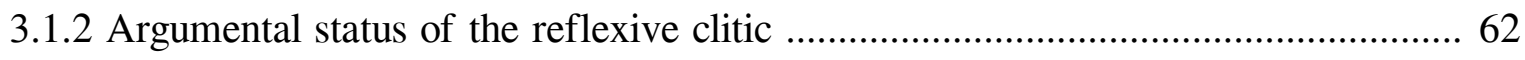

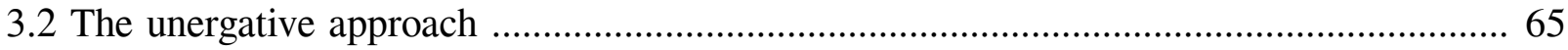

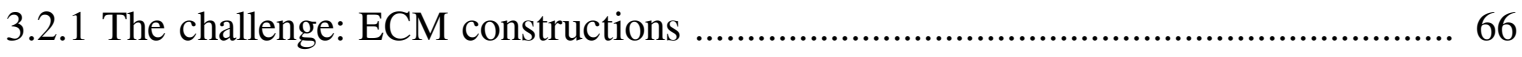

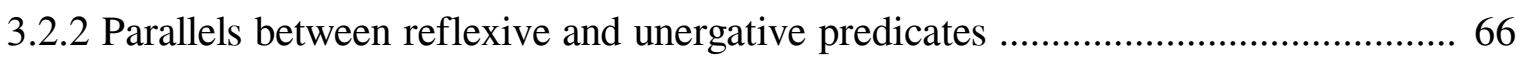

3.2.3 The reflexive clitic is not an argument .......................................................... 72

3.3 Evaluation and additional evidence in favour of a transitive approach .......................... 75

3.3.1 True reflexive clitics ain’t no case-dummies! ................................................... 75 
3.3.2 Bare postverbal subjects 77

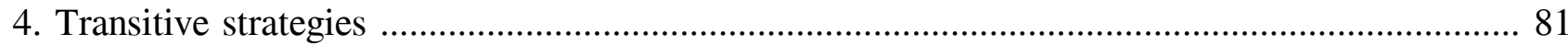

4.1 Referential identity created by Internal Merge ….................................................... 81

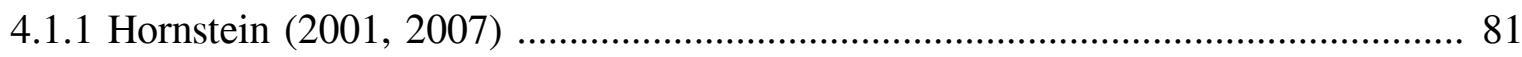

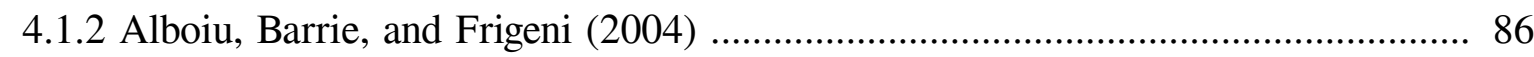

4.2 Referential identity created upon External Merge ...................................................... 89

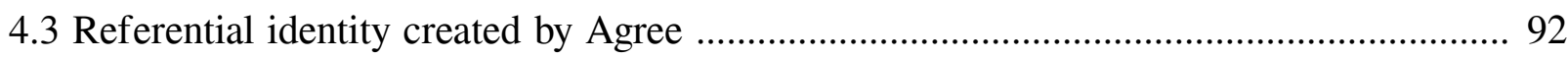

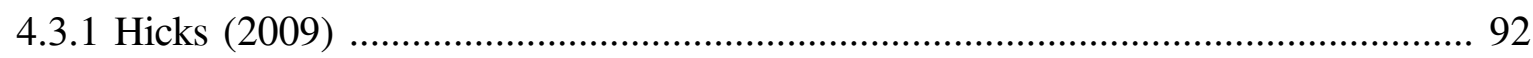

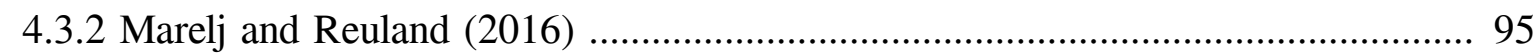

5. Referential properties of direct and indirect object pronouns …......................................... 101

5.1 Clitic doubling: disambiguation and focus ............................................................. 102

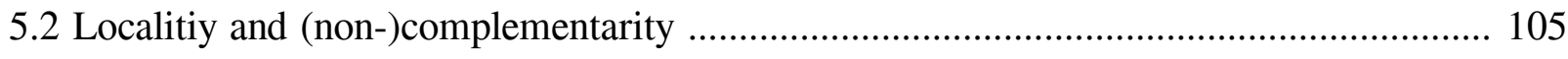

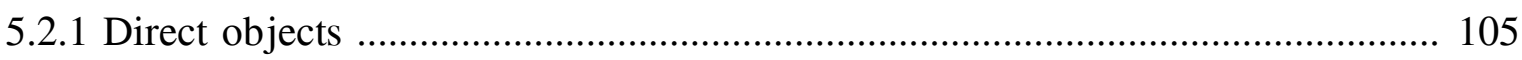

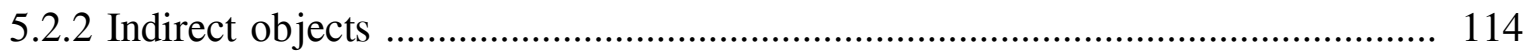

5.2.3 Clitic doubling and long-distance anaphora ............................................... 122

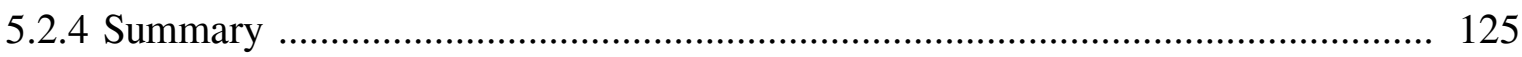

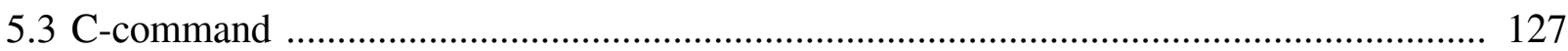

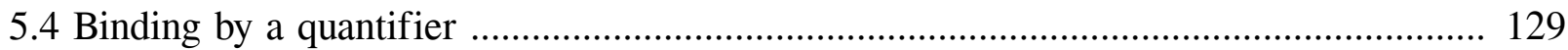

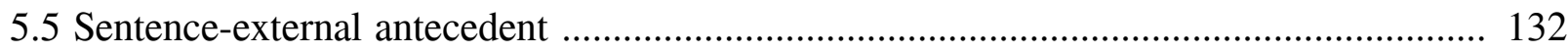

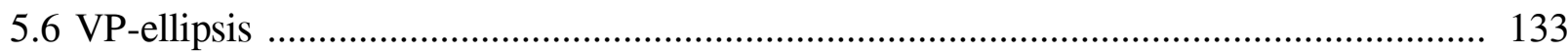

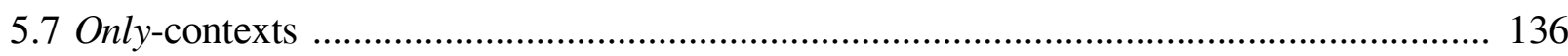

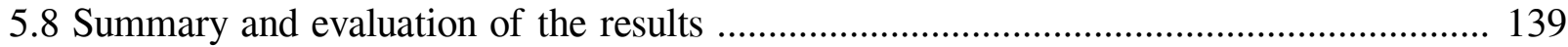

6. Referential deficiency and structural deficiency ........................................................... 143

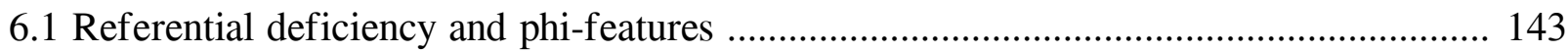

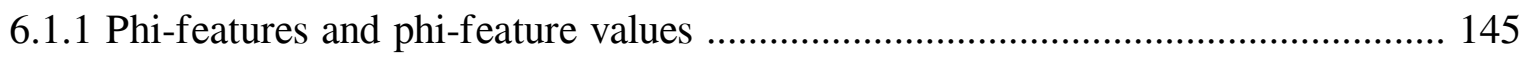

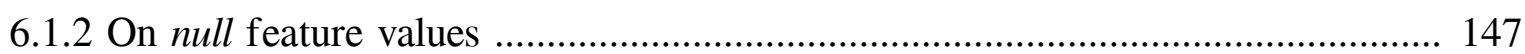

6.1.3 On Agree with null phi-feature values ........................................................... 155

6.2 Structural deficiency: the internal structure of clitics and strong pronouns ...................... 156

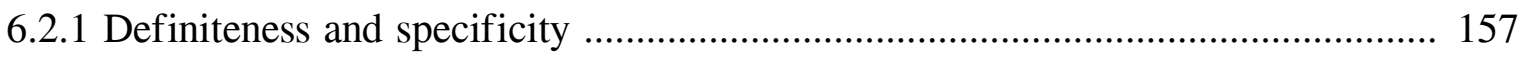

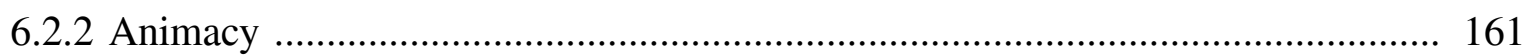

6.3 A brief syntax of mismo and mesmo/próprio ............................................................... 165

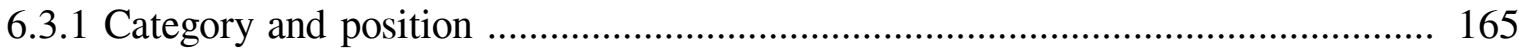

6.3.2 Agreement between the strong pronoun and the intensifier ............................. 167

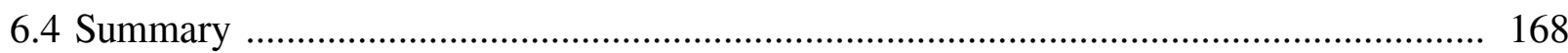

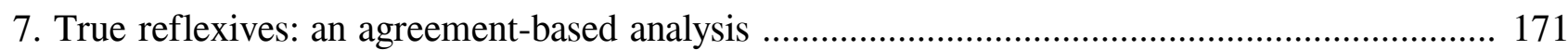

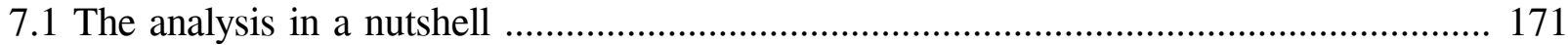

7.2 Cliticisation by agreement: Roberts (2010) ......................................................... 172 
7.3 Clitic doubling: the bigDP and the Matching Principle ............................................ 177

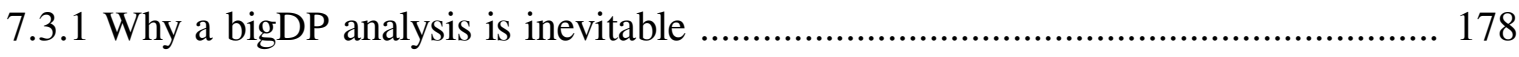

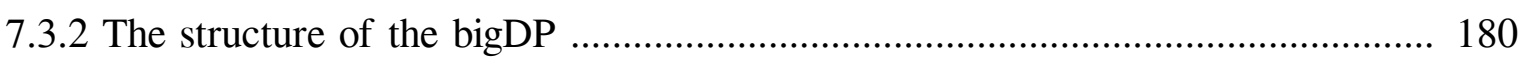

7.3.3 Match under Merge/Select: identity of features and feature values ...................... 188

7.4 Encoding reflexivity: downward Agree and upward valuation ...................................... 191

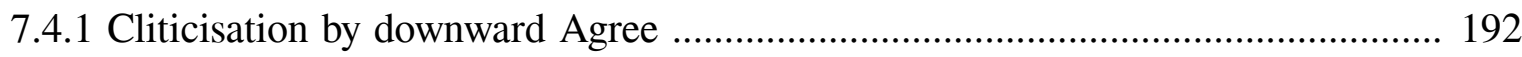

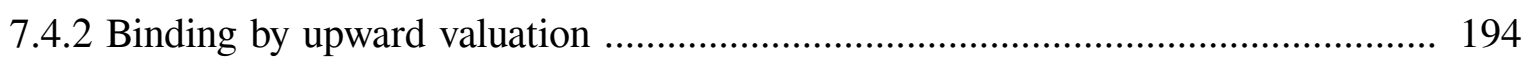

7.5 Reflexive subjects and the Anaphor Agreement Effect ............................................. 199

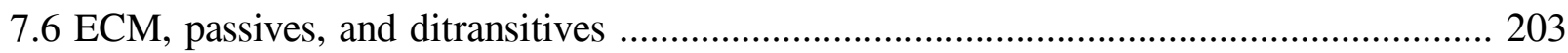

7.7 Agreement between the strong pronoun and the intensifier ......................................... 208

8. Referential properties of pronouns inside prepositional phrases ........................................ 211

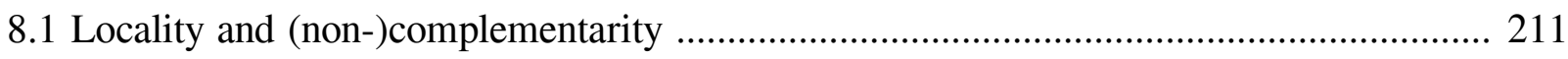

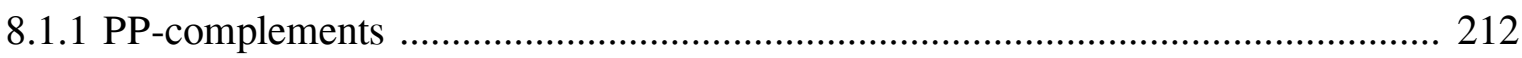

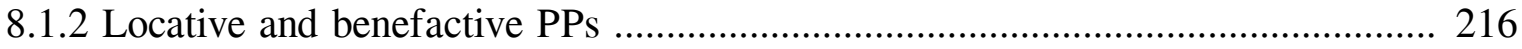

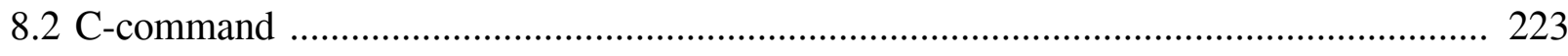

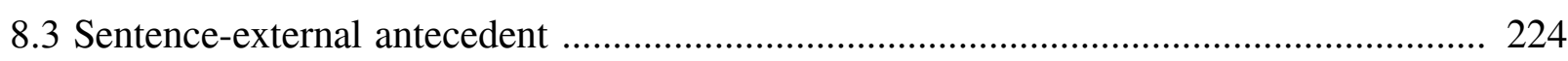

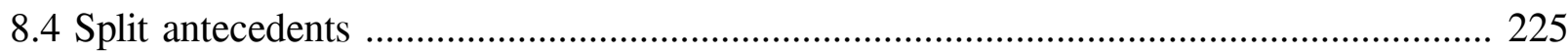

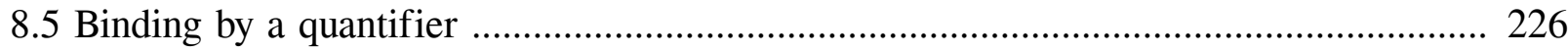

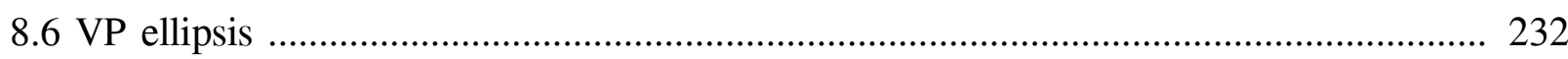

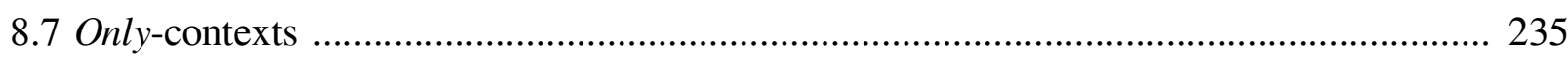

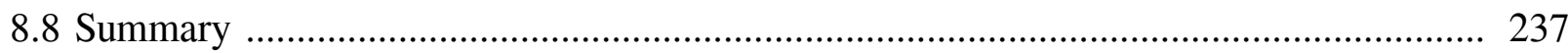

9. On the interpretation of pronouns and intensifiers ...................................................... 241

9.1 Pronouns at the syntax-semantics interface .............................................................. 242

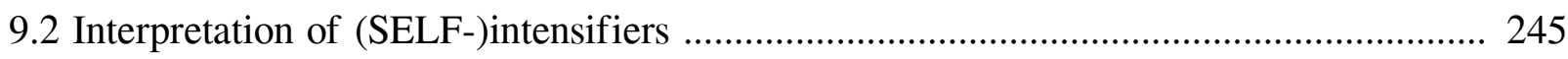

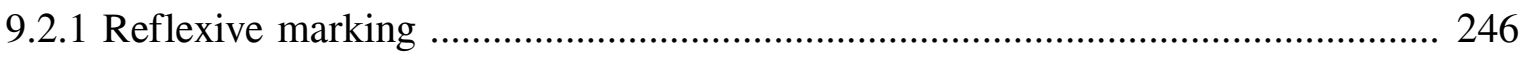

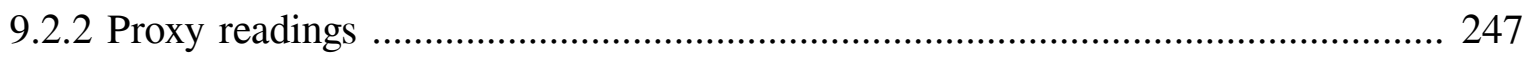

9.2.3 Adnominal intensifiers, actor-oriented intensifiers, and focus ........................... 250

9.3 On the interpretation of the reflexive intensifiers mismo and mesmo/próprio .................. 256

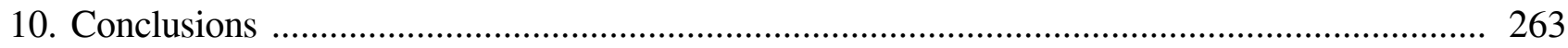

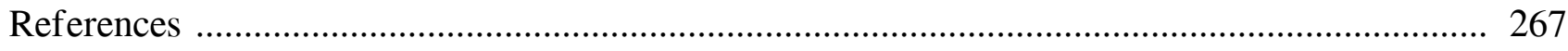

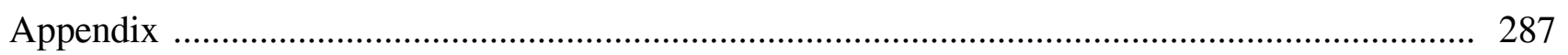





\section{Symbols and Abbreviations}

* ungrammatical sentence

?? not fully ungrammatical sentence

? degraded sentence

$\% \quad$ contradictory acceptability judgements from native speakers

\# infelicitous sentence

*() ungrammatical in the absence of the parenthesised material

(*) ungrammatical in the presence of the parenthesised material

aca. anticausative/inchoative

acc. accusative case

apa. antipassive

applP applicative phrase

AP adjective phrase

asp. aspectual

BT Binding Theory

cl. clitic pronoun

CP complementiser phrase

dat. dative case

DO direct object

DOC double object construction

DP determiner phrase

DPC dative prepositional construction

EM external Merge

fem. feminine gender

GB Government and Binding Theory

i interpretable feature

IM internal Merge

imp. impersonal

IO indirect Object

KP case phrase

LI lexical item

masc. masculine gender

mid. middle voice

nom. nominative case

NP noun phrase

obl. oblique case

OM object marker, the 'preposition' $a$ 


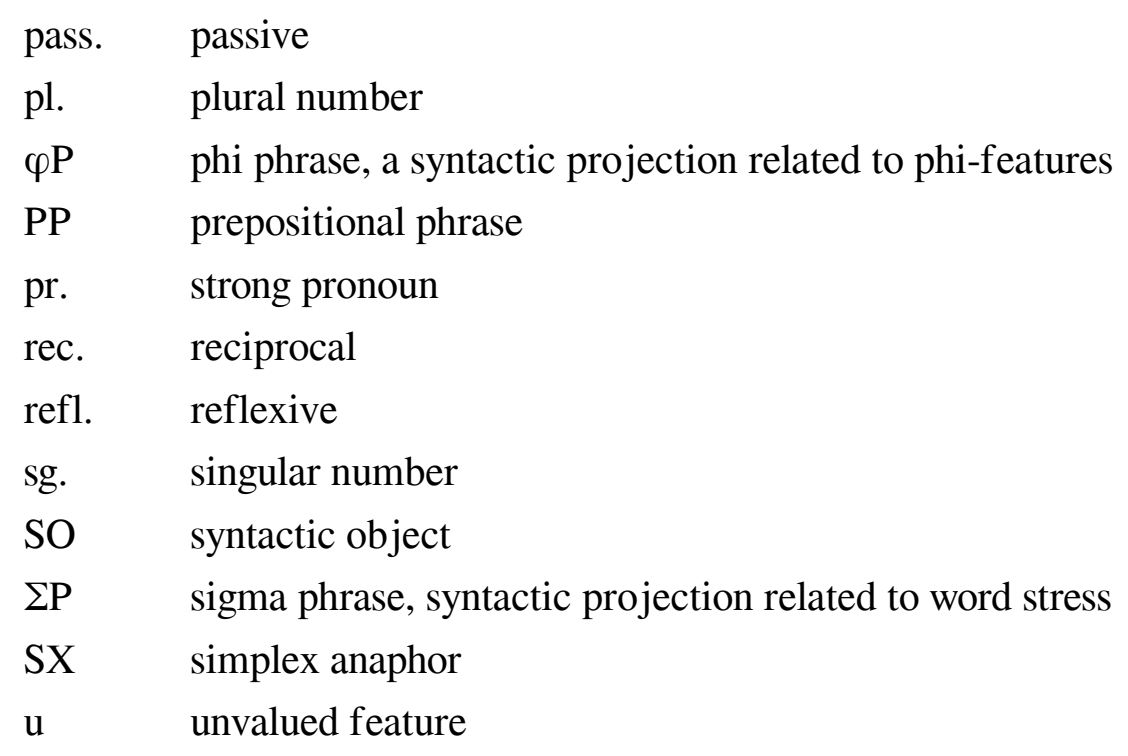




\section{Introduction}

This book is about anaphoric relations in Spanish and European Portuguese. Before I go into some of the theoretical bases and outline the structure of this introduction, let us briefly look at what anaphoric relations are. An anaphoric relation holds between two linguistic expressions if the interpretation of one expression is determined by the expression preceding it. The preceding expression is called the antecedent and the other expression is called the anaphor, which is typically a pronoun. For example, the pronoun she in (1) picks up the reference of the DP Rita, its antecedent. In (1a) the antecedent is within the same sentence: it is sentence-internal. In (1b) it is mentioned in the preceding sentence; it is sentence-external. The numerical indices annotate the intended reference of the expressions. If two expressions bear the same index, they are meant to have the same referent. If they have different indices, disjoint reference is intended.

(1) a.

Rita $_{\mathrm{i}}$ said that she $\mathrm{i}_{\mathrm{i} / \mathrm{k}}$ likes ice cream.

b. $\quad$ Rita $_{\mathrm{i}}$ is a girl. She $\mathrm{i}_{\mathrm{i} / \mathrm{k}}$ likes ice cream.

In both sentences in (1) the reference of the pronoun is construed following principles of discourse pragmatics like salience or accessibility, but only in (1a) is the anaphoric relation additionally constrained by lexical and morphosyntactic factors.

This book will be concerned with the lexical and morphosyntactic factors that constrain sentence-internal anaphoric relations in the standard varieties of Peninsular/Castilian Spanish (Sp.) and European Portuguese (EP), two Ibero-Romance null-subject languages. English examples will often be used for the purpose of illustration. The focus lies on anaphoric relations that involve reflexive and nonreflexive object pronouns. Resumptive uses of pronouns as well as demonstrative pronouns or forms of polite address will not be considered here. The pronominal syntax of Spanish and European Portuguese is particularly interesting for the study of anaphoric relations because both languages have obligatory clitic doubling of reflexive and non-reflexive pronouns. Other Romance languages such as (Standard) French and Italian have clitic pronouns, but no clitic doubling of reflexive and non-reflexive pronouns. The fact that reflexive and non-reflexive pronouns show a parallel (clitic doubling) syntax in Spanish and European Portuguese will allow for a parallel syntactic analysis of both types of pronouns, and, as we will see, for a Minimalist derivation of anaphoric relations.

Within Generative Grammar, the theoretical framework adopted in this book, the lexical and structural conditions on anaphoric relations have been accounted for with the Binding Theory (BT). Binding Theory was developed on the basis of English language data in Chomsky (1980) and modified in Chomsky (1981, 1986, 1995a). Within the Government and Binding (GB) framework introduced in Chomsky $(1981,1986)$, BT became an integral part of Universal Grammar, and its principles have been applied at all levels of thematic, syntactic, and semantic representation. The GB version of BT was most influential because it covers basic aspects of anaphoric relations and movement-based phenomena in many languages, including Spanish and European Portuguese. But GB-BT has also been 
shown to be empirically highly problematic not only for languages with a more articulated pronominal system than English, such as Dutch or the Romance languages, but also for English itself (see Reinhart \& Reuland 1991, 1993, and Rizzi 1990). In Chomsky (1995a), BT has been assessed according to Minimalist considerations with the result that the principles of BT are untenable as part of core grammar (syntax). The Minimalist turn as well as the empirical problems of GB-BT inspired ongoing research, in particular concerning the question as to whether an anaphoric relation is indeed established exclusively by semantic and discourse pragmatics or whether it is established by syntactic means. For English and other Germanic languages, movement-based and agreement-based analyses have been put forward in Hornstein (2001, 2007), Zwart (2002) Hicks (2009), Boeckx et al. (2010), Reinhart (2006), and Reuland (2011). For Romance languages, the Minimalist analyses of Alboiu et al. (2004), Reinhart \& Siloni (2004, 2005), and Marelj \& Reuland (2016) are mainly based on French and Italian. This book provides an Ibero-Romance perspective to this Minimalist programme for Binding Theory, and the topics discussed are centred on the role syntax plays for the interpretation of pronouns in Spanish and European Portuguese.

Section 1.1 of the introduction presents the central aspects of Binding Theory and presents the research programme for a Minimalist theory of anaphoric relations. Section 1.2 discusses the syntactic and semantic uses of the notions binding and coreference. This section provides the information necessary to understand the discussion in the main body of the disseration as well as the interpretive and structural diagnostics applied to Spanish and European Portuguese in order to tell a syntactic encoding apart from a semantic and discourse pragmatic encoding of an anaphoric dependency. Section 1.3 spells out the general theoretical assumptions of the probe-goal framework that I will adopt for the analysis of Spanish and European Portuguese pronominal morphosyntax. Section 1.4 highlights the importance of a Romance perspective for a Minimalist binding theory and gives an overview of this book.

\subsection{Binding Theory: Le roi est mort, vive le roi !}

The aim of the Binding Theory is to derive the interpretation and the distribution of nominal expressions from their lexical properties. The general reasoning behind BT will be briefly introduced by means of the examples in (2). The sentences in (2a)-(2c) contain a reflexive pronoun, a non-reflexive pronoun, and a definite DP, respectively. Compare the interpretation of the two types of pronouns: the reflexive pronoun is associated with the subject DP Rita and is incapable of independent reference to a clauseexternal antecedent such as the DP Marta in $\left(2 a^{\prime}\right)$. Furthermore, it is incapable of reference to any other salient, sentence-external antecedent. The non-reflexive pronoun in (2b) and ( $\left.2 b^{\prime}\right)$ shows exactly the opposite pattern. It cannot be associated with the clause-internal antecedent, the DP Rita. But it can refer independently to a clause-external antecedent, the DP Marta in (2b'), in addition to any salient antecedent present in discourse. An anaphoric interpretation of the definite DP in (2c) and $\left(2 c^{\prime}\right)$ seems to be impossible in any case. 


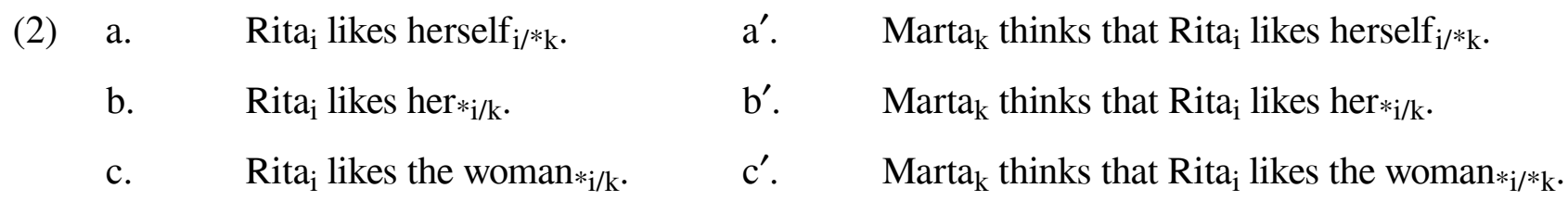

Based on these interpretive characteristics, Chomsky $(1980,1981)$ defines three types of nominal expressions: $R$ (referential)-expression, pronominal, and anaphor. ${ }^{1}$ These types are labels for a lexical property, which in Chomsky (1980) has been conceived as a kind of instruction for the interpretation of each type of nominal. In GB Binding Theory, these instructions became the binding principles listed in (3).

$$
\text { Binding Principles (GB) }
$$

(Chomsky 1981:188)
A An anaphor is bound in its governing category.
B A pronoun is free in its governing category.
C An R-expression is free.

The three types are associated with two modes of interpretation: bound and free. These modes are dependent on a syntactic domain, to be discussed below. Note that the terms bound and free are also used in semantic accounts, but with distinct definitions and implications, as will be explained in the next section. Starting with the terms bound and free, the definitions are given in (4).

$$
\text { Bound and Free (GB) }
$$

(Chomsky 1980:10)

We say that an anaphor $\alpha$ is bound in $\beta$ if there is a category c-commanding it and coindexed with it in $\beta$; otherwise, $\alpha$ is free in $\beta$.

The definition of bound contains two conditions: (i) coindexation, which indicates that the pronoun and its antecedent have the same referent, and (ii) the structural relation c-command, which concerns the position of the antecedent. The c-command conditions will remain central for syntactic and semantic accounts of anaphoric relations. Note that a free pronoun in the sense of BT may still become bound in the semantic sense of binding, as will be introduced in section 1.2.

As for coindexation, it represents the interpretive dependency, or more precisely, a referential identity relation. In Chomsky $(1973,1980)$ indexing was conceived as a mechanism that applies postsyntactically to the semantic representation of a sentence. Each lexical item in a sentence is indexed by an algorithm, and co-indexation is established or blocked by means of two rules of Construal: Bound Anaphora and Disjoint Reference Rule, respectively (see Chomsky 1980:39ff and Lasnik 1976:14). In GB, the referential indices are part of each lexical item, and for this reason an indexed syntactic structure is generated without the need for a particular indexing operation. This indexed syntactic structure

1 In GB, the labels have been associated with a set of binary features [+/-anaphoric] and [+/-pronominal]. This offered an interesting way to additionally account for the distribution of empty nominal categories such as movement traces and the covert pronoun PRO. 
is evaluated by the Binding Principles at different levels of representation. For example, coindexation of the anaphor in (2a') with the DP Marta is ruled out by Principle A. The principles are well-formedness conditions on somehow arbitrarily (co)indexed structures, whereas coindexing in pre-GB binding is generated or blocked by means of a mechanism or an operation.

In the Minimalist framework, indices have been eliminated on conceptual grounds by the Inclusiveness Condition, ${ }^{2}$ and the Binding Principles have been revised accordingly, as shown in (5).

$$
\text { Binding Principles (MP) }
$$

(Chomsky 1995a:194)

A If $\alpha$ is an anaphor, interpret it as coreferential with a c-commanding phrase in D.

B If $\alpha$ is a pronominal, interpret it as disjoint from every c-commanding phrase in D.

$\mathrm{C}$ If $\alpha$ is an r-expression, interpret it as disjoint from every c-commanding phrase.

The terms bound and free have been replaced with coreferential and disjoint, and reference to indices is avoided. Note that this terminological manoeuvre obscures the following fact. Indices have been essential for the generation or evaluation of an interpretive dependency and now they have simply vanished as a technical device. Chomsky (1995a:199, fn. 53) proposes that the relation annotated by indices should be 'replaceable without loss by a structural account'. For example, the Copy Theory of movement replaced indices and NP traces. But what about the anaphoric relations discussed so far? Chomsky (1995a:193/194) mentions two possibilities. First, the binding principles in (5) are instructions for interpretation, while coreference or disjoint reference is established at the semantic component of human language. This means that the 'coindexation problem' is delegated to semantics. Additionally, he points out that syntactic operations such as movement may be involved in the generation of an anaphoric dependency. Exploration of the latter possibility is the central concern of Minimalist approaches to Binding Theory. I will come back to this point below.

What remained unchanged in all versions of the binding principles put forward in Chomsky $(1980,1981,1986,1995 a)$ is the interdependence between a nominal type, a mode of interpretation and a syntactic domain. This syntactic domain is termed 'governing category' in (3), the domain $\beta$ in (4), and the domain D in (5). For example, Principle A and B state that an anaphor has to be bound/ coreferential in exactly the same domain in which a pronominal has to be free/disjoint in reference. This is an elegant way to account for the differences between the reflexive pronoun and the non-reflexive pronoun in (2) above. In the domain, let us say the TP, the anaphor has to be bound, but the pronoun has to be free. The definition of the binding domain has been revised several times in Chomsky's work. The details will not be discussed because the definitions make use of technical notions that are obsolete in the Minimalist framework. A discussion of these technical details would just draw attention away from the predictions made by all versions of BT.

\footnotetext{
2 "A "perfect" language should meet the condition of inclusiveness: any structure formed by the computation is constituted of elements already present in the lexical items selected for $\mathrm{N}$ (numeration); no new objects are added in the course of computation apart from rearrangements of the lexical properties (in particular, no indices, bar levels in the sense of X-bar Theory, etc.).' Chomsky (1995a:209)
} 
The first prediction is that anaphors and pronominals, if they appear in the same syntactic configuration, can never take the same antecedent. In this case we say that anaphors and pronouns are in complementary distribution, as for example in (2) above. However, this prediction is not borne out crosslinguistically, as shown in (6). The pronouns in (6) are inside a PP-complement in all three languages. This means that the pronouns are in the same syntactic environment, but that complementary distribution only holds in English, not in Spanish and European Portuguese.

(6) a. She ${ }_{\mathrm{i}}$ only thinks about herself $\mathrm{i}_{\mathrm{i}} /$ her $_{\mathrm{i}}$.

b. Sp. Ella $a_{\mathrm{i}}$ solo piensa en $\mathrm{sí}_{\mathrm{i}} /$ en ella $\mathrm{a}_{\mathrm{i}}$.

c. EP Ela $\quad$ só pensa em $\mathrm{si}_{\mathrm{i}} /$ nela $_{\mathrm{i}}$.

The locative adjunct PPs in (7) are an environment in which the reflexive and non-reflexive pronouns are not in complementary distribution in any of the three languages. This problematic fact has already been noted in Chomsky (1981:290) for English and for Spanish and European Portuguese in Otero (1999) and Menuzzi (1999), among others.

(7) a. She $\quad$ saw a snake next to herself ${ }_{\mathrm{i}} /$ her $_{\mathrm{i}}$.

b. Sp. Ella $a_{\mathrm{i}}$ vio una serpiente cerca de sí $\hat{i}_{\mathrm{i}} / \mathrm{de}$ ella $\mathrm{a}_{\mathrm{i}}$.

c. EP Ela $\mathrm{i}_{\mathrm{i}}$ viu uma serpente perto de $\mathrm{si}_{\mathrm{i}} / \mathrm{dela}_{\mathrm{i}}$.

Furthermore, in environments in which complementary distribution does not hold, anaphors can also take non-local and non-c-commanding antecedents, as in (8). This kind of long-distance anaphor or exempt anaphor has been discussed in, for example, Campos (1995), Reinhart \& Reuland (1991, 1993), Reuland (2011), and Büring (2005), just to mention a few.

The picture of herself $\mathrm{i}_{\mathrm{i}} /$ her $_{\mathrm{i}}$ on the front page of the Times confirmed the allegation Mary $y_{i}$ had been making over the years.

(Pollard \& Sag 1992:264)

In certain domains_-PPs and so-called picture-NPs_-anaphors and pronominals can take the same antecedent without being subject to structural conditions. Does this mean that anaphors and pronominals are interpreted in the same way? Following the Binding Principles the answer would be that both types are interpreted as coreferential with their antecedent in the examples (6)-(8). But this cannot be true, as shown in (9). The reflexive pronoun and the non-reflexive pronoun are not interpreted in the same way, even if they are not in complementary distribution. The non-reflexive pronoun allows for a coreferent interpretation with the sentence-external antecedent, but the reflexive pronoun does not. The reflexive pronouns do not have the same range of interpretive freedom.

(9) a.

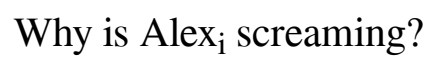

Paul $_{\mathrm{k}}$ said he $\mathrm{k}$ saw a spider near himself $*_{\mathrm{i} / \mathrm{k}} / \mathrm{him}_{\mathrm{i} / \mathrm{k}}$. 
b.

Do you know Peter $_{\mathrm{i}}$ ?

Yes, and Mary said that she had seen a picture of $*$ himself $_{\mathrm{i}} / \mathrm{him}_{\mathrm{i}}$ in the paper.

(Campos 1995:30)

BT does not cover the fact that the reflexive pronoun and the non-reflexive pronoun are interpreted differently. In section 1.2 some diagnostics will be introduced that help determine the way pronouns are interpreted in non-complementary contexts.

In those cases in which complementary distribution holds, BT runs into problems if a language has more than one type of anaphor, such as Dutch, for example. Consider the examples in (10) taken from Reuland (2011:100-101). The pronominal hem and the anaphors zich/zichzelf are in object position and both are c-commanded by the subject DP Willem. They are in the same domain and, as predicted by BT, the anaphors take the DP Willem as antecedent, while the pronominals are ungrammatical with such an interpretation. But BT does not account for the fact that the complex anaphor zichzelf is unacceptable in (10a) and the simplex anaphor zich is unacceptable in (10c), whereas both types of anaphors are possible in (10b).

(10) a. D

c.

Willem $_{\mathrm{i}}$ bewondert zichzelf $_{\mathrm{i}} / *_{\text {zich }_{\mathrm{i}} .}$ '
W. $\quad$ admires $\quad \operatorname{SXSELF} / * \mathrm{SX}$
'Willem admires himself.'

$\mathrm{a}^{\prime} . \quad *$ Willem $_{\mathrm{i}}$ schaamt hem $_{\mathrm{i}}$.

W. shames him

'\#Willem is ashamed of him.'

$\mathrm{b}^{\prime} . \quad *$ Willem $_{\mathrm{i}}$ wast $\quad$ hem $_{\mathrm{i}}$.

W. washes him

'\#Willem washes him.'

*Willem bewondert hem $_{\mathrm{i}}$.

W. admires him

'\#Willem admires him.'

These data suggest that the Dutch anaphors are subject to more fine-grained structural constraints than 'a c-commanding phrase in D'. At this point I want to briefly introduce the account presented in Reinhart \& Reuland (1991, 1993), Reinhart (2006), and Reuland (2011). These authors put forward an alternative theory that is similar to GB-BT in the sense that it is based on descriptive principles and rules. The technical details are not relevant for the present book, but I want to highlight the general reasoning behind their approach, because it harmonises—in my opinion—with the Minimalist Program and offers an interesting perspective on overcoming the coindexation problem as well as the domain problem of GB-BT.

Reinhart \& Reuland $(1991,1993)$ approach the domain problem from a semantic perspective. The domain in which anaphors and pronominals are in complementary distribution is the domain in which a reflexive predicate is formed. A predicate is reflexive if two arguments receive an identical interpretation (bound or coreferential in the terms of BT). The descriptive generalisation in (10) is that both types of anaphors are involved in the formation of a reflexive predicate and that the pronominal is excluded from this process. 
The formation of a reflexive predicate-or short reflexivisation-is a (lexical or syntactic) process that takes a transitive verb as input and transforms it into a reflexive predicate. In order to derive a reflexive predicate, languages employ quite distinct means, as observed by typological studies such as König \& Siemund (2000). Languages make use of intransitive strategies that affect the argument structure of a verb such as by valence reduction. Languages also make use of transitive strategies. In transitive strategies, specialised nominal expressions such as body-part expressions, reduplication of pronouns, or a reflexive pronoun are used. As for the Dutch examples above, the simplex form is taken to be a reflex of an intransitive reflexivisation strategy, making it incompatible with the transitive reflexive verb in (10c). The complex anaphor is involved in a transitive reflexivisation strategy and is not available with so-called inherent reflexive verbs, as in (10a).

Reinhart \& Reuland (1991, 1993) and Reuland (2001, 2011) argue that intransitive strategies involve formation of an A-chain created by movement or agreement. Lexical items such as zich are allowed as chain members because they are underspecified for phi-features and structural case. This chain is then interpreted as one single argument at the syntax-semantics interface, as shown in (11a). For the complex anaphor zichzelf, they argue that the reflexive predicate is formed by virtue of the lexical semantics of the affix -zelf. This element protects the second argument and assures an identical interpretation, as exemplified in (11b). Reuland (2011) assumes that protecting a variable involves movement of the zelf element. His approach will be discussed in more detail in sections 3.2.3.2 and 9.2.

(11)
a. Willem wast zich.
b. Willem wast zichzelf.
$a^{\prime}$.
Willem(x) wast(x)
$\mathrm{b}^{\prime} . \quad$ Willem(x) wast $\left(\mathrm{x}, \mathrm{x}_{\mathrm{SELF}}\right)$

In both strategies, an anaphoric dependency is generated by means of a syntactic process, and complementary distribution is the result of the inability of a pronoun to participate in that syntactic process. For example, the pronoun hem in $\left(10 a^{\prime}\right)$ and $\left(10 b^{\prime}\right)$ is excluded from chain formation because it is fully specified for phi-features and structural case. Furthermore, it lacks the zelf element, which is necessary for the identification of the two arguments of the transitive predicate bewonderen in (10c').

In order to distinguish a transitive encoding from an intransitive one, Reuland (2011) and Marelj \& Reuland (2016) use so-called proxy readings as a diagnostic. This reading has been observed in Jackendoff (1992). The sentence in (12) has two interpretations if uttered in an appropriate context, like a visit to the famous museum of Madame Tussauds (a museum that exhibits life-size wax figures of celebrities). The regular interpretation is given in (12a). The reflexive pronoun is associated with its antecedent - the person with the name Ringo-and is considered as non-referential. In (12b) the reflexive pronoun refers to the wax figure. This kind of interpretation has been called proxy reading, near-reflexive reading, or statue reading.

All of a sudden Ringo started to undress himself.

(Jackendoff 1992:4)

a.

'Ringo undressed the person-Ringo.'

bound reading

b.

'Ringo undressed his wax statue at Madame Tussauds.'

proxy reading 
Reuland (2011) and Marelj \& Reuland (2016) show that complex anaphors, but not simplex anaphors, allow for a proxy reading. This fact is interpreted as follows. The availability of a proxy reading indicates the presence of the second argument which can be associated with the proxy of the antecedent. The reflexive predicate thus has a transitive structure. If a proxy reading is unavailable, the second argument is not available and the reflexive predicate is intransitive.

Summarising, I want to present the reasons why the approach advocated by Reinhart \& Reuland (1991, 1993), Reuland (2001, 2005, 2011), and Reinhart (2006) is superior to BT. Their approach is more in the spirit of Minimalism because it assumes that the universal phenomenon is the reflexive interpretation of a predicate rather than a certain class of lexical items that is involved in the generation of a reflexive predicate. Syntax must be able to generate a syntactic object that satisfies the semantic requirements of a reflexive interpretation. More precisely, syntax must be able to generate an identity relation between two arguments of a predicate. The way this is done is subject to language-specific variation, in particular to variation with respect to the phi-feature content of the lexical items involved. The interpretation and distribution of pronouns in the context of complementary distribution is due to their morphosyntactic properties and the way they contribute to a compositional interpretation. The interpretation of pronouns in contexts of non-complementarity is a sign that no syntactic relation has been established. This has also been argued in Hornstein (2001, 2007), Zwart (2002) Hicks (2009), and Boeckx et al. (2010). In order to account for the interpretation of reflexive and non-reflexive pronouns in these contexts, Reuland (2001, 2011) and Reinhart (2006) propose that the anaphoric relation is established in the semantic component by means of variable binding or by means of pragmatic coreference.

A desired consequence of Reinhart \& Reuland's $(1991,1993)$ approach is that the terms anaphor, pronominal, and $R$-expression are no longer needed as interpretive instructions. Furthermore, the domain problem is resolved due to constraints on the syntactic operation involved in the generation of an anaphoric dependency. In the following, the terms anaphor and pronominal will only be used in the sense of Chomskyan Binding Theory, which will henceforth be referred to as classic BT.

This division of labour between the syntactic component and the semantic component can be represented as in (13). The syntactic component combines lexical items and generates a syntactic object. This syntactic object is translated into a semantic representation at the syntax-semantics interface. This semantic object is then interpreted and assigned a meaning. In principle, an anaphoric dependency can be established either in the syntactic component or in the semantic component. 


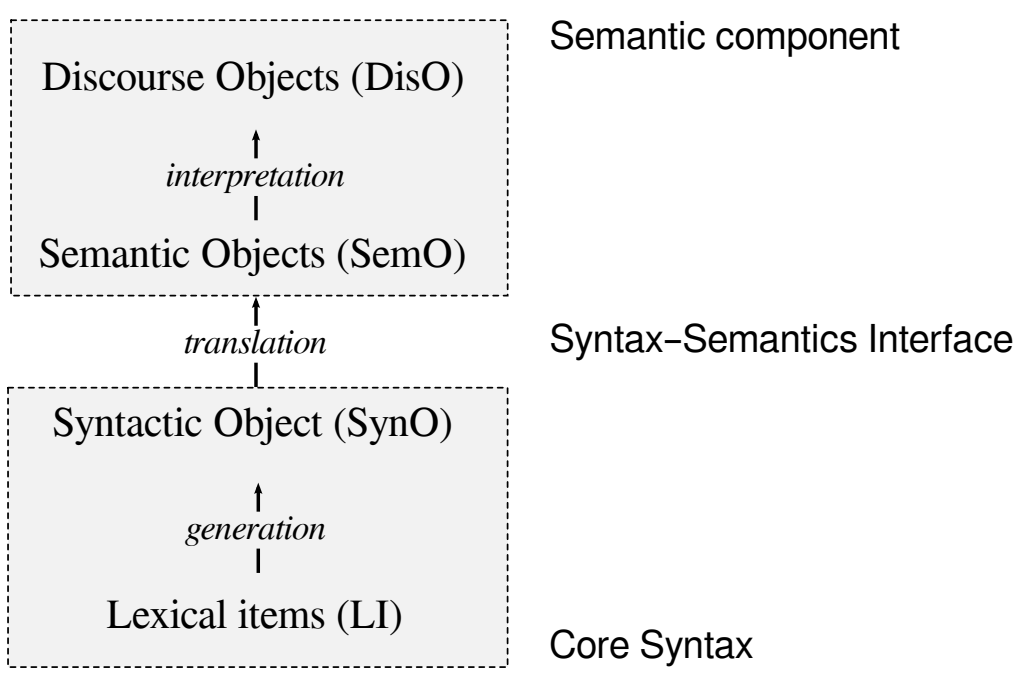

Reuland (2011:123ff) and Reinhart (2006:ch. 4) propose an economy hierarchy that manages the encoding at the distinct levels. If an anaphoric relation is encoded in syntax, this relation is translated accordingly at the syntax-semantics interface and cannot be altered in the semantic component. The same holds for the opposite situation. If syntax blocks such encoding, the anaphoric interpretation should not be 'sneaked in' by semantics. For example, the pronoun hem in $\left(10 \mathrm{a}^{\prime}\right)-\left(10 \mathrm{c}^{\prime}\right)$ should not be construed as a variable bound by the subject DP Willem or be interpreted as coreferential with the DP Willem. If syntax is not directly involved, an anaphoric relation can be established in the semantic component by means of variable binding or pragmatic coreference. The same reasoning holds here as well. If a relation is established by variable binding, it cannot be altered by pragmatic principles. If a variable binding is blocked, the dependency cannot be 'sneaked in'.

How the concepts of variable binding and pragmatic coreference are defined and how they can be distinguished will be introduced in the next section.

\subsection{Context and meaning, coreference and binding}

This section introduces the basic terminology necessary to describe and classify the interpretation of pronouns, in particular the notions coreference and variable binding. The general explanations are based on works of Löbner (2011), Lohnstein (2011), Speaks (2017), and Reimer \& Michaelson (2017).

Let us start with the term reference. It stands for a relation established between a linguistic expression, on the one hand, and objects or events in the world or in the universe of discourse, on the other hand. Reference is taken to be mediated by the descriptive and/or grammatical content of a linguistic expression. The descriptive content is the meaning of a linguistic expression. For example, in (14a), the noun cup in combination with the definite article picks out a certain object in a given situation that can be identified by means of all the descriptions associated with a cup such as is a container for hot beverages and has a handle. 
(14) a.

The cup is broken.

b.

It is broken.

The pronoun in (14b) also picks out a referent in the given discourse situation, but reference is not determined by means of lexical content. For pronouns, it is assumed that they lack lexical/descriptive content, which does not mean that the phi-features person, number, and gender, as well as lexical features like animacy, do not have an effect on their interpretation. For example, the person feature, or more precisely the meaning represented by this feature, has a crucial effect on the way the referent is determined. Compare the sentences in (15).

(15)
a. I like ice cream.
$a^{\prime} . \quad$ Rita thinks that I like ice cream.
b. $\quad$ You like ice cream.
$b^{\prime}$. Rita thinks that you like ice cream.
c. She likes ice cream.
$c^{\prime}$. Rita thinks that she likes ice cream.

Whoever utters the sentence in (15a) and $\left(15 \mathrm{a}^{\prime}\right)$ will be the referent of the pronoun $I$. Similarly for the second person pronoun, whoever the addressee is of the sentence in (15b) and (15b') is also the referent of the pronoun you. The referential value of first and second person pronouns depends on the context of the actual speech act. Such linguistic elements are called indexicals. ${ }^{3}$ The content of first and second person pronouns has been described as a stable rule interacting with the context. The content of first person pronouns is something like the bearer of the speech act role 'speaker', and of second person pronouns it is the bearer of the speech act role 'hearer'.

The reference of third person pronouns does not depend on the utterance context in the same way because it is not associated with a speech act role. Third person pronouns designate non-participants (see Forchheimer 1953, Benveniste 1966, Zwicky 1977, Harley \& Ritter 2002, Wechsler 2004, Kratzer 2009). The third person pronoun she in (15) refers to some individual that is salient or familiar in the given discouse settings. Let us assume that in both sentences (15c) and (15c') the individual with the name Rita is the salient antecedent. The only difference between the two sentences is the way in which Rita is rendered salient. In (15c) Rita becomes salient due to some extralinguistic event, for example, Rita passes with a cup of ice cream and a smile all over her face. In (15c') Rita becomes salient due to being mentioned in the linguistic context. In this latter case, the subject DP Rita and the pronoun she refer to the same individual, and this use is termed coreference.

3 In addition to first and second person pronouns, temporal and locative adverbials or demonstrative pronouns are also indexicals. It is an inherent property of indexicals that they have their semantic value fixed by the context of the utterance only and are thus directly referential in the sense that they pick out a referent without the mediation of morphosemantic features or a descriptive meaning. This conception of indexicals is put forward in Kaplan (1989). A consequence is that indexicals should not be affected by any logical operator. This view has been challenged by Rullmann (2004), who shows that first and second person pronouns allow a bound reading (see also Déchaine \& Wiltschko 2012). Furthermore, Schlenker (2003) showed that first person pronouns in Amharic may refer to attitude holders in embedded sentences, e.g. in Peter thinks that I am a hero the pronoun I may refer to Peter. 
Expressed in more formal terms, a pronoun is translated into a variable that denotes an individual (a variable of type <e>). Variables are interpreted by means of a function that assigns them a value. This is shown in (16c) by means of the sentence in (15c).

$$
\begin{aligned}
& \text { nat. lang. expression meaning } \\
& \text { She likes ice cream } \underset{\text { translation }}{\rightarrow}[\text { likes ice cream }]^{\prime}(\mathrm{x}) \underset{\text { interpretation }}{\rightarrow} \llbracket \text { like ice cream'(x)》M,g }
\end{aligned}
$$

The assignment function $g$ has an (arbitrary) definition, such as $\mathrm{g}(\mathrm{x}) \rightarrow$ Rita. Following Heim (2008:36), this definition represents the speaker's intention. The sentence is true if Rita is an element of 【Likes

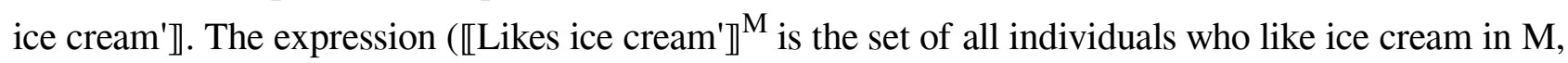
some model of the world. Pronouns/variables that are interpreted by means of an (arbitrary) assignment function are called free variables. Of course, a free pronoun can be coreferent with any other pronoun or DP.

Crucially, first and second person pronouns in most languages, including English, Spanish, and European Portuguese, cannot be construed from the linguistic context. In (15a') and (15b'), the pronouns still refer to the speaker and hearer of the sentence, despite the presence of a possible linguistic antecedent. For this reason, the present book will only consider third person pronouns. The semantic contribution of single phi-features to the interpretation of pronouns has received a lot of attention in recent research, such as Sauerland (2003), Heim (2008), Kratzer (2009), Spathas (2009), and Sudo (2012). The answer to the question as to how phi-features constrain the interpretation of pronouns in Spanish and Portuguese will be an important aspect of this book.

Let us now turn to the term coreference. Coreference is not limited to pronouns and their antecedents. Other nominal expressions can be coreferential, as in the famous example of the morning star and the evening star. The two NPs have different meanings, but refer to the same entity: the planet Venus. But under certain conditions, proper names can also be used as coreferential, as in (17).

(Not many people like John, but I believe) John likes John.

(Zwart 2002:277)

b.

(Surely if everybody likes John, then) John likes John.

As stated in Reuland (2011:25) and Heim \& Kratzer (1998), coreference is a general property of referring expressions, and the coreferent interpretation is determined by discourse-pragmatic principles such as salience or familiarity. But what happens if either the antecedent is non-referential, as in (18a), or the pronoun is not capable of independent reference, as in (18b)?

(18) a.

Every nerd $\mathrm{i}_{\mathrm{i}}$ thinks that $\mathrm{he}_{\mathrm{i} / \mathrm{k}}$ is clever.

b.

$$
\text { Rita }_{\mathrm{i}} \text { likes herself }_{\mathrm{i} / * \mathrm{k}} \text {. }
$$

Let us look first at (18a). As indicated by the indices, the pronoun can refer to some salient individual, but it can also be associated with the subject DP every nerd. The quantified DP every nerd does not refer to a particular individual and the pronoun cannot be interpreted as coreferential. Rather, the 
pronoun is construed as a bound variable. Informally, binding can be understood as some instruction or linking mechanism that assures that two variables $x$ and $y$ have identical values. Thus, whatever value is assigned to $x$ will be obligatorily assigned to $y$. Variable binding is a kind of covaluation process. Following Büring (2005:85ff) the bound reading of the pronoun in (18a) can be paraphrased as (19a).

Every nerd is in the set of those who consider themselves clever.

b. Every $\mathrm{x}(\mathrm{x}$ is a nerd) $\lambda \mathrm{x}$ [ $\mathrm{x}$ thinks that $\mathrm{x}$ is clever $]$.

The expression 'the set of those' used in (19a) is represented by the $\lambda$-operator ${ }^{4}$ in the formal representation in (19b). As described above, the pronoun is interpreted by an assignment function. The $\lambda$ operator assures that the assignment of the pronoun is not only evaluated once for $\mathrm{g}(\mathrm{x}) \rightarrow$ nerd $_{1}$, but for all assignment $\mathrm{g}(\mathrm{x}) \rightarrow$ nerd $_{1-\mathrm{n}}$. The definition of semantic binding is given in (20). Reinhart (2006:161) highlights the fact that logical (semantic) binding is a relation between operators and variables and should not be confused with the definition of binding in BT as given in (4) above. Binding in BT is a relation between arguments.

Semantic Binding / A-binding (logical syntax-based definition)

$\alpha$ binds $\beta$ iff $\alpha$ is the sister of a $\lambda$-predicate whose operator binds $\beta$.

Reinhart (2006:166/171)

An analysis as bound variable has also been assumed for the reflexive pronoun in (18b) because the reflexive pronoun is incapable of independent reference; it is not fully referential. Whatever value is assigned to its antecedent is automatically assigned to the reflexive pronoun. Thus, quantifier-variable binding and antecedent-pronoun binding is analysed in the same way as in Heim \& Kratzer (1998) and Reinhart (2006).

Semantic binding is also subject to the c-command requirement, as shown in (21a), but the coreferent interpretation of the pronoun her in (21b) is not. In chapters 5 and 8, c-command will be one diagnostic for distinguishing between a bound and a coreferential interpretation.

(21) a.

$\left[[\text { Rita's }]_{\mathrm{i}} \text { best friend }\right]_{\mathrm{k}}$ loves herself $*_{\mathrm{i} / \mathrm{k} / * \mathrm{~m}}$.

$a^{\prime}$.

[Rita's best friend] (x) $\lambda \mathrm{x}$ [x loves $\mathrm{x}]$

b.

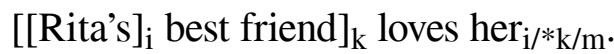

$b^{\prime}$.

[Rita's best friend] (x) $\lambda x$ [x loves $y]$

Note that the reflexive pronoun in (21a), is translated as a bound variable in the logical formula in (21a'). In order to indicate the bound interpretation, indentical variable names are used. The free pronoun has a variable name distinct from the subject DP. In (21), the reflexive and the non-reflexive pronoun are in complementary distribution and the translation is straightforward. But what about contexts as in (6)

4 The $\lambda$ operator is the abstraction of the external argument of the VP [thinks that he is clever]. The $\lambda$-abstract is the interpretation of an EPP-induced movement in Reinhart (2006:171) and von Stechow (2009). In Heim \& Kratzer (1998) and Büring (2005) it corresponds to a binder prefix inserted by Quantifier Raising or by an Index Transfer rule, respectively. 
and (7) above, in which the reflexive pronoun and non-reflexive pronoun are not in complementary distribution? Are the non-reflexive pronouns interpreted as bound variables? In the following, two diagnostics are introduced that help to distinguish a bound interpretation from a coreferential one.

For example, in (22) the pronoun is ambiguous between a bound and a coreferential reading. The pronoun her can either be bound by Rita as in (22a) or it can refer to Rita as shown in (22b). Thus, the sentence in (22) can be interpreted in two ways with the same results.

Rita $_{i}$ loves her ${ }_{i}$ gadget.

a. $\quad \operatorname{Rita}(\lambda x$ (x loves x's gadget))

binding

b. $\quad \operatorname{Rita}(\lambda x$ (x loves z's gadget $)) \& z=$ Rita

coreference

The interpretive differences between a bound and a coreferential interpretation can be made visible in so-called only-contexts, as shown in (23), and in VP ellipsis contexts, as shown in (24). These interpretive diagnostics will be applied to Spanish and European Portuguese in chapters 5 and 8 and explained in more detail there.

In (23), the focus particle only evokes alternatives for the subject DP, which is the external argument of the VP [loves her gadget]. These alternatives are individuals present in the discourse domain, such as Peter, Paul, and Mary. Additionally, the particle only entails that all alternative propositions are false. The alternative proposition vary according to a bound or a coreferential reading of the possessive pronoun. Under the bound reading of the pronoun, the alternative individuals love their (own) gadget and under a coreferential interpretation the set is definied as lovers of Rita's gadget as shown in (23a) and (23b), respectively.

$$
\text { Only Rita loves her gadget. }
$$

a.

Rita only $x(\lambda x$ (x loves x's gadget))

binding entails: other people do not love their gadget

b.

$$
\text { Rita only } x \text { ( } \lambda x \text { ( } x \text { loves z's gadget })) \& z=\text { Rita }
$$

coreference

entails: other people do not love Rita's gadget

The situation in (24) is similar. The pronoun in the elided VP [loves her gadget] can be interpreted either as bound or as coreferential, depending on the interpretation of the pronoun in the non-elided VP. If the pronoun is bound in the first conjunct, it is also bound in the elided part and Paul loves his own gadget, as shown in (24). If the pronoun is coreferential in the first conjunct, it is also coreferential in the elided part, as shown in (24b).

Rita thinks that she loves her gadget and Paul does too.

a.

$$
=\text { Paul } \lambda \mathrm{y} \text { (y loves y's gadget) }
$$

binding

b.

$$
=\text { Paul } \lambda \mathrm{y} \text { (y loves } \mathrm{x} \text { (=Rita's) gadget) }
$$

coreference

Finally, I want to mention cases in which pronouns are neither bound nor coreferential. This is the case in so-called donkey sentences, as in (25a) and (25b). The pronoun it and her are not in a configuration to be bound by their antecedents, the indefinite DPs a donkey and $a$ wife, respectively. The antecedents do not 
c-command the pronouns. The pronouns are not coreferential either because the sentence in (25a) does not mean that there is one specific donkey that is beaten by all these cruel donkey owners. Similarly, (25b) does not mean that there is one wife and every married man wants to sit next to her. ${ }^{5}$ Rather, the pronouns co-vary according to the higher QPs every man and every married man, respectively.

(25) a.

Every man that owns a donkey beats it.

b.

Every man who has a wife sits next to her.

In order to account for this type of pronominal interpretation, Evans (1977) defines so-called E-type pronouns. The meaning of E-type/D-type pronouns ${ }^{6}$ is defined as a 'systematically constructed definite description' following Partee (2008). Following this definition, the pronouns are replaced by a definite description and the sentences in (25) have an interpretation as in (26).

Every man (x) that owns a donkey beats [the donkey that $\mathrm{x}$ owns ].

b.

Every man (x) who has a wife sits next to [the woman $\mathrm{x}$ is married to].

A formal analysis of these phenomena is a matter of debate, and there are several semantic and pragmatic approaches on this issue (see Büring 2011 and Patel-Grosz \& Grosz 2009 for an overview). For example, Chierchia (1992) formalises E-type pronouns as a function from individuals to individuals $(\mathrm{f}(\mathrm{x}))$ and the range of this function, the definition of $f$, is determined by the antecedent of the pronoun. The pronouns in (25a) and (25b) stand for a donkey owned by $x$ and $a$ woman married to $x$ and the function maps owners onto their donkeys and men onto their wifes, respectively. This third type of pronominal interpretation will become relevant in chapter 8.5 .

\subsection{Basic theoretical assumptions: the probe-goal framework}

This section introduces the basic technical notions of the Minimalist Program, focussing in particular on the operations available to establish a relation between two lexical items. I will basically adopt the probe-goal framework of Chomsky (2000 et seqq.) with some minor modifications concerning head movement following Roberts (2010) and Rizzi (2016), as well as the operation Agree inspired by Bjorkman \& Zeijlstra (2014, 2019).

In the Minimalist Program, the cognitive ability that makes up the human faculty of language is conceived as a generative component with the properties of a recursive, combinatorial system. This system, Narrow Syntax, builds a syntactic object (SO) with a binary, hierarchical structure by means of two operations: Merge and Agree. The syntactic object is interpreted by other cognitive systems which are, roughly speaking, responsible for perceiving and coding information in sound and for evaluating propositions and managing concepts. These systems are called the Articulatory-Perceptual (A/P) systems and Conceptual-Intensional (C/I) systems. The syntactic component interfaces with these systems

5 For different truth conditions of donkey anaphora see Heim (1990), Chierchia (1992).

6 In E-type approaches, a definite description fixes the referent of an anaphoric pronoun. In D-type accounts, the pronoun itself has the semantics of a definite description. 
in the sense that syntax enables these independent systems to interact with each other, such as allowing an idea to be communicated by means of a sound wave (see Reinhart 2006). Irrespective of a production perspective or a perception perspective on language, a syntactic object has to be interpretable or legible at the interfaces with these cognitive systems.

The computation is taken to proceed in phases. In Chomsky (2004 et seqq.) the functional categories $v$ (erb) and $C$ (omplementiser) define a phase. ${ }^{7}$ The complement of a phase head is transferred to the interfaces. In the case that a syntactic object contains material that is not legible at the interfaces, the derivation does not converge. In the present book only aspects of the interface with the C/I system, the so-called syntax-semantics interface, are relevant. Recall from section 1.2 that syntactic objects are translated into a logical formula in order to be interpreted. This translation process is one aspect of the study of the syntax-semantics interface (see Stechow 1991, Sauerland \& Stechow 2001, and Partee 2014). Following Hackl (2013), the (empirical) goal of the study of the syntax-semantics interface is to determine to what extent the meaning of an expression and its syntactic properties are interdependent. This question will be pursued with respect to pronouns in Spanish and European Portuguese. In particular, the question will be examined as to which morphosyntactic properties determine the way clitic and strong pronouns are translated at the interfaces.

The computation of a linguistic expression starts with the selection of lexical and functional elements into a lexical array that can be understood as a kind of working memory. The lexical, morphophonological, and morphosyntactic properties of a linguistic item are represented by means of features. A feature is an attribute-value pair. For example, the phi-feature [number] can have the values singular and plural. Features are either interpretable or uninterpretable at the interfaces. Interpretable features are valued, and uninterpretable feature are unvalued. Unvalued features are located on phase heads and act as a probe that seeks matching valued features, a goal. The features are valued by means of the Agree operation in a way to be explained below. After Agree, the uninterpretable features are deleted and the SO converges at the interfaces.

A linguistic expression is built by the operation Merge. Merge selects two syntactic objects and combines them. The result is a larger syntactic object, which is represented as a binary, hierarchical structure as in (27) below. If Merge selects a lexical item from the lexical array, it is called External Merge (EM). If Merge selects an item from the already formed syntactic object, it is Internal Merge (IM). IM corresponds to transformation/movement in earlier generative frameworks and leaves a copy of the moved element, represented by the grey colour in (27b) and throughout the book.

7 Other categories like $D$ (eterminer) or $P($ reposition) are also considered to act as phases, as discussed in Citko (2014). 
(27) Numeration: $\{\alpha ; \beta ; \gamma ; \delta\}$

a. External Merge: $\gamma-\beta$

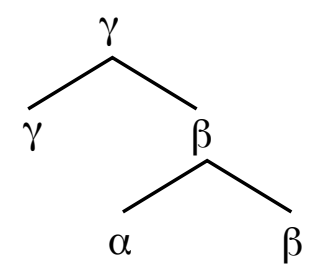

b. Internal Merge: $\alpha-\gamma$

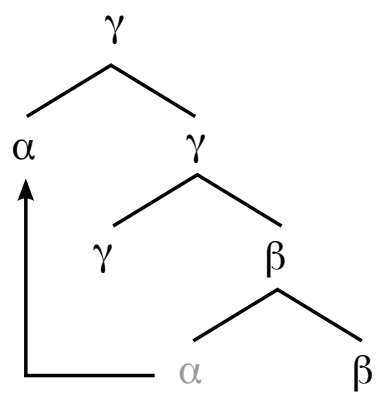

Merge selects minimal syntactic objects (heads) or complex syntactic objects (phrases). Complex syntactic objects have already been built. For example, nominal expressions have an internal structure that combines at least a root and a nominal category $\mathrm{n} / \mathrm{N}$, as suggested in Chomsky (2013). If $\gamma$ in (27) is the head of the structure, it determines the label of the newly formed structure. ${ }^{8}$ In the present work, I will follow Chomsky (2008:8), who states: 'The label selects and is selected in EM, and is the probe that seeks a goal for operations internal to the SO: Agree or IM.' Thus, the label contains all features of a syntactic object that are accessible for further operations of Merge and Agree. For the present work the following features are relevant: the phi-features [person], [number], and [gender], thematic selectional features, and case (accusative and dative).

Both IM and EM establish a relation between the two syntactic objects. The nature of this relation depends on the functional head involved, as will be introduced in more detail below. From a structural point of view, Merge creates the relation C(onstituent)-command. C-command has been defined in terms of dominance in Uriagereka (2012:121) and in terms of Merge in Epstein (1999:329). The definition of Uriagereka (2012:121) in (28) is altered according to the structure in (27a). The definition from Epstein (1999:329) is given in (29).

C-command

$\gamma$ c-commands $\alpha$ if

$\gamma$ does not dominate $\alpha$ and

All nodes dominating $\gamma$ dominate $\alpha$

C-command (Epstein 1999:329)

$\beta$ c-commands all and only the terms of the category $\alpha$ with which $\beta$ was paired by Merge or by Move in the course of the derivation.

8 Chomsky $(2008,2013)$ discusses labelling algorithms for Merge of XP with YP and $\mathrm{X}^{\circ}$ with $\mathrm{Y}^{\circ}$. In the former case, there are two possibilities: (i) If two phrases are merged by EM, movement of one phrase allows the label to be determined by the remaining phrase, e.g. movement out of a small clause. (ii) If two phrases are merged by IM and an Agree relation holds, the features involved in Agree determine the label, e.g. TP determines the label if merged with the subject DP. In the latter case, he proposes complex head formation with optional labelling as a phrase. For example, an NP is formed by Merge of a root and $n^{\circ}$. 
External Merge establishes a thematic relation between the selecting and selected item. Functional categories like $\mathrm{V} / \mathrm{v}$ or $\mathrm{N} / \mathrm{n}$ are related to the thematic structure of verbs and nouns. In the present book, only thematic relations within the V/v domain are relevant. Transitive litte $\mathrm{v}$ has a feature to select an external argument and assigns accusative case to the internal argument. The internal argument is selected by $\mathrm{V}$. Unergative little $\mathrm{v}$ does not assign accusative case and V selects no internal argument. In unaccusative structures, $\mathrm{V}$ selects the internal argument and little $\mathrm{v}$ is either a verbal category that lacks case and an external argument or it is absent altogether. Dative arguments of ditransitive verbs are selected by a separate verbal head labelled here as $\mathrm{appl}^{\circ}$ following Roberts (2010).

Internal Merge creates a relation between two syntactic positions associated with thematic, formal (case, agreement), or discourse-related properties. In Chomsky's (2000 et seqq.) Bare Phrase Structure, Internal Merge always extends the root node because a movement transformation of the syntactic object should yield discourse-related and scopal effects on the syntax-semantics interface (see Chomsky 2008:7). As a consequence, syntactic movement of heads/minimal categories was abandoned because it has no effect at the syntax-semantics interface. In this book, I will follow Roberts (2010) and Rizzi (2016), who argue that head movement is still available in Bare Phrase Structure. This modification will be relevant for the analysis of Spanish and European Portuguese clitics in chapter 7.

As mentioned above, each application of IM leaves a copy. At the S/M interface only one copy can be pronounced and the other copies need to be deleted. Alboiu et al. (2004) and Magro (2019), following Hornstein (2001, 2007), explored the possibilities of partial deletion/spell-out of a copy in order to account for clitic structures in Romance. In earlier versions of the probe-goal framework, Internal Merge is conceptually related to the Agree operation. An element enters first into an Agree relation and is then moved to satisfy some feature of higher category, such as an EPP feature or some feature of the CP domain. But an element that has entered into an Agree relation does not necessarily move. Rizzi (2016) proposed that elements can move and satisfy an EPP feature without first having entered into an Agree relation.

Agree creates a feature-based dependency between two lexical items. These features include phifeatures and case. Take, for example, the relation between $v$ and the direct object in (30).

(30)

a. Probe and Match

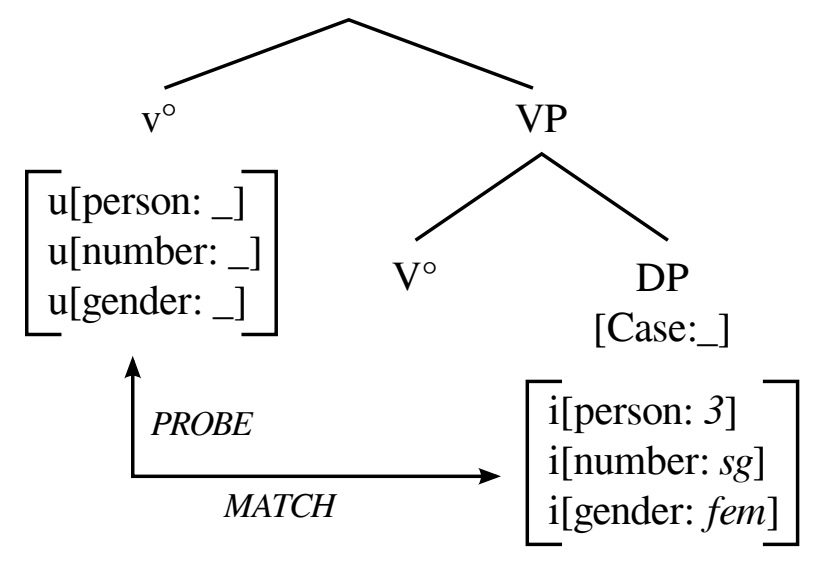

b. Copy and Delete

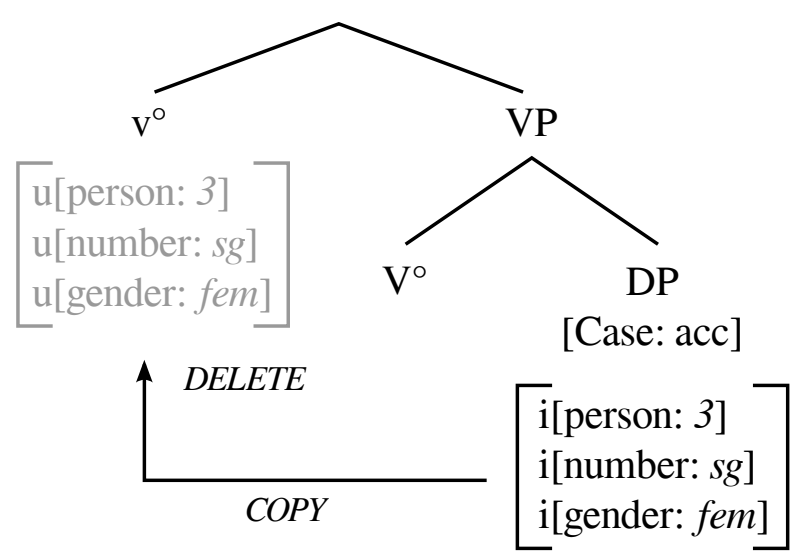


Little $\mathrm{v}$ has a full set of unvalued and uninterpretable phi-features: the phi-probe. The DP has a full set of valued and interpretable features. The probe searches its c-command domain for a goal. In the framework of Chomsky (2000 et seqq.), the probe searches downward, as will be also assumed here. A goal must be visible for the probe, and an unvalued case feature creates such visibility. Another condition for Agree to be successful is that the features on the probe match the features on the goal. The operation Match is defined in Chomsky (2001:5) as feature identity. In (30a) the features of the probe match the features of the goal, and valuation can take place. Valuation can be understood as copying the values from the goal onto the probe. The now valued uninterpretable features will be deleted, as shown in (30b). As result of Agree, the case feature is valued with accusative case.

Concluding this section, the syntactic component provides three types of relations: (i) Agree relates $\mathrm{a} \mathrm{X}^{\circ}$ and a $\mathrm{XP}$ and is induced by unvalued features on $\mathrm{X}^{\circ}$. (ii) Internal Merge creates a relation between two XPs or two Xs $s^{\circ}$. (iii) External Merge creates a relation between two XPs or an XP and an $\mathrm{X}^{\circ}$. In the latter case, thematic selectional features of $\mathrm{X}^{\circ}$ are involved.

\subsection{The Ibero-Romance perspective: topic and structure}

Classic Binding Theory, as well as Minimalist analyses of anaphoric relations such as put forward in Hornstein (2001,2007), Hicks (2009), Boeckx et al. (2010), Reuland (2011), and Zwart (2002), are based on English and other Germanic languages. The pronominal system of these languages crucially lacks clitic pronouns of the type found in (Ibero-)Romance languages. Spanish and European Portuguese, as well as other Romance languages like Italian (It.) or French (Fr.), have both reflexive and non-reflexive pronouns, and each lexical type has two morphosyntactic realisations: as a clitic and as a non-clitic pronoun. For non-clitic forms the term strong pronoun will be used throughout this book, following Cardinaletti \& Starke (1999). Minimalist or earlier generative analyses of anaphoric relations that claim to cover Romance languages, such as the analyses of Kayne (1988), Sportiche (1990, 1998), Alboiu et al. (2004), Reinhart \& Siloni (2004, 2005), and Marelj \& Reuland (2016), focus on reflexive contructions and are mostly based on French and Italian, languages that crucially lack clitic doubling of the Ibero-Romance type and that show strong evidence in favour of an intransitive reflexivisation strategy. The examples in (31a) and (31b) show that Spanish and European Portuguese have clitic doubling of reflexive and non-reflexive pronouns in the sense that the clitic is the obligatory element and the strong pronoun is the optional element. Furthermore, the strong pronoun is obligatorily marked by the object marker $a$ in both languages. Italian and French do not have this kind of obligatory object marking. In Italian, either the clitic or the strong pronoun has to be used. A co-occurrence of the clitic and the strong pronoun is ungrammatical with reflexive and non-reflexive pronouns, as shown in (31c). French allows for doubling of the reflexive clitic, but crucially not of the non-reflexive clitic, as exemplified in (31d) and (31d'). Another difference between French on the one hand and Spanish, Portuguese, and Italian on the other hand is that the latter languages have a form for the strong reflexive pronoun, whereas in French a combination of the non-reflexive pronoun and the intensifying element même is used. 
(31) a. Sp. Rita *(se) ama (a sí misma).

b. EP

A Rita ama-*(se) (a si própria).

c. It.

Rita (*si) ama se stessa.

d. Fr.
$\operatorname{Rita}_{i}^{*}(s)$ 'aime elle-même.

'Rita loves herself.' $a^{\prime} \quad$ Rita *(la) ama (a ella).

b.' A Rita ama-*(a) (a ela).

$c^{\prime}$. Rita (*la) ama lei.

d.' Rita l'aime (*elle).

'Rita loves her.'

In Ibero-Romance clitic doubling structures, only the clitic pronouns are in strict complementary distribution, but not the strong pronouns inside the $a$-marked phrase, as shown in (32).
a. Sp. $\quad \operatorname{Rita}_{\mathrm{i}} \mathrm{se}_{\mathrm{i}}$ ama a sí $i_{\mathrm{i}}$ misma.
$a^{\prime} \quad$ Rita $_{\mathrm{i}} \mathrm{se}_{\mathrm{i}}$ ama a ella $\mathrm{i}$ misma.
b. EP
A Rita $_{i}$ ama-se $_{i}$ a si $i_{i}$ própria.

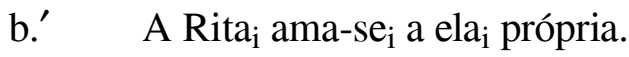
'Rita loves herself.'
'Rita loves herself.'
c. Sp. $\quad * \operatorname{Rita}_{\mathrm{i}} \mathrm{la}_{\mathrm{i}}$ ama $\left(\mathrm{a}\right.$ ella $\left.\mathrm{a}_{\mathrm{i}}\right)$.

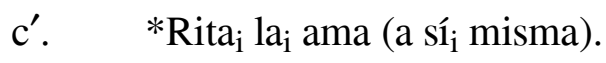
d. EP
*A Rita ama-a $_{\mathrm{i}}\left(\right.$ a ela $\left._{\mathrm{i}}\right)$.
d.' $\quad$ *A Rita ${ }_{\mathrm{i}}$ ama-a $\mathrm{a}_{\mathrm{i}}$ (a si $\mathrm{i}_{\mathrm{i}}$ própria).
'Rita loves her.'
'Rita loves her.'

Thus, strong pronouns are in non-complementary distribution not only in reflexive clitic doubling structures, but also in other prepositional contexts, as already mentioned in section 1.1. For the sake of illustration, examples (6) and (7) are repeated here in (33) and (34).

(33) a. Sp. Ella solo piensa en $s_{i} /$ en ella $a_{i}$.

b. EP $\quad$ Ela $_{\mathrm{i}}$ só pensa em $\mathrm{si}_{\mathrm{i}} /$ nela $_{\mathrm{i}}$.

'She only thinks about herself.'

(34) a. Sp. Ella $a_{\mathrm{i}}$ vio una serpiente cerca de sí $\mathrm{i}_{\mathrm{i}} / \mathrm{de}$ ella $\mathrm{i}_{\mathrm{i}}$

b. EP Ela viu uma serpente perto de $\mathrm{si}_{\mathrm{i}} / \mathrm{dela}_{\mathrm{i}}$.

'She saw a snake near herself.'

As stated in the previous sections, complementary distribution is one precondition for a syntactic encoding of an anaphoric dependency because the very same syntactic mechanism has to generate both the bound interpretation of the reflexive pronoun and the disjoint interpretation of the non-reflexive pronoun. In contexts of non-complementary distribution, the dependency may be due either to variable binding or to pragmatic coreference. The three modes of encoding an anaphoric dependency are represented in (33), a detailed version of the figure in (13). 

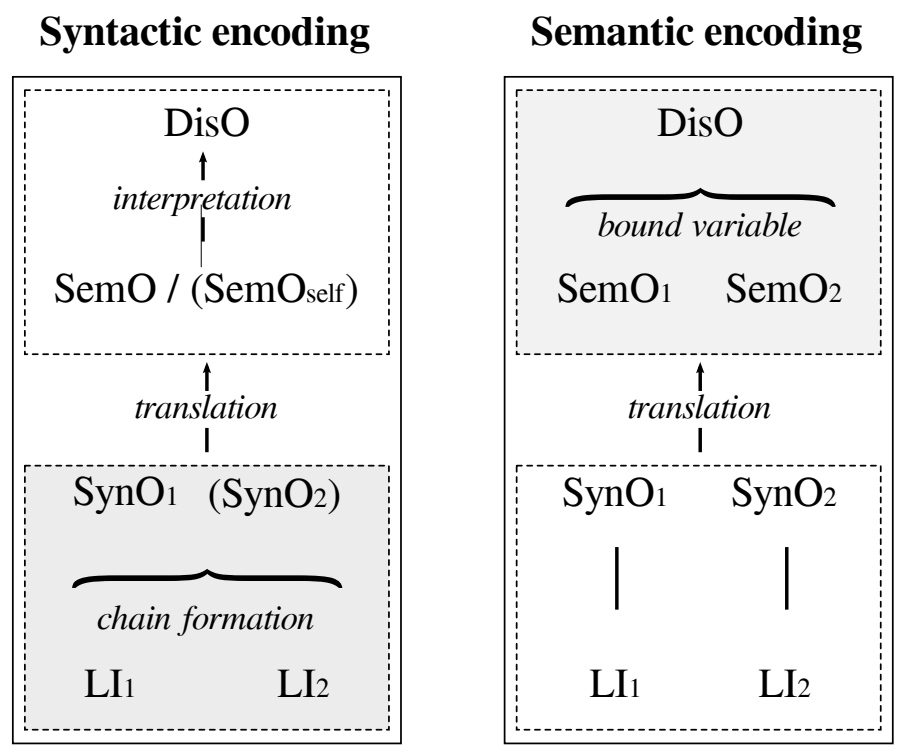

Pragmatic encoding

\begin{tabular}{|c|c|}
\hline $\mathrm{DisO}_{1}$ & $\mathrm{DisO}_{1}$ \\
\hline \multicolumn{2}{|c|}{$\underset{1}{\uparrow}$} \\
\hline $\mathrm{SemO}_{1}$ & $\mathrm{SemO}_{2}$ \\
\hline \multicolumn{2}{|c|}{$\begin{array}{c}\uparrow \\
\text { translation } \\
\mid\end{array}$} \\
\hline $\mathrm{SynO}_{1}$ & $\mathrm{SynO}_{2}$ \\
\hline $\mathrm{LI}_{1}$ & $\mathrm{LI}_{2}$ \\
\hline
\end{tabular}

In order to be sure about the mode of encoding, the diagnostics introduced in the previous section will be applied to pronouns in clitic doubling structures in chapter 5 and to pronouns in prepositional contexts in chapter 8 . In addition to the structural diagnostics for c-command and locality, the interpretive diagnostics, such as reference to a sentence-external antecedent, binding by a quantified antecedent, the VP ellipsis test, and the interpretation of pronouns in only-contexts, will be discussed. Both chapters provide a review of the data presented in the literature as well as additional and even new data based on corpus studies and speaker inquiries. ${ }^{9}$ The new data concern in particular clitic doubling of longdistance reflexives in European Portuguese (see section 5.2.3). Furthermore, the diagnostics reveal a strong influence from the elements mismo (Sp.) and mesmo/próprio (EP) on the interpretation of the strong non-reflexive pronoun, a fact which has not been observed yet in this systematic way. These elements have been classified as reflexive intensifier in König \& Siemund (2000) and Gast \& Siemund (2006) and I will use the short term intensifier throughout the disseration to designate the elements mismo and mesmo/próprio. The evaluation of the structural and interpretative diagnostics allows for a clear statement: an anaphoric dependency involving clitic pronouns is subject to a syntactic operation, whereas a dependency involving strong pronouns can only be subject to semantic or pragmatic principles.

The main focus of this book is on the syntactic encoding. Two main strategies have been introduced in section 1.1: an intransitive and a transitive strategy. For Romance reflexive clitics, there is a long tradition of intransitive accounts, such as Kayne (1988), Sportiche (1990, 1998), and Reinhart \& Siloni (2004, 2005), among many others. The argumentation of these accounts will be scrutinised with respect to Spanish and European Portuguese clitic doubling structures, and it will be concluded that re-

9 The following web corpora have been used. For European Portuguese the Reference Corpus of Contemporary Portuguese (CRPC) was used. It is accessible at http://alfclul.clul.ul.pt/CQPweb/. For Spanish the Corpus de Referencia del Español Actual (CREA) and the Corpus del Español Actual (CEA) were consulted. The annotated version of CREA is accesible at http://web.frl.es/CREA/view/inicioExterno.view, and the plain text version of CREA can be accessed at http://www.rae.es; the CEA can be accessed at http://spanishfn.org/tools/cea/english. 
flexivisation in Spanish and European Portuguese involves a transitive strategy. The existing transitive accounts make use of all three relations available within the probe-goal framework: in Hornstein (2001, 2007) and Alboiu et al. (2004) an anaphoric dependency is established by movement, in Zwart (2002) it is established by External Merge and movement, and in Hicks (2009) and Marelj \& Reuland (2016) it is established by agreement. These accounts will be scrutinised with respect to Spanish and European Portuguese clitic doubling structures, and I will conclude that Spanish and European Portuguese clitic doubling structures need their own tailor-made analysis, the main contribution of this book.

The heart and soul of this book is an agreement-based analysis of reflexive and non-reflexive clitic doubling structures. The referential defectiveness of reflexive pronouns will be expressed in terms of insubstantial phi-feature values (null-values), whereas non-reflexive pronouns have fully specified phi-feature values. This means that the clitic and strong versions of each lexical type-reflexive and non-reflexive-share the same phi-feature content. It will be argued that Agree with null-values is vacuous. This property of null-values will have different effects on strong reflexive pronouns and reflexive clitics. Given that only clitic pronouns are in complementary distribution, the process of syntactic encoding must be proper to clitic pronouns. The main morphosyntactic difference between clitic and strong pronouns is the fact that clitics must be associated with a verbal host. This process of cliticisation will be analysed as agreement in the sense of Roberts (2010). Cliticisation places the clitics in a configuration in which they can agree with the antecedent. As for reflexive clitics, the features with null-values are involved in agreement with the antecedent, but they do not trigger the application of a syntactic operation and they do not act as a probe. Due to their referential deficiency, reflexive clitics are construed with phi-agreement. Agreement with the antecedent is blocked for non-reflexive clitics because they have a full specification with phi-features. Furthermore, my analysis accounts for the ban of reflexive subjects in finite and non-finite sentences and derives Rizzi's (1990) Anaphor Agreement Effect by means of the assumption that Agree with null-values is vacuous.

The main body of the book starts with a brief introduction of the basic morphosyntactic properties of Spanish and European Portuguese pronouns in chapter 2. The intransitive and transitive strategies are reviewed in chapters 3 and 4, respectively. The structural and interpretive diagnostics are applied to clitic doubling structures in chapter 5. Chapter 6 motivates the null feature values as expression of the referential deficiency of reflexive pronouns and proposes an internal structure for clitics and strong pronouns in Spanish and European Portuguese. The agreement-based analysis is elaborated in chapter 7. As for pronouns in non-complementary environments, the diagnostics are presented in chapter 8. Chapter 9 is devoted to the intriguing effects of the reflexive intensifier, because there is no systematic and formal account of intensification in Ibero-Romance languages. Compared to chapter 7 , the discussion in chapter 9 is conceived as a pilot study evaluating existing proposals for the Germanic SELF-intensifier and making a tentative proposal of the interpretation of these elements in Spanish and European Portuguese. Finally, the findings are summarised in chapter 10. 



\section{Basic syntax of pronouns in Spanish and European Portuguese}

This chapter gives an overview of the main morphosyntactic properties of personal pronouns in Spanish and European Portuguese. For readers unfamiliar with these languages, this chapter provides the background necessary to understand the discussion in the following chapters. After a brief introduction of the pronominal paradigm in section 2.1 , section 2.2 provides an introduction to the main morphosyntactic properties of clitic and strong pronouns. This section focusses on clitic placement, clitic doubling, and object marking. Section 2.3 briefly presents the distinct uses of the reflexive clitic, showing that the clitic has very different effects on the interpretation of a verbal predicate, affecting aspects such as the argument structure, case properties, and aspectual properties. This section provides some background information for the discussion in chapter 3.

\subsection{The pronominal paradigm}

Spanish and European Portuguese have distinct forms for reflexive and non-reflexive pronouns, and each type has two morphosyntactic realisations, as a clitic and non-clitic pronoun. In grammars like Bosque \& Demonte (1999) and Mateus et al. (2003) the two types are non-clitic pronouns, referred to as pronombres tónicos (Sp.) / pronomes tónicos (EP), 'stressed pronouns', and clitic pronouns, which are called pronombre átonos (Sp.) / pronomes átonos (EP), 'unstressed pronouns'. The names derive from the fact that clitic pronouns cannot bear word stress. This phonological property correlates with the main morphosyntactic property of clitic pronouns: their association with another (lexical) category, which in the case of Spanish and European Portuguese is the verb, as described in Martins (2013) for European Portuguese and in Fernández Soriano (1999) for Spanish. In the typology of Cardinaletti \& Starke (1999) the stressed pronouns are further subdivided into weak and strong pronouns on the basis of their syntactic and semantic properties. For example, the covert pronoun pro is considered a weak pronoun because it cannot appear in prepositional contexts and does not show semantic restrictions such as a restriction to a human referent. Throughout the book I will use the terms clitic, or clitic pronoun, for the 'unstressed' forms and the term strong pronoun for the 'stressed' forms. The term pronoun is also used as a cover term for both types when a distinction is not relevant.

The presentation of the paradigms basically follows Otero (1999) for Spanish and Martins (2013) for European Portuguese. The paradigms of the non-reflexive pronouns are given in (36) for strong pronouns and in (37) for clitic pronouns. Indefinite pronouns, ${ }^{10}$ forms of politeness, ${ }^{11}$ and neuter resumptive pronouns are not considered here, but do note that in EP the pronoun si is used as a pronoun of polite address in contexts of prepositional case.

10 The indefinite (stressed) pronouns of European Portuguese are alguém 'somebody', algo 'something'. The indefinite (stressed) pronouns of Spanish are alguien 'somebody', algo 'something', and the indefinite pronoun uno 'one'. There are no indefinite clitic pronouns in either language.

11 In Spanish the pronoun of polite address is usted(es). The European Portuguese pronoun você(s) has the same diachronic origin as the Spanish pronouns, but is used differently in contemporary European Portuguese; in particular the singular form has lost its politeness features and is commonly replaced by other forms of polite address. 
(36) Non-reflexive strong pronouns

\begin{tabular}{|c|c|c|c|c|}
\hline & \multicolumn{2}{|c|}{ Spanish } & \multicolumn{2}{c}{ European Portuguese } \\
\hline & Nom & Acc / Dat / Obl & Nom & Acc / Dat / Obl \\
\hline$\left[1^{\text {st }}\right.$ sg. masc./fem. $]$ & yo & mí & eu & mim \\
\hline$\left[2^{\text {nd }}\right.$ sg. masc./fem. $]$ & tú & ti & tu \\
\hline$\left[3^{\text {rd }}\right.$ sg. masc./fem. $]$ & \multicolumn{2}{|c|}{ ele / ela } \\
\hline$\left[1^{\text {st }}\right.$ pl. masc./fem. $]$ & nosotros / nosotras & \multicolumn{2}{|c}{ nós, a gente } \\
\hline$\left[2^{\text {nd }}\right.$ pl. masc./fem. $]$ & vosotros / vosotras & \multicolumn{2}{|c}{ eles / elas } \\
\hline$\left[3^{\text {rd }}\right.$ pl. masc./fem. $]$ & \multicolumn{2}{|c|}{ ellos / ellas } & \multicolumn{2}{|c|}{} \\
\hline
\end{tabular}

(37) Non-reflexive clitic pronouns

\begin{tabular}{|c|c|c|c|c|c|c|}
\hline & \multicolumn{3}{|c|}{ Spanish } & \multicolumn{3}{|c|}{ European Portuguese } \\
\hline & Nom & Acc & Dat & Nom & Acc & Dat \\
\hline$\left[1^{\text {st }}\right.$ sg. masc./fem. $]$ & \multirow{6}{*}{$\varnothing$} & \multicolumn{2}{|c|}{ me } & \multirow{6}{*}{$\varnothing$} & \multicolumn{2}{|c|}{ me } \\
\hline$\left[2^{\text {nd }}\right.$ sg. masc./fem.] & & \multicolumn{2}{|c|}{ te } & & \multicolumn{2}{|c|}{ te } \\
\hline$\left[3^{\text {rd }}\right.$ sg. masc./fem. $]$ & & lo/la & le & & $\mathrm{o} / \mathrm{a}$ & lhe \\
\hline$\left[1^{\mathrm{st}} \mathrm{pl} . \mathrm{masc} . / \mathrm{fem}.\right]$ & & \multicolumn{2}{|c|}{ nos } & & \multicolumn{2}{|c|}{ nos } \\
\hline [2 $2^{\text {nd }}$ pl. masc./fem. $]$ & & \multicolumn{2}{|c|}{ vos } & & \multicolumn{2}{|c|}{ vos } \\
\hline$\left[3^{\text {rd }} \mathrm{pl} . \mathrm{masc} . / \mathrm{fem}.\right]$ & & los/las & les & & os/as & lhes \\
\hline
\end{tabular}

In both languages the paradigm is reduced with respect to case forms. The forms of the stressed pronouns show a case distinction only for first and second person singular. The clitic forms show that distinction only in the third person singular and plural. Both languages show a gender distinction in the third person form of the stressed and clitic pronouns. In Spanish the first and second person plural forms of the stressed pronoun are also marked for gender.

The paradigms of reflexive pronouns are shown in (38) for strong pronouns and in (39) for clitic pronouns. 
(38) Reflexive strong pronouns

\begin{tabular}{|c|c|c|c|c|c|c|}
\hline & \multicolumn{3}{|c|}{ Spanish } & \multicolumn{3}{|c|}{ European Portuguese } \\
\hline & Nom & Acc & Dat / Obl & Nom & Acc & Dat / Obl \\
\hline$\left[1^{\mathrm{st}}\right.$ sg. masc./fem. $]$ & \multirow{6}{*}{$\varnothing$} & & & \multirow{6}{*}{$\varnothing$} & \multicolumn{2}{|c|}{$\operatorname{mim}$} \\
\hline [ $2^{\text {nd }}$ sg. masc./fem.] & & & $\mathrm{i}$ & & \multicolumn{2}{|c|}{$\mathrm{ti}$} \\
\hline [3 ${ }^{\text {rd }}$ sg. masc./fem.] & & & '́1 & & \multicolumn{2}{|c|}{ si } \\
\hline$\left[1^{\mathrm{st}} \mathrm{pl} . \mathrm{masc} . / \mathrm{fem}.\right]$ & & noso & nosotras & & \multicolumn{2}{|c|}{ nós } \\
\hline [2 ${ }^{\text {nd }} \mathrm{pl}$. masc./fem. $]$ & & voso & vosotras & & \multicolumn{2}{|c|}{ vós } \\
\hline [3 ${ }^{\text {rd }}$ pl. masc./fem.] & & & أ́ & & \multicolumn{2}{|c|}{ si } \\
\hline
\end{tabular}

(39) Reflexive clitic pronouns

\begin{tabular}{|c|c|c|c|c|c|c|}
\hline & \multicolumn{3}{|c|}{ Spanish } & \multicolumn{3}{|c|}{ European Portuguese } \\
\hline & Nom & Acc & Dat & Nom & Acc & Dat \\
\hline$\left[1^{\mathrm{st}} \mathrm{sg} . \mathrm{masc} . / \mathrm{fem}.\right]$ & \multirow{6}{*}{$\varnothing$} & & & \multirow{6}{*}{$\varnothing$} & \multicolumn{2}{|c|}{ me } \\
\hline [ $2^{\text {nd }}$ sg. masc./fem.] & & & & & \multicolumn{2}{|c|}{ te } \\
\hline$\left[3^{\text {rd }}\right.$ sg. masc./fem.] & & & & & \multicolumn{2}{|c|}{ se } \\
\hline$\left[1^{\mathrm{st}} \mathrm{pl}\right.$. masc./fem.] & & & & & \multicolumn{2}{|c|}{ nos } \\
\hline [2 $2^{\text {nd }} \mathrm{pl}$. masc./fem.] & & & & & \multicolumn{2}{|c|}{ vos } \\
\hline$\left[3^{\text {rd }} \mathrm{pl}\right.$. masc./fem. $]$ & & & & & \multicolumn{2}{|c|}{ se } \\
\hline
\end{tabular}

The reflexive pronouns have no nominative forms in either language (see Martins 2013, Otero 1999). In first and second person, the forms of the reflexive and non-reflexive pronouns are identical. But the third person reflexive forms appear to be maximally reduced. They show no number, gender, or case distinction. The underlying feature specification will be crucial for the anaylsis put forward in chapter 7 .

\subsection{Special clitics and strong pronouns}

In the typology of Zwicky (1977), Romance clitic pronouns belong to the group of special clitics for two reasons: first, the clitic pronouns have a non-clitic counterpart, the strong pronoun, and secondly, the two types differ with respect to their distribution and morphosyntactic properties. Strong pronouns have the same distribution as other noun phrases while clitics exhibit, in terms of Zwicky (1977), a special syntax. For this reason, this section is primarily about clitic pronouns and clitic doubling structures.

Romance clitics are hybrid elements because they show properties both of bound words and of free words. On the one hand, clitics behave like bound words with respect to coordination, their placement next to a verbal host, the formation of morphophonological clusters, focus, and word stress 
(sections 2.2.1-2.2.3). On the other hand, clitics are like free words because they can realise arguments and may occupy several positions within a sentence. The generation of an enclitic or a proclitic position is subject to distinct conditions in European Portuguese and in Spanish. The most important conditions will be briefly introduced in sections 2.2.1-2.2.4. Another displacement phenomenon is so-called clitic climbing, which will be described in section 2.2.5. Some background information about clitic doubling and its connection with object marking is provided in section 2.2.6. The syntax of clitic doubling will be central for the analysis put forward in the present book (chapters 3 and 7).

In Spanish and European Portuguese, the non-reflexive clitic may realise the direct (accusative) and indirect (dative) object as shown in (40)/(41) and (42)/(43). Note that Spanish has obligatory clitic doubling of dative DPs (for details see section 2.2.6 and chapter 5). The examples also show that clitic pronouns realise a theta-marked argument, even though they do not occupy the same position as full DPs or strong pronouns. In the influential analysis of Kayne (1972), object clitics are taken to be basegenerated in a theta position just like full DPs and then moved to a position adjacent to the verb. This movement is represented in a simplified manner in $(40 b) /(41 b)$ for accusative clitics and in $(42 b) /(43 b)$ for dative clitics.

(40) a. Sp. La niña $\left[\mathrm{T}^{\circ} / \mathrm{v}^{\circ}\right.$ achucha [al hermano $]$. the girl hugs om.the brother

'The girl hugs the brother.'

b. La niña $\left[\mathrm{T}^{\circ} / \mathrm{v}^{\circ}\right.$ lo achucha $\left.[\mathrm{lo}]\right]$.

the girl him.CL.ACC= hugs him.CL.ACC

'The girl hugs him.'

(41) a. EP A menina $\left[\mathrm{T}^{\circ} / \mathrm{v}^{\circ}\right.$ abraça [o irmão ]]. the girl hugs the brother

'The girl hugs the brother.'

b. A menina $\left[\mathrm{T}^{\circ} / \mathrm{v}^{\circ}\right.$ abraça-o. $\left.[\mathrm{e}]\right]$. the girl hugs=him.CL.ACC him.CL.ACC

'The girl hugs him.'

(42) a. Sp. La niña $\left[\mathrm{T}^{\circ} / \mathrm{v}^{\circ}\right.$ le da [un beso [a la madre ]]]. the girl her.CL.DAT= gives a kiss to the mother 'The girl gives the mother a kiss.'

b. La niña $\left[\mathrm{T}^{\circ} / \mathrm{v}^{\circ}\right.$ le da [un beso [le ] $]$. the girl her.CL.DAT= gives a kiss her.CL.DAT 'The girl gives her a kiss.' 
(43) a. EP

A menina $\left[\mathrm{T}^{\circ} / \mathrm{v}^{\circ}\right.$ da [um beijo [à mãe ]]].

the girl gives a kiss to.the mother

'The girl gives the mother a kiss.'

b.
A menina $\left[\mathrm{T}^{\circ} / \mathrm{v}^{\circ}\right.$ da-lhe
[um beijo [the
]]].
the girl
gives=her.CL.DAT
a kiss her.CL.DAT
'The girl gives her a kiss.'

But this movement step, henceforth to be referred to as cliticisation, is distinct from other NP-movement configurations. As mentioned in Cardinaletti \& Starke (1999), the position of the DPs in examples (40)/(41) and (42)/(43) corresponds to the position where a nominal expression is base-generated and theta-marked. From their base positions, full DPs and strong pronouns can be dislocated, but clitics cannot. This is true for focus movement (cleft sentences or focus fronting) and different kinds of topicalisation structures. For the sake of brevity, just an example for clitic left dislocation is given in (44).

(44) a. Sp. [CP A Rita / A ella / * La [те no la invitaría a Rita. / a ella./la ]]. om R. / om her / her.cL not her.CL=invite om R. / omher / her.CL

b. EP [CP A Rita / Ela /*A [TP não a convidaria a Rita./ ela. / a ]]. the R. / her / her.CL not her.CL=invite the R. / her / her.CL 'As for Rita / her, I would not invite her.'

As mentioned above, both languages lack (nominative) clitics and prepositional clitics like French en/y. Finally, there are other uses of the non-reflexive clitics that are not the subject of the present book, such as the invariant, neuter clitic $o(\mathrm{EP}) /$ lo $(\mathrm{Sp})$, whose semantics correspond roughly to the semantics of the demonstrative pronoun and which replaces sentential complements and predicates (see Mateus et al. 2003:827-828 for European Portuguese and Fernández Soriano 1999:1260 for Spanish). The dative clitic is also used to express non-argumental datives, such as benefactive or ethical datives. These types of datives will not be discussed in the present work.

Irrespective of their interpretation, all clitics exhibit the same morphosyntactic properties with respect to clitic placement, their order in clitic clusters, and clitic climbing. These basic aspects of Spanish and European Portuguese clitic syntax will be introduced in the next subsections, with special attention to the differences between Spanish and European Portuguese.

\subsubsection{Focus and stress}

Clitic pronouns cannot be stressed, as shown in (45), or appear in isolation (without their verbal host), for example as answers to questions, as in (46). These two properties are also characteristic for bound morphemes such as agreement morphology.

Context: Is it true that you prefer him to her?

a. Sp. *No, LA prefiero.

no her.CL= prefer.1.SG b. EP *Não, A prefiro. no her.CL= prefer.1.SG 
Context: Whom did you call?

a. Sp. *La.

her.CL

b. $\mathrm{EP} * \mathrm{~A}$.

her.CL

In contrast to clitic pronouns, strong pronouns, like full DPs, may receive focal stress or appear in isolation. This is exemplified for Spanish and European Portuguese in (47) and (48). Note that a strong object pronoun is obligatorily doubled by the clitic in both languages, whereas doubling of a full DP is only possible in Spanish.

Context: Is it true that you prefer him to her?

a. Sp. No, *(la) prefiero a ELLA a'. EP Não, prefiro-*(a) a ELA

no her.CL=prefer.1.SG OM her

no prefer.1.SG=her.CL OM she

'No, I prefer her.'

'No, I prefer her.'

b. Sp. No, (la) prefiero a MARÍA. b'. EP Não, prefiro-(*a) a MARIA.

no her.CL= prefer.1.SG OM $\mathrm{M}$.

no prefer.1.SG=her.CL OM M.

'No, I prefer María.'

'No, I prefer Maria.'

Context: Whom did you call?

a. Sp. - (A) María. / - (A) ella.

b. EP - A María./ - Ela.

- ом M. / - ом her

- the M. / - her

\subsubsection{Coordination}

In Kayne's (1994) analysis of coordination structures, which may be called a standard analysis, coordination is limited to phrases (XPs). In the example (49) below, the coordinators $y$ and $e$ would be analysed as the head of a coordination phrase (CoordP) and the two strong pronouns (along with the object marker $a$ ) are in the complement position and in specifier position of Coord $^{\circ}$.
a. Sp. Los invité [CoordP a él [Coord ${ }^{\circ} \mathrm{y}$ a ella]]. them.CL=invited OM him and om her
'I invited them, him and her.'
b. EP Convidei-os, [CoordP a ele [Coord ${ }^{\circ}$ a ela]]. invited=them.CL $\quad$ OM him and om her
'I invited them, him and her.'

Under this analysis, heads are excluded from coordination because they cannot occupy a specifier position or a complement position. As exemplified in (50), clitics cannot be coordinated, and following the analysis of Kayne (1994), clitics behave like syntactic heads, at least in their final position.

(50) a. Sp. *No [lo y la ] invité.

no him.cL and her.cL invited 


b. EP *Não $\left[\begin{array}{llll}0 & \text { e } & \text { a }\end{array}\right]$ convidei.
no him.cL and her.cL invited

The properties illustrated so far are the properties that clitics share with bound morphemes such as verbal agreement affixes. They cannot appear in isolation, they cannot be stressed, and they cannot be coordinated. Differently from clitics, strong pronouns share the properties of free words with a phrasal status: they appear in isolation, they can be stressed, and they can be coordinated. But as mentioned above, clitics are hybrid categories, and they also exhibit properties of free words. Unlike bound morphemes, clitics do not have a fixed position in the sentence. The most important aspects concerning clitic placement are illustrated in the next sections.

\subsubsection{Clitic clusters and the Person-Case Constraint}

Whenever a dative clitic and an accusative clitic co-occur, they form a unit/cluster that is subject to morphophonological constraints. The constraints concern the order of clitics inside the cluster and the shape of the clitic cluster itself. For European Portuguese, the data and their description comes from Martins (2013) and Luís \& Kaiser (2016). For Spanish the relevant facts are summarised according to Ormazabal \& Romero (2007), Fernández Soriano (1999), and Franco (1999). As a general observation, it can be stated for both languages that the argumental dative clitic has to precede the accusative clitic (see Martins 2013, Luís \& Kaiser 2016, Ormazabal \& Romero 2007, and Fernández Soriano 1999). Hence, the correct order is DAT clitic $>$ ACC clitic and the order *ACC clitic $>$ DAT clitic is generally excluded, as shown in (51) for Spanish and in (52) for European Portuguese.
a. Sp.
Juan $\mathrm{se}_{\mathrm{i}}$
$1 a_{\mathrm{k}}$
dio (a Pedro $)_{\mathrm{i}}$.
(Franco 1999:178)
Juan him.CL.DAT=it.CL.ACC $=$ gave to Pedro
'Juan gave it to Pedro.'
b.
*la le/se enviaron.
her/it.CL.ACC $=$ him/her.CL.DAT=sent.3.PL
intended meaning: 'They sent her/it to him/her.'
(Ormazabal \& Romero 2007:318)

(52) a. EP Tenho de devolver-lho.

(Martins 2013:2235)

have to give.back=him/her.CL.DAT.=it.CL.ACC

'I have to give it back to him/her.'

b.
*A criança deu -o -lhe.
the child gave =it.CL.ACC $=$ him/her.CL.DAT
intended meaning: 'The child gave it to him.'

(Luís \& Kaiser 2016:212)

Note that the dative-accusative cluster is subject to morphophonological alternations in both languages. In Spanish, the most important alternation is the so-called spurious se. The dative clitic forms le/les are always replaced by the allomorph se in a cluster with an accusative clitic. In the example (51a), the clitic se represents the dative object a Pedro. In European Portuguese the dative-accusative cluster is 
subject to various shape alternations. A summary of all forms, as given in Luís \& Kaiser (2016), is repeated here for the sake of introduction.

(53) Clitic clusters in European Portuguese (Luís \& Kaiser 2016:212ff)

\begin{tabular}{|l|c|c|c|c|}
\hline dat. clitic acc. clitic & {$\left[3^{\text {rd }}\right.$ sg. masc. $]$} & {$\left[3^{\text {rd }}\right.$ sg. fem. $]$} & {$\left[3^{\text {rd }}\right.$ pl. masc. $]$} & {$\left[3^{\text {rd }}\right.$ pl. fem. $]$} \\
\hline$\left[1^{\text {st }} \mathrm{sg}\right.$. fem./masc. $]$ & mo & ma & mos & mas \\
\hline$\left[2^{\text {nd }} \mathrm{sg}\right.$. fem./masc. $]$ & to & ta & tos & tas \\
\hline$\left[3^{\text {rd }} \mathrm{sg} / \mathrm{pl} . \mathrm{fem} . / \mathrm{masc}.\right]$ & lho & lha & lhos & lhas \\
\hline$\left[1^{\text {st }} \mathrm{pl} . \mathrm{fem} . / \mathrm{masc}.\right]$ & no-lo & no-la & no-los & no-las \\
\hline$\left[2^{\text {nd }} \mathrm{pl} . \mathrm{fem} . / \mathrm{masc}.\right]$ & vo-lo & vo-la & vo-los & vo-las \\
\hline
\end{tabular}

The general rule that a dative clitic precedes an accusative clitic is further restricted by a person constraint. It has been first formulated in Bonet $(1991,2008)$ as the Person-Case Constraint (PCC) with a strong version and a weak version. Both versions are given in (54).

a. Strong version: the direct object has to be third person.

(Bonet 2008:104)

b. Weak version: if there is a third person it has to be the direct object.

Both the strong and the weak version capture the fact that a third person accusative clitic can be combined with a dative clitic in all persons, and, that a third person dative clitic cannot be combined with a first or second person accusative clitic, as exemplified in (55) below.

(55) a. Sp.

$$
\begin{aligned}
& \text { *Pedro } \mathrm{se}_{\mathrm{i}} \quad \mathrm{me}_{\mathrm{i}} \mathrm{e}_{\mathrm{k}} \quad \text { entregó } \quad\left[\begin{array}{lll}
\mathrm{a} & \text { la } & \text { policía }
\end{array}\right]_{\mathrm{i}} \text {. } \\
& \text { P. her.CL.DAT= me/you.CL.ACC= handed.over [to the police }] \\
& \text { intended meaning: 'Pedro handed me over to them (= the police).' }
\end{aligned}
$$

(Franco 1999:179)

b. EP *Nunca lhe me/te apresentarão.

never him.CL.DAT=me/you.CL.ACC= will.present

intended meaning: 'They will never present me/you to him.'

The strong version additionally states that all combinations of first and second person clitics should be ungrammatical. For examples the combinations of first + first person singular or plural and second + second person singular or plural are excluded in both languages. Additionally, combinations of referentially overlapping forms such as first person singular + first person plural are generally not accepted.

As for Spanish, it seems that the combination first person + second person is judged odd by all speakers, but there is variation with respect to the order second person + first person. Ormazabal \& Romero (2007:317) state that a first and second person accusative clitic can never co-occur with an argumental dative clitic, and they would exclude examples like (56b), which are taken to be perfectly grammatical in Fernández Soriano (1999:1267). 
(56) a.

*Pedro me te envía.

(Ormazabal \& Romero 2007:316)

P. me.CL.DAT $=$ you.CL.ACC $=$ sends

intended meaning: 'Pedro sends you to me.'

b.

Te me presentaron.

(Fernández Soriano 1999:1265)

you.CL.DAT $=$ me.CL.ACC $=$ presented

'They presented me to you.'

For European Portuguese, Martins (2013) and Luís \& Kaiser (2016) agree on the strong version of the PCC. Both combinations of first person + second person and second person + first person are ungrammatical, as exemplified in (57).

(57) a.

*O João entregou-me-te.

(Luís \& Kaiser 2016:212)

the J. handed.over=me.CL.DAT=you.CL.ACC

intended meaning: 'João handed you over to me.'

c.

*O João entregou-te-me.

(ibid.)

the J. handed.over=you.CL.DAT=me.CL.ACC

intended meaning: 'João handed me over to you.'

As for the position of the reflexive clitic, it precedes the dative clitic in both languages (for details on the different interpretations of the reflexive clitic see 2.3). In European Portuguese the reflexive clitic combines with a dative clitic, as in (58a), and it can head a dative-accusative cluster, as in (58b), but it is ungrammatical with an accusative clitic, as shown in (58c). Furthermore, two reflexive clitics cannot co-occur in a cluster, as exemplified in (58d).

(58)
a. EP
A boca abriu-se-te
de espanto.
(Martins 2013:2236)
the mouth opened=REFL.CL=yOu.CL.DAT by astonishment
'There you stood agape.'
b.
Enviou-se-vo-la
(a embalagem).
(Google, 24 July 2020)
send=REFL.CL=yOu.CL.DAT=it-CL.ACC (the packaging)
'People sent it to you.'
c.
*Ouve-se-os
gritar o tempo todo.
(Martins 2013:2236)
hears=REFL.CL=them.CL.ACC scream the time all
intended meaning: 'One hears them scream all the time.'
d.
*Casa-se-se.
(ibid.)
marry=REFL.CL=REFL.CL
intended meaning: 'People get married with each other.'

In Spanish, the reflexive clitic can combine with a dative clitic and with an accusative clitic, as shown in (59a) and (59b). But the co-occurance of two reflexive clitics or a reflexive clitic and a spurious se is not possible, as exemplified in (59c). 
(59) a.

La boca se te abrió.

the mouth REFL.CL=you.CL.DAT= opened

'There you stood agape.'

b.

Se la comió (la tarta).

REFL.CL=it.CL.ACC $=$ ate (the cake)

'He/She ate it (the cake).'

c.

*Los honores se se los $\quad$ da a los generales.
the honors REFL.CL=them.CL.DAT= them.CL.ACC= give to the generals
intended meaning: 'The honors, one gives them to them, the generals.'

(Perlmutter 1971:202)

\subsubsection{Clitic placement: proclisis and enclisis}

The major difference between Spanish and European Portuguese clitic syntax are the conditions for an enclitic or a proclitic position. In Spanish, clitic placement is determined by finiteness. With finite verbs, the clitic occurs in proclitic position, as shown in (60a), and with non-finite verbs it occurs in enclitic position, as shown in (60b).

a. Sp.

La niña la besa.

$a^{\prime}$.

*La niña besa la.

the girl her.CL= kisses the girl kisses =her.CL

'The girl kisses her.'

b.

Al verla
at.the see.INF=her.CL
'At seeing her.'

$b^{\prime}$.

*Al la ver

at.the her.CL= see.INF

In European Portuguese, the syntax of clitics is not determined by finiteness and is far more complex. As discussed in Martins (2013, 2016), several factors determine the enclitic, proclitc, and mesoclitic position. For the sake of introduction, only a few triggers are exemplified here. Whenever additional details are relevant for the analysis presented in this book, they are discussed in the corresponding sections.

The proclitic position is triggered by several conditions, such as negation, as in (61a); focalisation by adverbs, as in (61b); (some) quantifiers, as in (61c); contrastive fronting, as in (61d); wh-elements, as in (61e); and subordinating conjunctions, as in (61f).

(61) a. EP Os cães não a $\operatorname{assustam}\left(*^{*}\right.$-na).

(Martins 2013:2242)

the dogs not her. $\mathrm{CL}=\mathrm{scare}=$ her.CL

'The dogs did not scare her.'

b. Até o gato me mordeu(*-me).

(ibid.)

even the cat me.CL=bit=me.CL

'Even the cat bit me.' 
c.

Poucos cães a assustam(*-na).

(Martins 2013:2266)

few dogs her.cL=scare=her.CL

'Only a few dogs scare her.'

d.

PARA A RUA se escapeu(*-se) o Gaspar!

to the street REFL.CL=escaped=REFL.CL the G.

'It was down the street that Gaspar escaped.'

e. Quem te contou?

(ibid.)

who you.CL $=$ told

'Who told you that?'

f. Parece que se preparam $\left(*_{-s e}\right)$ grandes coisas.

(Martins 2013:2275)

seems that REFL.CL=prepare=REFL.CL big things

'It seems that big things are going on.'

If no proclisis trigger is present, the clitic appears in enclitic position. This is the case for all affirmative sentences (declarative, imperative, exclamative, or yes/no questions), as shown in Martins (2013:2239). Her examples are given in (62).

(62) a. EP As aventuras humilhavam-no, estava farto.

(Martins 2013:2240)

the adventures humiliated=him.cL, was fed.up

'The adventures humiliated him, he was fed up.'

b. $\quad$ E tu despacha-te, criadita!

(ibid.)

and you hurry=you.cL, little maid

'And you hurry up, little maid!'

c.

Você saiu-me um belo vigarista!

(ibid.)

you turned.out=me.CL a beautiful con.man

'You became a good con man!'

d. $\quad \mathrm{O}$ engenheiro disse-lhe onde estava a viver?

the engineer said=you.cL where was to live

'Did the engineer tell you where he was living?'

Note that the verb + enclitic combination in (62a) is subject to morphophonological alternations. Instead of the third person accusative form $o$ the $n$-allomorphs no, nos, na, and nas are used. ${ }^{12}$

12 The insertion of the $n$-allomorphs is due to the following configuration: the verb ends with a nasal diphthong and the clitic is/starts with a vowel. Luís \& Kaiser (2016:221) argue for a morphological process, because not all verbs that end with a nasal diphthong trigger this alternation. A second process concerning the verb + enclitic combination is the insertion of the $l$-allomorphs $l o(s)$ or $l a(s)$ and the deletion of verb-final consonant when it is $-s,-z$, or $-r$ and the clitic starts with a vowel. For a detailed presentation of other phonological and morphophonological processes affecting the verb-clitic complex and clitic clusters see also Luís \& Kaiser (2016) and references cited there. 
Finally, European Portuguese allows for a mesoclitic position. In case no proclisis trigger is present and the verb is in future or conditional tense, the clitic is placed in between the verbal suffix -er and the person and number ending, as shown in (63).

a. EP Speaker A: Achas que vamos conseguir?

(Martins 2013:2241)

think that going do it?

'Do you think we'll do it?'

Speaker B: Ver-se-á!

See=REFL.CL-FUT.3.SG

'We will see!'

b. Escrever-lhe-ia, como ela me pedira que fizesse.

(ibid.)

write=her.CL-COND.1.SG as she me.CL= had.asked that do

'I would write her, as she had asked me to do.'

In non-finite sentences that are not introduced by a preposition, the same triggers are relevant for proclitic or enclitic placement. Non-finite clauses introduced by a preposition allow both, enclisis or proclisis.

\subsubsection{Clitic climbing}

Another important aspect of Romance clitic syntax is the placement of clitics in embedded infinitival sentences. In these contexts, the clitic can attach to the infinitival verb, i.e. the verb it is semantically associated with, or 'climb up' to the higher, finite verb. The contexts for clitic climbing are subject control contexts, as in (65)/(66), Exceptional Case Marking (ECM) contexts, as in (67), and object control contexts, as in (64). Martins (2000) shows that Romance languages are not uniform with respect to the clitic climbing. For example, Spanish, but not European Portuguese, allows for clitic climbing in object control contexts. ${ }^{13}$

(64) a. Sp. Me lo aconsejó / permitió comprar.

(Martins 2000:184) you. $\mathrm{CL}=$ it. $. \mathrm{CL}=$ advised.3.SG. $/$ allowed.3.SG. buy.INF

'He/She advised/allowed me to buy it.'
b. EP *Aconselhou-mo a / *Permitiu-mo comprar. advised=me.CL=it.cL to / allowed=me.CL=it.cL buy.INF (ibid.)

In subject control contexts, the clitic may stay with the non-finite verb, as in (65), or climb to the finite modal or aspectual verb, as in (66).

(65) a. Sp. Quiero / Vengo a / Acabo de dártelo.

(Martins 2000:170) want.1.SG / come.1.SG to / finish.1.SG to give=you.CL=it.CL 'I want to give / come to give / just have given it to you.'

13 But see Barbosa et al. (2017) for variation within European Portuguese. 
b. EP O polícia quer / pode / vai multar-me por excesso de velocidade.

the policeman wants / can / go fine=me.cL for excess of speed

'The policeman wants / can / is going to fine me for breaking the speed limit.'

(66) a. Sp. Te lo quiero / vengo a / acabo de dar. (Martins 2000:170) you. $. \mathrm{CL}=$ it. $\mathrm{CL}=$ want.1.SG $/$ come.1.SG to $/$ finish.1.SG to give.INF

'I want to give / come to give / just have given it to you.'

b. EP O polícia quer-me / pode-me / vai-me multar por

(ibid.)

the policeman wants=me.CL / can=me.CL / go=me.CL fine.INF for

excesso de velocidade.

excess of speed

'The policeman wants / can / is going to fine me for breaking the speed limit.'

In ECM contexts the infinitival subject clitic has to be attached to the finite causative or perception verb, even though the clitic is thematically related to the non-finite verb. This is shown in (67).
a. Sp.
Te hice trabajar.
$a^{\prime} . \quad E P$
Faço-te trabalhar.
you. $\mathrm{CL}=$ made work
make=you.cL work
'I made you work.'
'I make you work.'
b.
*Hice trabajarte.
made work=you.cL
$\mathrm{b}^{\prime}$
*Faço trabalhar-te.
make work=you.cL

The present illustration of clitic climbing is sufficient to understand that the position of clitics may vary without affecting the interpretation of the sentence. These displacement patterns have been taken as an argument in favour of a phrasal status of clitics and as an argument against an analysis of clitics as pure agreement morphemes.

\subsubsection{Clitic doubling and object marking}

The syntactic derivation of the binding properties of reflexive and non-reflexive clitics put forward in chapter 7 is essentially based on the analysis of clitic doubling structures. In the present section some background information on clitic doubling is given that is necessary to understand the discussion in chapters 5 to 7.

The term clitic doubling describes the phenomena that an object clitic co-occurs with a coreferential stressed pronoun or noun. Differently from left or right dislocation structures, the doubled nominal is in its base position. If the pronoun or noun is (overtly) realised, then the clitic is obligatory. In other words, it is the clitic that is obligatory and not the pronoun/noun. The phenomenon of clitic doubling has been linked to the phenomena of differential/direct object marking in Jaeggli $(1982,1986)$ and Kayne (1975), and this correlation has become known as the Kayne/Jaeggli generalisation. It states 
that clitic doubling is possible if a DP receives accusative case by means of a preposition, in the case of Spanish and European Portuguese by means of the case marker $a$. This means that the case marker is a condition for clitic doubling, but it is not a trigger for it. Because clitic doubling phenomena are related to the syntax and semantics of direct object marking, the next subsections are dedicated to object marking in the languages under discussion.

For Peninsular and Latin-American Spanish, the structural and semantic conditions of direct object marking have been studied extensively, such as in Suñer (1988), Torrego (1998), von Heusinger \& Kaiser (2007, 2003), Leonetti (2007, 2003), García García (2007), and López (2012). In Peninsular Spanish, among the obligatorily marked DPs, only personal pronouns can and must be doubled in situ.

In European Portuguese, direct object marking is very limited in comparison to Spanish. But it shows similar patterns for obligatory doubling of reflexive and non-reflexive strong pronouns, as shown in Brito (2008) and Magro (2019).

As we will see, only a subset of the marked DPs allows for clitic doubling in Spanish and European Portuguese. In the following, the contexts for object marking and of optional and obligatory clitic doubling are briefly summarised for both languages.

\subsubsection{Object marking and clitic doubling in Spanish}

A direct object DP in Spanish is obligatorily marked if it bears the features [+animate], [+definite], and [+specific], as, for example, a proper name (see von Heusinger \& Kaiser 2007, 2003, Leonetti 2007, 2003, García García 2007). But it has been shown that neither of these features is a sufficient requirement for object marking. Indefinite DPs and the pronoun uno are obligatorily marked if they are [+animate] and [+specific], as shown in (68).

(68) a.

Mataron a $/ * \varnothing$ uno en Sunset Boulevard.

(Uriagereka 1999:270)

killed om / someone at Sunset Boulevard

'They killed someone on Sunset Boulevard.'

b. $\quad$ Ayer vi a $/ * \varnothing$ un estudiante mío en la biblioteca.

Yesterday saw ом / a student my in the library

'Yesterday I saw a student of mine in the library.'

López (2012) observes that object marking is also obligatory for [-specific] and [-definite] object DPs if they occur in the context of ECM small clauses, as in (69a), in causative constructions, as in (69b), and in object control contexts, as $(69 \mathrm{c})$. The [-specific] interpretation is assured by the subjunctive mood in the relative clauses modifying the indefinite DP.

(69) a.

Juan no considera honrado a $/ * \varnothing$ un hombre que acepte sobornos. J. not considers honourable oм / a man that accepts.suBj bribes

'Juan does not consider a man who accepts bribes to be honourable.' 
b.

Rosita hace quedarse en clase a /* $\varnothing$ un niño que no haya terminado R. makes stay in class ом / a child that not has.suBJ finished los deberes.

the assignments

'Rosita makes a child that has not finished his assignments stay in the classroom.'

c. Rosita forzaría a / * $\varnothing$ una empleada que tuviera depresión a venir R. forces.COND.3SG OM / a employee that has.suBJ depression to come al trabajo.

to.the work

'Rosita would force an employee that had a depression to come to work.'

Furthermore, object marking appears to depend on the meaning of the verb. According to Torrego (1998) object marking is obligatory with [+animate] DPs even if they are [-specific] and [-definite] in case the verb implies that the object is 'affected'. Verbs that select affected objects include golpear 'hit', odiar 'hate', castigar 'punish', ver 'see', esconder 'hide', encontrar 'find', or buscar 'search'. But animacy alone has also been demonstrated by Leonetti (2003) and García García (2007) to be an insufficient condition for licensing object marking. In existential contexts with haber and tener, marking of a [+animate], but [-definite] DP is ungrammatical.

(70) a.

Había *a / $\varnothing$ una enfermera.

(Leonetti 2003:8)

there.was ом/ a nurse

'There was a nurse.'

b. $\quad$ Ella tenía $*$ a $/ \varnothing$ un hermano.

(ibid.)

she had oм/ a brother

'She had a brother.'

García García (2007) observed that with transitive verbs, whose external arguments can be agentive or non-agentive, object marking is possible with inanimate DPs. For example in (71a), the external argument of the verb reemplazar 'replace' is interpreted as an agent and in (71b) it has a non-agentive interpretation. In the latter case, the two arguments are not thematically differentiated; both arguments bear the theta role theme. Only by means of object marking can the external argument be differentiated from the internal argument.

a. Sp.

[El profesor $]_{\mathrm{AGENT}}$

reemplaza [el libro $]_{\text {THEME }}$.

(García García 2007:70)

the teacher

replaces the book

'The professor replaces the book (with something else).'

b.

$$
\begin{aligned}
& {[\text { El profesor }]_{\text {THEME }} \text { reemplaza }[\mathrm{al} \text { libro }]_{\text {THEмE. }}} \\
& \text { the teacher } \quad \text { replaces oM.the book } \\
& \text { 'The professor takes the place of the book.' }
\end{aligned}
$$


As mentioned above, clitic doubling is dependent on object marking. But not all marked DPs can be doubled by a clitic, as shown by the examples from von Heusinger \& Kaiser (2003:55), reproduced here as (72). Only pronouns are obligatorily marked and obligatorily doubled by a clitic. With other marked DPs, such as proper names, definite or indefinite DPs, doubling is either optional or ungrammatical. ${ }^{14}$
a. Sp. $\quad *(\mathrm{La})$ veo a ella. her.CL $=$ see $\mathrm{OM}$ her
c. $\quad(* \mathrm{La})$ veo a la mujer.
her.CL $=$ see om the woman
b.
(??La ) veo a María.
her.CL $=$ see $\mathrm{OM} \quad \mathrm{M}$.
'I see her / Maria.'
d. $\quad(*$ La $)$ veo a una mujer.
her.CL $=$ see om a woman

As exemplified in (73), clitic doubling of reflexive and non-reflexive pronouns is in accordance with the Kayne/Jaeggli generalisation. Both types of strong pronouns are obligatorily marked by $a$ and doubled with the clitic. The examples in (73) show as well that the obligatory element is the clitic and not the strong pronoun. Or in other words: if the strong pronoun is (overtly) realised, it must be marked and doubled with a clitic.

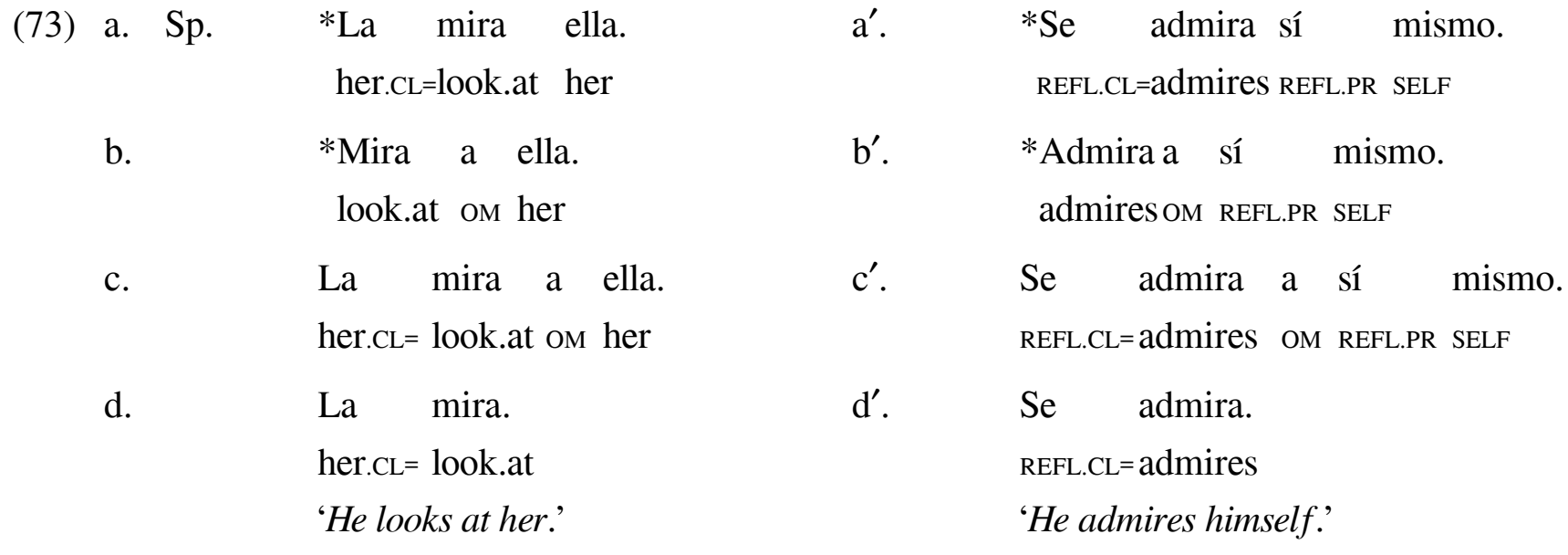

Clitic doubling of indirect (dative) objects is nearly unrestricted compared to clitic doubling of accusative objects. ${ }^{15}$ Dative object DPs are always marked by the dative preposition $a$, and doubling is not subject to lexical constraints such as definiteness of specificity. In (74), examples for clitic doubling of pronouns, proper names, a definite, and a indefinite DP are given.

14 In Latin-American varieties of Spanish, other DPs (inanimate, indefinite, and unspecific) may also be doubled by a clitic. A systematic overview of distinct doubling systems in these varieties is presented in Leonetti (2008). For a presentation of object marking and clitic doubling in Porteño Spanish see Suñer (1988).

15 As mentioned in Suñer (1988:395) and Cuervo (2003:43ff), only unmodified bare nouns cannot be doubled, as shown in (i). But clitic doubling becomes possible when the bare noun is modified as, for example, in (ii) by adjective, or in (iii) by means of coordiniation. But see chapter 7 for an argument that sentences like the one in (iii) are an instance of clitic right dislocation.
(i) Sp. *Les donaré todos mis bienes a museos.
(Suñer 1988:395)
(ii) Les donaré todos mis bienes a museos locales.
(Cuervo 2003:43)
(iii) Les donaré todos mis bienes a museos y bibliotecas. 


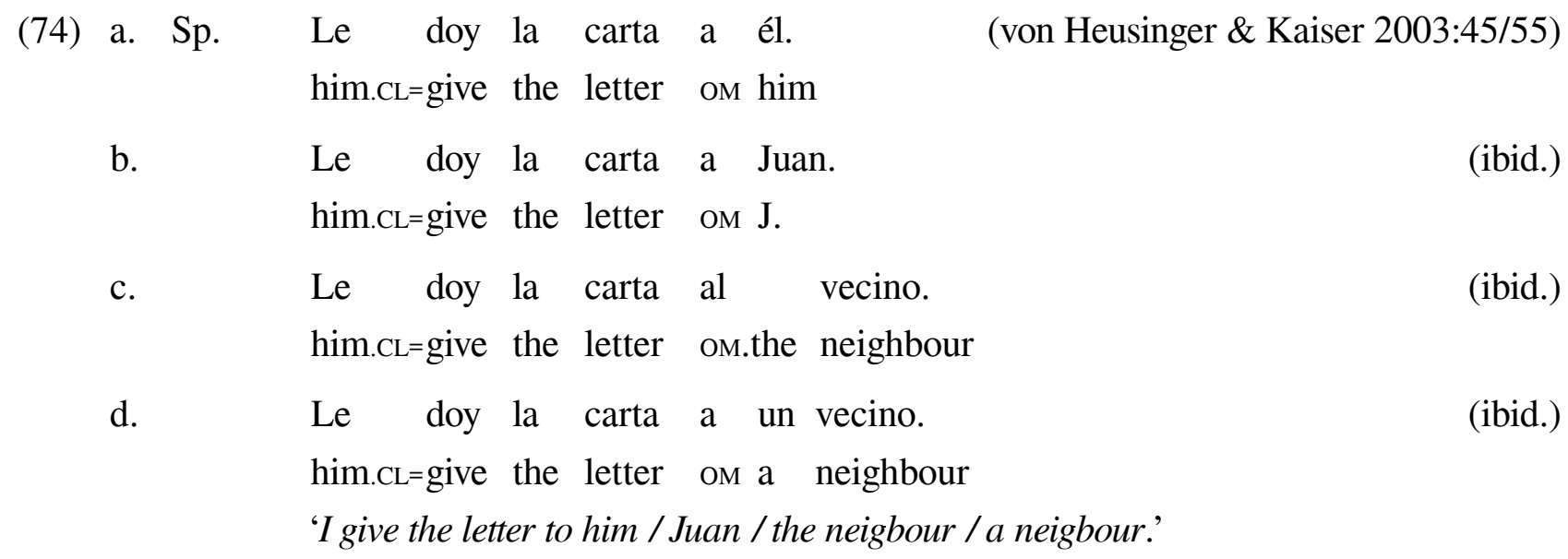

Clitic doubling of argumental dative DPs is the standard case and obligatory with pronouns. The examples in (75), involving verbs of transfer such as entregar 'hand over', enviar 'send', or dar 'give', show that clitic doubling of (non-pronominal) indirect objects is optional. Suñer (1988), Demonte (1995), and Cuervo (2003) argue that the optionality is only superficial and that (75a) and (75b) have two distinct underlying structures. They argue that $a$ is a case marker in (75a) and that the structure of this sentence is similar to English double object constructions, whereas $a$ is a (directional) preposition in (75b). Both structures will be discussed in more detail in chapter 5 .
a. Sp. Le entregué las llaves al conserje.
him.CL=gave the keys om.the janitor
'I gave the janitor the keys.'
b. Entregué las llaves al conserje.
gave the keys to.the janitor
'I gave the keys to the janitor.'

(ibid.)

In (76) the particle $a$ can only be interpreted as a directional preposition and clitic doubling is ungrammatical. ${ }^{16}$

$$
\begin{aligned}
& \text { Sp. } \quad * \mathrm{Le}_{\mathrm{i}} \text { mandé un paquete a } \text { Madrid }_{\mathrm{i}} \text {. } \\
& \text { it.cL=send a parcel to Madrid }
\end{aligned}
$$

(Demonte 1995:6)

For the sake of completeness, it should be mentioned that the Kayne/Jaeggli generalisation is also met with reflexive pronouns in indirect object position, as exemplified in (77). The reflexive pronoun in indirect object position shows the same doubling pattern as with direct objects: the clitic is the obligatory element, and if the strong pronoun is realised, it must be marked by the object marker $a$ and it is obligatorily doubled by the clitic.

16 López (2012:33/34) disagrees on that point. He argues that double object constructions are also possible without the clitic, but he agrees with Suñer (1988), Demonte (1995), and Cuervo (2003) on the observation that in the double object contruction the IO c-commands the DO and that in constructions involving a PP, the DO c-commands the PP. 
(77) a. Sp. *Juan se regaló el coche sí mismo.

J. REFL.CL=gave the car REFL.PR SELF

b. *Juan regaló el coche a sí mismo.

J. gave the car OM REFL.PR SELF

c. Juan $*(\mathrm{se})$ regaló el coche a sí mismo.

J. REFL.CL=gave the car OM REFL.PR SELF

d. Juan $*(\mathrm{se})$ regaló el coche.

J. REFL.CL=gave the car

'Juan gave the car to himself as a present.'

\subsubsection{Object marking and clitic doubling in EP}

As presented in Mateus et al. (2003:286), direct object marking is only obligatory ${ }^{17}$ with personal pronouns and with the relative pronoun quem. Other pronouns, proper names, or definite or indefinite DPs are not marked and cannot be doubled with a clitic. With direct object pronouns, reflexive and non-reflexive, European Portuguese shows the same pattern as Spanish and is in accordance with the Kayne/Jaeggli generalisation. This is exemplified in (78a) and (79a), following Mateus et al. (2003) and Gonçalves \& Raposo (2013:1169ff). Strong pronouns in direct object position are obligatorily marked by the object marker $a$, as shown in (78a) and (79a), respectively. Furthermore, the strong pronoun cannot appear without the clitic, as shown in (78b) and (79b), but the clitic can appear without the strong pronoun, as in (78c) and (79c). A grammatical sentence of a doubling structure is given in (78d) and $(79 \mathrm{~d}){ }^{18}$

(78) a. EP *Vi-os eles à saida do cinema. (Mateus et al. 2003:286) saw=them.cL them at.the exit of.the cinema

b. $\quad * V i$ a eles à saida do cinema. saw om them at.the exit of.the cinema

c. Vi-os à saida do cinema. saw=them.CL at.the exit of.the cinema

d. Vi-os a eles à saida do cinema. (Mateus et al. 2003:286) saw=them.cL om them at.the exit of.the cinema 'I saw them at the exit of the cinema.'

17 Among the optional cases of object marking are (i) the name of God and (ii) left dislocated or topicalised [+human] DPs. Furthermore, Mateus et al. (2003:823) mention that QPs may double a clitic, but only if the quantifier can co-occur with a personal pronoun, such as in a todos eles.

18 The data from Mateus et al. (2003) and Gonçalves \& Raposo (2013) presented here contradict Kaiser (1992:125ff), who claims that sentence-internal doubling of a third person direct or indirect object pronoun is ungrammatical in European Portuguese. 
(79) a. EP

*O Rui admira-se si próprio.

the R. admires=REFL.CL REFL.PR SELF

b. $\quad * O$ Rui admira a si próprio.

the R. admire OM REFL.PR SELF

c. $\quad \mathrm{O}$ Rui admira-se.

the $\mathrm{R}$. admire=REFL.CL

d. $\quad \mathrm{O}$ Rui admira-se a si próprio.

the R. admires=REFL.CL OM REFL.PR SELF

'Rui admires himself.'

With respect to clitic doubling of indirect pronouns, European Portuguese and Spanish behave quite distinctly. In European Portuguese, doubling of the indirect object is limited to strong personal pronouns, whereas in Spanish, doubling of the indirect object is obligatory with nearly all DPs. Martins (2013) shows that doubling of the clitic occurs in three contexts illustrated by means of examples from the CRPC $^{19}$ : (i) if the pronoun receives a contrastive focus interpretation, as in (80a), (ii) if the pronoun is modified by a relative clause, as in (80b), and (iii) if the pronoun is coordinated with another $\mathrm{DP}$, as in $(80 \mathrm{c})$.

(80) a. EP E conclui: «Era uma forma de pôr os jovens a pensar no que podem dar à sociedade e não só no que a sociedade lhes pode dar a eles.»

'And I conclude: 'It was a way to make the young people think about what they can give to society and not only what society can give to them.'

b. Mas, se eu lhe perguntar a ele, que nunca advogou, por que é que diz que o Ministro de Justiça é o «ministro do equipamento judicial», não saberia justificar.

'But, if I asked him, who never practised law, why he say that the Secretary of Justice is the "secretary of legal equipment", he would not be able to justify this.'

c. Quando o ouvirmos e percebermos que está comprometido a executar as condições vamos dar-lhe protecção a ele e ao seu grupo.

'As soon as we hear and see that he is unable to meet the condition, we will give protection to him and his group.'

In chapter 7.3.2 I will come back to clitic doubling and coordination and I will show that doubled pronouns cannot be coordinated and that the coordination structure in (80c) has to be a coordination of a verbal phrase (vP or TP).

Differently from Spanish, the indirect object pronoun can surface without the ciltic. This means that the ungrammatical patterns (78b) and (79b) above are grammatical with indirect pronouns, and that European Portuguese allows for so-called Dative Prepositional Constructions (DPC) independently of

19 Examples from the CRPC and CREA are only glossed if the internal structure is relevant for the discussion. 
a locative interpretation of the preposition (see chapter 5 for more details). This is exemplified with sentences from the CRPC in (81). In both sentences the pronoun appears without the clitic and receives a contrastive interpretation.

(81) a. EP [...] porque o Sr. Presidente se recusou a dar a palavra na altura devida ao Sr. Deputado Carlos Lage, dando a palavra a outros deputados antes de a ter dado a ele, como competia.

'[...] because, Mr President, you refused to give the floor to the MP Mr Carlos Lage at the proper moment, giving the floor to other MPs before having given it to him, as you should have.'

b. $\quad$ E a lógica parece simples: Então se eu dou sempre uma gorjeta ao funcionário do restaurante, e ele não faz mais do que a sua obrigação, porque é que não hei-de dar a ele?

'And the logic seems to be simple: well, if I always tip the waiter, and he does nothing but his job, then why shouldn't I tip him?' (him = a man who waves people into a free parking space)

Furthermore, European Portuguese allows for DPCs with reflexive indirect object pronouns, a construction that is ungrammatical in Spanish. Again, this construction is illustrated by means of examples from the CRPC in (82b) .

(82) a. EP Um adolescente prestes a encetar um estranho processo de fuga: fugia do «casulo» que construíra em criança e também do convívio pela simples razão de que nunca of erecera a si próprio a oportunidade de aprender a arte de comunicar.

'An adolescent ready to start a strange process of escape: escape from the "cocoon" that he built as a child and also from society for the simple reason that he never gave himself the opportunity to learn the art of communicating.'

b. A pouco e pouco, a ideia de dirigir actores foi ganhando forma, mas Luís impôs a si próprio uma espécie de regra: [...].

'Step by step, the idea to direct actors took shape, but Luís imposed on himself a kind of rule: $[\ldots]$..'

Thus, in European Portuguese the reflexive dative object can be realised either as a reflexive clitic or as a reflexive pronoun. Lobo (2013:2212, fn. 26) mentions that the choice for one or the other is not completely arbitrary, but somehow related to the semantics of the verb. Lobo (2013:2212ff) mentions that with some verbs, as for example agradar 'ask' or sorrir 'smile', the strong pronoun is preferred over the reflexive clitic. Another factor affecting the choice of the pronoun over the clitic is due to the fact that in $\mathrm{EP}^{20}$ the reflexive (dative) clitic is incompatible with a direct object clitic (see section 2.2.3

20 Varieties in Southern Portugual permit this combination, p.c. Ana Maria Marins 
above, in particular example (58)). In these cases the dative is realised as a strong reflexive pronoun. In addition to the realisation of the dative object as clitic or as DPC, clitic doubling of a reflexive IO pronoun is possible, as shown by the example in (83).

(83) a. EP [...] mas esse é o grau de comedimento que o cineasta, cuja carreira sofreu graves problemas e insucessos nos anos setenta, resolveu adoptar como forma de convívio com o sistema de produção e com o público e como modelo expressivo em que se move dentro de parâmetros que acaba por se impor a si próprio, com sucesso, deve dizer-se.

'[..] but this is the degree of moderation that the director, whose career was marked by severe problems and flops in the sixties, managed to adopt as a form of coexistence with the production system and with the audience, and as a kind of expressive model in which he moves according to parameters that he had imposed on himself, successfully, as you might say.'

b. Para isso já pode usar cosméticos, melhorar o seu aspecto, agradar-se a si próprio e aumentar o seu charme junto das mulheres.

'For this he can use cosmetics, improve his look, please himself, and increase his charm with women.'

Summarising this section, we can say that Spanish and European Portuguese have obligatory clitic doubling with direct object pronouns. But with respect to indirect objects, the languages behave differently: Spanish has a nearly generalised doubling of all kinds of DPs and disallows DPCs with reflexive and non-reflexive pronouns. In European Portuguese, clitic doubling is possible, but restricted to pronouns and allows for DPCs with both reflexive and non-reflexive pronouns. In chapter 5 I will come back to the patterns presented in this subsection.

\subsubsection{Approaches to clitic syntax in a nutshell}

The brief comparison of Spanish and European Portuguese clitic syntax showed that clitics in the two languages share many properties, but are subject to different constraints for clitic placement and clitic doubling. They share the affix-like properties, which are the ban from coordination, the fact that they cannot bear word stress, and the fact that they need a verbal host. Additionally, the clitic pronoun forms morphophonological clusters in both languages. With respect to their thematic status, clitics can be arguments (object clitics) or functional elements, as will be briefly reviewed in the next section (e.g. the aspectual use of the reflexive clitic). These mixed properties make them hybrid categories that show properties of both syntactic heads and phrases. This has been formalised in Chomsky (1995b:56) by assigning them a categorial status of being simultaneously an $X^{\max }$ and an $X^{\min }$ category. The syntax of Romance clitics is a very complex matter, a fact that is also reflected in the enormous number of analyses that have been put forward within the Generative framework. Those focussing on the syntactic 
process of cliticisation can be divided into two main types of approaches that also reflect the hybrid nature of clitics: the agreement approach and the movement approach.

The agreement approach (or base-generation approach) focusses on the affix-like properties of clitics. The main assumption is that clitics are base-generated together with their verbal host inside a verbal agreement projection (see Suñer 1988, Franco 1999, Zagona 2002, Kaiser 1992).

The movement approach focusses on the XP properties and basically assumes that the clitic is base-generated in argument positon and then moves to its final position, accounting for the fact that clitics represent arguments, are in complementary distribution with all or some DPs, and exhibit a flexible surface position (see Kayne 1975, Martins 1994, 2000, Sportiche 1998). Within the movement approach, the derivation of proclisis and enclisis has been a major topic, in particular for European Portuguese. Different approaches to clitic placement in syntax and phonology are summarised in Galves, Torres Morales \& Ribeiro (2005). For examples Duarte, Matos \& Gonçalves (2005) derive proclisis from an initial enclitic base position. Martins $(1994,2000)$ derives enclisis from an initial proclitic position by movement of the verb into a position above the clitic. For the purpose of the present book neither the derivation of enclisis or proclisis, nor the derivation of PCC patterns are relevant, and accounts that are concerned with these issues will not be discussed any further.

The BigDP analysis of Uriagereka (1995) is a version of the movement approach and aims to account for clitic doubling structures. This approach, in particular the version of Roberts (2010), will be introduced in detail in section 7.3 and adopted in the present book with some modifications.

\subsection{Reflexive and non-reflexive uses of the clitic se}

As indicated above, the combination of a verb and reflexive clitic is not exclusively interpreted as a reflexive predicate, but may receive several non-reflexive interpretations. A reflexive predicate is defined in the following way: two arguments of a (transitive) verb are identified and thus receive an identical interpretation (see Reuland 2011, Chierchia 1989/2004). In a more formal notation, the definition looks like in (84).

$$
\mathrm{V}_{\text {trans }}(\mathrm{x}, \mathrm{y}) \rightarrow \mathrm{V}_{\text {refl }}(\mathrm{x}, \mathrm{x})
$$

In the grammars of Spanish or European Portuguese, such as the Nueva gramática de la lengua española (2009-2011) henceforth NGLE, or Mateus et al. (2003), the classification of the non-reflexive uses is far from uniform. The uses are classified in different ways, depending on the theoretical perspective. Among the non-reflexive uses or interpretations, there are reciprocal, passive, impersonal, middle, anticausative, aspectual, and antipassive interpretations. The clitic se or the verb-se complex is often designated as a reflexive clitic or reflexive verb, respectively, even though the interpretation of the predicate is not reflexive according to the definition in (84) above. From this point on, the following glosses will be used: SE.REFL for the reflexive interpretation, SE.REC for the reciprocal, SE.PASS for passive, SE.IMP for impersonal, SE.MID for middle, SE.ASP for aspectual, SE.APA for antipassive, and SE.ACA for anticausative/inchoative. When the interpretation is not relevant, just SE will be used. 
In the present description of the reflexive and non-reflexive interpretations, I want to follow the classification put forward in the NGLE:3120 ff. The verb-se combination is classified as a verbo pronominal (Sp). This class is subdivided into pronominales alternantes and pronominales inherentes. Verbs of the first group have a (transitive) variant without a clitic, while verbs of the second group have no such variant. This is exemplified in (85) and (86). The verb-se complex in (85a) and (85a') is a reflexive predicate according to the definition in (84), and its transitive counterpart is shown in $(85 b)$ and $\left(85 b^{\prime}\right)$.
a. EP
O Rui admira-se.
a.' Sp.
Juan se admira.
the R. admires=SE.REFL
J. SE.REFL $=$ admires
'Rui admires himself.'
'Juan admires himself.'
b. EP
$\mathrm{O}$ Rui admira o Pedro.
the $\mathrm{R}$ admires the $\mathrm{P}$.
$b^{\prime}$. Sp.
Juan admira a Pedro.
'Rui admires Pedro.'
J. admira ом P.
'Juan admires Pedro.'

An example of an inherent reflexive verb is given in (86a) and (86b). Inherent reflexive verbs are a heterogeneous group of intransitive verbs that are lexicalised together with the reflexive clitic. This means that these verbs do not have a transitive counterpart and that the clitic has no additional effect on the interpretation, as shown in $\left(86 a^{\prime}\right)$ and $\left(86 b^{\prime}\right)$.

(86) a. EP

O Rui não se arrepende de nada.

the R. not $\mathrm{SE}=$ regrets of nothing

'Rui does not regret anything.'

b. Sp. Juan no se arrepienta de nada.

J. not SE=regrets of nothing

'Juan does not regret anything.' $\mathrm{a}^{\prime} . \quad{ }^{*} \mathrm{O}$ Rui arrepende o Pedro. the $\mathrm{R}$. regrets the $\mathrm{P}$.

$\mathrm{b}^{\prime}$. *Juan arrepienta a Pedro.

J. regret OM $\mathrm{P}$.

In following subsections, a brief introduction to the non-reflexive uses is given. It focusses on the first group of verbs because they allow a derivational perspective on the different uses of the clitic. The clitic se has often been described as an intransitiviser, case-absorber, or valence-reducer affecting the verb's argument structure and/or its case properties. In chapter 3, it will be argued that the reflexive clitic in true reflexive predicates is neither of these types, but realises the internal argument and does not affect the case properties of the verb.

The present section aims to show that a conception of the clitic as case-reducer and/or valence-reducer is empirically adequate only for interpretations different from the true reflexive or reciprocal interpretation. Furthermore, the most important syntactic and semantic differences between the distinct uses of $s e$ are presented. This overview aims at showing that a uniform analysis of all these uses, based on morphological similarity, should be abandoned, as suggested in Reinhart (2016:24ff). The clitic se may have distinct semanticosyntactic properties concerning its effect on (accusative) case. In addition to case, the presentation of the uses of $s e$ focusses on the following aspects: the alternation of the verb's 
argument structure (reduction/elimination of an argument), syntactic recoverability of the argument, and recoverability of the reduced argument for interpretation of PRO. Furthermore, it will be shown that case reduction does not imply argument reduction and that arguments can be morphosyntactically reduced but recovered for interpretation.

\subsubsection{True reflexive se}

Clitic doubling is the criterion for distinguishing true reflexives from inherent reflexives or from other non-reflexive uses. As shown in the previous section, clitic doubling is perfectly acceptable with a reflexive replacing the DO or IO. But doubling a non-argumental, inherent clitic is absolutely ungrammatical, as shown in (87).

(87) a. EP

*O Rui concentra-se a si próprio.

the R. concentrates=SE to REFL.PR SELF

b. Sp. *Juan se concentra a sí mismo.

J. $\quad$ SE $=$ concentrates OM REFL.PR SELF

Marelj \& Reuland (2016) claim that the reflexive versions of grooming verbs like lavar (EP/Sp) 'wash', afeitar (Sp) / barbear (EP) 'shave', peinar (Sp) / pentear (EP) 'brush, comb', and vestir (EP/Sp) 'get dressed' do not permit clitic doubling (the strong pronoun and the intensifier) although these verbs have a transitive counterpart. The apparent ban of clitic doubling is taken as an argument in favour of the intransitive nature of these reflexive predicates. But the unacceptability of the strong pronoun and the intensifier is not due to the lack of a second argument, as in (87), but due to interpretive reasons. By means of clitic doubling the second argument, here the patient argument, is focalised or highlighted. In the case of reflexive grooming verbs, a focalisation is judged odd because the normal situation is for one to perform such actions on oneself, at least nowadays (see chapter 5). Clitic doubling is grammatical in a context that licences highlighting/focalising of the theme argument. The sentences in (88) are possible, if, say, someone had an accident and is now learning again to perform everyday actions like eating, or getting dressed, and so forth.

(88) a. EP Ontem o Rui conseguiu vestir-se a si próprio pela primeira vez desde que teve o acidente.

b. Sp. Ayer Juan conseguió vestirse a sí mismo por primera vez desde que tuvo el accidente.

'Yesterday, Rui/Juan managed to dress himself for the first time since he had the accident.'

Thus, grooming verbs in Spanish and European Portuguese permit clitic doubling and may count as true reflexive predicates. Concering the discussion of the transitive or intransitive nature of true reflexive predicates in chapter 3, clitic doubling structures will be the central argument in favour of a transitive structure. 


\subsubsection{Reciprocal se}

In Spanish and Portuguese, a reciprocal predicate is formed by a transitive or ditransitive verb that obligatorily has a plural subject and the clitic se. True reflexives and reciprocal predicates are similar in the sense that two arguments of the verbal predicate are referentially related, but in a reciprocal predicate the two arguments are not identified, as in the definition in (84) above. A reciprocal predicate denotes a set of events in which the participants have changing roles. In a single event, the participants are either agent or patient, but never agent and patient of that single event. The second argument of a reciprocal predicate can be realised as a nominal construction with the pattern presented in (89a) for European Portuguese and (89b) for Spanish.
(89) a. EP
um/a(s) PREP DET outro/a(s)
b. Sp.
DET uno/a(s) PREP DET otro/a(s)

The indefinite pronouns uno/otro and um/outro agree with the subject, their antecdent. Furthermore, the selection of the preposition is determined by the reciprocal verb, as shown by the examples in (90).
a. EP
As crianças lavaram-se
umas às outras.
(Lobo 2013:2211)
the kids washed=SE.REC ones to.the others
'The kids washed each other.'
$a^{\prime}$ Vocês gostam muito um do outro.
you.PL like much one of the other
'You like each other very much.'
(Mateus et.al 2003:833)
b. Sp. Los niñosse golpearon los unos a los otros.
the kids SE.REC=hit the ones OM the others
'The kids hit each other.'
$\mathrm{b}^{\prime}$. $\quad$ Los abogados disputan siempre el uno con el otro.
(Otero 1999:1485)
the lawyers argue always the one with the other
'The lawyers always argue with each other.'

If the reciprocal strong pronouns were omitted in (90a) and (90b), the sentences would be ambiguous between a true reflexive and a reciprocal interpretation. Therefore, the strong reflexive double or the reciprocal pronoun serve to disambiguate the two interpretations. The reciprocal clitic also realises the internal argument and does not affect the case properties of the verb. Thus, reciprocal and reflexive clitics are similar with respect to these properties.

\subsubsection{Impersonal se}

Constructions with impersonal se can be formed with transitive, intransitive, and copular or modal verbs, but only if they are third person singular. The agent argument is interpreted as a generic or 
quasi-universal [+human] referent (see Martins \& Nunes 2016 and Bosque \& Gutiérrez-Rexach 2016). Examples of the impersonal use are given in (91).

$\begin{array}{llll}\text { (91) a. Sp. Se busca a los asesinos. } & \text { (Bosque \& Gutiérrez-Rexach 2016:419) }\end{array}$ 'One searches for the murclerer.'

'One searches for the murderer.'

b. EP Ouviu-se muitas explosões ontem.

(Martins \& Nunes 2016:8)

heard.3.SG=SE.IMP many explosions yesterday

'People heard many explosions yesterday.'

It is assumed that impersonal constructions have a pro arb argumental subject. Concerning the argumental status of impersonal subjects, Martins (2009) shows that some European Portuguese dialects (indicated by $\%)^{21}$ allow for doubling with a strong pronoun.

$$
\begin{aligned}
& \text { \%EP Chama-se-lhe a gente espigas. } \\
& \text { call=sE.IMP=it.cL the people spikes } \\
& \text { 'We call it spikes.' }
\end{aligned}
$$

Furthermore, impersonal constructions with transitive verbs assign accusative case to their objects. Thus, similar to reciprocal constructions, neither the argument structure, nor the case properties of the verb are reduced, but the realisation of the external argument is affected. In standard varieties, it has to be a covert pronoun.

\subsubsection{Passive se}

The passive interpretation of the combination verb-se is exemplified by means of the sentences in (93a) for Spanish and in (93b) for European Portuguese.
(93) a. Sp. Se encontraron.3.PL los libros. SE.PASS $=$ found.3.PL the books
'The books were found.'
b. EP Os artigos publicaram-se no último número da revista. the articles published.3.PL=SE.PASs in.the last number of.the journal 'The articles were published in the last issue of the journal.'

(Mateus et al. 2003:521)

Se-passives are similar to verbal passives in the sense that in both types of passives the theme argument of the (former) transitive verb becomes the nominative subject, accusative case is reduced, and the

21 The example in (92) was retrieved from CORDIAL-SIN, the Syntax-Oriented Corpus of Portuguese Dialects [http:// www.clul.ulisboa.pt/en/10-research/695-cordial-sin-syntax-oriented-corpus-of-portuguese-dialects]. As stated in Carrilho \& Magro (2010), the example comes from the AAL dialect area, which consists of the regions of Castelo de Vide, Porto da Espada, S. Salvador de Aramenha, Sapeira, Alpalhão, and Nisa (Portalegre). 
agent argument is not realised. However, while in verbal passives the agent argument of the (former) transitive verb can be realised by a por-PP, this is impossible in se-passive constructions, as exemplified in (94) and (95). ${ }^{22}$

(94) a. EP *Os artigos publicaram-se pelo editor.

(Mateus et al. 2003:532) the articles published=SE.PASS by.the editor

b. Os artigos foram publicados pelo editor. the articles were published by.the editor

'The articles were published by the editor.'

(95) a. Sp. *Se encontraron los libros por Juan.

SE.PASS=found the books by $\mathrm{J}$.

b. Los libros fueron encontrados por Juan.

the books were found by $\mathrm{J}$.

'The books were found by Juan.'

As discussed in Mateus et al. (2003) and Mendikoetxea (1999), the agent role, although it cannot be realised by a por-PP, is still present or active for interpretation. It is available for the interpretation of PRO, as shown in (96). But the implicit agent argument is restricted to a [+human] referent (see Martins \& Nunes 2016, Mateus et al. 2003, Bosque \& Gutiérrez-Rexach 2016, and Mendikoetxea 1999).

(96) a. Sp. Se usaron las navajas para PRO cortar la barba. SE.PASS $=$ used.3.PL the knifes for PRO cut the beard

'The knives were used for cutting the beard.'

b. EP Os canivetes usaram-se para PRO cortar pão.

the knifes used.3.PL=SE.PASS for PRO cut bread

'The knives were used for cutting bread.'

Thus, the clitic does not eliminate the agent argument completely because it is still available as [+human] implicit agent. However, accusative case is eliminated, as shown by the ungrammaticality of the sentences in (97), in which the theme argument is realised as an accusative clitic.
a. Sp.
*Se $\quad$ los
encontraron.
SE.PASS $=$ them. CL.ACC $=$ found
intended meaning: 'They were found.'
b. EP
*Podem-se comprá-los amanhã. can=SE.PASS buy=them.CL.ACC tomorrow intended meaning: 'They can be bought tomorrow.'

(Martins \& Nunes 2016:326)

\footnotetext{
22 Bosque \& Gutiérrez-Rexach (2016:418ff) mention that a realisation of the agent by a por-PP is possible in formal/official Spanish, as, for example, in the sentence Se firmó la paz por los embajadores.
} 
In the case of se-passives, the clitic can be associated with the elimination of accusative case and of the external argument. Furthermore, se-passives pattern with other unaccusative verbs with respect to word order. For both types of predicates the neutral word order is verb-subject (see Martins \& Nunes 2016, Bosque \& Gutiérrez-Rexach 2016, and Mensching \& Weingart 2016).

\subsubsection{Middle se}

So-called middle passive or middle voice constructions are similar to se-passive constructions in the sense that the external argument of a transitive verb is affected by the alternation. The difference is that the external argument is completely absent with middle constructions and is neither recoverable by a por-PP nor available for control, as exemplified in (98) for European Portuguese and in (99) for Spanish.

(98) a. EP Dantes, eles bebiam este vinho.

(Duarte 2013:456/457)

before they drank.3.PL this wine

'Then, they drank this wine.'

b. Dantes, este vinho bebia-se (bem).

(ibid.)

before this wine drank.3.SG=SE.MID well

'Then, this wine went down easily.'

c. *Dantes, este vinho bebia-se bem pelos apreciadores.

(ibid.)

before this wine drank.3.SG=SE.MID well by.the connoisseurs

d. *Dantes, este vinho bebia-se bem para PRO ficar contente. (ibid.)

before this wine drank.3.SG=SE.MID well for PRO be happy

(99) a. Sp. Antes, ellos solo bebían este vino.

before they just drank.3.PL this wine

'Then, Juan just drank this wine.'

b. Antes, este vino se bebía bien.

before this wine SE.MID= drank well

'Then, this wine went down easily.'

c. *Antes, este vino se bebía bien por los aficionados.

before this wine SE.MID= drank well by the connoisseurs

d. *Antes, este vino se bebía bien para PRO estar feliz.

before this wine SE.MID= drank well for PRO be happy

\subsubsection{Anticausative se}

An anticausative predicate is formed by the reflexive clitic and by a change-of-state verb. Mateus et al. (2003), Duarte (2013), Bosque \& Gutiérrez-Rexach (2016), and Mendikoetxea (1999) distinguish 
between two subclasses of causative verbs: transitive verbs with an agent/causer as external argument and a patient or experiencer as internal argument like hundir (Sp.) / afundar (EP) 'sink', quemar (Sp.) / queimar (EP) 'burn', or mover (EP/Sp.) 'move' and unaccusative verbs with an internal cause like empalidecer (EP) / palidecer (Sp.) 'turn pale' or florir (EP) / florecer (Sp.) 'bloom'. The verbs of the latter group do not have a transitive variant. As I want to focus on the alternation of the verb's argument structure, I will only discuss the first group. As shown in (100a) and (101a), the transitive verb can have a [-human] cause or a [+human] agent as its external argument. In (100b) and (101b) the anticausative versions are given, showing that the internal argument-the affected object-has become the nominative subject.

(100)a. Sp. Juan / Un golpe de viento abrió la puerta. Mendikoetxea (1999:1594) J. I a impact of wind opened the door

'Juan / a gust of wind opened the door.'

b. La puerta se abrió.

(ibid.)

the door SE.ACA=opened

'The door opened.'

(101)a. EP O Rui / O vento abriu a porta.

(Duarte 2013:450)

the R. / the wind opened the door

'Rui / The wind opened the door.'

b. A porta abriu-se.

(Duarte 2013:451)

the door opened=SE.ACA

'The door opened.'

In the analysis of Schäfer \& Vivanco (2015) the cause/agent argument is eliminated and is therefore not recoverable for interpretation. This is supported by the fact that the cause/agent argument can be neither realised as PP-adjunct nor is it active for the interpretation of PRO, as shown in (102) and (103). ${ }^{23}$

(102) a.

*La puerta se abrió por Juan.

(Mendikoetxea 1999:1592) the door $\quad$ SE.ACA=opened by $\mathrm{J}$.

b. * * abrió para PRO airear la habitación. the door SE.ACA=opened for PRO air the room

(103)

$\begin{array}{ll}\text { EP } \quad \text { A porta abriu-se } & \text { pelo Rui. } \\ \text { the door opened=SE.ACA } & \text { by.the } \mathrm{R} . \\ \text { *A porta abriu-se } & \text { para PRO entrar ar fresco. } \\ \text { the door opened=SE.ACA } & \text { for PRO enter air fresh }\end{array}$

(Duarte 2013:452)

23 Note that these examples are only ungrammatical in the anticausative interpretation, but perfectly fine if the clitic is interpreted as impersonal or passive. 
But the elimination is not as complete as suggested by Schäfer \& Vivanco (2015). Only an agentive/intentional or a [+human] causer cannot be recovered by a PP, but a non-agentive ([-volitional], [-human]) cause can be realised as a PP-adjunct, as exemplified in (104) and (105) (see Mateus et al. 2003, Duarte 2013, and Mendikoetxea 1999).

(104) Sp. La puerta se abrió a causa de un golpe de viento. the door SE.ACA=opened to cause of a impact of wind 'The door opened due to a gust of wind.'

(Mendikoetxea 1999:1594)

$$
\begin{array}{llll}
\text { EP A porta abriu-se com o vento. } & \text { a door opened=sE.ACA by the wind }
\end{array}
$$

'The door opened due to the wind.'

In Spanish the cause argument can only be recoved by the complex preposition a causa de, but not by a por-PP as with passives. In European Portuguese usually the preposition com is used for this purpose, but the complex preposition pela força de 'due to the power of' can also be used. In a reduction or elimination approach, this pattern remains unclear. Furthermore, the cause argument can be realised by a por-PP if it contains the reflexive pronoun together with the intensifiers sólo/só, meaning 'alone', 'without help' as in (106a) and (107a). Note that, differently from English, the reflexive intensifiers mismo/próprio are ungrammatical, as shown in (106b) and (107b). As will be proposed in chapter 9, the reflexive intensifiers in Spanish and European Portuguese identifiy two arguments of a verb and, as anticausative verbs lack the external argument, this interpretation is impossible.
(106) a. Sp.
La puerta se
abrió por sí
sóla.
(Mendikoetxea 1999:1593)
the door SE.ACA=opened by it.REFL.PR alone
'The door opened by itself.'
b.

$\begin{array}{llll}\text { *La puerta se abrió por sí misma. } & \\ \text { the door } & \text { SE.ACA=opened by } & \text { it.REFL.PR } & \text { SELF }\end{array}$
(107) a. EP A porta abriu-se por sí só.
the door opened=SE.ACA by it.REFL.PR alone
'The door opened by itself.'
b. $\quad *$ A porta abriu-se por sí próprio.
the door opened=SE.ACA by it.REFL.PR SELF

These data support Chierchia's (1989/2004) proposal that the anticausative alternation is a kind of intransitivisation process, which identifies the object and the subject yielding an unaccusative verb. But as the present book is not about anticausative constructions, nothing more will be said about the appropriateness of either Chierchia's (1989/2004) or Schäfer \& Vivanco's (2015) analysis. The important 
point here is that the reflexive clitic may be a case-reducer and affect the external argument, giving rise to an anticausative interpretation.

\subsubsection{Antipassive se}

The alternation presented in (108) for Spanish an (109) for European Portuguese is termed as antipassive in Bosque \& Gutiérrez-Rexach (2016), citing Masullo (1992). In (108a) and (109a) the transitive version of the experiencer verbs olvidar (Sp.) and esquecer (EP) 'forget' are given. Note that the experiencer arguments bear nominative case and the theme arguments bear accusative case. In (108b) and $(109 \mathrm{~b})$ the clitic is present. The clitic alters the case properties of the verb-accusative case is reduced-but the internal argument is not affected. It is realised as a PP-complement.

(108) a. Sp. Pepe olvidó las llaves.

P.3.SG.NOM forgot.3.SG the keys.3.PL.ACC

'Pepe forgot the keys.'

b. Pepe se olvidó de las llaves.

P.3.SG.NOM SE.APA= forgot.3.SG of the keys.3.PL.OBL

'Pepe forgot the keys.'

(109) a. EP A Rita esqueceu as chaves.

the R.3.SG.NOM forgot.3.SG the keys.3.PL.ACC

'Rita forgot the keys.'

b. A Rita esqueceu-se das chaves.

the R.3.SG.NOM forgot.3.SG=SE.APA of.the keys.3.SG.OBL

'Rita forgot the keys.'

This kind of alternation shows that the clitic may affect the case properties of the verb without affecting the argument structure of the transitive verb.

\subsubsection{Aspectual se}

Last but not least, in Spanish the clitic se can also affect the aspectual properties of a verb. The se.asp can be combined with a transitive and an unergative verb. Among other restrictions presented in Otero (1999) and Bosque \& Gutiérrez-Rexach (2016), the main contribution of the clitic is that it induces a telic interpretation of the verb, as shown by the ungrammaticality of a durational temporal adjunct in (110b).

(110) a. Sp. Se bebió la cerveza en un minuto. (Bosque \& Gutiérrez-Rexach 2016:423) SE.ASP=drank the beer in one minute

'He drank the beer in a minute.'

b. $\quad$ Se bebió la cerveza *[durante un minuto].

$\mathrm{SE} . \mathrm{ASP}=$ drank the beer $\quad$ [for one minute] 


\subsubsection{Summary}

The table in (111) summarises the properties of the different se-constructions, focussing on the case structure and the argument structure of the transtive verb, and on aspects of semantic or syntactic recoverability. These two latter aspects are only relevant if the clitic affects the argument structure of the verb, reducing or eliminating the argument role from the verbal grid.

The table shows that passive, middle, and anticausative se generates syntactically, and to a certain degree a semantically, intransitive predicates. But se may also realise an argument in case of recipro$\mathrm{cal} / \mathrm{reflexive}$ and impersonal se without affecting the case properties of the verb. Additionally, it may affect only the case properties without altering the argument structure, as in case of antipassive se or it may lack to affect any of these properties, as in the case of aspectual se.

(111)

\begin{tabular}{|l|ll|c|c}
\hline \multicolumn{1}{|c|}{ Type of $\boldsymbol{s e}$} & \multicolumn{1}{|c|}{ Case } & \multicolumn{1}{c|}{ Argument } & $\begin{array}{c}\text { Semantic } \\
\text { recoverability }\end{array}$ & $\begin{array}{c}\text { Syntactic } \\
\text { recoverability }\end{array}$ \\
\hline passive & acc elimination & EA reduction & yes & no \\
\hline middle & acc elimination & EA elimination & no & no \\
\hline anticausative & acc elimination & $\begin{array}{c}\text { EA reduction } \\
\text { elimination }\end{array}$ & no & yes \\
\hline reflexive & unaffected & IA realisation & & - \\
\hline reciprocal & unaffected & IA realisation & & - \\
\hline impersonal & unaffected & EA realisation & & - \\
\hline aspectual & unaffected & unaffected & & - \\
\hline antipassive & acc elimination & unaffected & & - \\
\hline
\end{tabular}




\section{Intransitive strategies}

The aim of this chapter is to scrutinise intransitive approaches to Romance reflexive structures. All accounts to be discussed here share the assumption that reflexive predicates are syntactically derived intransitive predicates. The combination of 'reflexive' and 'intransitive' should have perplexed the reader because these terms make opposite statements. The interpretation of a reflexive predicate is such that two arguments receive an identical referent. This is formally represented in (112) following Chierchia (1989/2004) and Reinhart (2002).

$$
\lambda \mathrm{x}\left(\mathrm{V}_{\mathrm{refl}}(\mathrm{x}, \mathrm{x})\right)
$$

But an intransitive predicate is a one-place predicate. It has just one argument, as shown in the schematic representation in (113).

$$
\mathrm{V}_{\text {refl }}(\mathrm{x})
$$

How can a predicate with the syntactic structure as in (113) have the interpretation of (112)? The process that makes this combination available is called reflexivisation and all accounts to be reviewed here assume this process. This process takes a transitive verb with the thematic roles agent-patient or experiencer-theme. This process alters the theta grid and the case properties of the verb in such a way that it is syntactically intransitive, but nevertheless has the interpretation given in (112).

All accounts agree that reflexivisation reduces or eliminates accusative case from the transitive predicate. As a consequence, only one argument can be structurally licensed. But what happens to the remaining argument/theta role? How is it made available for an interpretation such as the one in (112)? Several answers have been proposed to this question. The so-called unaccusative approach assumes that the external role is retained on the verbal grid, as, for example, in Kayne (1988) and Sportiche (1990, 1998), or eliminated, as in Marantz (1984). The so-called unergative approach assumes that the internal role is affected by a bundling operation, as in Reinhart \& Siloni $(2004,2005)$. Something that all accounts have in common is that the reflexive clitic is a morphological reflex of this operation. The clitic absorbs or eliminates accusative case from the verb.

The basic idea of the unaccusative approach is that reflexive predicates are derived like passive and unaccusative structures. What passive and unaccusative predicates have in common is that they lack an external argument and accusative case, while they do assign an internal theta role and nominative case. Thus, the thematic object has to move into a position in which it can satisfy its case requirement. Marantz (1984) assumes that se eliminates the external argument role and accusative case. This type of approach is represented schematically in (114). 
(114) Non-argumental unaccusative approach (Marantz 1984)

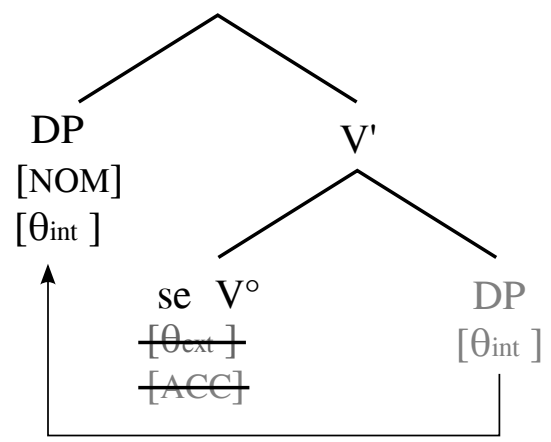

Sportiche (1990, 1998) and Kayne (1988) assume that the reflexive clitic eliminates accusative case, but realises or retains the external argument role and bears a [+anaphoric] feature. The thematic structure of the transitive verb is preserved and only accusative case is reduced from the verbal grid. The internal argument is syntactically realised and moves to a position in which it can get case. This is represented in (115).

(115) Argumental unaccusative approach (Sportiche 1990, 1998)

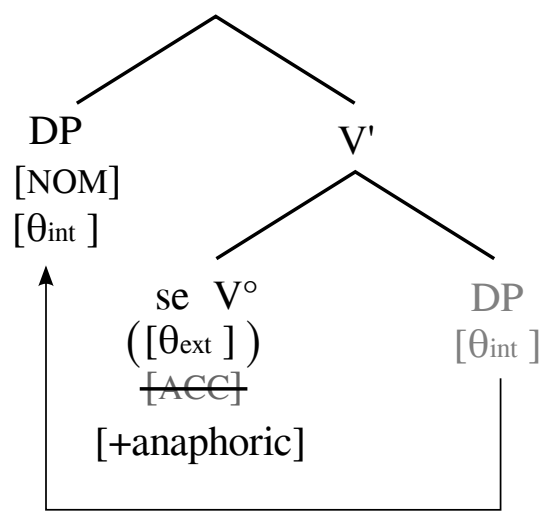

The unergative approach of Reinhart \& Siloni $(2004,2005)$ also assumes that the reflexive verb has two thematic roles, but reflexivisation is taken to be a bundling operation that creates a complex theta role. The reflexive clitic eliminates accusative case, and only the external argument position is syntactically realised. Upon merger of the external argument DP, the internal argument role is bundled with the external argument role and the DP receives a complex role. A simplified structural representation of this process is given in (116). 
(116) Non-argumental unergative approach (Reinhart \& Siloni 2004, 2005)

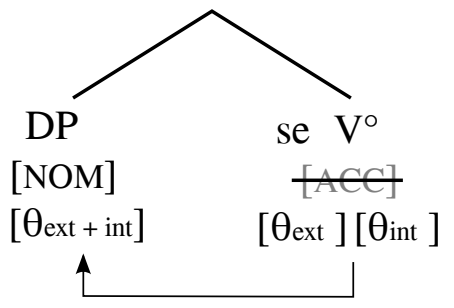

In the following, the arguments for the unaccusative and unergative approach are presented and evaluated with respect to their validity for Spanish and European Portuguese. I will not go into the technical details of the individual analyses, in particular the technical assumptions of approaches that are based on the early GB framework, such as Marantz (1984). It will be shown that there is no empirical evidence in Spanish and European Portuguese that justifies an intransitive analysis. In particular, reflexive predicates in Spanish and European Portuguese do not pattern with unaccusative/passive predicates with respect to (i) auxiliary selection, (ii) past participle agreement, or (iii) availability of postverbal bare subjects. Nor do they pattern with unergative predicates with respect to clitic placement in fairecausatives. Furthermore, the reflexive clitic is not a pure case absorber because reflexive predicates are distinct from antipassive alternations. Finally, the reflexive double is not an adjunct, as assumed by Alboiu et al. (2004), but an argument, due to the availability of clitic doubling in ECM constructions. This chapter will be concluded with the statement that reflexive predicates in Spanish and European Portuguese are thematically and syntactically transitive.

\subsection{The unaccusative approach}

The presentation of the unaccusative approach mainly follows Sportiche (1990, 1998), but occasionally makes reference to Marantz (1984). The unaccusative analysis has been elaborated on the basis of French and Italian because in these languages unaccusative, passive, and reflexive predicates pattern with respect to auxiliary selection, dislocation (object movement), and past participle agreement. The arguments of this approach will be illustrated by means of the French examples from Sportiche (1990, 1998) and equivalent constructions in Spanish and European Portuguese. Section 3.1.1 presents the parallels between passive, unaccusative, and reflexive predicates, and section 3.1.2 focusses on the pros and cons of an argumental status of the reflexive clitic.

\subsubsection{Parallels between passive, unaccusative, and reflexive predicates}

The central argument in favour of the unaccusative analysis is based on the fact that reflexive clitics are incompatible with predicates that lack an external argument role such as passives, as shown in (117), and raising verbs, as in (118). Due to this incompatibility, the clitic is taken to realise or absorb the external argument role and, following Burzio's generalisation, accusative case as well. 
(117) a. Fr. *Marie s' est [décrite Marie].(par Jean)

(Sportiche 1990:87)

$$
\text { M. SE.REFL=is.AUX described M. (by Jean) }
$$

b. EP *O Rui foi-se [entregue eRui à polícia]. the R. Was.AUX=SE.REFL handed.over the R. to.the police

c. Sp. *Juan se fue [entregado Juan a la policía].

J. SE.REFL= Was.AUX handed.over $J$. to the police

The same explanation is given for the ungrammaticality of the reflexive clitics with raising verbs like paraître (Fr) and parecer (EP, Sp), as shown in (118). Raising verbs lexically lack an external argument and a combination with the reflexive clitic is impossible.

(118) a. Fr. *Marie se paraissait [Marie malade].

(Sportiche 1990:87)

M. SE.REFL= appeared M. ill

intended meaning: 'Marie seemed to herself to be ill.'

b. EP *A Maria parece-se [a Mariadoente].

the $\mathrm{M}$. seems=SE.REFL the $M$. ill

intended meaning: 'Maria seems to herself to be ill.'

c. Sp. *Juan se parece [Juan enfermo].

J. SE.REFL $=$ seems $\quad$ J. ill

intended meaning: 'Juan seems to himself to be ill.'

But clitics are not generally ungrammatical with raising verbs. In French, the experiencer argument of raising verbs can be realised by the non-reflexive dative clitic, as shown in (119). Sportiche (1990, 1998) argues that the ungrammaticality of (118a) is explained if the reflexive clitic is associated with the external argument role because, if it were to realise the internal argument, such as the experiencer in (119), a reflexive raising verb should be possible, contrary to fact.

Fr. Marie lui paraissait malade.

(Sportiche 1990:87)

M. him.CL.DAT= appeared ill

'Marie appeared ill to him.'

European Portuguese also allows for a dative experiencer clitic with raising verbs, as mentioned in Raposo (2013b:1313). As for Spanish, there seems to be variation among speakers. Torrego (1996) accepts the dative experiencer clitic with the adjective inteligente 'inteligent', but not with descalzo 'barefoot'. In Ausín \& Depiante (2000) the difference is attributed to the distinction between individual-level predicates and stage-level predicates. They claim that [parecer + experiencer] is an opinion verb that needs to take an individual-level complement. If parecer lacks an experiencer, it is a perception verb that only takes stage-level predicates as complement. The examples are given in (120). 
(120) a. EP As crianças parecem-lhe [as crianças doentes/inteligentes].

the kids seem=him.CL.DAT the kids ill/intelligent

'The kids seem ill/intelligent to him/her.'

b. Sp. Los niños me parecen [los niños*?enfermos/inteligentes].

the kids me.CL.DAT= seem the kids ill/intelligent

'The kids seem ill/intelligent to me.'

Sportiche's $(1990,1998)$ conclusion about the status of the reflexive clitics as external argument is not compulsory. The fact that the reflexive clitic is ungrammatical with passive verbs and raising verbs, is also explained if the clitic is the internal argument and needs accusative or dative case. In passive, accusative case is unavailable. As for raising verbs, they are not transitive but rather similar to copular verbs, as argued in Moro (1997). Raising verbs select for a predicative complement (an AP or a small clause), rather than for a DP/NP complement to which they assign accusative case. Under the analysis put forward in chapter 7, these examples will be ruled out because the derived subject DP and a reflexive clitic (the reflexive version of the experiencer in (120) above) do not enter into a configuration in which the clitic and the subject can be associated. They are never the complement (reflexive) and the specifier (antecedent) of the same head that enters into an Agree relation with both elements. Since non-reflexive clitics, like the dative clitic in (120), do not need to enter into this relation, they are not ruled out. Furthermore, the raising verb parecer in combination with the reflexive clitic is lexicalised as an inherent reflexive verb that takes a PP-complement in both languages. The verbs parecerse $a$ and parecer-se com in Spanish and European Portuguese, respectively, are lexicalised with the meaning 'to resemble'. Thus, the reflexive clitic is also unavailable in (118b) and (118c) because the lexicon of both languages already contains an inherent reflexive entry for this verb.

\subsubsection{Auxiliary selection, past participle agreement, and NP-movement}

As mentioned above, the unaccusative analysis is based on mainly French and Italian. In both languages, reflexive verbs share morphosyntactic properties with unaccusative and passive structures. These properties are auxiliary selection and past participle agreement. Sportiche $(1998,1990)$ shows for French that there is a connection between object movement, object clitics, and past participle agreement. I will briefly present the main data and show that the same line of reasoning is not feasible in Spanish and Portuguese.

In French, transitive and unergative verbs select the auxiliary HAVE (avoir), as in the examples (121a) and (121b), respectively. Reflexive and unaccusative verbs select the auxiliary BE (être), as shown in (121c) and (121d).

$\begin{array}{llllll}\text { (121) a. Fr. Jean a mordu sa petite sour. } & \text { (transitive) } \\ & \text { J. } \text { has.Aux bitten his little sister } \\ & \text { 'Jean bit his little sister.' }\end{array}$ 

b.
Jean a dormi.
(unergative)
J. has.Aux slept
'Jean has slept'.
c.
Jean s' est mordu.
(reflexive)
J. SE.REFL=is.AUX bitten
'Jean has bitten himself.'
d. Jean est arrivé.
(unaccusative)
J. is.AUX arrived
'Jean has arrived.'

Predicates that select the auxiliary BE also show obligatory past participle agreement. This is shown for passives, unaccusatives, and reflexives in (122). The default form of the participle is the singular masculine form.

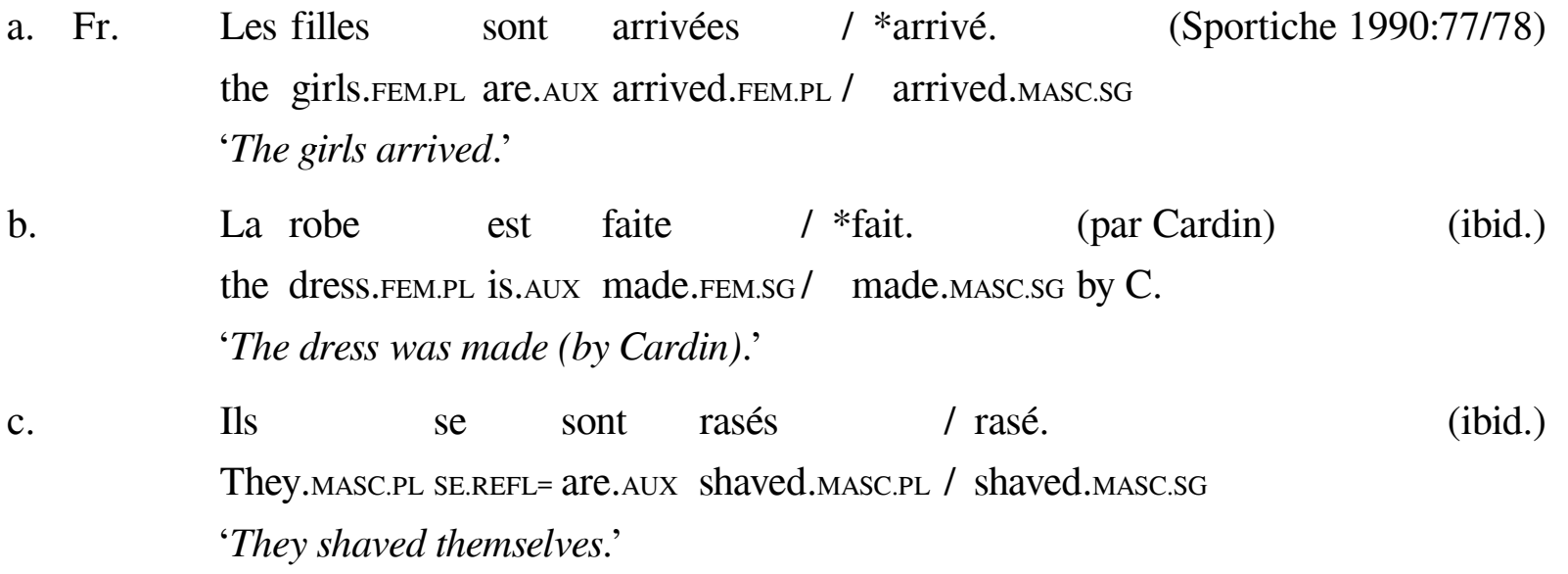

In Sportiche (1990,1998), the subject DP of the sentences in (122) is moved from the internal argument position to its case position. He assumes that this movement targets a position in which the DP agrees with the past participle. If the reflexive sentence in (122c) is derived in the same way, the agreement patterns, although not obligatory, get a straightforward explanation.

The correlation between object movement and past participle agreement in reflexives, unaccusative, and passive structures is found neither in Spanish nor in European Portuguese. In both languages, the auxiliary BE (ser) and past participle agreement is restricted to analytic passive clauses, as shown by the examples in (123).
(123) a. SP
Las chicas
fueron
mordidas
/ *mordido
por este perro.
the girls.FEM.PL were.AUX bitten.FEM.PL/ bitten.MASC.SGby this dog
b. EP As meninas foram mordidas /*mordido por este cão.
the girls.FEM.PL were.AUX bitten.FEM.PL/ bitten.MASC.SGby this dog
'The girls were bitten by this dog.' 
With all other verbs (unergative, unaccusative, or transitive) including reflexives and se-passives, both languages take the auxiliary HAVE (haber in Sp. and ter in EP) and do not show past participle agreement. The past participle has the invariant masculine singular ending - $o$. This is exemplified in (124)-(126) for transitive/unergative, unaccusative, and reflexive verbs.
(124) a. SP
Juan ha comido
(la manzana).
(unergative / transitive)
J. has.AUX eaten.MASC.SG (the apple)
'Juan has eaten the apple.'
b. EP
O Rui já tinha comido (a maçã).
the R. alreadyhad.Aux eaten.MASC.SG the apple
'Rui has already eaten the apple.'
(125)a. SP Las chicas han llegado.
the girls have.Aux arrived.MASC.SG
(unaccusative)
'The girls have arrived.'
b. EP As meninas já terão chegado.
the girls already have.FUT.AUX arrived.MASC.SG
'The girls have probably already arrived.'

(126) a. SP $\quad \begin{aligned} & \text { Las chicas se han mordido. } \\ & \text { the girls SE.REFL= have.AUX bitten.MASC.SG } \\ & \text { 'The girls have bitten themselves.' }\end{aligned}$
b. EP As meninas tinham-se mordido.
$\begin{aligned} & \text { the girls had.AUX=SE.REFL bitten.MASC.SG } \\ & \text { 'The girls had bitten themselves.' }\end{aligned}$
(reflexive)

\subsubsection{Expletive constructions}

Another parallel between reflexives and unaccusatives in French has been noted in Kayne (1975), cited in Reinhart \& Siloni (2004, 2005) and Alboui, Barrie \& Frigeni (2004). In French, expletive constructions are resricted to lexical or derived unaccusative verbs like in (127a) and (127b). With transitive verbs, expletive constructions are absolutely unacceptable, as shown in (127c). The fact that reflexives are allowed in expletive contructions, as shown in (127d), is taken as evidence for an unaccusative derivation of reflexive predicates.

(127) a. Fr. Il est arrivé trois filles hier soir. (Reinhart \& Siloni 2004:172) EXPL is.AuX arrived three girls yesterday evening

'There arrived three girls yesterday evening.'

b. Il s' est cassé beaucoup de verres dans ce lave-vaisselle. (ibid.) EXPL SE.ACA=is.AUX broken many of glasses in this dishwasher

'Many glasses have broken in this dishwasher.' 
c. $\quad *$ Il a mangé Jean (une pomme).

EXPL has.AUX eaten J. an apple

d. ?Il s' est lavé beaucoup de touristes dans ces douches

EXPL SE.REFL=is.AUX washed many of tourists in these showers

publiques, récemment.

(ibid.)

public recently

'Many tourists washed in these public showers recently.'

In Reinhart \& Siloni (2005:392), these examples are interpreted in a different manner, as will be presented in the next section. These data cannot be reproduced in Spanish and Portuguese because these languages do not have an overt expletive with the same grammatical function as French (see Mensching \& Weingart 2016 and references cited there).

Summarising, we can state that in Spanish and Portuguese reflexive predicates are not parallel to unaccusative or passive predicates.

\subsubsection{Argumental status of the reflexive clitic}

As mentioned in 3.1 above, Marantz (1984) assumes that the external argument is eliminated and that the clitic is a functional element. Sportiche $(1990,1998)$, however, provides evidence that reflexive clitics and non-reflexive clitics should be analysed in the same way: as argumental clitics. This section presents two arguments in favour of an argumental analysis.

\subsubsection{Clitic placement and topicalisation}

Let us start with the argument from Sportiche (1990,1998). The sentences in (128) contain a clitic object. In (128a), it is a direct object clitic and past participle agreement is possible though not obligatory. In (128b), it is an indirect object clitic, but here past participle agreement is not acceptable. As mentioned in the previous section, participle agreement is related to movement of the object through an intermediate position in which it agrees with the participle. This position is available for direct/accusative objects but not for indirect/dative objects.

(128) a. Fr. (La robe), Jean l' a décrit(e) à la femme. the dress J. it.CL.ACC.FEM.SG= has.AUX described.MASC.SG(FEM.SG) to the woman 'The dress, Jean described it to the woman.'

(similar in Sportiche 1990:73)

b. (À la femme), Jean lui a décrit $\left(*_{\mathrm{e}}\right)$ la robe.

to the woman J. her.CL.DAT.FEM.SG= has.AUX described.MASC.SG(FEM.SG) the dress 'Jean described the dress to her/the woman.' 
The same effect is visible with the reflexive clitic. In (129a) the direct object is replaced by the reflexive clitic and participle agreement is optional. In (129b) the indirect object is involved and participle agreement is not acceptable.

(129) a. Fr. Marie s' est décrit(e) aux enfants.

M. SE.REFL=is.AUX described.MASC.SG.(FEM.SG) to.the children

'Marie described herself to the children.'

(Sportiche 1990:85)

b. Marie s' est décrit $(*$ e) la robe.

M. SE.REFL=is.AUX described.MASC.SG(FEM.SG) the dress

(ibid.)

'Marie has described the dress to herself.'

Sportiche takes the parallel between (128a) and (129a) as well as between (128b) and (129b) as an indication that reflexive clitics and the (non-reflexive) object clitics should be analysed in the same way. Both types of clitics represent arguments, and the only difference is that the former are [+anaphoric] and the latter [+pronominal]. Spanish and European Portuguese show past participle agreement only in analytical passive sentences and hence the French data cannot be reproduced. But as for the argumental status of the reflexive clitic, I will come to the same conclusion at the end of this chapter on the basis of other data.

\subsubsection{ECM constructions}

An argument for the non-argumental status of the clitic comes from reflexives in ECM constructions and was put forward in Marantz (1984) in favour of the unaccusative analysis. I will exemplify his argument with Spanish and European Portuguese examples. The ECM verb considerar (Sp/EP) 'consider' in (131) takes an AP complement containing the DP Max and the adjective inteligente. The DP Max is thetamarked by the adjective, but gets its case from the ECM verb.

(130) a. Sp. Juan considera [AP a Max inteligente].

J. considers OM M. intelligent

'Juan considers Max intelligent.'

a. EP O Luís considera [AP o Max inteligente].

the L. considers the M. intelligent

'Luís considers Max intelligent.'

In the analysis of Marantz (1984), the reflexive clitic reduces the external argument and accusative case of the ECM verbs. He argues that the clitic cannot realise or affect the internal argument of the ECM verb because these verbs select and theta-mark the entire complement clause. Under his analysis, the DP Max in the examples in (131) moves from its base position, the AP complement, to the subject position, where it receives nominative case. 
(131) a. Sp. Max se considera [AP Max inteligente].

M. SE.REFL=considers M. intelligent

'Max considers himself intelligent.'

b. EP O Max considera-se [AP O Max inteligente].

the $\mathrm{M}$. considers=SE.REFL the M. intelligent

'Max considers himself intelligent.'

But this kind of analysis cannot be true for Spanish and European Portuguese because both languages allow for clitic doubling in ECM constructions, as shown in (132) for non-reflexive clitics and in (133) for reflexive clitics. These clitic doubling structures are problematic for Marantz's analysis for several reasons. First, the non-reflexive double and the reflexive double are both case-marked by $a$. If the reflexive clitic, but not the non-reflexive clitic, is a case reducing item, then this parallel case-marking is left unexplained. Secondly, the fact that the strong reflexive double is realised inside the AP is a severe problem for his assumption that the derived subject DP is base-generated in this position.

(132) a. Sp. Juan lo considera [AP a él inteligente].

J. him.CL=considers OM him intelligent

'Juan considers him intelligent.'

b. EP O Luís considera-o [AP a ele inteligente].

the L. considers=him.CL OM him intelligent

'Luís considers him intelligent.'

(133) a. Sp. Juan se considera [AP a sí mismo inteligente].

J. SE.REFL=considers OM REFL.PR SELF intelligent

'Juan considers himself intelligent.'

b. EP O Luís considera-se [AP a si próprio inteligente].

the L. considers=SE.REFL OM REFL.PR SELF intelligent

'Luís considers himself intelligent.'

The fact that clitic doubling is possible in reflexive ECM structures is a clear indication for the argumental status of the reflexive clitic (see Franco 1999). The parallel between reflexive and non-reflexive clitics will be reflected by the analysis presented in chapter 7. For ECM structures, I will assume that the pronominal double is base-generated together with the clitic inside a bigDP. The bigDP is basegenerated inside the small clause complement. The clitic undergoes cliticisation by agreement with $\mathrm{v}^{\circ}$, and the subject DP is directly merged into specvP. This creates a configuration in which the clitic and the subject are in an agreement configuration within the domain of $v^{\circ}$. The difference between a reflexive and a non-reflexive clitic is that the former, but not the latter, enters into an agreement relation with the subject due to its phi-feature values. 


\subsection{The unergative approach}

Reinhart \& Siloni $(2004,2005)$ argue against the unaccusative analysis and in favour of an unergative analysis of reflexive predicates. They propose that reflexivisation is a (syntactic) operation on the theta grid of a transitive verb in the sense that the internal theta role is bundled with the external role. The formal representation of the bundling operation is reproduced from Reinhart (2002:249) in (134). The syntactic part of the bundling operation is presented in (134a). A transitive predicate undergoes reflexivisation, and the result is a one-place predicate with a complex theta role. This predicate is interpreted as in (134b). The single argument has a referent and due to its complex theta role, this unique referent is simultaneously the agent and the patient of the reflexive verb.

\section{Reflexivisation as bundling of theta roles}

a.

$$
\mathrm{V}\left[\theta_{\text {int }}, \theta_{\text {ext }}\right] \rightarrow \mathrm{R}(\mathrm{V})\left[\theta_{\text {int }}+\mathrm{ext}\right]
$$

b.

$$
\mathrm{x}_{\theta}\langle\text { int }+ \text { ext }\rangle(\lambda \mathrm{x} V(\mathrm{x}))
$$

(interpretation)

They argue that reflexivisation is a universal property of languages and the application of this operation, as well as any other operation affecting the argument structure, is controlled by the lex-syn parameter. This parameter allows for arity operations to take place either in the lexicon or in syntax (see Reinhart \& Siloni 2005:398). For Romance languages, Reinhart \& Siloni $(2004,2005)$ assume that the parameter is set to syntax. ${ }^{24}$ Syntactic reflexivisation is subject to two conditions, as presented in (135).

$$
\text { Reflexivisation in syntax }
$$

(Reinhart \& Siloni 2005:404)

a. Case: $\quad$ Case is reduced by appropriate morphology (such as the clitic se).

b. Bundling: the Operation (134) applies to unassigned $\theta$-roles, upon merger of the external $\theta$-role.

The clitic reduces accusative or dative case. Furthermore, the clitic is considered to be a morphological reflex of the bundling operation. With reflexive clitics, the internal role is bundled with the external role. Under this assumption, reflexive predicates are incompatible with passive and raising verbs, as shown in section 3.1.1 above (in particular the examples (117) and (118)), because the external argument role is not available with these verbs and reflexivisation cannot apply. Recall that raising verbs do not select for an external argument and that passive morphology eliminates the external argument role from the theta grid of transitive verbs. ${ }^{25}$

\footnotetext{
24 Languages that have the parameter set to lexicon disallow reflexive ECM verbs and a binding relation between the direct and the indirect object in ditransitive structure, as for example Hebrew.

25 For passives and derived unaccusatives (anticausatives), Reinhart \& Siloni $(2004,2005)$ argue that the external argument is reduced by an expletivisation operation. The morphological similarities between unaccusative/passive and reflexive predicates are due to the fact that both types of predicates are subject to an arity operation.
} 


\subsubsection{The challenge: ECM constructions}

As introduced above in section 3.1.2.2, the existence of reflexive ECM verbs has been an argument for the unaccusative approach, at least for languages without clitic doubling. In the following, Reinhart \& Siloni's $(2004,2005)$ analysis of ECM constructions with an AP complement is explained, showing that they have to make a particular assumption about the saturation of theta roles. Their derivation will be illustrated with the Spanish example given in (131), repeated here as (136).

$$
\begin{array}{lllr}
\text { Sp. Juan } & \text { se considera } & \text { inteligente. } \\
& \text { J. } & \text { SE.REFL=considers } & \text { intelligent }
\end{array}
$$

The derivation is presented step by step in (137). The numeration contains the ECM verb with an accusative case feature and two theta roles. These are marked as c. 1 and $c .2$ in order to distinguish them from the adjective's theta role $i .1$. The first step in their derivation is shown in (137a). The reflexive ECM verb has already checked its case feature due to the presence of the clitic. The verb has selected the AP as its complement, and the entire AP has received the internal theta role $\theta_{c .2}$. Note that the adjective has still an open, unsaturated theta role when merged with the verb. Given that the theta role of the AP remains free, the bundling operation can take place upon merger of the external argument of the ECM. The result of the bundling operation is shown in (137b): the external argument DP Juan received the complex theta role $\left\langle\theta_{\mathrm{c} .1}+\theta_{\mathrm{i} .1}\right\rangle$.

$$
\text { Numeration: } \quad\left\{\text { considera }\left\langle\theta_{\text {c. } 1}, \theta_{\text {c. } 2}\right\rangle \text {, acc; inteligente }\left\langle\theta_{\text {i.1 }}\right\rangle ; \text { Juan ; se } \text { refl. }_{\text {. }}\right\}
$$
a.
[ se considera $\left\langle\theta_{\mathrm{c} .1}, \theta_{\mathrm{e} .2}\right\rangle$ [inteligente $\left.\left.\left\langle\theta_{\mathrm{i} .1}\right\rangle\right]_{\theta_{\mathrm{c} .2}}\right]$
b.

$$
\left[\operatorname{Juan}_{\left\langle\theta_{\mathrm{c} .1}+\theta_{\mathrm{i} .1}\right\rangle}\left[\text { se considera }\left\langle\theta_{\mathrm{e} .1}, \theta_{\mathrm{e} .2}\right\rangle\left[\text { inteligente }_{\left\langle\theta_{\mathrm{i} .1}\right\rangle}\right]_{\theta_{\mathrm{c} .2}}\right]\right]
$$

Reinhart \& Siloni $(2004,2005)$ have to assume that the theta role of the AP remains unchecked until the external argument of the ECM verb is merged. This assumption raises the question as to why adjectives can behave like this only with reflexive ECM verbs. With non-reflexive ECM verbs, the adjective satisfies its theta role before it merges with the ECM verb. As far as I can see, in theory, nothing prevents the adjective to be first-merged with the DP Juan. But a more severe challenge to their analysis are the clitic doubling structures in ECM constructions. Reinhart \& Siloni $(2004,2005)$ need to assume that the reflexive double/bigDP does not satisfy the theta role of the adjective and that it is not case-marked by the verb. Given the parallel between reflexive and non-reflexive clitic doubling structures, at least the former assumption cannot be true.

\subsubsection{Parallels between reflexive and unergative predicates}

In this section I will discuss the arguments that support the analysis of reflexive predicates as unergative verbs. These are based on French faire-infinitives and on French and Italian ne/en-cliticisation. 


\subsubsection{1 faire-infinitives}

The sentences in (138) exemplify so-called faire-infinitives. The French causative verb faire 'to make', takes a non-finite clause as complement. In (138a) the non-finite verb is the transitive verb laver 'wash'. Its agent argument is realised as the dative PP à Paul and its patient argument is realised as the accusative clitic le, which cliticises to the finite causative verb after clitic climbing. In (138b) and (138c), the non-finite verbal complement is unergative and reflexive, respectively. The agent argument of the unergative verb, as well as of the reflexive verb, is assigned accusative case, instead of dative. With respect to case assignment to the agent argument, reflexive verbs pattern with unergative verbs and not with transitive verbs. Reinhart \& Siloni $(2004,2005)$ interprete this parallel as an indication that reflexive predicates have an underlying unergative structure.

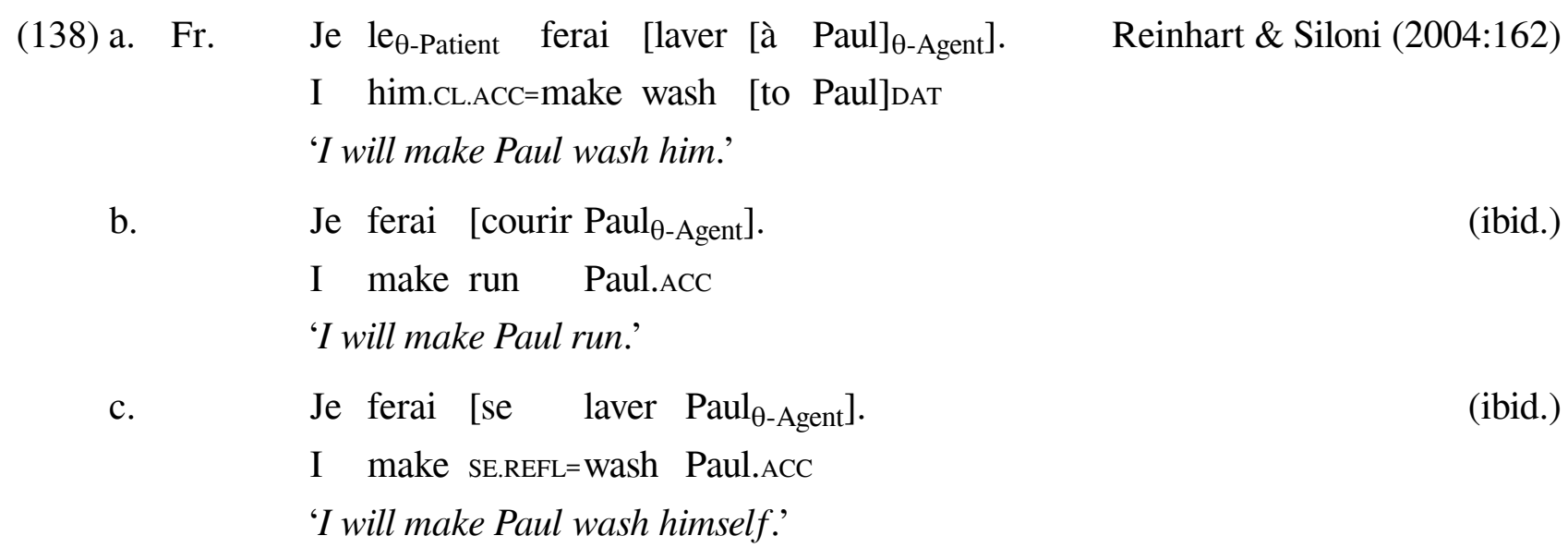

Additionaly, the different positions of the clitics in (138a) and (138c) have been taken as evidence against an argumental analysis of the reflexive clitic. The reflexive clitic in (138c) has to stay with the non-finite verb, but the non-reflexive accusative clitic in (138a) climbs up to the finite causative verb. Reinhart \& Siloni $(2004,2005)$ argue that if the reflexive clitic were an argumental clitic, it should be allowed to climb up to the finite verb, just like the argumental accusative clitic does. Due to this difference in placement, they conclude that the reflexive clitic and the non-reflexive clitic are distinct elements. Based on French faire-infinitives, the authors present these two arguments in favour of an unergative analysis: (i) reflexive verbs pattern with unergative verbs and not with transitive verbs because the agent argument of a reflexive and an unergative non-finite complement bear accusative case, and (ii) the reflexive clitic is not an argumental clitic because it occupies a position distinct from the non-reflexive, argumental clitic.

Now, let us return to Spanish and European Portuguese. In the following I will show that the arguments in favour of an unergative analysis put forward in Reinhart \& Siloni $(2004,2005)$ do not carry over to these languages. Starting with EP, there are two types of causative constructions that are similar to the French faire-infinitive structures (see Gonçalves 1999, Barbosa \& Raposo 2013, and Gonçalves, Carrilho \& Pereira 2016). The first type, shown in (139a), corresponds to the French faireinfinitive with respect to case and clitic placement, and the second type, exemplified in (139b), is an ECM construction with different clitic syntax and case properties. 


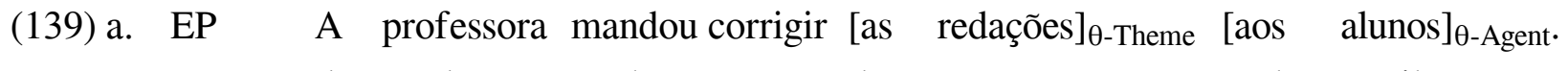
the teacher made correct the essays.ACC to.the pupils.DAT 'The teacher made the pupils correct the essays.'

(Barbosa \& Raposo 2013:1962)

b. A professora mandou $[\text { os alunos }]_{\theta-\text { Agent }}$ corrigir [as redações $]_{\theta-T h e m e}$. the teacher made the pupils.ACC correct the essays.ACC

'The teacher made the pupils correct the essays.'

(ibid.:1964)

According to Gonçalves (1999), Barbosa \& Raposo (2013), and Gonçalves, Carrilho \& Pereira (2016), the faire-infinitive type has a monoclausal structure in which the causative verb and the non-finite verb form a verbal complex. Like in French, the agent argument of the non-finite verb bears dative case and the theme/patient argument bears accusative case. The causative ECM construction has a biclausal structure: the agent argument is assigned accusative case by the causative verb, and the theme argument gets accusative case by the non-finite verb. One characteristic of the causative ECM construction is the preinfinitival position of the agent argument.

The two types also differ with respect to the position of the clitic that realises the theme argument of the non-finite verb. In the faire-infinitive type the clitic raises to the finite verb, just like in the French example above. This is shown in (140a). In the causative ECM construction given in (140b) the clitic cannot climb up to the finite verb and has to stay with the non-finite verb.

(140) a. EP A professora mandou-as ${ }_{\theta-T h e m e}$ corrigir $[\text { aos alunos }]_{\theta-\text { Agent }}$. the teacher made=them.CL.ACC correct to.the pupils.DAT

'The teacher made the pupils correct them.'

(Barbosa \& Raposo 2013:1965)

b. A professora mandou(*-as $\left.{ }_{\theta-T h e m e}\right)[o s \text { alunos }]_{\theta-\text { Agent }}$ corrigi-las ${ }_{\theta-T h e m e}$. the teacher made=them.CL.ACC the pupils.ACC correct=them.CL.ACC 'The teacher made the pupils correct them.'

(ibid.:1965)

Crucially, a reflexive non-finite verb, similar to the French example (138c) above, is impossible with the faire-infinitive type and only grammatical with the causative ECM construction, as shown in (141). The faire-infinitive type in (141a) is ungrammatical with a reflexive non-finite verb, irrespective of 
the position of the clitic. ${ }^{26}$ The causative ECM constructions in (141b) allows for a reflexive non-finite complement, but the clitic has to stay with the non-finite verb (see Martins 2004).

(141) a. EP $\quad * O \quad$ João $_{\mathrm{k}} \operatorname{mandou}\left(-\mathrm{se}_{\mathrm{i}}\right) \quad \operatorname{lavar}_{\left(-\mathrm{se}_{\mathrm{i}}\right)}$ (a)os meninos $\mathrm{i}_{\mathrm{i}}$

the J. made=SE.REFL wash=SE.REFL to.the kids

intended meaning: 'João made the kids wash themselves.'

(Gonçalves, Carrilho \& Pereira 2016:548)

b. $\quad \mathrm{O}$ João $\mathrm{K}_{\mathrm{k}}$ mandou( $\left(*_{-} \mathrm{se}_{\mathrm{i}}\right)$ os meninos lavar-se $_{\mathrm{i}}$.

the J. made=SE.REFL the kids wash=SE.REFL

'João made the kids wash themselves.'

Therefore, a comparison between transitive, unergative, and reflexive infinitival complements makes sense only for the causative ECM contruction. As can be seen in (142a), the agent argument of an unergative infinitival complement bears accusative case and cliticises to the finite verb. This is also true for transitive and reflexive infinitival complements, as shown in (142b) and (142c), respectively. Furthermore, the clitic that realises the theme argument has to stay with the non-finite verb with transitive and with reflexive complements.

(142) a. EP $\mathrm{O}$ treinador mandei-os -Agent $_{\theta}$ jogar com os miúdos da equipa $\mathrm{B}$. the coach made=them.CL.ACC play with the kids of.the team B 'The coach made them play with the kids from the B team.'

b. A professora mandou-os ${ }_{\theta-A g e n t}\left(*^{*}\right.$ las $\left._{\theta-T h e m e}\right)$ corrigi-las $_{\theta-T h e m e}$. the teacher made=them.CL.ACC correct=them.CL.ACC 'The teacher made them correct them.'

(Barbosa \& Raposo 2013:1965)

c. $\quad \mathrm{O} \quad$ João $_{\mathrm{k}}$ mandou-os $\mathrm{\theta}$-Agent lavar-se $_{\mathrm{i}}$.

the J. made=them.CL.ACC wash=SE.REFL

'João made them wash themselves.'

These data from European Portuguese allow for the following conclusion: there are no differences in case assignment and clitic placement for a transitive infinitival complement on the one hand, and a reflexive and unergative infinitival complement on the other hand. Thus, the arguments put forward by Reinhart \& Siloni $(2004,2005)$ concerning the faire-infinitives do not carry over to European Portuguese. The data discussed here even show that reflexive predicates pattern with transitive ones.

26 Under the monoclausal analysis, the sentence in (141a) is ungrammatical for the same reason the double object construction in (i) is ungrammatical. The direct and indirect object cannot be referentially related by means of the reflexive clitic.

(i) $\quad \mathrm{EP} \quad *$ A meditação devolveu-se $\mathrm{i}_{\mathrm{i}}$ ao Pedro $_{\mathrm{i}}$.

The analysis presented in 7 accounts for this fact in the following way: the reflexive clitic and its antecedent are associated via a head that enters into an agreement relation with both elements. The DO and IO are not in such a configuration. 
As for Peninsular Spanish, it has similar causative constructions formed with a causative finite verb and an infinitival complement (see Franco \& Landa 1995, Treviño 1992, and Iglesias Bango 1992). As shown in (143) and (144), the agent argument of the infinitival complement can be realised as dative or as accusative complement irrespective of the verbal type of the infinitival complement. ${ }^{27}$ In (143a-c), the agent of a transitive, unergative, and reflexive infinitival complement is realised as dative clitic doubling a dative DP.

(143) a. Sp. Juan le $e_{i \text {-Agent }}$ hizo pagar $[\text { la renta }]_{\theta-T h e m e}(a \text { Pedro })_{\theta-A g e n t}$.

J. him.CL.DAT= made pay the rent.ACC to P.DAT

'Juan made Pedro pay the rent.'

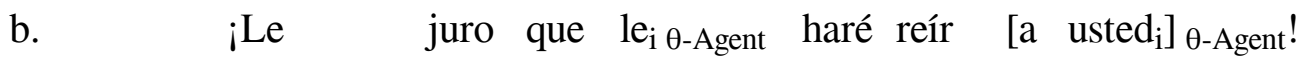

you.CL.DAT $=$ swear that you.CL.DAT=make laugh to you.DAT

'I swear that I will make you laugh.'

(CREA: Luca de Tena, T. 1979. 'Los renglones torcidos de Dios'.)

c. Se quitan de en medio y nadie pregunta qué fue lo que $\mathrm{le}_{\mathrm{i} \theta \text {-Agent }}$ $\mathrm{SE}=$ take.away of in middle and nobody asks what was it that him.CL.DAT= hizo matarse ${ }_{i}$ [a su vecino $]_{\theta-\text { Agent }}$.

madekill=SE.REFL to his neighbour

'They connive and nobody asks what was it that made his neighbour commit suicide.'

(CREA: Carrión, I. 1995. 'Cruzar el Danubio'.)

In (144), the agent of the transitive, unergative, and reflexive infinitival complement is realised as an accusative clitic. $^{28}$

(144) a. Sp. Juan lo $_{\theta \text {-Agent }}$ hizo leer estos libros ${ }_{\theta-T h e m e}$.

(Treviño 1992:311)

J. him.CL.ACC $=$ made read these books.ACC

'Juan made him read these books.'

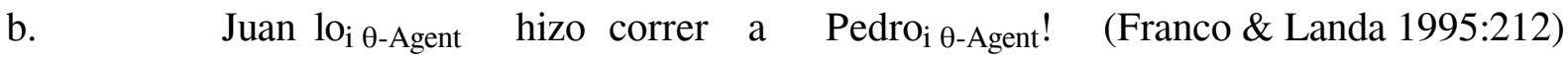

J. him.CL.ACC $=$ maderun OM $P$.

'Juan made Pedro run.'

27 As mentioned in Iglesias Bango (1992), the realisation of a dative or accusative clitic may also depend on phenomena such as leísmo and laísmo/loísmo. The fact that these phenomena may influence the choice of clitic, is not important for the point to be made in this section, namely that reflexive predicates do not pattern with unergative verbs.

28 The fact that a reflexive infinitival complement is allowed in these structures suggests that the sentences in (143) and (144) do not have a monoclausal structure. 
c.

La mirada de ella es, [...], el efecto especular que, [...], la $a_{i} \theta$-Agent hace prothe look of her is [...] the mirror effect that [...] her.CL.ACC=makes proyectarse $_{i}$ a sí $_{i} \quad$ misma más allá de los límites del espectáculo ject=SE.REFL OM REFL.PR SELF morebeyond of the limits of.the show puesto en escena;

put in stage

'Her look is the mirror effect that makes her project herself beyond the staged show.'

(CREA: Aparicio, J. P. 1989. 'Retratos de ambigú'.)

These data show that reflexive and unergative predicates are just like transitive predicates with respect to the realisation of the agent argument in causative constructions. Thus, Reinhart \& Siloni's (2004, 2005) argument that reflexive predicates pattern with unergative predicates with respect to case does not carry over to Spanish. With respect to clitic climbing, the situation in Spanish is as follows. Like in European Portuguese, the reflexive clitic cannot climb up to the causative verb, as shown in (145a). A comparison to a non-reflexive clitic representing the theme argument is not possible because the sentence in (145b) that corresponds to the French sentence in (138a) above is ungrammatical. The ungrammaticality of the sentence is not affected by the position of the dative PP and due to the fact that the accusative clitic cannot appear without the dative clitic. The grammatical version of the sentence is given in (145c). These examples show that the argument of Reinhart \& Siloni $(2004,2005)$ does, again, not carry over to Spanish.

(145) a. Sp. Yo $\left(*^{s_{i}} \mathrm{i}_{\mathrm{i}}\right)$ hice a Pedro $\operatorname{lavar}_{\mathrm{i}}\left(\mathrm{se}_{\mathrm{i}}\right)$.

I SE.REFL $=$ made $O M$ P. wash=SE.REFL

'I made Pedro wash himself.'

b. $\quad * J_{u a n} \operatorname{las}_{\mathrm{j} \theta-T h e m e}$ hizo (a los alumnos) abrir (a los alumnos).

J. them.CL.ACC = made (to the students) open (to the students)

'Juan made the students open them.'

(similar in Iglesias Bango 1992:105)

b. $\quad \operatorname{Juan}_{\mathrm{i}} \mathrm{se}_{\mathrm{j} \theta \text {-Agent } \quad \text { las }_{\mathrm{k}} \theta \text {-Theme hizo abrir. (a los alumnos }}$, las ventanas la $_{\mathrm{k}}$ )

J. them.CL.DAT= them.CL.ACC $=$ made open (to the students, the windows)

'Juan made them (the students) open them (the windows).'

(ibid:143)

Summarising, I conclude that the arguments of Reinhart \& Siloni $(2004,2005)$ concerning case and clitic placement in French faire-infinitives cannot be replicated for Spanish and European Portuguese, and causative constructions do not provide evidence for a non-argumental analysis of true reflexive clitics in these two languages. 


\subsubsection{2 ne/en-cliticisation}

Another argument against the unaccusative analysis and in favour of an unergative analysis comes from Italian and French ne/en-cliticisation. I will exemplify this argument with the French examples in (146). The partitive clitic en resumes the DP-part of a quantified DP or a partitive PP. The examples in (146) illustrate en-cliticisation applied to the sentences given in (127) above. The clitic en replaces the DP filles 'girls', in (146a), the DP verres 'glasses' in (146b), and the DP touristes 'tourists' in (146c).

(146) a. Fr. Il en est arrivé trois hier soir. EXPL of .them.CL= is.AUX arrived three yesterday evening

(Reinhart \& Siloni 2004:172)

b. Il s' en est cassé beaucoup dans ce lave-vaisselle. EXPL SE $=$ of.them. $. \mathrm{CL}=$ is.AUX broken many in this dishwasher

c. *Il s' en est lavé beaucoup dans ces douches publiques, EXPL $\mathrm{SE}=$ of. them. $\mathrm{CL}=$ is. AUX washed many in these showers public récemment.

recently

With unaccusative and anticausative verbs en-cliticisation is possible, as shown in (146a) and (146b), but it is ungrammatical with reflexive verbs, as in (146c). Reinhart \& Siloni $(2004,2005)$ interpret this pattern in the following way. The unaccusative verb and the anticausative verb assign an internal argument role to the QPs trois filles and beaucoup de verres, respectively. As reflexive predicates are derived by a bundling operation, the internal argument is available neither for the DP beaucoup de touristes nor for the clitic en. ${ }^{29}$

Again, this diagnositic cannot be replicated for Spanish and European Portuguese because both languages lack this kind of partitive clitic.

\subsubsection{The reflexive clitic is not an argument}

Reinhart \& Siloni (2004, 2005) and Marantz (1984) assume that the reflexive clitic is a case-reducing morpheme and therefore a non-argumental, functional element. In the following, the data that support their assumption will be reviewed.

\subsubsection{Expletive contructions}

Recall from section (3.1.1.2) that expletive constructions in French are possible with unaccusative and anticausative verbs, but are ungrammatical with transitive verbs. Reflexive verbs have been judged as

29 Sportiche (2014) argues against this argument claiming that (146c) represents a conflict in c-command requirements. On the one hand, the clitic en needs to c-command its trace, while on the other hand the clitic se needs to be c-commanded by its antecedent, which is the trace of en. Note that this argument is based on the conception of se as an anaphor that needs a c-commanding antecedent. 
'not that bad', and these judgements have been taken as an indication for the unaccusative nature of reflexive predicates. Reinhart \& Siloni $(2004,2005)$ interpret this fact as an indication for the nonargumental nature of the reflexive clitic. They argue on the basis of the examples in (147) that the reflexive clitic cannot be an argument (internal or external) of the reflexive verb because the sentence with a reflexive clitic in (147a) would then be as ungrammatical as the sentence with a non-reflexive clitic in (147b). But the sentence with the reflexive clitic is less bad, and Reinhart \& Siloni $(2004,2005)$ conclude that the reflexive clitic must be a functional element.

(147) a. Fr. ?Il s' est dénoncé trois mille hommes ce mois-ci. EXPL SE.REFL=is.AUX denounced three thousand men this month-here.

'Three thousand men denounced themselves this month.'

Reinhart \& Siloni (2004:161)

b. *Il les a dénoncé trois mille hommes ce mois-ci.

EXPL them.CL=has.AUX denounced three thousand men this month-here.

intended meaning: 'Three thousand men denounced them this month.'

(ibid.)

Once more the diagnositic cannot be replicated for Spanish and European Portuguese because both langages lack expletive subject pronouns of the kind found in non null-subject languages (see Mensching \& Weingart 2016 and Carrilho 2005, 2008).

\subsubsection{No proxy readings with intransitive reflexives}

Another diagnostic concerning the argumenthood of Romance reflexive clitics is presented in Marelj \& Reuland (2016) by means of Italian examples. They claim that a proxy reading is only possible if the reflexive clitic or the strong reflexive pronoun realise an argument. Recall that Italian has no clitic doubling of reflexive and non-reflexive pronouns. For example, in (148a), the strong reflexive pronoun in Italian realises the internal argument of the verb lavar 'wash' and a proxy reading is available. The fact that the internal argument is available for interpretation is indicated by the $f(x)$ in the semantic representation of the sentence in $\left(148 \mathrm{a}^{\prime}\right)$.

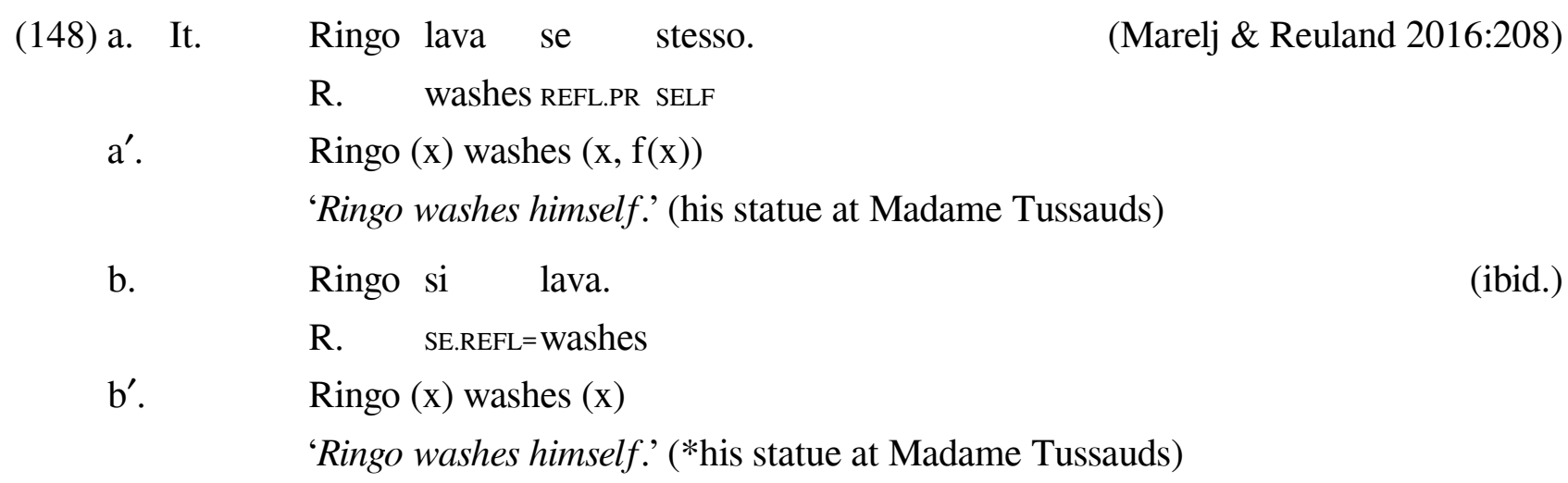


The proxy reading is unavailable if the reflexive clitic is used, as in (148b). In order to explain the difference between clitic and strong reflexive pronouns, Marelj \& Reuland (2016) argue that the reflexive grooming verb in (148b) is formed in the lexicon, with the result that the verb is syntactically intransitive, but has a complex theta role. ${ }^{30}$ In $\left(148 b^{\prime}\right)$ there is only one argument that satisfies the complex agent-theme role. As a result, reflexive grooming verbs are semantically intransitive, but still have a case feature. Marelj \& Reuland (2016) argue, following Reinhart \& Siloni $(2004,2005)$ that the reflexive clitic is needed to satisfy the case feature. Under this analysis, the absence of a proxy reading is explained by the non-argumental nature of the reflexive clitic.

A fact that seems to support their assumption about inherent true reflexive predicates comes from prefixing with auto-. The prefix auto- is a lexical reflexiviser similar to English self-. Auto- is only available with transitive verbs, as in (149a), but is ungrammatical with grooming verbs, as shown in (149b).

(149) a. It. Ringo si è autodistrutto.

(Marelj \& Reuland 2016:204)

R. SE.REFL=has selfdestroyed

b. Gianni si (*auto)-lava.

R. SE.REFL=self-washes

The ungrammaticality of (149b) is explained in the following way. The meaning of auto- is that of a lexical reflexiviser: it maps two theta roles onto one argument variable. Thus, it needs to combine with a transitive verb. But grooming verbs, according to Marelj \& Reuland (2016), have only one argument, so auto- cannot be interpreted.

My application of the diagnostic for proxy readings and auto- prefixation had the following results. In Spanish and European Portuguese, a proxy reading is available with grooming verbs, even in non-doubling structures, according to native speakers. Of course, the sentences in (150) need an appropriate context such as a visit to Madame Tussauds Museum and the peculiar situation of the person Ringo taking care of his wax figure.

(150) a. Sp. Ringo se peina.

R. SE.REFL=brushes

b. EP Ringo pentea-se.

R. brushes=SE.REFL

'Ringo brushes himself.' (his statue at Madame Tussauds)

Furthermore, the conception of the prefix auto- as a lexical intransivising element seems to be incorrect, at least for Spanish and European Portuguese. If auto- alters the verb's argument structure, no

30 Marelj \& Reuland (2016) claim that bundling in the lexicon only applies to grooming verbs. All other reflexive verbs are derived in a different way because they allow for a proxy reading (see section 4.3.2 in the next chapter). Thus, grooming verbs are visible to a lexicon operation, while all other transitive verbs are not. This explanation seems to me to be quite stipulative. 
verb prefixed with auto- should be allowed in clitic doubling structures. This predication is not borne out, as shown by the examples in (151) and (152) from the CRPC and CREA, respectively. These examples additionally suggest that both auto- and the reflexive double are associated with intensification or (contrastive) focus.

(151) a. EP [...], o Governo se autocensurou a si próprio. (CRPC: A155551.)

'The government self-censored itself.'

b. «Não lembra ao diabo» pôr o Estado, que é o detentor do jus puniendi, a autopunirse a si mesmo pelo crime dos titulares dos cargos públicos. (CRPC: A127420.)

'It's a harebrained idea to make the State, who is the holder of the jus puniendi, selfpunish itself for the crimes of the holders of public office.'

(152) a. Sp. S Primero luchan por la abolición de la censura, y luego, se autocensuran a sí mismo. 'First they fight for the repeal of censorship and then they self-censor themselves.'

(CREA: Marciano, M. M. 1984. 'El poder de la imaginación'.)

b. Pero Barcelona no necesita o no atrae a los grabadores extranjeros: se autoabastece a sí misma.

'But Barcelona does not need or does not attract the foreign printers: it provides them by itself.'

(CREA: Gallego Gallego, A. 1990. 'Historia del grabado en España'.)

Thus, in Spanish and European Portuguese, there is no positive evidence for the assumption that true reflexive predicates have an intransitive structure. As we will see in the final section, there is evidence in favour of a transitive analysis.

\subsection{Evaluation and additional evidence in favour of a transitive approach}

Before summarising the results so far, some additional evidence against a non-argumental analysis of reflexive clitics and in favour of a transitive analysis will now be presented.

\subsubsection{True reflexive clitics ain't no case-dummies!}

The unergative and the unaccusative approach take into account that the reflexive clitic is associated with accusative case. All approaches discussed here would correctly predict the fact that the reflexive clitic is ungrammatical with (thematically transitive) verbs that do not assign accusative case, but select for a PP-complement. The Spanish and European Portuguese sentences in (153) are absolutely unacceptable with the reflexive clitic.

(153) a. Sp. Juan (*se) confía en sí mismo.

J. SE.REFL=trusts in REFL.PR SELF

'Juan trusts himself.' 

b. EP
O Rui confia-(*se) em si
próprio.

the R. trusts=SE.REFL in REFL.PR SELF

'Rui trusts himself.'

The non-argumental approaches claim that the clitic is a mere case reducing morpheme. But this conception of the clitic is problematic with respect to so-called antipassive alternations introduced in section (2.3.7). The examples (108) and (109) are repeated here as (154) and (155). With this type of alternation, the reflexive clitic reduces accusative case and the argument structure is not affected. The former direct object of (154a) and (155b) is realised as a PP-complement in (154b) and (155b).

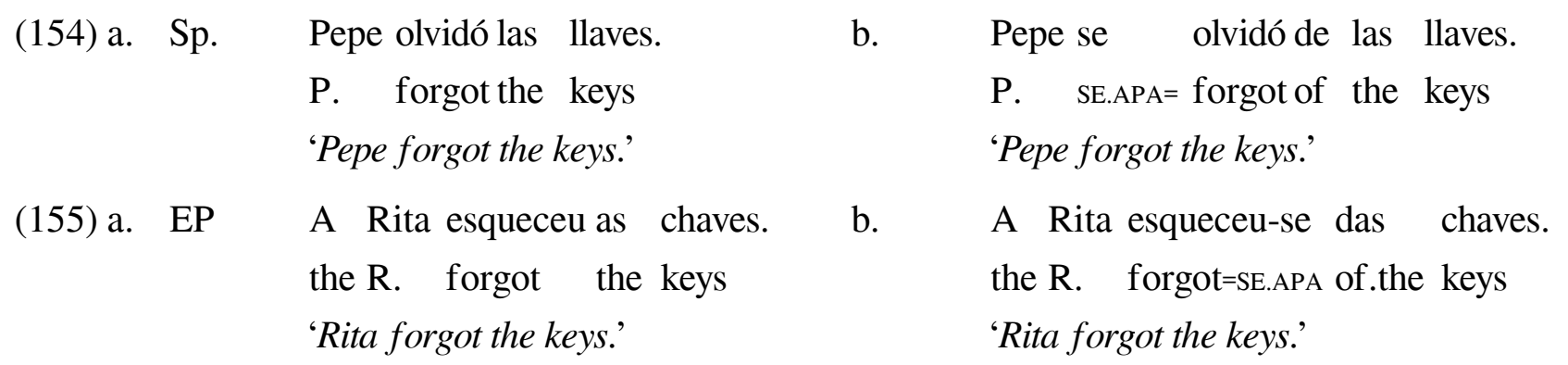

Now, compare the sentences in (156) for Spanish and (157) for European Portuguese. At first sight, the two sentences seem to have the same structure: the clitic se reduces the accusative case of the transitive verbs olvidar and admirar, and the internal argument is realised by the strong pronoun inside a PP. Furthermore, both sentences in (156) and (157) are reflexive in the sense that two co-arguments have an indentical referent.

(156) a. Sp. $\operatorname{Juan}_{\mathrm{i}} \mathrm{se}_{\mathrm{i}}$ olvida de $\mathrm{sí}_{\mathrm{i}}$ mismo.

J. SE.APA=forgets of REFL.PR SELF

b. Juan $\mathrm{se}_{\mathrm{i}}$ admira a $\mathrm{sí}_{\mathrm{i}}$ mismo.

J. SE.REFL=admires OM REFL.PR SELF

(157) a. EP A Rita esqueceu-se $_{i}$ de $\mathrm{si}_{\mathrm{i}}$ própria.

the R. forgot=SE.APA de REFL.PR SELF

b. A Rita admira-se $_{i}$ a $\mathrm{si}_{\mathrm{i}}$ própria.

the R. admires=SE.REFLOM REFL.PR SELF

According to the non-argumental accounts, the reflexive clitic is a functional element and cannot be associated with a thematic role. This conception of the reflexive clitic correctly predicts the ungrammaticality of (158a) and (158b). A non-reflexive clitic is not allowed in antipassive constructions because the clitic has to be a non-argumental, case-reducing morpheme.

(158) a. Sp. $\quad * J_{u a n} l_{\mathrm{j}} \quad$ olvida de él $\mathrm{l}_{\mathrm{j}}$.

J. him.CL=forgets of him 
b. EP *A Rita esqueceu-o $_{j}$ dele $_{j}$.

the R. forgot=him.cL of.him

If the (true) reflexive clitic in (156b) and (157b) were such a case-reducing morpheme, one would expect the non-reflexive clitic to be ungrammatical too, contrary to fact, as shown in (156).

(159) a. Sp. $\operatorname{Juan}_{\mathrm{i}} \mathrm{lo}_{\mathrm{j}}$ admira a él $\mathrm{j}_{\mathrm{j}}$.

J. him.CL=admires of him

b. EP A Rita admira-o $_{j}$ a ele . $_{\text {. }}$.

the R. admires=him.CL OM him.

Furthermore, if case reduction also occurred in true reflexive predicates, the reflexive double should be realised as an obligatory PP-complement. Recall from the previous chapter that the pronominal double is an optional element in true reflexive clitic doubling structures. I conclude that the differences between true reflexive clitic doubling structures and antipassive structures are due to distinct properties of the clitic se. The antipassive clitic is a non-argumental case-reducing morpheme, but the true reflexive clitic is argumental and patterns therefore with the non-reflexive clitics.

\subsubsection{Bare postverbal subjects}

Alboiu, Barrie \& Frigeni (2004:114) provide additional evidence against an unaccusative analysis of reflexives and in favour of an unergative/transitive analysis. They show for European Portuguese that reflexive predicates pattern with unergative and transitive verbs with respect to the acceptability of bare postverbal subjects. Unergative, transitive, and reflexive verbs do not allow for a bare postverbal subject, as in (160b)-(160d), but unaccusative verbs do, as shown in (160a).

$\begin{array}{llll}\text { (160) a. EP } & \text { Caíam rochas das montanhas. } & \text { (Alboiu, Barrie, \& Frigeni 2004:114) } \\ & \text { fell rocks from.the mountains } & & \text { (ibid.) } \\ \text { b. } & \text { Trabalham crianças. } & & \\ & \text { work } & \text { children } & \\ \text { c. } & \text { ? } \text { Criticaram jornalistas os políticos. } & \text { (ibid.) } \\ \text { c. } & \text { * Lavam-Se crianças na banheira. } & \text { journalists the politians } \\ & \text { wash=SE.REFL children in.the bathtub }\end{array}$

But these examples are problematic for two reasons: first, the sentences with the unaccusative and unergative verbs do not have the same structure. The sentence with the unaccusative verb contains a locative PP that is missing in the sentence with the unergative verb, and the presence or absence of this PP crucially affects the acceptability of the sentences, as shown in (161a) and (161b). If the locative PP is absent, the acceptability of the unaccusative sentence degrades significantly, and its presence makes 
the sentence with the unergative verb perfectly acceptable. ${ }^{31}$ As can be seen in $(160 \mathrm{~d})$, the presence of the locative PP na banheira has no positive effect on the acceptability of the reflexive sentence. The same is true for the transitive sentence. Adding the locative PP nessa sala to the transitive sentence in (160c) does not affect its acceptability. The sentence remains ungrammatical, as shown in (161c).

(161) a. EP $\quad \begin{aligned} & \text { ??Caíam rochas. } \\ & \text { fell }\end{aligned}$
b.
$\begin{aligned} & \text { Trabalham crianças naquelas fábricas. } \\ & \text { work children in.these factories } \\ & \text { c. }\end{aligned} \quad \begin{aligned} & \text { * Criticaram jornalistas os políticos nessa sala. } \\ & \text { criticise journalists the politicians in.that room }\end{aligned}$

Secondly, the postverbal subject is associated with different information-structural interpretations in sentences with intransitive verbs on the one hand, and with transitive verbs on the other hand. It is a well-known fact that sentences with unaccusative verbs permit a presentational reading of the postverbal subject in addition to a (contrasitve) focus reading (see Costa 2004). The former reading is also available for the unergative sentence in (161b), but not for the sentences with a transitive verb and a reflexive verb. Crucially transitive and reflexive verbs require a (contrasitve) focus interpretation of the postverbal subject. If the ungrammatical sentences in (160c) and (160d) are presented in an appropriate context licensing a contrasitve reading of the subject, they become perfectly acceptable, as shown in (162).

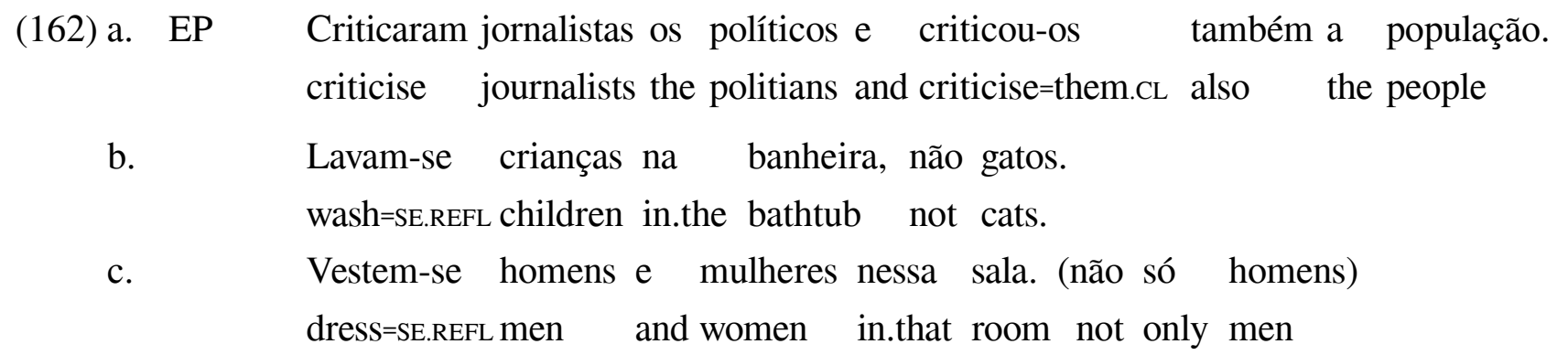

It has been shown that bare postverbal subjects in European Portuguese are not per se ungrammatical with unergative, transitive, and reflexive verbs, but that their acceptablility depends on distinct licensing conditions for intransitive verbs on the one hand, and transitive and reflexive verbs on the other hand. A closer look at the diagnostic presented in Alboiu, Barrie \& Frigeni (2004) revealed that reflexive predicates even pattern just with transitive predicates.

In Spanish, things are slightly different. A postverbal bare subject is possible with unaccusative verbs even without an additional locative PP, as in (163a). But for unergatives verbs, the presence of the preverbal locative PP is decisive, as shown in (163b) and (163c). Note that the locative PP in (163c)

31 Thanks to Ana Maria Martins for the discussing and pointing out the examples in (161) and (162) to me. 
has to be preverbal and the sentence is an instance of locative inversion with a presentational reading of the VP.

(163) a. Sp. Aparecieron niños.

(Mendikoetxea 1999:1611)

appeared children

b. $\quad$ *Juegan niños.

c. En este patio juegan niños.

In this backyard play children

Contrary to intransitive verbs, transitive and reflexive verbs do not permit bare postverbal subjects, with or without locative inversion, as shown in (164c) (see Mendikoetxea $1613 \mathrm{fn} .39$ ).

(164) a. Sp. $\quad$ ?*Criticaron periodistas a los políticos.

(Mendikoetxea 1999:1611) criticise journalists om the politicians

b. $\quad$ ?*En esta sala criticaron periodistas a los políticos. in this room criticise journalists om the politicians

c. $\quad$ ?*En esta sala se criticaron periodistas.

in this room SE.REFL=criticise journalists

The presence of a locative PP has no positive effect on the acceptability of a postverbal bare subject in sentences with a transitive and a reflexive verb. The diagnostic for postverbal bare subjects allows for the conclusion that reflexive predicates in Spanish and European Portuguese pattern only with transitive verbs.

Let us summarise the discussion of this chapter. The main empirical support for an intransitive analysis of reflexive predicates in Romance has been based on French and Italian data. In these languages intransitive predicates - unaccusative or unergative-are distinct with respect to auxiliary selection, past participle agreement, expletive constructions, and clitic placement in faire-causatives. All these diagnostics are unavailable in Spanish and European Portuguese, and there is no positive evidence in favour of an intransitive analysis. The crucial difference between Spanish and European Portuguese on the one hand and French and Italian on the other hand is that the former have clitic doubling for reflexive and non-reflexive pronouns. Reflexive ECM constructions constitute evidence in favour of a transitive analysis of reflexive predicates. Furthermore, the reflexive clitic in doubling structures cannot be a non-argumental element because these structures are distinct from antipassive alternations that contain a real case-reducing clitic. Finally, reflexive predicates pattern with transitive predicates with respect to the acceptability of bare postverbal subject. Based on these results, I assume that reflexive predicates in Spanish and European Portuguese behave like transitive verbs, and that both the clitic and its double represent the internal argument.

The next chapter is dedicated to transitive approaches and discusses the most influential Minimalist accounts to Binding Theory. 



\section{Transitive strategies}

This chapter is devoted to accounts that pursue a transitive strategy for the syntactic encoding of a referential dependency. Recall from section 1.1 that a syntactic encoding is limited to those environments in which anaphors and pronominals are in complementary distribution, as in (165a) and (165b), those in which c-command and locality requirements are fulfilled, as in (165c) and (165d), and those in which the uniqueness is not violated, as in (165e).

(165) a. John gave the money to himself / *him.

complementary distribution

b. John loves himself / *him.

complementary distribution

c. John's mother loves *himself / him.

c-command requirement

d. John thinks that Mary loves *himself / him.

locality requirement

e. John told Mary about *themselves / them.

split-antecedent

The analyses presented here share the following aim. The referential dependency between the anaphor and its antecedent should be established by the (blind) application of a syntactic operation, and the locally bound pronominal should be excluded due to the failure of this operation. Locality and c-command should fall out from the operation itself. Within the probe-goal framework, there are three ways to establish a syntactic dependency: by means of Internal Merge, External Merge, and Agree. All three operations are in principle possible candidates for a syntactic encoding of an anaphoric dependency. But the decision for one operation or the other entails different assumptions about the morphosyntactic nature of anaphors and pronominals, such as their internal structure and feature composition, and about the way how referential defectiveness of reflexives or anaphors should be formalised. For this reason, the present chapter is structured according to the syntactic operation assumed. Section 4.1 reviews the movement / Internal Merge-based analyses of Hornstein (2001, 2007) and Alboiu, Barrie \& Frigeni (2004). The accounts of Zwart (2002) and Kayne (2002), who propose an analysis based on External and Internal Merge, are examined in section 4.2. Section 4.3 presents the Agree-based accounts of Hicks (2009) and Marelj \& Reuland (2016). These accounts, and, in particular, their assumptions about the morphosyntactic nature of anaphors and pronominals will be evaluated with respect to Spanish and European Portuguese.

\subsection{Referential identity created by Internal Merge}

This section presents the movement-based account put forward in Hornstein $(2001,2007)$ and its application to Romance languages in Alboiu, Barrie \& Frigeni (2004).

\subsubsection{Hornstein $(2001,2007)$}

Hornstein $(2001,2007)$ proposes a Minimalist account to binding phenomena based on Internal Merge / movement. He motivates his analysis by structural and interpretive parallels between NP-traces, oblig- 
atory controlled (OC) PRO, and locally bound anaphors. These parallels have been already observed in Chomsky (1981) and Lebeaux (1985). Hornstein $(2001,2007)$ argues that the locality and c-command requirements for locally bound reflexives fall out from conditions on movement such as the Minimal Link Condition or the Shortest Move Condition, and, consequently, that OC PRO and reflexive pronouns are residues of A-movement. The present section focusses on the derivation of reflexive and non-reflexive pronouns, so analyses of OC PRO will not be reviewed here. ${ }^{32}$

The central prediction of Hornstein $(2001,2007)$ is that whenever (A-)movement is possible, complementarity between non-reflexive pronouns and reflexive pronouns must hold, as in (166a) and (166b).

(166) a. $\quad \mathrm{John}_{\mathrm{i}}$ likes himself $\mathrm{i}_{\mathrm{i}}$

(Hornstein 2007:359)

b. $\quad * J_{o h n}$ likes him $_{\mathrm{i}}$.

Hornstein $(2001,2007)$ argues that complementarity in (166) is due to economy considerations. The derivation of (166a) is more economical than the derivation of (166b). In order to apply economy considerations to two derivations, the derivations must be comparable. A necessary condition for a comparison is that the two derivations start with the same numerations. The derviations of (166a) and (166b) have therefore the numeration given in (167). For the sake of clarity, the numeration only contains the material necessary to explain the derivation of the referential dependency; all other features and functional categories are omitted. ${ }^{33}$

(167) a. Numeration: $\operatorname{John}_{[+ \text {nom }]} ;$ like $_{\left[\theta_{\text {Agent }}, \theta_{\text {Patient }}\right],[- \text { acc }]}$

(Hornstein 2007:359)

Crucially, the pronouns and the affix -self are not part of the numeration. Hornstein $(2001,2007)$ assumes that reflexives and bound pronouns are vacuous grammatical formatives. ${ }^{34}$ This means that reflexive pronouns and bound non-reflexive pronouns do not have any lexical content and their phifeatures are without any semantic import (see Hornstein 2007:360). ${ }^{35}$ The derivation of (166) starts as shown in (168a). The DP John merges with $\mathrm{V}^{\circ}$, from which it receives a theta role. The self element is

32 For a movement-based analysis of OC PRO see, for example, Boeckx et al. (2010).

33 The analyses in Hornstein $(2001,2007)$ are elaborated within the early Minimalist framework, and he assumes the Checking Theory of features as put forward in Chomsky (1995a). Under the Checking Theory, a feature such as, for example, a [+nom] feature, needs to be checked in a certain syntactic configuration by its negative counterpart, a [-nom] feature. As a consequence, a linguistic item enters the derivation fully inflected and needs to check its features in course of the derivation.

34 '.... [ reflexive pronouns per se make no semantic contribution to the interpretation of the sentence. They are not (co-)referential expressions, or bound expressions or operators that change the additicity of predicates. They are semantically inert.' Hornstein (2001:157).

35 This perspective is similar to the so-called 'minimal pronoun' approach proposed in Heim (2008), Kratzer (1998, 2009), and von Stechow (2003). The basic idea of the minimal pronoun approach is that (reflexive or non-reflexive) bound pronouns do not have semantically active phi-features. The fact that bound pronouns agree with their antecedent in phi-features is taken to be due to a morphophonological reflex of binding. Bound pronouns are base-generated with an empty or incomplete set of phi-features, which is filled in with the features of the binding DP by means of a PF process such as Feature Transmission. 
taken to be a case-checking affix, without any lexical content or phi-features. It is adjoined to the DP John in order to check off the DP's accusative case feature.

(168) a.

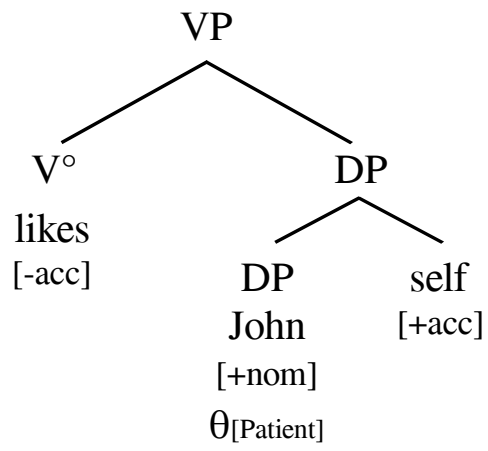

b.

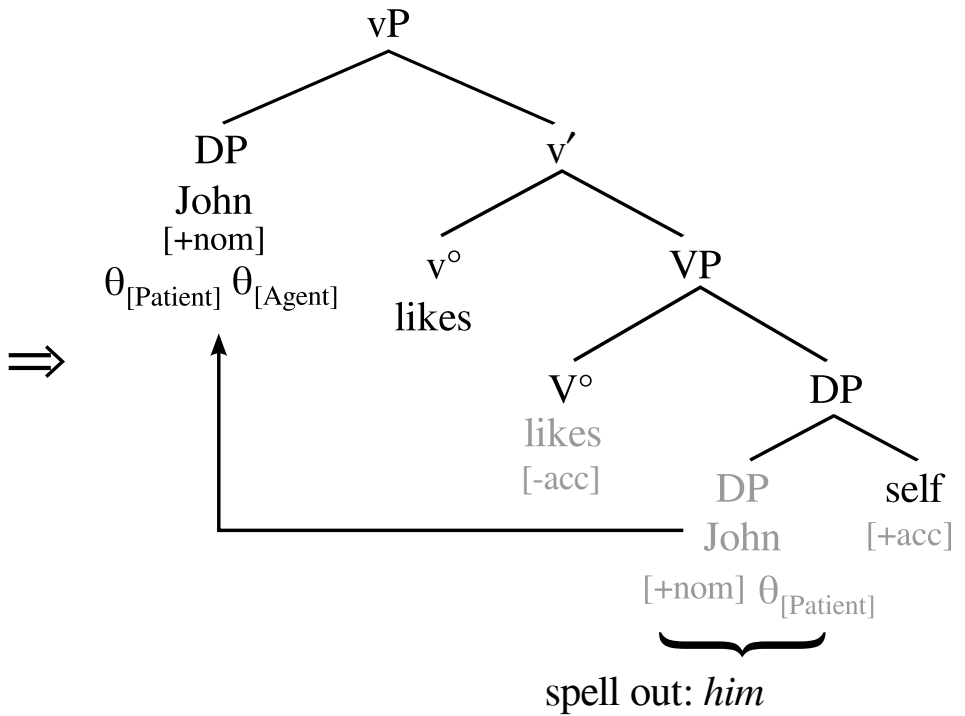

In (168b), the DP raises to vP and gets the agent theta role. The DP now has two theta roles, accounting for the reflexive interpretation of (166a). Hornstein $(2001,2007)$ argues that the copy of the DP gets spelled out because the affix self needs morphophonological support and the Spell-Out of the pronoun as him is due to a morphophonological process similar to do-insertion.

The locally bound pronoun in (166b) is ruled out because its derivation would involve insertion of a pronoun. Pronominalisation is considered to be less economical than the derivation involving movement. Thus, the locally bound pronoun in (166b) is excluded due to derivational economy. As the derivation in (168) succeeds, a derivation involving pronominalisation can never take place. Note that the movement approach crucially depends on the nature of self. In the analysis of Hornstein $(2001,2007)$, it is added in the course of the derivation, a step that violates the Inclusiveness Condition. Nevertheless, Hornstein defends his assumption and claims that self is a purely grammatical item without any semantic effect and that the Inclusiveness Condition only holds for lexical material.

The fact that the pronoun in (166b) would be perfectly grammatical with a referential interpretation is explained in the following way. The referential pronoun-or deitic pronoun in his termsbears stress. This requirement makes the deitic/referential pronoun distinct from bound pronouns and prevents the derivations from competing because the pronoun is needed to realise the stress feature (see Hornstein 2001:176).

In the following, I will to discuss the two core assumptions: (i) the phi-features of bound pronouns and (local) reflexive pronouns are semantically inert, and (ii) the self element has no effect on the interpretation. Starting with phi-features, Hornstein (2007) aims to support his assumption about the semantical inertness of phi-features with the examples in (169). 
(169) a. [ Only John $]_{\mathrm{i}}$ thinks that he $\mathrm{i}_{\mathrm{i}}$ is smart.

(Hornstein 2007:361)

b. NOT: Mary thinks that she is smart.

c. NOT: The boys over there think that they are smart.

d. NOT: I think that I am smart.

The interpretation of the focus particle only, within the framework of alternative semantics of Rooth $(1985,1992)$, can be explained in two steps: first, the particle only evokes alternatives for the phrase in its scope. In case of (169a), it evokes alternative values for the DP John. These alternatives are all the paradigmatic substitutes for John that are contextually given: here these are Mary, the boys over there, and $I$. The important point is that the anaphoric pronoun in the subordinate clause is also substituted according to the alternative antecedent. $H e$ is substituted with she, them, and $I$, respectively. This substitution takes place only if the pronoun $h e$ is interpreted as bound variable. The fact that the anaphoric pronoun varies according to the alternative antecedent is taken as evidence that the phi-features on bound pronouns are not interpreted. The subsitution does not take place if the anaphoric pronoun is interpreted by means of coreference, as exemplified in (170). The sentence in (170b) is a possible reaction to the sentence in (170a). In these examples, the pronoun he is interpreted as coreferential with the DP John and its phi-features have interpretive force and are not affected in the focus alternative.

(170) a.

[Only $\mathrm{John}_{\mathrm{i}}$ ] thinks that he $\mathrm{i}_{\mathrm{i}}$ is smart.

(Hornstein 2007:361)

b.

Wrong! Mary thinks that he is smart as well.

Secondly, if the sentence in (169a) is true, then all its alternative propositions-(169)b-c-are necessarily false. If John is the only one who thinks that he is smart, then it's true that all the other people don't think that they are smart. Thus, the sentences containing only entails that the negation of its alternative propositions is true.

Recently, Bassi \& Longenbaugh (2017), Sauerland (2013), Jacobson (2012), and Spathas (2009) argue that the semantic inertness of phi-features in examples like (169) is crucially related to the interpretation of focus and the focus particle only and not to binding. ${ }^{36}$ The importance of focus for interpretation is shown by means of examples such as (171a). The focus particle only has scope over the complex DP that contains the antecedent of the pronoun. In (171), the pronoun it is a so-called donkey pronoun. Recall from section 1.2 that donkey pronouns are not bound due to the lack of c-command, but still show covariation with their antecedent. This is shown by means of the focus alternatives in (171b) and (171c).

\footnotetext{
36 The mimimal pronoun approach predicts that the antecedent and the pronoun share phi-features due to binding. This kind of account runs into problems with the donkey anaphora in (171) because the pronoun covaries with its antecedent, even though it is not bound. Binding is impossible because the pronoun is not c-commanded by its antecedent. Recall from section 1.2 that binding in semantics and syntax implies a c-command relation between the binder and the bindee.
} 
(171) a.

[[Only the students[who took phonology]] thought it was cool].

b. NOT: The students who took syntax thought it (=syntax) was cool.

c. NOT: The students who took semantics thought it (=semantics) was cool.

(Bassi \& Longenbaugh 2017)

Covariation is possible because the phi-features of the pronoun it are semantically inert. But the semantic inertness of the phi-features cannot be due to binding, and the authors conclude that it has to be related to the interpretation of focus. In the following, the focus-related explanation will be briefly sketched, ignoring technical differences between the accounts. All cited accounts claim that phi-features on a pronoun introduce a presupposition that constrains the set of possible antecedents. For example, the pronoun in (171a) has the features [ $3^{\text {rd }}$ person, neuter, singular], which restrict the range to a non-human, singular antecedent. The pronoun in $(169 \mathrm{a})$ has the features $\left[3^{\text {rd }}\right.$ person, masculine, singular], which restrict the set of possible referents to male individuals that are not the speaker or the hearer in the speech act context. It is assumed that the presuppositions are cancelled, but only in the focus alternatives and not in the regular interpretation, the ordinary semantic value. For example, the ordinary semantic value of the pronouns in (169a) and (171a), is the interpretation in which the phi-features of the pronouns he and it impose a restriction on the antecedent. The fact that the phifeatures are active is shown by the ungrammaticality of the sentences in (172). The antecedent and the pronoun do not share the same phi-features, and the sentences are ungrammatical. Thus, the content of the features must have an effect at this level of interpretation and they cannot be generally inert.

*Only $\mathrm{John}_{\mathrm{i}}$ thinks that it ${ }_{\mathrm{i}}$ was smart.

b. $\quad *$ Only the students who talked to [the phonology professor $]_{\mathrm{i}}$ thought $\mathrm{it}_{\mathrm{i}}$ was cool.

In the focus semantic alternatives, the phi-features of the pronouns are inactive; the presupposition is cancelled, and covariation is possible, as shown by means of the alternatives in (171b) and (169b)-(169d) above. Thus, it is the effect of focus that makes bound pronouns to appear as semantically inert elements. In the light of this approach to the interpretation of phi-features, Hornstein's (2007) assumption that all bound pronouns_-reflexive and non-reflexive_-are grammatical formatives without any semantic contribution is difficult to maintain.

As for the assumptions about the affix self, Hornstein $(2001,2007)$ states that it is a case-checking affix, a purely grammatical item. Furthermore, its insertion in the course of the derivation does not violate inclusiveness because it is semantically inert. But in Hornstein (2001:166), it is noted that the self element contributes to the interpretation, in the sense that it allows for a proxy interpretation of the reflexive pronoun (the internal argument). Compare (173a) and (173b). In both sentences, Ringo is both the agent and the patient of the dressing event, but only in (173b) is a proxy interpretation allowed.

b.

Ringo dressed.

no proxy reading 
On the basis of his own examples and arguments, the claim that self is semantically inert cannot be maintained, and self-insertion essentially violates the Inclusiveness Condition. Thus, the two core assumptions of Hornstein $(2001,2007)$ are difficult to maintain. This critique mainly affects the technical implementation of his approach. The fact that movement phenomena and local binding phenomena are related has also been explored for Romance pronouns in the account of Alboiu, Barrie \& Frigeni (2004). Their account will be presented in the next section, and it will be shown that an application of a movement-based approach to Ibero-Romance data is highly problematic from a conceptual as well as an empirical point of view.

\subsubsection{Alboiu, Barrie, and Frigeni (2004)}

The approach of Alboiu, Barrie \& Frigeni (2004) aims at a cross-linguistic account for reflexive clitics in Romance languages (Italian, French, Romanian, Spanish, and Portuguese). They follow basically Hornstein $(2001,2007)$ and take locally bound reflexives to be the spell-out of a copy left behind by movement. But they depart from Hornstein $(2001,2007)$ with respect to two main theoretical assumptions: (i) they do not assume a competition-based account to complementary distribution, and (ii) they do not assume a case-checking item such as the self element. In this section their account is briefly sketched and evaluated with respect to Spanish and European Portuguese.

Differently from English, Romance languages have clitic and strong versions of reflexive and non-reflexive pronouns. In order to account for the complementary distribution of reflexive and nonreflexive pronouns, as exemplified in (174) with Italian sentences, they assume that the reflexive clitic is the spell-out of a copy, while the non-reflexive clitic is a lexical item. As for the strong reflexive pronoun in (174a'), Alboiu, Barrie \& Frigeni (2004) do not make a clear statement about their nature, but it seems that they consider them to be spell-out elements, too. This might be a solution for Italian, but recall from section 1.4 that sentences like $\left(174 a^{\prime}\right)$ and $\left(174 b^{\prime}\right)$ are ungrammatical in Spanish and European Portuguese because the strong pronoun has to be doubled with a clitic.

\begin{tabular}{|c|c|c|c|}
\hline (174) a. It. & $\begin{array}{llr}\text { Gianni }_{i} & \mathrm{Si}_{\mathrm{i}} \quad \text { difende. } \\
\text { G. } & \text { SE.REFL=defends }\end{array}$ & $a^{\prime}$ & $\begin{array}{llll}\text { Gianni }_{i} & \text { difende } & \text { se }_{i} & \text { (stesso). } \\
\text { G. } & \text { defends } & \text { REFL.PR SELF }\end{array}$ \\
\hline & 'Gianni defends himself.' & & 'Gianni defends himself.' \\
\hline b. & ${ }^{*}$ Gianni $_{i} l_{\mathrm{i}} \quad$ difende. & $\mathrm{b}^{\prime}$ & ${ }^{*}$ Gianni $_{i}$ difende lui $i_{i}$ \\
\hline & G. him.CL=defends & & G. defends him \\
\hline
\end{tabular}

(Alboiu et. al. 2002:7/8)

In order to rule out a bound interpretation of the non-reflexive clitic in (174b) and of the non-reflexive strong pronoun in (174b'), they assume the Chain Conditon of Reinhart \& Reuland (1991, 1993) and Reuland (2011). This condition states that an A(argument)-chain may contain just one element that is fully specified for both phi-features and case. Thus, an anaphoric pronoun forms an A-chain with its antecedent, only if it is underspecified for phi-features and/or case. The clitic and strong reflexive pronoun in (174a) and (174a'), respectively, form a legitimate A-chain with their antecedents because 
reflexives are not fully specified for phi-features. For these reasons, reflexives are a legitimate tail of a movement chain and qualify as a licit spell-out object in the account of Alboiu, Barrie \& Frigeni (2004) . The bound pronouns in (174b) and (174b') are ruled out by the Chain Condition because nonreflexive pronouns are fully specified for phi-features and case.

Now, let us look in more detail at the movement operations in the derivation of (174a) illustrated in (175) below. Alboiu, Barrie \& Frigeni (2004) assume the framework as put forward in Chomsky (2000 et seqq.). Movement is defined there as a combination of three operations: Agree, Internal Merge, which is a combination of copy and merge, and pied-piping. The details of the agreement or piedpiping are not relevant here, but keep in mind that under these assumptions, all features of a moved DP are copied and internally merged to the new position. In the analysis proposed by Alboiu, Barrie \& Frigeni (2004), the subject DP Gianni is base-generated in the thematic object position. In this position it receives the patient role and accusative case. After merger of $\mathrm{v}^{\circ}$, the DP moves into specvP, where it additionally receives the agent role of the transitive verb. In specvP it is the target for nominative case assignment by $\mathrm{T}^{\circ}$ and it moves to specTP, probably for checking an EPP feature. At the end of the derivation the lowest copy of the DP is spelled out as the reflexive clitic.

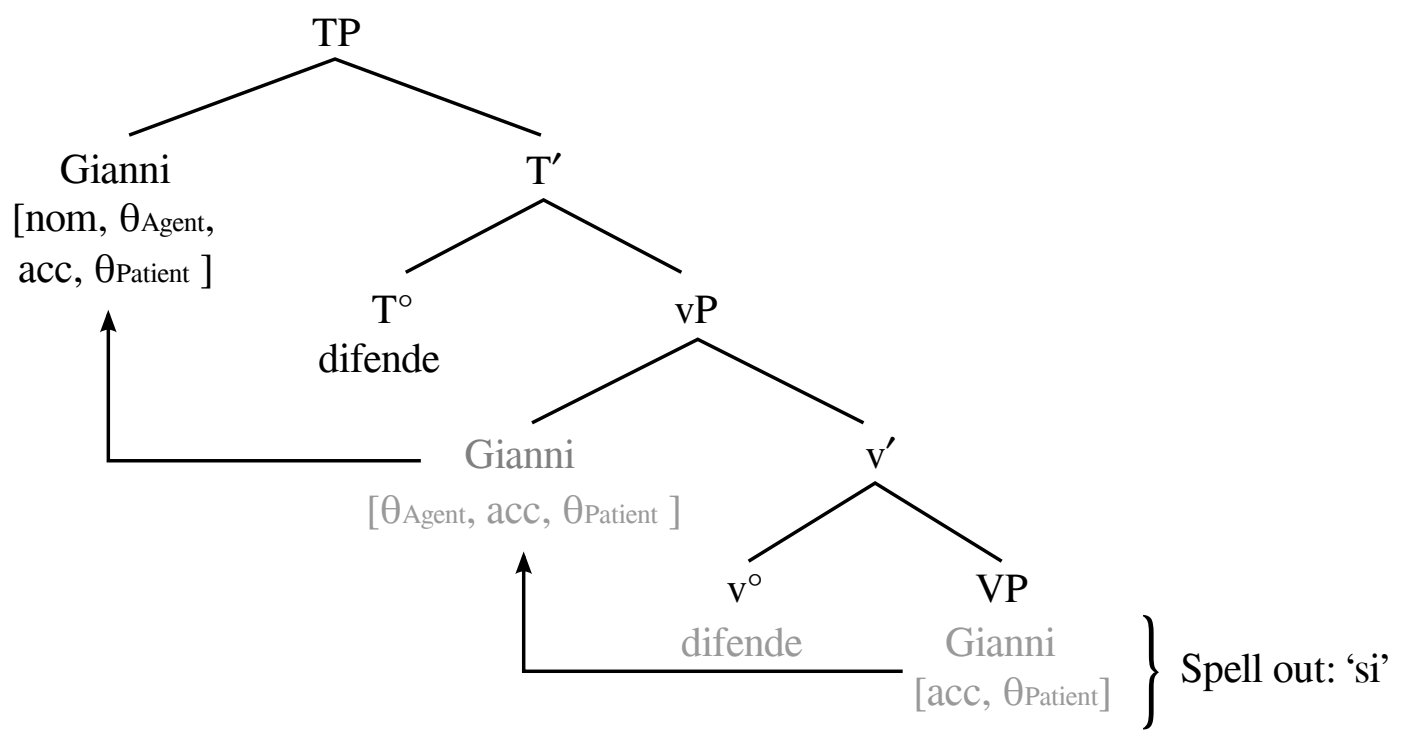

Even though Alboiu, Barrie \& Frigeni (2004) argue that the reflexive clitic realises the accusative case feature, the subject DP bears two case features, in addition to two theta roles at the end of the derivation. This result has far-reaching consequences and needed independent justification. It seems that the authors ignored this problem. Another problem of the analysis is the assumption that the clitic is the spell-out of a copy. The clitic is inserted post-syntactically by means of some morphophonological process. This assumption has far-reaching implications for the syntax of Romance clitics. If clitics are born post-syntactically, the process of cliticisation (the process by which the clitic is associated with its verbal host) has to be a post-syntactic morphological process. Thus, cliticisation and all constraints on clitic placement, such as on clitic climbing, must be determined post-syntactically as well. A post- 
syntactic account for clitics is, in principle, a theoretically possible option, but Alboiu, Barrie \& Frigeni (2004) assume additionally that non-reflexive clitics are lexical items. As a consequence, reflexive clitics and non-reflexive clitics are objects of distinct levels of grammar. The former is a spell-out morpheme and the latter is a lexical item, but both are still sensitive to the same conditions. Alboiu, Barrie \& Frigeni (2004) would need to formulate all conditions on cliticisation and clitic placement as rules within syntax and additionally as post-syntactic morphological rules, a consequence that seems to be undesirable under Minimalist economy considerations (Chomsky 1995 et seqq.).

In addition to these conceptual problems, the movement analysis has also empirical problems. Alboiu, Barrie \& Frigeni (2004) propose the same analysis for Italian emphatic pronouns in (176a) and Spanish and Portuguese clitic doubling structures in (176b) and (176c).

\begin{tabular}{|c|c|c|}
\hline (176) a. & It. & 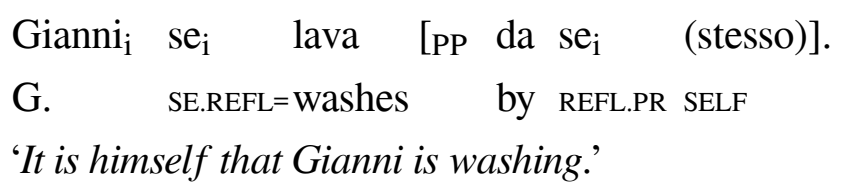 \\
\hline b. & Sp. & $\begin{array}{lllll}\mathrm{Juan}_{\mathrm{i}} & \mathrm{Se}_{\mathrm{i}} \quad \text { lava } \quad \text { [PP a } & \mathrm{Si}_{\mathrm{i}} & \text { mismo }] . \\
\mathrm{J} . & \text { SE.REFL=washes } & \text { OM } & \text { REFL.PR } & \text { SELF } \\
\text { 'Juan } & \text { washes himself.' }\end{array}$ \\
\hline c. & EP & $\begin{array}{l}\mathrm{O} \quad \mathrm{João}_{\mathrm{i}} \text { lava-se }_{\mathrm{i}} \quad\left[\begin{array}{llll}\mathrm{PP} & \text { a } & \mathrm{si}_{\mathrm{i}} & \text { próprio }\end{array}\right] \\
\text { the } \mathrm{J} . \quad \text { washes=SE.REFL } \\
\text { 'João } \text { washes himself.' }\end{array}$ \\
\hline
\end{tabular}

They assume that the PP containing the strong pronoun is an adjunct with an emphatic interpretation similar to an it-cleft, as indicated by the translation of the Italian sentence (176a). Following Krifka (2007), it-clefts induce an exhaustive focus interpretetation of the clefted material, and the sentence (176a) entails something like 'Gianni washed nobody but himself'. This kind of interpretation may be true for Italian, but it is not for European Portuguese and Spanish. Recall from chapter 2 that the pronominal double (reflexive and non-reflexive) is associated with a contrastive focus interpretation that is not necessarily exhaustive. Furthermore, it will be shown in chapter 5.1 that the strong reflexive double may also serve as disambiguating element for the otherwise ambiguous reflexive clitic. This means that the pronominal double is not necessarily associated with a focus interpretation. Additionally, the claim that the PP is an adjunct in Spanish and European Portuguese is simply not correct. Both languages allow for clitic doubling in ECM contexts, which is a clear indication of the argumental status of the pronominal double.

Alboiu, Barrie \& Frigeni (2004) ignored (or abstracted away from) the language-specific properties of clitic doubling syntax and interpretation for the sake of a generalisation for Romance languages. This leads to wrong predictions about reflexive and non-reflexive clitic doubling structures in Spanish and European Portuguese. Furthermore, an account along their lines needs to make highly problematic assumptions about the nature of clitics. The movement approach has been shown to be inadequate for 
an analysis of Spanish and European Portuguese clitic doubling structures and is therefore not considered in this book.

\subsection{Referential identity created upon External Merge}

Zwart (2002) and Kayne (2002) propose that an anaphoric dependency between a pronoun and its antecedent is created upon merger. The basic idea of both accounts is that the pronoun is first-merged together with its antecedent. The pronoun and the antecedent form a kind of bigDP. ${ }^{37}$ The antecedent then moves out of the bigDP into its final position. But Zwart (2002) and Kayne (2002) differ substantially with respect to the constraints on the movement of the antecedent. Kayne (2002) allows movement of the antecedent DP across finite clauses as in (177a) and (177b) and even across sentence borders as in $(177 \mathrm{c})$.

(177) a. John thinks [John he] is smart.

(Kayne 2002:137)

b. John thinks she's in love with [John him].

(ibid:141)

c. John is famous. [John $\mathrm{He}]$ is smart too.

(ibid:138)

The fact that Kayne (2002) radically departs from commonly accepted constraints on movement operations has been gently but firmly criticised in Zwart (2002) and Reuland (2011). The account of Kayne (2002) will not be discussed any further because the assumptions made in his approach are not desired in the present book, and this section focusses exclusively on the account of Zwart (2002).

Zwart's (2002) approach is based on the following assumptions about the nature of pronouns (in English). He argues against the classification of NPs in classic BT because the classification by means of the features [+/- anaphoric] [+/- pronominal] makes pronouns and anaphors maximally distinct from each other. An anaphora is [+anaphoric, -pronominal], and a pronominal is [-anaphoric, +pronominal]. This means they do not share any feature with each other, while they have a feature in common with R-expressions that are [-anaphoric, -pronominal]. Zwart (2002) argues that this cannot be true from a morphological point of view. Morphologically, anaphora and pronouns share more features with each other than they share with R-expressions. At least in English, a reflexive is formed by a pronoun and the intensifier self. Zwart (2002) proposes another typology based on referentiality. In his typology, Rexpressions, pronouns, and anaphora are referential elements. But differently from R-expressions, pronouns and anaphors lack semantic content. Pronouns and anaphors are referentially dependent on another DP and therefore belong to the same category. This category is a default category for all pronominal elements, called PRONOUN, which is conceived as an underspecified 'elsewhere' category with the properties +REFERENTIAL and +VARIABLE (see Zwart 2002:274). Zwart's (2002) hierarchy of nominal expressions is presented in (178).

37 Kayne (2002) makes explicit reference to clitic doubling and to Uriagereka's (1995) the bigDP analysis. However, as will become clear below, reflexive clitic doubling is problematic for the Merge-based account. 
(178)

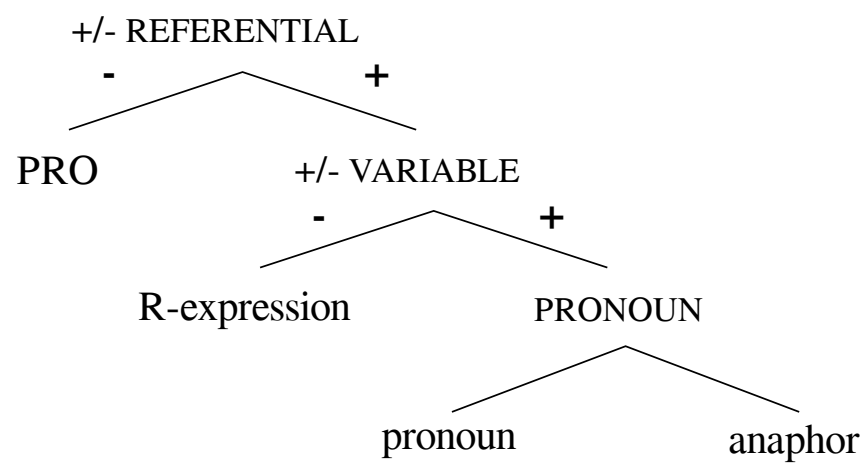

Both, the reflexive and the non-reflexive pronoun-anaphor and pronoun in his terms-enter the syntactic derivation as PRONOUN. This underspecified item PRONOUN acquires features in the course of the derivation. On basis of PRONOUN's feature content, its morphological shape is determined at PF, and its interpretation is determined at LF. In order to derive the reflexive form, Zwart assumes the feature [+coreferential]. This feature is acquired if PRONOUN is merged with an antecedent DP. Referential identity is generated upon merger, as stated in (179).

In the following, it will be shown how Zwart (2002) accounts for the complementary distribution of locally bound reflexive and non-reflexive pronouns. For the sake of illustration, the well-known examples are repeated in (180).

(180) a.

$\mathrm{John}_{\mathrm{i}}$ likes himself $_{\mathrm{i}}$.

b. $\quad \operatorname{John}_{\mathrm{i}} \operatorname{likes}_{\mathrm{him}} / *_{\mathrm{i}}$.

Let us start with the derivation of (180a). It proceeds as illustrated in (181a) below. PRONOUN merges with the DP John and acquires the feature [+coreferential]. This feature determines that PRONOUN will be spelled out as himself, and that PRONOUN is bound by the DP John. The big nominal phrase (XP) is then merged with the verbal categories, and the DP John moves into the position of the external argument. The ungrammaticality of the locally bound non-reflexive pronoun in (180b) is explained in the following way: if PRONOUN should become a locally bound pronoun, it needs to aquire the [+coreferential] feature. But this feature always gives rise to a reflexive form, and hence the spell-out of a locally bound non-reflexive pronoun is impossible.

In order to derive (180b) with a disjoint interpretation of him, PRONOUN merges directly with the verb, as illustrated in (181b). In this position, PRONOUN cannot acquire the [+coreferential] feature and is therefore spelled out as him with an obligatory disjoint reference.

38 Note that Zwart (2002) uses the terms bound and coreferential as synonyms. For coreference, as defined in chapter 1, Zwart (2002) uses the term accidential coreference. 
(181) a. Derivation of (180a)

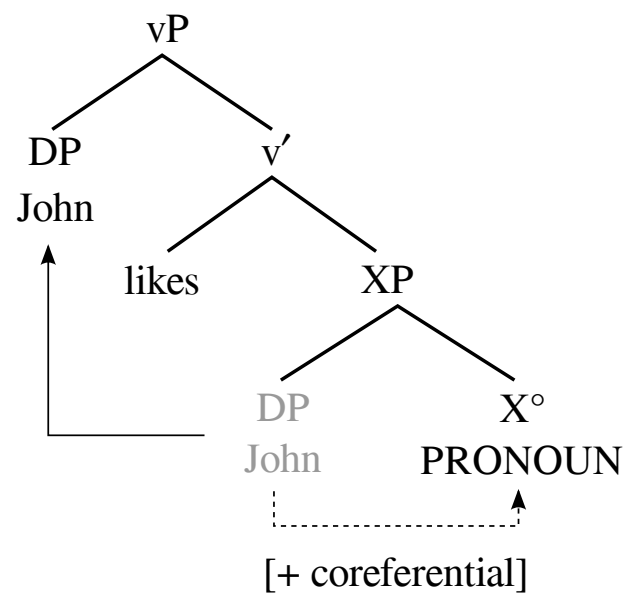

b. Derivation of (180b)

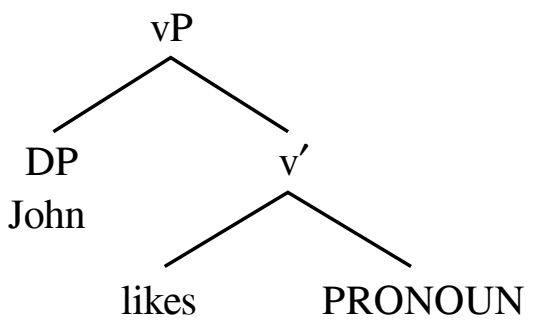

The c-command requirement and the locality requirement on the anaphor-antecedent relation are derived by constraints on A-movement, similar to Hornstein $(2002,2007)$. As for the free (coreferential) interpretation of the non-reflexive pronouns in (177), Zwart (2002) argues that it is possible if a movement dependency between the pronoun and its antecedent is blocked, as in (177b) and (177c). As for the bound interpretation of the pronoun in (177a), Zwart (2002) assumes a semantic binding relation similar to operator-variable relation.

Let us now turn to the application of Zwart's (2002) approach to Spanish and European Portuguese clitic doubling structures. In order to aquire a [+coreferential] feature, the antecedent has to be merged not only with the reflexive clitic, but also with its strong pronominal double. The clitic and the strong pronoun enter the derivation as PRONOUN and receive the [+coreferential] feature upon merger with the antecedent. Consequently one 'BIG-bigDP' would be formed. The [+coreferential] feature serves as an instruction for morphophonological spell-out and as an instruction for interpretation. The latter instruction is unproblematic, but as for morphophonological spell-out, Zwart's account predicts that a reflexive clitic can only be doubled by a reflexive strong pronoun. This prediction is not borne out in Spanish and European Portuguese. Recall from section 1.4 that Spanish and European Portuguese allow for a reflexive clitic to be doubled by a non-reflexive pronoun. The examples (32a) and (32b) are repeated here in $(182 b)$.

(182) a. Sp. Rita $_{i} \mathrm{se}_{\mathrm{i}}$ ama a ella misma.

R. SE.REFL=loves OM her SELF

'Rita loves herself.'

b. EP A Rita ama-se $_{i}$ a ela $a_{i}$ própria.

the R. loves=SE.REFL OM her SELF

'Rita loves herself.'

Furthermore, it will be shown in chapter 5 that there are also combinations of a non-reflexive clitic doubled with a reflexive strong pronoun. In Zwart (2002), these combinations are predicted to be 
impossible because a non-reflexive pronoun cannot acquire a [+coreferential] feature and a reflexive pronoun needs a [+coreferential] to be spelled out as such. Due to these empirical shortcomings and the need to justify a 'BIG-bigDP', the Merge-based account will not be pursued in this book.

\subsection{Referential identity created by Agree}

This last section discusses the Agree-based accounts of Hicks (2009) and Marelj \& Reuland (2016).

\subsubsection{Hicks (2009)}

Hicks (2009) explores the idea that an anaphoric dependency between a pronoun and its antecedent is established by means of the operation Agree. Recall from section 1.3 that Agree in the sense of Chomsky (2000 et seqq.) is basically phi-agreement, and an Agree-relation is established between unvalued features on a functional head and valued features on a DP. Although anaphoric pronouns share phi-features with their antectedent, a phi-feature-based approach is dismissed by Hicks (2009) because an anaphoric dependency holds between two DPs and not between a functional head and a DP.

In order to be able to establish an Agree relation between to DPs, Hicks (2009) assumes that nominal items carry the semanticosyntactic features [var] and [op]. These features can be understood as a kind of instruction to the semantic component to translate a DP with a [var] feature as variable and a DP with an [op] feature translates as an operator in the sense of predicate logic. The values of [var] are variable names $(x, y$, or $z)$ or semantic indices that help to identify the referent of a pronoun. For anaphors, he assumes that they come with an unvalued [var] feature and that R-expressions and pronominals have a valued [var] feature. The unvalued [var] feature acts like a probe and searches for a goal with a valued [var] feature. Agree takes place, and the feature value of the goal is copied onto the probe. As a result, the two DPs have the same value such as [var:x]. The reader may have immediately noticed that the [var] feature is the probe-goal version of the referential index of classic Binding Theory, as mentioned by Hicks (2009:115) himself.

In order to derive the restrictions on locally bound anaphors such as c-command and locality, the domain of Agree has to be restricted. Furthermore, locally bound pronouns have to be excluded. Before addressing the domain problem, a bit more has to be said about probing.

Let us look at the sentence in (183a). In order to establish an Agree relation between the anaphor himself and its antecedent John, the unvalued [var] feature needs to probe upward to find the valued features of its antecedent. Hicks (2009) argues that upward probing is possible if downward probing has been unsuccessful, as illustrated in (183b). Upward probing is thus a kind of last resort probing. The unvalued [var] feature of the anaphor is located in $\mathrm{D}^{\circ}$, which selects an NP complement containing the self element. The unvalued feature probes downward into the NP, but it does not find a matching goal. Due to the internal structure of the reflexive pronoun, downward probing will always be unsuccessful. For this reason, an anaphor without a c-commanding antecedent will always be ungrammatical. 
(183) a.

b.

John loves himself.

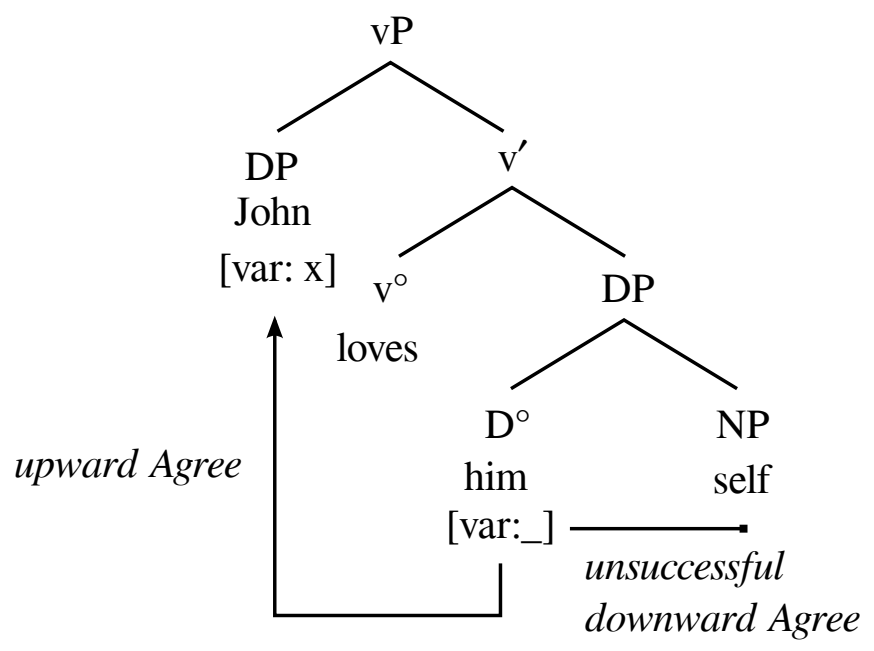

At the moment the external argument DP John merges, the unvalued [var] feature probes upward and finds the valued [var] feature of the DP. Agree takes place and an anaphoric dependency is established between the DP John and the reflexive pronoun himself.

Another difference from the operation Agree as defined in Chomsky (2000 et seqq.) is that the [var] feature on the anaphor does not delete after valuation. Following Adger \& Ramchand (2005), Hicks (2009) argues that features on lexical items do not delete because they have to be interpretable either at the $\mathrm{C} / \mathrm{I}$ interface, or the S/M interface, or at both interfaces. The [var] feature is a semanticosyntactic feature that is interpretable at the syntax-semantics interface, and it must not delete after Agree. Furthermore, a lexical item has additional morphosyntactic features that are only interpretable at the S/M interface. Hicks (2009) follows Epstein \& Seely (2002) and argues that Transfer/SpellOut is not necessarily a simultaneous operation for the interfaces, but may apply separately to semanticosyntactic features at one stage of derivation and to morphosyntactic features at another stage. As a consequence, there are distinct points for Transfer, and phases are divided into LF phases and PF phases. The former only read off semanticosyntactic features and the latter read off morphosyntactic features. The LF phases coincide with the phases vP and CP of Chomsky (2000 et seqq.) due to their propositional nature. The PF phases are vP, CP, and additionally PP and DP.

With this in mind let us return to the locality restrictions on Agree mentioned above. Hicks approaches the domain problem of classic BT by means of a Minimalist 'reformulation' of principle $\mathrm{A}$ and $\mathrm{B}$ in terms of these phases. He defines distinct domains for anaphors and pronominals in terms of LF and PF phases as given in (184).

(184) a. The unvalued [var] of an anaphor has to find a matching goal within its LF phase. (LF phases are $\mathrm{vP}, \mathrm{CP}$, and $\mathrm{nP}$.)

b. $\quad$ Pronominals have to be free in their PF phase. (PF phases are vP, CP, DP with a subject, and PP with a lexical preposition.) 
A PF phase is defined by the head that values the case feature of a pronoun. If the pronoun has a valued case feature, it is inactive/invisible for any other syntactic operation. ${ }^{39}$

Let us see how his account works for anaphors and pronominals inside PPs, in particular how it excludes locally bound pronouns. ${ }^{40}$ Consider the examples in (185) put forward in Chomsky (1981:290) and Reinhart \& Reuland (1993:689). In (185a) and (185b), the pronouns are inside a locative PP. A locative preposition is a lexical preposition that assigns a theta role and case. This means that the locative $\mathrm{PP}$ is the PF domain for the non-reflexive pronoun. The non-reflexive pronoun is free in this domain, and the sentences are correctly predicted to be grammatical. In (185c) and (185d), the preposition is taken to be a dummy preposition that assigns neither case nor a theta role. The pronouns are casemarked and theta-marked by the verb, and the PF domain is therefore the vP. The pronoun would be bound inside its PF domain, a configuration that is correctly ruled out by (184b).

(185) a.

$\operatorname{Max}_{[v a r: x]}$ rolled the carpet over $\operatorname{him}_{[\mathrm{var}: \mathrm{x}]} /$ himself $_{[\mathrm{var}: \mathrm{x}]}$.

(Hicks 2009:176)

b.

$\operatorname{John}_{[\operatorname{var}: x]}$ saw a snake near him ${ }_{[\operatorname{var}: x]} /$ himself $_{[\operatorname{var}: x]}$.

c.

$\mathrm{John}_{[\operatorname{var}: \mathrm{x}]}$ talked about $* \operatorname{him}_{[\mathrm{var}: \mathrm{x}]} / \operatorname{himself}_{[\operatorname{var}: \mathrm{x}]}$.

d.

$\mathrm{John}_{[\operatorname{var}: \mathrm{x}]}$ wrote a letter to $* \operatorname{him}_{[\operatorname{var}: \mathrm{x}]} /$ himself $_{[\operatorname{var}: \mathrm{x}]}$.

As for the reflexive pronouns, they are allowed in all types of PPs because they are sensitive to LF phases and not to PF phases. Their domain is the smallest LF phase, the vP that contains the antecedent in all examples.

Note that the explanation given for the ungrammaticality of locally bound non-reflexive pronouns is not derivational, in the sense that it is due to the failure of Agree or any another syntactic operation, but is instead based on a descriptive principle. In order to rule out these pronouns in a derivational way, Hicks (2009) proposes the principle of Maximise Featural Economy given in (186). This economy-based explanation is very similar to the approach presented in Reinhart \& Reuland (1991,1993), Reuland (2001), and later work.

Establish dependencies via syntactic operations where possible.

Locally bound pronouns are ruled out by derivational economy as follows. Non-reflexive pronouns have a valued [var] feature that can be by definition an active [var] feature. Hicks (2009) argues that the features are deactivated for operations at the moment case is valued. In (185c) and (185d), the PF phase is the $\mathrm{vP}$ and crucially the $\mathrm{vP}$ is also a LF phase in which Agree takes place. The pronouns in (185c) and (185d) are in a configuration in which Agree could have applied, but as it did not apply due to the

39 The fact that case is relevant for the binding of an anaphoric pronoun has already been noticed by Chomsky (1981), Reinhart \& Reuland (1991, 1993), and many others not mentioned here.

40 Hicks's (2009) analysis for anaphors in picture nouns is not presented here because the present book does not consider this type of construction. 
inactive features of the pronoun, the principle in (186) is violated. Therefore a bound interpretation of the pronouns is ruled out.

In order to explain the complementary distribuiton of pronouns in local domains, Hicks needs to introduce the principle in (186), in addition to many assumptions concerning features, Agree, and phases. Although he aims at a Minimalist, derivational account, his account seems to remain at a descriptive, presentational level. Furthermore, his economy principle runs into a problem with the application of Agree in sentences like (187). In (187a), the reflexive pronoun inside the picture NP can take all three DPs—John, Bill, and Paul—as antecedent. The picture DP moves from its base position through an intermediate position to its final position. These steps are illustrated in (187b)-(187c).

(187) a.

$\operatorname{John}_{[\operatorname{var}: \mathrm{x}]}$ wondered [which picture of himself $\left.{ }_{[\mathrm{var}: \mathrm{x}, \mathrm{y}, \mathrm{z}]}\right]$ Bill $_{[\mathrm{var}: \mathrm{y}]}$ claimed $\operatorname{Paul}_{[\mathrm{var}: \mathrm{z}]}$ had bought.

b. $\quad\left[{ }_{\mathrm{vP}} \mathrm{Paul}_{[\mathrm{var}: \mathrm{z}}\right.$ had bought [which picture of himself $[$ var:_] $\left.]\right]$.

c. $\quad$ Bill $_{[\text {var:y] }}$ claimed [CP [which picture of himself ${ }_{[\text {var:_] }]}$ Paul $_{[\operatorname{var}: z]}$ had bought [which picture of himself $[$ var:__]].

d. $\quad \operatorname{John}_{[\operatorname{var}: \mathrm{x}]}$ wondered [CP $\left[\right.$ which picture of himself $\left.{ }_{\left[\mathrm{var}: \_\right]}\right]$Bill ${ }_{[\mathrm{var}: \mathrm{y}]}$ claimed [which

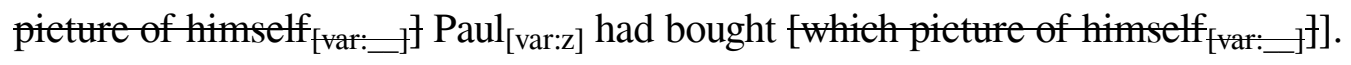

At each step, Agree between the unvalued [var] of the anaphor and the DP Paul, Bill, and John is possible. Hicks (2009:158-159) argues that the application of Agree can 'wait' until the intended antecedent is merged. The fact that speaker's intention has an effect on the application of Agree goes against his own principle (186) and against general considerations on the application of syntactic operations. Agree applies blindly at the moment the unvalued featues are introduced. Due to these conceptual shortcomings, the general idea of probing anaphors is not pursued in the present book.

\subsubsection{Marelj and Reuland (2016)}

Marelj \& Reuland (2016) present a phi-feature-based account for reflexive and passive uses of the reflexive clitic in Romance and Slavic. The part on Romance is mainly based on Italian and French data, but they occasionally generalise to Spanish and the other Romance languages. They follow the theory of Reuland (2011) and Reinhart \& Siloni (2004, 2005), as introduced in chapters 1 and 3, respectively.

Reinhart (2006) and Reuland (2011) argue that a reflexive predicate with an underlying transitive structure needs a special reflexive marker in order to be grammatical. In English and Dutch the reflexive-marker is the SELF intensifier. The effect of this element is to make the co-argument variables formally distinct as in the representation in (188b) and (188c). Reinhart (2006) and Reuland (2011) claim that the interpretive system of human language cannot handle structures like $\mathrm{V}(\mathrm{x}, \mathrm{x})$ because the two variables are non-distinct and this representation will be ruled out by a principle called Inability to Distinguish Indistinguishables (see Reuland 2011:186). In order to avoid a predicate with the strucutre $\mathrm{V}(\mathrm{x}, \mathrm{x})$, there are two possibilities: (i) create an intransitive predicate $\mathrm{V}(\mathrm{x})$, as proposed in Reinhart \& 
Siloni $(2004,2005)$, or (ii) make the two variables formally distinct, as in (188). The SELF-element of complex anaphors has essentially this effect. It protects the second argument variable from being ruled out by the principle Inability to Distinguish Indistinguishables. Reuland (2011) argues that it is due to this principle that reflexivity is licensed cross-linguistically, by some nominal or verbal reflexivisation strategy.

(188) a. John loves himself.

b. $\quad \mathrm{V}_{\text {loves }}\left(\operatorname{John}(\mathrm{x}), \mathrm{f}_{\text {self }}(\operatorname{him}(\mathrm{x}))\right.$

c. $\quad \mathrm{V}\left(\mathrm{x}_{\theta_{1}}, \mathrm{f}\left(\mathrm{x}_{\theta_{2}}\right)\right)$

For Romance reflexive clitic constructions, they assume an intransitive and a transitive derivation. The intransitive strategy has already been discussed in chapter (3) and shown to be inappropriate for Spanish and European Portuguese clitic doubling structures. For this reason, only the transitive derivation will be considered here.

The main focus of Marelj \& Reuland (2016) is on the semantic aspects of the derivation, and they aim at showing how reflexive clitics are able to introduce an operator that protects the second variable, as in the representation in (188) above. Let us therefore start with their assumptions about reflexive clitics. Marelj \& Reuland (2016) follow Chomsky (1995b) and take the category of cliticsboth reflexive and non-reflexive clitics—to be simulaneously XP and $\mathrm{X}^{\circ}$, which means that they can be base-generated in an argument position as XP and later move as an $\mathrm{X}^{\circ}$ category to their verbal host. Furthermore, they assume that reflexive clitics need case and have defective phi-features.

As for reflexive clitics, they do not spell out their feature content. The authors just mention that they adopt Reuland's (2011) analysis of Dutch zich to Romance reflexive clitics. Reuland (2011) assumes the feature theory of Pesetsky \& Torrego (2004), ${ }^{41}$ and the referential defectiveness of anaphors is formalised by means of unvalued but interpretable phi-features. For zich, Reuland (2011:140) assumes that it has an unvalued number and gender feature, but a valued person feature. Later in the book, Reuland (2011:177) assumes an unvalued phi-feature set and an unvalued case feature. Due to this uncertainty, it is not easy to evaluate the morphosyntactic part of Marelj \& Reuland's (2016) proposal.

As for cliticisation, or better the interpretation of cliticisation, this process is crucial for the semantic part of their analysis. They adopt the analysis of Baauw \& Delfitto (2005). These authors propose that non-reflexive clitics, although merged in a theta position, do not (semantically) saturate the open argument of the predicate, but only impose a restriction on the interpretation of the argument variable by means of their phi-features. The syntactic process of cliticisation is interpreted as a type of predicate abstraction, which introduces an operator (OP) that imposes an interpretive restriction on the variable it binds. In the following, Marelj \& Reuland's (2016) derivation of an Italian reflexive sentence is exemplified step by step.

41 Pesetsky \& Torrego (2004) assume that interpretable as well as uninterpretable features can be valued or unvalued. Furthermore, they assume probing of unvalued tense features. The details of their theory are not necessary to understand Marelj \& Reuland's (2016) approach and are therefore not spelled out here. 
In Marelj \& Reuland (2016:199), the syntactic and the semantic derivation are represented in a single tree structure. For the purpose of exposition, their tree structure is split into a morphosyntactic tree structure on the left hand and a semantic tree structure on the right hand. They exemplify their analysis by means of the Italian sentences given in (189).

$$
\begin{aligned}
& \text { It. Gianni } \mathrm{i}_{\mathrm{i}} \mathrm{si}_{\mathrm{i}} \text { ammira. } \\
& \text { G. SE.REFL=admires }
\end{aligned}
$$

\section{'Gianni admires himself.'}

In (190a), the Italian transitive verb ammirare 'admire' is merged with the reflexive clitic si, which bears the internal theta role of the verb. But, as shown in the semantic tree structure (190b), the clitic does not satisfy the argument variable by means of lambda conversion.

(190) a.

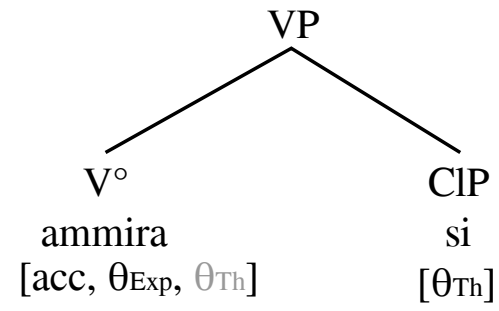

b.

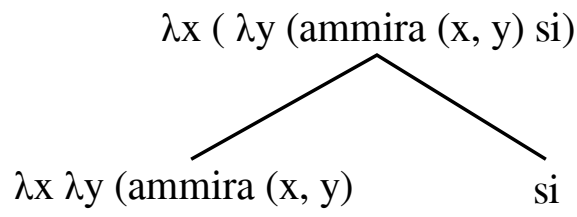

The next step is merger of a case phrase KP which is responsible for accusative case assignment. Casechecking is a purely syntactic operation and does not contribute to the interpretation. For this reason the semantic representation remains as in (190b). As for the syntactic part, the verb moves to $\mathrm{K}^{\circ}$ and the clitic moves to specKP in order to satisfy its case feature. The KP merges with $v^{\circ}$, as illustrated in (191a). The vP is the domain for cliticisation and the domain in which the external argument enters the derivation and receives the external theta role, here the experiencer role. The semantic effects of cliticisation are represented in (191). Cliticisation is taken to add a restriction on the interpretation of the internal argument variable. This restriction is visualised by replacing the $\lambda y$ with the operator $\mathbf{O} \mathbf{p}_{\mathbf{s i} /}$ y. This means that the internal argument variable is unsaturated, but bound by the clitic-operator.

(191) a.

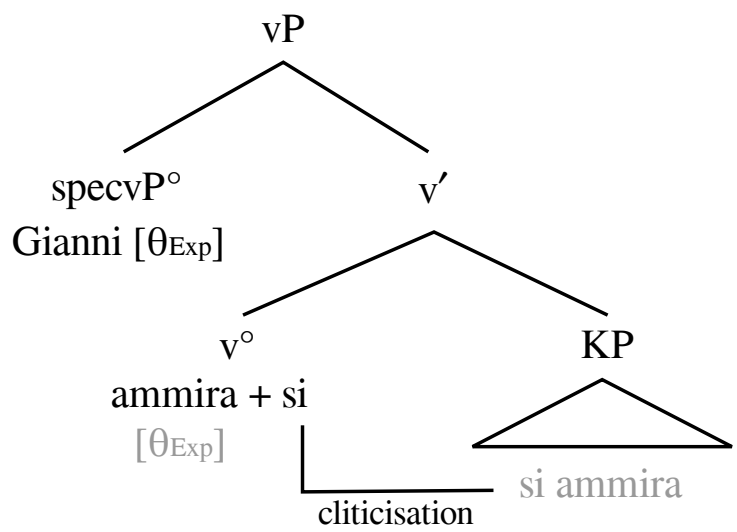

b.

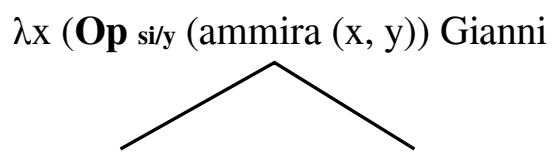

Gianni $\lambda \mathrm{x}(\mathbf{O p}$ si/y $(\operatorname{ammira}(\mathrm{x}, \mathrm{y}))$

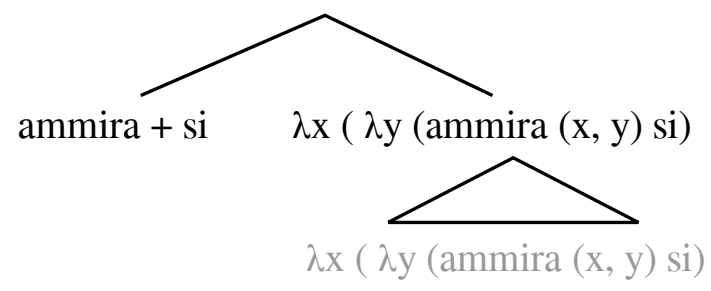


The essential steps for licensing the reflexive interpretation via phi-agreement take place inside the TP domain. A dependency between the clitic, the phi-features on $\mathrm{T}^{\circ}$, and the antecedent DP is established via phi-agreement/feature sharing. The technical details of Agree/feature sharing are not spelled out in detail. $^{42}$ They just mention that Romance reflexive clitics are similar to the Dutch simplex anaphor zich. In Reuland (2011:176-177), Agree/feature sharing is described as follows: the unvalued $\varphi$-features on $\mathrm{T}^{\circ}$ probe the simplex anaphor zich, which is in a position above the external argument. The unvalued features on $\mathrm{T}^{\circ}$ establish an agreement link and probe again, and finding the valued features on the external argument. By virtue of this agreement, the simplex anaphor and the antecedent are part of an agreement chain.

The tree structure in (192a) contains a representation of feature sharing that is my interpretation of these statements. I have added the unvalued phi-features to the clitic and to $\mathrm{T}^{\circ}$ and the valued phifeatures to the antecedent DP. The unvalued features on $\mathrm{T}^{\circ}$ probe the external argument Gianni. The clitic's phi-features get their value from $\mathrm{T}^{\circ}$ 's now valued phi-features. In this way, a phi-feature dependency is established between the antecedent and the reflexive clitic. Agreement or feature sharing between the clitic and $\mathrm{T}^{\circ}$ takes place inside the complex head formed by movement of the verb and the clitic to $\mathrm{T}^{\circ}$. As Marelj \& Reuland (2016:199) do not spell out any detail about this structure or about the feature sharing/Agree process itself, this decisive step in their derivation is impossible to evaluate. The semantic effect of feature sharing between the clitic and the subject DP is shown in (192b). The external argument DP indirectly saturates the internal argument because it shares phi-features with the clitic that is an operator binding the internal argument variable. In the tree structure of Marelj \& Reuland (2016:199), this process is visualised by changing the bold operator $\mathbf{O} \mathbf{p}_{\text {si/y }}$ into the bold-italic operator $\boldsymbol{O} \boldsymbol{p}_{\text {si }}$.

(192) a.

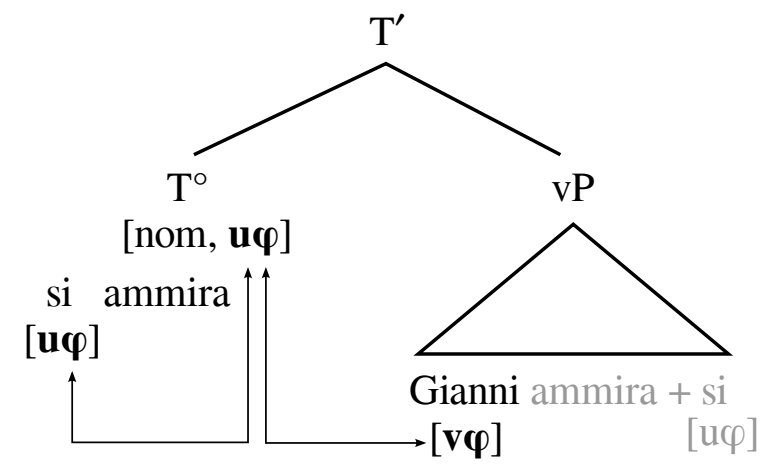

b.

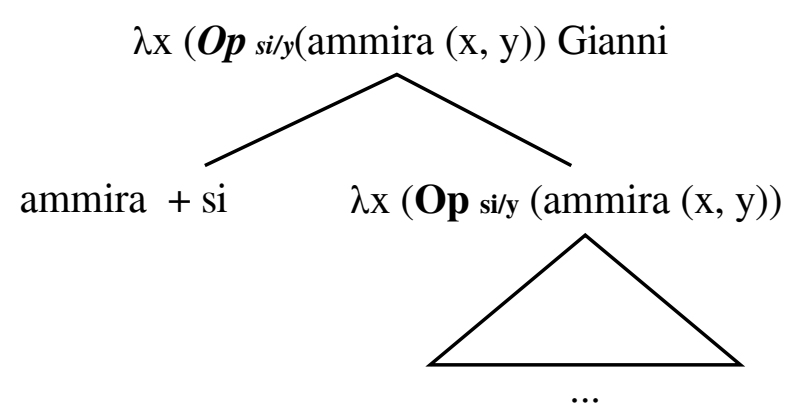

42 They give the following description of the role of the reflexive clitic: ' $\mathrm{SE}_{\mathrm{cl}}$ is $\Phi$-feature-deficient. Consequently, its features may be valued by Agree. Being deficient, it can check/absorb offending features in narrow syntax. In the case of reflexives, upon merger in Theme position, $\mathrm{SE}_{\mathrm{cl}}$ will move and check the $\mathrm{ACC}$ feature. Upon subsequent head movement, its features will be valued by the $\mathrm{T}_{\mathrm{Agr}} / \mathrm{SPEC}$,TP, which allows it to saturate the argument position in which it was merged.' Marelj \& Reuland (2016:200) 
The dependency created between the antecedent DP and the clitic does not qualify as an A-chain because the clitic in $\mathrm{T}^{\circ}$ is in a non-argument position at the moment of phi-feature sharing. According to Marelj \& Reuland (2016:200), the subject DP and the clitic form an A-A'-A dependency because the base position of the clitic is an argument position, and its position after cliticisation is an $\mathrm{A}^{\prime}$ position. As mentioned above, cliticisation is interpreted as an operator-variable expression. This operator has the function of protecting the internal argument variable. It keeps the two arguments of the reflexive verb formally distinct, even though they receive an identical interpretation via feature sharing. These interpretive steps are illustrated schematically in (193).

(193) a.

[A Gianni [A si ammira [A si]]]

b.

$\mathrm{V}_{\text {ammira }}\left(\operatorname{Gianni}(\mathrm{x}), \mathrm{Op}_{\mathrm{si}}(\mathrm{si}(\mathrm{x}))\right.$

c.

$\mathrm{V}\left(\mathrm{x}_{\theta_{1}}, \mathrm{f}\left(\mathrm{x}_{\theta_{2}}\right)\right)$

The fact that the feature sharing process is not spelled out makes the analysis Marelj \& Reuland (2016) very difficult to evaluate and to apply to Spanish and European Portuguese. As mentioned above, feature sharing between the clitic and the phi-features of $\mathrm{T}^{\circ}$ takes place inside a complex head. Agree/ feature sharing inside a complex head is problematic with respect to clitic clusters, as in the Spanish example in (194). The clitic forms part of the $\mathrm{T}^{\circ}$-verb complex, and as soon as valued phi-features are available on that head, the clitic shares features with it. In (194), the clitic cluster is formed before the verb-clitic complex reaches $\mathrm{T}^{\circ}$. Thus, the unvalued features on the reflexive clitic would be valued by the features of the direct object clitic before the external argument, the antecedent of the clitic, enters the derivation.

$$
\begin{aligned}
& \text { Sp. } \quad \operatorname{Juan}_{\mathrm{i}} \mathrm{se}_{\mathrm{i}} \quad \mathrm{la}_{\mathrm{k}} \quad \text { dio a } \quad \mathrm{sí}_{\mathrm{i}} \quad \text { mismo. } \\
& \text { J. SE.REFL=it.CL.ACC= gave to REFL.PR SELF } \\
& \text { 'Juan gave it to himself.' }
\end{aligned}
$$

As for Spanish and European Portuguese, the crucial problem of Marelj \& Reuland's (2016) analysis is their formalisation of referential defectiveness or anaphoric underspecification. They state that reflexive clitics have unvalued interpretable phi-features that act as a probe. Probing features on a reflexive clitic are problematic for the derivation of clitic doubling structures, in particular for doubling of a reflexive clitic and a non-reflexive strong pronoun. Recall the examples mentioned in section 4.2 above, repeated here again in (195b) for the sake of illustration.
(195) a. Sp.
Rita $_{\mathrm{i}} \mathrm{se}_{\mathrm{i}}$ ama a ella $\mathrm{i}_{\mathrm{i}}$ misma.
b. EP
A Rita ama-se $_{i}$ a ela $a_{i}$ própria.

In chapter 7, I will show that in every analysis of clitic doubling-agreement-based or bigDP-based - the clitic and its pronominal double are base-generated inside a configuration in which Agree or feature sharing would be possible. Thus, in examples like in (195), the reflexive clitic and its nonreflexive double are in a configuration in which the unvalued features of the reflexive would be valued 
by the features of the non-reflexive double. This would happen before the external argument merges and before the verb-clitic complex reaches $\mathrm{T}^{\circ}$.

It can be concluded that the analysis of Marelj \& Reuland (2016) fails to explain these core cases of reflexive clitic doubling in Spanish and European Portuguese, because referential defectiveness is expressed in terms of unvalued phi-features. Although the authors claim to account for Romance reflexives, their analysis is empirically not adequate for Spanish and European Portuguese. For this reason, my phi-feature based analysis presented in chapters 6 and 7 explores a different formalisation of referential defectiveness that will be based on the more restrictive features system of Chomsky (2000 et seqq.). Furthermore, it will be shown that it is the syntactic aspects of cliticisation that are crucial for a syntactic encoding of reflexivity in an Agree-based approach. 


\section{Referential properties of direct and indirect object pronouns}

This chapter focusses in detail on the way clitic and strong pronouns are interpreted and how this interpretation is constrained by structural/syntactic factors. The interpretive and structural properties will be identified by a set of structural and interpretive diagnostics that were introduced in 1.2. As discussed throughout the previous chapters, locality, c-command, and complementary distribution are the structural preconditions for a syntactic analysis of an anaphoric dependency. The interpretive diagnostics help to tell a bound interpretation from a coreferential interpretation. These two modes of interpretation can be distinguished by means of the following diagnostics: the ability to take a sentence-external antecedent, and the interpretation of pronouns in VP ellipsis and in so-called only-contexts. Whenever a bound interpretation is obligatory and complementarity holds in a local domain, a syntactic mechanism (Agree, Merge) should be involved. If these conditions are not met, an anaphoric dependency is not encoded by means of a syntactic operation, but the result of semantic or pragmatic principles.

The present chapter is devoted to reflexive and non-reflexive clitic doubling structures. Strong pronouns inside PP-complements or adjuncts will be examined in chapter 8 for the following reasons. The distribution of a clitic/clitic doubled complement and a PP-complement depends on distinct case properties of the verb. A verb that assigns accusative or dative case takes an object clitic and allows, with certain restrictions, for clitic doubling. Verbs that select a PP-complement do not assign structural case and are ungrammatical with a clitic pronoun. This general picture is valid for reflexive and nonreflexive pronouns, as exemplified with an European Portuguese example in (196).

direct object
a. EP
A Rita admira-se (a si própria).
'Rita admires herself.'
b.
A Rita admira-o (a ele).
'Rita admires him.'
c.
*A Rita admira- $\varnothing$ a si própria.
d.
$\mathrm{a}^{\prime}$. $\quad$ A Rita pensa em sí própria.
'Rita thinks of herself.'
$\mathrm{b}^{\prime}$. $\quad$ A Rita pensa nele.
'Rita thinks of him.'
$c^{\prime} . \quad *$ A Rita pensa-se.
d'. *A Rita pensa-o/lhe.

As indicated by the brackets, the double is optional, in the sense that the sentences (196a) and (196b) are grammatical without it. But its realisation is associated with a (contrastive) focus interpretation, as will be introduced in section 5.1. This interpretive effect is absent with the strong pronouns in PPs (both complements and adjuncts) and is thus proper to clitic doubling syntax.

This chapter is organised as follows. Sections 5.2 and 5.3 are dedicated to the structural diagnostics for locality, complemenatry distribution, and c-command. These diagnostics will show quite clearly that it is the clitics rather than the strong pronouns that are in complementary distribution. Furthermore, they show that it is the clitics that determine the interpretation of the verbal predicate and not the strong pronouns. The lexical type of the strong pronominal double, whether reflexive or non-reflexive, does 
not effect the interpretation of the predicate. The interpretive diagnostics for binding by a quantifier, a sentence-external antecedent, VP ellipsis, and only-contexts are discussed in the sections 5.4-5.7. A summary of the results is given in section 5.8.

Throughout this chapter, I will occasionally make reference to the interpretive effect of the elements mismo (Sp.) and mesmo/próprio (EP). For these elements the term intensifier will be used. In those cases where the presence or absence of the intensifier does not have a crucial effect on the interpretation of a sentence, it will be represented within brackets. A closer look at the syntax and the interpretation of these elements will be taken in chapter 9 .

\subsection{Clitic doubling: disambiguation and focus}

Before applying the diagnostics to reflexive and non-reflexive pronouns, I want to recall the particular characteristics of clitic doubling structures. The examples in (197) show that the reflexive clitic can be optionally doubled with a strong reflexive pronoun. Optional doubling means that the strong reflexive pronoun is neither necessary for a reflexive sentence to be grammatical nor can it license a reflexive predicate on its own. The examples in (198) are ungrammatical due to the absence of the clitic pronoun.

(197) a. Sp. Juan se admira (a sí mismo).

J. SE.REFL=admire OM REFL.PR SELF

'Juan admires himself.'

b. EP O Rui admira-se (a si próprio).

the R. admires=SE.REFL OM REFL.PR SELF

'Rui admires himself.'

(198) a. Sp. *Juan admira a sí mismo.

J. admire OM REFL.PR SELF

a. EP *O Rui admira a si próprio.

the R. admires OM REFL.PR SELF

Thus, the clitic is obligatory from a grammatical point of view, and it is sufficient to license a reflexive interpretation. But the clitic alone is not unambiguously interpreted as reflexive, as already introduced in section 2.3. The clitic se has several interpretations, depending on the morphosyntactic and thematic properties of the verb it combines with. Even if it combines with a transitive verb that selects for an agent/experiencer external argument and a patient/theme internal argument, the clitic se does not impose a reflexive interpretation on the verbal predicate. For example, in (199) the agentive subject is plural and the verb-clitic complex is ambiguous between a reciprocal and a reflexive reading. For this reason, the clitic se is not a reflexive marker in the sense of Reinhart \& Reuland $(1991,1993)$ and Reuland (2011). Only the presence of the pronominal double, either the strong reflexive pronoun or the reciprocal phrase, can disambiguate the two interpretations. 
(199) a. Sp. Se acarician.

$\mathrm{SE}=$ caress

'They caress themselves/each other.'

$a^{\prime}$. Se acarician a sí mismos.

$\mathrm{SE}=$ caress OM REFL.PR SELF

'They caress themselves.'

a". Se acarician el uno al otro.

$\mathrm{SE}=$ caress the one to.the other

'They caress each other.' b. EP Acariciam-se. caress $=\mathrm{SE}$

'They caress themselves/each other.'

$\mathrm{b}^{\prime}$. Acariciam-se a si próprios.

caresS $=$ SE OM REFL.PR SELF

'They caress themselves.'

$b^{\prime \prime}$ Acariciam-se um ao outro.

caress $=\mathrm{SE} \quad$ one to.the other

'They caress each other.'

The reflexive double does more than just disambiguate the interpretation of the clitic se; its presence is also an indication of the transitive nature of the reflexive predicate. For example, with verbs like magoar, ferir (EP) and herir, lesionar, dar un golpe (Sp) meaning 'hurt', 'harm', or 'injure', the structure of the sentences in (200a) and (200b) is ambiguous between an intransitive and a transitive structure. The sentences can be interpreted in two ways: first as an unaccusative structure with a derived subject, which is a [+human] causee, and secondly as a reflexive structure with a [+human] agent or causer subject. But as soon as the strong reflexive double is present, the unaccusative interpretation disappears. This is shown by the asterisk in the translation of the examples $\left(200 a^{\prime}\right)$ and $\left(200 b^{\prime}\right)$.

(200) a. Sp.

Rita se lesionó.

R. $\quad S E=$ injured

b. EP
A Rita magoou-se.

the R. hurt=sE

'Rita got hurt/injured.'

'Rita hurt/injured herself.' á. $\quad$ Rita se lesionó a sí misma.

R. $\quad S E=$ injured herself

b'. A Rita magoou-se a si própria.

the R. hurt=sE herself

*'Rita got hurt/injured.'

'Rita hurt/injured herself.'

The pronominal double realises the direct object, which prevents an unaccusative derivation. Furthermore, the intensifier seems to support an agentive interpretation of the subject DP, but see chapter 9 for a detailed discussion of their interpretation.

In addition to the role as a disambiguating element, the most important contribution of the pronominal double-reflexive and non-reflexive-is that it gives rise to a contrastive focus reading of the internal argument, as in (201).

(201) a. Sp. Juan se admira a sí mismo (y no a otra persona).

J. SE.REFL=admires OM REFL.PR SELF (and not some other person)

b. EP O Rui admira-se a si próprio (e não a ela).

the R. admires=SE.REFL OM REFL.PR SELF (and not her)

Additionally, the reflexive double allows for a contrast on the agent/experiencer argument of the reflexive predicate. This can be best exemplified with so-called grooming verbs. Recall from chapter 2 
that the pronominal double is judged odd with this type of verbs, if uttered in an out-of-the-blue context. Differently from inherent reflexive verbs, the reflexive double is not ungrammatical, but infelicitous in a presentational sentence. In order to be felicitous, a context or background is required that calls into question the agentive properties or the ability to perform such actions, as in the sentences in (202).

(202) a. Sp. Este paciente 3 meses atrás no se podía poner de pie y ahora puede caminar, puede comer y beber por sí solo sin ningún tipo de ayuda. También puede vestirse a sí mismo abotonarse su camisa y pantalones.

'Three months ago, this patient could't get up, and now he can walk, eat, and drink on his own without any kind of support. Also he can dress himself, he can button up his shirt and trousers.'

(Google, 4 April 2018 )

b. EP No primeiro caso, trata-se de ela poder vestir-se a si mesma, presumivelmente por ser uma pessoa saudável.

'In the first case, it's about her being able to dress herself, probably because she's a healthy person.'

(Google)

In the Spanish example in (202a), the context is quite explicit. The sentence comes from a report about a patient with movement disorders, which makes him unable to perform basic actions such as walking, eating, and getting dressed. The use of the reflexive double establishes a contrast between the reflexive situation in which the person performs the action on himself and a situation in which that person is not the agent, but only the patient of the grooming action (e.g. someone else performs the action on that person). Thus, the reflexive double allows for a contrastive interpretation not only of the internal argument, but also of the external argument of the sentence.

Generally speaking, the contrastive/emphatic interpretation of the strong pronominal double is a property of clitic doubling structures in both languages. But Spanish and European Portuguese differ with respect to the interpretation of the double in non-reflexive contexts. Following Martins (2013), the double of a non-reflexive clitic is always associated with an emphatic or contrastive interpretation. In Spanish, neither the reflexive nor the non-reflexive double is necessarily interpreted contrastively. As noted in Franco (1994:733ff), the direct ${ }^{43}$ object double is also possible with a neutral interpretation.

For the following sections, it should be kept in mind that the realisation of the reflexive and non-reflexive double can be associated with a contrastive/emphatic interpretation. When applying the structural and interpretive diagnostics to the double, this fact is only mentioned if it has an effect on the results.

43 In Spanish, doubling of the indirect object is obligatory with nearly all kinds of DPs and not linked to a specific information-structural interpretation, whereas in European Portuguese, doubling of the indirect object is decreasing and is even more restricted than doubling of direct object pronouns. 


\subsection{Localitiy and (non-)complementarity}

In this section, it will be shown that reflexive and non-reflexive clitic pronouns are in complementarity distribution, but not the strong pronominal doubles. In both languages, the canonical clitic doubling patterns are those with a reflexive clitic doubled by a reflexive strong pronoun and those with a nonreflexive clitic doubled by a non-reflexive strong pronoun. Section 5.2.1 is devoted to clitic doubling of direct object pronouns, while section 5.2.2 discusses the doubling of indirect object pronouns. Each subsection starts with the canonical patterns, repeating the well-known facts that the pronouns in these patterns are well-behaved with respect to classical Binding Theory, in the sense that reflexive pronouns require a local antecedent while non-reflexive pronouns require a non-local antecedent. The main part of each subsection is devoted to the non-cannonical pattern-doubling of the reflexive clitic with a nonreflexive pronoun-and its (non-lexical) licensing conditions. The lexical restrictions on the antecedent of a strong pronoun such as animacy and definiteness will be discussed in sections 6.2 and 8.5. Section 5.2.3 introduces new data concerning doubling of a non-reflexive clitic with a reflexive strong pronoun. It will be shown that European Portuguese and, in a very limited way, Spanish allow for this doubling pattern. The findings are summarised in section 5.2.4.

\subsubsection{Direct objects}

Let us start with the uncontroversial clitic doubling patterns in (203) and (204). In these examples, the reflexive clitic is doubled with a reflexive strong pronoun, and the non-reflexive clitic is doubled with a non-reflexive pronoun. In both languages, the reflexive clitic/strong pronouns must take an antecedent inside the TP domain, here the DPs Juana and $o$ João, whereas the non-reflexive clitic/strong pronouns must not take an antecedent inside the TP. A coreferent interpretation of the non-reflexive clitic/strong pronoun and a local subject DP is absolutely unacceptable.

(203) a. Sp. [TP Juana ${ }_{i}\left[\mathrm{~T}^{\circ} \mathrm{se}_{\mathrm{i}}\right.$ ha denunciado a sí $_{\mathrm{i}}$ misma ]]. Juana $=\mathrm{se} / \mathrm{sí}^{\prime}$ J. SE.REFL=AUX reported OM REFL.PR SELF

'Juana reported herself to the police.'

a'. [тр Juana a $^{\prime}\left[\mathrm{T}^{\circ} \mathrm{la} *_{\mathrm{i} / \mathrm{j}}\right.$ ha denunciado a ella $\left.\left.*_{\mathrm{i} / \mathrm{j}}\right]\right] . \quad$ Juana $\neq$ la/ella J. her.CL=AUX reported om her

'Juana reported her to the police.'

b. EP $\quad\left[\mathrm{TP}_{\mathrm{O}} \mathrm{O} \quad \mathrm{João}_{\mathrm{i}} \quad\left[\mathrm{T}^{\circ}\right.\right.$ denunciou-se $_{\mathrm{i}}$ a $\mathrm{si}_{\mathrm{i}} \quad$ próprio $\left.]\right] . \quad$ João $=\mathrm{se} / \mathrm{si}$

the J. reported=SE.REFL OM REFL.PR SELF

'João reported himself to the police.'

$\left.\left.\begin{array}{llllll}b^{\prime} . & {[\mathrm{TP} O} & \text { João }_{\mathrm{i}} & {\left[\mathrm{T}^{\circ} \text { denunciou= } \mathrm{O} *_{\mathrm{i} / \mathrm{j}}\right.} & \text { a } & \text { ele } *_{\mathrm{i} / \mathrm{j}}\end{array}\right]\right] . \quad$ João $\neq$ o/ele

the J. reported=him.CL OM him

'João reported him to the police.' 
The sentences in (204) contain two possible antecedents for the pronouns: the subject DPs of the embedded TP, María and $o$ Luís, and the subject DPs of the matrix sentences, Juana and o João, respectively. The reflexive clitic/strong pronouns have to take the subject of the embedded sentence as their antecedent, whereas the non-reflexive pronouns are ungrammatical with this interpretation. The nonreflexive pronouns can be coreferent with the subject of the matrix sentence or with some other individual present in discourse.

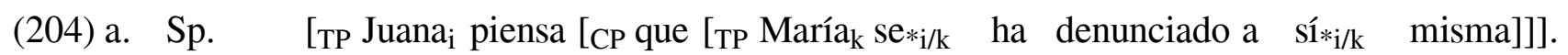
J. thinks that M. SE.REFL= AUX reported OM REFL.PR SELF 'Juana thinks that María reported herself to the police.'

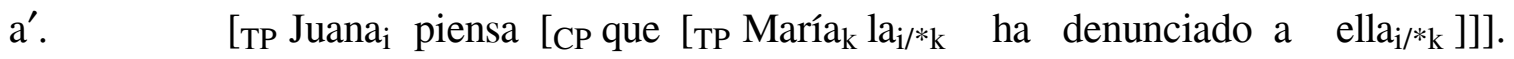
J. thinks that M. her.CL= Aux reported OM her $\mathrm{i}_{\mathrm{i} /{ }^{\mathrm{k}}}$ 'Juana thinks that María reported her to the police.'

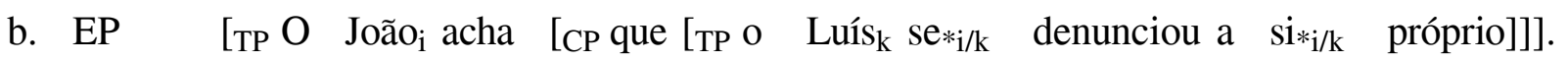
the J. thinks that the L. SE.REFL= reported OM REFL.PR SELF 'João thinks that Luís reported himself to the police.'

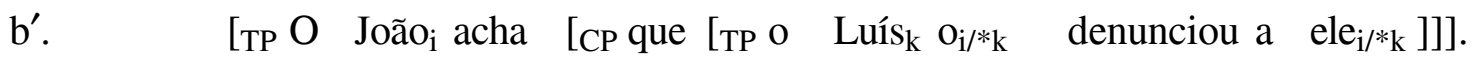
the J. thinks that the L. him.CL=reported om him 'João thinks that Luís reported him to the police.'

On the basis of these examples it could be concluded that the reflexive clitic/strong pronouns are anaphors in the sense of classic Binding Theory, and the non-reflexive clitic/strong pronouns are pronominals. The former have to be bound inside the TP domain, while the latter have to be free inside the TP. But Principle B of classic BT predicts that a non-reflexive pronoun cannot take a local antecedent, contrary to fact. In both languages, a reflexive clitic can be doubled with a non-reflexive pronoun. The non-reflexive pronoun is thus an instance of a pronominal with a local antecedent and essentially contradicting Principle B. This phenomena has been discussed in Torrego (1995) and Otero (1999:1503) for Spanish and in Lobo (2013) for European Portuguese. Compared to Spanish, the judgements for European Portuguese are quite uncontroversial. I will therefore start with the Spanish data.

\subsubsection{Spanish}

The examples from Torrego (1995) are reproduced in (205).

(205) a. Sp. María $\mathrm{se}_{\mathrm{i}}$ criticó a sí $i_{\mathrm{i}}$ misma / ella $\mathrm{i}_{\mathrm{i}}$.

(Torrego 1995:231)

M. SE.REFL=criticised OM REFL.PR SELF / her

'Maria criticised herself.'

b. Juan $\mathrm{se}_{\mathrm{i}}$ admira a sí $i_{\mathrm{i}} \quad$ mismo / él $\mathrm{l}_{\mathrm{i}}$.

J. SE.REFL=admires OM REFL.PR SELF / him

'Juan admires himself.' 
c. El policía $\mathrm{i}_{\mathrm{i}}$ se hirió a sí $\hat{i}_{\mathrm{i}}$ mismo / él $*_{\mathrm{i}}$.

(ibid.)

the policeman SE.REFL=hurt OM REFL.PR SELF / him

'The policeman hurt himself.'

According to Torrego (1995), the non-reflexive double is acceptable in (205a) and (205b), but not in (205c). The difference in acceptability is attributed to selectional properties of the verbs. Torrego (1995) generalises that the verbs of the criticar type select for an argumental clitic and allow for a reflexive and a non-reflexive double. Verbs of the herir type select for a non-argumental clitic. The nonargumental clitic only permits for doubling with a reflexive pronoun. The two classes of verbs are not defined by means of an independently motivated lexical or semantic property, but seem to be based on her own grammaticality judgements. This is problematic because the judgements are not robust across speakers. Otero (1999), who comments on Torrego (1995), states that most speakers he consulted did not accept the sentences with the non-reflexive double at all. Some speakers accepted the non-reflexive double, but only with the intensifier mismo. Note that the non-reflexive pronoun appears without the element mismo in Torrego's examples. In order to get a 'third opinion' on these kind of sentences, I presented them to four speakers of Peninsular Spanish and all of them rejected the examples, with and without the intensifier mismo. Why are the judgements so contradictory? A hint to the solution of the problem comes from Otero (1999:1503 fn. 98), who mentions in a footnote, without discussing the issue any further, that the sentence in (205c) becomes acceptable (for him) in the following context:

(206) Sp. En vez de herir a aquel infeliz, a todas luces inocente, el policía optó por herirse a él mismo.

'Instead of injuring this poor devil, most obviously innocent, the policeman decided to injure himself.'

(Otero 1999:1503 fn. 97)

The sentence establishes a contrast between a situation in which a policeman injures himself and a situation in which the policeman injures another person. The non-reflexive pronoun becomes acceptable if it bears (strong) contrastive focus. The example of Otero (1999) shows that the acceptability of the locally bound pronoun depends on the information structure and on the context, rather than on some lexical/selectional property of the verb.

In order to shed some more light on the contexts in which locally bound pronouns are used, a corpus study was conducted. ${ }^{44}$ The CREA contained just 17 sentences with a true reflexive predicate and a non-reflexive double as direct object. The sentences can be classified according to the following two types of readings:

(i) contrastive or correction readings (Type I) and

\footnotetext{
44 The query él/ellos/ella/ellas + mismo $(s) / a(s)$ yielded 243 sentences of which just 17 sentences contained a true reflexive predicate with a direct object non-reflexive double. The results can be found in the appendix. Compared to the 2,529 occurrences of the reflexive double, the use of the non-reflexive double is indeed a rare phenomenon.
} 
(ii) proxy or statue readings in the context of dreams, mental illness, or other extraordinary psychological states (Type II).

In sentences of Type I, the contrast is established between a situation in which the action is directed towards others, and a situation in which the action is directed towards oneself. The reflexive situation contradicts or corrects the non-reflexive situation. This type can be summarised with the following formula: It is believed/stated that 'A towards B', but actually it is 'A towards A'. In both situations the agent of the action remains the same, but the referent of the theme or patient changes. Type I has two subtypes. In the first subtype, the two situations are given in the immediate linguistic context, in most cases by repeating the same verb, as in the example of Otero (1999). In the second subtype, the contrast is established in the broader linguistic or extralinguistic context. In the following, some representative examples are given for each type. ${ }^{45}$

Type I is illustrated by the sentences in (207) and (208). The first subtype is illustrated in (207a) and (207b). In both examples, the first occurrence of the verb, engañar 'cheat, deceive' and ayudar 'help', is transitive and denotes an action directed towards others. The second occurrences of engañar and ayudar are reflexive. The use of the strong pronoun + intensifier emphasises the fact that the referent of the internal argument is identical to the referent of the external argument. The use of the focus particle sólo in (207b) supports the contrast between the two situations.

(207) a. Sp. Hay que seguir haciéndolo para acabar enérgicamente con esos atletas que tratan de engañarnos a todos dopándose y que terminan engañándose a ellos mismos. (CREA, El Mundo, 03/10/1994)

'One must keep doing it in order to vigorously finish off those athletes who try to deceive everybody by taking drugs and who end up deceiving themselves.'

b. Los taxistas estamos dejados de la mano de Dios y nuestro primer y principal problema son nuestros dirigentes, que no ayudan al taxi: sólo se ayudan a ellos mismos. (CREA: El Mundo, 22/11/1994.)

'We taxi drivers are left on our own and our primary problem is our managers, who do not support the taxi: they only support themselves.'

An example for the second subtype is given in (208). The pronoun ellos mismos is coreferent with the noun estos lunáticos indeliberantes, which refers, in the broader context, to individuals who are (hobby-)speleologists. One of the interlocutors talks about the need for a special police force that is able to rescue speleologists trapped in caves. He proposes that the members of that special force should be recruted from the group of speleologists. The sentence in (208) is the reaction to his proposal.

45 Note that the examples contain only non-finite or gerundive verb forms, but this is pure coincidence. The list of results in the appendix also contains examples with finite forms. The examples given here were chosen because they were the most illustrative and the shortest. 
(208) Sp - Coño, chaval. Eso es como darse un martillazo en la cabeza para poder tomar una aspirina. O sea que, según tú, estos lunáticos indeliberantes realizan una buena labor porque así podrían formar parte de un cuerpo especial formado por ellos mismos para rescatarse a ellos mismos cuando ellos mismos se perdieran en las cuevas. (CREA: Aparicio, J. P. 1989. 'Retratos de ambigú'.)

'Bullshit, man. This is like hitting your head with a hammer just so you can take an aspirin. Let's say that, as you say, these crazy bastards do a good job, because that way they can be part of a special force that is made up of themselves in order to rescue themselves in case they themselves get lost in the caves.'

The personal pronoun ellos mismos is used three times. In addition to its use as pronominal double of a true reflexive verb (in bold face), it realises the agent of a passive verb and the subject of the inherent reflexive verb (the underlined cases). The latter uses will be discussed in relation with the interpretation of the element mismo in chapters 8 and 9. For the moment, the interesting use is that as pronominal double. The speaker of the sentence in (208) points out to the interlocutor that his proposal contradicts common sense. Common sense would be a situation in which the two arguments of the verb rescatar have distinct referents. By using the non-reflexive double with the reflexive verb, the speaker strongly emphasises the absurd reflexive situation in which the rescuer is identical to the person being rescued. The list in (209) shows the verbs that occurred in this type. The reflexive predicates were formed with different kinds of verbs such as experiencer verbs, attitude verbs, perception verbs, and agent/patient verbs denoting actions or activities. Thus, the lexical or selectional properties of the verbs do not affect the acceptability of the non-reflexive double.

\section{(209) Spanish verbs used in Type I (constrastive focus)}

$\begin{array}{lll}\text { comprender } & - & \text { 'understand' } \\ \text { degradar } & - & \text { 'degrade' } \\ \text { embalar } & - & \text { 'pack' } \\ \text { delatar } & - & \text { 'denounce' } \\ \text { criticar } & - & \text { 'criticise' } \\ \text { ayudar } & - & \text { 'help' }\end{array}$

$\begin{array}{lll}\text { tolerar/soportar } & - & \text { 'tolerate' } \\ \text { engañar } & - & \text { 'betray' } \\ \text { buscar } & - & \text { 'search / look for' } \\ \text { revelar } & - & \text { 'reveal' } \\ \text { legalizar } & - & \text { 'legalize' }\end{array}$

Type II-the proxy or statue reading - is illustrated in (210). The sentence comes form a context in which a dream sequence is narrated. The protagonist sees himself, his dream counterpart, who is in this 'dream reality', an entity distinct from the dreamer.

(210) Sp. De improviso, todo eran sombras a su alrededor. La pesadilla volvía. Se veía en lo alto, mirándose a él mismo, y muerto. (CREA: Tomás García, J. L. 1984. 'La otra orilla de la droga'.)

'All of a sudden, everything around him was shadows. The nightmare returned. He saw himself in the heights, looking at himself, and dead.' 
The interpretation of the non-reflexive double is similar to the proxy reading of a reflexive pronoun in the Madame Tussauds context discussed in chapters 1 and 3. The non-reflexive pronoun in (210) is not bound, but it refers to the dream counterpart.

The verbs used in sentences of type II are mostly perception verbs, which is a predictable result because these verbs facilitate a proxy reading. The list of verbs is given in (211).

\section{(211) Spanish verbs used in Type II (proxy or statue readings)}

\begin{tabular}{lll|lll} 
mirar & - & 'look at' & oír & - & 'hear' \\
soñar & - & 'dream' & contar & - & 'tell' \\
gobernar & - & 'control' & & &
\end{tabular}

Let us summarise the results for Spanish. Reflexive and non-reflexive strong pronouns as double of a reflexive clitic are not in complementary distribution in the strict sense, meaning that the non-reflexive pronoun would be ungrammatical. Complementarity holds in neutral contexts in which the double serves as a disambiguating element, but it can be overwritten by pragmatic means such as a strong contrastive focus or proxy readings. Note that the presence of the intensifier is crucial for the acceptance of the non-reflexive pronoun. Furthermore, the non-reflexive double occurrs with different kinds of verbs such as experiencer verbs, attitude verbs, perception verbs, and agent/patient verbs denoting actions or activities. Hence, I conclude —against Torrego (1995) and in favour of Otero (1999)—that the acceptablity of the non-reflexive double is not determined by an inherent lexical property of a verb, but licensed by contrastive focus and by proxy readings.

\subsubsection{European Portuguese}

For European Portuguese, Lobo (2013) states that the reflexive and the non-reflexive strong pronoun are equally possible as a double of the reflexive clitic. Lobo (2013) deals primarily with strong pronouns in PP-complements, but she explicitly mentions the function of the double as a disambiguating and emphasising element. The present section will take a closer look at these functions and the distribution of the non-reflexive pronoun as double of true reflexive predicates. For this purpose a corpus study using the CRPC has been conducted. ${ }^{46}$ In total, 2,131 true reflexive predicate sentences with a pronominal double were identified, of which 102 contained a non-reflexive double. The numbers show that the non-reflexive double is not used frequently and that the use of the reflexive double is the standard case. About half of the 102 occurrences are found in focus contexts, either in the contrastive context of Type I, or in the scope of focus particles such as só, apenas, até, or também. In addition to the focus contexts, there are two occurrences of so-called statue readings with perception verbs, the Type

46 For the corpus study several queries were run on the CRPC (restricted to European Portuguese) looking for the third person reflexive ciltic (enclitic and proclitic) in combination with any verbal form followed by the preposition $a$ and the reflexive and non-reflexive pronoun. The results have been sorted by the occurrence of the elements mesmo/próprio, and most duplicates have been eliminated. As the use of the non-reflexive pronoun is uncontroversial in European Portuguese, the examples are not listed in the appendix. 
II described above. But differently from Spanish, the non-reflexive double is also used without a (contrastive) focus interpretation. It is used in neutral contexts as a disambiguating element. For European Portuguese the following environments that license doubling of a reflexive clitic by a non-reflexive have been identified:

(i) contrastive or correction readings (Type I),

(ii) proxy or statue readings (Type II), and

(iii) disambiguation in neutral context (Type III).

As in Spanish, there are no restrictions with respect to the finiteness or some lexical property of the reflexive verb. ${ }^{47}$ Furthermore, the vast majority of the examples with a non-reflexive double come from oral contexts such as transcripts of parliamentary debates or cited direct speech in articles. This fact will support the conclusion that the non-reflexive and reflexive double are indeed in free alternation and that their acceptablitiy depends on information structure and possibly even on socio-pragmatic factors. In the following, the results with a non-reflexive pronoun are presented.

Type I is exemplified in (212). Recall that this type can be summarised by the formula: It is believed/stated that 'A towards B', but actually it is 'A towards A'. In (212), the first occurrence of the verb criticar is transitive and denotes an action against others. The second occurrence of the verb is reflexive, and a contrast is established between the two situations.

EP [...] para criticar um eventual deslize legislativo do Governo, na justa medida em que, ao criticá-lo, critica-se a ela própria por esse excesso de confiança que depositou no Executivo. (CRPC: A109114.) 'in order to criticise a potential legislative mistake of the government, and because by criticising it, she criticises herself for the overconfidence she had in the executive.'

As in Spanish, the contrast can also be established in the broader context. In (213), the referent of the pronoun eles refers to the board of an association that awards an art prize which includes financing an exhibition. In the broader context, it is criticised that, after awarding the prize, no efforts have been made to promote the artist's work. Moreover, the association is suspected of using the prize exclusively for their own marketing purposes.

EP $\quad O$ que acaba por acontecer é que eles se promovem a eles próprios e não lhes interessam os artistas. (CRPC: Público, noCOD_1055850.)

'What is happening right now is that they are promoting themselves and are not interested in the artists.'

47 The non-reflexive double occurs with differnt kinds of verbs such as experiencer verbs, attitude verbs, perception verbs, and agent/patient verbs denoting actions or activities. 
Furthermore, the non-reflexive double occurs in the scope of the focus particles such as só, até, and também. For each particle a representative example is given in (214).

(214) a. EP Onde é que está aos olhos dos portugueses a moral política dos que vão dar essa possibilidade àqueles senhores que só se representam a eles próprios? (CRPC: A124800.)

'Where is, in the opinion of the Portuguese, the political moral of those who give this opportunity to those gentlemen who only represent themselves?'

b. «Permitindo que Cohen seja morto», diz Charyn, Isaac pune Marilyn e «Olhos Azuis» mas também se castiga a ele próprio. (CRPC: Público, noCOD_1040953.) "It's possible that Cohen is dead", says Charyn, Issac punishes Marilyn and "Blue Eyes", but he also punishes himself.'

c. Penso mesmo que, em certos momentos, até se superaram a eles próprios. (CRPC: O Jogo, J30692.)

'Actually I think, at certain moments, they even outperform themselves.'

As for Type II, there are only two occurrences of so-called statue readings with perception verbs. One example with ver 'to see' is given in (215).

EP São uma casta de gente que tenta preservar-se de possíveis «males» que venham de fora. Pessoas desconfiadas porque, como explica o padre Aníbal Rodrigues, «são muito recatadas, não se gostam de ver a elas mesmas. São alérgicas às fotografias». (CRPC: Página Eugénio Pinto, V0301.)

'They are this kind of people that try to protect themselves from "the bad things" that possibly come from outside. They are mistrustful people because-as Aníbal Rodrigues says - 'they are very cautious, they don't like to see themselves. They are allergic to photographs".'

But differently from Spanish, the non-reflexive double is also used without a (strong) contrastive interpretation and without a clear focus interpretation. The double is used in a neutral way, meaning that no contrast is established between the referent of the pronoun and another entity present in the discourse. The sentences in (216) and (217) are examples of this 'neutral' use of the non-reflexive and the reflexive double. Note that doubling is necessary in these sentences in order to create the reflexive interpretation. Without the pronominal double the sentences would be ambiguous and hard to process. ${ }^{48}$ For example, without the pronominal double, the reflexive clitic in $(216 \mathrm{a})^{49}$ could be interpreted as passive, in (216b) as impersonal, and in (217a) as reciprical.

48 Thanks to Ana Maria Martins (p.c.) for pointing out this fact to me.

49 Note that this example contradicts the common opinion that a non-reflexive strong pronoun is restricted to a [+human] referent in clitic doubling contexts. (see, e.g., Brito 2008 and Magro 2019). 
(216) a. EP No decorrer desse trabalho há uma simbologia que se vai criando a ela própria. (CRPC: Público, J106711.)

'In the proceeding of this work there is a symbolism that is continuously creating itself.'

b. Twain põe Eva a dizer «é isso que eu sou - uma experiência, só uma experiência, nada mais que uma experiência» e vai mais longe ainda: Eva, a mulher, é o primeiro ser, cria-se a si mesma, assim como o seu semelhante, Adão [(...)]; (CRPC: Público, noCOD_1052399.)

'Twain has Eva say "this is what I am-an experience, only an experience, nothing more than an experience", and he yet goes a step further: Eva, the woman, is the first being, creates herself, as well as her fellow man, Adam [(...)].'

(217) a. EP Eu vejo os abandonos e as coisas todas que ele está a passar um bocadinho como as provas nas histórias tradicionais - as provas que os príncipes e os heróis têm que passar para crescer ou para se encontrarem a eles próprios. (CRPC: Público, noCOD_1040419.)

'I see the trouble and all the things that he goes through a little bit like the challenges that the princes and heroes have to pass through in order to grow and to find themselves.'

b. É a história de Maria que mata Miguel e da irmã dela, Ana, que, incapaz de perceber as razões que levaram a cometer um crime, ruma a Coimbra em busca de uma resposta. Pelo caminho, Ana encontra-se a si mesma. (CRPC: Público, J108603.) 'This is the story of Maria, who kills Miguel, and of her sister, Ana, who, incapable of understanding the reasons that made her commit the crime, sets out for Coimbra in search of an answer. On the way, Ana finds herself.'

These data show that in European Portuguese neither the non-reflexive double nor the reflexive double is restricted to contrastive or exclusive focus contexts. Differently from Spanish, both types of pronouns can serve as a disambiguating element.

Summarising this section, it can be stated that in both languages complementarity in its strict grammatical sense holds for the clitic pronouns, but not for strong pronouns doubling a reflexive clitic. In Spanish, a non-reflexive double is limited to strong contrastive focus or statue readings, whereas the reflexive double is used additionally in neutral contexts as a disambiguating element. In European Portuguese the non-reflexive and the reflexive double can be used as a disambiguating element in neutral contexts, in addition to the contexts of contrastive and exclusion focus. In both languages the intensifier plays a crucial role for the interpretation of the non-reflexive pronoun in local contexts, as will be discussed in more detail in chapter (8). 


\subsubsection{Indirect objects}

This section focusses on pronominal $\operatorname{argumental}^{50}$ dative objects of mainly ditransitive verbs. Ditransitive sentences in Spanish and European Portuguese have been analysed analogously to the English double object construction (DOC) and the dative prepositional construction (DPC) exemplified in (218) (see Demonte 1995, Cuervo 2003, Bleam 2003, López 2012, and Morais 2006). DOCs in Spanish and European Portuguese involve a dative clitic and the object marker $a$, and DPCs are characterised by the absence of the clitic and the fact that the indirect object is introduced by a lexical (locative) preposition (see Demonte 1995, Cuervo 2003 for Spanish and Brito 2008, 2015 and Gonçalves 2015 for European Portuguese).

(218) a.

Peter gave Mary a book.

DOC

a'. Sp. Pedro le dio un libro a María.

$a^{\prime \prime}$. EP Pedro deu-lhe um livro a ela.

b. $\quad$ Peter gave a book to Mary.

DPC

$\mathrm{b}^{\prime}$. Sp. $\quad$ Pedro dio un libro a María.

$b^{\prime \prime}$. EP Pedro deu um libro à Maria.

Another difference between DOCs and DPCs concerns the position of the indirect object. It has been assumed by Demonte (1995), Cuervo (2003), Bleam (2003), and López (2012) that the indirect object (IO) is structurally higher than the direct object (DO) in DOCs and that the DO is higher than the IO in DPCs. The authors assume basically the structures as in (219). ${ }^{51}$
(219) a. DOC
$\left[\mathrm{IO}_{\mathrm{a}-\mathrm{DP}} \mathrm{X}^{\circ}[\mathrm{V} \mathrm{DO}]\right]$
b. DPC
$[\mathrm{DO}[\mathrm{V} \mathrm{IO}$ a-PP $]$

This assumption has been recently challenged in Pineda (2013) for Spanish and Gonçalves (2015) and Brito (2015) for European Portuguese. The discussion about the underlying structures of the two types of ditransitive sentences is far from being settled, in particular the question whether Spanish and Eu-

50 I will not consider non-argumental datives such as benefactive or ethical datives.

51 Note that in (219a), $\mathrm{X}^{\circ}$ represents different projections in the cited accounts. IO is base-generated in specXP with $\mathrm{X}^{\circ}$ labelled as appl ${ }^{\circ}$ in Cuervo (2003) and $\alpha^{\circ}$ in López (2012:39/40). IO is moved into specXP, with $\mathrm{X}^{\circ}$ labelled as DatCl ${ }^{\circ}$ in $\mathrm{Demonte}$ (1995:18), AgrIO $^{\circ}$ in Franco (1999:178), and appl ${ }^{\circ}$ in Roberts (2010:137). 
ropean Portuguese have an English-type dative alternation at all (see Gonçalves 2015). ${ }^{52}$ Nevertheless, I will use the terms DOC and DPC as descriptive terms without a commitment to a specific syntactic analysis.

The first part of this section is dedicated to DPCs and in particular to the differences between European Portuguese and Spanish. European Portuguese permits DPCs with reflexive and non-reflexive pronouns, which are ungrammatical in standard Spanish according to Zagona (2002), Fernández Soriano (1999), and Bosque \& Gutiérrez-Rexach (2016). However, examples from CREA suggest that there is variation with respect to the acceptablitiy of reflexive pronouns in DPCs. In the second part DOCs involving clitic doubling are discussed. It will be shown that pronouns in indirect object position behave like the pronouns in direct object position with respect to locality and complementarity.

52 Demonte (1995) uses binding as diagnostic to determine the position of the IO and DO in the two types of ditransitive sentences. She argues on the basis of the examples in (ia) and (ib) in favour of the structure in (219a) and on the basis of the examples in (iia) and (iib) in favour of the structure in (219b). These results have been adopted in, e.g., Cuervo (2003), Bleam (2003), and López (2012). But only Pineda (2013) noted that Demonte (1995) uses embedded anaphors for testing DOCs and non-embedded anaphors for testing DPCs. If the same type of anaphor is used for testing each structure, the binding asymmetry disappears, as shown in (ic) and (id) for DOCs and (iic) and (iid) for DPCs.

(i) a. Sp. El tratamiento le devolvió [la estima de síi misma $]_{\mathrm{i} O}$ [a María $]_{\mathrm{i}}$ IO.

(Demonte 1995:10)

the therapy her.CL= gave-back the esteem of REFL.PR SELF OM M.

'The therapy gave the selfesteem back to María .'

b. *El tratamiento le devolvió [a María $]_{\mathrm{DO}}$ [a la estima de sí misma $]_{\mathrm{IO}}$.

c. El tratamiento $\mathrm{l}_{\mathrm{i}}$ devolvió [a María $]_{\mathrm{DO}}\left[\mathrm{a} \mathrm{sí}_{\mathrm{i}} \text { misma }\right]_{\mathrm{IO}}$.

(Pineda 2013: 190)

the therapy her.CL= gave-back omM. To REFL.PR SELF

'The therapy gave María back to herself.'

d. *El tratamiento le devolvió [a síi misma $]_{D O}$ [a María $\left.]_{\mathrm{i}}\right]_{\mathrm{IO}}$.

(ibid.)

(ii) a. Sp. El tratamiento reintegró [a María $]_{\mathrm{DO}}\left[\begin{array}{lll}\mathrm{a} & \text { sí } & \text { misma }\end{array}\right]_{\mathrm{IO}}$.

(Demonte 1995:10)

b. *El tratamiento reintegró [a síi misma $]_{\mathrm{DO}}$ [a María $]_{\mathrm{i}} \mathrm{IO}$.

c. *El tratamiento devolvió [a María $]_{\mathrm{DO}}$ [a la estima de síi misma $]_{\mathrm{IO}}$.

(Pineda 2013: 190)

d. El tratamiento devolvió [la estima de síi misma $]_{D O}$ [a María $\left.{ }_{\mathrm{i}}\right]_{\mathrm{IO}}$.

Gonçalves (2015) and Brito (2015) use only embedded reflexive pronouns and show that there is no binding asymmetry between the DO and IO. Gonçalves (2015) argues in favour of a DPC with the element $a$ as case marker, while Brito (2015) argues in favour of two distinct base structures for the objects of ditransitive verbs: [VP IO [V $\left.\left.{ }^{\circ} \mathrm{DO}\right]\right]$ and [VP DO [V IO]]. But it seems that the authors ignored the fact that embedded reflexives are not sensitive to c-command, as shown in (iii) and (iv).

(iii) $\mathrm{EP} \quad \mathrm{O}$ sucesso do $\mathrm{Rui}_{\mathrm{i}}$ dependeu de cada foto de $\mathrm{si}_{\mathrm{i}}$ próprio que demostrava que é um super-herói. the success of.the R. depended on every foto of REFL.PR SELF that showed that is a superhero 'Rui's success depended on every foto that showed that he is a superhero.'

(iv) Sp. El testimonio de Juan ${ }_{i}$ fue suficiente para que aparecieran fotos de sí i mismo en todos los matutinos. the testimony of J. was sufficient for that appeared fotos of REFL.PR SELF in all the papers 'Juan's testimony was sufficient to ensure that there would be pictures of himself all over the papers'

(Campos 1995:46 fn. 19)

For this reason only examples with non-embedded reflexives should be used for testing the position of an anaphor, which is difficult because in European Portuguese dative clitic doubling is more restrictive and sentences equivalent to the Spanish sentences in (ia) and (ib) are ungrammatical in European Portuguese. 


\subsubsection{Dative prepositional constructions (DPC)}

Let us start with the DPC. In (standard) Spanish, an indirect object pronoun is obligatorily doubled by a clitic (see Zagona 2002:142ff, Fernández Soriano 1999:1248ff, and Bosque \& Gutiérrez-Rexach 2016:603), whereas doubling is optional in European Portuguese, as described in Lobo (2013). ${ }^{53}$ This difference in dative clitic doubling seems to be the reason why Spanish disallows reflexive and nonreflexive pronouns with a local antecedent in DPCs, as shown in (220), and the reason why European Portuguese allows DPCs, as in (221). Gonçalves (2015), citing Brito (2008:34), mentions that the use of DPC with personal pronouns is considered to be non-standard colloquial European Portuguese and viewed as a strategy to avoid the clitic pronoun. Furthermore, both authors agree that the strong pronouns in DPCs is not associated with contrastive focus. As for the use of the non-reflexive pronoun in DPCs, Brito (2008:34 fn. 8) considers it to be a common feature of colloquial speech.

(220) a. Sp. $\quad * J_{u a n}$ regala un viaje a $\mathbf{s i}_{\mathrm{i}}$ mismo.

J. gives a trip to REFL.PR SELF

b. *Juan regala un viaje a ella.

J. gives a trip to her

(221) a. EP A Rita $\mathrm{i}_{\mathrm{i}}$ oferece um carro a $\mathrm{si}_{\mathrm{i}}$ própria.

the R. gives a car to REFL.PR SELF

'Rita gives herself a car.'

b. A Rita deu um livro a ele.

the R. gave a book to him

'Rita gave a book to him.'

The interpretation of the non-reflexive pronoun in European Portuguese crucially depends on the presence or absence of the intensifier, as exemplified in (222). The intensifier is present in (222a) and the pronoun has to be coreferent with the subject. In (222b), coreference between the pronoun and the subject DP is possible, but clearly dispreferred to an interpretation in which the pronoun and the subject DP are disjoint in reference. Thus, if the clitic is absent, the strong reflexive pronoun can take a local, human antecedent.

(222) a. EP A Rita $a_{\mathrm{i}}$ oferece um carro a ela $\mathrm{i} / *_{\mathrm{k}}$ própria.

the R. gives a car to her SELF

b. A Rita oferece um carro a ela??i/k.

the R. gives a car to her

'Rita gives her/herself a car.'

In Spanish, the ban of DPCs with personal pronouns does not seem to be a pure morphosyntactic fact, but rather depended on the semantic properties of the pronoun's referent as well as on the position

53 Recall from chapter 2 that clitic doubling of the IO in Spanish is obligatory for nearly all kinds of DPs. 
of the antecedent. As noted by Demonte (1995), a DOC is ungrammatical if the indirect object DP denotes a location and $a$ is a locative preposition. In this case, a DPC with a pronoun is possible, as shown in (223). Note that the antecedent of the non-reflexive pronoun is non-local in (223).

Sp. La comisión de cultura de la Asociación de Vecinos de Villaamil realizó una encuesta casa por casa, en la que se preguntaba si, caso de terminarse el colegio para el año que viene, las familias enviarían sus hijos a él. (CREA: El País, 05/05/1976.) 'The comission of culture of the neighbourhood association of Villaamil conducted a door-to-door survey asking whether, should the school (building) be finished by the next year, the families would want to send their children to it.'

Furthermore, there are at least two configurations in which a reflexive pronoun is possible in DPCs. In (224a), the antecedent of the reflexive pronoun is a non-referential, quantified subject DP, and in $(224 b)^{54}$ the antecedent is the direct object (see also example (iia) in fn.52).

(224) a. Sp. Estoy convencido de que la suya es la mejor de las técnicas, y que cada cantante puede aplicarla a sí mismo a partir de las imágenes que Kraus emplea. (CREA: ABC Cultural, 01/11/1996.)

'I am convinced that his technique is the best and that every singer can apply it to himself following the images that Kraus uses.'

b. $\quad$ El dolor, el mareo, los desmayos le ocupan mucho, casi todo el día, pero no TODO el día; de pronto, unos segundos de alivio lo devuelven a sí mismo; (CREA: Azúa, F. de. 1987. 'Diario de un hombre humillado'.)

'The pain, the nausea, the fainting fits occupy him a lot, nearly all day, but not the ENTIRE day; suddendly, some seconds of relieve give him back to himself.'

These examples indicate that some speakers of Spanish allow for a DPC with a reflexive pronoun and a local antecedent.

\subsubsection{Double object constructions (DOCs)}

Let us now turn to the DOCs. As for the reflexive clitic and its double, the regular pattern is doubling with a reflexive strong pronoun, but the non-reflexive double is also possible. Both patterns are shown in $(225)$.

(225) a. Sp. $\operatorname{Juan}_{\mathrm{i}} \mathrm{se}_{\mathrm{i}}$ regala un viaje a $\mathrm{sí}_{\mathrm{i}}$ mismo / él $\mathrm{l}_{\mathrm{i}}$ mismo.

J. SE.REFL=gives a trip OM REFL.PR SELF / him SELF

'Juan gives himself a trip.'

54 According to Fernández Soriano (1999:1266) and Franco (1999:178), these sentences should be ungrammatical (see also section 2.2.3). 
b. EP $\mathrm{O}$ João deu-se $\mathrm{S}_{\mathrm{i}}$ um livro a $\mathrm{si}_{\mathrm{i}}$ próprio / ele $\mathrm{e}_{\mathrm{i}}$ próprio.

the R. gave=SE.REFL a book OM REFL.PR SELF / him SELF

'João gave himself a book.'

The antecedent of the reflexive clitic and its double has to be strictly local, as shown in (226). This locality restriction holds for the non-reflexive double as well.

(226) a. Sp. Pedro piensa que $\operatorname{Juan}_{\mathrm{i}} \mathrm{se}_{\mathrm{i} /{ }_{\mathrm{j}} \mathrm{j}}$ regala un viaje a $\mathrm{si}_{\mathrm{i} / * \mathrm{j}}$ mismo / P. thinks that J. SE.REFL=gives a trip OM REFL.PR SELF / él $\mathrm{i}_{\mathrm{i} / \mathrm{j}}$ mismo.

him SELF

'Pedro thinks that Juan gives himself a trip.'

b. EP $\mathrm{O}$ Paulo $\mathrm{j}_{\mathrm{j}}$ acha que o $\mathrm{João}_{\mathrm{i}} \mathrm{se}_{\mathrm{i} / *_{\mathrm{j}}}$ deu um carro a $\mathrm{si}_{\mathrm{i} /{ }^{\mathrm{j}}}$ próprio / the P. thinks that the J. SE.REFL=gave a car OM REFL.PR ele $\mathrm{i}_{\mathrm{i} / \mathrm{j}}$ próprio.

him SELF

'Paulo thinks that João gave himself a book.'

With respect to the distribution of the non-reflexive and reflexive double in datives, an examination of the CREA and CRPC allows for the same conclusions as for direct objects in the previous section. The occurrence of the non-reflexive double is not lexically restricted, ${ }^{55}$ but licensed by focus. In Spanish, the strong reflexive pronoun is the standard case in disambiguation contexts and in contrastive contexts. The non-reflexive double becomes acceptable if the intensifer is present and if it is associated with a strong contrastive reading (Type I) or with a statue reading (Type II). The CREA contained seven sentences with true reflexive ditransitive verbs and the non-reflexive double. In (227), some representative examples for Type I and II are given.

55 The use of the non-reflexive double is not systematically restricted by lexical properties of the verb, neither in European Portuguese nor in Spanish. The lists in (i) and (ii) present the verbs that occurred with a non-reflexive double in both languages. In European Portuguese, both doubles are mostly used with attitude verbs and most verbs of transfer occurred only with the reflexive double. Interestingly, for the verbs oferecer 'give' and explicar 'explain' there is only one occurrence of a doubling structure and it is with the non-reflexive pronoun. For the verb entregar 'assign' no cases of clitic doubling with the dative pronoun were identified in the CRPC (for Portugal). These results suggest that there is a tendency for verbs of transfer to disfavour the non-reflexive double.

(i) Reflexive and non-reflexive double (EP)

\begin{tabular}{ll|ll|ll|l} 
atribuir & - 'attribute' & colocar & - 'put' & impôr & - 'impose' & responder \\
perguntar & - 'ask' & & & &
\end{tabular}

Similarily the use of the non-reflexive double in Spanish is not systematically restricted by the lexical properties of the verb. The non-reflexive double is used with verbs of transfer and with attitude verbs.

(ii) Reflexive and non-reflexive double (Sp.)

\begin{tabular}{ll|ll|ll|l} 
explicar & - 'explain' & poner & - 'put' & decir & - 'impose' & regalar - 'give as present' \\
declarar & - 'declare' & transferir & - 'transfer' & preguntar & - 'ask' &
\end{tabular}


(227) a. Sp. En una ocasión me confesó que tenía el vicio, aunque bien ves que era una virtud, porque a él de niño nunca le habían regalado nada. Ni un simple caramelo. Entonces deduje que posiblemente lo que le ocurría al Burguete era que veía en el niño al que obsequiaba su propia niñez, la de Burguete, huérfana de los pequeños detalles propios de la ternura. Es decir, que se regalaba a él mismo los dichosos caramelos. (CREA: Zaragoza, C. 1981. 'Y Dios en la última playa'.)

'On one occasion he confessed to me that he had this bad habit-although it is obviously a virtue-because as a child, he never got anything as a present. Not even a simple piece of candy. So, I deduced what was possibly happening to Burguete was that he saw in the child who he was giving presents his own childhood, Burguete's childhood, lacking all the small gestures that are proper to tenderness. In other words, he was giving the bloody candies to himself.'

b. La relación de Conde con las sociedades suizas Kaneko Holding, Asni Investment y Jamuna son más que evidentes para los peritos del Banco de España. Tan evidentes, que han afirmado en su informe entregado al juez Manuel García-Castellón, que Mario Conde es el propietario real de esas sociedades, que utilizó para transferirse fondos a él mismo desde el exterior.(CREA: El Mundo, 07/02/1996.)

'The relations of Conde with the Swiss companies Kaneko Holding, Asni Investment, and Jamuna are more than evident to the experts of the Banco de España. So evident that they afirmed in the report passed to judge Manuel García-Castellon that Mario Conde is the real owner of these companies and that he used them to transfer money to himself from abroad.'

c. ¿Serás capaz? murmuró Estefanía como si se lo preguntara a ella misma, sintiendo en el vientre el tósigo de una defraudación inconsolable. (CREA: Caballero Bonald, J. M. 1981. 'Toda la noche oyeron pasar pájaros'.)

'Would you be able? Estefania murmured as if she asked it to herself, feeling in her belly the poison of an inconsolable betrayal.'

As for European Portuguese, Brito (2015:339) states that clitic doubling with (non-reflexive) dative pronouns belongs to the oral register. The results from the CRPC support Brito's (2015) view; the examples in (228) and (229) are all from transcripts of direct speech and show that both the reflexive and non-reflexive double bear contrastive focus or are needed for disambiguation. 
(228) a. EP No orçamento de despesa das juntas, será inscrita anualmente, sob a designação de Fundo de melhoramentos, a importância julgada possível e conveniente a quem chamámos para servir a Nação e que afinal se serviram a eles próprios. (CRPC: A57098.)

'The annual budget of the communes will include, under the designation of Fundo de melhoramentos, an appropriate amount of money for whom we call to serve the nation, and who are, in the end, serving themselves.'

b. Quer-me parecer que a EPAC continuou no ritmo da Junta Nacional dos Produtos Pecuários, das Frutas e outros mais, ou seja, em vez de ouvir os agricultores, foram organismos que se serviram a si próprios. (CRPC: A118085.)

'It seems to me that the EPAC continued like the National Board of Livestock Products, of Fruits, and many others, or let's say, instead of listening to the farmers, they were organisations that served themselves.'

(229) a. EP Qual o maior conselho que pode dar aos jovens pais? Berry Brazelton - «Acho que temos de ter em conta a pergunta prioritária que os jovens pais se colocam a eles próprios como é que eu vou criar esta criança?» (CRPC: Público, J104370)

'What is the best advice you can give to young parents? Berry Brazelton: "I think we have to consider the prime question that young parents are asking themselves, how am I going to raise this child?"

b. $\quad$ No texto já referido, Noronha da Costa conclui que as perguntas que se coloca a si próprio -e ao público- relativamente à imagem talvez sejam, ainda e também, um problema de imagem. (CRPC: Público, J98725)

'In the aforementioned text, Noronha da Costa concluded that the questions that he asked himself — and the public — in relation to the image, may be, still and additionally, a problem of image.'

In the case of the non-reflexive clitic, complementarity holds in its strict sense and reference to a local antecedent is ungrammatical. The sentences in (230) exemplify the ungrammaticality of a locally bound non-reflexive clitic and its non-reflexive double.

(230) a. Sp. $\operatorname{Juan}_{\mathrm{i}} \quad \mathrm{le}_{* \mathrm{i} / \mathrm{k}} \quad$ regala un coche a él $*_{\mathrm{i} / \mathrm{k}}$.

J. him. $\mathrm{CL}=$ gives a car $\mathrm{OM}$ him

'Juan gives him a car.'

b. EP A Rita oferece-lhe $*_{i} / \mathrm{k}$ um carro a ela $*_{\mathrm{i} / \mathrm{k}}$.

the R. gives=her.cL a car om her

'Rita gives her a car.'

With respect to locality as well, the non-reflexive dative pronouns are well behaved in the sense of Principle B. The sentences in (231) exemplify that the non-reflexive clitic and its double only allow for 
a non-local sentence-internal antecedent. The dative pronoun can be coreferent only with the subject DP of the matrix clause, Pedro in (231a) and a Marta in (231b).

(231) a. Sp. Pedro ${ }_{k}$ piensa que $\mathrm{Juan}_{\mathrm{i}} \mathrm{le}_{*_{\mathrm{i}} / \mathrm{k}}$ va a regalar un coche a él $*_{\mathrm{i} / \mathrm{k}}$. P. thinks that J. him.CL=will to give a car om him 'Pedro thinks that Juan will give him a car.'

b. EP A Marta acha que a Rita vai-lhe $*_{i} / k$ oferecer um carro a ela $*_{i / k}$. the M. thinks that the R. will=her.cL give a car om her 'Marta thinks that Rita will give her a car.'

Thus, complementarity in its strict sense only holds for the clitic pronoun, but not for the pronominal double. In both languages the non-reflexive pronoun is possible as a double of the reflexive clitic. In European Portuguese it can be associated with focus or used for purposes of disambiguation, whereas in Spanish it must be associated with a strong contrastive focus. As for the non-reflexive clitic and its non-reflexive double, they are perfectly compatible with classic Binding Theory. As predicted by Principle B, they cannot be bound by a local antecedent, but they can be bound by an antecedent outside the local domain (TP), such as the subject DP of the matrix clause in (231).

Finally, I want to draw attention to the example from Pineda (2013) cited in fn.52, ex. (ic), here repeated in (232). In this sentence, the strong reflexive pronoun is doubled with a non-reflexive clitic, and the antecedent is the direct object DP. ${ }^{56}$

$$
\begin{aligned}
& \text { Sp. El tratamiento le devolvió } \left.\mathrm{l}_{\mathrm{i}} \text { María }\right]_{\mathrm{DO}}\left[\begin{array}{lll}
\mathrm{a} & \mathrm{sí}_{\mathrm{i}} & \text { misma }
\end{array}\right]_{\mathrm{IO}} \text {. } \\
& \text { the therapy her.CL= gave-back oM M. to REFL.PR SELF } \\
& \text { 'The therapy gave María back to herself.' }
\end{aligned}
$$

(Pineda 2013: 190)

An equivalent sentence in European Portuguese is judged as unacceptable by native speakers, as shown in (233a). If the clitic is absent, as in (233b), the sentence is acceptable with the binding relation indicated.

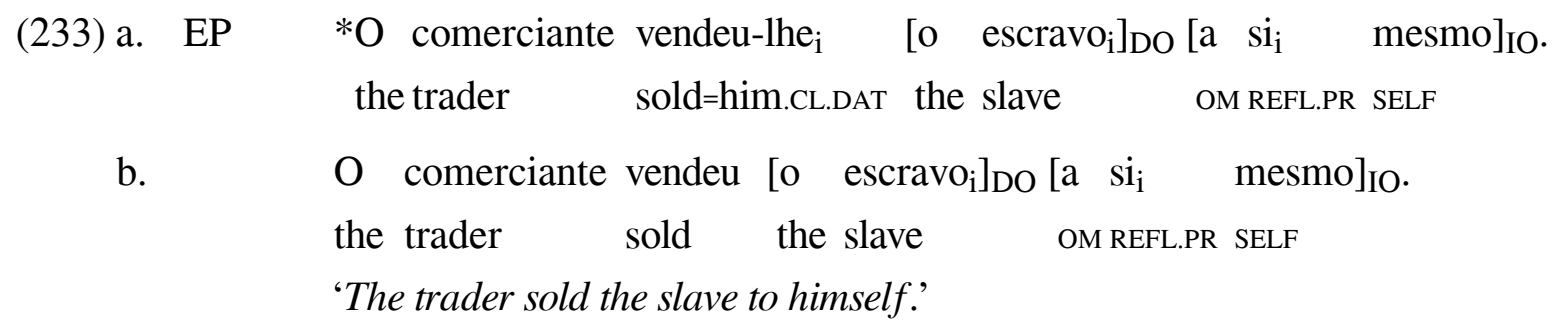

In these examples a non-reflexive dative clitic is doubled by a reflexive strong pronoun. But the two pronouns have distinct locality requirements. Locality is met for the strong reflexive pronoun, but it is violated for the non-reflexive clitic, and coreference should not be impossible. Why is it possible to

56 A similar example can be found in López (2012:41). 
violate the locality requirement in Spanish, but not in European Portuguese? In chapter 6 we will see that the difference in grammaticality is due to the nature of the dative clitic. In Spanish, dative clitic doubling is possible even with non-referential, quantified DPs, and it seems that the clitic is a mere grammatical formative in these cases, as it is in (232) when doubling a reflexive pronoun. In European Portuguese, the dative clitic is a fully referential pronoun and it cannot double a non-referential reflexive pronoun. This peculiar Spanish doubling pattern motivated a closer look at the doubling of a non-reflexive clitic with a strong reflexive pronoun. The next section is devoted to this pattern, and it will be shown that European Portuguese, but not Spanish, allows for this doubling pattern with long-distance reflexives.

Summarising this section: Spanish and European Portuguese are alike with respect to the interpretation of pronouns in DOCs, but differ with respect to the acceptability of DPCs. In DOCs, it is the clitics that are in strict complementary distribution, and it is also the clitics that determine the interpretation of their double. The reflexive clitics need a local antecedent and the non-reflexive clitics require a non-local antecedent. Furthermore, both languages allow for doubling of a reflexive clitic with a non-reflexive pronoun. This means that the strong pronouns as double of the reflexive clitic are not in complementary distribution. As for DPCs, the two languages are different. In Spanish, the DPC is limited to reflexive pronouns and unavailable with non-reflexive pronouns. European Portuguese allows for DPCs with reflexive pronouns and with non-reflexive pronouns. Interestingly, the non-reflexive pronoun may take a local antecedent. This fact makes European Portuguese essentially distinct from English and other Germanic languages such as German or Dutch (see Reuland 2011:111ff). In these languages the indirect object pronouns are in strict complementary distribution, as in the example in (234).

$$
\text { Lucie }_{i} \text { explained Max to } * \text { her }_{\mathrm{i}} / \text { herself }_{\mathrm{i}} \text {. }
$$

Reuland (2011:111)

The important result of this section is that the domain for syntactic binding in European Portuguese and Spanish is the domain in which the clitic and its verbal host meet with the subject. Strong pronouns inside dative PPs or as the pronominal double of a clitic are not in complementary distribution, essentially contradicting classic Binding Principle B.

\subsubsection{Clitic doubling and long-distance anaphora}

The peculiar example in (232) above from Pineda (2013) was the reason to take a closer look at the doubling of a non-reflexive dative clitic with a reflexive pronoun. In Pineda's example, the non-reflexive clitic is doubled with a reflexive double and they are in a local configuration with their antecedent, the direct object. This example is surprising because a non-reflexive clitic cannot take a local antecedent even if it is doubled by a reflexive strong pronoun, as shown in (235) for a dative clitic and in (236) for an accusative clitic.

(235) a. Sp. *Juan $\mathrm{le}_{\mathrm{i}}$ da un libro a $\mathrm{sí}_{\mathrm{i}}$ (mismo).

J. him.CL $=$ gives a book OM REFL.PR SELF 
b. EP *O Rui da-lhe $_{\mathrm{i}}$ um livro a $\mathrm{si}_{\mathrm{i}} \quad$ (próprio).

the R. gives=him.cL a book OM REFL.PR SELF

(236) a. Sp. *Juan ${ }_{i} l_{i} \quad$ admira a sí $_{i} \quad$ (mismo).

J. him.CL=admire OM REFL.PR SELF

b. EP *O Rui ${ }_{i}$ admira-o $\mathrm{O}_{\mathrm{i}}$ a $\mathrm{si}_{\mathrm{i}} \quad$ (próprio).

the R. admires=him.cL OM REFL.PR SELF

In European Portuguese, doubling a non-reflexive clitic with a strong reflexive pronoun becomes acceptable, if the antecedent is non-local. This type of doubling, previously not mentioned in the literature on clitic doubling, as for example in Brito (2008) and Magro (2019), is shown in (237a) and (237b). ${ }^{57}$

(237) a. EP Mas o profeta $a_{i}$ insistiu para que lhe $\mathrm{i}_{\mathrm{i}}$ desse primeiro a $\mathrm{si}_{\mathrm{i}}$ de but the prophet insisted for that him.CL=give.SUBJ first OM REFL.PR to comer, [...]..$^{58}$

eat, $\quad[\ldots]$

'But the prophet insisted that she should give him first something to eat, [...].'

(CRPC: Grandes Personagens da Bíblia, L1025.)

b. $\quad \mathrm{O}$ Rui $i_{i}$ quer que $\mathrm{o}_{\mathrm{i}}$ consultem a $\mathrm{si}_{\mathrm{i}} \quad$ primeiro.

the R. wants that him.CL=consult.SUBJ OM REFL.PR first

'Rui wants them to consult him first.'

Equivalent sentences in Spanish are absolutely unacceptable, as shown in (238) for dative and accusative clitics.

(238) a Sp. * *Juana ${ }_{i}$ quiere que $\mathrm{le}_{\mathrm{i}}$ pidan permiso a $\mathrm{sí}_{\mathrm{i}}$ primero.

J. wants that her.CL=ask.SUBJ permission OM REFL.PR first intended meaning: 'Juana wants them to ask her permission first.'

b. $\quad * J_{u a n a}$ quiere que $\mathrm{la}_{\mathrm{i}}$ retraten a sí $\mathrm{i}_{\mathrm{i}}$ primero.

J. wants that her.CL= portray.SUBJ OM REFL.PR first intended meaning: 'Juana wants them to portray her first.'

This difference in acceptablity is not surprising because, in constrast to Spanish, European Portuguese allows for long-distance reflexives in context of lexical prepositions, as we will see in chapter 8 (see also Lobo 2013 and Otero 1999). Note that the verbs that select the clitic/double in (237a) and (237b)

57 Thanks to the participants of the CLUL Séminiario (25/07/2018, Lisbon) for their comments, and in particular to Ana Maria Martins and Catarina Mago for their judgements.

58 The sentence continues as follows: confiando em que o Deus de Israel lhe providenciaria o sustento. 'trusting the God of Israel will take care of her subsistence.' 
are in subjunctive mood ('conjuntivo' in Portuguese, 'subjuntivo' in Spanish); in indicative mood, longdistance reflexives are ungrammatical, as exemplified in (239).

(239) a. EP $\quad * O \quad$ Rui $_{i}$ sabe que $o_{i} \quad$ consultam sempre a $\mathrm{si}_{i}$ primeiro. the R. knows that him.CL=consult.IND always OM REFL.PR first intended meaning: 'Rui knows that they always consult him first.'

b. $\quad * O$ Rui $i_{i}$ sabe que sempre $l^{2} e_{i}$ dão o livro a $\mathrm{si}_{\mathrm{i}}$ primeiro. the R. knows that always him.CL=give.IND the book OM REFL.PR first intended meaning: 'Rui knows that they always give him the book first.'

Furthermore, the presence of the intensifier makes a long-distance anaphor ungrammatical. This effect will reappear with long-distance reflexives inside PPs in chapter 8 . The intensifier will be analysed as an operator that restricts the referent of a pronoun to an element of its co-argument domain (see chapter 9). Under this analysis, the judgements in (240) receive a straightforward explanation.

(240) a. EP $\quad * \mathrm{O}$ Rui $\mathrm{i}_{\mathrm{i}}$ quer que $\mathrm{o}_{\mathrm{i}} \quad$ consultem a $\mathrm{si}_{\mathrm{i}}$ próprio primeiro.

the R. wants that him.CL=consult.SUBJ OM REFL.PR SELF first intended meaning: 'Rui wants them to consult him first.'

b. $\quad * \mathrm{O}$ Rui $\mathrm{R}_{\mathrm{i}}$ pediu que lhe $\mathrm{i}_{\mathrm{i}}$ dessem a $\mathrm{si}_{\mathrm{i}}$ próprio o livro. the R. asked that him.CL=give.SUBJ OM REFL.PR SELF the book intended meaning: 'Rui asked that they should give him the book.'

Most intriguing is the limitation of long-distance reflexives to a singular antecedent, as shown in (241). I will come back to this restriction in chapter 6.
(241) a. EP
*Eles $\mathrm{i}_{\mathrm{i}}$ querem que $\mathrm{os}_{\mathrm{i}}$ consultem a $\mathrm{si}_{\mathrm{i}} \quad$ primeiro. they want that them.CL=consult.SUBJ OM REFL.PR first intended meaning: 'They want them to consult them first.'
b. $\quad *$ Eles $_{\mathrm{i}}$ pediram que lhes $\mathrm{s}_{\mathrm{i}}$ dessem a $\mathrm{si}_{\mathrm{i}}$ o livro. they asked that them.CL= give.SUBJ OM REFL.PR the book intended meaning: 'They asked that they should give them the book first.'

Before discussing an interesting example from the CREA, let us briefly summarise the restrictions on doubling a long-distance reflexive: (i) the verb selecting the clitc/double has to be in subjunctive mood, (ii) the intensifier has to be absent, (iii) and most intriguingly, the antecedent of the bare reflexive has to be singular. Chapter 6 aims to give an explanation for the restriction to a singular antecedent, and the absence of the intensifier is accounted for in chapter 9. The restriction to subjunctive mood may turn out to be related to pragmatic factors such as the report of viewpoint, as in Speas (2004). (Reflexive) pronouns whose reference depends on discourse-pragmatic factor such as view point or perspective are labelled logophors in Speas (2004) and references cited within. A detailed study into these phenomena in European Portuguese has to be left for future work. 
Even though Spanish does not permit long-distance reflexives, the CREA contained one sentence with a non-reflexive dative clitic doubled with a reflexive pronoun. The example is given in (242).

Sp. $\quad$ Si asumimos que el individuo promedio tiende progresivamente a dedicarle más tiempo a la tele que a la comunicación interpersonal asumimos también que del flujo "creíble" de la TV absorbe buena parte del universo simbólico con el cual interpreta lo que le ocurre a sí mismo en relación a todo lo demás. (CREA: LópezPumarejo, T. 1987. 'Aproximación a la telenovela: Dallas / Dinasty / Falcon Crest'.) 'If we assume that the average individual tends to devote increasingly more time to television than to interpersonal communication, we also assume that it absorbs from the "credible" flow of the TV a large part of the symbolic universe with which it interprets what happens to itself in relation to everything else.'

The acceptability of this sentence is the result of a combination of conflicting factors. In order to explain this conflict, the relevant part of the sentence is represented with glosses in (243).

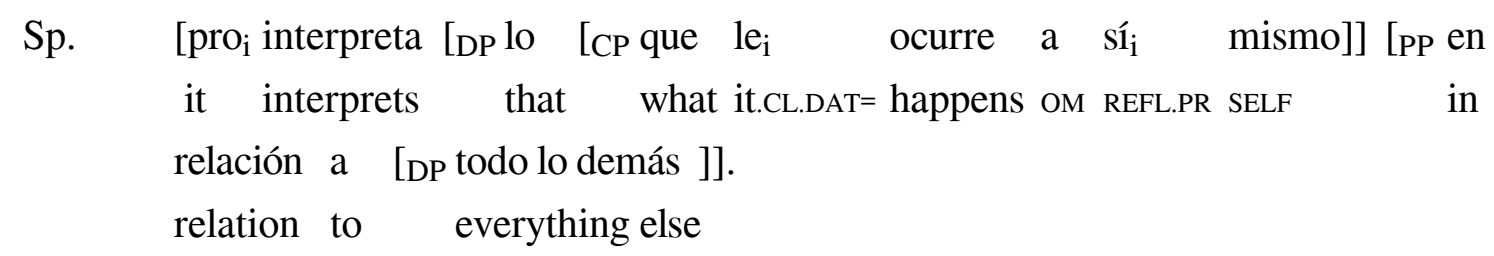

The dative clitic le and its reflexive double are inside a relative clause. Their antecedent is the pro subject of the verb interpretar in the higher (relative) clause. Thus, the non-reflexive clitic has a nonlocal antecedent, as required, while the localitiy requirement of the reflexive pronoun is violated. There are in principle two ways to avoid the locality violation: (i) use the clitic without doubling and (ii) use the non-reflexive double. Why are these strategies not applied? As for clitic doubling, it seems that it is required here because the relative clause containing the clitic/double is part of the relational expression en relación $a$ and a contrast needs to be established. As for the non-reflexive strong pronoun, it cannot be used here because the antecedent of the clitic - the pro subject-refers to the generic DP el individuo promedio 'the average individual'. As we will see in more detail in section 6.2, the nonreflexive strong pronoun as well as the non-reflexive accusative clitic are restricted to definite/specific referents and only the reflexive pronoun and the non-reflexive dative clitic may take non-referential or generic antecedents. This indicates that the interpretive requirement is more important than the locality requirement of the reflexive pronoun.

\subsubsection{Summary}

In both languages, complementarity in its strict sense only holds for the clitic pronouns. This means that the domain for syntactic binding is the domain in which the clitic meets its antecedent, the subject DP. In chapter 7 , it will be proposed that this domain is little $\mathrm{v}$ and its specifier. 
With respect to locality, the reflexive clitic obligatorily takes a local antecedent, while the nonreflexive clitic takes a non-local antecedent. In both languages, the reflexive clitic can be doubled with a reflexive or a non-reflexive pronoun if the antecedent is local, as shown in (244).

\begin{tabular}{|c|c|c|c|c|c|}
\hline & \multirow[t]{2}{*}{ Antecedent } & \multirow[t]{2}{*}{ Clitic } & \multirow[t]{2}{*}{ Double } & \multicolumn{2}{|c|}{ Languages } \\
\hline & & & & Sp. & $\mathrm{EP}$ \\
\hline a. & local & se $(\mathrm{DO}, \mathrm{IO})$ & si/sí & $\checkmark$ & $\checkmark$ \\
\hline$a^{\prime}$. & local & se $(\mathrm{DO}, \mathrm{IO})$ & ele/él & $\checkmark$ & $\checkmark$ \\
\hline b. & non-local & se $(\mathrm{DO}, \mathrm{IO})$ & si/sí & $*$ & $*$ \\
\hline$b^{\prime}$. & non-local & se $(\mathrm{DO}, \mathrm{IO})$ & ele/él & $*$ & $*$ \\
\hline
\end{tabular}

As for the interpretation of the reflexive double, it has a contrastive interpretation and an interpretation as a disambiguating element in both languages. As for the non-reflexive double, it is obligatorily associated with a strong contrastive focus interpretation in Spanish, whereas in European Portuguese it is interpreted similarly to the reflexive double.

The non-reflexive clitic is ungrammatical with a referential non-local antecedent irrespective of the nature of its double, as summarised in (245a) and (245b).

\begin{tabular}{c|c|c|c|cc} 
& Antecedent & Clitic & Double & \multicolumn{2}{|c}{ Languages } \\
\hline $\mathrm{a}$. & local & o/lo & si/sí & $*$ & SP. \\
\hline $\mathrm{a}^{\prime}$. & local & lhe/le & si/sí & $*$ & $*$ \\
\hline $\mathrm{b}$. & local & o/lo & ele/él & $*$ & $*$ \\
\hline $\mathrm{b}^{\prime}$. & local & lhe/le & ele/él & $*$ & $\checkmark$ \\
\hline $\mathrm{c}$. & non-local & o/lo & ele/él & $\checkmark$ & $\checkmark$ \\
\hline $\mathrm{c}^{\prime}$. & non-local & lhe/le & ele/él & $\checkmark$ & $\checkmark$ \\
\hline $\mathrm{d}$. & non-local & o/lo & si/sí & $*$ & $\checkmark$ \\
\hline $\mathrm{d}^{\prime}$. & non-local & lhe/le & si/sí & $(\checkmark)$ &
\end{tabular}

In the case of a non-local antecedent, the double of the indirect object clitic and the direct object clitic is associated with a contrastive interpretation in European Portuguese, whereas in Spanish, only the DO double is necessarily associated with a contrastive interpretation. In standard Spanish, clitic doubling of the indirect object is obligatory with all DPs, but with unmodified bare nouns (see chapter 2). The canonical doubling patterns are given in $(245 c)$ and $\left(245 c^{\prime}\right)$. Differently from Spanish, European 
Portuguese allows for a long-distance reflexive as a double of the DO and IO clitic in the context of subjuntive mood and a singular antecedent. In Spanish, only the IO clitic is compatible with a longdistance interpretation, but only if the use of a non-reflexive double violates the lexical restrictions imposed by the antecedent. These patterns are summarised in (245d) and (245d').

Another difference between Spanish and European Portuguese is the occurrence of pronouns in DPCs. In Spanish, availability of a DPC seems to be subject to variation. In the standard variety of Spanish, both types of strong pronouns are ungrammatical in DPCs, if the antecedent has a human referent. But, as the data from the CREA suggest, some speakers allow for a DPC with the reflexive pronoun. A non-reflexive pronoun becomes acceptable in DPCs if the antecedent is non-local and has a non-animate/non-human referent. In European Portuguese, the reflexive and the non-reflexive pronoun are possible in DPCs. The interpretation of pronouns in DCPs is identical to that of pronouns inside other PPs. For a detailed discussion of the interpretation of strong pronouns inside PPs, I refer the reader to chapters 8 and 9 .

\subsection{C-command}

This subsection summarises the well-known facts that a reflexive clitic and its reflexive double need a local and c-commanding ${ }^{59}$ antecedent (see Mateues et al. 2003:810ff for European Portuguese and Bosque \& Gutiérrez-Rexach 2016:565ff for Spanish, and Müller \& Riemer (1998:102ff) for Romance languages in general). A non-reflexive clitic and its double must take a non-local antecedent, an antecedent outside the TP domain, as shown in the previous section, or it may corefer with a local but nonc-commanding antecedent. The latter case can be exemplified with embedded DPs, which are local, but not in a position to c-command the reflexive pronoun. The embedded DPs, o João and Juana, in (246a) and (246b) respectively, do not c-command the reflexive pronoun (clitic and its double) and thus cannot be its antecedent. The antecedent has to be the entire subject DP, which is the only constituent that c-commands the reflexive pronoun.

(246) a. EP $\quad\left[\mathrm{O}\right.$ pai $\mathrm{d}\left[\mathrm{o} \quad \mathrm{João}_{\mathrm{i}}\right]_{\mathrm{k}}$ denunciou- $\mathrm{se}_{\mathrm{k} / *_{\mathrm{i}}}$ a $\quad \mathrm{si}_{\mathrm{k} / *_{\mathrm{i}}}$ próprio. the father of the J. reported=SE.REFL OM REFL.PR SELF

'João's father reported himself to the police.'

b. Sp. [La madre de $\left.[\mathrm{Juana}]_{\mathrm{i}}\right]_{\mathrm{k}}$ se $*_{\mathrm{i} / \mathrm{k}}$ ha denunciado a $\mathrm{s}_{1} *_{\mathrm{i} / \mathrm{k}}$ misma. the mother of J. SE.REFL=AUX reported OM REFL.PR SELF

'Juana's mother reported herself to the police.'

59 Within the GB framework, the level of application of binding and hence of c-command has been a matter of discussion, in particular for anaphors embedded in complex wh-phrases, such as which picture of himself, or otherwise dislocated anaphors that are not c-commanded by their antecedent at surface structure. The fact that c-command holds in all-new declarative sentences has been taken as an indication that it must hold in other sentence types with different (surface) word orders as well. Several solutions have been disscussed in the GB literature. For example, Belletti \& Rizzi (1981) propose on the basis of Italian that the Binding Principles apply at D-structure. Chomsky (1986, 1995a) assumes that a dislocated anaphor reconstructs to a lower position at LF in which it is c-commanded by its antecedent. 
The opposite is true for the non-reflexive pronoun, as shown in (247). Due to the lack of c-command, the embedded DPs $o$ João and Juana can act as the antecedent of the non-reflexive clitic/double, but the entire subject DP cannot.

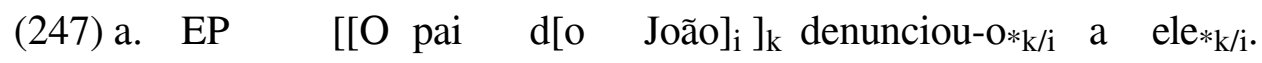
the father of the J. reported=him.CL om him

'João's father reported him to the police.'

b. Sp. [La madre de $\left[\mathrm{Juana}_{\mathrm{i}}\right]_{\mathrm{k}} \mathrm{la}_{\mathrm{i} /{ }^{\mathrm{k}}}$ ha denunciado a ella $\mathrm{a}_{\mathrm{i} /{ }^{\mathrm{k}}}$. the mother of J. her.CL=Aux reported om ella

'Juana's mother reported her to the police.'

The same pattern holds for the pronoun in indirect object position. The reflexive clitic can only be anaphorically related to the c-commanding subject DP, but not to the embedded, hence non-c-commanding DP. Again, for the non-reflexive clitic and strong pronoun the opposite is true. The non-reflexive pronoun can be related to the local and non-c-commanding DP, but not to the local and c-commanding DP. The examples are given in (249) and (248).

(248) a. Sp. [[El padre de [Luis $\left.]_{\mathrm{i}}\right]_{\mathrm{k}} \mathrm{se}_{\mathrm{k} / *_{\mathrm{i}}}$ regaló un coche a él $*_{\mathrm{i} / \mathrm{k}} / \mathrm{s}{ }^{\prime} *_{\mathrm{i} / \mathrm{k}} \quad$ mismo. the father of L. SE.REFL= gave a car to him / REFL.PR SELF 'Luis's father gave himself a car.'

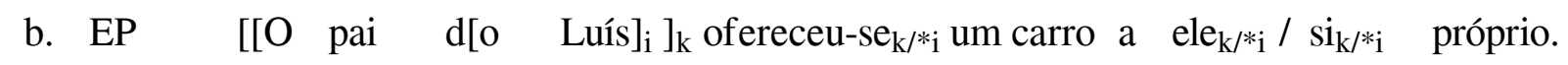
the father of the L. gave=SE.REFL a car to him / REFL.PR SELF 'Luís's father gave himself a car.'

(249) a. Sp. $\quad\left[\left[E l \text { padre de }[\text { Luis }]_{\mathrm{i}}\right]_{\mathrm{k}} \mathrm{le}_{*_{\mathrm{k}} / \mathrm{i}}\right.$ regaló un coche a él $\mathrm{i}_{\mathrm{i}}$. the father of L. him.CL=gave a car to him Luis's father gave him a car.'

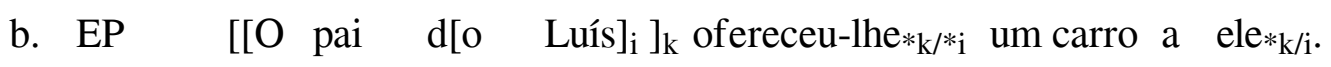
the father of.the L. gave=him.cL a car to him 'Luis's father gave him a car.'

The c-command diagnostic with embedded DPs can be reinterpreted also in terms of co-argumenthood, as for example in Reinhart \& Reuland (1991, 1993) and Reuland (2011). In the examples discussed above, the complex subject DP is the co-argument of the direct or indirect object pronoun, but not of the embedded DP. A reflexive predicate is formed, if two co-arguments have the same referent. Thus, the reflexive pronoun can only be associated with the entire subject DP because it is its coargument. The non-reflexive pronoun does not participate in reflexivisation, and for this reason it can be associated with the embedded DP, but not with a co-argument DP. 


\subsection{Binding by a quantifier}

Recall from section 1.2 that antecedent-pronoun binding and quantifier-variable binding have received a parallel analysis in Heim \& Kratzer (1998). In (250), the subject pronoun he can be bound by the quantifier, as in $\left(250 \mathrm{a}^{\prime}\right)$, or by a referential DP, as in (250b'). In both examples, it can be also free and refer to another entity present in discourse, such as the person with the name Claus.

(250) a. $\quad$ Everybody said that he loves ice cream.

$a^{\prime}$ Every $(x)$ said that $x$ loves ice cream

$a^{\prime \prime} . \quad$ Every $(x)$ said that $y$ loves ice cream $(y=$ Claus $)$

bound variable

b. Peter said that he loves icecream.

$b^{\prime}$. Peter (x) said that $x$ loves ice cream

free variable

$\mathrm{b}^{\prime \prime}$. Peter $(\mathrm{x})$ said that y loves ice cream $(\mathrm{y}=$ Claus $)$

bound variable

free variable

This diagnostic helps to distinguish a coreferent from a semantically bound interpretation of a pronoun, in particular if the pronouns are not in complementary distribution (see chapter 1 and section 8.5 ). A pronominal quantifier or a quantified DP such as nobody and every student, respectively, are nonreferential in the sense that they are unable to pick out a certain individual or a group of individuals in the universe of discourse. A quantifier phrase (QP) acts as an operator that binds a variable and therefore allows a statement about all entities that can be the value of that variable. For example, the QP every student allows statements about all individuals that are students. If a pronoun is ungrammatical with a QP antecedent, the pronoun cannot be bound because it needs to corefer with a referential antecedent. If a pronoun is grammatical with a QP antecedent, it is interpreted as a bound variable.

This section applies the diagnostic to clitic pronouns and their strong pronominal double. I will show that both reflexive and non-reflexive clitic pronouns may take a quantified antecedent, in Spanish as well as in European Portuguese. But the acceptability of the non-reflexive double with a QP antecedent varies with respect to the type of quantifier: pronominal quantifier or (complex) determiner quantifier. $^{60}$

Let us start with the non-reflexive clitic. In both languages, the non-reflexive clitic can be bound by different types of quantifiers, as shown in (251) and (252) (see Alonso-Ovalle \& D'Introno 2005:89ff, Bosque \& Gutiérrez-Rexach 2016:554ff for Spanish). This means that the non-reflexive clitic pronoun may translate into a bound variable at the syntax-semantics interface. In contrast to the non-reflexive clitic, the strong non-reflexive pronoun cannot be bound by all QPs. In Spanish, the nonreflexive double is ungrammatical with the QPs todo el mundo and nadie, as shown in (252b) and (251b). This indicates that the strong non-reflexive pronoun is interpreted as coreferential, free variable. In European Portuguese, there is a difference between the QP todos and ninguém. The ungrammaticality

60 Pronominal quantifiers are alguém (EP) / alguien (Sp.) 'somebody' and ninguém (EP) / nadie (Sp.) 'nobody'. Determiner QPs are, for example, nenhum (EP) / ningún (Sp.) 'no', algum (EP) / algún (Sp.) 'some', muito (EP) / mucho (Sp.) 'many'. As for $\operatorname{todos}(\mathrm{EP}), \mathrm{I}$ take it to be a determiner QP, because there is only one form for its bare use and its determiner use. 
of the negative QP antecedent in (251a), points to a obligatorily coreferent interpretation of the strong pronoun. The fact that the strong pronoun is grammatical with todos is surprising under the asumption that a strong non-reflexive pronoun needs to take a referential antecedent. This pattern will reappear with pronouns in PP-complements and PP-adjuncts in section 8.5.

(251) a. EP Ninguém ${ }_{i}$ quer que $o_{i}$ tratem mal $\left(* a e^{*} e_{i}\right)$.

nobody wants that him.CL=treat bad om him

intended meaning: 'Nobody wants to be treated badly.'

b. Sp. $\quad$ Nadie $_{\mathrm{i}}$ quiere que $\mathrm{lo}_{\mathrm{i}}$ traten mal (*a él $\mathrm{l}_{\mathrm{i}}$ ).

nobody wants that him.CL=treat bad om him

intended meaning: 'Nobody wants to be treated badly.'

(252) a. EP Todos $_{\mathrm{i}}$ querem que $\mathrm{os}_{\mathrm{i}}$ tratem bem (a eles ${ }_{\mathrm{i}}$ ).

everybody wants that them.CL=treat well om them

'Everybody wants to be treated right.'

b. Sp. Todo el mundo quiere que $\mathrm{lo}_{\mathrm{i}}$ traten bien $\left(* \mathrm{a} \quad \mathrm{e}_{\mathrm{i}}\right.$ ).

everybody wants that him.CL=treat well om him

intended meaning: 'Everybody wants to be treated right.'

The fact that 'referential material' inside a negative QP affects the acceptability of the non-reflexive double is shown in (253). The non-reflexive double becomes significantly less unacceptable in both languages if the QP is complex. These facts will be discussed and interpreted in section 8.5.

(253) a. EP ??Nenhumaluno $i$ quer que este professor $o_{i}$ vigie a ele . $_{i}$

no pupil wants that the professor him.CL=watch om him intended meaning: 'No student wants this professor to supervise him.'

b. Sp. ??Ningún alumno quiere que este professor $\mathrm{l}_{\mathrm{i}}$ vigile a él $\mathrm{l}_{\mathrm{i}}$. no pupil wants that this professor him.CL=watch om him intended meaning: 'No student wants this professor to supervise him.'

With respect to doubling of the reflexive clitic and the reflexive double, both languages show the same pattern. The reflexive double is perfectly acceptable even with the negative quantifier, as shown in (254).

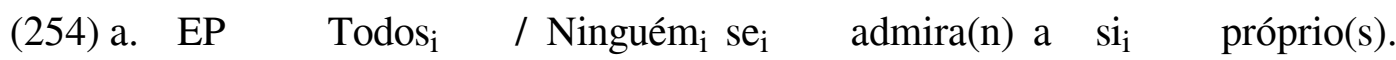
everybody / nobody SE.REFL=admire(s) OM REFL.PR SELF 'Everbody / Nobody admires himself.'

b. Sp. Todo el mundo $\mathrm{i}_{\mathrm{i}} / \mathrm{Nadie}_{\mathrm{i}} \mathrm{se}_{\mathrm{i}}$ gobierna a $\mathrm{sí}_{\mathrm{i}}$ mismo. everybody / nobody SE.REFL=governs OM REFL.PR SELF 'Everbody / Nobody governs himself.' 
Interestingly, doubling with the non-reflexive pronoun is not permitted in either language, as shown in (255), contrary to (252a) above.

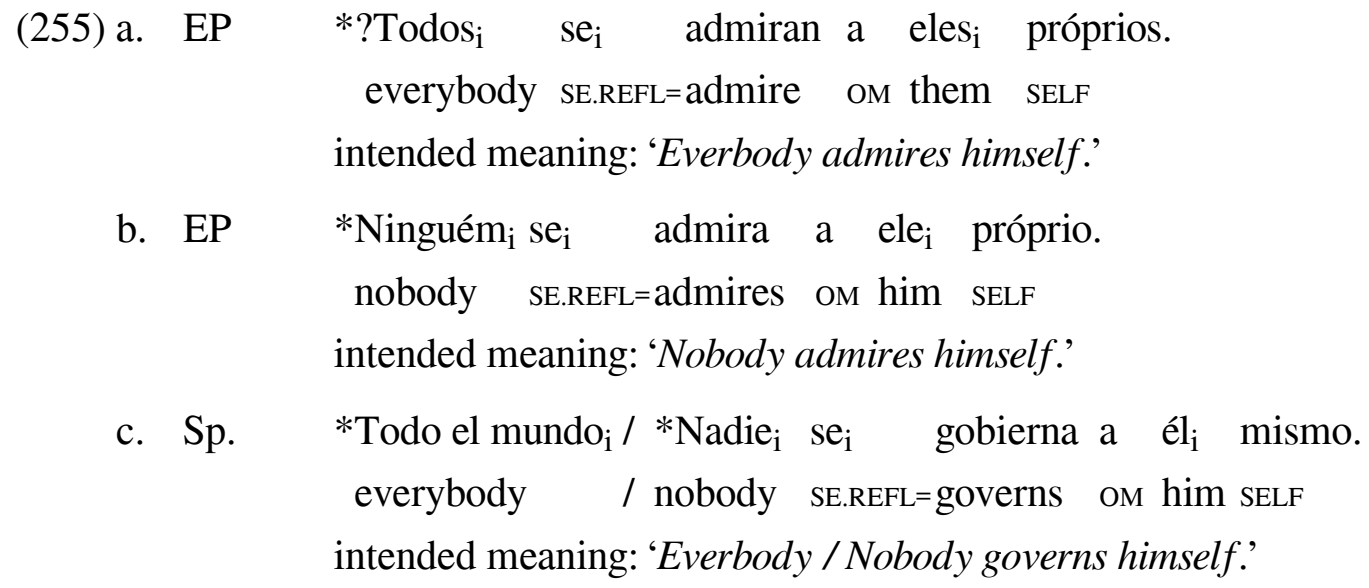

Furthermore, doubling of the reflexive clitic with the non-reflexive double is not even permitted with a complex QP, as exemplified in (256). These judgements could be related to the (strong) contrastive interpretation of the strong pronominal double. The QPs do not have a specific referent and for this reason no contrast can be established between the QP and another entity present in the linguistic contrast.

(256) a. EP ??Cada / *Nenhum vocalista $\mathrm{se}_{\mathrm{i}}$ admira a ele $\mathrm{e}_{\mathrm{i}}$ próprio. every / no singer SE.REFL=admires OM him SELF intended meaning: 'Every / No singer admires himself.'

b. Sp. $\quad$ ?*Cada / *Ningún cantante $\mathrm{se}_{\mathrm{i}} \quad$ admira a él $_{\mathrm{i}}$ mismo. every / no singer SE.REFL=admires OM him SELF intended meaning: 'Every / No singer admires himself.'

These data show that both clitic pronouns and the strong reflexive pronoun may act as true bound variables, but the non-reflexive strong pronoun resists binding by a QP. Given this observation, it is not surprising that a long-distance reflexive may take all types of QPs as an antecedent. This is exemplified in (257).

(257) a. EP Cada um quer que $\mathrm{o}_{\mathrm{i}}$ tratem bem a $\mathrm{si}_{\mathrm{i}}$. Everyone wants that him.CL=treat well OM REFL.PR 'Everyone wants to be treated right.'

b. $\quad$ Ninguém $_{i}$ quer que $\mathrm{o}_{\mathrm{i}}$ tratem mal a $\mathrm{si}_{\mathrm{i}}$. Nobody wants that him.CL=treat bad OM REFL.PR 'Nobody wants to be treated badly.'

The findings of this section are summarised in the table in (258). The reflexive and the non-reflexive clitic can be bound by all types of quantifiers, given that the respective locality requirements are met. 
The results for the accusative clitics discussed in the present section carry over to dative clitics in both languages. The reflexive strong pronoun goes along with the reflexive clitic. It is the strong non-reflexive pronoun that resists binding by a quantifier and that is sensitive to referential material contained in a complex determiner QP. The results will be interpreted in section 8.5.

(258) Summary

\begin{tabular}{|c|c|c|c|c|c|c|c|}
\hline & \multirow[t]{2}{*}{ Antecedent } & \multirow[t]{2}{*}{ Clitic } & \multicolumn{2}{|c|}{ Languages } & \multirow[t]{2}{*}{ Double } & \multicolumn{2}{|c|}{ Languages } \\
\hline & & & Sp. & $\mathrm{EP}$ & & Sp. & EP \\
\hline a. & pronominal QP & lo/o, le/lhe & $\checkmark$ & $\checkmark$ & él/ele & $*$ & $*$ \\
\hline$b^{\prime}$. & determiner QP & lo/o, le/lhe & $\checkmark$ & $\checkmark$ & él/ele & $*_{-} ? ?$ & $? ?-\checkmark$ \\
\hline a. & pronominal QP & se $(\mathrm{DO}, \mathrm{IO})$ & $\checkmark$ & $\checkmark$ & si/sí & $\checkmark$ & $\checkmark$ \\
\hline b. & determiner QP & se $(\mathrm{DO}, \mathrm{IO})$ & $\checkmark$ & $\checkmark$ & si/sí & $\checkmark$ & $\checkmark$ \\
\hline $\mathrm{a}^{\prime}$. & pronominal QP & se $(\mathrm{DO}, \mathrm{IO})$ & $\checkmark$ & $\checkmark$ & él/ele & $*$ & $*$ \\
\hline $\mathrm{b}^{\prime}$. & determiner QP & se $(\mathrm{DO}, \mathrm{IO})$ & $\checkmark$ & $\checkmark$ & él/ele & $*_{-} * ?$ & $*_{-} ? ?$ \\
\hline
\end{tabular}

\subsection{Sentence-external antecedent}

The ability to take a sentence-external antecedent is a good diagnostic for a free, coreferent interpretation of a pronoun. The inability to take a sentence-external antecedent is an indication that the pronoun is obligatorily interpreted anaphorically and that it has some lexical property that prohibits an interpretation by discourse-pragmatic means. In Spanish and European Portuguese, a non-reflexive pronoun (clitic or strong) can take a sentence-external antecedent, but a reflexive pronoun (clitic or strong) can never do so. ${ }^{61}$ This is shown in (259) for a reflexive and non-reflexive clitic and in (260) for a strong reflexive and non-reflexive pronoun.

Context: Do you know Pedro $_{i}$ ?

a. EP Conheço, mas não $*^{*} \mathrm{se}_{\mathrm{i}} / \mathrm{o}_{\mathrm{i}} \quad$ vejo há muito tempo. yes, but not SE.REFL=/ him. $. \mathrm{LL}=$ see has much time

b. Sp. Sí, pero no $*^{*} \mathrm{se}_{\mathrm{i}} \quad / \mathrm{lo}_{\mathrm{i}} \quad$ veo desde hace mucho tiempo. yes, but not SE.REFL $=/$ him.CL=see since much time intended meaning: 'I know him, but I haven't seen him for a long time .'

(260)

Context: Can I trust Peter $_{i}$ ?

a. EP Podes. Eu confio nele $\mathrm{i}_{\mathrm{i}} / \mathrm{em}^{*} \mathrm{si}_{\mathrm{i}}$ cegamente.

yes, I trust in.him / in REFL.PR blindly

61 This is also true for reflexive pronouns inside of PP-complements of picture nouns, as shown in Campos (1995) for Spanish and p.c. Ana Maria Martins for European Portuguese. 
b. Sp. Sí, yo confío en él $l_{i} / *^{*} i_{i} \quad$ ciegamente.

yes, I trust in him / REFL.PR blindly

'Yes, I trust him blindly.'

The presence or absence of the elements mismo, mesmo/próprio has no effect on the grammaticality of the reflexive pronoun. This means that the reflexive pronoun can never be interpreted as free, coreferent variable, and, that it always needs a sentence-internal antecedent. Of course, a free, coreferent interpretation is not limited to a sentence-external antecedent. A pronoun may be coreferent with a sentence-internal DP, yielding an interpretation indistinguishable from a bound interpretation, as discussed in Reinhart (2006). The diagnostic VP-ellipsis and only-contexts, presented in the next sections 5.6 and 5.7, respectively, help to determine whether a pronoun is bound and/or interpreted by sentence-internal coreference.

\subsection{VP-ellipsis}

It has been observed by Ross (1967) that a pronoun inside an elided VP can have two readings. These are exemplified for the possessive pronoun his in the sentences in (261). The strict identity reading is shown in (261a), and the sloppy identity reading in (261b).

John scratched his arm and Mary did so too.

(Ross 1967:207)

a.

Mary scratched his (= John's) arm

strict identity

b.

Mary scratched her own arm

sloppy identity

The way the pronoun is interpreted in the elided VP is taken as an indication for the interpretation of the pronoun in the non-elided VP. The strict reading is the result of a free variable or coreferential interpretation, represented in (262a), while the sloppy reading is the result of a bound variable interpretation, as in (262b). Thus, if the pronoun is a bound variable in the elided VP, then it is also bound in the non-elided VP, and if the pronoun is coreferential in the elided VP, then it is coreferential in the non-elided DP.

$$
\begin{array}{llr}
\text { a. } & \operatorname{John}(\mathrm{y}) \text { [scratched y's arm] and Mary (z) [scratched y's arm] }(\mathrm{y}=\mathrm{John}) & \text { free } \\
\text { b. } & \operatorname{John}(\mathrm{x}) \text { [scratched x's arm] and Mary(z) [scratched z's arm] }
\end{array}
$$

Sag (1980) and Hicks (2009) applied this test to English reflexive pronouns (in direct object position) and showed that reflexive pronouns only allow for the sloppy reading/bound variable interpretation.

In the following, this interpretive diagnostic will be applied to Spanish and European Portuguese reflexive and non-reflexive pronouns in clitic doubling structures. The sentences in (263) and (264) are coordinated sentences. The first conjunct contains the reflexive (clitic and strong) pronoun, and in the second conjunct the VP is elided. The paraphrases in (263a) and (264a) exemplify the sloppy/bound 
reading of the pronoun in the elided VP. The paraphrases in (263b) and (264b) represent the strict/ coreferential reading of the pronoun. In the two languages, the reflexive (clitic and strong) pronoun is obligatorily interpreted as a bound variable. A coreferential/strict interpretation is impossible.

Sp. Juana se denunció a sí misma y María también.

J. SE.REFL=reported OM REFL.PR SELF and M. too

'Juana reported herself, and María did so too.'

a. $\rightarrow$ María reported herself.

b. $\quad \rightarrow$ *María reported her (=Juana).

(264) EP O João denunciou-se a si próprio e o Rui também.

the J. reported=SE.REFL OM REFL.PR SELF and the R. also

'João reported himself, and Rui did so too.'

a. $\rightarrow$ Rui reported himself.

b. $\quad \rightarrow$ Rui reported him (=João).

This diagnostic also supports the findings from above, in particular the fact that the clitic (reflexive or non-reflexive) is decisive for the interpretation of the double and not vice versa. In (265) and (266), the reflexive clitic is doubled with a non-reflexive pronoun, and still the bound reading is the only possible interpretation of the pronoun in the elided VP. A coreferential reading is not acceptable, as shown in (265b) and (266b). A possible context for the sentences, allowing the non-reflexive double in Spanish, could be a situation of fictional time travel in which the individuals can observe their future selves.

Sp. Juan se oyó a él mismo y Pedro también.

J. SE.REFL=heard OM him SELF and P. too

'Juan heard himself, and Pedro did so too.'

a. $\quad \rightarrow$ Pedro heard himself.

b. $\quad \rightarrow$ *Pedro heard Juan.

(266) EP A Rita viu-se a ela própria e a Ana também. the R. Saw=SE.REFL OM her SELF and the A. also 'Rita saw herself, and Ana did so too.'

a. $\quad \rightarrow$ Ana saw herself.

b. $\quad \rightarrow *$ Ana saw Rita.

The non-reflexive clitic receives only a strict/coreferential interpretation if the antecedent is local and non-c-commanding, as shown in (267) and (268). The antecedent of the pronoun is the embedded DP, João and Juana, respectively. 
(267) EP O colega do João denunciou-o e o colega da Rita também. the colleague of.the J. reported=him.cL and the colleague of.the R. also 'João's colleague reported him, and Rita's colleague did so too.'

a. $\quad \rightarrow$ ??-*Rita's colleague reported her (= Rita).

b. $\quad \rightarrow$ Rita's colleague reported him (= João).

(268) Sp. El colega de Juan lo denunció y el colega de Marta también. the colleague of J. him.CL=reported and the colleague of $\mathrm{M}$. also 'Juan's colleague reported him, and Marta's colleague did so too.'

a. $\quad \rightarrow$ ??Marta's colleague reported her (= Marta).

b. $\quad \rightarrow$ Marta's colleague reported him (= Juan).

But if the antecedent of the clitic is in a non-local, but c-commanding position, the sloppy reading of the pronoun becomes available. Of course, the examples in (269) and (270) are not instances of VP ellipsis, but rather of CP ellipsis.

(269) a. EP O Rui quer que todos o admirem e a Rita também quer. the R. wants that everybody him. $\mathrm{CL}=$ admires and the R. also wants 'Rui wants everybody to admire him, and Rita wants that too.'

a. $\quad \rightarrow$ wants everybody to admire her (= Rita).

b. $\quad \rightarrow$ wants everybody to admire him (= Rui).

(270) Sp. Juan quiere que todo el mundo lo ame e Marta también lo quiere. J. wants that everybody him.CL= loves and $\mathrm{M}$. also it.CL= wants 'Juan wants everybody to love him, and Marta wants that too.'

a. $\quad \rightarrow$ wants everybody to loves her (= Marta).

b. $\quad \rightarrow$ wants everybody to love him (= Juan).

The contrast between (269)/(270) and (267)/(268) corroborates the claim that a non-reflexive clitic pronoun can be interpreted as bound variable, but only if the antecedent is non-local and in a position to c-command the pronoun. As for dative pronouns in doubling structures, there is no need to represent analogous examples because the indirect object clitics are interpreted in the same way and do not provide additional information.

But, if the dative pronoun is realised in a DPC, as is common in European Portuguese, the intensifier plays a crucial role in the interpretation of the non-reflexive pronoun. Recall that in a DPC the strong pronoun is realised without clitic doubling. In (271) the IO is realised as a pronoun accompanied by the intensifier. The diagnostic shows that the only possible interpretation of the pronoun is a bound variable interpretation. 
(271) EP A Maria ofereceu uma viagem a ela própria e o Rui também. the M. gave a trip to her SELF and the R. also 'Maria gave herself a trip, and Rui did so too.'

a. $\quad \rightarrow$ Rui gave himself a trip.

b. $\quad \rightarrow$ ??Rui gave her (= Maria) a trip.

In (272) the same sentence is tested, but without the intensifier. In this case, the pronoun cannot receive a sloppy/bound interpretation, but only a strict/coreferential interpretation. The pronoun may be coreferent with any salient, non-local, and non-c-commanding discourse entity matching its phifeatures [fem, sg.].

EP $\quad$ A Maria ofereceu uma viagem a ela e o Rui também.
the M. gave a trip to her and the R. also
'Maria gave her a trip, and Rui does so too.'
a. $\quad \rightarrow$ *-??Rui gave him (= Rui) a trip.
b. $\quad \rightarrow$ Rui gave her (= Maria or other) a trip.

The diagnostic shows an important effect of the intensifier. Its presence seems to alter the referential properties of the pronoun in a way that it needs a local and c-commanding antecedent. For a discussion of the interpretive effects of the intensifier see chapter 9 .

\subsection{Only-contexts}

So-called only-contexts are the second interpretive diagnostic that helps to distinguish between a bound variable reading and a coreferential interpretation of a pronoun. The interpretation of (English) reflexive and non-reflexive pronouns in this context has been discussed in Horn (1969) and applied to English by Boeckx, Hornstein, and Nunes (2010:197) and Hicks (2009). The reasoning of this diagnostic is as follows. In the sentence in (273) the DP Muriel is modified by the focus particle only. Recall from section 4.1.1 that the interpretation of the focus particle only, within the framework of alternative semantics of Rooth $(1985,1992)$, can be explained in two steps illustrated again in (273b). First, the particle evokes alternatives for the phrase in its scope. In case of (273), it evokes alternative values for the DP Muriel. These alternatives are all paradigmatic substitutes for Muriel that are contextually given, such as Muriel's classmates: Peter, Paul, and Mary. Secondly, if the sentence containing the exclusive particle is true, then all the alternative propositions, such as Peter likes ice cream, are necessarily false. If Muriel is the only one who likes ice cream, then it is also true that none of the other kids like ice cream. Thus, the sentence with the focalised phrase entails that the negation of its alternative propositions is true. As the set of alternatives has to be exhaustive, it can be negated by the negative quantifier nobody else. 
(273) a.

Only Muriel likes ice cream.

b.

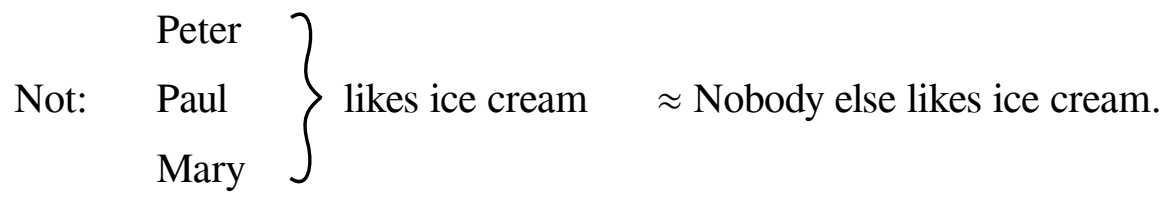

Now let us see how the interpretation of the focus particle only helps to determine the interpretation of a pronoun. In (274) the antecedent of the possessive pronoun, the DP Muriel, is modified by only. As discussed in Horn (1969), the sentence has two entailments: one in which the pronoun is bound, as in (274a), and another one in which the pronoun has a coreferential reading, as given in (274b). Horn (1969:102) accepts only the bound reading, but Boeckx, Hornstein, and Nunes (2010:197) accept both the bound and coreferential reading of the possessive pronoun.

$$
\text { Only Muriel voted for her brother. }
$$

(Horn 1969:98/99)
a.
Nobody else voted for his/her own brother.
bound reading
b.
Nobody else voted for Muriel's brother.
coreferential reading

In Hicks (2009) the tests are also applied to English reflexive pronouns. The diagnostic shows that a reflexive pronoun is only acceptable under the bound interpretation. In the following, the diagnostic is applied to Spanish and Portuguese reflexive and non-reflexive pronouns. In (275) and (276) the antecedent of the reflexive clitic and its double ${ }^{62}$ is in the scope of the focus particle solo and só, respectively. The reflexive pronoun is unambiguously interpreted as a bound variable in either language. The entailment with a coreferential reading of the reflexive pronouns in (275b) and (276b) is absolutely unacceptable.

Sp. $\quad$ Solo Juan se admira a sí mismo / ??-*él mismo.

only J. SE.REFL=admires OM REFL.PR SELF / himSELF

'Only Juan admires himself.'

a. $\quad$ Nobody else admires himself.

b. $\quad$ *Nobody else admires Juan.

(276) EP Só o João se admira a si próprio / ele próprio.

only the J. SE.REFL=admires OM REFL.PR SELF / him SELF

'Only João admires himself.'

a. Nobody else admires himself.

b. $\quad *$ Nobody else admires João.

62 The non-reflexive double of the reflexive pronoun was rejected by native speakers, possibly because two foci-an exclusion focus on the subject DP and a strong contrastive focus on the object DP-is impossible to process. 
As for non-reflexive clitics, this diagnostic can be applied if the clitic's antecedent, the modified DP, is non-local, as in (277) and (278). The antecedent of the clitic is the DP Juana and João, respectively. In both languages only the entailment with a coreferential reading of the pronoun was accepted and the bound reading was rejected all native speakers.

Sp. Solo Juana piensa que Pedro la admira.

only J. thinks that P. her.CL=admires

'Only Juana thinks that Pedro admires her.'

a. ??Nobody else thinks that Pedro admires him.

b. Nobody else thinks that Pedro admires her (= Juana).

(278) EP Só o João pensa que a Rita o admira.

only the J. thinks that the R. him.CL=admires

'Only João thinks that Rita admires him.'

a. ??Nobody else thinks that Rita admires him.

b. $\quad$ Nodbody else thinks that Rita admires him (=João).

The diagnostic shows that non-reflexive clitic pronouns allow only for a coreferential interpretation with a non-local antecedent. Again, the dative clitic is interpreted in the same way, and for the sake of brevity, no examples are represented here.

As for the dative prepositional constructions, the reflexive pronoun is interpreted exclusively as a bound variable. Interestingly, the non-reflexive pronoun with the intensifier shows the same interpretation. This is shown in (279) below.

EP Só a Maria ofereceu uma viagem a ela própria / si própria. only the M. gave a trip to her SELF / REFL.PR SELF 'Only Maria gave herself a trip.'

a. $\quad \rightarrow$ Nobody else gave himself a trip.

b. $\quad \rightarrow *$ Nobody else gave her (= Maria) a trip.

The intensifier shows the same effect as in VP-ellipsis contexts. It licenses a bound interpretation of a pronoun that would be otherwise interpreted as coreferential. In (280), the same sentence is tested without the intensifier.

(280) EP Só a Maria ofereceu uma viagem a ela.

only the M. gave a trip to her

'Only Maria gave her a trip.'

a. $\quad \rightarrow$ ? Nobody else gave himself a trip.

b. $\quad \rightarrow$ Nobody else gave her (= Maria) a trip. 
In this case, the entailment with the coreferential interpretation is clearly the preferred option. As for the bound reading, the judgements were not clear: some speakers rejected the interpretation as a first reaction, but then wondered whether it might be actually possible.

\subsection{Summary and evaluation of the results}

In Spanish and in European Portuguese, the diagnostic for complementary distribution was positive only for clitic pronouns, but not for strong pronouns as a double of a clitic or in DPCs. The table in (281) summarises the results for the clitic pronouns in Spanish and European Portuguese.

(281) Referential properties of reflexive and non-reflexive clitics

\begin{tabular}{|c|c|c|c|}
\hline \multirow{2}{*}{ Diagnostics } & \multicolumn{3}{|c|}{ Clitics } \\
\hline & reflexive & DO & IO \\
\hline \multicolumn{4}{|l|}{ (i) Internal Antecedent } \\
\hline a. local and c-commanding & $\checkmark$ & $*$ & $*$ \\
\hline b. local and non-c-commanding & $*$ & $\checkmark$ & $\checkmark$ \\
\hline c. non-local & $*$ & $\checkmark$ & $\checkmark$ \\
\hline (ii) External Antecedent & $*$ & $\checkmark$ & $\checkmark$ \\
\hline \multicolumn{4}{|l|}{ (iii) Quantifier binding } \\
\hline a. local and c-commanding & $\checkmark$ & $*$ & $*$ \\
\hline b. non-local and commanding & $*$ & $\checkmark$ & $\checkmark$ \\
\hline \multicolumn{4}{|l|}{ (iv) VP-ellipsis } \\
\hline a. local and c-commanding & sloppy & - & - \\
\hline b. local and non-commanding & - & strict & strict \\
\hline c. non-local and commanding & - & \multicolumn{2}{|c|}{ sloppy and strict } \\
\hline \multicolumn{4}{|l|}{ (v) Only-contexts } \\
\hline a. local and c-commanding & bound & - & - \\
\hline b. local and non-commanding & - & coreferential & coreferential \\
\hline
\end{tabular}

The reflexive clitic needs a local, c-commanding antecedent; it cannot refer to a sentence-external antecedent by means of pragmatic coreference, and it is obligatorily interpreted as a bound variable. The non-reflexive direct and indirect object clitic share all properties. They cannot take a local c-commanding antecedent, but they can take a local non-c-commanding antecedent. In this configuration they are not bound, but interpreted by means of coreference, as shown by the interpretive dianostics VP-ellipsis and only-contexts. If they have a non-local but c-commanding antecedent, they may also be interpret- 
ed as bound variables, as indicated by the results of the diagnostics VP-ellipsis and quantifier binding. Furthermore, they can refer to a sentence-external antecedent by means of pragmatic coreference.

Thus, the reflexive clitic and the non-reflexive clitic are in strict complementary distribution and can be classified as anaphors and pronominals in the sense of classic Binding Theory. Under Minimalist assumptions, the reflexive clitic fulfils all requirements for a syntactic derivation of its obligatory locally bound interpretation. Furthermore, the same mechanism should account for the fact that the nonreflexive clitic disallows a bound interpretation in the same configuration. The interpretation of the non-reflexive clitic itself is a matter not of syntax, but of semantic binding or pragmatic coreference. The important results of this chapter are the following. It has been shown that the strong pronouns (reflexive and non-reflexive) as a double of a reflexive clitic are not in complementary distribution in either language. Furthermore, it has been shown that the (bare) reflexive pronoun can double a non-reflexive clitic, of course under the right conditions, and can therefore be non-locally bound. Thus, strong object pronouns in Spanish and European Portuguese are incompatible with classic Binding Theory. The table in (282) below summarises the results of the structural and interpretive diagnostics of each clitic-double combination.

(282) Referential properties of the reflexive and non-reflexive clitic-double combinations

\begin{tabular}{|c|c|c|c|c|c|c|}
\hline \multirow{3}{*}{ Diagnostic } & \multicolumn{3}{|c|}{ sí (mismo) / si (próprio) } & \multicolumn{3}{|c|}{ él (mismo) / ele (próprio) } \\
\hline & \multicolumn{3}{|c|}{+} & \multicolumn{3}{|c|}{+} \\
\hline & SE.CL & DO.CL & IO.CL & SE.CL & DO.CL & IO.CL \\
\hline \multicolumn{7}{|l|}{ (i) Internal Antecedent } \\
\hline a. local and c-commanding (SU) & $\checkmark$ & \multicolumn{2}{|c|}{$*$} & $\checkmark$ & \multicolumn{2}{|c|}{$*$} \\
\hline b. local and c-commanding (DO) & $*$ & $*$ & $\begin{array}{l}\text { EP:*, } \\
\text { Sp.:\% }\end{array}$ & - & - & - \\
\hline c. local and non-c-commanding & $*$ & $*$ & - & $*$ & \multicolumn{2}{|c|}{$\checkmark$} \\
\hline d. non-local & $*$ & $\begin{array}{l}\text { EP: } \checkmark \\
\text { Sp.:* }\end{array}$ & $\begin{array}{l}\text { EP: } \sqrt{ } \\
\text { Sp.: } \checkmark\end{array}$ & $*$ & \multicolumn{2}{|c|}{$\checkmark$} \\
\hline (ii) External Antecedent & $*$ & \multicolumn{2}{|c|}{$*$} & $\checkmark$ & \multicolumn{2}{|c|}{$\checkmark$} \\
\hline \multicolumn{7}{|l|}{ (iii) Quantifier binding } \\
\hline a. local and c-commanding & $\checkmark$ & - & - & $*$ & - & - \\
\hline b. non-local and c-commanding & - & \multicolumn{2}{|c|}{$\mathrm{EP}: \boldsymbol{} \boldsymbol{S \mathrm { Sp }} .{ }^{*}$} & - & \multicolumn{2}{|c|}{$\%$} \\
\hline \multicolumn{7}{|l|}{ (iv) VP-ellipsis } \\
\hline a. local and c-commanding & sloppy & - & - & sloppy & - & - \\
\hline b. local and non-c-commanding & - & - & - & - & \multicolumn{2}{|c|}{ strict } \\
\hline c. non-local and c-commanding & - & - & - & - & \multicolumn{2}{|c|}{ sloppy and strict } \\
\hline
\end{tabular}




\begin{tabular}{|c|c|c|c|c|c|c|}
\hline \multirow{3}{*}{ Diagnostic } & \multicolumn{3}{|c|}{ sí (mismo) / si (próprio) } & \multicolumn{3}{|c|}{ él (mismo) / ele (próprio) } \\
\hline & & + & & & + & \\
\hline & SE.CL & DO.CL & IO.CL & SE.CL & DO.CL & IO.CL \\
\hline \multicolumn{7}{|l|}{ (v) Only-contexts } \\
\hline a. local and c-commanding & bound & - & - & $\begin{array}{l}\text { bound } \\
\text { (EP: } \checkmark \\
\text { Sp.?*) }\end{array}$ & - & - \\
\hline b. local and non-c-commanding & - & - & - & - & core & ential \\
\hline
\end{tabular}

Although both types of strong pronouns can double a reflexive clitic, only the reflexive strong pronoun is interpreted as a true bound variable. Even if the diagnostics VP-ellipsis and only-contexts indicated that the non-reflexive pronoun can have a sloppy/bound interpretation, the diagnostic for quantifier binding clearly showed that the non-reflexive strong pronoun resists a true bound variable interpretation for the following reasons: first, the non-reflexive double is unacceptable with a reflexive clitic and a QP antecedent, and secondly, the acceptability of the non-reflexive pronoun depends on the type of quantifier and whether it contains referential material or not. These findings will be supported by the results for the non-reflexive and reflexive pronouns in non-doubling contexts such as PP-complements or locative PPs in chapter 8. For pronouns in DPCs, it has been shown in the present chapter that the interpretation of the non-reflexive pronoun crucially depends on the presence of the intensifier, which will be discussed in chapter 9 .

These results will lead us to conclude that the domain for a syntactic encoding of an anaphoric dependency is the domain in which the clitic and the subject are in a local configuration. Thus, the syntax of cliticisation and the derivation of clitic doubling will define the domain and the mechanism for a syntactic encoding of this anaphoric dependency in Spanish and European Portuguese. The domain will be shown to be the $\mathrm{vP}$, and the mechanism will be the operation Agree.

Furthermore, the interpretation of the pronominal double depends crucially on the interpretation of the clitic, but the clitic cannot impose a bound interpretation on a non-reflexive double. Thus, the lexical properties of the strong pronouns-its phi-feature content and its internal structure-crucially affect the ability of being a bound variable or being a referential item. 



\section{Referential deficiency and structural deficiency}

The notion of (structural) deficiency was elaborated in Cardinaletti \& Starke (1999) for pronouns in Romance languages. Clitic pronouns are deficient as compared to strong pronouns because they lack properties such as case or the ability to bear word stress. As these properties are expressed by means of syntactic projections, clitics are structurally deficient as compared to strong pronouns because they lack these projections. The notion deficiency in relation to anaphoricity has been explored in Reinhart \& Reuland (1991, 1993), Reuland (2011), and Marelj \& Reuland (2016) in the following way: reflexive pronouns (anaphors) are referentially deficient with respect to non-reflexive pronouns (pronominals) because they are incapable of independent reference.

This chapter aims at formalising referential deficiency—the distinction between reflexive and non-reflexive pronouns-in terms of phi-feature values and at formalising of the differences between clitic and strong pronouns in terms of syntactic structure following the line of research of Cardinaletti \& Starke (1999), Déchaine \& Wiltschko (2002, 2003, 2017), and Roberts (2010). The internal syntactic structure of strong and clitic pronouns and the feature composition of reflexive and non-reflexive pronouns elaborated in this chapter will play a crucial role in the derivations discussed in the chapters 7 and 9.

In the first part of this chapter, it will be argued that the referential deficiency of reflexive clitics and reflexive strong pronouns is related to an underspecification with respect to phi-feature values along the following lines: if the a feature distinction is not morphologically marked and it does not trigger a semantic constraint on the antecedent, this feature has a null-value. The null-value is motivated in section 6.1.2. Section 6.1.3 introduces the effects of agreement with a null feature value.

The second part of this chapter is devoted to the internal syntactic structure of strong and clitic pronouns. The discussion is guided by the interpretative effects associated with clitic doubling structures, such as definiteness, specificity, and animacy. It will be shown that there is no need to express properties like definiteness and specificity either by means of features or by means of syntactic projections. The internal structure for clitic and strong pronouns is proposed at the end of section 6.2.2.

Section 6.3 briefly introduces the basic syntactic aspects of the elements mismo and mesmol próprio, in particular their category, their position, and agreement with the strong pronoun. Section 6.4 gives a summary of this chapter.

\subsection{Referential deficiency and phi-features}

Within the probe-goal framework of Chomsky (2000 et seqq.) - the framework adopted for this analysis-phi-features are defined as attribute-value pairs and may be either interpretable or uninterpretable. Interpretable features enter the derivation valued, whereas uninterpretable features are unvalued. The former act as goals, and the latter act as probes that search for a matching goal in order to get their phi-features valued. Furthermore, the set of phi-features of a given lexical item may be complete or incomplete, as discussed in Chomsky $(2001,2004)$. 
For the interpretable features on nouns and pronouns Zwart (1997:170) introduces the distinction between intrinsic and variable features. Intrinsic features are, for example, the gender feature of common nouns, such as the Spanish and European Portuguese noun mesa.FEM 'table', because the value of the gender feature is fixed to feminine in the lexicon. An intrinsic gender feature does not express the property of a noun's referent; it is purely grammatical. Variable features are, for example, the number feature of common nouns or pronouns because the value is not fixed, but determined by the utterance situation. Note that a gender feature can be a variable feature too, if the noun refers to humans, as for example the European Portuguese nouns cantador/cantadora, which refer to a male and a female singer, respectively.

Despite the difference between intrinsic and variable features, both types of features are taken to be valued before the lexical item enters the derivation (see Mensching \& Weingart 2016, following Zwart 1997). As for pronouns, it is commonly assumed that they have a complete set of variable phifeatures. If all pronouns-reflexive and non-reflexive-enter the derivation with a full set of valued and interpretable phi-features, then the feature set [3p, fem, sg] would correspond to five pronominal forms, as illustrated in (283).

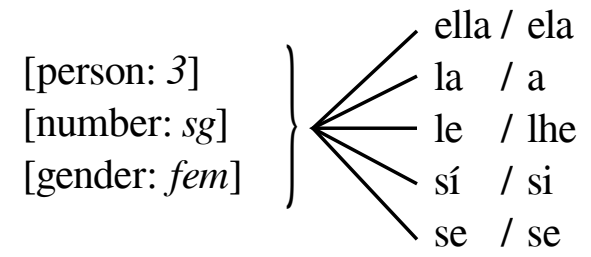

Given that the reflexive and non-reflexive pronouns both have a full set of interpretable and valued phifeatures, the different referential properties have to be encoded by means of an additional descriptive feature such as [+/-anaphoric] and [+/-pronominal] in Chomsky (1981 et seqq.), [+/-referential] in Reinhart \& Reuland (1991, 1993), [+/- coreference] in Zwart (2002) or a [var]-feature in Hicks (2009). This is a comprehensible step for English because English reflexive pronouns differ from non-reflexive pronouns only with respect to the self-suffix, but not with respect to the pronominal form.

As Spanish and European Portuguese have distinct forms for reflexive and non-reflexive pronouns, this analysis aims at deriving their interpretation from their specification with phi-features. This aim corresponds to the research programme of Reinhart \& Reuland (1991, 1993) and Reuland (2001, 2005, 2011), introduced in section 1.1. But differently from Reuland (2011), Marelj \& Reuland (2016), and also Schäfer (2007), who formalise the property of being an anaphor in terms of unvalued phifeatures, it will be argued that the referential defectiveness of reflexive pronouns is related to an unspecific feature value that reflects the interdependency between the absence of morphological marking of a feature distinction and the absence of a semantic contribution of that unmarked feature. This interdependency will be expressed by means of a null feature value. 


\subsubsection{Phi-features and phi-feature values}

Before motivating the null feature value, I will discuss the following two possibilities to lexically encode the difference between reflexive and non-reflexive pronouns in terms of phi-features:

(i) The reflexive pronoun lacks a feature that is present on the non-reflexive pronoun (see Menuzzi 1996).

(ii) The reflexive pronoun lacks a feature value that is present on the non-reflexive pronoun (see Reuland 2011, Marelj \& Reuland 2016, Schäfer 2007).

It will be shown that both possibilities are emprically inadequate for the analysis of Spanish and European Portuguese. On the basis of this discussion, I will argue that the referential defectiveness of reflexive pronouns is expressed by a null feature value. Thus, the reflexive pronoun lacks a specific feature value that is present on the non-reflexive pronoun.

As for the first possibility, let us start with the form of third person reflexive and non-reflexive pronouns. The pronominal paradigm presented in chapter 2 is repeated here in (284) for the third person pronouns. The non-reflexive pronouns have a form for each feature combination, a cell in the table in (284). The reflexive pronouns have only one form, and they mark a person distinction. Thus, it could be assumed that the reflexive pronouns only have a person feature and lack the features for number and gender.

(284) European Portuguese and Spanish third person pronouns

\begin{tabular}{|c|c|c|c|c|c|c|}
\hline \multirow{2}{*}{$\begin{array}{l}\text { third } \\
\text { person }\end{array}$} & \multicolumn{3}{|c|}{ non-reflexive pronoun } & \multicolumn{3}{|c|}{ reflexive pronoun } \\
\hline & strong & clitic (IO) & clitic (DO) & strong & clitic (IO) & clitic (DO) \\
\hline$[\mathrm{sg}, \mathrm{fem}]$ & ella / ela & le / lhe & la / a & sí / si & $\mathrm{se} / \mathrm{se}$ & $\mathrm{se} / \mathrm{se}$ \\
\hline$[\mathrm{sg}$, masc $]$ & él / ele & le / lhe & lo /o & sí / si & $\mathrm{se} / \mathrm{se}$ & $\mathrm{se} / \mathrm{se}$ \\
\hline$[\mathrm{pl}, \mathrm{fem}]$ & ellas / elas & les / lhes & las / as & sí / si & $\mathrm{se} / \mathrm{se}$ & $\mathrm{se} / \mathrm{se}$ \\
\hline$[\mathrm{pl}, \mathrm{masc}]$ & ellos / eles & les / lhes & los /os & sí / si & $\mathrm{se} / \mathrm{se}$ & $\mathrm{se} / \mathrm{se}$ \\
\hline
\end{tabular}

But under Minimalist assumptions, the morphological form of a pronoun is not directly related to its phi-feature content. This means that the reflexive pronoun has, despite the reduced paradigm, a full set of phi-features. Each feature combination is realised by a morphophonological item, as assumed in morphological theories, such as Distributed Morphology (see Halle \& Marantz 1993, 1994). The non-reflexive strong pronoun and the accusative clitic have an item for each cell, but the dative clitic only realises the number distinction and is underspecified for gender. The reflexive pronouns have a distinction just for person and are underspecified for all feature combinations of gender and number. The syncretic forms of the third person reflexive pronouns are not the result of missing features in syntax, but due to a morphological process that assigns a morphophonological realisation to a certain 
feature combination (see Harley 2008). This Minimalist conception of phi-features on pronouns is supported by the agreement between the strong pronoun and the intensifier. Under the assumption that the syncretic form and the anaphoric properties were the result of missing phi-features for number and gender, the agreement pattern in (285) would remain a mystery. The intensifiers show adjective-like agreement in gender and number with the strong pronouns.

(285) a. Sp. Juan solo piensa en él mismo / sí mismo.

J. only thinks in him SELF / REFL.PR SELF

b. EP O Paulo só pensa nele próprio/ em si próprio.

theP. only thinks in.him SELF / in REFL.PR SELF

In order to derive this agreement pattern, there must be an Agree relation between the intensifer and the strong pronoun. In section 6.3, this relation will be discussed in more detail, but for the time being it is sufficient to state that the intensifier has unvalued features that probe and get their values from the pronoun's valued features. Agreement with the non-reflexive pronoun and the reflexive pronoun is represented schematically in (286). In the case of the non-reflexive pronoun, shown in (286a), valuation of the intensifier's features is straightforward. But Agree is impossible if the reflexive pronoun lacks features for number and gender, as shown in (286b), because the probe would not find a matching goal.

(286) a.

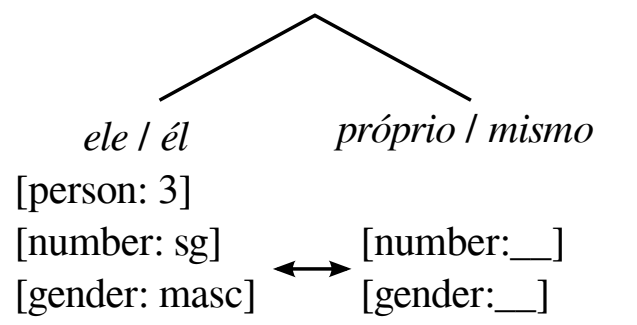

b.

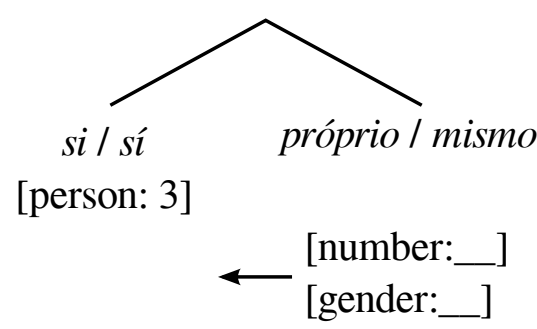

Thus, the absence of morphological marking of a feature distinction cannot mean that this feature is missing in the underlying structure and so this possibility can be dismissed.

As for the second possibility, Reuland (2011) and Marelj \& Reuland (2016) argue that the obligatory bound reading of (simplex) anaphors and reflexive clitics is due to a 'referential' underspecification in terms of underspecification of feature values. Reuland (2011) does not directly relate morphological underspecification/syncretism and referential defectiveness, but rather argues that the property of being obligatorily bound by a local and c-commanding antecedent is expressed by the lack of feature values. Recall from chapter 4.3.2 that Reuland (2011) and Marelj \& Reuland (2016) adopt the account of Pesetsky \& Torrego (2004), who propose that interpretable features as well as uninterpretable features may come valued or unvalued and consequently act as probes. For simplex anaphors and reflexive clitics, Reuland (2011) and Marelj \& Reuland (2016) assume that these enter the derivation with a valued person feature, but with unvalued number and gender features. The unvalued features trigger Agree with the pronoun's antecedent. Due to this agreement relation, the referential identity between the pronoun and the antecedent is generated in syntax. As mentioned in chapter 4.3.2, their proposal is 
problematic for Spanish and European Portuguese clitic doubling structures because the reflexive clitic can be doubled with a non-reflexive pronoun. Clitic doubling structures involve a bigDP analysis, as will be discussed in more detail in the next chapter. In order to build a bigDP, the clitic merges with its double, as shown in a simplified way in (287).

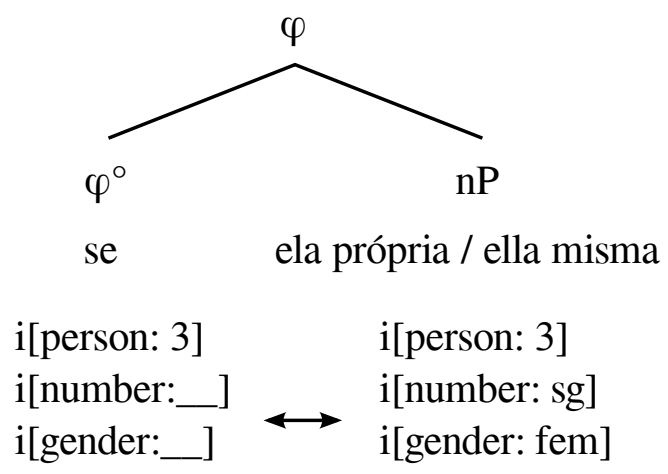

Under the analysis of Reuland (2011) and Marelj \& Reuland (2016), the unvalued features of the reflexive clitic would probe immediately and find the strong pronominal double as a matching goal. Agree takes place and the reflexive clitic has now a full set of valued features. As a consequence, the reflexive clitic loses its anaphoric properties and the ability to agree with its antecedent. For this reason, their account is not applicable to Spanish and European Portuguese and will not be pursued any further. In the next section it will be argued that the referential defectiveness of reflexive pronouns is expressed by a null feature value.

\subsubsection{On null feature values}

In this section, I will motivate a null-value for interpretable phi-features as expression of the anaphoric properties of reflexive pronouns. From a Minimalist point of view, morphological marking of a phifeature distinction on pronouns is not relevant for the syntactic expression of these phi-features. As we have seen above, all pronouns have a full set of phi-features, and the absence of morphological marking of a feature should not be expressed in terms of missing features or missing feature values (unvalued features).

But morphological marking of a distinction is relevant for the interpretation of a pronoun. For example, the form ela/ella can only take a female, singular antecedent, whereas the dative clitic lhe/le can take a masculine and feminine antecedent due to the missing gender distinction. The morphological marking of a distinction is relevant for the interpretation of a pronoun because it allows this feature to be semantically contentful. Semantically contentful phi-features are analysed as presupposition (see Heim 2008, Sauerland 2003, 2008, 2013, Spathas 2009, Jacobson 2012, Bassi \& Longenbaugh 2017). A phifeature introduces a presupposition; or more precisely, a phi-feature value introduces a presupposition that acts as a condition or constrain on the possible antecedents/referents of a pronoun.

As already mentioned in chapter 4 , the phi-features on bound and free pronouns are taken to introduce a presupposition (see Sauerland 2003, 2008, 2013, Spathas 2009, Jacobson 2012, Bassi \& 
Longenbaugh 2017). ${ }^{63}$ In (288), the presuppositional meaning of the phi-features under discussion is given as an identity function (see Heim 2008). The value of the person feature presupposes an entity that is neither the speaker (s) nor the hearer (h) in the utterance context (c). The values of the number feature presuppose that the referent is an atomic or a non-atomic entity. The values of the gender feature presuppose that the discourse value of the referent is a female or male entity. ${ }^{64}$

\begin{tabular}{|c|c|c|}
\hline \multirow{2}{*}{$\begin{array}{r}\text { (288) a. } \\
\text { b. }\end{array}$} & person: & $\llbracket 3 r d \rrbracket^{c}=\lambda x_{e}: x$ excludes $s_{c}$ and $h_{c} \cdot x$ \\
\hline & number: & $\llbracket$ singular $\rrbracket=\lambda \mathrm{x}_{\mathrm{e}}: \mathrm{x}$ is an atom. $\mathrm{x}$ \\
\hline & & $\llbracket$ plural $\rrbracket=\lambda \mathrm{x}_{\mathrm{e}}: \mathrm{x}$ is a plurality. $\mathrm{x}$ \\
\hline c. & gender: & $\llbracket$ feminine $\rrbracket=\lambda \mathrm{x}_{\mathrm{e}}: \mathrm{x}$ is female $\mathrm{x}$ \\
\hline & & $\llbracket$ masculine $\rrbracket=\lambda \mathrm{x}_{\mathrm{e}}: \mathrm{x}$ is male. $\mathrm{x}$ \\
\hline
\end{tabular}

(Heim 2008: 36/37)

The formal implementation of presuppositions and their computation are not relevant here, but note that the semantic computation proceeds bottom-up, and it is therefore the antecedent or referent that must satisfy the presupposition introduced by a pronoun. For example, the reflexive pronoun in (289) is morphologically marked as third person, singular, masculine. These features presuppose that the antecedent of the pronoun is a male individual that is not a discourse participant. If all these conditions were satisfied by the referent of the name Lisa, the sentence would be perfectly acceptable. The deviance of the sentence is due to the fact that Lisa is commonly used for females and that this mismatch in gender values causes a presupposition failure.

\#Lisa invited himself.

The important point here is, that the semantic contribution of a feature value depends on the morphologically marking of a feature distinction.

In the following, I will argue that the absence of morphological marking together with the absence of a semantic restriction can be formalised syntactically as an unspecified value, which I will term a null-value. In my analysis, the null feature values will be responsible for the anaphoric properties of

63 Within the minimal pronoun approach proposed in Heim (2008), Kratzer (1998, 2009), and von Stechow (2003), only free pronouns have phi-features that introduce a presupposition. Bound pronouns (reflexive or non-reflexive) do not have semantically active phi-features. Depending on the analysis, bound pronouns are taken to be base-generated with an empty or incomplete set of phi-features. The missing features are added by means of a process, such as Feature Transmission, shown in the version of Heim (2008) in (i) and in the version of Kratzer (2009) in (ii). The fact that bound pronouns agree with their antecedent is a reflex of feature transmission.

(i) Feature transmission under variable binding:

(Heim 2008:50)

In the derivation of PF, all features of a DP must be copied onto all variables that it binds.

(ii) Feature Transmission under Binding:

(Kratzer 2009:195)

The $\Phi$-feature set of a bound DP unifies with the $\Phi$-feature set of the verbal functional head that hosts its binder.

64 The neuter value is not considered here because it is not relevant for pronouns denoting an animate entitiy. 
reflexive pronouns and clitics and crucially for a syntactic encoding of referential identity. The term 'null' has been chosen in order to avoid confusion with unvalued features and with other approaches. ${ }^{65}$ The idea of a null-value is based on the following considerations.

Let us look first at the straightforward cases of morphological marking: the non-reflexive strong pronouns. The forms are represented in the tables in (290a)-(290d). The entries for each pronominal form are organised as follows. The first row of each table shows the syntactic phi-features and their values. The second row shows a (possible) decomposition of the pronoun into items that correspond to a morphological realisation of a phi-feature value. The last row shows whether the morphological marking of a feature value is associated with a presupposition, a semantic condition on the antecedent or referent.

(290) a. ELLAS / ELAS

\begin{tabular}{lcc|c}
\hline Phi-features & i[ Person: 3] & i[ Gender: fem] & i[ Number: pl] \\
\hline Morph. marking & ell- / el- & -a- & -s \\
\hline Condition on antecedent & -speaker. -hearer & female & plural
\end{tabular}

b. ELLOS / ELES

\begin{tabular}{l|cc|c}
\hline Phi-features & i[ Person: 3] & i[ Gender: masc] & i[ Number: pl] \\
\hline Morph. marking & ell- & $-0-$ & $-s$ \\
\hline Sem. condition & -speaker, -hearer & at least one male & plural
\end{tabular}

c. ELLA / ELA

\begin{tabular}{l|cc|c}
\hline Phi-features & i[ Person: 3] & i[ Gender: fem] & i[ Number: sg] \\
\hline Morph. marking & ell- /el- & $-\mathrm{a}$ & $-\varnothing$ \\
\hline Sem. condition & -speaker, -hearer & female & singular
\end{tabular}

d. ÉL / ELE

\begin{tabular}{l|cc|c}
\hline Phi-features & i[ Person: 3] & i[ Gender: masc] & i[ Number: sg] \\
\hline Morph. marking & el- & $-\varnothing-/-\mathrm{e}$ & $-\varnothing$ \\
\hline Sem. condition & -speaker, -hearer & male & singular
\end{tabular}

65 For example, Roberts (2010) assumes that the third person value may be unspecified because it is unmarked in the sense of Harley \& Ritter (2002). In Harley \& Ritter's (2002) feature geometry, only first person and second person exist as feature values of a participant feature, but not third person. In Roberts (2010), this unspecified value is similar to an unvalued feature, but it does not need to be valued by Agree; rather it is specified postsyntactically. A similar proposal is put forward in Kučerová (2018) for variable, context-dependent features on nouns, in particular for gender features. The variable gender feature enters the derivation as an unvalued feature, and the process of valuation is conceived as a postsyntactic process that has access to context information.

66 In the plural, the masculine gender value is semantically unmarked in the sense that the group of people denoted by the pronoun does not consist exclusively of male individuals, whereas the feminine plural excludes male individuals from the group. 
In Spanish and European Portuguese, plural is marked by /s/ and singular has no overt realisation, the latter being represented by a $\varnothing$-realisation. The $\varnothing$-realisation receives a singular interpretation because the distinction between singular and plural is marked. In Spanish, the same is true for gender marking in the singular forms. Feminine is marked by /a/, and the $\varnothing$-marking on the singular form él can be interpreted as masculine. In the European Portuguese forms, as well as in the Spanish plural forms, each gender value is morphologically marked. The important point here is that the $\varnothing$-realisation of a feature value is only associated with a condition on an antecedent, if the other values have an overt morphological realisation.

The table in (291) shows the forms of the dative clitic. For accusative clitics, the results are equal to the non-reflexive strong pronouns above. For this reason they are not repeated here. The dative clitic is morphologically underspecified for gender; the distinction between feminine and masculine is not morphologically marked. This absence of morphological marking has the effect that no semantic condition on the antecedent is introduced. Even if one assumed that the item /e/ realises both valuesfeminine and masculine - this is equal to a $\varnothing$-realisation because no distinction is introduced. Thus, the absence of morphological marking coincides with the absence of a semantic restriction on the antecedent. This combination makes up a null feature value. A null-value on an interpretable phi-feature does not need to be valued or to be deleted at the syntax-semantics interface because it is an instruction that the phi-feature does not introduce a presuppostion.

\section{(291) a. LES / LHES}

\begin{tabular}{lcc|c}
\hline Phi-features & i[ Person: 3] & i[ Gender: fem /masc] & i[ Number: pl] \\
\hline Morph. marking & le- / lhe- & $-\varnothing-$ & -s \\
\hline Sem. condition & -speaker, -hearer & $\varnothing$ & plural
\end{tabular}

b. LE / LHE

\begin{tabular}{lcc|c}
\hline Phi-features & i[ Person: 3] & i[ Gender: fem /masc] & i[ Number: pl] \\
\hline Morph. marking & le- / lhe- & $-\varnothing-$ & $-\varnothing$ \\
\hline Sem. condition & -speaker, -hearer & $\varnothing$ & singular
\end{tabular}

As for the reflexive clitic in Spanish and European Portuguese, it does not mark a distinction for gender and number values, and no restrictions on the antecedent are introduced. As shown in (292) by means of an European Portuguese example, the antecedent of the reflexive clitic may be feminine or masculine, singular or plural.

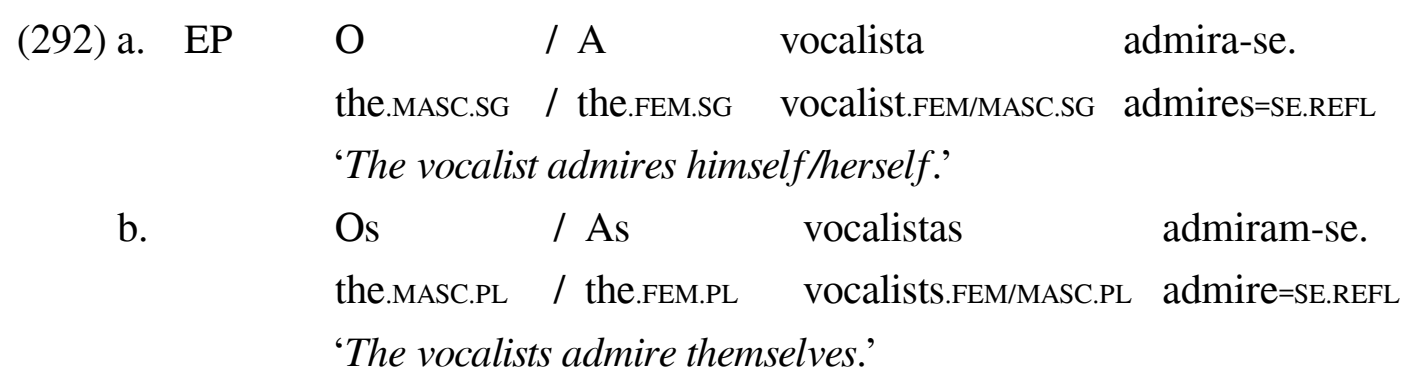


The lack of morphological marking and the lack of a semantic restriction for gender and number is shown in (293). I will assume that this fact is expressed by means of a null-value for gender and number on the reflexive clitics in Spanish and European Portuguese.

SE (Sp./EP), SÍ (Sp.)

\begin{tabular}{lcc|c}
\hline Phi-features & i[ Person: 3] & i[ Gender: fem /masc] & i[ Number: sg/pl] \\
\hline Morph. marking & se- / se- & $-\varnothing-$ & $-\varnothing$ \\
\hline Sem. condition & -speaker, -hearer & $\varnothing$ & $\varnothing$
\end{tabular}

As for the strong reflexive pronoun, Spanish and European Portuguese are distinct, as already mentioned in section 5.2.3 on the doubling of a long-distance reflexive. In Spanish, the bare strong reflexive pronoun is similar to the reflexive clitic. It can take a singular or plural antecedent, which can be either a feminine or masculine antecedent. This is shown by means of the examples in (294).

(294) a. Sp. Ella $a_{\mathrm{i}} \quad / \mathrm{É}_{\mathrm{i}} \quad$ siempre habla de sí $i_{\mathrm{i}}$.

(Otero 1999:1443)

she.3P.FEM.SG / he.3P.MASC.SG always talks of REFL.PR

'She/He always talks about herself/him-

self.'

b. $\quad$ Ellas $_{\mathrm{i}} \quad /$ Ellos $_{\mathrm{i}}$ siempre hablan de $\mathrm{si}_{\mathrm{i}}$.

(ibid.)

they.3P.FEM.PL / they.3P.MASC.PIalways talks of REFL.PR

'They always talk about themselves.'

The reflexive strong pronoun in Spanish has a null-value for gender and number, just like the reflexive clitic.

As for the strong reflexive pronoun in European Portuguese, the examples in (295)-(297) suggest that it is different with respect to the specification for number. The bare reflexive was accepted only with a singular antecedent. This fact is independent of its syntactic position and the type of antecedent. In (295), it is the double of a direct object; In (296), it is inside a PP-complement, and in (297), it is inside a PP-adjunct. Note that in (297) the plural antecedent is quantified, but nevertheless unacceptable.

(295) a. EP Ele admira-se a si.

he.3P.MASC.SG admire=SE.REFL OM REFL.PR

'He admires himself.'

b. *Eles admiram-se a si.

they.3P.MASC.PL admire=SE.REFL OM REFL.PR

'They admire themselves.'

(296) a. EP Ele $_{\mathrm{i}}$ só pensa em si.

he.3P.MASC.SG only thinks in REFL.PR

'He only thinks about himself.' 
b.
*Eles ${ }_{\mathrm{i}}$
só pensam em $\mathrm{si}_{\mathrm{i}}$.

they.3P.MASC.PL only think in REFL.PR

'They only think about themselves.'

(297) a. EP
Cada um
trabalha por $\mathrm{si}_{\mathrm{i}}$.
everyone.3P.MASC.SG works.3P.SG for REFL.PR
'Everyone works for himself.'

b.

*Todos $_{\mathrm{i}} \quad$ trabalham por $\mathrm{si}_{\mathrm{i}}$.
everybody.3P.MASC.PL work.3P.PL for $\mathrm{REFL.PR}$
'Everybody works for himself.'

But this restriction is not a general property of the bare reflexive pronoun because in the sentences in (298), the bare reflexive pronoun allows for a plural antecedent. ${ }^{67}$ As for (298a), it could be argued that the meaning of the preposition entre, 'between', facilitates a reciprocal interpretation in which the antecedent is not a plurality, but the single individuals that alternate between the agent role and the beneficiary role of the action of sharing out. But this argument certainly cannot be applied to (298b). In this example, the antecedent may well be a proper plurality.

(298) a. EP Os herdeiros ${ }_{i}$ que pro $_{\mathrm{i}}$ hajam já partilhado entre $\mathrm{si}_{\mathrm{i}} \mathrm{a}$ the heirs.3P.PL that pro.3P.PLhave.3P.PL already shared-out between REFL.PR the herança [...]. inheritance [...].

'The heirs that already have shared out the inheritance between them....'

b. [...] porque os agricultores $\mathrm{i}_{\mathrm{i}}$ que pro $_{\mathrm{i}}$ adquiriam para $\mathrm{si}_{\mathrm{i}}$ aquelas [...] because the farmers.3P.PL that pro.3P.PLbought.3P.PL for REFL.PR these máquinas [...]. machines [...].

'.. because the farmers that bought these machines for themselves...'

67 The context of the phrases in (298) is given in (i) and (ii)

(i) EP Os herdeiros que hajam já partilhado entre si a herança respondem pelas dívidas do falecido na medida da quota que herdaram e nada mais. (CRCP: Reader's Digest. 1996. 'Guia Prático Da Lei'.)

'The heirs that already have shared out the inheritance are accountable for the debt of the deceased according to the percentage of their share and nothing more.'

(ii) Há presentemente reclamações de industriais que trabalham com debulhadoras e enfardadeiras, porque os agricultores que adquiriram para si aquelas máquinas passaram a fazer o serviço de debulha de cereais e de enfardamento a outros agricultores da sua região, provocando assim uma concorrência ilegal e desregrada com os respectivos industriais. (CRPC: A22460.)

'There are at the moment complaints from businessmen that work with harvesters and hay balers because the farmers that bought these machines for themselves started to offer the service of threshing cereals and compressing raked crop to other farmers in the region, thereby starting an illegal and disordered competition with the aforementioned businessmen..' 
Furthermore, a plural antecedent becomes perfectly acceptable in the sentences in (295b)-(297b) above when the intensifier is present. This is shown in (299).

\begin{tabular}{|c|c|}
\hline (299) a. EP & $\begin{array}{l}\text { Eles admiram-se a si próprios. } \\
\text { they.3P.MASC.PL admire=SE.REFL OM REFL.PR SELF.MASC.PL } \\
\text { 'They adimre themselves.' }\end{array}$ \\
\hline b. & $\begin{array}{l}\text { Eles }_{\mathrm{i}} \text { só pensam em } \mathrm{si}_{\mathrm{i}} \text { próprios. } \\
\text { they.3P.MASC.PL only think in REFL.PR SELF.3P.MASC.PL } \\
\text { 'They only think about themselves.' }\end{array}$ \\
\hline c. & $\begin{array}{lllll}\text { Todos }_{i} & \text { trabalham } & \text { por } & \mathrm{si}_{\mathrm{i}} & \text { próprios. } \\
\text { everybody.3P.MASC.PL } & \text { work } & \text { for } & \text { REFL.PR } & \text { SELF.3P.MASC.PL } \\
\text { 'Everybody works for himself.' } & & & \end{array}$ \\
\hline
\end{tabular}

In the sentences in (298) and (299), the specification of the number feature allows for a singular and plural antecedent, but in (295)-(297) only the singular antecedent is accepted. How to account for this pattern? I want to propose that the restriction to a singular antecedent is the consequence of what Rezac (2011) terms a syntax-interpretation mismatch. The term describes a phenomena in which the phi-features of a noun or pronoun that are involved in syntactic processes, such as agreement, differ from those that correspond to its interpretation. For example, the European Portuguese pronoun a gente in (300a) can trigger either $\left[3^{\mathrm{rd}}, \mathrm{sg}\right]$ or $\left[1^{\mathrm{st}}, \mathrm{pl}\right]$ agreement on the verb, but it is always interpreted as $\left[1^{\text {st }}, \mathrm{pl}\right]$ (see Costa \& Pereira 2013). Another example discussed in Rezac (2011) is the French pronoun on. As shown in (300b), the pronoun is morphosyntactically $\left[3^{\mathrm{rd}}, \mathrm{sg}\right]$, but has a $\left[1^{\mathrm{st}}, \mathrm{pl}\right]$ interpretation, in addition to a quasi-generic and quasi-existential interpretation (see Rezac 2011:287ff).

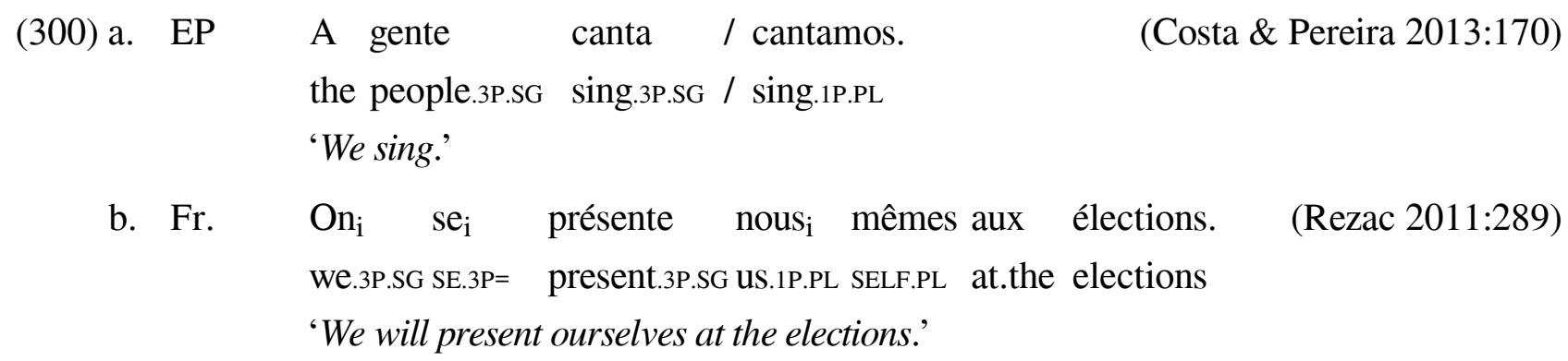
For the strong reflexive pronoun in European Portuguese, I assume that the morphosyntactic realisation of the number feature is a null-value, but this null-value can be associated with the presupposition for singular. The unacceptability of the sentences in (295)-(297) is therefore the result of a presupposition failure. The plural antecedent does not satisfy the presupposition introduced by the reflexive pronoun. The fact that the null-value can be associated with the presupposition for singular may be speaker-de- 
pendent or a broader grammatical phenomena. ${ }^{68}$ As a detailed analysis of these mismatch phenomena is out of the scope of the book, I will simply propose a notation for this peculiar situation in European Portuguese, as shown in (301). ${ }^{69}$

(301) a. SI (EP)

\begin{tabular}{lcc|c}
\hline Phi-features & i[ Person: 3] & i[ Gender: fem /masc] & i[ Number: sg] \\
\hline Morph. marking & se- / se- & $-\varnothing-$ & $-\varnothing-$ \\
\hline Sem. condition & -speaker, -hearer & $\varnothing$ & $\varnothing^{\text {singular }}$
\end{tabular}

The interpretive differences between the bare reflexive strong pronouns in Spanish and European Portuguese (the availability of long-distance anaphora in chapter 5 and 8) are possibly due to this interpretation of the null-value on the number feature.

Summarising this section, null-values on interpretable phi-features have been motivated on the basis of morphological and semantic considerations, in particular by the observation that the absence of morphological marking of a feature distinction coincides with the absence of a semantic restriction on the pronoun's antecedent. A null feature value is an unspecific value of an interpretable phi-feature. For the reflexive clitic and the reflexive pronoun, the feature composition is shown in (302). Both types of reflexive pronouns have a full set of phi-features and the features for gender and number have unspecified values, which are realised as a null-value. For European Portuguese, the null-value on number can be associated with a singular interpretation. This is indicated by the subscript on the null-value.

(302) Phi-feature values of the reflexive pronouns

strong pronoun

Sp.

\begin{tabular}{|l|}
\hline [person: 3] \\
[number: null ] \\
[gender: null] \\
\hline
\end{tabular}

EP

[person: 3$]$
[number: null $\left._{(s g .)}\right]$
[gender: $n u l l]$

clitic

$\mathrm{EP} / \mathrm{Sp}$.

[person: 3]

[number: null ]

[gender: null]

68 Ana Maria Martins (p.c.) mentions that the peculiar interpretation of the strong reflexive pronoun may be diachronically related to the development of si as a singular form of polite address in Modern Portuguese. Another factor that may influence this phenomena is the diachronic development of plural marking. For example, the dative clitic had the invariant form lhe in Old Portuguese, and it was used with singular and plural antecedents. This use was possible until the 17th century (see Nunes 1930:236ff and Paiva de Faria 1988:45ff). In Modern Portuguese, a plural interpretation needs overt marking, and hence the form thes has to be used. The $\varnothing$-realisation of number is now associated with a singular interpretation. These intriguing issues have to be left for future research.

69 Syntax-interpretation mismatches have received a lot of attention in crosslinguistic studies on agreement. As a detailed review is out of the scope of the book, I would like to mention just the influencial accounts of Wechsler \& Zlatić (2003) and Wechsler (2011), who propose that these patterns are the result of multiple phi-feature sets. For a recent implementation of this idea see Landau (2016), and for an overview of this phenomena in Romance see d'Alessandro \& Pescarini (2016). 
The feature values of non-reflexive clitics and strong pronouns are represented in (303). The strong pronouns and the direct object clitics have the same values. Only the dative clitic has a null-value for gender.

(303) Phi-feature values of the non-reflexive pronouns

strong pronouns

$\mathrm{EP} / \mathrm{Sp}$.

\begin{tabular}{|l|}
\hline [person: 3] \\
[number: $\mathrm{sg} / \mathrm{pl}$ ] \\
[gender: fem / masc ]
\end{tabular}

DO clitics

$\mathrm{EP} / \mathrm{Sp}$.

\begin{tabular}{l}
\hline [person: 3] \\
[number: $\mathrm{sg} / \mathrm{pl}$ ] \\
[gender: fem / masc]
\end{tabular}

IO clitics

$\mathrm{EP} / \mathrm{Sp}$.

[person: 3]

[number: $s g / p l]$

[gender: null]

The null-values on the phi-features of reflexive pronouns are the expression of their anaphoric nature and are taken to have the following syntactic and semantic effects: in chapter 9, I will argue that the nullvalue on an interpretable feature serves as an instruction to translate a pronoun as a bound variable at the syntax-semantics interface. In the next section, it will be argued that Agree with null phi-feature values is vacuous. This assumption will be the basis of syntactically encoding the anaphoric dependencies in reflexive and non-reflexive clitic doubling structure in chapter 7.4, and the derivation of the Anaphora Agreement Effect in chapter 7.5. The lexical property of being an anaphor or a pronominal in the sense of classic Binding Theory is thus encoded in terms of phi-feature values.

\subsubsection{On Agree with null phi-feature values}

In this section, I will argue that Agree between a phi-probe and a goal with null-values is vacuous, similar to vacuous Agree in Roberts (2010) and Kučerová (2018). Roberts (2010:144) assumes that Agree is vacuous if the goal has an unspecified value. He claims that vacuous Agree equals the absence of Agree. This means that the unvalued features of the probe stay unvalued. Kučerová (2018) analyses DP-internal agreement phenomena. She assumes that variable features on nouns, such as gender on human-denoting nouns, enter the derivation unvalued on the NP. In the course of the derivation the NP enters into Agree with other DP-internal items, such as the determiner or an adjective. She assumes that Agree takes place between the unvalued feature on $\mathrm{D}^{\circ}$ or $\mathrm{Adj}^{\circ}$ and the unvalued feature on the noun. An agreement link is established without valuation. The gender features on the NP, as well as on the determiner or the adjective, will be valued postsyntactically according to context information.

For my analysis, I will assume that Agree with null feature values is vacuous in the following way. The operation Agree consists of two suboperations: Match and Copy. The operation Match is defined in Chomsky (2001:5) as feature identity. This means that Match checks for the identity of feature names and not for the identity of feature values: for example [number] matches [number] irrespective of the value of the number feature. For this reason, a probe matches a goal with null-values. As for the operation Copy, I propose that it cannot operate on null-values. If a goal contains a feature with a nullvalue, the value will not be visible for Copy and the unvalued feature of the probe remains unvalued. 
Agree does not fail completely; only Copy applies vacuously. Thus, an Agree link is established between the probe and its goal, but no values are copied onto the probe.

In my analysis, there are three scenarios for agreement with a null feature value. The first scenario is agreement between a phi-probe and the strong reflexive pronoun, the second scenario concerns agreement between the intensifier and the reflexive pronoun, and the third scenario is cliticisation as agreement. In all three cases, the unvalued features of the probe match the features of the goal, but only the specific values are copied onto the probe. The null-values are not copied and the probe's features remain unvalued. This is illustrated for the first scenario in (304). Here a phi-probe matches the features on the strong reflexive pronoun. Copy is only successful with the person feature, because it has a specified value. The null-values of the number and gender feature cannot be copied, and these features remain unvalued on the probe. A probe with uninterpretable unvalued features cannot delete, and the derivation will not converge at the interfaces. This is a problematic result, but, as will become clear in section 7.5, a desirable one.

(304) Agreement with null-values
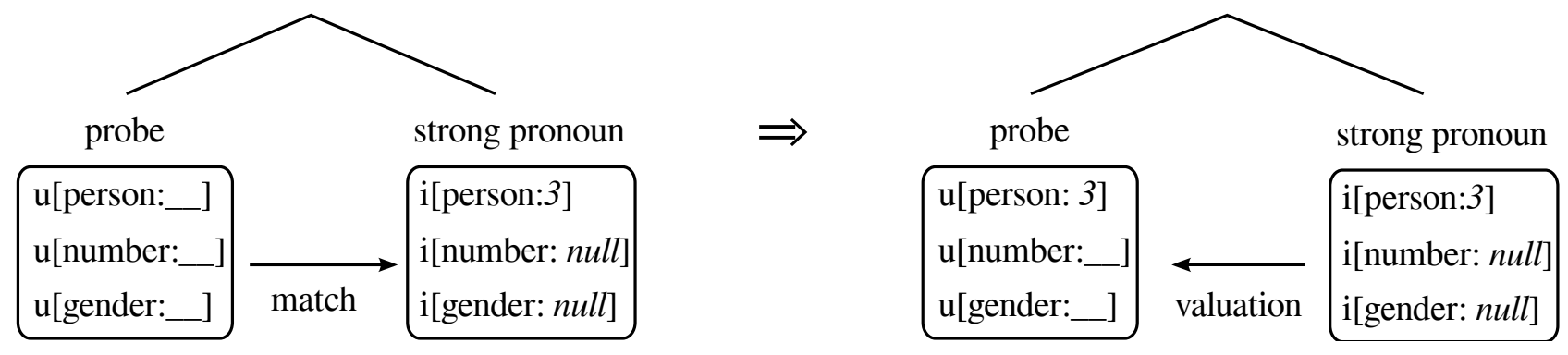

The second scenario is agreement with the intensifer and will be discussed in section 6.3 below. The approach to cliticisation as agreement presented in Roberts (2010) will be introduced in section 7.2 and cliticisation with null feature values will be discussed there.

\subsection{Structural deficiency: the internal structure of clitics and strong pronouns}

Recall from chapter 2 that clitic doubling and object marking are related to definiteness, specificity, and animacy. These properties have been analysed in terms of features on the clitic and strong pronouns in Uriagereka (1995) and Martins (1994, 2000) or in terms of functional projections, as in Longobardi (1994), Déchaine \& Wiltschko (2002), and Cardinaletti \& Starke (1999). In this section, it will be argued that the interpretive effects associated with a [+specific] feature or a [+definite] feature/projection can be explained in a compositional analysis, as in Leonetti (2007, 2008) and Roberts (2010). At the end of this section, an internal structure for strong and clitic pronouns will be proposed. Clitic pronouns are taken to be simultaneously minimal and maximal categories that consist of phi-features only, as proposed in Roberts (2010). For strong pronouns, a more elaborate structure that consists of projections such as NP, $\Phi$, and $\Sigma \mathrm{P}$ will be assumed. 


\subsubsection{Definiteness and specificity}

This section discusses the role of definiteness and specificity for the syntax and the interpretation of strong and clitic pronouns. It will be shown that no lexical feature or syntactic projection for specificity or definiteness is needed to account for the interpretation of non-reflexive pronouns, in particular for the interpretation of non-reflexive clitics. The result of this discussion allows for the conclusion that clitics in Spanish and in European Portuguese consist of phi-features only.

The notion of specificity is closely related to the notion of definiteness. Von Heusinger (2002) states that specific (indefinite) DPs have a referent that is known or identifiable by the speaker, contrary to non-specific DPs. The same is true for definite DPs. They have a uniquely identifiable referent. Thus, definite DPs are always specific, but indefinite DPs vary with respect to a specific or unspecific interpretation.

The fact that strong pronouns are interpreted as definite and specific is most prominently formalised in Longobardi (1994). For Spanish and European Portuguese see also Otero (1999), Fernández Soriano (1999), and Martins (1994, 2000). Longobardi (1994) proposes that pronouns realise the D head of a definite DP for the following reasons: (i) pronouns lack a lexical meaning and are hence nondenotational, rigid designators. Other nouns, including proper names, have lexical content realised in the NP layer. The determiner governs the interpretation of the NP. (ii) Pronouns are in complementary distribution with a determiner such as the definite or indefinite article, as shown in (305).

(305) a. Sp. *la / *una / *esta ella

b. EP
*a / *uma / *esta ela the/ a / this she the/ a / this she

Longobardi's (1994) structures of definite DPs and pronouns are reproduced in (306).

(306) a. definite/indefinite DP

b. non-reflexive pronoun
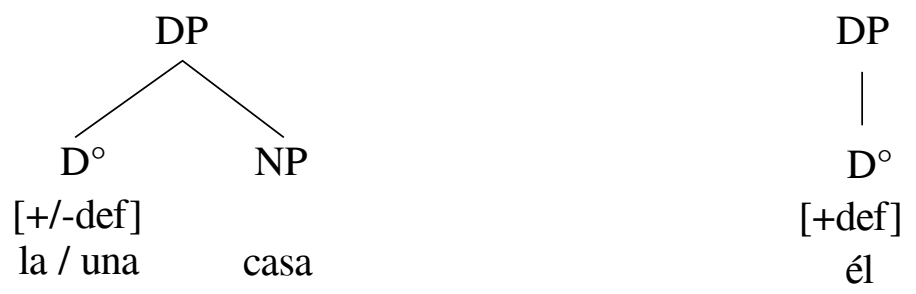

This structural parallelism between pronouns and determiners seems to be superficial for two reasons. First, pronouns are unlike determiners because they cannot be used in the $\mathrm{D}^{\circ}$ position of an NP. This is true for third person pronouns in both languages. ${ }^{70}$
(307) a. Sp. *ellos lingüistas
b. EP
*eles linguistas
they linguists

70 EP, like English, allows for first and second person (plural) pronouns modifying an NP. This is impossible in Spanish. 
Secondly, definiteness on pronouns is interpreted differently from definiteness on nouns in the form of a definite or indefinite article. Craige Roberts (2003) shows on the basis of the example in (308) that the definiteness of pronouns does not give rise to uniqueness effects. ${ }^{71}$ The definite description the woman in (308a) cannot pick out one of the women mentioned in the previous sentence, but the pronoun in (308b) can, and it takes the maximal salient DP-the woman who entered from the right -as its antecedent.

A woman entered from stage left. Another woman entered from stage right.

a. \#The woman was carrying a basket of flowers.

b. She was carrying a basket of flowers.

(Roberts 2003:324)

The fact that the definiteness of pronouns is linked to salience, anaphoric accessibility, or familiarity is reflected in different approaches, as for example in von Heusinger (2002), von Heusinger \& Kaiser (2003:44), Leonetti (2007), and other approaches summarised there. Specificity and definiteness have been defined in terms of familiarity in von Heusinger (2002) and von Heusinger \& Kaiser (2003), respectively. The term familiarity essentially describes the fact that a definite DP is referentially dependend on an entity already present in the discourse. Heim (1989) formalises familiarity as identity of referential indices. Thus, familiarity-definiteness-specificity is nothing but a reflex of the anaphoric nature of pronouns.

In the present analysis, the anaphoric nature should find its expression in terms of features, rather than in terms of indices. Following Wechsler (2011) and Pollard \& Sag (1992), the referential index of a pronoun is associated with or equal to the interpretable phi-features on the pronouns. In Kučerová (2018), the referential index is associated with the person feature. Thus, definiteness/specificity on pronouns can be related to phi-features, in particular to a full set of interpretable and valued features. If the specific and definite interpretation of non-reflexive pronouns_clitic and strong-is due to a full specification for phi-features with specific values, then a pronoun that is underspecified for phi-feature and phi-feature values should not be sensitive to definiteness and specificity. This prediction is borne out for the reflexive pronouns. Recall from chapter 5 that the reflexive clitic and its reflexive double may even take a negative quantifier as antecedent. Additionally, the reflexive clitic and its double may be used with an impersonal antecedent, as shown in (309). The antecedent is the $\mathrm{PRO}_{\text {arb }}$ subject of the infinitive. Note that the non-reflexive double is ungrammatical in these cases.

71 Uniqueness is part of Russel's (1905) formalisation of the meaning of the definite and indefinite article. Following Ludow (2013), the essence of Russel's proposal is that the indefinite description in a sentence involves an existence claim, formalised as $\exists$ in (i), and the use of a definite description also involves, in addition to an existence claim $(\exists)$, a uniqueness claim ( $\forall$ ), as shown in (ii).

(i) A dog is barking.

$\exists x[\operatorname{dog}(x) \& \operatorname{barking}(x)]$ (ii) The dog is barking. $\exists \mathrm{x}[\operatorname{dog}(\mathrm{x}) \& \forall \mathrm{y}[\operatorname{dog}(\mathrm{y}) \Rightarrow \& \operatorname{barking}(\mathrm{y})](\mathrm{x}=\mathrm{y})$ 


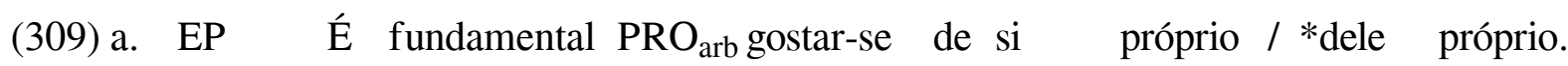

is fundamental like=SE.REFL of REFL.PR SELF / de.him SELF

'It is important to like oneself.'

(Lobo 2013:2225)

b.

PRO $_{\text {arb Medicar-se a si próprio / *ele próprio é perigoso. }}$
medicate=SE.REFL to REFL.PR SELF / him SELF is dangerous
'To medicate oneself is dangerous.'

The same is true for Spanish. As shown by the examples in (310), the reflexive pronoun, but not the non-reflexive pronoun can take an impersonal or indefinite antecedent.

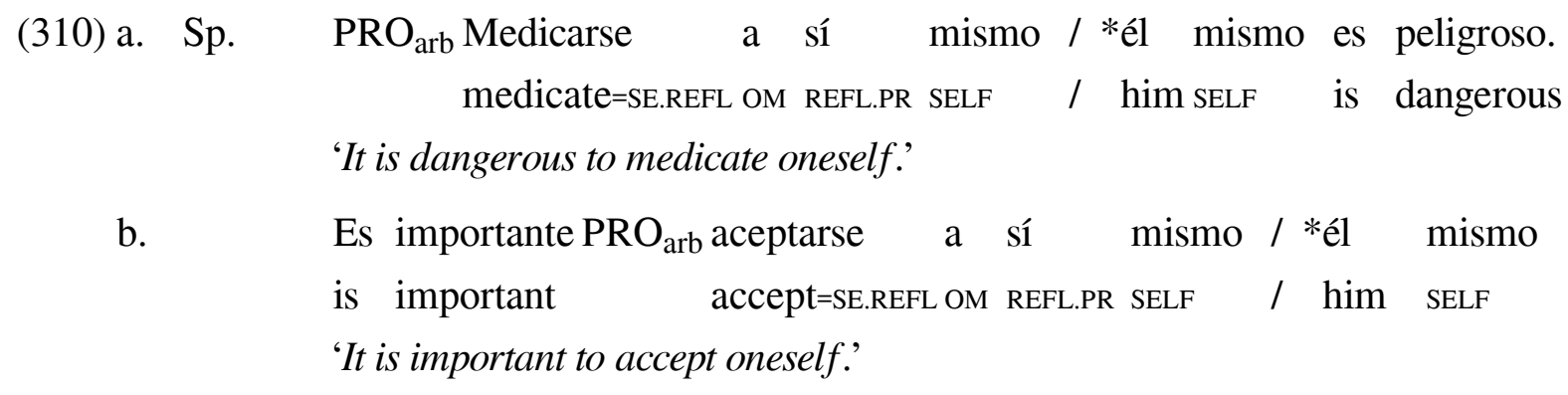

But this account also predicts that all pronouns with a full specification for phi-features should be restricted to a definite, specific antecedent. This is true for European Portuguese clitic pronouns, but not for the Spanish dative clitic. In Spanish, the dative clitic may double all types of DPs, even the negative quantifier nadie and the indefinite pronoun uno, as shown in (311). This is surprising considering its referential uses.

(311) EP Las amigas tenían, de una en una, bastante con su vida, y a nadie le gusta oír lamentarse de lo que a uno mismo le duele [...]. (CREA: Gala, A. 2002. 'Los invitados al jardín'.)

'The friends, each one of them, had enough with their own lifes, and nobody likes to hear someone moan about what hurts him.'

Contrary to the indirect object, the direct object clitic is restricted to a definite and specific antecedent, just like the non-reflexive clitics in European Portuguese. This is shown by means of the example in (312) from Uriagereka (1995). Doubling of the indefinite pronoun ${ }^{72}$ with a DO clitic is ungrammatical.

$$
\begin{array}{ll}
\text { Sp. } \quad(* \text { Lo }) \quad \text { vimos a uno. } \\
\text { CL.ACC }=\text { see om one }
\end{array}
$$

'We saw someone.'

Leonetti (2007) mentions that the differences between DO and IO clitics may be derived if the clitics have a different categorial status and are subject to distinct mechanisms for clitic doubling. For example, the direct object clitic is a DP, whereas the indirect object clitic is derived by object agreement

\footnotetext{
72 Note that European Portuguese has no equivalent to Spanish uno.
} 
(see Roca 1996, Bleam 1999, or Gutiérrez-Rexach 2000). Alternatively, Roberts (2010) proposes that the edge position of transitive little $\mathrm{v}$, the landing site of cliticisation, is associated with a specific interpretation. This proposal may be extended in order to explain the difference between IO and DO clitics in Spanish. The position of the IO clitic — the edge position of appl ${ }^{\circ}$ —is optionally associated with specificity, whereas the edge position of DO clitic is obligatorily marked for specificity. In European Portuguese, both edge positions are associated with specificity, with the effect that both clitics are restricted to a definite and specific antecedent. Under such an account no feature or projection is needed to represent specificity/definiteness on the clitic pronouns.

As for strong pronouns, the relation between phi-features and referentiality/definiteness has been explored in Déchaine \& Wiltschko (2002) for the Halkomelem ${ }^{73}$ pronominal system. Following Cardinaletti \& Starke (1999), they propose that morphosyntactic and semantic properties are expressed by means of functional projections. For morphologically simplex personal pronouns, they propose the structure in (313a). These pronouns consist of an empty NP layer and a $\varphi \mathrm{P}$, containing the phi-features. With respect to binding, $\varphi \mathrm{Ps}$ are interpreted as pronominal in the sense of BT. For morphological complex pronouns (in Halkomelem), Déchaine \& Wiltschko (2002) propose the structure in (313b).

(313) a.

$$
\text { pronominal } \varphi \mathrm{P}
$$

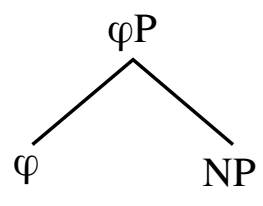

$\varnothing$ b. pronominal DP

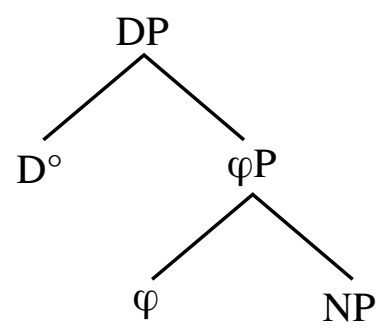

$\varnothing$

DP-pronouns resist a bound variable interpretation, even in non-local contexts, as shown in (314a). The Halkomelem complex pronoun tú-tl'òlem in (314a) cannot be bound by the quantified antecedent. The same is true of the European Portuguese strong non-reflexive pronoun. As shown in (314b), the QP cannot be the antecedent of the pronoun used in a similar possessive construction.

(314) a. Hal. *[Mékw' ye swíyeqe $]_{i}$ kw’ákw’ets-et-es te stóles-s [tú-tl'òlem] $]_{i}$. every DET man looking-TRANS-3.SUBJ DET wife-3.POSS DET-3.PL intended meaning: 'All men ${ }_{i}$ are looking at their ${ }_{i}$ wives.'

(Déchaine \& Wiltschko 2002: 414)

b. EP *Cada menino gosta do bici dele $_{i}$. Every kid likes of.the bike of.him intended meaning: 'Every kid likes his $_{i}$ bike.'

73 Halkomelem is a Central Coast Salish language, a Native American language spoken along the Northern Pacific coast in the United States and Canada. 
Recall from section 5.4 that clitic pronouns and strong reflexive pronouns in European Portuguese and in Spanish may be bound by all types of quantifiers, while strong non-reflexive pronouns resist being bound by a (bare) quantifier (see also chapter 8 for the same binding facts with pronouns inside complement PPs and adjunct PPs). ${ }^{74}$ In Déchaine \& Wiltschko (2002) the different binding behaviour of complex pronouns and simplex pronouns in Halkomelem is attributed to the additional DP layer. For Spanish and European Portuguese strong pronouns, I propose that the additional layer is not a DP layer, but the $\Sigma$ P of Cardinaletti \& Starke (1999) because this projection is associated with word stress, and therefore with the ability to bear focus. Recall from section 2.2.1 that strong pronouns, but not clitic pronouns, can bear focus and word stress. For this reason, Cardinaletti \& Starke (1999) propose that clitic pronouns lack the $\Sigma \mathrm{P}$ layer. For my analysis, I assume that clitics are just $\varphi \% \varphi \mathrm{P}$, as in Roberts (2010), and that overt strong pronouns are $\Sigma$ P. The (preliminary) structure for strong pronouns is shown in (315a) and for clitic pronouns in (315b).

(315) a.

strong pronouns

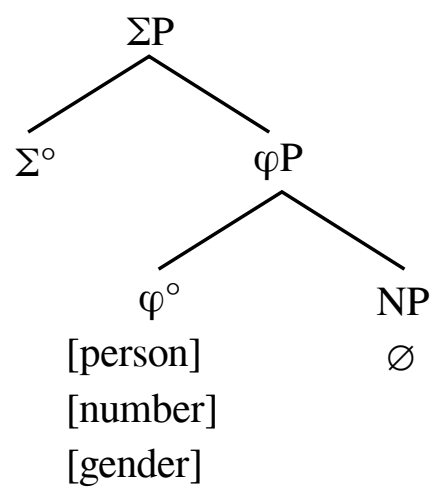

b. clitic pronouns

$$
\begin{gathered}
\varphi^{\circ} / \varphi \mathrm{P} \\
\text { [person] } \\
\text { [number] } \\
\text { [gender] }
\end{gathered}
$$

\subsubsection{Animacy}

For clitic doubling structures, it has been observed that the strong (non-reflexive) ${ }^{75}$ pronoun is limited to a human referent, whereas the clitic alone is not subject to this restriction (see Magro 2019, Brito 2008, Gonçalves 1999 for European Portuguese and von Heusinger \& Kaiser 2003, Fernández Soriano

74 Overt subject pronouns also resist a bound reading in Spanish and European Portuguese. The overt pronouns ellos and eles in (i) and (ii) can only be interpreted as referential, either referring to some salient group of people or to the group of students and kids, respectively. A bound interpretation is only possible if the overt pronoun is replaced with the covert pronoun pro.

(i) Sp. Todos los estudiantes reconocieron que ellos habían llegado tarde.

(Bosque \& Gutiérrez-Rexach 2016:553) all the students recognised that they had arrived late

All the students ( $\mathrm{x}), \mathrm{x}$ recognised that $\mathrm{y}$ have arrived late.

Not: All the students (x), $\mathrm{x}$ recognised that $\mathrm{x}$ have arrived late.

(ii) EP Todos os meninos disseram que eles vinham á festa.

(Lobo 2013:2200)

all the kids said that they came to.the party

All the kids (x), $\mathrm{x}$ said that $\mathrm{y}$ were coming to the party.

Not: All the kids ( $\mathrm{x}$ ), $\mathrm{x}$ said that $\mathrm{x}$ were coming to the party.

75 The reflexive pronoun itself is unrestricted with respect to animacy, but since true reflexive predicates are limited to agentpatient/theme verbs or experiencer verbs, the subject of a reflexive sentence necessarily has agentive properties. 
1999 for Spanish). This is exemplified for Spanish, and European Portuguese in (316) and (317), respectively. The Spanish example comes from Fernández Soriano (1999:1226) and the European Portuguese example from Brito (2008:34).

(316) a. Sp. Le di un golpe. [le = María / la mesa her.CL= gave a hit

b. Le di ungolpe a ella. [ella = María / *la mesa] her.CL= gave a hit to her

'I hit her ( = María) / it ( = the table $)$ '

(317) a. EP A Dina viu-o.

[o = o Paulo / o disco voador $]$

the D. saw=him.CL

b. A Dina viu-o a ele. [ele $=$ o Paulo $/ *_{0}$ disco voador $]$

the D. saw=him.cL om him

'Dina saw him ( = Paulo) /it ( = the flying saucer)'

The animacy restriction has been analysed in two ways: (i) the strong pronouns itself bears a feature for animacy and (ii) the object marker $a$ bears this feature. The first approach is proposed, for example, in von Heusinger \& Kaiser (2003). Animacy is represented in a hierarchy of features that consists of several subfeatures with the boolean instances [+/-human] and [+/-animate]. Under this analysis, the pronominal double in (316) and (317) bears a [+human] feature. The clitic may be marked by [+/animate] or it may simply lack a feature for animacy. For the clitic pronoun, I will adopt the latter option. For strong pronouns, the [+human] value is not a fixed, intrinsic property, as shown in (223) for Spanish, repeated here as (318), and in (319) for European Portuguese.

(318) Sp. La comisión de cultura de la Asociación de Vecinos de Villaamil realizó una encuesta casa por casa, en la que se preguntaba si, caso de terminarse el colegio para el año que viene, las familias enviarían sus hijos a él. (CREA: El País, 05/05/1976.) 'The comission of culture of the neighbourhood association of Villaamil conducted a door-to-door survey asking whether, should the school (building) be finished by the next year, the families would want to send their children to it.'

(319) a. EP Cavaco Silva, lê a imprensa e preocupa-se muito com ela. (CRPC: Diário da Assembleia da República. 1996, A0100)

'Cavaco Silva, reads the press and keeps himself busy with it.'

The fact that the strong pronouns may refer to a [-human] and [-animate] entity was related to the fact that they are inside a lexical PP in the sentences in (318) and (319). But in the clitic doubling structures in (316) and (317) above, the pronouns are inside a PP too, but reference to a [-human] and [-animate] entity is impossible. In order to account for the difference between lexical PPs and PPs introduced 
by $a$, Brito (2008) and also Cardinaletti \& Starke (1999) assume that the object marker $a$ bears the [+human] feature. This predicts that a pronoun with an object marker can never refer to a non-human referent. This prediction is not borne out, as shown by the example in (216), repeated here as (320). In (320a), the referent of the double is clearly inanimate. As for the Spanish example given in (320b), the context seems to impose an animate interpretation of the otherwise inanimate antecedent. But still, the pronoun ella does not refer to a single, female individual, but to a corporation which is non-human.

(320) a. EP No decorrer desse trabalho há uma simbologia que se vai criando a ela própria. (CRPC: Público, J106711)

'In the proceeding of this work there is a symbolism that is continuously creating itself.'

b. Sp. Time intenta comprar la Warner para que la Paramount no la compre a ella, [...]. (CREA: ABC Justicia, 28/06/1989)

'Time tries to buy Warner so that Paramout cannot buy it.'

These examples suggest that the [+human] feature should not be encoded lexically either on the pronoun, or on the object marker $a$. In the following, I will show that the animacy restriction in clitic doubling contexts is the result of the contrastive focus interpretation of the pronominal double.

Recall from section (5.1) that the strong non-reflexive pronoun in clitic doubling structures is necessarily associated with a contrastive focus interpretation. Using a pronoun in order to establish a contrast between two entities, the lexical content the contrast can be based on consists only of the phifeatures. For example, the pronouns ella and ela in (321a) and (321b), respectively, are third person, feminine, singular, and a contrast can be established on the basis of person and gender.

(321) a. Sp. Juan la admira a ella. Y no a ti / a él.

J. her.CL= admires om her and not you / him

b. EP O Rui admira-a a ela. E não a ti / a ele.

the R. admires=her.cL om her and not you / her

But in order to establish a contrast on the basis of the gender feature, gender has to be a semantically contentful feature of the referent. This is only the case for human or anthropomorphous referents. For example, in the contrastive topic constructions in (322) and (323), the overt subject pronouns cannot be used to refer to non-human antecedents, even though the pronouns bear emphatic stress. ${ }^{76}$ The masculine pronouns éllele and the feminine pronouns ella/ela cannot be used to identify or to establish

76 In neutral contexts, overt subject pronouns are limited to a [+human] antecedent in Spanish, but if the subject pronouns are focalised, the restriction is inactive, as shown by the examples in (i).

(i) Sp. No es necesario escayolar [este hueso]i. Se soldará él $l_{i}$ sólo.

(Fernández Soriano 1999:1226)

not is necessary plaster this bone SE.REFL=heal he alone

'It's not necessary to put this bone in plaster. It will heal by itself.'

For European Portuguese, Raposo (2013a:912ff) cites several examples from the CRPC with an overt subject pronoun referring to an inaninimate antecedent. But these uses and judgements are not shared by all speakers (p.c. Ana Maria Martins). 
a contrast between a table or an armchair by means of their gender because the gender feature on the common nouns mesa and armário is purely grammatical and does not denote a property of the referent.

$$
\begin{aligned}
& \text { Sp. Compré [una mesa } \mathrm{i}_{\mathrm{i}} \text { ] } \quad \text { [un sillón } \mathrm{k}_{\mathrm{k}} \text { ]. (Fernández Soriano 1999:1220) } \\
& \text { bought a table.FEM and a armchair.MASC } \\
& * \text { Él } \mathrm{l}_{\mathrm{k}} \text { tiene tapizado de cuero y ella } \mathrm{a}_{\mathrm{i}} \text { es de diseño italiano. } \\
& \text { he has upholstery of leather and she is of design italian } \\
& \text { 'Ibought a table and an armchair. It has leather upholstery, and it is of Italian design.' }
\end{aligned}
$$

$$
\begin{aligned}
& \text { EP Comprei [uma mesa }{ }_{\mathrm{i}} \text { ] e [um armário }{ }_{\mathrm{k}} \text { ]. } \\
& \text { bought a table.FEM and a wardrobe.MASC } \\
& \text { \#-* Ela } \mathrm{k}_{\mathrm{k}} \text { é de vidrio e ele tem } \mathrm{i}_{\mathrm{i}} \text { decoração futurista } \\
& \text { she is of glass and he has a decoration futuristic }
\end{aligned}
$$

If the referent of the pronoun is [+human], as shown in (324) and in (325), the contrast on basis of the gender feature is perfectly acceptable.

$$
\begin{aligned}
& \text { Sp. } \quad \underline{\text { A: }} \text { ¿Quién es esa pareja? } \\
& \text { 'Who is this couple?' } \\
& \text { B: Pues, él } l_{k} \text { es mi primo Juan y ella } a_{i} \text { es su vecina. } \\
& \text { well, he is mycousin } \mathrm{J} \text {. and she is his neighbour } \\
& \text { 'Well, He is my cousin Juan, and she is his neighbour.' }
\end{aligned}
$$

(325) EP Materializa Seixas Santos esse tempo e essa viagem em dois personagens [...]: um professor universitário estéril ([...]), e uma jovenzinha de 20 anos [...]. Ele é Rui Mendes e ela é Maria de Medeiros - há uma década atrás. (CRPC: Expresso, J9250) 'Seixas Santos materialises this time and this journey in two characters [...]: a sterile university professor [...] and a 20-year-old woman [..]. He is Rui Mendes, and she is Maria de Medeiros—decades ago.'

These examples show an interesting correlation between the interpretation of contrastive focus, gender, and animacy. With human referents, the gender feature is semantically contentful in the sense that gender is a distinctive property of humans. A human entity can be identified by its gender, be it female, male, or any other value for the gender feature. Thus, if a contrast is established between two entities on the basis of the gender feature, as it is the case with third person pronouns, these entites have to be human or anthropomorphous. The fact that the pronominal double in clitic doubling structures necessarily refers to a human entity is thus a consequence of the interpretation of gender and contrastive focus.

Therefore, I assume that the strong non-reflexive pronouns have an animacy feature that is not intrinsically fixed to [+human], but that receives a value from the (linguistic) context, as proposed for 
example in Kučerová (2018). For reflexive and non-reflexive clitics and for reflexive strong pronouns, I assume that they lack a feature for animacy in both languages. The final structures together with the phi-features for reflexive and non-reflexive clitic and strong pronouns is given in (326) and (327).

(326) Strong pronouns (final)

a. non-reflexive

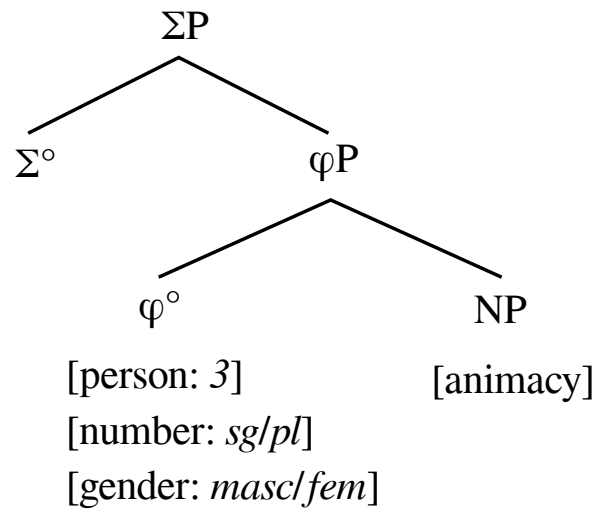

b. reflexive

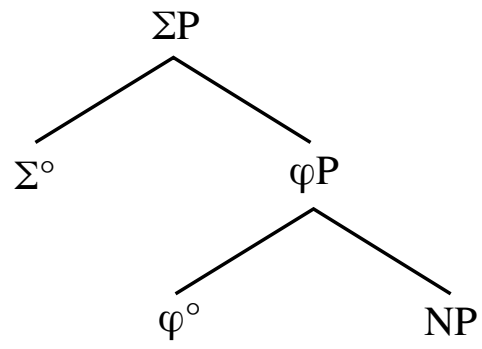

[person: 3]

$\varnothing$

[gender: null]

(327) Clitic pronouns (final)

a.

$$
\begin{aligned}
& \text { non-reflexive } \\
& \qquad \varphi^{\circ} / \varphi \mathrm{P} \\
& \text { [person: } 3 \text { ] } \\
& \text { [number: } \mathrm{sg} / \mathrm{pl} \text { ] } \\
& \text { [gender: } \mathrm{masc} / \mathrm{fem} \text { ] }
\end{aligned}
$$

b. reflexive

$$
\varphi^{\circ} / \varphi \mathrm{P}
$$

[person: 3]

[number: $n u l l]$

[gender: null]

\subsection{A brief syntax of mismo and mesmo/próprio}

In this section, I will briefly discuss the basic syntactic aspects of the elements mismo and mesmo/ próprio, in particular their category, their position within the $\Sigma \mathrm{P}$, and agreement with the strong pronoun.

\subsubsection{Category and position}

The elements mismo and mesmo/próprio are hybrid elements. On the one hand, they are like adjectives with respect to agreement and their distribution, on the other hand they are unlike adjectives because they combine with pronouns. The elements mismo and mesmo/próprio occur prenominally with both common and proper nouns. In this position, they are interpreted as attributive adjectives with a meaning similar to 'same' and 'own, appropriate', respectively. If they combine with pronouns, the elements mismo and mesmo/próprio are obligatorily postnominal, and they agree in number and gender with the pronoun, as shown in (328).
(328) a. Sp.
ella misma
$a^{\prime} \cdot \mathrm{EP}$
ela
própria
she.3.SG.FEM SELF.FEM.SG
she.3.SG.FEM SELF.FEM.SG 

b. Sp.
*misma ella
$b^{\prime} . \mathrm{EP}$
*própria ela
SELF.FEM.SG She.3.SG.FEM
SELF.FEM.SG she.3.SG.FEM

The fact that mismo and mesmo/próprio combine with pronouns makes them distinct from all other adjectives because adjectives cannot combine with pronouns, as shown in (329) by means of prenominal and postnominal adjectives.

\begin{tabular}{|c|c|c|c|}
\hline (329) a. Sp. & $\begin{array}{l}\text { *ella / sí bonita } \\
\text { she / REFL.PR pretty }\end{array}$ & $a^{\prime} . E P$ & $\begin{array}{l}\text { *ela / si linda } \\
\text { she / REFL.PR pretty }\end{array}$ \\
\hline b. & $\begin{array}{l}\text { *gran ella / sí } \\
\text { great she /REFL.PR }\end{array}$ & $b^{\prime}$. & $\begin{array}{l}\text { * grande ela / si } \\
\text { great she / REFL.PR }\end{array}$ \\
\hline
\end{tabular}

The hybrid nature of the pronominal intensifiers can be deduced from the history of Spanish and European Portuguese. The elements mismo and mesmo developed from a combination of the Latin intensifier IPSE and the intensifying affix MĚT. Both elements combine with nouns and in particular with pronouns, as in EGOMET IPSE 'I myself'. These elements have the function of an intensifier and an identity marker, respectively. In Zumpt (1845:103ff) IPSE was classified as adjunction because it adjoins to the right of the pronoun.

According to Penny (2002:142ff) and Manoliu (2011:475ff), in Late Latin IPSE lost its intensifying function and shifted to the demonstrative system, yielding the modern forms of the demonstrative pronouns ese (Sp.) and esse (EP). Due to this process, the combinations of MĚT (now as prefix) + IPSE took over the intensifying function. From a morphosyntactic point of view, the affix MĔT merges with IPSE. This combination presumably maintained the properties of an adjunction. The fact that METIPSE had been used in the superlative as METIPSISSIMUM (> METIPSIIMUM) signals an assimilation to the category of adjectives. The modern forms mismo and mesmo developed from the superlative form in Spanish through MEDIPSIMUM > MEDÉSSIMO/MEDÍSSIMO > MEÍSMO/MEÉSMO (see Penny 2002:143) and in European Portuguese through METIPSIMUM $>*$ METISSIMU $>*$ MEDESMO $>*$ MEESMO (see Coutinho 1973:257). Furthermore, it is during this transition that the elements also take over the meaning of the Latin pronoun IDEM $^{77}$ meaning 'same' denoting an identity relation (see Penny 2002). This meaning is also attested for Late Latin IPSE in Manoliu (2011:477).

In the (modern) Romance languages, these two meanings seem to be differentiated by means of word order. In prenominal position, mismo and mesmo are attributive adjectives and interpreted as an identity predicate similar to English 'same', while in postnominal position they are interpreted as the intensifiers.

As for the adjective próprio, ${ }^{78}$ Delille (1970) states that its use as pronominal intensifier is documented since the 16th century and that its use is increasing, while the use of mesmo is decreasing in

\footnotetext{
77 IDEM is composed of the third person personal pronouns IS, EA, and ID and the suffix -DEM. IPSE is composed of IS, EA, and ID and the suffix -PSE (see Kühner \& Stegmann 1912:244ff, 596ff).

78 In its attributive use próprio has the meaning of 'own'.
} 
contemporary European Portuguese. It seems that próprio is taking over the function of mesmo as a reflexive intensifier, and I will therefore assume that próprio and mesmo occupy the same syntactic position and have the same interpretation when used as a reflexive intensifier.

The fact that the adjectives mismo and mesmo/próprio can combine with pronouns only in postnominal position has a straightforward explanation if these elements are merged within the pronominal structure. I will assume that they adjoin to $\varphi \mathrm{P}$, as shown in (330).

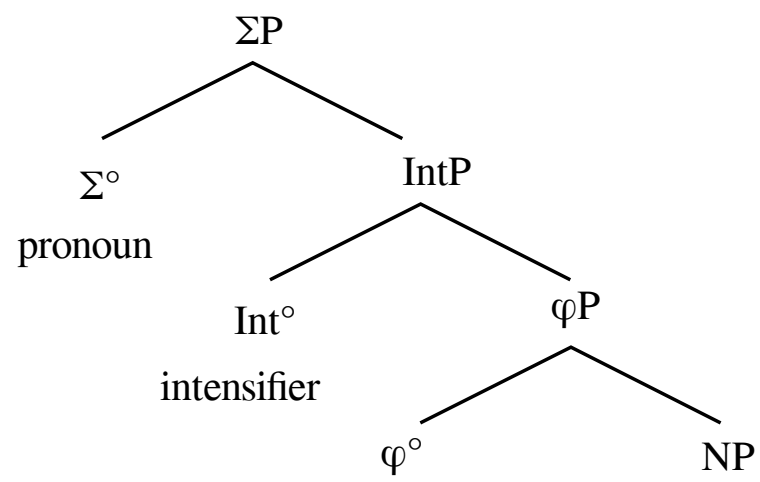

\subsubsection{Agreement between the strong pronoun and the intensifier}

In this section, I want to return to the question about agreement between the intensifier and the pronoun, in particular the reflexive pronoun. Recall from section 6.1.3 that agreement between a phi-probe and null-values on a goal results in vacuous agreement. Given the structure of the pronoun in (330), the intensifier in (331a) probes the phi-features of the reflexive pronoun. Agree is vacuous and the features on the intensifier remain unvalued. After Agree, the pronoun moves to its final position in $\Sigma^{\circ}$, as shown in (331b).

(331) a.

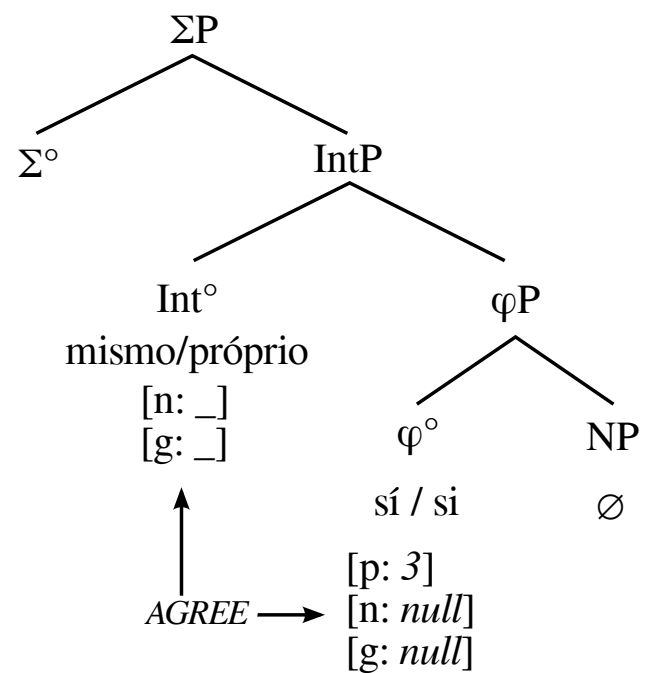

b.

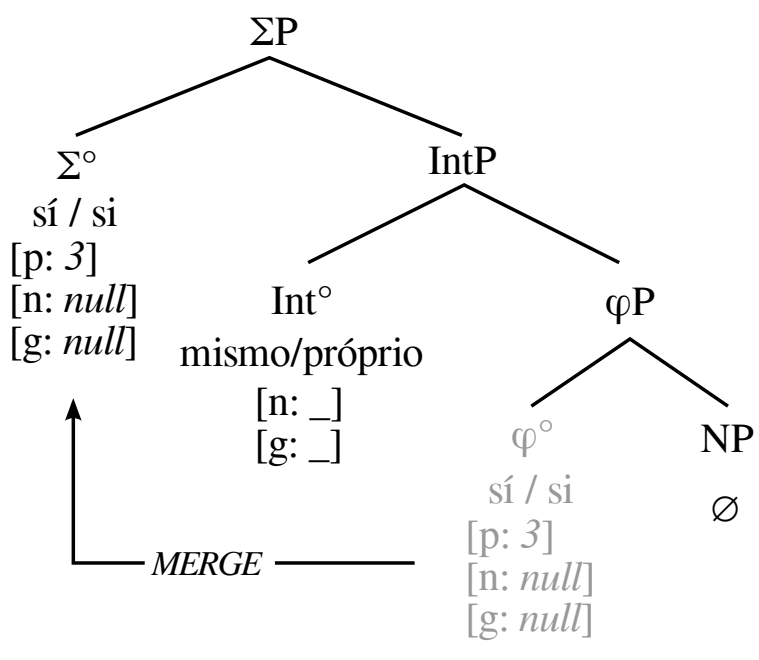

Obviously, the unvalued features on the intensifier cannot remain like this. The question how the features get their values from the antecedent will be answered in chapters 7 and 9 . 


\subsection{Summary}

The distinction between reflexive and non-reflexive pronouns was formalised by means of the distinction between specific phi-feature values and null phi-feature values. Only specific values introduce a semantic presupposition. Null-values are the syntacitic expression of phi-feature values that do not introduce a semantic presupposition and that do not impose a restriction on the antecedent. It has been shown that this distinction allows one to account for the interpretive differences between reflexive and non-reflexive pronouns that have been related to definiteness and specificity. As reflexive pronouns (clitic and strong) have null-values on the gender and number feature, they are less restrictive and can take definite and indefinite as well as specific and unspecific antecedents. Non-reflexive pronouns (clitic and strong) have specific values on all phi-features and are thus restricted to definite/specific antecedents. As for the expression of the distinction between clitic and strong pronouns, the syntactic structure proposed in Cardinaletti \& Starke (1999) and Roberts (2010) was adopted with some modifications. The table in (332) summarises the feature composition of reflexive and non-reflexive pronouns together with the syntactic structure assumed for clitic and strong pronouns. Additionally, it indicates at which level of grammar the referential properties of the pronouns will be derived in chapters 7 and 9 .

(332) Referential properties of reflexive and non-reflexive clitics

\begin{tabular}{|c|c|c|c|c|}
\hline & \multicolumn{2}{|c|}{ Non-reflexive } & \multicolumn{2}{|c|}{ reflexive } \\
\hline & strong & clitic & strong & clitic \\
\hline \multirow[t]{5}{*}{ Projections and features } & $\Sigma \mathrm{P}$ & - & $\Sigma \mathrm{P}$ & - \\
\hline & $\varphi \mathrm{P}$ & $\varphi^{\circ} / \varphi \mathrm{P}$ & $\varphi \mathrm{P}$ & $\varphi^{\circ} / \varphi \mathrm{P}$ \\
\hline & $\begin{array}{c}\text { [p:3] } \\
\text { [n:sg./pl] } \\
\text { [g:fem/masc] }\end{array}$ & $\begin{array}{c}\text { [p:3] } \\
\text { [n:sg./pl] } \\
\text { [g:fem/masc] }\end{array}$ & $\begin{array}{c}\text { [p:3] } \\
{[\mathrm{n}: n u l l]} \\
{[\mathrm{g}: n u l l]}\end{array}$ & $\begin{array}{c}\text { [p:3] } \\
{[\mathrm{n}: n u l l]} \\
{[\mathrm{g}: n u l l]}\end{array}$ \\
\hline & NP & - & NP & - \\
\hline & [animacy] & - & - & - \\
\hline Anaphora resolution & $\Downarrow$ & $\Downarrow$ & $\Downarrow$ & $\Downarrow$ \\
\hline in syntax & & locally free & & locally bound \\
\hline in semantics & free & $\begin{array}{c}\text { non-locally } \\
\text { bound and free }\end{array}$ & bound & - \\
\hline
\end{tabular}

The special syntax of clitics allows for a syntactic encoding of a local anaphoric dependency between reflexive and non-reflexive clitics and their antecedents. As will be presented in the next chapter, it is the null-values on the reflexive clitic that allow for an Agree link to be established between the clitic and the antecedent. This Agree link is equivalent to an operator-variable relation at the syntax-semantics in- 
terface and explains the obligatorly bound interpretation of reflexive clitics. Non-reflexive clitics have fully specified phi-feature values that block the generation of such an Agree link. This accounts for the fact that non-reflexive clitics cannot be bound by or be coreferential with a local antecedent. Non-local binding or coreference will be resolved in the semantic component of human language, as indicated in the table in (332). The fact that strong non-reflexive pronouns resist a bound variable interpretation will be attributed to the fact that strong pronouns are nearly DP-like in their feature composition. They have not only fully specified phi-feature values, but also a case feature and a lexical feature for animacy. In chapter 9 it will be proposed that this feature combination serves as an instruction at the syntax-semantics interface to interprete the pronoun as a free variable. ${ }^{79}$ Differently from non-reflexive strong pronouns, the non-reflexive clitic can be (non-locally) bound by all types of quantifiers. A reason might be that clitic pronouns lack the $\Sigma \mathrm{P}$ and NP projection and case. As for the strong reflexive pronoun, a bound interpretation is required due to the null-values and despite the fact that they have the $\Sigma \mathrm{P}$ and NP layer and case. At the syntax-semantics interface, the phi-features serve as instruction to interprete the reflexive pronoun as a bound variable.

79 I want to briefly mention the following implication of my analysis for the interpretation of the covert pronoun pro. Pro can be used as free and bound variable. If a bound interpretation is either licensed by null feature values or by the lack of $\Sigma \mathrm{P}$, the binding behaviour of pro could receive an explanation along the following lines. Pro has a full set of phi-features with specified values, just like overt strong pronouns, but the NP-layer lacks a feature for animacy. The $\Sigma$ P-layer specifies the covert realisation of the phi-features and pro cannot bear word stress or focus. It is the inability to bear word stress and focus that makes a bound interpretation possible. 



\section{True reflexives: an agreement-based analysis}

This chapter starts with a brief summary of the central questions of this book and the findings of the previous chapters and introduces the main aspects of the analysis 'in a nutshell'.

A syntactic generation of an anaphoric dependency is possible under three structural and interpretive conditions:

(i) Reflexive and non-reflexive pronouns are in complementary distribution. This means that the pronouns occupy the same structural position, but necessarily receive a distinct interpretation.

(ii) The relation between the antecedent and the pronoun is subject to structural constraints (locality and c-command).

(iii) A referential dependency generated by a syntactic operation is unambiguously interpreted as a bound variable dependency.

In chapter 5, the structural and interpretive diagnostics were applied to reflexive and non-reflexive direct and indirect object pronouns. In this context, the strong pronoun is obligatorily doubled with a clitic. It has been shown that only clitics fulfil the conditions for a syntactic encoding, whereas strong pronouns do not. Strong pronouns in Spanish and European Portuguese did not pass all tests; most importantly they do not show a strict complementary distribution. Thus, the analysis has to be built on the syntax of clitics and clitic doubling structures.

In chapters 5 and 2, it was shown that reflexive and non-reflexive pronouns show the same syntactic restrictions with respect to clitic doubling and should therefore be analysed in a uniform manner. This intuitively plausible idea challenges a long tradition of analyses that argue that (Romance) reflexive clitics are distinct from non-reflexive object clitics because the former, but not the latter, alter the thematic structure of the verb and create an intransitive predicate. In chapter 3, the Romance data and arguments were reviewed and it was shown for European Portuguese and Spanish that a uniform treatment of (true) reflexive and non-reflexive clitics is justified: both types of clitics represent the internal arguments of a transitive or ditransitive predicate and show the same clitic doubling syntax. Thus, the process of encoding must be dependent on the morphosyntax of cliticisation and clitic doubling on the one hand, and on the lexical property of being a reflexive and a non-reflexive pronoun on the other hand. The latter property has been formalised in terms of phi-feature values in the previous chapter. Null feature values are motivated on the basis of morphological and semantic considerations and are taken to express the referential defectiveness of reflexive pronouns (clitic and strong). The referential independence of non-reflexive pronouns is due to fully specified phi-feature values.

\subsection{The analysis in a nutshell}

The analysis put forward in this chapter is based on a uniform analysis for reflexive and non-reflexive clitic doubling structures and will show that the interpretation of the clitics falls out as a consequence of 
Agree in the sense of Chomsky (2000 et seqq.). It will be the peculiar behaviour of null feature values within the process of cliticisation that creates a configuration in which a dependency is established or, in the case of non-reflexive clitics, is blocked. If Agree applies between the clitic and the antecedent, referential identity is generated. If it does not apply, the result is a disjoint interpretation. In addition to the syntactic encoding of reflexivity and cliticisation, the analysis has to take into account the agreement dependencies proper to clitic doubling structures. The analysis consists of four different agreement relations illustrated schematically in (333).

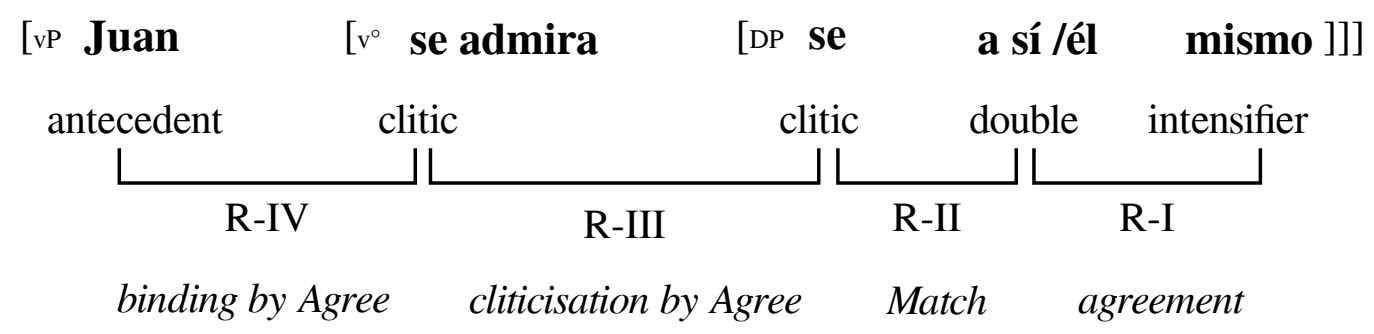

Starting from the right, the relation R-I is agreement between the double and the intensifier. This relation was discussed in section 6.3 and I will come back to it in section 7.7. The relations R-II and $\mathrm{R}$-III are crucial for a unified analysis of reflexive and non-reflexive clitic doubling structures. R-III is cliticisation, the process that relates the clitic to its verbal host, which will be implemented as agreement following Roberts (2010). Section 7.2 provides an introduction to the main aspects of Roberts's (2010) analysis. R-II is agreement between the clitic and the double, which will be implemented as a modified version of Chomsky's (2001:5) Match in section 7.3. This section starts with a compelling argument in favour of a bigDP analysis and discusses the structure of the bigDP. On the basis of considerations about case and coordination, a modified structure will be proposed. The relation R IV will be discussed in section 7.4. This relation is the agreement relation that holds when cliticisation has created a configuration in which upward valuation is possible. By means of upward valuation a referential dependency is established between the reflexive clitic and the subject DP. In the case of non-reflexive clitics, the configuration for upward valuation cannot be generated, upward valuation is impossible, and hence a referential relation between the subject and the non-reflexive clitic is blocked in syntax. In section 7.5, it will be shown how the analysis accounts for the Anaphora Agreement Effect. Section 7.6 focusses on the derivation of reflexive ECM predicates and of passive and ditransitive structures.

\subsection{Cliticisation by agreement: Roberts (2010)}

Given that reflexive and non-reflexive clitics realise arguments, they are base-generated in argument position. Under standard assumptions, the position of the direct object is the complement of VP, and the position of the indirect object is an applP. Differently from other DPs, the clitic cannot stay in this position. It must raise to a verb-related projection. This process is referred to as cliticisation. Recall from chapter 2.2.7 that this hybrid status of clitics, being both like free words (arguments) and 
like bound morphemes (affixes), has been explained by their hybrid categorial status as simultaneously minimal/ $\mathrm{X}^{\circ}$ and maximal/XP categories ${ }^{80}$ in Chomsky (1995b:62). Due to this hybrid status, clitics may behave as minimal and maximal categories with respect to movement and agreement. If the clitic moves as an XP element, cliticisation is basically a post-syntactic, morphological process. If the clitic moves as an $\mathrm{X}^{\circ}$ to a verb-related head, the result is incorporation of the clitic into the verbal head and cliticisation is a syntactic process. Roberts (2010), and recently Rizzi (2016), argue in favour of head movement within Minimalist phrase structure. ${ }^{81}$ The central argument in Roberts (2010) is that head movement is formally indistinguishable from agreement if defective $e^{82}$ elements are involved in the operations. By defining clitics as defective elements, cliticisation by head movement is formally indistinguishable from cliticisation by Agree. Clitics are defective or deficient with respect to the following properties. First, clitics are deficient with respect to their feature content. They consist only of a full set of interpretable phi-features and lack a case feature and a category feature. Secondly, clitics are deficient because their label is non-distinct from the label of their host. The label of a clitic is its phifeatures, represented as $\varphi^{\mathrm{min} / \mathrm{max}}$. This will allow clitics to incorporate into the verbal head. Finally, clitics are characterised as defective goals, as defined in (334).

A goal G is defective iff G's formal features are a proper subset of those of G's Probe P.

(Roberts 2010:62)

Roberts (2010) argues that Agree with a defective goal has the following consequence: the goal deletes and the probe will remain visible. Due to the defective feature content (just phi-features), the phi-probe and the clitic are identical. If the goal deletes and the probe remains visible, the PF effects of a movement operation are obtained. Under this assumption, head movement and Agree with a defective goal are conceptually indistinguishable (see Roberts 2010:61). An important consequence of this analysis is that the clitic literally becomes the probe on the verbal head. In the following, the main aspects of Roberts's approach to cliticisation are explained in more detail.

80 A minimal category is defined in Chomsky (1995a:245ff) as a terminal element that consists only of features and has no underlying parts. A head is a minimal element combined with a category label $\mathrm{X}$ and annotated as $\mathrm{X}^{\circ}$. In later work, Chomsky repeatedly revises the role of the label in the syntactic computation. In Chomsky (2008) the label is the locus of the probe, whereas in Chomsky (2013) labels are absent from the syntactic computation and the structure is labelled post-syntactically. Roberts (2010:54) mentions that the distinction between a minimal category and a head is probably not relevant for bare phrase structure. He uses the notation $X^{\min }$ and $X^{\max }$, instead of $X^{\circ}$ and XP. Accordingly, $X^{\min }$ and $X^{\max }$ will be used during the presentation of his approach, but they will later be replaced by the commonly used notation $\mathrm{X}^{\circ}$ and $\mathrm{XP}$, respectively.

81

Within the probe-goal framework, merge of two heads is excluded by the Extension Condition: 'The extension condition requires that displacement from within $\alpha$ be to the edge of $\alpha$ ' of Chomsky (2004:113) or by the No Tampering Condition: 'Merge of X and Y leaves the two SOs unchanged' of Chomsky (2008:138).

82 Roberts (2010) makes use of the concept of (structural) deficiency that was elaborated in Cardinaletti \& Starke (1999) and Déchaine \& Wiltschko (2002) (see chapter 6). 
The tree structure in (335) illustrates the structure in which the clitic merged as the complement of a VP $\left(\mathrm{V}^{\max }\right){ }^{83}$ The transitive little $\mathrm{v}\left(\mathrm{v}^{*{ }^{\mathrm{min}}}\right)$ has a phi-probe that enters into agreement with the clitic. Note that clitics are taken to be visible to the probe, even though they lack a case feature. This is one property that makes up a defective goal.

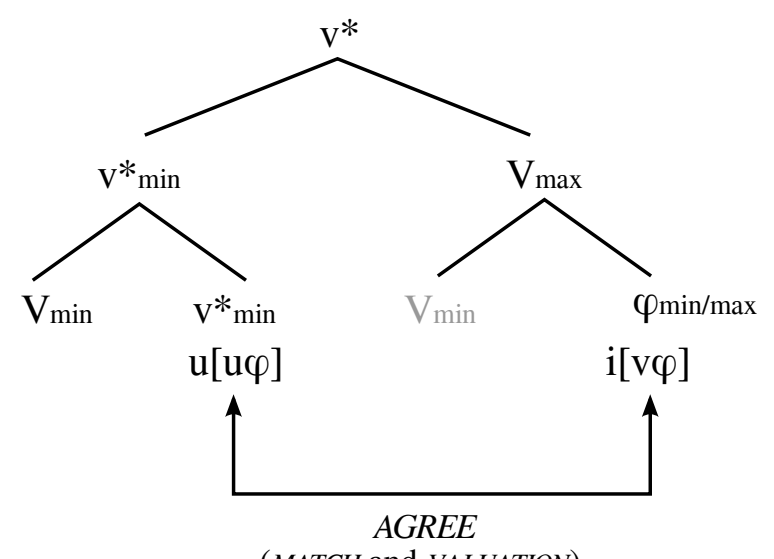

(MATCH and VALUATION)

After agreement, the features on the probe are valued and the clitic can undergo movement, Internal Merge with $\mathrm{v}^{* \min }$. The structure in (336) shows two possibilities to merge $\varphi^{\min / \max }$ with little $\mathrm{v}^{*}$ : via route $(\mathrm{A})$ or $(\mathrm{B})$.

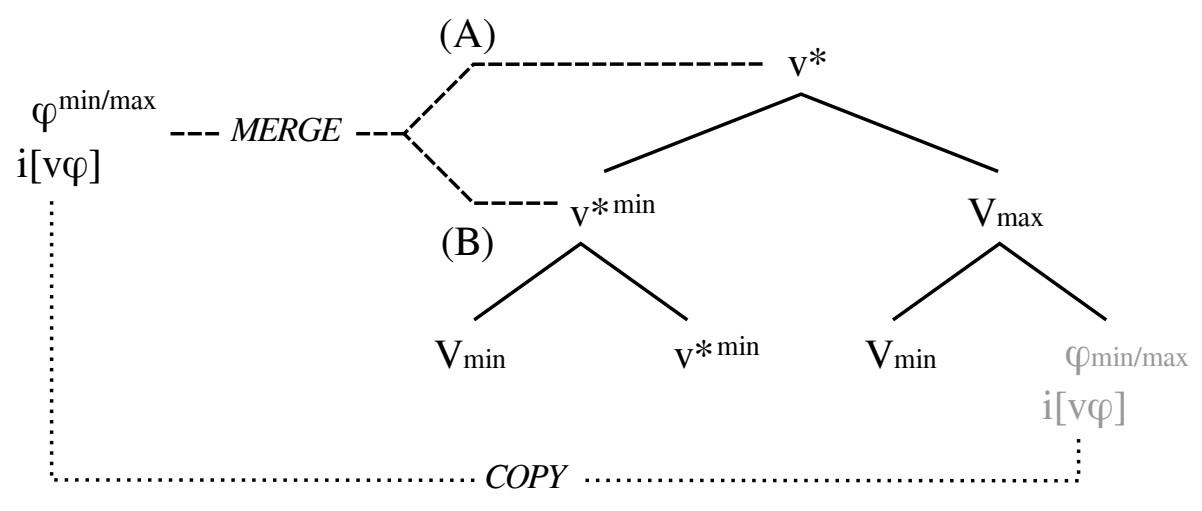

If Merge takes route (A), it targets the root of the syntactic object. This is the standard assumption in Minimalism, ${ }^{84}$ but Roberts (2010) and recently Rizzi (2016) ${ }^{85}$ argue in favour of route (B): Merge of two heads, which creates a complex head, as in (337).

83 An aspect that has been omitted for the purpose of illustration is the fact that $\mathrm{V}^{\mathrm{min}}$ has moved to $\mathrm{v}^{* \text { min }}$ before the clitic has moved. Roberts (2010:52), following Hornstein (2009), accounts for this ordering of movement operations in terms of a prominence rule. In short, less prominent elements may be moved before more prominent elements.

84 Following Chomsky (2008:145), Merge of $\varphi^{\min / \max }$ with little $\mathrm{v}^{*}$ will create a vP, due to the labelling algorithm in (i) or a $\varphi \mathrm{P}$ due to the labelling algorithm in (ii).

(i) If $\alpha$ is internally merged to $\beta$, forming $\{\alpha, \beta\}$, then the label of $\beta$ is the label of $\{\alpha, \beta\}$.

(ii) $\quad$ In $\{H, \alpha\}, H$ an LI, $H$ is the label. 


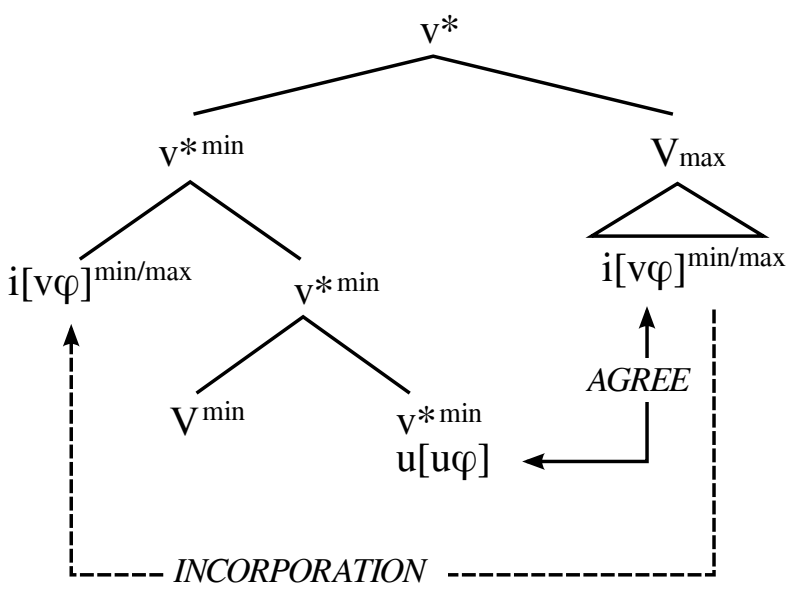

Roberts (2010) assumes that this structure is possible for two reasons: (i) $v^{* \min }$ is a phase and provides an edge position. He adopts the concept 'words as phases' of Marantz (2001, 2006). Lexical words are minimal phases because they form a unit at the interfaces and are the basic sound-meaning pairs. The clitic adjoins to the edge position of $v^{* \text { min }}$, and the two elements will form a unit at the interfaces. (ii) Formation of the complex head is possible because the label of a clitic is non-distinct from the label of $\mathrm{v}^{\mathrm{m}^{\mathrm{min}}}$, its verbal host. The property of non-distinctness is derived from the following definitions of minimal and maximal categories in (338).

(338) a. The label $\mathrm{L}$ of category $\alpha$ is minimal iff $\alpha$ dominates no category $\beta$ whose label is distinct from $\alpha$ 's.

b. The label $\mathrm{L}$ of category $\beta$ is maximal iff there is no immediately dominating category $\alpha$ whose label is non-distinct from $\beta$ 's.

Roberts (2010:54)

Due to the definition in $(338 \mathrm{a}), \mathrm{v}^{* \min }$ can remain minimal after merger with $\varphi^{\min / \max }$ because clitics do not affect the status of little $\mathrm{v}$ as mimimal category. In other words, the clitic does not cause little $\mathrm{v}$ to project a vP. In order to see the effect of the condition in (338b), let us look at the structure in (337). The topmost label, the label of $\left\{\mathrm{v}^{* \min }\left\{\mathrm{V}^{\max }\right\}\right\}$, is represented as $\mathrm{v}^{*}$ and not as $\mathrm{v}^{\text {max }}$ because there is no category dominating it yet with a label distinct from $\mathrm{v}^{\mathrm{min}}$.

Roberts (2010:61) argues that this type of head movement is formally indistinguishable from Agree with a defective goal. In the following, I will illustrate how the structure in (337) can be derived by Agree alone. In (337) there are three occurrences of the clitic's phi-feature set. The first occurrence is the clitic in its base position. Due to Agree, its phi-feature values have been copied onto the probe. Thus, the phi-probe on $v^{*}$ is identical to the clitic. Finally, the clitic has been moved to the edge position of $v^{* \text { min }}$, generating another instance of the clitic.

85 Rizzi (2016:119) claims that Internal Merge may target 'the whole root structure (phrasal movement), or just the root head, the probe'. This is possible if the No Tampering Condition ('Merge of X and Y leaves SO unchanged') applies only to the complement of a head/probe and not to heads themselves. 
Under standard assumptions, only the incorporated occurrence survives because (i) the probe deletes after valuation, and (ii) the lower copy deletes for PF reasons. Now, Roberts (2010) proposes that agreement with a defective goal causes the goal to delete and the probe to remain. This means that the features of the defective goal are copied onto the probe, and this copying exhausts the goal. As for cliticisation, this means that the probe of $v^{* \min }$ becomes the clitic and incorporation is no longer needed. Note that this implies that the uninterpretable features of the probe become interpretable. Cliticisation as agreement is illustrated in (339). The complex V/ ${ }^{*}$ min is simplified because it does not affect the position of the probe/clitic. A probe can be located in the label (or be the label), as discussed in Chomsky (2008:141), or the probe is located in the head, in case there is no label, as in Chomsky (2013). Both positions are taken to be equivalent with respect to minimal search. Thus, the locus of the probe can be either the label or the head itself. ${ }^{86}$ The internal structure of the complex head as assumed by Roberts (2010) is not decisive for my analysis because the probe can either be located in the label or on the head. In (339a), the phi-probe matches the clitic. The values of the clitic are copied onto the probe, and the clitic deletes in its base position, as illustrated in (339b).

(339) a.

Probing

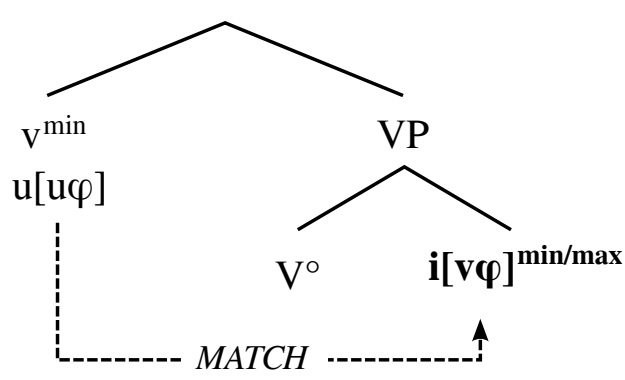

b. $\quad$ Copy and deletion

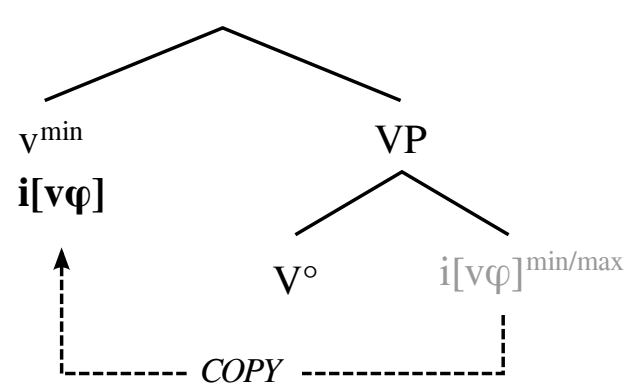

As the present analysis is not concerned with clitic placement or ordering in clitic clusters, I will not elaborate any further on the surface realisation of the clitics. The important implication of Roberts (2010) for my analysis is the fact that by copying the feature values of the clitic onto the probe, the probe literally becomes the clitic. Cliticisation with non-reflexive clitics will proceed as in (339). But reflexive clitics have null-values for gender and number and Agree with null values was defined as vacuous in section 6.1.3. The figure in (340) illustrates cliticisation with a reflexive clitic. The phi-probe matches the features of the reflexive clitic, and Copy takes place. The person feature has a specific value that can be successfully copied, and the former uninterpretable feature of the probe is now interpretable. But the null values of the number and gender features cannot be copied, and consequently the unvalued features of the probe remain without a specified value. They remain unvalued and uninterpretable. Although copying has been partially vacuous, the goal deletes and the probe remains.

86 Any agreement analysis that takes the clitic to be the spell-out of the probe, as for example in Mensching (2018), needs to assume some locus for clitic, and this might well be the edge position of a complex head, as argued by Roberts (2010). 
(340) Agree with null feature values on a defective goal
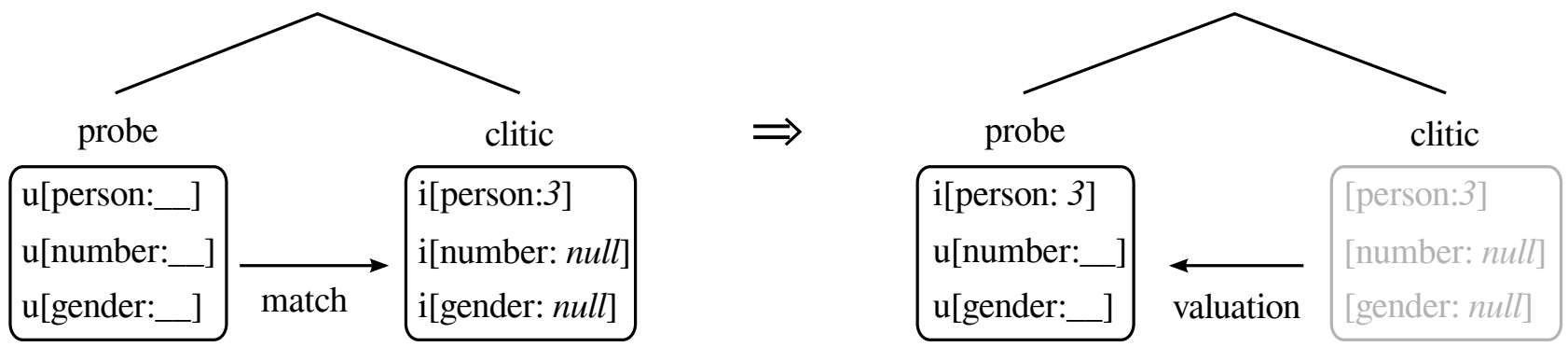

The result of cliticising a reflexive clitic is a probe with unvalued and uninterpretable number and gender features. Before illustrating how this result creates a configuration for binding by upward valuation inside little $\mathrm{v}$, let us first build up the base structure for clitic doubling, the complement of $\mathrm{V}^{\circ}$.

\subsection{Clitic doubling: the bigDP and the Matching Principle}

The generative approaches to clitic doubling in Romance address two central issues: first, the syntactic mechanisms that generate a clitic doubling structure, in particular the fact that the clitic and its double match in phi-features and have the same referent. In Suñer (1988), this fact is referred to as the matching principle. ${ }^{87}$ Among the Minimalist approaches to the matching principle, there are agreement-based, movement-based, and bigDP analyses (see for example Franco 1999, Margo 2019, Uriagereka 1995, Roberts 2010, and Gutiérrez-Rexach 2001). The second issue concerns distinct doubling systems, in particular the question why clitic doubling is required, optional, or unacceptable with certain types of DPs and how clitic doubling affects the interpretation of a sentence. For example, Gutiérrez-Rexach (2001) and Leonetti $(2007,2008)$ examine the different doubling systems in the varieties of Spanish and argue in favour of an account in terms of selection.

All the analyses mentioned above only consider non-reflexive clitics and non-reflexive doubles (pronouns and full DPs). Therefore, matching between the clitic and the double always requires identity in features and feature values. Depending on the analysis, these features are phi-features, [+spec] features, D-features, or referential indices. This strict identity is either generated by movement, agreement, or 'doubling, 88

In the next section, I will show that agreement-based or movement-based analyses fail to explain the clitic-double patterns observed throughout chapter 5 and will argue that only a bigDP analysis can, in principle, account for these patterns. The structure of the bigDP that is proposed in the present analysis

87 In Suñer (1988), clitics (in doubling structures) are agreement morphemes and are generated in $\mathrm{V}^{\circ}$ with valued features. The double is the complement of VP. An (agreement) chain is established between the clitic and the double due to the Matching Principle. An agreement chain in GB is well formed if (i) there is no clash in features (Suñer 1988:403), (ii) the clitic and its double are coindexed, (iii) the clitic c-commands its double, and (iv) the chain has one case feature and one theta role. Roberts (2010:132) simply states that 'clitic doubling quite literally involves doubling of the formative $l a$ [in the example La veo a la niña, addition by A.W.], with one occurring in $\mathrm{D}^{\circ}$ and one in $\varphi^{\circ}$. Uriagereka (1995:86 fn. 20) is also quite vague on the way 'doubling' takes place, and he only mentions that 'Romance clitics agree in person, gender, and number with their doubles'. 
is introduced in section 7.3.2. In section 7.3.3, the clitic-double patterns are derived by means of a modified version of Match that operates on phi-feature values.

\subsubsection{Why a bigDP analysis is inevitable}

The table in (341) shows all possible combinations of a clitic and a pronominal double, as discussed in the sections 2.2.6 and 5.2. The rows in (341a) and (341b) represent the patterns for doubling a reflexive clitic: it can be doubled with either a reflexive pronoun or a non-reflexive pronoun. The rows (341c) and $\left(341 c^{\prime}\right)$ show the patterns of the non-reflexive clitic doubled with a non-reflexive pronoun. The non-primed rows give the patterns for the direct object clitic and the primed rows show the patterns of the indirect object clitics. The rows (341d)-(341e') repeat the findings concerning doubling a nonreflexive clitic with a reflexive pronoun. These patterns are limited to non-local contexts and are subject to language-specific constraints. ${ }^{89}$

(341) Clitic-double combinations

\begin{tabular}{cccccc} 
& Clitic & Double & \multicolumn{2}{c}{ Languages } & Antecedent \\
a. & se & si / sí (DO, IO) & EP $\checkmark$ & Sp. $\checkmark$ & local \\
\hline b. & se & ele / él (DO, IO) & EP $\checkmark$ & Sp. $\checkmark$ & local \\
\hline c. & o(s) / lo(s) & ele(s) / él(ellos) & EP $\checkmark$ & Sp. $\checkmark$ & non-local \\
c'. & lhe(s) / le(s) & ele(s) / él(ellos) & EP $\checkmark$ & Sp. $\checkmark$ & non-local \\
\hline d. & o / lo & si & EP $\checkmark$ & Sp. $*$ & non-local \\
d'. & os / los & si / sí & EP $*$ & Sp. $*$ & non-local \\
\hline e. & lhe $/$ le & si /sí & EP $\checkmark$ & Sp. $\checkmark$ & non-local \\
$\mathrm{e}^{\prime}$. & lhes $/$ les & si /sí & EP $*$ & Sp. $\checkmark$ & non-local
\end{tabular}

Every analysis of clitic doubling that takes the clitic to be a copy of its double, generated either by agreement (Suñer 1988, Franco 1999) or by movement (Magro 2019 and references cited within), has trouble explaining the patterns in (341b) and all cases of doubling a long-distance reflexive, the cases in (341d) and (341e,e'). The two types of approaches will be briefly illustrated, and it will be shown that these analyses can only generate clitics that are identical copies of the (phi-)features and the phi-feature values of their double, such as the doubling patterns in (341a) and (341c, $\left.c^{\prime}\right)$. The agreement analysis is schematically represented in (342). In this type of analysis, the clitic is taken to be the spell-out of agreement features on the verb. The verb agrees with the strong pronominal double. This agreement is represented in (342a) as a probe-goal relation. The valued phi-features on the verb's probe will be spelled out as the clitic, as exemplified in (342b).

89 European Portuguese allows for long-distance reflexives in clitic doubling structures, but only with a singular antecedent and a verb in subjunctive mood. In Spanish, this phenomena is an exception and restricted to special contexts (see section 5.2.3). 
(342) a. Agreement of verb and double

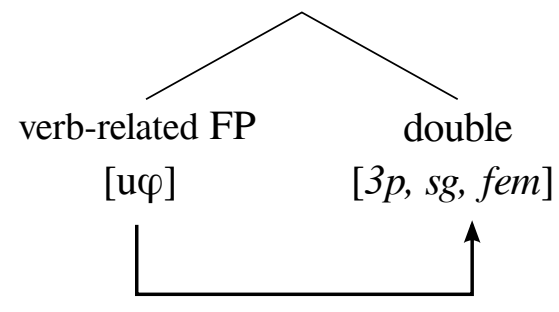

b. Clitic as spell-out of agreement features

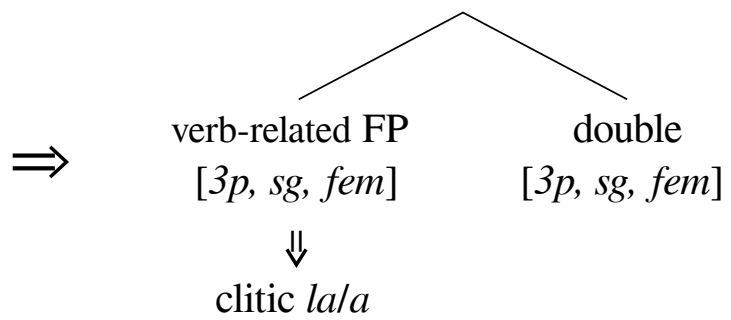

The movement analysis is represented in (343). As discussed in Magro (2019), several approaches explore the possibility of deriving the clitic from the copy generated by movement of the double. The first step, shown in (343a), is agreement between transitive little $\mathrm{v}$ and the pronoun. After agreement, an EPP feature on $\mathrm{v}^{\circ}$ triggers movement of the double to specvP, as illustrated in (343b).

(343) a.

Agreement of verb and double

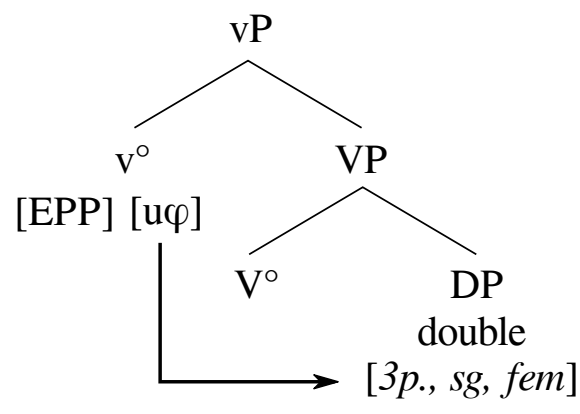

b. Clitic as spell-out of the higher copy

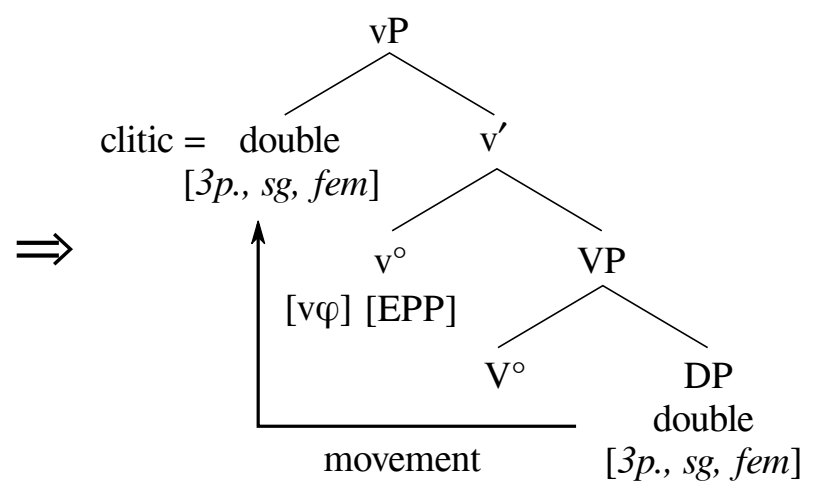

Under standard assumptions about movement/Internal Merge, only one copy can survive at Transfer/Spell-Out, and all other copies must delete. But this is crucially not the case in this type of analysis. The lower copy will be spelled out as the double, and the higher copy will become the clitic. In order to derive the clitic, a reduction process is assumed that eliminates all features except a D-feature and phi-features from the higher copy. This reduced feature set is then spelled out as the clitic. Again, the phi-features of the clitic and the double are identical.

With respect to the clitic-double combinations in table (341) above, all these analyses are empirically inadequate because they predict identity of the clitic and the double in features and feature values. Only an analysis that takes the clitic and its double as two distinct lexical items can, in principle, account for these doubling patterns. Such an analysis is Uriagereka's (1995) bigDP analysis.

The structure of the bigDP assumed for the analysis of Spanish and European Portuguese clitic doubling structures will be introduced in the next section, after a brief discussion of Uriagereka's (1995) bigDP, the Minimalsit version of Roberts (2010) and the structure proposed in Gutiérrez-Rexach (2001). 


\subsubsection{The structure of the bigDP}

Uriagereka's (1995) bigDP is illustrated in (344) together with the Minimalist version of Roberts (2010) and the structure proposed in Gutiérrez-Rexach (2001). Before introducing a modified version, the analyses will be briefly presented focussing on the following aspects: the base position of the clitic and the double, the position and the role of the case element $a$, and their account for the matching principle.

(344) a. Uriagereka (1995)

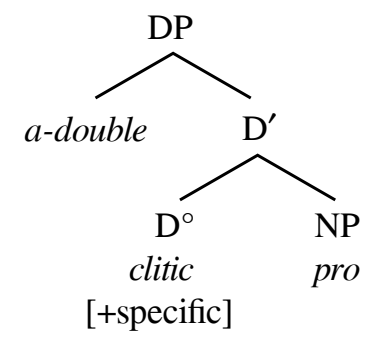

b. Roberts (2010)

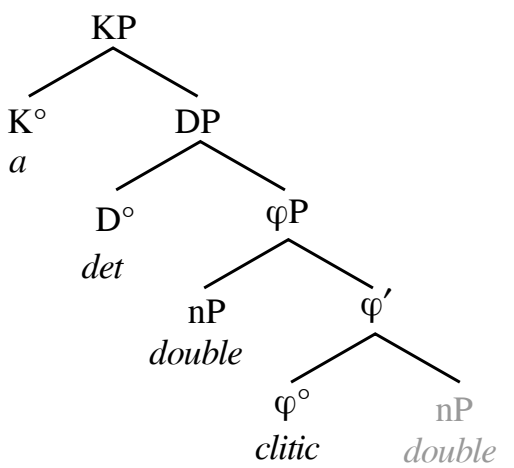

c. Gutiérrez-Rexach (2001)

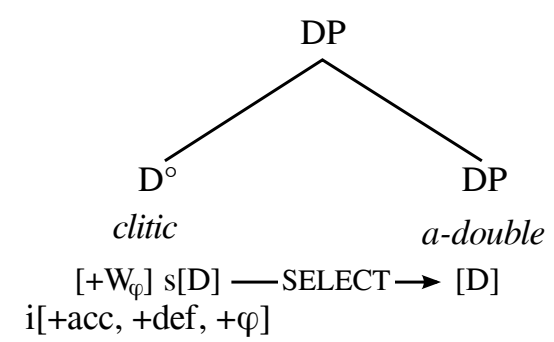

Uriagereka (1995) assumes that the clitic is a $\mathrm{D}^{\circ}$ element that merges with a pro complement. The double is base-generated in the specifier of this $\mathrm{D}^{\circ}$, forming the bigDP. He motivates the bigDP on the basis of the morphological and semantic similarity between the definite article and the direct object clitic in Spanish and Galician. Roberts (2010:132) takes up this intuition and states that a clitic is essentially a double of the determiner. Note that he limits his discussion of clitic doubling to full definite DPs. This type of doubling is possible in Latin-American varieties of Spanish, but not in Standard Penisular Spanish. In his structure, the $\mathrm{D}^{\circ}$ position is occupied by the definite article, but the nominal part of the double is base-generated as the complement of the clitic. The $\mathrm{nP}$ raises to $\operatorname{spec} \varphi \mathrm{P}$ in order to license its specific interpretation (see Roberts 2010:134). ${ }^{90}$ In Gutiérrez-Rexach (2001), the clitic selects for the doubled DP as its complement. Selection is formalised as checking of semantic and categorial features. It is under selection that phi-agreement between the clitic and its double takes place. Unlike Roberts (2010) and Uriagereka (1995), Gutiérrez-Rexach (2001) gives an explicit account to the matching principle (see footnote 88). For this reason, Gutiérrez-Rexach's (2001) base structure will be adopted for the present analysis with some modifications that will be introduced below.

As for the element $a$, all three analyses consider it to be a case-assigning preposition in the sense of the Kayne/Jaeggli generalisation (see section 2.2.6 ). Note that $a$ is part of the double in Uriagereka (1995) and Gutiérrez-Rexach (2001), but in Roberts (2010) it realises a K(ase) Phrase heading the bigDP. This position and its role as case assigner is crucial for Agree (cliticisation) to successfully target the clitic. Roberts' (2010) Agree-based approach to cliticisation was presented in the previous section and will be adopted here because it relies on phi-features only and is independent of categorial features

90 This movement is triggered by an $\mathrm{N}$ feature and an EPP feature on $\varphi^{\circ}$. These features are taken to represent the 'strength' of determiners in Uriagereka's (1995) analysis. 
or features for definiteness and specificity. ${ }^{91}$ In Uriagereka (1995) and Gutiérrez-Rexach (2001), cliticisation is formalised as movement triggered by semantic and prosodic features, respectively. ${ }^{92}$

In the following, I will present arguments in favour of the structure in (345). These arguments are based on data from coordination and on considerations about case. I will argue against the conception of $a$ as a case-assigning preposition, as assumed in Uriagereka (1995), Gutiérrez-Rexach (2001), and Roberts (2010) and in favour of the analysis of Cardinaletti \& Starke (1999). They argue that $a$ realises the pronoun's case feature and is therefore an integral part of the pronominal structure. In their split-DP system, the projection that hosts the case marker is labelled CP, in analogy with the sentence structure. In the present analysis, the label KP will be used. Based on the findings from the previous chapters, the pronoun (without case) is taken to realise a $\Sigma \mathrm{P}$, and its topmost projection is a KP that hosts the element $a$ and an unvalued case feature.

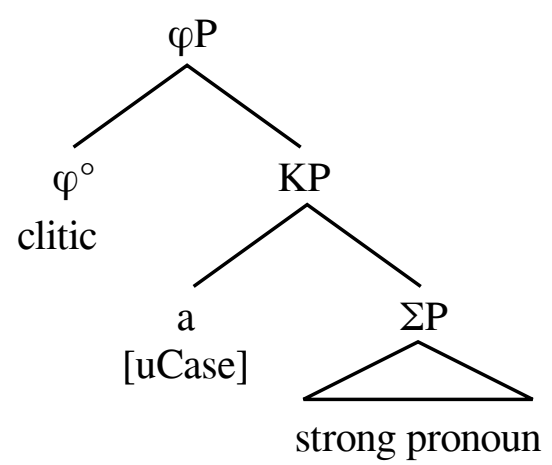

As for the position of the clitic, I will follow Gutiérrez-Rexach (2001) and assume that the clitic merges with the KP-double as its complement. It will be upon Merge that matching between the clitic and the pronouns phi-features takes place. But let us start with the role of $a$ as a case-assigning preposition.

\subsubsection{The role of $a$ : case assigner or case marker?}

As mentioned above, the element $a$ as a case-assigning preposition plays a crucial role in the analysis of Roberts (2010). The role of $a$ in his analysis is illustrated in (347) below by means of Roberts' (2010) example from Porteño Spanish (PSp.), a Latin-American variety of Spanish that allows for clitic doubling of definite DPs. The sentence is given in (346).

91 Leonetti $(2007,2008)$ also argues against a [+specific] feature on object clitics and proposes that a specific interpretation of clitic doubling may be derived compositionally as in the (formal) semantic account of Gutiérrez-Rexach (1999).

92 In Uriagereka (1995), it is the [+specific] feature on the clitic that prevents it from staying inside the VP. According to the Mapping Hypothessis of Diesing (1992), all [+specific] material must be outside the VP at LF. The movement operation itself is triggered by the clitic's need for a referential index, which is provided in F, a verb-related projection. The referential index is associated with the person feature. Strong pronouns have a person feature and may stay in situ, but determiners do not. Thus, the determiner-clitic needs to acquire the person feature in F in order to license the pro complement (see Uriagereka (1995:93f). In Gutiérrez-Rexach (2001), cliticisation is conceived as PF movement triggered by the weak prosodic feature $\left[\mathrm{W}_{\Phi}\right]$ which is checked against a strong $\left[\mathrm{W}_{\Phi}\right]$-feature of the verbal host. 


$$
\begin{aligned}
& \text { PSp. La veo a la niña. } \\
& \text { her.CL= see.1.SG OM the girl } \\
& \text { 'I see the girl.' }
\end{aligned}
$$

In (347a), the bigDP [a la niña la] merged with little $\mathrm{v}$ that hosts a phi-probe. Now the phi-probe of $\mathrm{v}^{\circ}$ searches the bigDP and has three potential matching goals: the phi-features of the determiner $l a$ in $\mathrm{D}^{\circ}$, the phi-features of the nP niña and the clitic la in $\varphi^{\circ}$. The clitic is the desired goal, but it is the most deeply embedded element and has no chance to become the goal. Here is where $a$ comes into play. Roberts (2010) argues that it is the preposition $a$ that inactivates the determiner and the $\mathrm{nP}$ as potential goals, as illustrated in (347b). The preposition $a$ has a valued case feature that satisfies the unvalued case feature on the $\mathrm{nP}$. The $\mathrm{nP}$ is now invisible for the probe. Furthermore, $a$ itself has unvalued phifeatures that probe and agree with the determiner. Due to these properties, $a$ inactivates the $\mathrm{nP}$ and the $\mathrm{D}^{\circ}$ as potential goals, and the clitic is the only goal left for the probe on $\mathrm{v}^{\circ}$.

(347) a. Probing the bigDP 93

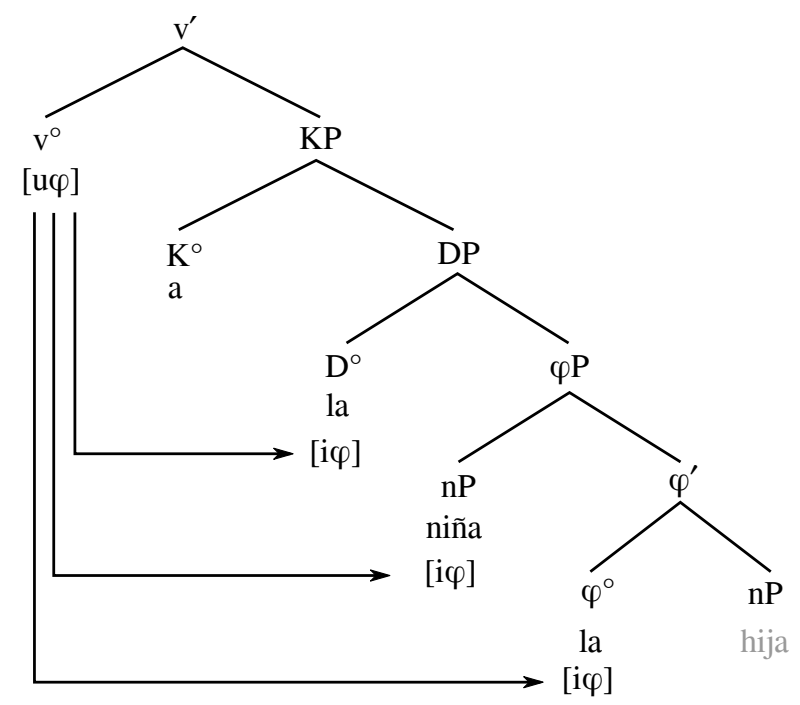

b. Inactivating goals

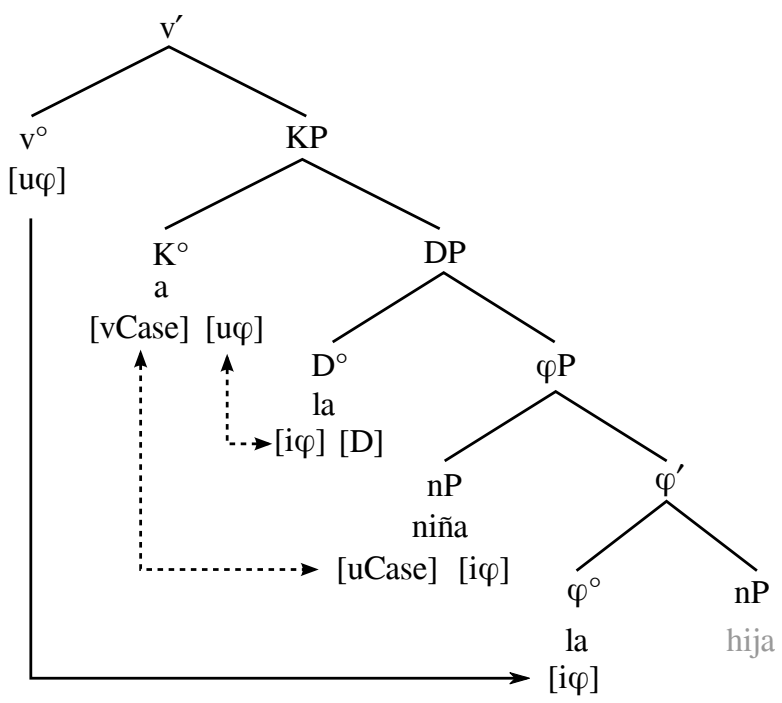

This is an elegant solution, but what seems to remain unexplained is why clitic doubling is possible only with $a$ and not with other case-assigning prepositions. Recall the pattern in (196), repeated here as (348) with examples from European Portuguese. Both verbs-admirar and confiar-are thematically transitive verbs. Either verb has an experiencer subject and selects for a theme complement, but only admirar allows for an object clitic and clitic doubling. The sentence with confiar and an object clitic is ungrammatical. Intuitively, this difference is due to the case properties of the verbs. Verbs of the admirar type assign accusative case and select for a DP-complement, whereas verbs of the confiar type do not assign case and select for a PP-complement.

93 For the sake of convenience, the labels $\mathrm{X}^{\mathrm{min}}$ have been replaced by the common notation for terminal elements using $\mathrm{X}^{\circ}$ and the label $\mathrm{X}^{\mathrm{max}}$ is replaced by XP. 
Direct object

a.

$a^{\prime}$.
A Rita admira-o (a ele)

' $R$. admires him.'

*A Rita admira- $\varnothing$ a ele
PP-complement

b. A Rita confia nele.

'R. trusts in him.'

$\mathrm{b}^{\prime} . \quad *$ A Rita confia-o/lhe

This intuition is not captured in the analysis of Roberts (2010). Instead, $a$ assigns case to the np/NP, just as other prepostions do. With respect to case, the KP and the PP are indistinguishable. Let us assume the following situation: the preposition $a$ is merged with a DP such as una mujer, 'a woman', and $a$ values the case feature of the DP. Now, this DP merges with a transitive verb, but the probe on $\mathrm{v}^{\circ}$ does not find an active goal. The derivation should crash because the probe's features remain unvalued and cannot delete at the interfaces. Thus, $a$-marking without clitic doubling is predicted to be impossible, contrary to the Spanish data presented in chapter 2, such as $a$-marking of indefinite DPs. For this reason, I reject the conception of $a$ as a case-assigning preposition and adopt instead the proposal of Cardinaletti \& Starke (1999) that $a$ realises the pronoun's case feature and acts as a case marker.

\subsubsection{Coordination and the position of $a$}

As for the position of the case marker $a$, two different proposals have been put forward in the literature. Cardinaletti \& Starke (1999) argue that $a$ is an integral part of the pronominal structure and realises the case feature in the topmost position of their split-DP system. López (2012) argues against Cardinaletti $\&$ Starke (1999) and assumes that $a$ realises a head independent of the nominal or pronominal structure. Thus, the case marker is either part of the double, as in Uriagereka (1995) and Gutiérrez-Rexach (2001), or it is outside, as in Roberts (2010). Both Cardinaletti \& Starke (1999) and López (2012) base their proposal on coordination data.

Cardinaletti \& Starke (1999) show by means of the Italian examples in (349) that in a coordination of two pronouns, each pronoun has to be $a$-marked. The ungrammaticality of the coordination in (349b) in which $a$ heads the coordination is attributed to the fact that $a$ cannot be separated from the pronouns.

(349) a. It. Ho parlato [[KP a loro ]e [KP a loro ]]. (Cardinaletti \& Starke 1999:180) have spoken OM them and OM them

'I talked to them and to them.'

b. $\quad *$ Ho parlato [KP a [[DP loro] e [DP loro ]]].

(ibid.)

have spoken oM them and them

'\#I talked to them and them.'

The case marker is thus not an independent head that selects for the pronoun or a coordination of pronouns, but an integral part of the pronominal structure.

López (2012) argues against Cardinaletti \& Starke's (1999) proposal on the basis of the examples in (350). Due to the grammaticality of (350a) and (350b), he assumes that $a$ realises a separate head $\mathrm{K}^{\circ}$ that selects either a DP or a coordination of DPs. 
(350) a. Sp. Juan encontró [[a un hombre] y [a una mujer ]].

(López 2012:50)

J. met ом a man and ом a woman

'Juan met a man and a woman.'

b. Juan encontró [a [un hombre y una mujer ]].

(ibid.:51)

J. met oM a man and a woman

'Juan met a man and a woman.'

Note that (350a) and (350b) differ with respect to their interpretation. Camacho (2003:64) points out that a coordination of DPs headed by $\mathrm{K}^{\circ}$, as in (350b), involves a single event and the coordination of DPs is interpreted collectively. But a coordination of KPs, as in (350a), is interpreted distributively. There are two events: one event of meeting a man and one event of meeting a woman. How this is related to coordination of pronouns in Spanish and European Portuguese will become clear in a moment.

Neither the examples from Cardinaletti \& Starke (1999) nor the examples from López (2012) involve clitic doubling. The Spanish and European Portuguese equivalents to the Italian example in (349) above come in two versions, given in (351) and (352). In (351), the clitic shows plural agreement and in (352) the clitic only agrees with the first conjunct.

(351) a. Sp. Juana nos quiere mucho [a ti y a mí ].

J. us.1.PL.CL=loves much OM you.2.SG and om me.1.SG

'Juana loves us very much, you and me.'

b. EP A Rita admira-nos [a ti e a mim ].

the R. admira=us.1.PL.CL om you.2.SG and om me.1.SG

'Rita admires us, you and me.'

(352) a. Sp. Juana te quiere mucho [a ti y a mí ].

J. you.2.SG.CL=loves much om you.2.SG and om me.1.SG

'Juana loves you very much, and she loves me very much.'

b. EP A Rita admira-te [a ti e a mim ].

the R. admira=you.2.SG.CL om you.2.SG and om me.1.SG

'Rita admires you, and she admires me.'

In both types of sentences, the element $a$ has to be present with the single pronouns. The sentences in which $a$ selects for a coordination of pronouns is ungrammatical, as shown in (353). These examples support the analysis of Cardinaletti \& Starke (1999) that $a$ is an integral part of the pronominal structure.

(353) a. Sp. *Juana nos quiere mucho [a $\left[\begin{array}{llll}\mathrm{ti} & \mathrm{y} & \mathrm{mí}\end{array}\right]$.

J. us.CL=loves much om you and me

b. EP *A Rita admira-nos [a $\left[\begin{array}{lll}\text { ti } & \text { e } & \text { mim}\end{array}\right]$.

the R. admira=us.CL om you and me 
c. Sp. *Juana te quiere mucho [a $\left[\begin{array}{lll}\text { ti } & \text { y míl] }\end{array}\right]$

J. you.cL=loves much om you and me

d. EP *A Rita admira-te [a $\left[\begin{array}{lll}\text { ti } & \text { e } & \text { mim }\end{array}\right]$.

the R. admira=you.cL om you and me

But the examples in (351) and (352) differ not only with respect to the agreement patterns of the clitics, but also with respect to their interpretation and their underlying structure. In (351), the first person plural clitic represents the enitre coordination and the coordinated DPs are interpreted collectively. In (352), the collective interpretation is not available. The coordination must be interpreted distributively. From a structural point of view, the sentences in (351) are an instance of clitic (right) dislocation and only the sentences in (352) are real clitic doubling structures. The difference can be shown by means of a dislocation test. The coordination in (351) can be moved to the left periphery, as shown in (354), but not the coordination in (352), as shown in (355).

(354) a. Sp. [A ti y a mí ] Juana nos quiere mucho.

OM you.1.SG and om me.1.SG J. us.cL.1.PL= loves much

'You and me, Juana loves us very much.'

b. EP [A ti e a mim ] a Rita nos admira.

OM you.2.SG and om me.1.SG the R. us.CL.1.PL=admira

'You and me, Rita admires us.'

(355) a. Sp. * * A ti y a mí ] Juana te quiere mucho. om you.2.SG and om me.1.SG J. you.CL.2.SG=loves much

b. EP *[A ti e a mim ] a Rita te admira. om you.2.SG and om me.1.SG the R. you.CL.2.SG=admira

The ungrammaticality of (355) indicates that the sequences [a ti y a mí] and [a ti e a mim] cannot be a coordination of two KPs or DPs. The structure of (352) most probably involves the coordination of a verbal phrase at the vP/TP level with subsequent deletion of all material but the object pronoun. ${ }^{94}$ That kind of structure is additionally supported by the distributive interpretation. On the basis of these examples, it can be concluded that the double of a clitic cannot be coordinated. Thus, coordination is not an appropriate diagnostic for the position of $a$ in clitic doubling structures. But the explanation for the ban of coordinating a double of a clitic along the lines of Sauerland (2003) offers an argument in favour of the position of the clitic assumed in the structure in (345) above.

94 The structure in (i) represents such a type of coordination, but a detailed answer is beyond of the scope of the present analysis. (i) Sp./EP [[te VERB a ti] e [me VERB a mí / a mim]] 


\subsubsection{Coordination and the position of the clitic}

Sauerland (2003) discusses the interpretation of phi-features, in particular of number, and he illustrates his account with sentences similar to the ones in (356). The two DPs inside the coordination are singular, but the entire coordination as subject of the sentence is interpreted as plural and it triggers plural agreement on the verb.

(356) a. Sp. [Rita y Marta] son mejores amigas. [R.SG and M.sG]=PL are.PL best friends

b. EP [A Rita y a Marta] são melhores amigas.

[the R.SG and the M.SG]=PL are.PL best friends

'Rita and Maria are best friends.'

This phenomenon has been formalised in Sauerland (2003) as follows: he proposes that only those features of a DP that are relevant for its interpretation are projected to a $\varphi \mathrm{P}$, which is the topmost projection of a DP. ${ }^{95}$ A similar proposal is made in Landau (2016), following Danon (2011). ${ }^{96}$ In a coordination of DPs, each DP and the coodination itself projects its own $\varphi \mathrm{P}$, as shown in (357). The DPs are both third person singular, but the coordinated phrase is interpreted as third person plural and it triggers plural agreement on the verb. Thus, there is some process that unifies the features of the conjuncts and forms one set of phi-features that is involved in DP-external agreement and in interpretation.

Coordination of two singular DPs (Sauerland 2003)

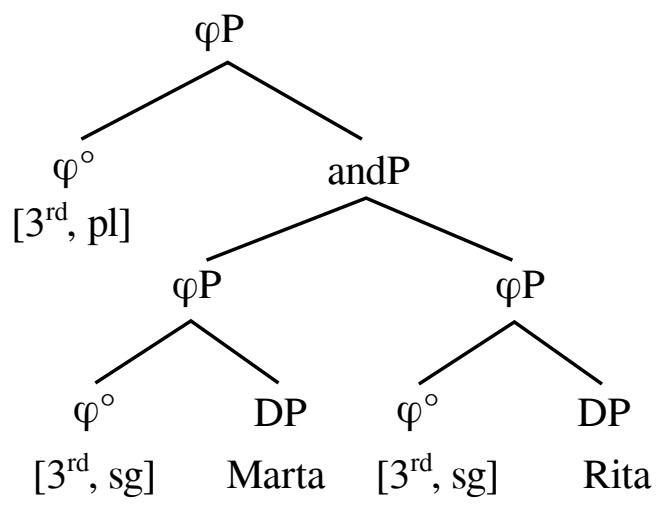

In the clitic left/right dislocation in (351) and (354), the clitic is similar to the topmost $\varphi \mathrm{P}$ in (357): the clitic represents the interpretation of the entire coordination, and it enters into agreement with the verb (cliticisation). Thus, a similar process could be involved in the formation of the clitic in these structures. The pronouns are in the first and second person singular, but the entire coordination is represented by

95 In Sauerland (2003), only those features that are projected to the $\varphi \mathrm{P}$ will be interpreted semantically. Occurrences of the same feature inside the DP, such as on the noun, determiner, or adjective, are not interpreted and are taken to be purely grammatical.

96 In their accounts, the features relevant for interpretation are those that are involved in subject-verb agreement. They are located in the highest head of a DP or a coordinated DP. 
a first person plural clitic. The clitic can be understood as the realisation of Sauerland's (2003) $\varphi \mathrm{P}$, and the coordinated pronouns in clitic left/right dislocations have the structure as in (358).

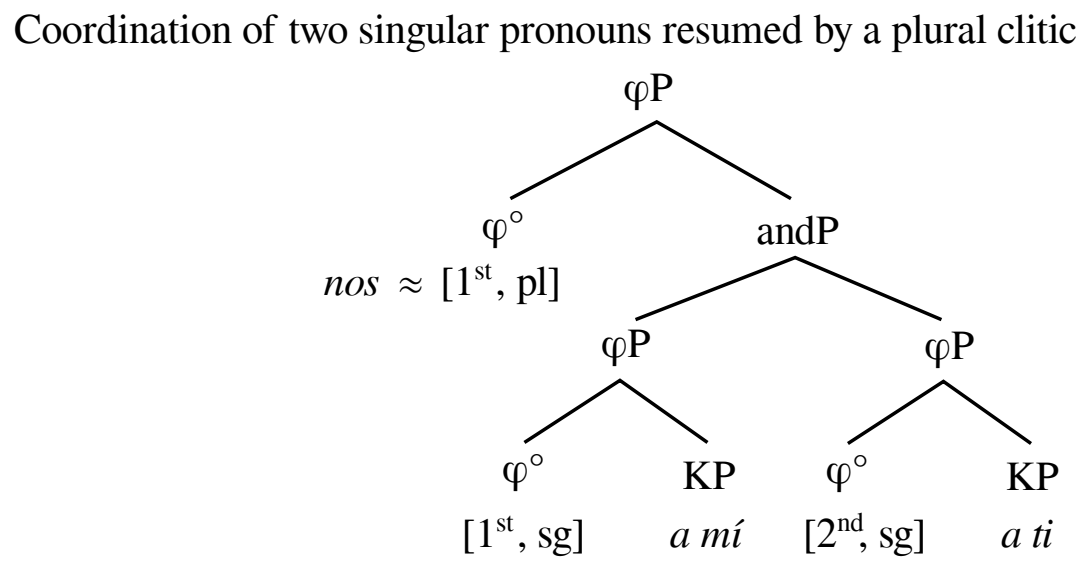

Now let us see how this comparison offers a way to account for the ban of a clitic doubling a coordination. If the sentences in (352) above were a coordination of two pronouns doubled by a clitic, the structure would look as in (359). The first conjunct is a bigDP with the clitic base-generated above the $\mathrm{KP}$, and the second conjunct is a simple KP. Now, the topmost $\varphi \mathrm{P}$ should contain a $\left[1^{\text {st }}, \mathrm{pl}\right.$.] feature set representing the interpretation of the entire coordination, but it is the clitic te that will enter into agreement with the verb (cliticisation) and it is second person singular. This creates a mismatch between the topmost $\varphi \mathrm{P}$ and the clitic. Another reason for the ungrammaticality of clitic doubling a coordination could be that the clitic prevents the formation of the topmost $\varphi \mathrm{P}$ because lexical material cannot be altered during the derivation.

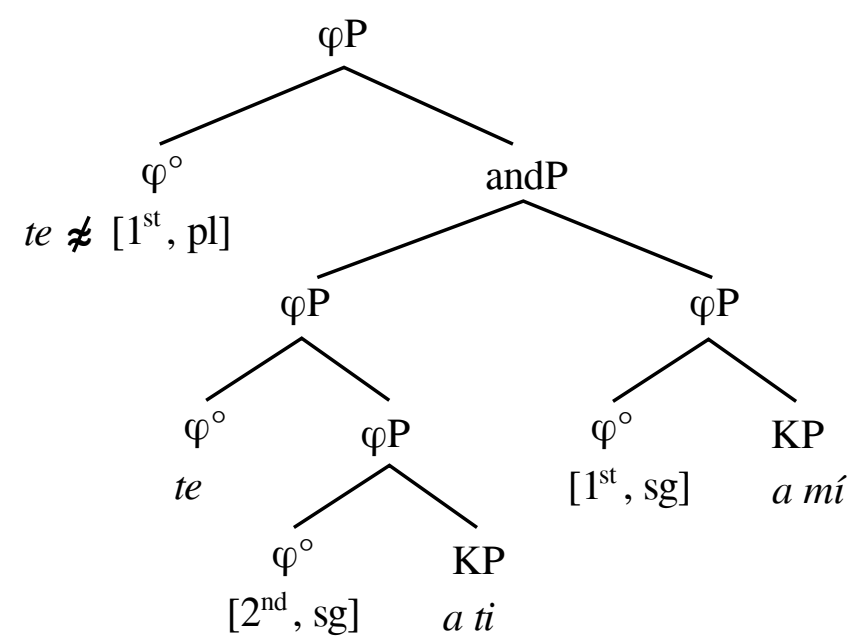

Similar to Sauerland's (2003) $\varphi \mathrm{P}$, the clitic determines the interpretation of the double, as we have seen throughout chapter 5. This intuition is captured in the analysis of Gutiérrez-Rexach (2001). The clitic selects for its double, as in the structure in (345) above, and by means of this selectional process it determines the interpretation of the double. The next section is devoted to a modified version of this approach in order to account for the clitic-double patterns presented at the beginning of this section. 


\subsubsection{Match under Merge/Select: identity of features and feature values}

The matching relation proposed here is inspired by the accounts of Gutiérrez-Rexach (2001) and Leonetti (2007, 2008), according to which clitic doubling involves selection. The clitic selects for a DP complement and forms a bigDP. In Gutiérrez-Rexach (2001), the clitic is the selecting element because it imposes its interpretation on the double. ${ }^{97}$ For example, in Latin-American Spanish varieties, the clitic forces a specific interpretation of its indefinite DP double. The clitic has a selectional feature, a Dfeature, or a combination of a D-feature and a [+animate] feature, if doubling is additionally restricted by animacy. In Gutiérrez-Rexach (2001), the clitic selects a DP, and the DP has to match the lexical and categorial features of the clitic. This is represented schematically in (360).

$$
\text { Match under select (Gutiérrez-Rexach 2001, Leonetti 2007, 2008) }
$$

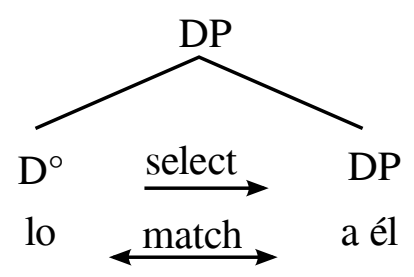

In the languages under discussion here, (Standard) Peninsular Spanish and European Portuguese, clitic doubling is obligatory with reflexive and non-reflexive pronouns. This means that the clitic obligatorily selects for an overt or covert pronominal double and determines its interpretation. The interpretation of pronouns is analysed in terms of phi-features and phi-feature values. Thus, in order to account for the referential identity between the clitic and its double, I assume that clitic doubling involves matching of phi-features upon Merge/Select. ${ }^{98}$ Differently from Match defined as suboperation of Agree in Chomsky (2001:5), Match in clitic doubling involves two sets of interpretable and valued features. This means that Match in clitic doubling checks not only for the identity of feature names, but also for the identity of phi-feature values. Recall from chapter 6 that the phi-feature values on the pronouns introduce a presupposition, they restrict the set of possible referents and antecedents. For example, a specified value, such as singular, presupposes that the pronoun's referent is an atomic entity, and a null-value does not introduce a specific presupposition. Therefore, checking for the identity of feature values includes checking for compatible presuppositions. The phi-feature values are evaluated

97 Leonetti $(2007,2008)$ argues in favour of the approach of Gutiérrez-Rexach (2001) because it allows one to account for distinct clitic doubling systems by means of a language-specific matching relation. For example, certain Latin-American varieties of Spanish such as Porteño Spanish allow not only for doubling of pronouns, full definite DPs, or proper names, but also doubling of indefinite DPs. In Spanish-Quechua contact varieties doubling may even involve invariant, non-matching clitics (see Leonetti 2008, citing Sánchez 2003). The matching relation is distinct for each type of doubling system. (Standard) Peninsular Spanish belongs, according to Leonetti (2008:49), to the set of languages with 'the most severe case of identity requirement' because obligatory doubling is limited to (definite) pronouns. This is also true for European Portuguese.

98 This is also in the line with Boeckx (2003), who conceives selection as a subtype of Match/Agree. His proposal is based on West Flemish agreeing complementisers. $\mathrm{C}^{\circ}$, the host of the complementiser, selects finite phi-complete $\mathrm{T}^{\circ}$. Under Match, the complementiser agrees with $\mathrm{T}^{\circ}$. 
as follows: if the clitic has a specified value, the double has to have an indentical value. If the clitic has a feature with a null-value, every value on the double will match. The matching relation for clitic doubling - Match-ClD—is represented more formally in (361). The condition in (361c) states that a null-value on the clitic matches every value on the pronoun, and vice versa.

Match in clitic doubling (Match-CID)

(I) $\mathrm{f}$ is an interpretable, valued feature,

(II) $\mathrm{f}_{\text {clitic }}$ is identical to $\mathrm{f}_{\text {pronoun, }}$

(III) the presupposition introduced by the value of $\mathrm{f}_{\text {clitic }}$ is compatible with the presupposition introduced by the value of $\mathrm{f}_{\text {pronoun }}$.

Let us see how this proposal accounts for the clitic-double combinations presented above in (341), represented schematically in (362)-(366) as feature bundles. The conditions I and II of Match-CID are satisfied in all cases because the clitics and the strong pronouns have a full set of valued and interpretable phi-features. The important condition is condition III, which expresses the requirement for referential identity between the clitic and the double. The illustration in (362) shows the combination of a nonreflexive DO clitic and a non-reflexive strong pronoun. In (362a), the conditions of Match-CID are satisfied because the clitic and the pronoun have indentical values and the respective presuppositions are compatible. The example in (362b) shows a clitic and a pronoun with non-matching values. The patterns with incompatible presuppositions introduced by the distinct number and gender feature values are ruled out by condition III.

(362) DO clitic-double combinations (Sp. and EP)

a.

$$
\mathrm{O} / \mathrm{LO}
$$

[person: 3]

[number: sg]

[gender: masc]
ELE/ÉL

[person: 3]

[number: sg] [gender: masc] b.

$\mathrm{O} / \mathrm{LO}$

ELAS/ELLAS

$*$\begin{tabular}{ll} 
[person: 3$]$ & [person: 3$]$ \\
\hline [number: $\mathrm{sg}$ ] & [number: $\mathrm{pl}]$ \\
[gender: masc] & [gender: fem]
\end{tabular}

The indirect object clitic represented in (363) has a null-value for gender. As the null-value does not introduce a presupposition, it is compatible with all other gender values on the pronominal double, as shown in (363a) and (363b). But the combination in (363b) is ruled out by condition III because the distinct values on the number features introduce incompatible presuppositions.

(363) IO clitic-double combinations (Sp. and EP)

a.

LHE/LE

ELE/ÉL

[person: 3]

[number: sg]

[gender: null] [person: 3]

[number: sg]

[gender: masc]

b.

LHE/LE

ELAS/ELLAS

\begin{tabular}{|c|c|}
\hline [person: 3] & [person: 3] \\
\hline [number: sg] & [number: pl] \\
\hline [gender: $n u l l]$ & [gender: fem] \\
\hline
\end{tabular}


The reflexive clitic has a null-value for gender and number, as illustrated in (364). The null-value does not introduce a presupposition, and consequently every feature value of the pronominal double (reflexive or non-reflexive) will successfully pass condition III.

(364) Reflexive clitic-double combinations (Sp. and EP)

a.

SE

SI/SÍ

[person: 3]

[number: $n u l l]$

[gender: $n u l l]$ [person: 3]

[number: null]

[gender: $n u l l]$ b.

SE

ELE/ÉL

\begin{tabular}{|ll} 
[person: 3$]$ & [person: 3$]$ \\
\hline $\begin{array}{l}\text { [number: } \text { null] } \\
\text { [gender: } \text { null] }\end{array}$ & [number: sg] \\
\hline
\end{tabular}

Let us turn now to the combination of a non-reflexive clitic (DO and IO clitic) with a reflexive pronoun. These combinations are represented for European Portuguese in (365) and for Spanish in (366) below.

Recall from section 5.2.3 that European Portuguese allows for clitic doubling of long-distance reflexives with DO and IO clitics. Long-distance doubling is possible if the reflexive pronoun is bare (it comes without the intensifier), if the verb selecting the bigDP is in subjunctive mood, and if the antecedent of the clitic/double is singular. ${ }^{99}$ The restriction to a singular antecedent in some contexts was analysed as a syntax-interpretation mismatch: the null-value on the number feature can be associated with a presupposition for singular that causes a presupposition failure with a plural antecedent. Given that the null-value is associated with a presupposition for singular, the patterns in (365) are evaluated in the following way. The clitics in (365a) and (365b) have a number feature with a singular value, and the strong reflexive pronoun has a null-value associated with a singular presupposition. This pattern satisfies condition III. Due to this singular presupposition, the combinations with a plural clitic in $\left(365 a^{\prime}\right)$ and $\left(365 b^{\prime}\right)$ are ruled out by condition III because the presuppositions introduced by the number feature values are incompatible.

(365) DO/IO Clitic-reflexive double combinations (EP)

a.

$\mathrm{O}$

SI

\begin{tabular}{|ll|} 
[person: 3$]$ & [person: 3$]$ \\
\hline [number: $\mathrm{sg}]$ & [number: null $\left._{(\mathrm{sg})}\right]$ \\
\hline [gender: masc] & [gender: null]
\end{tabular}

$a^{\prime}$.

OS

SI

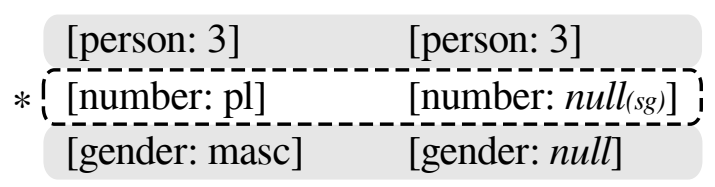

b. LHE SI

\begin{tabular}{ll} 
[person: 3$]$ & [person: 3$]$ \\
\hline$[$ number: $\mathrm{sg}]$ & {$\left[\right.$ number: null $\left._{(\mathrm{sg})}\right]$} \\
\hline [gender: $\boldsymbol{n u l l}]$ & {$[$ gender: null] }
\end{tabular}

$\mathrm{b}^{\prime}$. LHES SI

\begin{tabular}{|c|c|}
\hline [person: 3] & [person: 3] \\
\hline [number: $\mathrm{pl}]$ & [number: null $\left._{(s g)}\right]$ \\
\hline [gender: null] & [gender: null] \\
\hline
\end{tabular}

99 It was shown in section 6.1 that the restriction to a singular antecedent is not a general, intrinsic requirement of the bare reflexive pronoun. 
Note that the null-value without the associated presupposition meets condition III. This is the case for the Spanish combinations of a non-reflexive clitic and a reflexive double. The number or gender features of the non-reflexive clitics (DO and IO) in (366) have a specific value, and the strong reflexive pronoun has a null-value for these features. As the null-value does not introduce a presupposition, condition III is satisfied.

(366) DO/IO Clitic-reflexive double combinations (Sp.)

\begin{tabular}{|c|c|c|c|}
\hline LO,LA/LOS, LAS & SÍ & LE/LES & SI/SÍ \\
\hline [person: 3] & [person: 3] & [person: 3] & [person: 3] \\
\hline [number: $\mathrm{sg} / \mathrm{pl}$ ] & [number: null] & [number: $\mathrm{sg} / \mathrm{pl}$ ] & [number: null] \\
\hline [gender: masc/fem] & [gender: null] & [gender: null] & [gender: null] \\
\hline
\end{tabular}

Match CID assures referential identity of the clitic and its double, but it cannot account for the fact that doubling a non-reflexive clitic with a reflexive pronoun is ungrammatical in local and non-local contexts in Spanish and in local contexts in European Portuguese. It is at this point that the reasoning of Gutiérrez-Rexach (2001) comes into play.

As mentioned above, it is the clitic that determines the interpretation of the double. This includes the locality restrictions of the two types of pronouns, and, as observed throughout chapter 5, it is the clitic's restrictions that are imposed on the pronominal double. As we will see in the next section, the anaphoric relation between a clitic and its antecedent will be determined within syntax: the reflexive clitic has to take the subject as its antecedent, and the non-reflexive clitic is blocked from such a local relation; The non-reflexive clitic must take a clause-external antecedent. It is for that reason that the pattern in (365) and (366) are impossible in local contexts in Spanish and European Portuguese. As for the non-local contexts in Spanish, we will see in more detail in chapters 8 and 9 that the strong reflexive pronoun is restricted to a clause-internal antecedent. In general, this locality conflict leads to the unacceptablility of this pattern in Spanish. ${ }^{100}$

The approach of Gutiérrez-Rexach (2001) inspired the definition Match-CID that checks for referential identity of the clitic and its double upon merger and that opened the way to account for the clitic-double patterns in European Portuguese and Spanish. In the next section, we will see how the assumptions about the structure and the feature content of reflexive and non-reflexive big $\varphi$ Ps interact with cliticisation and finally how the interpretation of the reflexive and non-reflexive clitic falls out from Agree.

\subsection{Encoding reflexivity: downward Agree and upward valuation}

In this section, the pieces will be put together. The $\operatorname{big} \varphi \mathrm{P}$ merges as complement of a transitive or ditransitive verb. For the present discussion, the important categories are the functional categories involved in cliticisation: little $v$ hosts the accusative clitic, and as a reflex of Agree, it assigns accusative

100 The locality restriction was overwritten in the example (242) due to several conflicting factors, discussed in section 5.2.3. 
case to its complement. In ditransitive structures, there is an additional verbal head that hosts the dative clitic. This category has been labelled appl ${ }^{\circ}$ in Cuervo (2003) and in Roberts (2010), $\alpha^{\circ}$ in López (2012:39/40), DatCl $^{\circ}$ in Demonte (1995:18), and AgrIO ${ }^{\circ}$ in Franco (1999:178). In the following, I will use the term $\operatorname{appl}^{\circ}$, without commitment to a certain analysis of ditransitive structures (see section 5.2.2 ). Furthermore, little v selects for the external argument. The verbal complex v/appl establishes an Agree relation with its complement via cliticisation and a thematic relation with the external argument via External Merge. I will argue that it is exactly in this configuration in which the reflexive clitic is related to its antecedent by means of phi-agreement, and this kind of phi-agreement is impossible with a non-reflexive clitic. Thus, the locally bound and locally disjoint interpretation of the reflexive and non-reflexive clitic, respectively, is generated within the syntactic component. In sections 7.4.1 and 7.4.2, the single steps of the derivation are illustrated in detail.

\subsubsection{Cliticisation by downward Agree}

Let us assume that the derivation of a simple reflexive predicate has reached the following stage: the transitive $\mathrm{VP}$ that contains the $\operatorname{big} \varphi \mathrm{P}$ merges with functional verbal categories $\mathrm{v}^{\circ}$ or $\mathrm{appl}^{\circ}$, as shown in (367). The phi-probe on these functional categories search for an active goal. Note that clitics need no case feature to be an active goal, but the $\operatorname{big} \varphi \mathrm{P}$ has an unvalued case feature, so visibility is guaranteed. Cliticisation as agreement with a non-reflexive clitic proceeds as follows. The probe searches its ccommand domain and finds the non-reflexive clitic, represented in (367) in its dative and accusative form for Spanish and European Portuguese. For the sake of clear exposition, the VP layer was omitted and $\mathrm{v}^{\circ}$ appears directly above the big $\varphi \mathrm{P}$.

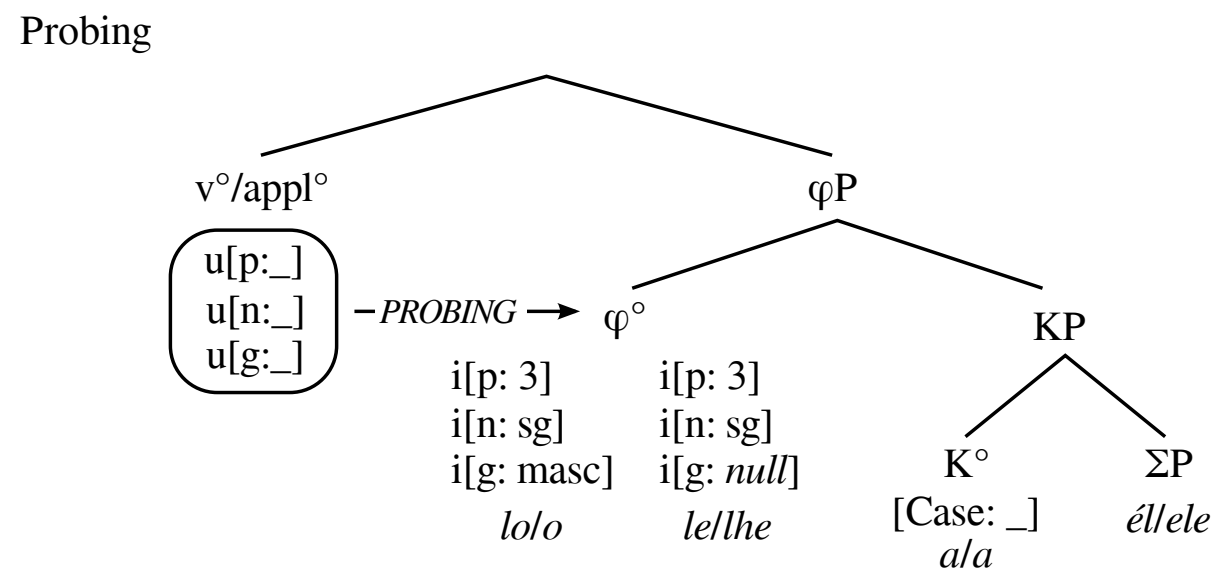

The probe and the clitic match and the probe's features are valued. All feature values are copied from the goal onto the probe. Recall that the clitic is a defective goal and due to this property it deletes after valuation, while the probe remains visible. Crucially, the former uninterpretable and unvalued features of the probe are now interpretable and valued. The case feature of the big $\varphi \mathrm{P}$ is valued or satisfied on $\mathrm{K}^{\circ}$ as a reflex of Agree. The result is shown in (368a) for direct objects and in (368b) for indirect objects. 
(368) a. Valuation with a DO clitic

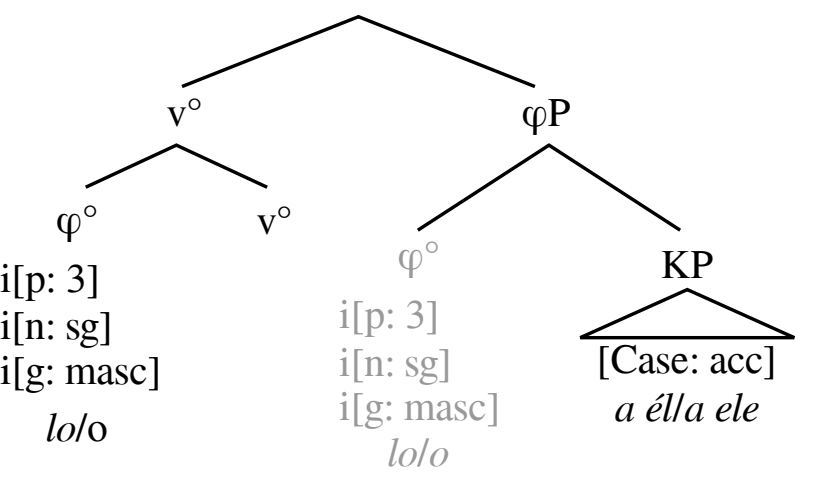

b. Valuation with an IO clitic

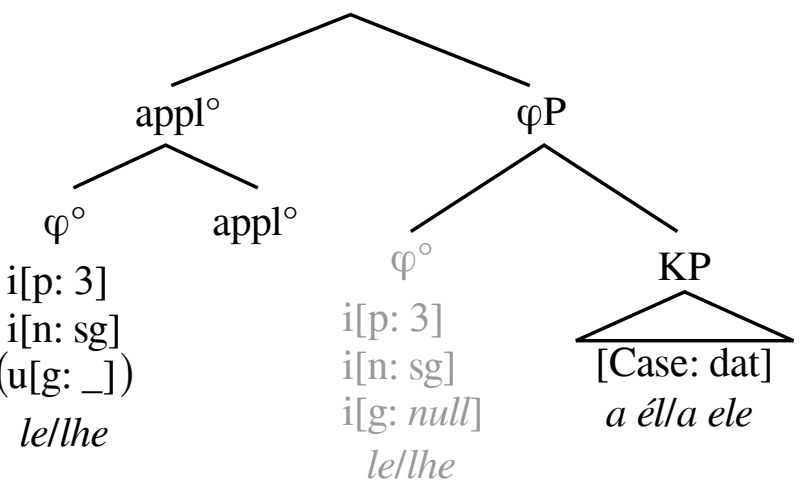

Note that the probe on appl $l^{\circ}$ finds a null-value for gender. As argued in section 6.1.3, the probe matches a null-value, but copying a null-value is vacuous. As a consequence, the gender feature remains without a value. In order to account for this result, it could be assumed that the probe on appl ${ }^{\circ}$ lacks a gender feature. ${ }^{101}$

Cliticisation of the reflexive clitic proceeds, as shown in (369). The reflexive clitic has a nullvalue on its number features, in addition to a gender feature with a null-value. The probe on little $\mathrm{v}$ or $\mathrm{appl}^{\circ}$ finds the clitic, their features match, but crucially only the person feature contains a specified value that can be copied onto the probe. The null-values are not copied, and the features on the probe remain unvalued and uninterpretable.

(369) a. Probing

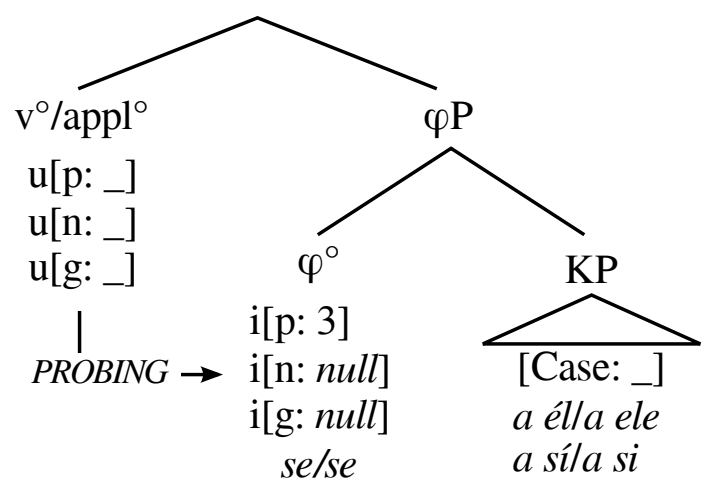

b. Valuation with a reflexive clitic

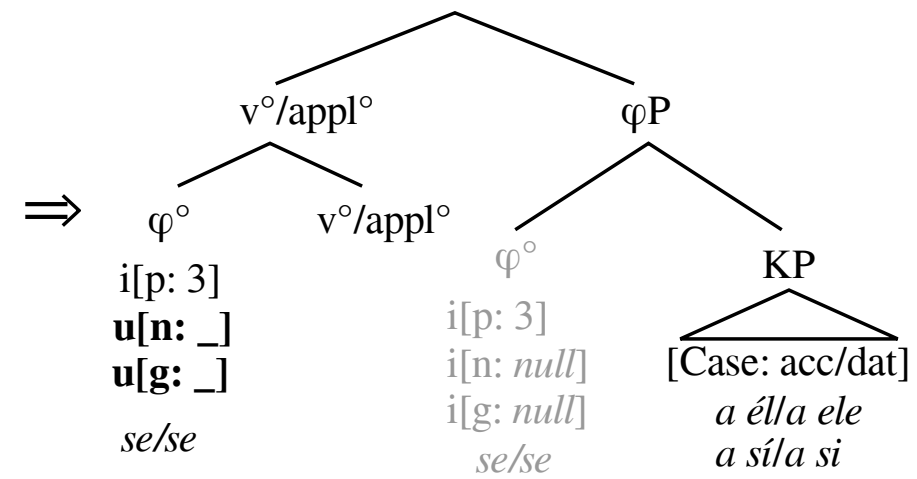

Now the uninterpretable and unvalued features on the probe could continue their search and probe further into the $\operatorname{big} \varphi \mathrm{P}$. If the $\operatorname{big} \varphi \mathrm{P}$ contains a non-reflexive double, this would be a problem. The nonreflexive pronoun is fully specified for phi-features, and the probe will value its number and gender features. Multiple Agree would turn the reflexive clitic into a fully valued, and hence non-reflexive clitic. The analysis would incorrectly predict that a reflexive clitic could never be doubled with a non-

101 The proposal that the probe on appl $l^{\circ}$ lacks a gender feature is along the lines of research of Wechsler (2011) or Landau (2016). In their approaches, two types of phi-features are assumed: INDEX features and CONCORD features. Gender and number are typically CONCORD features and are found in DP-internal agreement between nouns and adjectives. Person and number are typically INDEX features and are involved in predicate-argument agreement. For this reason, a phi-probe would be sensitive only to INDEX-features, but not to gender. 
reflexive pronoun. Probing into the big $\varphi \mathrm{P}$ is inhibited for the following reason. At the moment the probe agrees with the clitic, the case feature of the $\operatorname{big} \varphi \mathrm{P}$ is valued at the position of the case marker $a$. Due to valuation of the case feature, the case marker is now indistinguishable from a lexical, caseassigning preposition. The KP is no longer an active goal, and its content is now invisible for the probe. As a consequence, the unvalued features of the clitic/probe remain unvalued, but only until the next step: merge of the external argument.

\subsubsection{Binding by upward valuation}

Our sample derivation reached the following stage: transitive little $v$ contains the reflexive clitic and has assigned accusative case to its complement. But the external argument position is still unsaturated. A transitive verb requires a DP as its external argument, and the DP will be associated with an agentive interpretation. According to Chomsky (2008:160 fn. 32), the external argument merges with vP (here $v^{\prime}$ ) and satisfies v's edge feature. The edge feature expresses the general property of linguistic items to undergo Merge that targets the edge of a syntactic object. Merge of the external argument involves checking of v's edge feature in order to 'project' a specifier. In Chomsky (1995a et seqq.) theta role assignment is purely configurational. The fact that the specifier of $\mathrm{vP}$ is assigned a theta role is considered a requirement of the $\mathrm{C} / \mathrm{I}$ interface. ${ }^{102}$

The configurational view of thematic relations has been challenged by several (Minimalist) accounts, such as Fanselow (2001), Neeleman \& Reinhart (1998), and Reinhart (2002), who relate theta role assignment to feature-checking. The important point for my analysis is the fact that Merge of the external argument satisfies a feature on $\mathrm{v}^{\circ}$ and establishes a dependency between the external argument and $\mathrm{v}^{\circ}$ by means of feature-checking or Agree. Whether this feature is an edge feature or a theta feature as in Reinhart (2002) and Bošković \& Takahashi (1998) is not decisive.

For expository purposes, I will use the D-feature from Roberts (2010) to illustrate this dependency. In the probe-goal framework, a checking relation is formalised by means of unvalued and valued features. For this reason, I will take the D-feature on $v^{\circ}$ to be unvalued. The $u D$-feature on $v^{\circ}$ is additionally associated with the external argument role and represented as $\mathrm{uD}_{\mathrm{EA}} \cdot{ }^{103}$ The $\mathrm{uD}_{\mathrm{EA}}$ feature will be satisfied upon External Merge with a DP that carries a D-feature. At the moment $\mathrm{uD}_{\mathrm{EA}}$ is satisfied, not only is a specifier position created, but a thematic dependency is also established between $\mathrm{v}^{\circ}$ and the external argument. This is illustrated in (370) for a reflexive predicate.

\footnotetext{
102 'The predicate-internal subject hypothesis asserts that C-I will also assign a theta role to second EM to $\mathrm{v}^{*}$, that is, to its specifier, the external argument EA.' Chomsky (2008:143)

103 Alternatively, one could assume the thematic features proposed in Reinhart (2002). She analyses thematic roles as combinations of two features: $[+/-\mathrm{m}]$ for mental involvement and $[+/-\mathrm{c}]$ for cause. An agent is $[+\mathrm{m},+\mathrm{c}]$, and an experiencer has the features $[+\mathrm{m},-\mathrm{c}]$. The $\mathrm{uD}$ feature of the transitive verbs under discussion here could be represented as a $[+\mathrm{m},+/-\mathrm{c}]$ feature.
} 
(370) Merge of the external argument DP

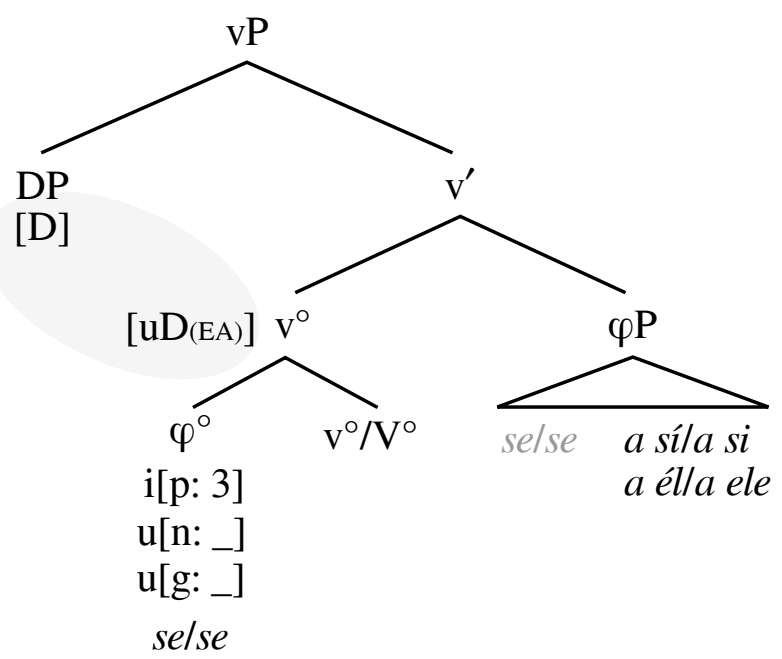

The structure in (370) contains the reflexive clitic/probe that has an unvalued gender and number feature. As Agree is always downward, the unvalued features cannot be valued by the subject DP and the derivation will not converge at the interfaces. It is at this point that the thematic relation established with the external argument becomes relevant. In (370), little $v$ has established two feature-based relations: an Agree relation with the reflexive big $\varphi \mathrm{P}$, which gave rise to cliticisation, and a checking/Agree relation with the external argument. This structural condition corresponds to a configuration discussed in Bjorkman \& Zeijlstra $(2014,2019)$ within their system of upward Agree. They discuss a configuration in which a partially valued probe may be valued by a goal that is not in its search space, but that has been linked to the probe's host by means of another Agree relation. Let's look in detail at the configuration discussed in Bjorkman \& Zeijlstra $(2014,2019)$ presented in (371).

Upward Agree and Partial Downward Valuation

$\begin{array}{lll}{[\gamma} & {[\alpha} & [\beta]]] \\ {[\mathrm{i} \varphi ; \pi]} & {[\mathrm{u} \varphi ; \pi, v]} & {[\mathrm{i} \varphi ; \pi, v]} \\ & {[\mathrm{iK}]} & {[\mathrm{uK}]}\end{array}$

The Greek letters $\gamma, \alpha$, and $\beta$ represent lexical items. The item $\gamma$ has an incomplete set of interpretable phi-features [i $\varphi ; \pi]$, the item $\alpha$ has a complete phi-probe $[\mathrm{u} \varphi ; \pi, v]$ and a valued case feature [iK]. The item $\beta$ has a complete set of interpretable phi-features $[i \varphi ; \pi, v]$ and an unvalued case feature. Bjorkman \& Zeijlstra $(2014,2019)$ assume an upward Agree system, which means that $\alpha$ probes $\gamma$, with the result that the probe on $\alpha$ is only partially valued. But $\alpha$ has also entered into an Agree relation with the $\mathrm{uK}$ feature of $\beta$. The $\mathrm{uK}$ feature of $\beta$ probes upward and gets a value from $\alpha$ 's [iK] feature. Now $\alpha$ has established an agreement link with $\gamma$ and $\beta$, respectively. I will call this agreement configuration the Bjorkman \& Zeijlstra configuration. By virtue of these agreement links, Bjorkman \& Zeijlstra (2014, 2019) argue that valuation may be downward, even though the direction of Agree is by definition upward. Thus, the unvalued features of $\alpha$ can be valued via downward valuation from $\beta$. 
As illustrated in (372) below, the configuration established by reflexive cliticisation and merger of the external argument is the exact mirror image of the Bjorkman \& Zeijlstra configuration in a downward Agree system. The probe on $\mathrm{v}^{\circ}$ is partially valued due to Agree/cliticisation with the reflexive $\operatorname{big} \varphi \mathrm{P}$, and $\mathrm{v}^{\circ}$ established an agreement link with the external argument. I want to argue that in this configuration upward valuation may take place in a downward Agree system and the unvalued features of the reflexive clitic get a value from the external argument. After valuation, the features are marked for deletion at the interfaces.

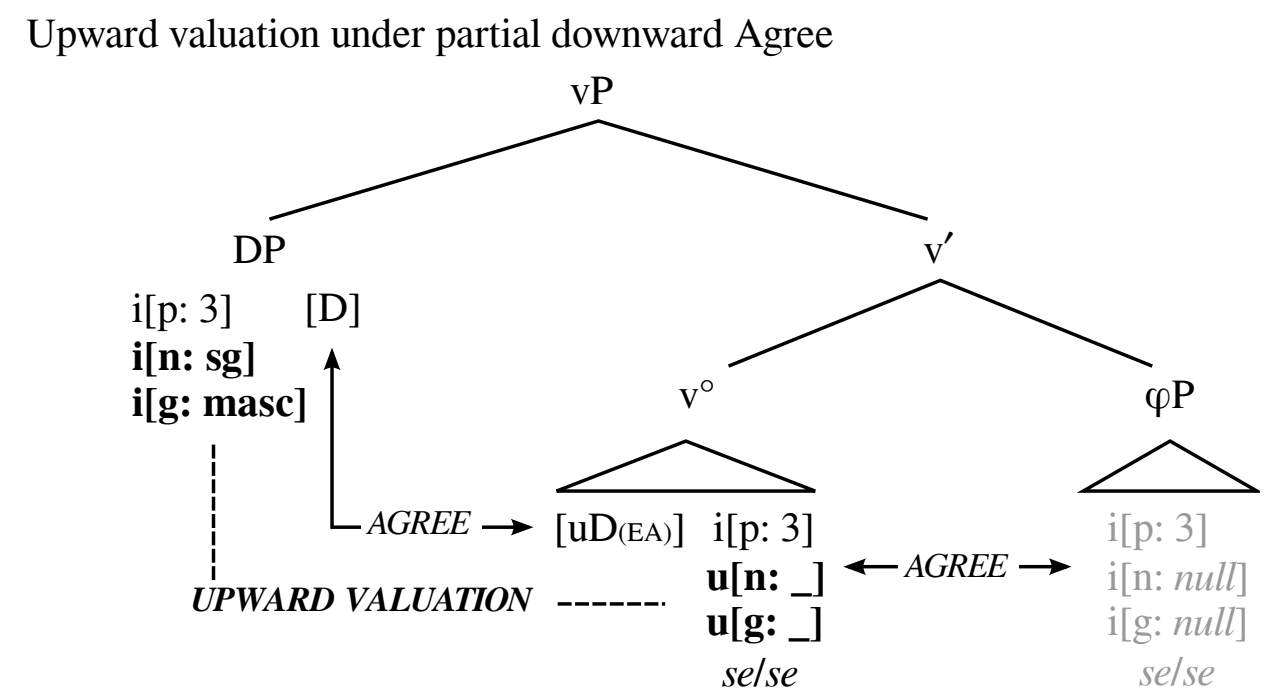

Note that upward valuation is not upward Agree. The unvalued features on the probe/clitic do not probe upward, as in Hicks (2009) or in Marelj \& Reuland (2016) (see section 4.3). The configuration that allows upward valuation in a downward Agree system is only available due to the process of cliticisation as agreement with a goal that has null feature values and due to the fact that an agreement link was established between $\mathrm{v}^{\circ} / \mathrm{appl}^{\circ}$ and the external argument. Furthermore, upward valuation requires Match of phi-features. Only if the person feature of the external argument and the probe match will valuation take place. This is a valid condition because valuation as well as Match are suboperations of Agree, and Match needs not be motivated independently. The result of deletion is illustrated in (373). In order to complete our sample derivation, the CP phase including TP has to be merged. This step will be omitted because with respect to our research interest nothing exciting happens there. 
(373) Upward valuation under partial downward Agree

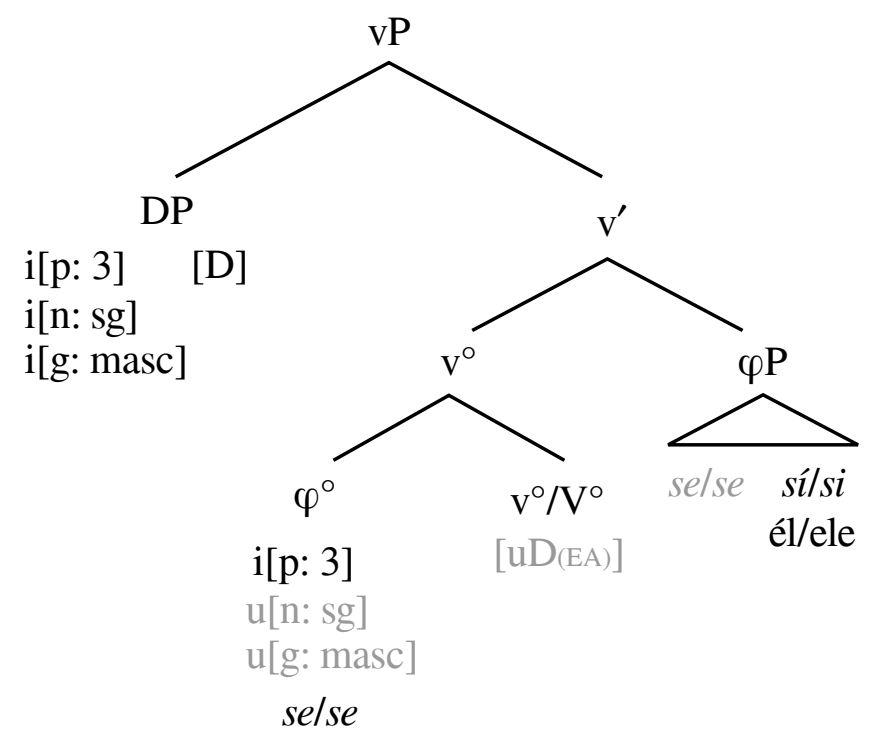

Let us recapitulate the analysis. Due to the lexical and morphosyntactic properties of reflexive clitics (their phi-feature content and the fact that clitics undergo cliticisation), a syntactic dependency is established between the external argument, the verb-clitic complex in little $\mathrm{v}$, and the internal argument. By means of agreement, the reference of the external argument and the internal argument are unified. This syntactic dependency translates into a referential dependency at the syntax-semantics interface. The internal and external argument variables are translated into either identical variable names or identical indices, depending on the formalism used.

What remains to be accounted for is the fact that reflexive and non-reflexive clitics are in complementary distribution. The important difference between the two types of clitics is their phi-feature content and not their morphosyntactic properties. Non-reflexive clitics participate in cliticisation by agreement in the same way as reflexive clitics do, but crucially with a different result, as illustrated in (374). The probe on $\mathrm{v}^{\circ} / \mathrm{appl}^{\circ}$ finds the clitic, and Agree takes place. Due to the feature content of the clitic, the probe is fully valued. At the moment the external argument merges, an agreement link is established between little $\mathrm{v}$ and the external argument. Although the structural conditions for upward valuation are given, valuation does not take place because the non-reflexive clitic/probe has specified values. 


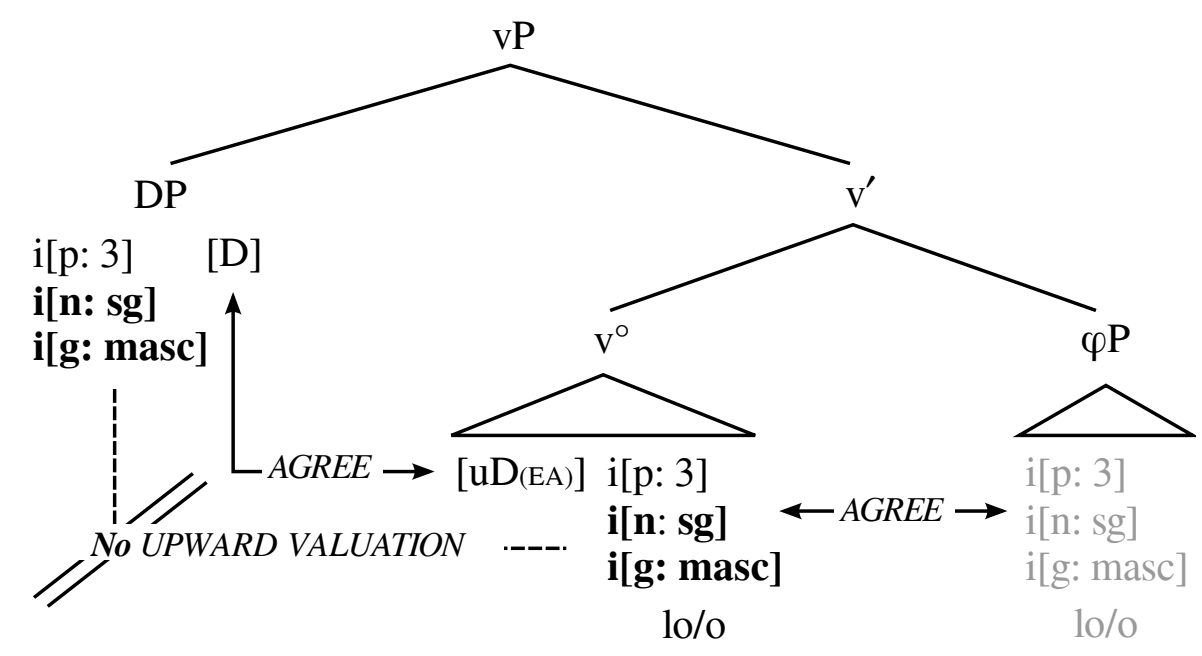

The semantically contentful phi-features block any type of valuation or any other type of feature unification, even though the structural configuration would permit it. As a consequence, the clitic and its double are necessarily disjoint in reference from the subject DP. Disjoint reference is thus derived from the clitic's phi-features. Note that in (374) the external argument and the clitic have the same phifeatures; both have a set of $\left[3^{\text {rd }}\right.$, sg., masc] features. But each phi-set will be related to a distinct referent, and at the syntax-semantics interface the internal argument variable and the external argument variable will be translated into variables with distinct names or distinct indices.

The analysis put forward in this section derives the complementary distribution of reflexive and non-reflexive clitics attested in chapter 5 in the following way: reflexive clitics are interpreted as locally bound variables because the internal argument variable is identified with the external argument by means of the syntactic process of upward valuation. This interpretation is obligatory because the syntactic process cannot be altered at the interfaces, following the economy considerations of Reuland (2011) and Reinhart (2006) (see section 1.1). Furthermore, it accounts for the fact that non-reflexive clitics are interpreted as disjoint from a local antecedent because the syntactic process of upward valuation is blocked in syntax. The blocked syntactic dependency too remains unaffected by operations at the interfaces. The locality and c-command requirement for reflexive clitics fall out from cliticisation by Agree and the Bjorkman \& Zeijlstra configuration. In order to test the c-command requirement in local contexts, a complex DP has been used in subject position, as in the examples (246), repeated here as (375). The reflexive pronoun can only be associated with the head of the complex DP, the DPs pai and madre, respectively. Given that the label of the complex DP contains the phi-features of the projecting head, only the features of the DPs pai and madre, respectively, are accessible for upward valuation.

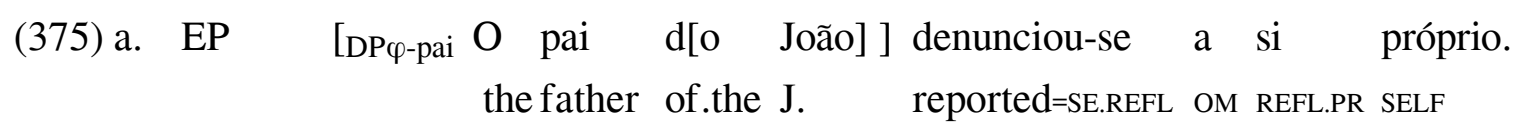

'João's father reported himself to the police.' 
b. Sp. [DP $\varphi$-madre La madre de Juana $]_{k}$ se $*_{i / k}$ ha denunciado a sí $*_{i / k}$ misma. the mother of J. SE.REFL=AUX reported OM REFL.PR SELF

'Juana's mother reported herself to the police.'

The analysis presented here accounts for all three interpretive and structural conditions for a syntactic encoding of reflexivity mentioned at the outset of this chapter: (i) reflexive and non-reflexive pronouns are in complementary distribution, (ii) the antecedent must be local and c-commanding, (iii) the dependency generated by a syntactic operation is obligatorily and unambiguously interpreted as referential identity.

In the following two sections it will be shown that the analysis extends to other phenomena discussed throughout chapters 3 and 5. In section 7.5, Rizzi's (1990) Anaphor Agreement Effect will be derived. In section 7.6, I will discuss the derivation of reflexive ECM predicates, the ban of reflexive clitics in passives, and the fact that a direct object and an indirect object cannot be referentially related by means of a reflexive clitic in ditransitive structures.

\subsection{Reflexive subjects and the Anaphor Agreement Effect}

In English, as well as in Spanish and European Portuguese, the reflexive pronoun is barred from the subject position of finite and non-finite clauses. This is exemplified in (376) for subjects of simple sentences and in (377) for subjects of embedded sentences.

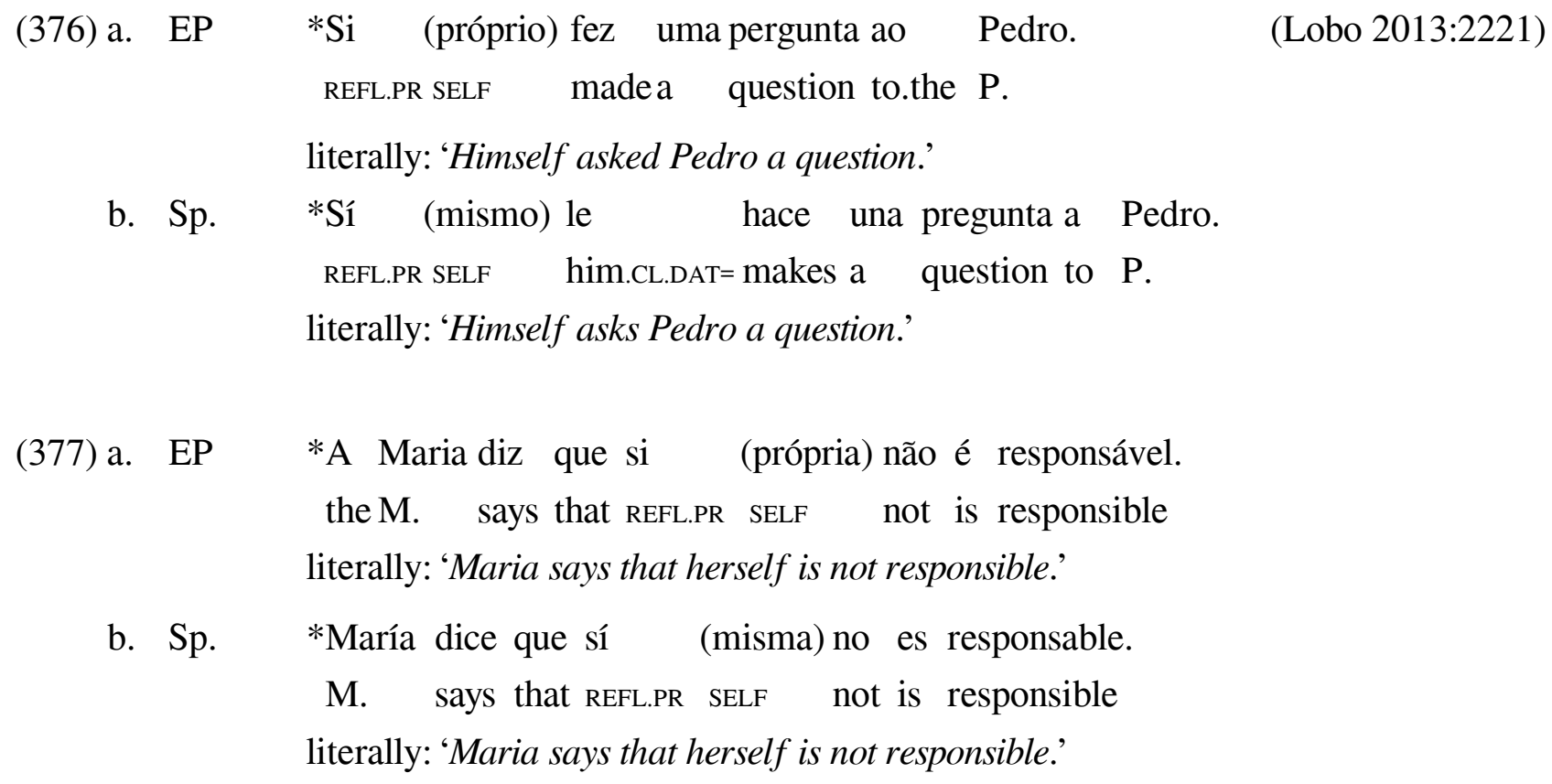

(Bosque \& Gutiérrez-Rexach 2016:570)

All sentences in (376) and (377) become perfectly acceptable if the reflexive pronoun is replaced by a non-reflexive pronoun. These are well-known facts, and there is no need to present the grammatical examples here. The question why reflexive pronouns are excluded from subject position has received 
different answers in the generative literature. In (classic) Binding Theory, the reflexive pronoun is excluded from subject position because it is not c-commanded by a local antecedent in this position. Lobo (2013) and Otero (1999) argue for European Portuguese and Spanish, respectively, that the reflexive pronoun cannot bear nominative case and/or is incompatible with an agentive thematic role. As for the incompatibility with an agent role, this possibility can be excluded for the following reasons. First, the reflexive pronoun in (377) does not bear an agent role, but it is nevertheless ungrammatical. Secondly, the reflexive pronoun is perfectly compatible with an agent role, as for example in the by-phrase of the passive sentences given in (378).

(378) a. EP O cavaquismo foi derrotado por si mesmo. (CRPC: Expresso, 1999) the Cavaquism was defeated by REFL.PR SELF 'Cavaquism was defeated by itself.'

b. Sp. Tampoco se diga que estos señores fueron votados por sí mismos. neither SE.IMP=say that these gentlemen were elected by REFL.PR SELF 'Neither should you say that these gentlemen have been elected by themselves.'

(CREA: ABC, Política 15/04/1989)

These examples show that the ungrammaticality can only be due to the incompatibility with nominative case. There are two possible ways to explain this. First, it could be argued that there is simply no morphological form available for the spell-out of a reflexive nominative pronoun. Secondly, the reflexive pronoun is incompatible with the structural position or mechanism associated with nominative case assignment. $^{104}$

Within the first line of reasoning, nothing prevents the assignment of nominative case to the reflexive pronoun. The reflexive bears nominative case, but there would simply be no morphological realisation/form, and the sentences are ungrammatical due to a failure of vocabulary insertion in the sense of Distributed Morphology (see Harley 2008). This line of reasoning is supported by the fact that the lack of nominative reflexive pronouns is not a universal phenomenon. For example, Bresnan et al. (2016:237) cite Malayalam, a Dravidian language spoken in Southern India, which has a specific form for nominative reflexive pronouns.

The second line of reasoning is put forward in Rizzi (1990). He argues that the absence of nominative anaphors (reflexive subjects) is due to a general incompatibility of anaphors and agreement. This constraint is called the Anaphor Agreement Effect (AAE). This principle states that anaphors cannot be construed with agreement. He discusses, among many other examples, the Italian dative experiencer constructions reproduced in (379). These constructions are particularily interesting because the reflexive pronoun se stessi is in a position in which it can be bound by the dative experiencer me 'me'. Thus, the principles of classic Binding Theory predict the grammaticality of a bound interpretation, contrary

${ }^{104}$ Within earlier Minimalism, nominative case assignment was formalised as feature checking in a specifier-head configuration, while within the probe-goal framework, it is associated with an Agree relation between a functional head $\left(\mathrm{T}^{\circ}\right)$ and a DP. 
to fact. Note that the reflexive pronoun se stessi should agree with the verb and bear nominative case, just like its non-reflexive counterpart in (379b).

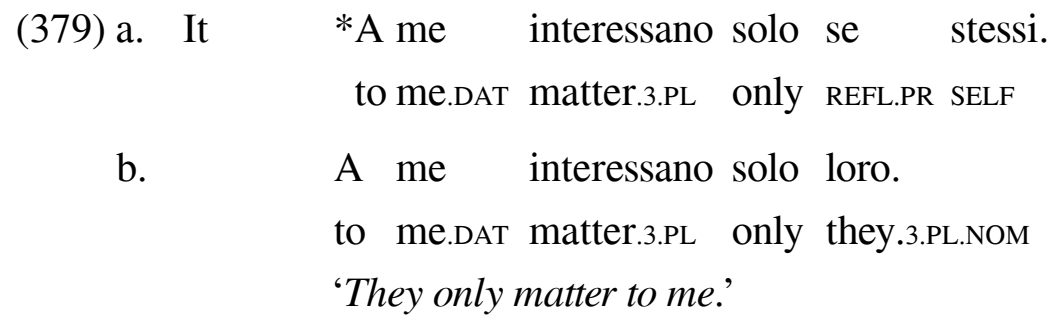

(Rizzi 1990:32)

Rizzi (1990) gives the following explanation for the AAE. He assumes the GB framework in which agreement is formalised by means of AGR-features. AGR-features are taken to be a pronominal element and must therefore obey Principle B (see Rizzi 1990:36). But as the anaphor is subject to principle $\mathrm{A}$, agreement between the verb and the anaphor creates a configuration in which either principle $\mathrm{A}$ or B are violated. If principle A is satisfied for the anaphor then principle B is violated for the AGR features, and vice versa.

Within the probe-goal framework assumed here, the explanation for the AAE needs to be implemented in different terms. As I do not want to make any claim about reflexive pronouns in Italian, the analogous dative experiencer constructions in Spanish and European Portuguese will be discussed. These constructions are exemplified in (380) for Spanish and in (381) for European Portuguese. The verbs interesar (Sp.) and interessar (EP) 'matter, interest' have an external experiencer argument that receives dative case. The internal argument bears the theme role, triggers agreement on the verb, and receives nominative case. ${ }^{105}$

(380) a. Sp. A mí me interesan sólo ellos.

to me me.CL.DAT=matter.3.PL only they.3.PL.NOM

'Only they matter to me.'

b. *A ellos les interesan sólo sí mismos.

to them them.CL.DAT=matter.3.PL only REFL.PR SELF

intended meaning: 'Only they matter to themselves.'

(381) a. EP Não me interessam eles.

not me.CL.DAT=matter.3.PL they.3.PL.NOM

'They do not matter to me.'

b. *Não lhes interessam si próprios.

not them.CL.DAT $=$ matter3.PL REFL.PR SELF

intended meaning: 'They do not matter to themselves.'

\footnotetext{
105 The Spanish dative PPs a mí, 'to me' and a ellos, 'to them' in (380) are possibly raised to a topic position above TP, but these details are not relevant for the present analysis.
} 
The analysis put forward in this book accounts for these facts in the following way. Let us assume that the $\mathrm{vP}$ has been generated with the reflexive pronoun as the external argument. At this point, $\mathrm{T}^{\circ}$ merges with the vP, as shown in (382a) for the European Portuguese example. Finite $\mathrm{T}^{\circ}$ has a phi-probe that will find the reflexive pronoun as the matching goal. Agree takes place, but copying of the null-values for gender and number is vacuous. The number and gender features on the probe remain unvalued, as shown in (382b), and cannot delete. If a syntactic object contains uninterpretable and unvalued features at the moment of Spell-Out, the derivation does not converge at the interfaces.

(382) a.

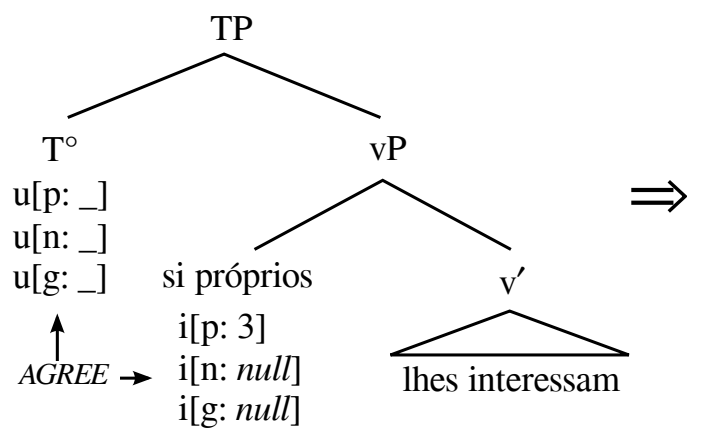

b.

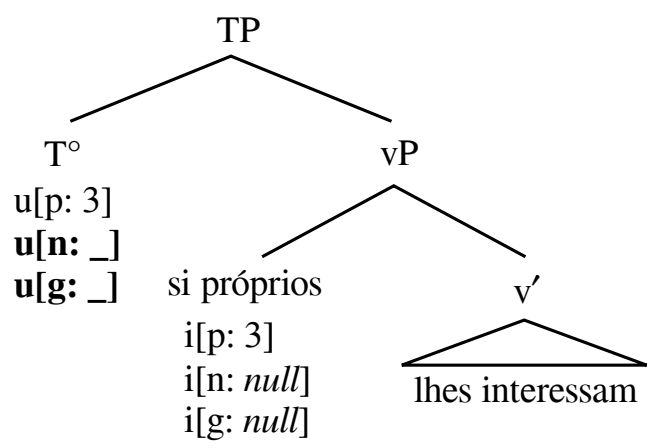

Due to the behaviour of null-values with respect to Agree, my analysis predicts that a strong reflexive pronoun is ungrammatical in every context in which it is the goal of phi-agreement. Note that the strong reflexive pronoun is not a defective goal and cannot cliticise. Here again, the difference between clitics and strong pronouns shows its utter importance for the analysis of anaphoric dependencies in IberoRomance languages. ${ }^{106}$

My analysis also accounts for the ungrammaticality of reflexive subjects in infinitive clauses, exemplified in (383). Note that the languages at issue generally permit overt pronominal subjects in infinitive clauses (see Mensching 2000). The sentences in (383) become perfectly grammatical if the reflexive pronoun is replaced with a non-reflexive pronoun.

(383) a. EP *Não me importa $[\mathrm{si} \quad$ (próprios) chegarem sempre atrasados].
not me.CL=bother REFL.PR SELF arrive.INF.3.PL always late
Intended meaning: 'I don't care if they are always late.'

b. Sp. *[Nada más llegar sí (mismos) a casa], sonó el teléfono. nothing more arrive.INF REFL.PR SELF at home rang the phone Intended meaning: 'Immediately after they arrived at home, the phone rang.'

In European Portuguese, the non-finite verb shows agreement with the subject pronoun, whereas in Spanish there is no overt agreement morphology on the non-finite verb. According to Mensching

\footnotetext{
106 Note that Rizzi (1990) does not discuss clitic pronouns, but only strong pronouns. Despite this fact, his Anaphor Agreement Effect has been generalised to anaphors, irrespective of their morphosyntactic type, such as in Preminger (2018). In light of my analysis, a general ban of reflexive pronouns from entering a phi-agreement relation seems to be unjustified.
} 
(2000), these subject pronouns bear nominative case in both languages. ${ }^{107}$ In Mensching \& Remberger (2006), his analysis is implemented within the probe-goal framework and nominative case is assigned as a reflex of Agree with a phi-probe in $\mathrm{T}^{\circ}$. My analysis accounts for the ungrammaticality of reflexive specified subjects of infinitive clauses because Agree between $\mathrm{T}^{\circ}$ and the reflexive pronoun is vacuous and the phi-probe will have uninterpretable and unvalued features at the end of the derivation. Such a derivation will be ruled out at the interfaces.

\subsection{ECM, passives, and ditransitives}

In this section, I return to some data discussed in chapter 3, starting with a sample derivation of reflexive ECM structures. An account for the incompatibility of reflexive clitics in passives and ditransitive sentences will also be presented. Finally, I will discuss why a direct object DP and an indirect object DP in ditransitive structures cannot be referentially related by means of a reflexive clitic.

The reflexive ECM predicates presented in (133) are repeated here as (384). The derivation will be exemplified by means of the Spanish example, but the analysis is the same for European Portuguese.

(384) a. Sp. Juan se considera [AP a sí mismo inteligente].

J. SE.REFL=considers OM REFL.PR SELF intelligent

'Juan considers himself intelligent.'

b. EP O Luís considera-se [AP a si próprio inteligente].

the L. considers=SE.REFL OM REFL.PR SELF intelligent

'Luís considers himself intelligent.'

In the tree structure in (385a), the adjective inteligente has merged with the reflexive big $\varphi \mathrm{P}$ and formed a small clause (SC) (see Moro 1997 for a small clause analysis of ECM sentences). The next step is External Merge of the ECM verb considerar. As shown in (385b), it merges with the small clause. For the sake of clear exposition, the VP layer and the internal structure of the reflexive $\Sigma \mathrm{P}$ have been omitted. The verb moves to little v, which has a phi-probe that searches for a matching goal. Due to the unvalued case feature, the $\operatorname{big} \varphi \mathrm{P}$ is active and will be found by the probe. Cliticisation and valuation proceed as presented in the previous sections.

${ }^{107}$ In Mensching (2000:188-190), specified subjects are licensed by a weak nominative feature on infinitival $\mathrm{T}^{\circ}$ in the two languages. The overt agreement morphology and the preverbal position of the subject pronoun in European Portuguese is derived by strong features (a D-feature and phi-features) on $\mathrm{AgrS}^{\circ}$. Differently from European Portuguese, Spanish has weak features on $\mathrm{AgrS}^{\circ}$ because it allows for postverbal subjects only and shows no overt agreement morphology on the infinitive. 
(385) a.

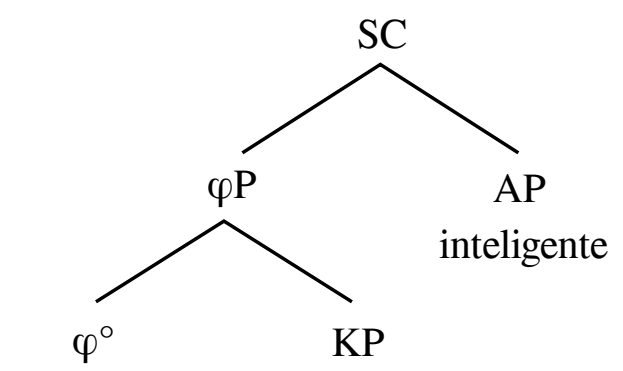

i[p: 3]

i[n: $n u l l]$

i[g: null]

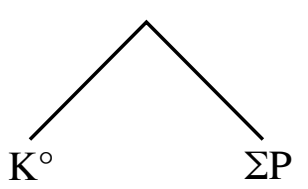

[Case:__] sí mismo b.

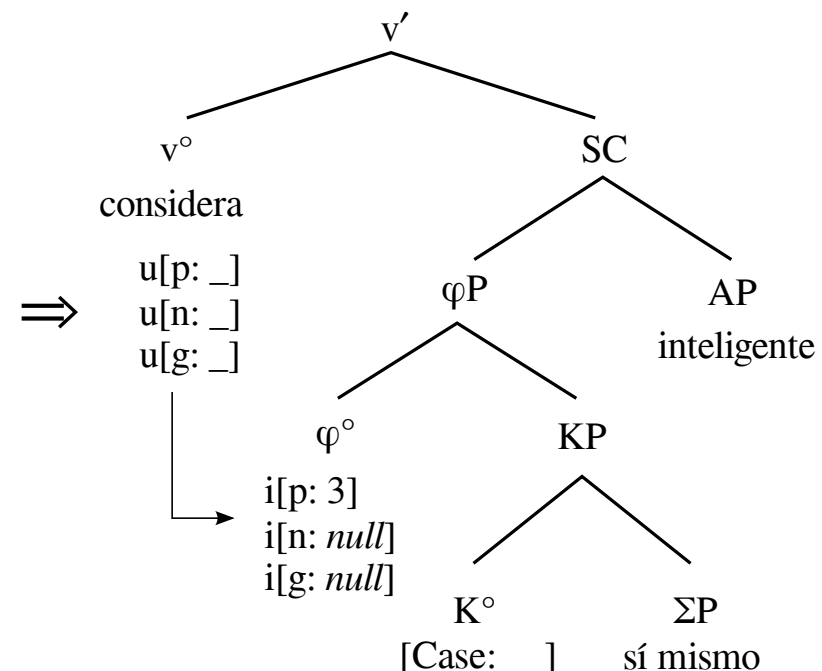

Now, the ECM verb hosts the reflexive clitic, and merger of the external argument to the specifier position of $\mathrm{vP}$ creates the Bjorkman \& Zeijlstra configuration that is necessary for upward valuation, as shown in (386). The unvalued features of the reflexive clitic get a value form the external argument DP Juan, and referential identity is generated between the external and the internal argument.

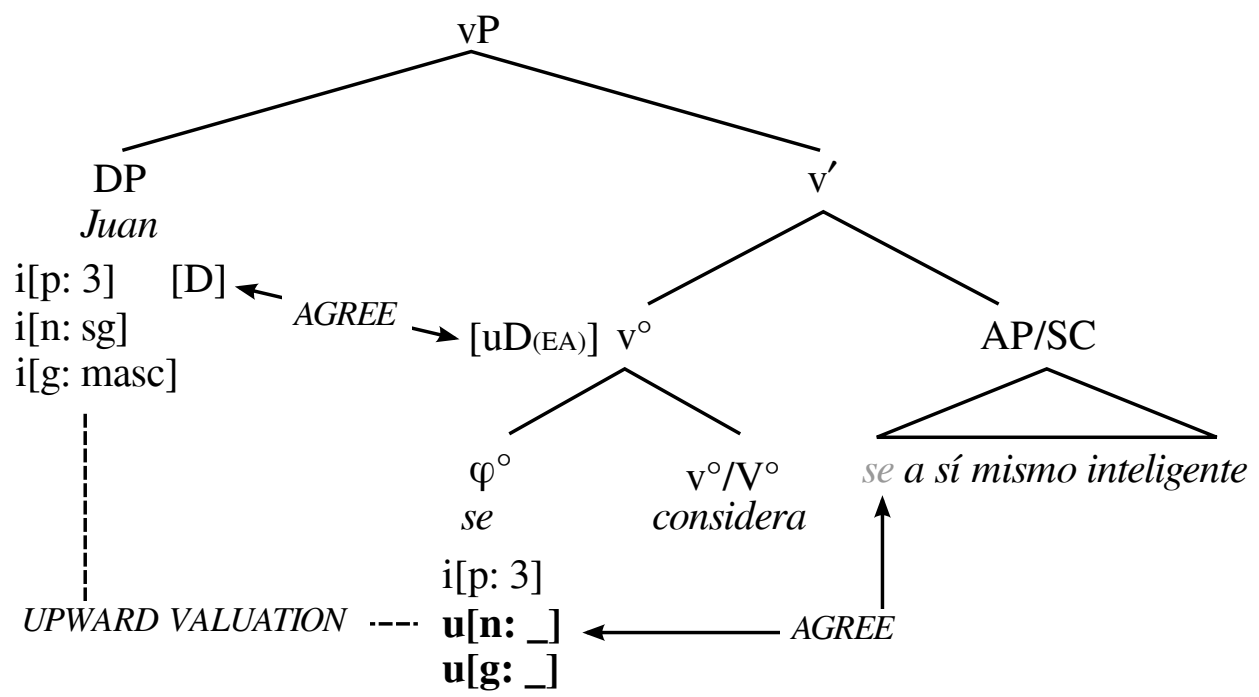

Under the analysis presented here, reflexive and non-reflexive ECM predicates are not a challenge, but can be analysed straightforwardly.

Let us turn now to reflexive clitics in passive predicates. Recall from chapter 3 that intransitive approaches to reflexivisation argued that reflexive clitics are non-argumental, case-reducing morphemes. These accounts argued against a unified analysis of reflexive and non-reflexive clitics on the basis of sentences similar to the ones in (387) and (388). The passive ditransitive predicate in (387) contains an argumental, non-reflexive dative clitic. If reflexive clitics were argumental too, the dative 
clitic should be replaceable with a reflexive dative clitic in these sentences. Crucially, the reflexive clitic is ungrammatical, as shown in (388).

(387) a. Sp. El premio Nobel le fue concedido a Cela el año pasado.

the prize Nobel him.CL= was awarded to $\mathrm{C}$. the year last

'The Nobel prize was awarded to Cela last year.'

(Demonte 1995:12)

b. EP $O$ acórdão foi-lhe entregue na passada sexta-feira.

the ruling was=him.cL handed.over in.the past Friday

'The ruling was handed over to him on last Friday.'

(388) a. Sp. *Juan se fue entregado a sí mismo.

J. SE.REFL= was handed.over to REFL.PR SELF

intended meaning: 'Juan was handed over by himself.'

b. EP *O Rui foi-se entregue a si próprio.

the R. Was=SE.REFL handed.over to REFL.PR SELF

intended meaning: 'Rui was handed over by himself.'

The exponents of an intransitive account concluded that reflexive clitics must be distinct from argumental accusative or dative clitics. In the light of the analysis presented in this chapter, their conclusion is not the only one possible. In the following, I will show that the ungrammaticality of (388) is explained precisely because my analysis assumes a parallel treatment of the two types of clitics. I will use the European Portuguese sentences (387b) and (388b), but the analysis carries over to the Spanish examples too. Let us start with the base structure of a ditransitive sentence. In all analyses introduced in section 5.2.2, the DO and the IO are merged into their thematic positions before any functional category is merged. The simplest assumption is that the DO and the IO are merged in a VP, as shown in (389). The tree structure presents the reflexive and non-reflexive sentences at the same time: the IO clitic is represented in its reflexive and non-reflexive form and both direct object DPs are given in the DO position.

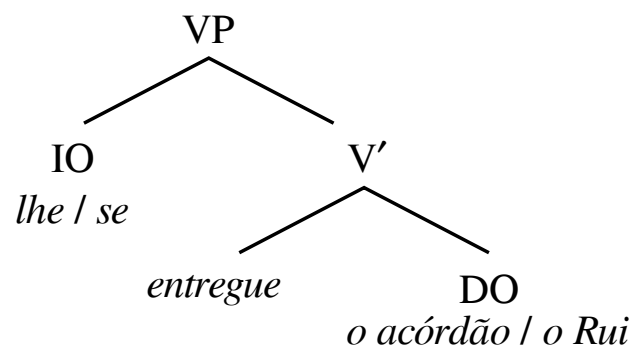

The ungrammaticality is solely due to Agree with the null-values of the reflexive clitic. Let us see how this works. In the next step of the derivation, the applicative head merges, and cliticisation takes place 
as described above. This step is illustrated in (390). If the probe finds the reflexive clitic, the gender and number features remain uninterpretable and unvalued. In case the non-reflexive clitic, all features are copied onto the probe. In both cases, the goal deletes.

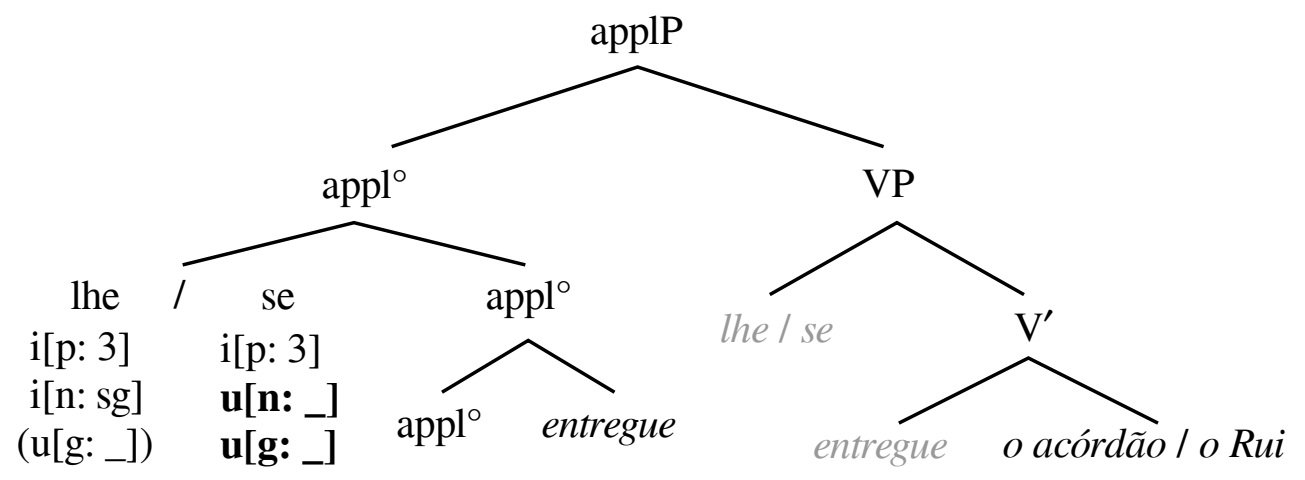

Passive predicates lack accusative case and do not select for an external argument. Chomsky (2000 et seqq.) and Radford (2004) state that these properties are the result of the absence of little $\mathrm{v}$ or, alternatively, a featureless little v. The vP is omitted in the next step because in either case there is no vP-phase and the VP remains accessible for probing. The next step in the derivation is merger of $\mathrm{T}^{\circ}$ that hosts the passive auxiliary and two phi-probes. One probe is associated with nominative case and an EPP feature, the other probe is associated with clitic climbing. The u $\varphi$-nom probe finds the direct object DP o acórdão/o Rui, which will move to spec TP. But differently from active predicates, the complex appl/V head does not move to $\mathrm{T}^{\circ}$. The clitic cannot move together with the verbal head; it does not get a free ride, but has to climb up to the finite auxiliary. Thus, an additional process is needed to raise the clitic to $\mathrm{T}^{\circ}$. Note that movement of the clitic is obligatory because clitics can never be attached to a past participle in either language. Roberts (2010:206ff) proposes that clitic climbing proceeds in the same way as the initial cliticisation process. A phi-probe agrees with the clitic, and copying the values into the probe exhausts the goal. After Agree, the clitic deletes and the probe remains visible. ${ }^{108}$ This process is illustrated in (391).

108 This subsequent probing is equivalent to excorporation of a head followed by incorporation into a higher head. 


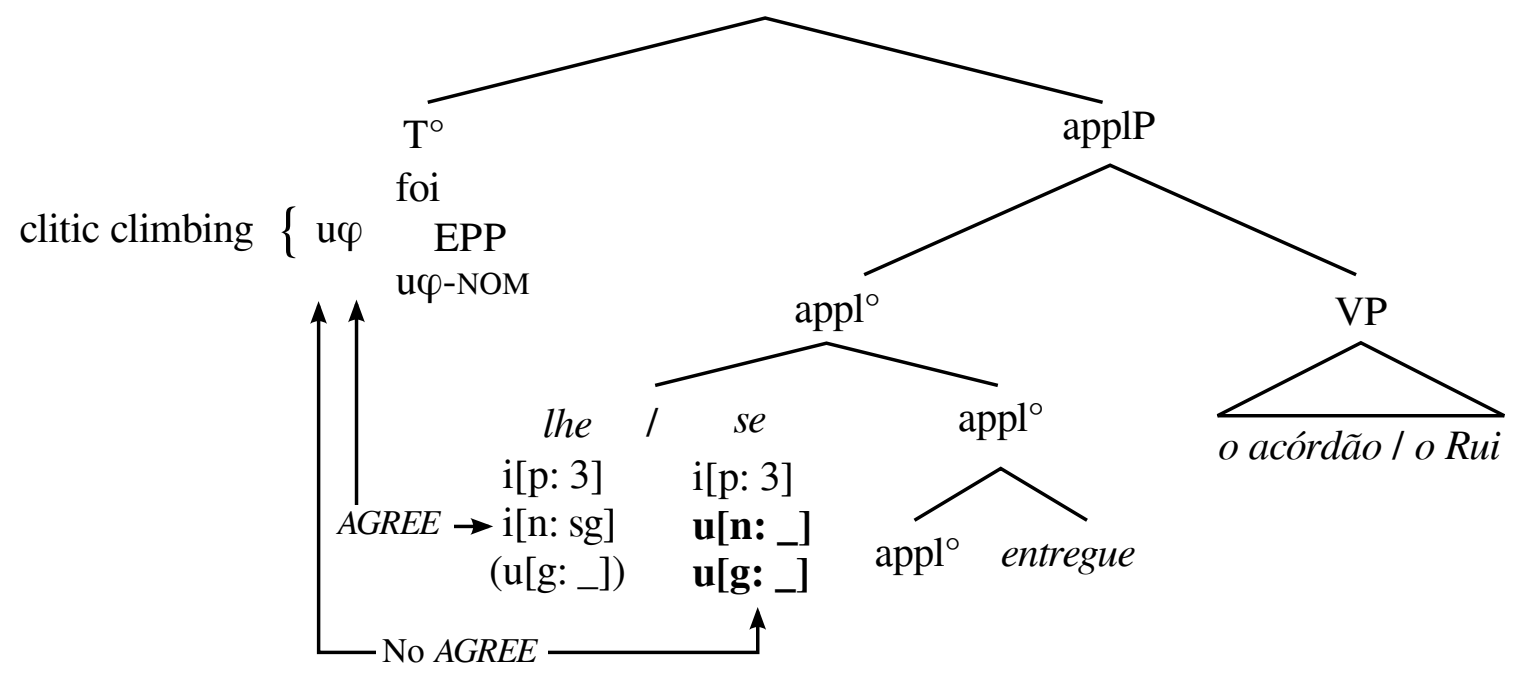

The phi-probe designated for clitic climbing probes and finds the clitic. In the case of the non-reflexive dative clitic, clitic climbing gets a rubber stamp. But in the case of the reflexive clitic, cliticisation by $\mathrm{T}^{\circ}$ fails for the following reason. The reflexive clitic still contains uninterpretable and unvalued features. These features of the clitic cannot successfully agree with the uninterpretable and unvalued features of the phi-probe. The derivation does not converge at the interfaces because the probe on $\mathrm{T}^{\circ}$ has features that are still unvalued and uninterpretable, and because the clitic cannot leave the $a p p 1^{\circ} / \mathrm{V}$ complex, even though it is required to do so.

Finally, I want to address the example (141b) mentioned in section 3.2.2.1, repeated here as (392). This example is ungrammatical because the direct object and the indirect object are referentially related by means of a reflexive clitic.

$$
\begin{gathered}
\text { EP *A meditação devolveu-se }{ }_{i} \quad\left(\text { a si } i_{i} \text { próprio }\right) \text { ao Pedro }{ }_{i} . \\
\text { the meditation gave.back=SE.REFL (himself) to.the } \mathrm{P} . \\
\text { intended meaning: 'The meditation gave Pedro back to himself.' }
\end{gathered}
$$

As mentioned above, the DO and the IO are merged into their thematic position before a functional category is merged. The functional categories that trigger cliticisation, $\mathrm{v}^{\circ}$ or appl ${ }^{\circ}$, merge above the base positions of the DO and the IO. In the case of $\mathrm{v}^{\circ}$, it is obvious that IO won't move into specvP in order to create a Bjorkman \& Zeijlstra configuration because the external argument merges first. In the case of appl ${ }^{\circ}$, movement of DO into the specifier of applP must be motivated. To my knowledge, there is no independent requirement to move the DO into the specifier position of a dative head in ditransitive structures. The ungrammaticality of (392) is thus due to the fact that DO and IO cannot enter into a Bjorkman \& Zeijlstra configuration with each other, and a reflexive clitic cannot be licensed with the intended interpretation.

What remains to be accounted for is the agreement relation between the intensifier and the strong reflexive pronoun. The last section is devoted to this agreement relation. 


\subsection{Agreement between the strong pronoun and the intensifier}

Recall from section 6.1.3 that agreement between the intensifier and the reflexive pronoun left the phifeatures of the intensifer unvalued. The tree structure in (331b) is repeated here as (393).

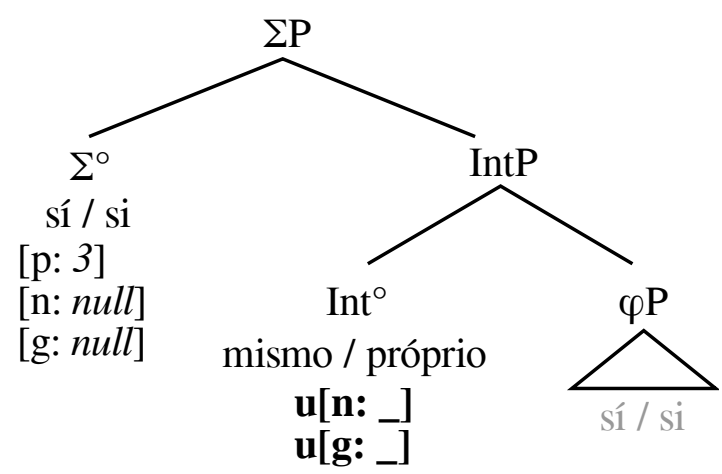

Obviously, the unvalued features on the intensifier cannot remain like this. They need to be valued, and they need to be valued according to the phi-features of the pronoun's antecedent. The question is how they get the values from the antecedent. In the case of the clitic doubling structures discussed so far, there is a chain of agreement links that connects the antecedent of the pronoun with the intensifier. The agreement links have been introduced at the outset of this chapter, and the illustration is repeated here in (394).

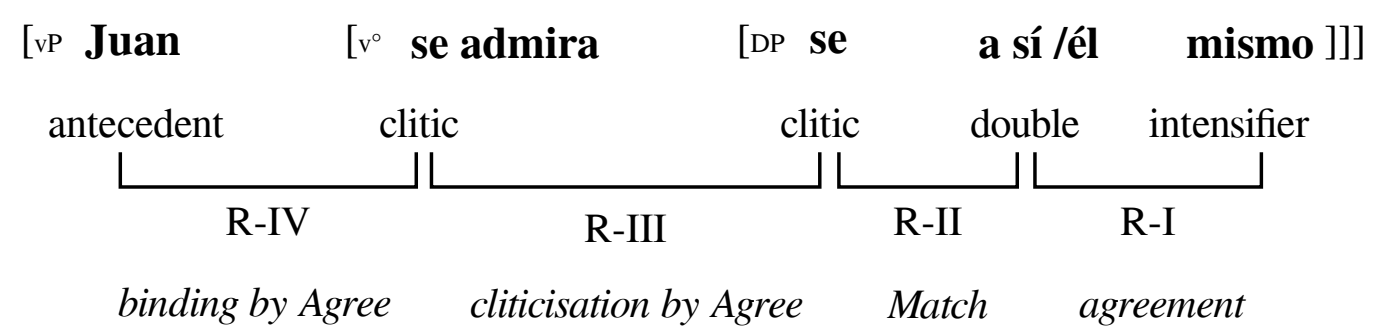

I want to propose that by virtue of the agreement chain the unvalued phi-features of the intensifier are valued by means of a post-syntactic valuation process similar to the process assumed in Kučerová (2018). In her account, it is contextual information that determines the values of natural gender on human denoting DPs. Heim (2008) and Kratzer (2009) propose a process of feature transmission that relies on information from syntactic or semantic binding. I do not want to make a commitment to any of the analyses because I believe that the mechanism that ensures that anaphoric pronouns agree with their sentence-internal or sentence-external antecedent in phi-features, and hence values the reflexive intensifier in Spanish and European Portuguese, is of a more general nature. I want to propose that the process that values the features of the intensifier depends on the way a strong pronoun is interpreted and is thus subject to syntactic, semantic, and discourse pragmatic principles and processes. For example, in (395), the pronoun has to have the same phi-features and there is no semantic binding relation or any syntactic agreement that is able to related the two DPs across sentence boundaries. 
Rita $_{i}$ loves ice cream. She ${ }_{i}$ eats a sundae every day.

The same mechanism that assures matching phi-features in (395) is possibly at work in (396) as well. There is no (syntactic) agreement link between the reflexive pronoun and the antecedent in either sentence. Furthermore, no operator-variable binding is possible between the reflexive pronoun embedded in the DP and its antecedent, either in (395) or in (396).

(396) a. EP A Joana $\mathrm{i}_{\mathrm{i}}$ perguntou que foto de $\mathrm{si}_{\mathrm{i}}$ própria o Pedro $_{\mathrm{k}}$ viu. the J. asked which photo of REFL.PR SELF.FEM.SG the P. saw 'Joana asked which photo of herself Pedro saw.'

b. Sp. Pedro ${ }_{i}$ dijo que Maria vio una foto de sí $i_{i}$ mismo. P. said that M. saw a photo of REFL.PR SELF.MASC.SG 'Pedro said that Maria saw a photo of himself.'

(Campos 1995:28)

I want to propose that the same mechanism that ensures matching phi-features in (395) and in (396) is also responsible for post-syntactic valuation of the reflexive double in clitic doubling structures. This mechanism may access contextual-intentional, semantic, and syntactic information. The access to this information seems to be dependent on the way a pronoun is interpreted and how its reference is resolved.

The last two chapters are devoted to the interpretation of the reflexive and non-reflexive strong pronouns inside PPs and to the effects of the intensifiers on the interpretation of the pronouns. 



\section{Referential properties of pronouns inside prepositional phrases}

This chapter is dedicated to the interpretation of pronouns inside prepositional phrases. I will focus on pronouns inside four types of prepositional phrases:

(i) argumental PPs (PP-complements) selected by so-called prepositional verbs such as falar de (EP), hablar de (Sp.) 'talk about', lutar contra (EP), luchar contra (Sp.) 'fight against', confiar em/en (EP, Sp.) 'trust',

(ii) argumental locative PPs selected by verbs such as colocar (Sp., EP) or pôr (EP), poner (Sp.) 'put',

(iii) locative adjunct PPs of perception verbs, and

(iv) benefactive adjunct PPs.

We have already seen throughout chapter 5 that reflexive and non-reflexive strong pronouns are not in complementary distribution in the $a$-marked phrase in clitic doubling structures. In clitic doubling structures, it was the clitic that determined the reference of the strong pronoun. As a clitic is ungrammatical in the constructions under discussion here, the reference of the strong pronoun must be resolved in a different way. In order to determine the way reflexive and non-reflexive pronouns are interpreted, the same structural and interpretive diagnostics that were introduced in chapter 5 are applied in the present chapter to strong pronouns inside PPs. The structural diagnostics for locality and c-command will be discussed in sections 8.1 and 8.2. In sections 8.3-8.7 the following interpretive diagnostics will be discussed in order to distinguish a free, coreferential interpretation from a bound interpretation: the diagnostic for a sentence-external antecedent, a split antecedent, quantifier binding, VP ellipsis, and only-contexts. A summary of the results will be presented in section 8.8 .

\subsection{Locality and (non-)complementarity}

It is a well-known fact that pronouns in Spanish and European Portuguese are not in complementary distribution inside PPs if the antecedent is local. This is true for pronouns inside PP-complements, locative PPs (adjuncts and arguments), and for pronouns inside PP-arguments of picture nouns (see Lobo 2013, Estrela 2006, Lobo \& Menuzzi 2016 for European Portuguese, and Fernández Soriano 1999, Bosque \& Gutiérrez-Rexach 2016 for Spanish). The examples (6) and (7) from section 1.1 are repeated here as (397) and (398). Similar examples can be found in the work of the cited authors.

(397) a. $\quad$ She $_{\mathrm{i}}$ only thinks about herself $\mathrm{i}_{\mathrm{i}} /$ her $_{\mathrm{i}}$.

b. Sp. Ella $a_{\mathrm{i}}$ solo piensa en síi $/ \mathrm{i}_{\mathrm{en}}$ ella $\mathrm{i}_{\mathrm{i}}$.

c. EP Ela $\mathrm{i}_{\mathrm{i}}$ só pensa em $\mathrm{si}_{\mathrm{i}} /$ nela $_{\mathrm{i}}$.

(398) a. $\quad$ She $_{\mathrm{i}}$ saw a snake next to herself ${ }_{\mathrm{i}} /$ her $_{\mathrm{i}}$.

b. Sp. Ella $a_{i}$ vio una serpiente cerca de $s i_{i} / d e$ ella $a_{i}$.

c. EP Ela $\mathrm{i}_{\mathrm{i}}$ viu uma serpente perto de $\mathrm{si}_{\mathrm{i}} / \mathrm{dela}_{\mathrm{i}}$. 
Most accounts focus on the non-reflexive pronoun with a local antecedent because this pattern challenges the assumptions of classical BT that are based primarily on English data. Clearly, whatever explanation is given for the English facts, it will not carry over to Spanish and European Portuguese because the distinction between complement PPs and locative PPs does not play a role. ${ }^{109}$ The following subsections consider the distribution and interpretation of both types of pronouns with local and nonlocal antecedents.

\subsubsection{PP-complements}

Menuzzi (1999), following a study of Zribi-Hertz (1980) on French, showed for Brazilian Portuguese (BP) and Lobo \& Menuzzi (2016) and Estrela (2006) ${ }^{110}$ for European Portuguese that reflexive and non-reflexive pronouns are not arbitrarily interchangeable inside complement PPs. The authors argue that the interpretation of the non-reflexive pronoun inside a complement PP is affected by the lexical properties of the selecting verb. Menuzzi (1999) defines three types of prepositional verbs: (i) verbs of obligatory reflexivity such as the expressions ter para (EP/BP) 'to be convinced' or 'to believe' and levar con (EP/BP) 'to carry sth. with sb.', (ii) verbs of possible reflexivity such as confiar em (EP/BP) 'to trust', falar de (EP/BP) 'to talk about', or pensar em (EP/BP) 'to think about', and (iii) verbs of reflexivity unlikely such as lutar contra (EP/BP) 'fight against'. With verbs of the type obligatory reflexivity, the non-reflexive pronoun obligatorily takes the external argument as its antecedent. ${ }^{111}$ With verbs of the type possible reflexivity, the non-reflexive pronoun can be interpreted either as coreferent or as disjoint

${ }^{109}$ In English, reflexive and non-reflexive pronouns are in complementary distribution in complement PPs, including the dative PP of DPCs (see section 5.2.2), but not inside locative PPs and in PPs selected by so-called picture nouns (see Chomsky 1981, 1986, Hornstein 2001, 2007, Hicks 2009, and Reuland 2011).

${ }^{110}$ Estrela (2006) conducted a speaker inquiry for European Portuguese, corroborating Menuzzi’s (1999) findings.

111 The example of Lobo \& Menuzzi (2016:344) is given in (i), and a corresponding Spanish example in (ii).

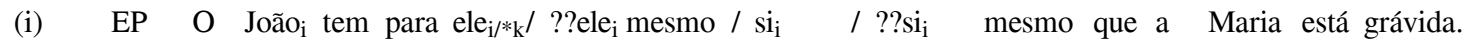
the J. has to him / him SELF REFL.PR / REFL.PR SELF that the M. is pregnant 'João believes that Maria is pregnant.'

(ii) Sp. Ese hombre $\mathrm{i}_{\mathrm{i}}$ vendrá para llevarte con él $\mathrm{l}_{\mathrm{i} /{ }_{\mathrm{k}}} /$ ??él $\mathrm{l}_{\mathrm{i}}$ mismo / consigo $\mathrm{i}$ / ??consigo $\mathrm{i}_{\mathrm{i}}$ mismo. this man will.come to take=you.cL with him / him SELF / with.REFL.PR / with.REFL.PRSELF 'This man will come and take you with him.'

The non-reflexive pronoun cannot refer to another entity distinct from the subject, as indicated by the index $k$. This means that the interpretation of the pronoun is not derived and that the pronoun does not represent an independent argument of the verb. In this sense it is similar to the clitic of inherent reflexive verbs. Recall from section 2.3 that inherent reflexive verbs do not allow for clitic doubling because the double and the intensifier realise the internal argument. It seems that this is also the reason for the unacceptablity of the intensifiers in (i) and (ii). 
with the external argument. ${ }^{112}$ With verbs of the type reflexivity unlikely, the non-reflexive pronoun is preferred with an interpretation as disjoint from the external argument. ${ }^{113}$ The results of Menuzzi (1999), Lobo \& Menuzzi (2016), and Estrela (2006) are based on sentences with a local subject DP as antecedent. But if the sentences contain two potential antecedents, the distinction between verbs of the type possible reflexivity and verbs of the type reflexivity unlikely disappears. Let us look at the example in (399). There are two possible antecedents for the non-reflexive pronoun: the DP o Pedro and the embedded DP o Rui. The continuation of the context sentence in (399a) contains a verb of the type possible reflexivity and the continuation in (399b) contains a verb of the type reflexivity unlikely. If a lexical property of the verb were to determine the interpretation of the pronoun, it would be expected that coreference between the pronoun and the subject DPs pro/o Pedro is more easily available with verbs of the type possible reflexivity than with verbs of the type reflexivity unlikely. This prediction is not borne out.

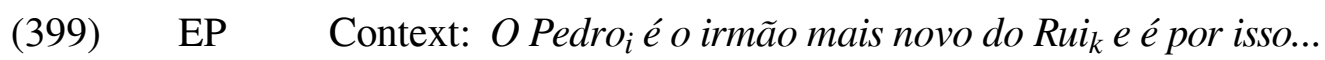

a. que pro $_{i}$ confiará nele $?$ ? $/ \mathrm{k}$.

[possible reflexivity] that pro will.trust in.him

'Pedro is Rui's little brother, and that is why he trusts him.'

b. que pro $_{i}$ luta contra ele??i/k.

[reflexivity unlikely] that pro fights against him

'Pedro is Rui's little brother, and that is why he fights against him.'

The judgements of three European Portuguese native speakers were clear: with both types of verbs the non-reflexive pronoun is interpreted as coreferent with the embedded DP $o$ Rui, and coreference with pro/o Pedro is judged odd with both types of verbs. Thus, with a non-local antecedent, the distinction between verbs of the types possible reflexivity and reflexivity unlikely disappears.

112 Lobo \& Menuzzi's (2016) judgement of sentences like (i) suggest that both pronouns are equally possible, with or without the intensifier, but the results from Estrela (2006) show that the reflexive pronoun (with/without the intensifier) is accepted by more speakers $(83 \% / 80 \%)$ than the non-reflexive pronoun with/without the intensifier $(61 \% / 57 \%)$.

(i) EP O Paulo confia nele $\mathrm{i}_{\mathrm{i} / \mathrm{k}} /$ ?nele $_{\mathrm{i} / * \mathrm{k}}$ próprio $/ \mathrm{em} \mathrm{si}_{\mathrm{i} / * \mathrm{k}} / \mathrm{em} \mathrm{si}_{\mathrm{i} / * \mathrm{k}}$ próprio.

(Estrela 2006:59/60)

the P. trusts in.him / in.him SELF / in REFL.PR / in REFL.PR SELF

'Paulo trusts him/himself.'

113 According to Lobo \& Menuzzi (2016) and Estrela (2006), coreference between the subject and the bare non-reflexive pronoun is rejected by most speakers of European Portuguese. The judgements are closely related to the presence and absence of the intensifier, which positively affects the acceptablilty of a coreferent interpretation. Under a coreferent interpretation, $13,3 \%$ of the speakers consulted by Estrela (2006) accepted the bare non-reflexive pronoun without the intensifier, while $41 \%$ accepted the non-reflexive pronoun with the intensifier. The judgements are represented in the example in (i) .

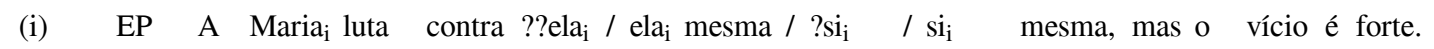

the M. fights against her / her SELF / REFL.PR/ REFL.PR SELF but the vice is strong

'Maria fights against herself, but the vice is strong.'

(Lobo \& Menuzzi 2016:344) 
As for Spanish, the sentences in (400) were presented to native speakers and no difference between verbs of the types possible reflexivity and reflexivity unlikely was obtained. With both types of verbs, the speakers clearly preferred the reflexive pronoun with the intensifier over all other options. Furthermore, the non-reflexive pronoun with the intensifier was preferred over the bare pronouns. The comment was made that use of the bare reflexive was unusual. As for the bare non-reflexive pronoun, the first (spontaneous) interpretation was an interpretation as disjoint from the subject DP. Only after asking whether the pronoun could corefer with the subject was this interpretation confirmed.

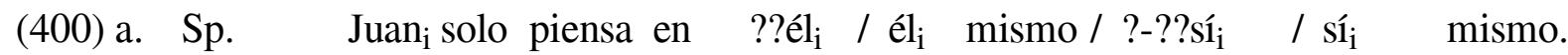

J. only thinks about him / him SELF / REFL.PR / REFL.PR SELF

'Juan only thinks about himself.'

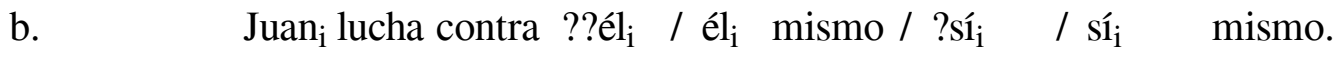

J. fights against him / him SELF / REFL.PR/ REFL.PR SELF

'Juan fights against himself.'

These results indicate that the factors that determine the judgements with verbs of the types possible reflexivity and reflexivity unlikely are essentially distinct from those of type obligatory reflexivity (see the examples in footnote 111). The lexical semantics of the latter type effectively constrains the interpretation of the pronouns. This means that the interpretation of the pronouns is not derived, but lexically predetermined. I will therefore not consider this type any further. With verbs of the types possible reflexivity and reflexivity unlikely, a coreferent or a disjoint interpretation is not exclusively determined by the lexical meaning, but also by factors such as the presence of a second possible antecedent. ${ }^{114}$ For this reason, I will not consider the distinction between verbs of the types possible reflexivity and reflexivity unlikely.

The data presented so far allow for the general conclusion that in the case of a local antecedent, reflexive and non-reflexive pronouns are not in complementary distribution in complement PPs. But, differently from Spanish, the use of the bare pronoun is preferred in European Portuguese over the use of the pronoun together with the intensifier. As we will now see, in the case of a non-local antecedent, the general non-complementarity disappears in Spanish, but not in European Portuguese.

Long-distance reflexives inside PP-complements, as exemplified in (401), have been attested in Lobo (2013) and Menuzzi (1996). In (401a), there are two possible antecedents for the pronouns: a local clause-internal antecedent and a non-local clause-external one. In $(401 \mathrm{~b})$, there are three possible antecedents: a local antecedent and two non-local ones. According to Lobo (2013) and Menuzzi (1996), the long-distance interpretation of the reflexive is preferred over the local interpretation in these examples. Note that in (401b), the reflexive exclusively takes the c-commanding non-local DP as antecedent, whereas the non-reflexive pronoun can take either non-local DP as antecedent.

\footnotetext{
114 According to Nicol \& Swinney (2008), the interaction between lexical semantics and the preference for a certain reading belongs to the realm of (experimental) psycholinguistic studies. These approaches, as well as other pragmatic aspects, are beyond the scope of this book.
} 


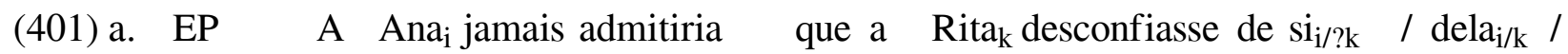
the A. never would.admit that the R. mistrusts.CON of REFL.PR / of.her / de $s i{ }_{i} / \mathrm{k}$ própria / dela $*_{\mathrm{i} / \mathrm{k}}$ própria.

of REFL.PR SELF / of.her SELF

'Ana would never admit that Rita mistrusts her/herself.'

(similar in Menuzzi 1996:189)

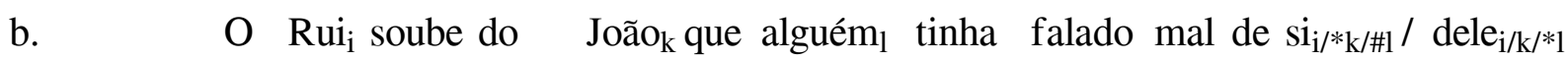
the R. knew of.the J. that someone AUX.INDSpoken bad of REFL.PR / of.him de $\mathrm{si} *_{\mathrm{i} /} / \mathrm{k} / \mathrm{l}$ próprio.

of REFL.PR SELF

'Rui found out from João that someone had spoken bad things about him/himself.'

(similar in Lobo 2013:2222)

Recall from chapter 5 that long-distance reflexives in clitic doubling contexts were possible if the intensifier was absent, if the sentence was in subjunctive mood, and if the antecedent was singular. ${ }^{115}$ Long-distance reflexives inside PPs are also limited to a bare reflexive. As soon as the intensifier is present in the sentences in (401), the pronouns have to take a local antecedent. The restriction to a singular antecedent is active with long-distance reflexives inside a complement PP too. As shown in (402), a plural DP cannot act as an antecedent for a long-distance reflexive and only the local interpretation of the bare reflexive is possible.

EP Os pais ${ }_{i}$ desejam que o miúdo ${ }_{\mathrm{k}}$ confie em $\mathrm{si} *_{\mathrm{i} / \mathrm{k}}$.
the parents wish that the kid trusts in REFL.PR
'The parents want the kid to believe in himself.'

But differently from long-distance reflexives in clitic doubling contexts, subjunctive mood is not a licensing condition for long-distance reflexives inside PPs. Compare the sentences in (401): in (401a), the verb of the subordinate clause is in subjunctive mood, but it is in indicative mood in (401b) and in both sentences the long-distance interpretation is available. Although mood is not important, there are pragmatic factors that constrain the acceptability of a long-distance reflexive. In (401a) and (401b), the subject DP of the matrix clause is the attitude holder of the sentence. But if the attitude holder is

\footnotetext{
115 In Spanish, this type of construction was judged as absolutely ungrammatical. In chapter 6 it was argued that the difference between Spanish and European Portuguese is manifest in the phi-feature content of reflexive pronoun. In European Portuguese, the null-value of the number feature is associated with a presupposition for singular, so the bare reflexives can introduce a semantically relevant restriction on the antecedent and may act as long-distance anaphor. In Spanish, the nullvalue for number is semantically inhert, and a long-distance interpretation is impossible.
} 
sentences-external as in (403), the local reading of the bare reflexive pronoun becomes the preferred option. $^{116}$

$$
\text { EP }
$$

In Spanish, the (bare) reflexive pronoun inside PPs cannot act as long-distance anaphor (see Otero 1999 and Menuzzi 1996). This fact is exemplified in (404). The strong reflexive pronoun is always related to the closest clause-internal antecedent, whereas the non-reflexive pronoun can take the local and the non-local DP as its antecedent. Note that the intensifier blocks the non-local reading of the non-reflexive pronoun.

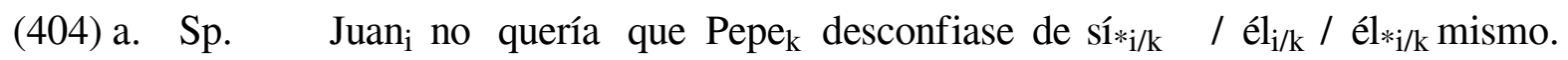

J. not wanted that P. mistrust of REFL.PR / him / him SELF

'Juan did not want Pepe to mistrust him/himself.'

b. $\quad$ Anna $_{\mathrm{i}}$ se enteró por Teresa $\mathrm{k}_{\mathrm{k}}$ que alguien $\mathrm{m}_{\mathrm{m}}$ había hablado mal de $\mathrm{s}^{1} *_{\mathrm{i}} / *_{\mathrm{k}} / \mathrm{m} /$

A. SE= find-out by $\mathrm{T}$. that someone AUX spoken bad of REFL.PR /

ella $\mathrm{i}_{\mathrm{i} / \mathrm{k} / \mathrm{m}} /$ ella $\mathrm{i}_{\mathrm{i} / * \mathrm{k} / * \mathrm{~m}}$ misma.

of.her / her SELF

'Ana found out from Teresa that someone had spoken bad things about her/herself.'

Let us summarise this section so far: in contexts of a local antecedent, the reflexive and the non-reflexive pronoun are not in complementary distribution in Spanish and European Portuguese. In subordinate sentences with two potential antecedents, the two languages differ with respect to the availability of long-distance reflexives, but show the same restrictions on the interpretation of the non-reflexive pronoun. The non-reflexive pronoun may take the local and non-local DP as an antecedent, but as soon as the intensifier is present only the local antecedent is acceptable. This is also true for long-distance reflexives in European Portuguese, which come necessarily without the intensifier and are restricted to a singular antecedent.

\subsubsection{Locative and benefactive PPs}

The sentences at issue in this section basically have the structure as in (405). The pronoun inside the locative or benefactive PP has two potential antecedents: the subject DP (SU) or the direct object DP (DO). In this sense these sentences are similar to ditransitive sentences.

$$
\text { [SU Verb DO [ } \left.\left.\mathrm{P}_{\text {loc, bene }} \text { Pronoun }_{\text {reflexive, non-reflexive }}\right]\right]
$$

\footnotetext{
${ }^{116}$ Pronouns whose reference depends on discourse pragmatic factors such as view point or perspective are called logophors in Speas (2004); for a similar use of the term see Reuland (2001). A detailed study of these phenomena in European Portuguese must be left for future work.
} 
First, I will examine the patterns with the direct object and the subject as possible antecedents of the pronouns and then I will focus on non-local antecedents, such as subject of a higher clause.

Let us start with the Spanish data. According to Bosque \& Gutiérrez-Rexach (2016:578) and Otero (1999), the reflexive pronoun inside these PPs obligatorily takes the most local DP as antecedent, which is the direct object DP in the sentences in (406). In (406a) the pronoun is inside the locative adjunct PP of a perception verb, and in (406b) it is inside a locative argument PP. In both sentences, coreference with the subject DP requires use of the non-reflexive pronoun. ${ }^{117}$

(406) a. Sp. Luis $_{\mathrm{i}}$ vio un pájaro junto a sí $*_{\mathrm{i} / \mathrm{k}} \quad /$ él $\mathrm{l}_{\mathrm{i} / \mathrm{k}_{\mathrm{k}}}$.

(Otero 1999:1499)

L. saw a bird near to REFL.PR / him

'Luis saw a bird next to him.'

b. José $e_{\mathrm{i}}$ puso la $\operatorname{manta}_{\mathrm{k}}$ encima de $\mathrm{s}^{1} *_{\mathrm{i} / \mathrm{k}} /$ él $\mathrm{l}_{\mathrm{i} /{ }^{*} \mathrm{k}}$.

(ibid.)

J. put the blanket over to REFL.PR / him

'José pulled the blanket over him.'

But these judgements are not shared by all speakers. Mellado \& Pavón (2002) show on the basis of examples from the CREA that the reflexive pronoun can take the subject DP as antecedent and that this interpretation is actually the preferred one. Their examples are given in (407a) and (407b).

(407) a. Sp. Juan

(Mellado \& Pavón 2002:213)

J. put the book behind of REFL.PR

'Juan put the book behind him.'

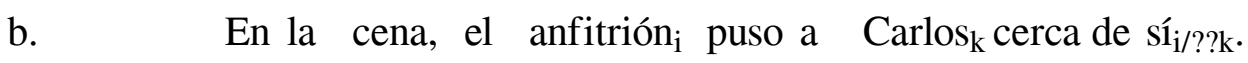

(ibid.)

At the dinner the host put oM C. near of REFL.PR

'At the dinner, the host seated Carlos next to him.'

Mellado \& Pavón (2002) assume the principles of classic BT, and they need to argue that the binding domain for the reflexive pronoun is not the PP, but the entire clause. They propose that this is due to a reanalysis of the PP. The adverbial part of the complex preposition, such as junto 'near' or lejos 'far', becomes part of the verbal phrase, and the remaining prepositional element $d e$ or $a$ behaves like a dummy preposition. As a consequence, the PPs no longer count as the binding domain, and the reflexive can now be bound by the subject DP. Mellado \& Pavón's (2002) reanalysis is schematically represented in (408).

117 On the basis of these data, Otero (1999) argues in favour of the Chomskyan analysis that takes the complex preposition to constitute a predicate that forms the binding domain for the pronouns. This PP predicate selects for an external PRO agrument, which is controlled by the object DP, as shown in (i).

(i) Sp. $\quad$ Luis $_{\mathrm{i}}$ vio un pájaro ${ }_{\mathrm{k}}\left[\mathrm{PP} \mathrm{PRO}_{\mathrm{k}}\right.$ junto a sí $*_{\mathrm{i} / \mathrm{k}} /$ él $\left.\mathrm{l}_{\mathrm{i} /{ }_{\mathrm{k}}}\right]$.

The reflexive pronoun is bound inside the PP by PRO and the non-reflexive pronoun is free in this domain and can be interpreted as coreferent with the subject DP. 


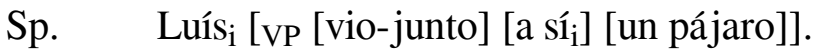

Their analysis is motivated by the following observations. First, many sentences in which the reflexive pronoun is bound by the subject have the word order $\left[\mathrm{SU}_{\mathrm{i}} \mathrm{V} \mathrm{PP} \mathrm{P}_{\mathrm{i}} \mathrm{DO}\right]$, rather than $\left[\mathrm{SU}_{\mathrm{i}} \mathrm{V} \mathrm{DO} P \mathrm{P}_{\mathrm{i}}\right]$. In the former word order pattern, the object DP does not intervene between the PP and the verb. Secondly, most occurrences of this binding pattern contained the verbs arrojar, lanzar, and tirar, all meaning 'to throw', with the complex preposition lejos de, 'far away from'. Mellado \& Pavón (2002) argue that the locative preposition is semantically closely related to the meaning of the motion verbs. This semantic relatedness is the trigger for the reanalysis.

If this reanalysis were a necessary condition for the reflexive pronoun to be bound by the subject, sentences with motion verbs and the structure [SU V DO PP ] should not allow for this interpretation, contrary to fact. In (409), the sentences have the word order pattern [SU V DO PP] and the reflexive is anaphorically related to the (pro) subject.

(409) a. Sp. Lo intentó tres veces y en todas ellas metió la mano en la manga equivocada. A la cuarta desistió y [arrojó el chaquetón lejos de sí], prefiriendo morir de neumonía a seguir interpretando el papel de nazareno. (CREA: Trías, C. 1990. 'El encuentro'.) 'He tried it three times, and each time he put his hand in the wrong sleeve. The fourth time he gave up and [threw the jacket far from himself], preferring to die of pneumonia to continuing to play the role of the Nazarene.'

b. Deja el tenedor y [acerca las velas hacia sí], mirando las llamas abstraído. (CREA: Pedrero, P. 1989. 'Invierno de luna alegre'.)

'He lets go of the fork and [brings the candles closer to himself], lost in thought watching the flames.'

Thus, the claim that a close semantic relatedness between the verb and the preposition triggers a structural reanalysis is not tenable. Furthermore, the dependency between word order and pronominal interpretation is not conclusive because the two patterns [SU V DO PP] and [SU V PP DO] allow for the subject to be the antecedent of the reflexive pronoun. ${ }^{118}$

118 In fact, the important difference between the word order patterns [SU V DO PP] and [SU V PP DO] is related to information structure. In the sentences in (409), the direct object DP represents given information, but in the case of the pattern [SU V PP DO] the direct object is focalised or represents new information, as shown in (i) and (ii).

(i) Sp. Ya se había acostumbrado al rumor fatigado de su propia respiración cuando, de repente, [escuchó junto a sí un sonido distinto y poderoso], el rumor de una respiración que no era la suya. (CREA: Martínez de Pisón, I. 1985. 'La ternura del dragón'.)

'He had gotten already used to the gasping noise of his own respiration, when, suddenly, he heard near himself a different and mighty sound, the noise of a respiration that was not his.'

(ii) Ahora las presencias de los veladores eran tan próximas que podía sentir sus alientos en la cara, e incluso llegó a notar sobre sí el tacto de sus manos heladas; (CREA: Hernández, F. 1989 'Naturaleza'.)

'Now the presence of the guardians was so close that he could feel their breath in his face, and he could even note the touch of their ice-cold hands over himself.' 
These data from the CREA, Mellado \& Pavón (2002), Bosque \& Gutiérrez-Rexach (2016), Otero (1999), and other native speakers allows for the following conclusion: for some speakers of Spanish the subject DP and the direct object DP are equally possible antecedents for the reflexive pronoun, while other speakers only accept the direct object DP as antecedent of the reflexive pronoun. But the speakers seem to agree on the reference of the non-reflexive pronoun. It is clearly preferred with the subject as antecedent, as shown in the example in (410). A similar example can be found in Mellado \& Pavón (2002:216).

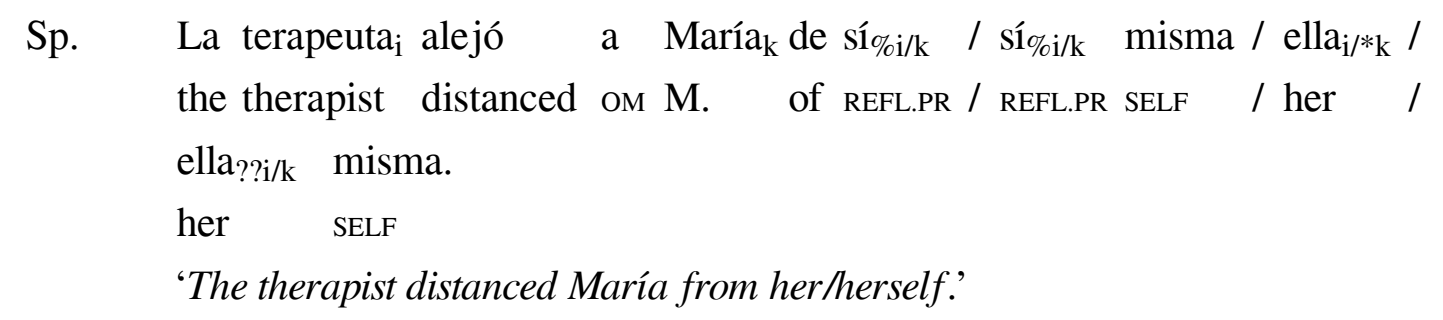

In (410), the effect of the intensifier becomes visible. It limits the range of the reflexive and nonreflexive antecedent to the most local antecedent, but the judgements are less clear for the reflexive pronoun that has been accepted with the subject as the antecedent by native speakers (cf. Mellado \& Pavón 2002).

The results for Spanish are briefly summarised in table (411). The bare reflexive and non-reflexive pronoun are in complementary distribution if they take the direct object as antecedent. But the complementarity disappears as soon as the intensifier is present. The intensifier effectively licenses this interpretation of the non-reflexive pronoun. Furthermore, the subject as antecedent of the bare non-reflexive pronoun was accepted by all speakers, but the reflexive pronoun was allowed only by some speakers. The contradictory judgements are indicated by the symbol \% in (411). Interestingly, these judgements are unaffected by the presence or absence of the intensifier.

(411) Summary for pronouns inside locative and benefactive PPs (Sp.)

\begin{tabular}{ccc|c|l}
\multicolumn{3}{c|}{ Antecedent } & \multicolumn{2}{c}{ Pronoun } \\
\hline$[$ SU & Verb & DO & {$[$ PP } & Pronoun ]] \\
\hline$\%$ & & $\checkmark$ & & sí \\
\hline$\checkmark$ & $*$ & & él \\
\hline$\%$ & $\checkmark$ & & sí mismo \\
\hline$*$ & $\checkmark$ & & él mismo
\end{tabular}

As for European Portuguese, the reflexive and non-reflexive pronoun can take the subject DP as their antecedent, as shown in Lobo (2013:2223), Estrela (2006:57), Menuzzi (1996:188), and Lobo \& Menuzzi (2016). This is exemplified for a locative adjunct PP in (412a), a PP-complement in (412b), and a benefactive PP in (412c). 
(412) a. EP $\mathrm{O}$ João viu uma cobra atràs de $\mathrm{si}_{\mathrm{i}} \quad$ (?próprio)/ dele $\mathrm{e}_{\mathrm{i}}$ (??próprio). the J. saw a cobra behind of REFL.PR SELF / of.him SELF 'João saw a cobra behind him/himself.'

(Estrela 2006:57)

b. $\quad \mathrm{O}$ Rui $_{\mathrm{i}}$ colocou o estojo diante de $\mathrm{si}_{\mathrm{i}} /$ dele $_{\mathrm{i}}$. the R. put the case in front of REFL.PR / of.him 'Rui put the case in front of himself/him.'

c. A Maria ${ }_{\mathrm{i}}$ comprou um carro para $\mathrm{si}_{\mathrm{i}}$ (?própria)/ ela $\mathrm{i}_{\mathrm{i}}$ (?própria). the M. bought a car for REFL.PR SELF / her SELF 'Maria bought a car for herself/her.'

(Estrela 2006:58)

As in Spanish, the reflexive pronoun, but not the non-reflexive pronoun, can be anaphorically related to the direct object, as shown in (413).

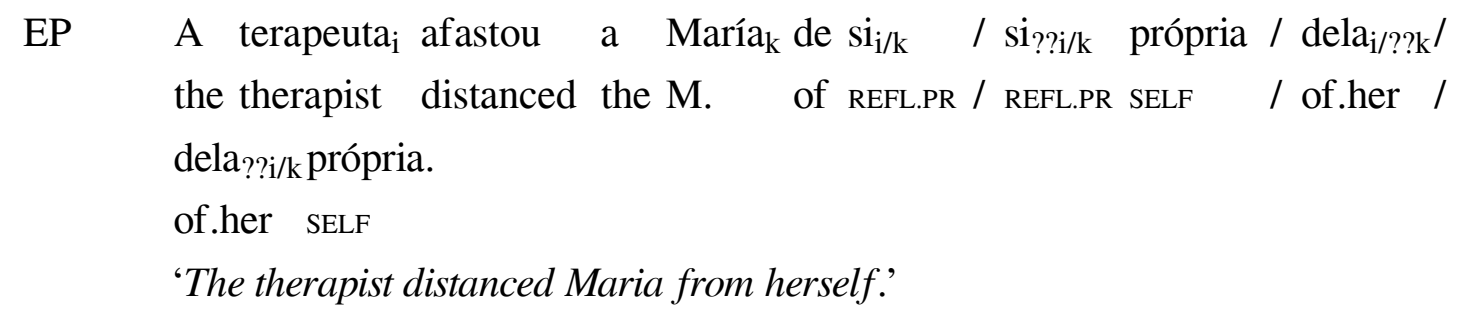

Note that the intensifier favours a local reading of the reflexive pronoun in (413). According to Estrela (2006), the intensifier has a negative effect on the acceptability in the examples in (412), but it does not lead to an overall rejection of the examples.

In European Portuguese, the results are clear: the bare reflexive and non-reflexive pronouns are not in complementary distribution if they refer to the subject, but the non-reflexive pronoun becomes hardly acceptable with the direct object as antecedent. In the latter context, the effect of the intensifier becomes visible: the non-reflexive pronoun becomes acceptable with the local DO as its antecedent, and both types of pronouns become less acceptable with the subject as antecedent. These results are summarised in (412)

(414) Summary for pronouns inside locative and benefactive PPs (EP)

\begin{tabular}{|c|c|c|c|c|}
\hline \multicolumn{3}{|c|}{ Antecedent } & \multicolumn{2}{|r|}{ Pronoun } \\
\hline$[\mathrm{SU}$ & Verb & DO & {$[\mathrm{PP}$} & Pronoun ]] \\
\hline$\checkmark$ & & $\checkmark$ & & si \\
\hline$\checkmark$ & & $? ?$ & & ele \\
\hline$\checkmark-? ?$ & & $\checkmark$ & & si próprio \\
\hline$? ?$ & & $\checkmark$ & & ele próprio \\
\hline
\end{tabular}

As for a non-local antecedent, European Portuguese permits long-distance reflexives in all three types of PPs, as shown in (415). In (415), there are two possible antecedents for the pronouns: the subject 
of the embedded clause-the DP a Maria-and the subject of the matrix clause-the DP a Rita. In all sentences, the local and non-local interpretation of the reflexive pronoun was accepted, but with a preference for the local reading. The non-reflexive pronoun is equally possible with the local and the non-local antecedent.

(415) EP A Rita jamais admitiria que...

the R. never would.admit that...

a. a Maria $a_{\mathrm{i}}$ comprasse um carro para $\mathrm{ela}_{\mathrm{i} / \mathrm{k}} / \mathrm{si}_{\mathrm{i} / ? \mathrm{k}}$.

the M. bought a car for her / REFL.PR

b. a Maria ${ }_{\mathrm{i}}$ visse uma cobra atràs dela $_{\mathrm{i} / \mathrm{k}} /$ de $\mathrm{si}_{\mathrm{i} / \mathrm{k}}$.

the M. saw a cobra behind of.her / of REFL.PR

c. a Maria ${ }_{\mathrm{i}}$ colocasse o estojo diante dela $\mathrm{a}_{\mathrm{i} / \mathrm{k}} / \mathrm{de}_{\mathrm{i}} \mathrm{i} /$ ??k .

the M. put the case in front of.her / of REFL.PR

As for the restriction to a singular antecedent, recall the example (298b), repeated here as (416). The long-distance anaphor can take a plural antecedent as its antecedent. Thus, the restriction is not general, but possibly a speaker-dependent phenomena. ${ }^{119}$

EP $\quad[\ldots]$ porque os agricultores ${ }_{i}$ que pro $_{\mathrm{i}}$ adquiriam para $\mathrm{si}_{\mathrm{i}}$ aquelas
$[\ldots]$ because the farmers.3P.PL that pro.3P.PLbought.3P.PL for REFL.PR these
máquinas $[\ldots]$.
machines $[. .]$.
'.. because the farmers that bought for themselves these machines....

Lobo (2013:2222ff), citing Brito (2003), observes that long-distance reflexives may be additionally constrained by the thematic properties of the verbs. Compare (417a) and (417b): the subject of the verb significar 'mean' is a theme argument and the PP is an experiencer. In (417b), the verb trabalhar 'work' has an agentive subject and selects a benefactive PP (adjunct). In the former example, but not in the latter, the reflexive pronoun may be associated with the non-local subject DP.

(417) a. EP Ela $a_{\mathrm{i}}$ sabia o quanto ele $\mathrm{k}_{\mathrm{k}}$ significava para $\mathrm{si}_{\mathrm{i} / \mathrm{k}_{\mathrm{k}}}$.

she knew the how.much he meant for REFL.PR

'She knew how much he meant to her/herself.'

b. Ela $\mathrm{i}_{\mathrm{i}}$ sabia o quanto ele $\mathrm{k}_{\mathrm{k}}$ trabalhava para $\mathrm{si}{ }_{\mathrm{i} / \mathrm{k}}$.

she knew the how.much he worked for REFL.PR

'She knew how much he worked for himself.'

\footnotetext{
${ }^{119}$ More research into the licensing contexts and the interpretation of long-distance reflexives and the bare reflexive in general is needed to give an explanation for these data. These topics have to be left for future research.
} 
In Spanish, long-distance reflexives are ungrammatical inside of all types of PPs. In (418) it is shown that the reflexive pronoun is restricted to the clause-internal antecedent, whereas the non-reflexive pronoun is free for coreference with either a local or a non-local antecedent.

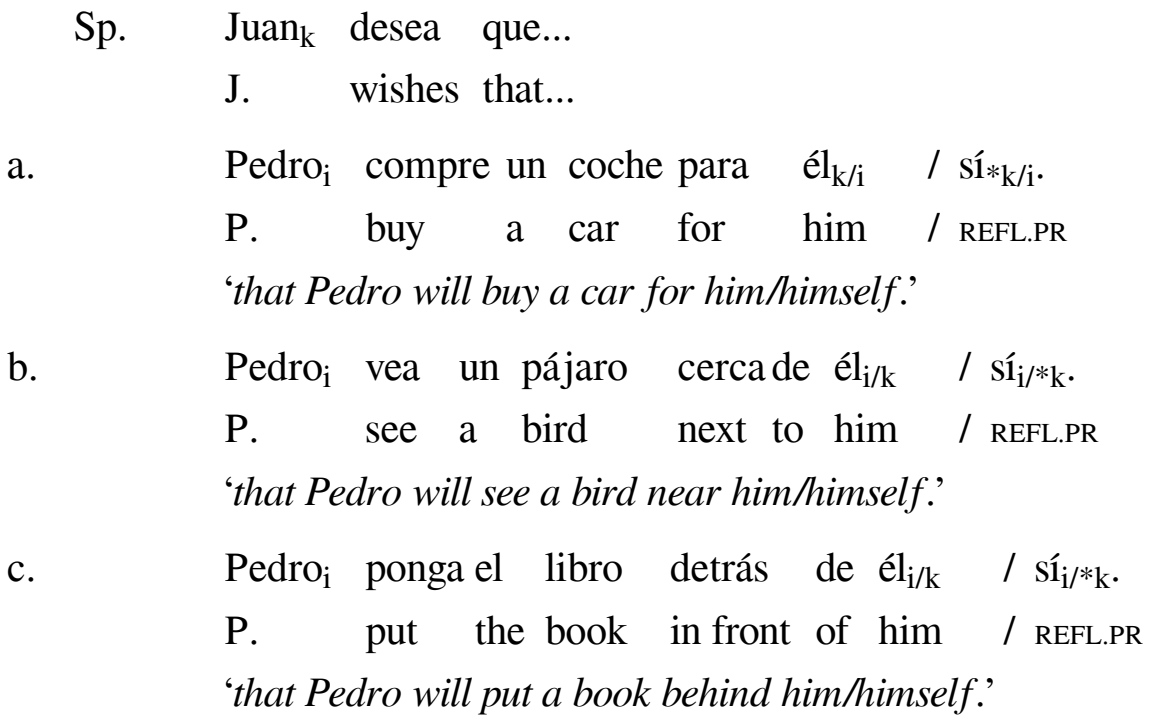

Long-distance reflexives are also ungrammatical with verbs whose thematic structure favoured a longdistance interpretation in European Portuguese. In (419), only the non-reflexive pronoun is allowed for coreference with the subject DP.

Sp. Anna sabía cuanto él significaba para sí $*_{\mathrm{i} / \mathrm{k}} / \mathrm{ella}_{\mathrm{i}}$.
A. knew how.much he meant for REFL.PR / her
'Anna knew how much he meant to her.'

Let us summarise the results of the diagnostic for locality. As a general conclusion it can be stated that the reflexive and the non-reflexive pronouns are not in complementary distribution in any of the types of PPs examined here. In sentences with complement PPs, the two types of pronouns are clearly not in complementary distribution in both languages, but the languages differ with respect to the acceptability of the intensifier. The preferred options are marked with the symbol of in the table in (420). In sentences with a locative or benefactive PP, there are two clause-internal antecedents: the subject and the direct object. If the subject is chosen as antecedent, both pronouns- the bare reflexive and the bare non-reflexive pronoun - can be used in European Portuguese and by some speakers of Spanish. If the intensifier is present the non-reflexive pronoun is acceptable with the direct object as its antecedent in European Portuguese and Spanish. 
(420) Result of the locality diagnostic

\begin{tabular}{|c|c|c|c|c|}
\hline \multirow{2}{*}{ Diagnostics } & \multicolumn{2}{|c|}{ Reflexive pronoun } & \multicolumn{2}{|c|}{ Non-reflexive pronoun } \\
\hline & - intensifier & + intensifier & - intensifier & + intensifier \\
\hline (i) Clause-internal antecedent & \multicolumn{4}{|c|}{ in complement PPs } \\
\hline \multirow[t]{2}{*}{ SU } & $\checkmark\left(\mathrm{EP}: \frac{\mathrm{d}}{\mathrm{d}}\right)$ & $\checkmark(\mathrm{Sp} .:$ : & $\checkmark\left(\mathrm{EP}: \mathrm{de}_{\mathrm{d}}\right)$ & $\checkmark(\mathrm{Sp} .:$ : $8 \mathrm{~g})$ \\
\hline & \multicolumn{4}{|c|}{ in locative and benefactive PPs } \\
\hline a. SU & Ep: $\checkmark, S p .: \%$ & $\begin{array}{c}\text { EP: } \checkmark-? ? \\
\text { Sp.:\% }\end{array}$ & $\checkmark$ & $\mathrm{EP}: ? ?, \mathrm{SP} .:^{*}$ \\
\hline b. DO & $\checkmark$ & $\checkmark$ & $\mathrm{Sp} .:^{*}, \mathrm{EP}: ? ?$ & Sp.: $\checkmark, E P: \checkmark$ \\
\hline (ii) Clause-external antecedent & \multicolumn{4}{|c|}{ in complements PPs and locative and benefactive PPs } \\
\hline SU & $\mathrm{EP}: \mathcal{}, \mathrm{Sp} .:^{*}$ & $*$ & $\checkmark$ & $*$ \\
\hline
\end{tabular}

Differently from Spanish, European Portuguese allows for long-distance reflexives with all types of PPs, given that the above mentioned conditions are fulfilled. A long-distance interpretation is impossible with the intensifier because it requires the most local antecedent for the pronoun it modifies. The effects of the intensifier on the interpretation of the pronouns will be examined in more detail in the next chapter.

\subsection{C-command}

Recall from section 1.2 that c-command is a condition for semantic binding. Thus, if a pronoun requires a c-commanding antecedent, then its interpretation is encoded by means of semantic binding rather than by pragmatic coreference.

As exemplified in (421) with a PP-complement, the reflexive pronouns in Spanish and European Portuguese require a c-commanding antecedent. An anaphoric relation with the embedded DP, $o$ João and Luisa, respectively, is not acceptable. But the non-reflexive pronouns can take either DP as antecedent: it can refer to the subject DP or the embedded DP.

(421) a. EP $\quad\left[\mathrm{O}\right.$ pai $\mathrm{d}\left[\mathrm{o} \quad \mathrm{João}_{\mathrm{i}}\right]_{\mathrm{k}}$ confia em si $*_{\mathrm{i} / \mathrm{k}} \quad$ (próprio) / nele $\mathrm{i}_{\mathrm{i} / \mathrm{k}} /$ nele $_{*} \mathrm{i} / \mathrm{k}$ próprio. the father of.the J. trust in REFL.PR SELF / in.him / in.him SELF 'João's father trusts him/himself.'

b. Sp. $\quad\left[\text { La madre de }[\text { Luisa }]_{\mathrm{i}}\right]_{\mathrm{k}}$ confía en sí $*_{\mathrm{i} / \mathrm{k}}$ misma / ella $\mathrm{i}_{\mathrm{i} / \mathrm{k}} / \mathrm{ella} *_{\mathrm{i} / \mathrm{k}} \mathrm{misma}$. the mother of L. trust in REFL.PR SELF / her / her SELF 'Luisa's mother trusts her/herself.'

Again, the intensifier affects the interpretation of the non-reflexive pronoun. If it is present, it can only refer to the subject DP, the external argument of the verb. Pronouns inside locative PPs or benefac- 
tive PPs show the same results with respect to binding by a local c-commanding and a local non-ccommanding antecedent. For the sake of brevity, only an example for a locative PP is given in (422).

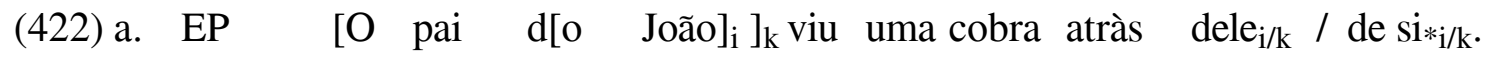
the father of.the J. Saw a cobra behind of.him / REFL.PR 'João's father saw a cobra behind him/himself.'

b. Sp. [La madre de $\left.[\text { Luisa }]_{\mathrm{i}}\right]_{\mathrm{k}}$ vio una cobra detrás de ella $\mathrm{i}_{\mathrm{i} / \mathrm{k}} / \mathrm{s} \mathbf{s}_{\mathrm{i}} \mathrm{i} / \mathrm{k}$. the mother of L. Saw a cobra behind of her / REFL.PR 'Luisa's mother saw a cobra behind her/herself.'

Thus, reflexive strong pronouns require a c-commanding antecedent, irrespective of the presence or absence of the intensifier. The bare non-reflexive pronoun is not subject to this condition, but interestingly, the intensifier is able to restrict the reference of the non-reflexive pronoun to a c-commanding antecedent.

\subsection{Sentence-external antecedent}

This diagnostic essentially distinguishes between pronouns that are able to refer independently and pronouns that are dependent on a sentence-internal antecedent. In both languages, the reflexive pronoun is restricted to a sentence-internal antecedent and only the non-reflexive pronoun can take a sentence-external antecedent. This is true for pronouns in all the PPs under discussion here. Examples are given for pronouns in a PP-complement in (423) and for pronouns inside a benefactive PP-adjunct in (424).

\section{Context: Can I trust Peter ${ }_{i}$ ?}

a. EP Acho que sim. O Rui k $_{\mathrm{k}}$ confia em $\mathrm{si}_{*_{\mathrm{i}}} \quad /$ nele $_{\mathrm{i}}$.

I think that yes the R. trust in REFL.PR / in.him

'I think you can. Rui trusts him.'

b. Sp. Creo que sí. $\operatorname{Juan}_{\mathrm{k}}$ confía en $\mathbf{s i ́}^{*}$ / él $\mathrm{i}_{\mathrm{i}}$.

I think that yes. J. trust in REFL.PR / him

'I think you can. Juan trusts him/himself.'

Context: Did Maria buy this book for herself or for her sister ${ }_{i}$ ?

a. EP Comprou-o para $\mathrm{si} *_{\mathrm{i}} \quad /$ ela $_{\mathrm{i}}$.

bought=it.CL for REFL.PR / her

'She bought it for her.'

b. Sp. Lo compró para sí $*_{\mathrm{i}} \quad /$ ella $_{\mathrm{i}}$

it.CL=bought for REFL.PR / her.

'She bought it for her/herself.' 
Note that in (423) the presence of the intensifier would alter the referential behaviour of the non-reflexive pronoun in both languages. If it is present, reference to a sentence-external antecedent becomes odd and the sentence-internal antecedent is chosen, even though this interpretation is incoherent in the given context.

\subsection{Split antecedents}

The diagnostic testing for a split antecedent was, to my knowledge, first introduced by Lebeaux (1985) in order to distinguish locally bound and non-locally bound reflexives. A split antecedent is a plural antecedent that combines reference to two DPs that are in distinct structural positions. For example, in (425) the split antecedent is the subject DP John and the object DP Mary. In (425a), the reflexive pronoun inside a PP-complement cannot be related to the split antecedent and therefore counts as a locally bound reflexive. But the reflexive pronoun inside a picture DP, as in (425b), can refer to the split antecedent (see Hornstein 2001, Hicks 2009, and Lebeaux 1985).

(425) a.

${ }^{*} \mathrm{John}_{\mathrm{i}}$ told Mary $\mathrm{k}_{\mathrm{k}}$ about themselves $[\mathrm{i}+\mathrm{k}]$.

(Lebeaux 1985:346)

b. $\quad \mathrm{John}_{\mathrm{i}}$ told Mary $\mathrm{k}_{\mathrm{k}}$ that there were some pictures of themselves ${ }_{[i+\mathrm{k}]}$ for sale on Ebay.

(Hicks 2009:137)

Similar in Spanish and European Portuguese, a reflexive pronoun inside a PP-complement cannot take a split antecedent, as shown in (426). The example in (426a) is taken from Bosque \& Gutiérrez-Rexach (2016:564).

(426) a. Sp. $\quad$ Juan $_{\mathrm{i}}$ solo le $\mathrm{k}_{\mathrm{k}}$ habla a María $_{\mathrm{k}}$ de [sí mismos $]_{[\mathrm{i}+\mathrm{k}]}$.

J. just her.CL=talks to $\mathrm{M}$. de REFL.PR SELF intended meaning: 'Juan just talks with María about themselves.'

b. EP *O João $\mathrm{i}_{\mathrm{i}}$ conversou com a Maria $\mathrm{k}_{\mathrm{k}}$ sobre $[\mathrm{si} \text { próprios }]_{[\mathrm{i}+\mathrm{k}]}$. the J. talked with the M. about REFL.PR SELF intended meaning: 'João talked with Maria about themselves.'

But differently from English, neither language permits split antecedents inside so-called picture nouns either, as shown in (427) (see Campos 1995 for Spanish).

(427) a. Sp. *Juan ${ }_{\mathrm{i}}$ le contó a María $\mathrm{k}_{\mathrm{k}}$ que las fotos de [sí mismos $]_{[\mathrm{i}+\mathrm{k}]}$ están en J. her.CL=told to M. that the photos of REFL.PR SELF are for venta en internet.

sale in internet

intended meaning: 'Juan told María that some photos of themselves are for sale online.' 
b. EP $\quad * O$ Rui $i_{i}$ contou á Maria $a_{\mathrm{k}}$ que algumas fotos de $[\mathrm{si} \quad \text { próprios }]_{[\mathrm{i}+\mathrm{k}]}$ estão the R. told to.the M. that some photos of REFL.PR SELF are á venda na internet.

for.the sale in.the internet intended meaning: 'Rui told Maria that some photos of themselves are for sale online.'

Only a non-reflexive pronoun can take a split antecedent in Spanish and European Portuguese. The examples in (426) and (427) become perfectly grammatical, when the reflexive pronouns are replaced by matching non-reflexive pronouns. This is exemplified for PP-complements in (428).

(428) a. Sp. Juan ${ }_{\mathrm{i}}$ solo le $\mathrm{k}_{\mathrm{k}}$ habla a María $_{\mathrm{k}}$ de $[\mathrm{ellos}(\operatorname{mismos})]_{[\mathrm{i}+\mathrm{k}]}$.

J. just her.CL=talks to $\mathrm{M}$. de them SELF

'Juan only talks with María about them.'

b. EP O João $\mathrm{i}_{\mathrm{i}}$ conversou com a Maria $\mathrm{k}_{\mathrm{k}}$ sobre [eles (próprios) $]_{[\mathrm{i}+\mathrm{k}]}$.

the J. talks with the M. about them SELF

'João talked with Mary about them.'

Thus, the structural environment does not alter or influence the fact that reflexive pronouns cannot refer independently in either language. This fact supports my assumption about the phi-feature content of the reflexive pronoun. Due to the null-values, independent reference is impossible.

\subsection{Binding by a quantifier}

Recall from section 5.4 that the diagnostic for quantifier binding helps to differentiate between a coreferent interpretation and a semantically bound interpretation of a pronoun, in particular if the pronouns are not in complementary distribution. For the strong pronominal double in clitic doubling structures, it has been shown that the reflexive pronoun can be bound by all types of QPs, but that the nonreflexive double resists binding by pronominal QPs, but allows it with complex QPs (determiner QPs). We will see in this section that strong pronouns inside argumental and adjunct PPs show the same interpretive pattern. In the first part of this section, the data for Spanish and European Portuguese will be introduced. In the second part, I will discuss two ways to explain this puzzling interpretive pattern. The first proposal comes from Martins (1992, 2013). She assumes that some QPs are referential, and, as a consequence, the strong non-reflexive would be interpreted as coreferential with a QP antecedent. The second proposal is based on the assumption that the non-reflexive pronoun is interpreted neither as a bound variable nor as a coreferential variable, but as an E-type pronoun.

Let us start with the data. The sentences in (429) and (430) contain a complement PP, and the antecedent for the reflexive and the non-reflexive pronouns is a negative quantifier and an indefinite quantifier, respectively. With a bound interpretation, the non-reflexive pronoun is ungrammatical, whereas the reflexive pronoun is perfectly acceptable in Spanish and in European Portuguese. 
(429) a. EP Ninguém ${ }_{i}$ confia demasiado *nele ${ }_{i} /$ em si $_{i}$.

(Estrela 2006:96) nobody trusts too. much in.him/ in REFL.PR

'Nobody trusts too much in him/himself.'

b. Sp. Aquí nadie ${ }_{\mathrm{i}}$ confia en ??él (mismo) / sí $i_{\mathrm{i}}$ mismo.

here nobody trusts in him SELF / REFL.PR SELF

'Here nobody trusts in himself/him.'

(430) a. EP Alguém $_{i}$ pensou * nele $_{\mathrm{i}}$ próprio / em si $\mathrm{i}_{\mathrm{i}}$ próprio.

(Estrela 2006:96) someone thought in.him SELF / in REFL.PR SELF

'Someone thought about himself.'

b. Sp. Alguien ${ }_{\mathrm{i}}$ solo ha hablado de ??*él $\mathrm{l}_{\mathrm{i}}$ mismo / sí $i_{\mathrm{i}}$ mismo. someone only AUX talked of him SELF / REFL.PR SELF 'Someone has only talked about himself.'

The non-reflexive pronoun becomes acceptable with a universal QP as its antecedent, as shown in (431). This is true for European Portuguese and for some speakers of Spanish. According to Baauw (2002), some Spanish speakers accepted (431b), while others did not. The contradictory judgements are indicated by the symbol $\%$.

(431) a. EP No país da vaidade, todos ${ }_{i}$ gostam de falar sobre eles ${ }_{i}$ próprios. in the land of vanity everybody likes to talk about them SELF 'In the land of vanity, everybody likes to talk about themselves.'

b. Sp. $\quad \%[\text { Todo el mundo }]_{i}$ hablaba de él ${ }_{i}$.

(Baauw 2002:147) everybody talked of him

'Everybody talked about himself.'

With complex QPs, negative or universal, the judgements become uniform, as shown in (432) and in (433), respectively. As observed in Menuzzi (1996, 1999) and Lobo \& Menuzzi (2016) for European Portuguese and in Baauw (2002) for Spanish, the non-reflexive pronoun can take a complex QP as its antecedent. These findings have also been corroborated by the speakers' inquiry conducted in Estrela (2006) for European Portuguese and by the Spanish speakers consulted for this book.

(432) a. EP $\quad[\text { Nenhum rapaz }]_{\mathrm{i}}$ confia demasiado ?-??nele $\mathrm{i}_{\mathrm{i}} / \mathrm{em} \mathrm{si}_{\mathrm{i}}$.

(Estrela 2006:96) no boy trusts too.much in.him / in REFL.PR

'No boy trusts too much in him/himself.'

b. Sp. Aquí [ningún alumno] $]_{i}$ desconfía de $s_{i}$ / ?él $i_{i}$.

here no pupil mistrusts of REFL.PR / him

'Here no pupil mistrusts himself/him.' 
(433) a. EP [Todos os rapazes $]_{i}$ confiam demasiado ?neles / em si.

(ibid.)

all the boys trust too.much in.them / in REFL.PR

'All the boys trust too much in them/themselves.'

b. Sp. Aquí [todos los alumnos] $]_{\mathrm{i}}$ confían en ellos $\mathrm{i}_{\mathrm{i}}$ mismos / sí $i_{\mathrm{i}} \quad$ mismos.

here all the pupils trust in them SELF / REFL.PR SELF

'Here every pupil trusts himself/him.'

The same interpretive pattern is found for locative adjunct PPs and benefactive PPs. For the sake of brevity only examples with locative PPs are given here. In European Portuguese, the non-reflexive pronoun is clearly unacceptable with the negative pronominal QP in (434a), but it becomes acceptable with the complex negative QP, as shown in (434b). The judgements of Spanish speakers are again not uniform, according to Baauw (2002). Some speakers of Spanish accepted the non-reflexive pronoun in (435a), while others did not. In the case of a complex QP, the judgements become uniform, and the speakers who did not accept (435a), did accept (435b).

(434) a. EP Ninguém ${ }_{\mathrm{i}}$ tinha visto o livro atrás de $\mathrm{si}_{\mathrm{i}} \quad / *_{\text {dele }}$. $\quad$ (Menuzzi 1996:183) nobody had seen the book behind of REFL.PR / of.him

'Nobody had seen the book behind him/himself.'

b. $\quad[\text { Nenhum aluno }]_{i}$ tinha visto o livro atrás de ?si $i_{i} /$ dele $_{\mathrm{i}}$.

(ibid.)

no pupil had seen the book behind of REFL.PR/ of.him

'No pupil had seen the book behind him/himself.'

(435) a. Sp. \% $\quad$ Nadie ${ }_{\mathrm{i}}$ vio una culebra cerca de él $\mathrm{i}_{\mathrm{i}}$.

(Baauw 2002:147) nobodysaw a snake near to him

'Nobody saw a snake next to him.'

b. $\quad$ ?[Cada estudiante $]_{i}$ puso una maleta detrás de él ${ }_{\mathrm{i}}$.

(ibid.) every student put a suitcase behind of him

'Every student put a suitcase behind him.'

Interestingly, if the QP antecedent is non-local, the non-reflexive pronoun becomes acceptable in Spanish, but not in European Portuguese, as shown in (436).

(436) a. Sp. Nadie ${ }_{i}$ quiere que María hable de él $l_{i} / * *_{i} i_{i}$.

(Montalbetti 1984:87) nobody wants that M. talks of him / REFL.PR

'Nobody wants María to talk about him.'

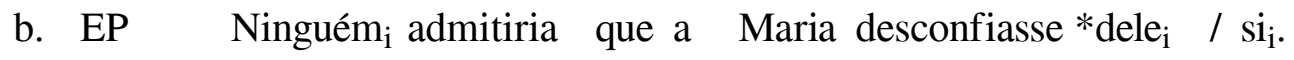
nobody admits.CON that the M. mistrusts of.him/ REFL.PR 'Nobody would admit that Maria mistrusted him.' 
In European Portuguese, both types of pronouns are possible in a long-distance configuration, but only the reflexive pronoun is acceptable with the pronominal QP antecedent. Spanish does not permit longdistance reflexives. This means that a bound interpretation of a non-reflexive pronoun seems to be available exactly because the reflexive pronoun is unavailable for other reasons. This indicates that a principle like Montalbetti's (1984) Overt Pronoun Constraint ${ }^{120}$ could be involved in (436a) because the reflexive and the non-reflexive pronoun are in complementary distribution. But clearly no version of Montalbetti's constraint can explain the binding facts observed with a local antecedent. There are distinct QP-binding behaviours for the non-reflexive pronoun and the reflexive pronoun, even though they appear in the same syntactic configuration. With non-reflexive pronouns, binding is possible with determiner QPs, ${ }^{121}$ but not with pronominal QPs (alguém and ninguém).

How can these facts be explained? One possibility is to assume that the non-reflexive pronoun is not interpreted as a bound variable, but as a free, coreferential variable. The second possibility is to assume that the pronoun is neither bound nor coreferential, but interpreted by means of an E-type strategy. Let us start with the first possibility.

Recall from section 1.2 that a coreferential interpretation requires the antecedent to be referential. Given this condition, the QPs in (431), (432), and in (433) have to be interpreted as non-quantificational or, in term of Martins (1992, 2013), as absolute or referential. Martins (1992, 2013) observes that the position of a pronominal clitic is an indication for the way a complex QP is interpreted. In (437a), the clitic is in enclitic position, and the QP subject muitas pessoas has an absolute/referential interpretation. In (437b), the clitic is in proclitic position and the QP has a quantificational/relative interpretation. $^{122}$

(437) a. EP Muitos pessoas vacinam-se todos os anos. many people vaccinate $=$ SE.REFL all the years

'There are many peple that get vaccinated very year.'

${ }^{120}$ Montalbetti (1984) showed for Spanish that a bound variable interpretation is restricted to the covert subject pronoun pro, while the overt subject pronoun is always interpreted as a free variable, unless it is focussed (see Alonso-Ovalle \& D'Introno 2001). The Overt Pronoun Constraint simply states that overt pronouns cannot be bound, if the alternation overt/empty obtains. It is also active in European Portuguese, as shown in Lobo (2013). The sentences in (i) and (ii) exemplify the bound and the free interpretation of Spanish and European Portuguese overt and covert subject pronouns.

(i) Nadie cree que él/pro es inteligente.

(Montalbetti 1984:23)

a. Nobody $(\mathrm{x})$ believes that $\mathrm{x}$ is intelligent

*él; ${ }^{\mathrm{ok}}$ pro

b. Nobody ( $\mathrm{x}$ ) believes that $\mathrm{y}$ is intelligent

$$
{ }^{\mathrm{ok}} \text { él; *pro }
$$

(ii)

Cada um contou os problemas que ele/pro tinha tido.

a. Every ( $\mathrm{x}$ ) talked about the problems that $\mathrm{x}$ had

$$
\begin{aligned}
& * \text { ele; }{ }^{\mathrm{ok}} \text { pro } \\
& { }^{\mathrm{ok}} \text { ele: }{ }^{*} \text { pro }
\end{aligned}
$$

(Lobo 2013:2200)

b. Every ( $\mathrm{x}$ ) talked about the problems that $\mathrm{y}$ had

The Overt Pronoun Constraint predicts that whenever there is no alternation between overt and covert pronouns, the overt pronoun can be bound. Applied to prepositional phrases, this means the non-reflexive pronoun should never allow for a bound interpretation, when reflexive and non-reflexive pronouns are in alternation.

${ }^{121}$ I take todos to be a determiner QP, because there is only one form for its bare use and its determiner use.

122 The terms are used as in Martins (1992), following Fodor \& Sag (1982). 
b. Muita gente se vacinam todos os anos.

(ibid.)

much people SE.REFL=vaccinate all the years

'Many people get vaccinated every year.'

The main difference between the two interpretations is that in the absolute use the number of people is measured according to some implicit scale, while in the relative use the number is compared to a reference set (see Martins 1992, following Fodor \& Sag 1982). In (437a), the existence of a certain number of people is asserted, and the sentence is true if this high number of people get vaccinated every year. In (437b), the set of people that get vaccinated every year (set A) is compared to the reference set, here the set of people that do not get vaccinated (set B). The sentence in (437b) is true if set A has more members than set $\mathrm{B}$.

The referential account is problematic for two reasons: first, the complex QP with the negative quantifier cannot receive an absolute/referential interpretation, but it can still be the antecedent of a non-reflexive pronoun. Secondly, according to Martins (2013), the QP with todos has only a collective reading, but not a distributive reading in its referential/absolute use. The distinction between the two readings is visible due to the position of the clitic. A referential/collective reading is associated with enclisis and a distributive reading with proclisis. This is shown by means of the sentence in (438). The predicate descalçarar 'take off one's shoes' requires a distributive reading of a plural subject like todas as balerinas 'every dancer' and, consequently, enclisis associated with a collective reading is ungrammatical.

$$
\begin{aligned}
& \text { EP Todas as balarinas (se) descalçaram- }(* \text { se). } \\
& \text { all the dancers SE.REFL=took.off.shoes=SE.REFL }
\end{aligned}
$$

'All the dancers took off their shoes.'

This is also true for interpretation of the QP todos rapazes in (433) above. The QP clearly has a distributive interpretation. It means that each individual in the group of boys trusts himself, and not that a group of students trusts in itself as a group. Thus, the pronoun cannot be coreferential, but it covaries with the quantified antecedent.

The second possibility is to assume that the non-reflexive pronoun is neither bound nor interpreted via coreference, but by means of an E-type strategy. The E-type/D-type approach takes pronouns to be 'definite descriptions in disguise' (see Büring 2011, Partee 2008). An in-depth discussion of these accounts in connection with the present problem is far beyond the scope of this book. But some observations are presented that point in the direction that non-reflexive pronouns inside PPs are in fact interpreted as E-type pronouns.

According to Büring (2011) and Partee (2008), Evans (1977) defines E-type pronouns on the basis of the well-known donkey sentences in (439). E-type pronouns have a quantified antecedent, but they are not bound by them. The pronoun it and her are not in a configuration to be bound by their antecedents; the indefinite DPs a donkey and a wife do not c-command the pronouns. Additionally, the pronoun is not coreferential with some donkey or wife because it covaries with the higher QP every 
man. The sentence does not mean that one specific donkey is beaten by all these cruel donkey owners, but that every man beats his own donkey. ${ }^{123}$

(439) a. $\quad$ Every man that owns a donkey beats it.

a'. $\quad$ *Every donkey owner beats it.

b. $\quad$ Every man who has a wife sits next to her.

$\mathrm{b}^{\prime} . \quad$ *Every married man sits next to her.

As stated in Partee (2008), the meaning of E-type/D-type pronouns is that of a 'systematically constructed definite description'. How this systematic way is to be formalised is a matter of debate, and there are many semantic and pragmatic approaches to this problem. ${ }^{124}$ For example, in Chierchia (1992), Etype pronouns are interpreted as a function from individuals to individuals $(\mathrm{f}(\mathrm{x}))$ and the range of this function, the definition of $f$, is determined by the antecedent of the pronoun. The pronouns it and her in (439) stand for a donkey owned by $x$ and for a wife married by $x$, respectively, and the function maps owners onto their donkeys and men onto their wives.

The ungrammatical sentences in $\left(439 a^{\prime}\right)$ and $\left(439 b^{\prime}\right)$ show that the pronoun needs an overt NP antecedent. The DP donkey owner and the adjective married are not sufficient to license the E-type pronoun. Although these expressions imply that a donkey owner owns a donkey and that a married man has a wife, but this is not enough to license the E-type pronoun. This fact has been described as formal link problem in Evans (1977) and Heim (1990).

Let us see now how the E-type/D-type approach helps to understand the puzzling interpretation of non-reflexive pronouns in Spanish and European Portuguese. For European Portuguese, I want to argue that the non-reflexive pronouns inside the PPs are not bound by a quantifier and that the acceptability of the sentences with a complex QP is due to an E-type strategy. The pronouns need an NP antecedent, and, in the case of QPs such as nenhum rapaz in (432a) above, the pronoun is interpreted as a function that maps boys onto boys. This is a way to license a distributive interpretation without binding. The sentences with a pronominal QP are ungrammatical because the pronoun needs an overt NP antecedent in order to be interpretable. The formal link problem gives an explanation for the fact that the pronominal quantifiers ninguém and alguém are impossible as the binder of a non-reflexive pronoun.

But what about the bare universal quantifier todos in (431a)? There is no overt NP, but the nonreflexive pronoun is still possible. The difference between todos on the one hand and ninguém and alguém on the other hand would be explained if todos were a determiner quantifer that selects a pro complement. This covert NP complement licenses the E-type reading. The pronominal QPs ninguém and alguém do not select for a complement and no E-type pronoun is allowed. Additionally, todos is plural, which seems to play an important role. In the English examples in (440), the QP can only be the antecedent of the pronoun if it is plural. Thus, plural is able to license E-type pronouns in

\footnotetext{
${ }^{123}$ For different truth conditions of donkey-anaphora see Heim (1990) and Chierchia (1992).

${ }^{124}$ I refer the reader to Büring (2011) and Patel-Grosz \& Grosz (2009) for an overview.
} 
English. It seems that the covert NP complement and overt plural marking is enough to license an Etype interpretation of non-reflexive pronouns also in European Portuguese. ${ }^{125}$

b.

On the basis of these observations, I want to conclude that non-reflexive pronouns in European Portuguese are never bound by a QP, but are interpreted by means of a kind of E-type strategy. In Spanish, the diverging native speaker judgements indicate that there are different strategies available. The speakers who disallow binding by a pronominal QP and the universal QP, but allow it with a complex QP antecedent, seem to apply the same strategy as in European Portuguese. The speakers who allow for binding by all types of QPs possibly use a variable binding strategy. Furthermore, all speakers allow for a pronominal QP antecedent in contexts in which the non-reflexive pronoun is the only option.

\subsection{VP ellipsis}

Another diagnostic that helps to distinguish between a bound variable interpretation and a coreferential interpretation is the so-called VP ellipsis test. Let us start with the uncontroversial data, the interpretation of the reflexive pronoun. In both languages, it is exclusively interpreted as a bound variable. The examples for PP-complements in (441) and (442) show that only the sloppy/bound reading of the pronoun was accepted by native speakers of Spanish and European Portuguese (for European Portuguese see also Lobo \& Menuzzi 2016).

(441) Sp. Juan confía en sí mismo y María también.

J. trusts in REFL.PR SELF and M. too

'Juan trusts himself, and María too.'

a. María trusts herself.

b. $\quad$ *María trusts him. (him = Juan)

(442) EP A Joana confia em si e o Jorge também. (Lobo \& Menuzzi 2016:348) the J. trusts in REFL.PR and the J. too

'Joana trusts in her, and Jorge too.'

a. Jorge trusts himself.

b. $\quad *$ Jorge trusts her. (her $=$ Rita)

125 Similarily, plural is responsible for the licensing of a referential interpretation of QPs, as shown in Martins (2013). In (i), the QP algúm aluno is singular and cannot feature in a clitic left dislocation structure. In (ii), it is plural and now it is possible as an antecedent of the clitic, which is in enclitic position signaling a referential interpretation of the QP.

(i)

*Algum aluno meu (o) vi-(o) na televisão.
some student mine him.cL=saw=him.cL in.the television

(Martins 2013:2247)

(ii)

Alguns alunos meus vi-os ontem na televisão.
some students mine saw=them.cL yesterday in.the television
'Some students of mine, I saw them yesterday on television.'

(ibid.) 
The same is true for reflexive pronouns in PP-adjuncts, as shown by means of the examples in (443) and (444) with a benefactive PP. Only the bound interpretation is acceptable. A coreferent interpretation of the reflexive pronoun in the elided VP is clearly ungrammatical.

(443) EP $\mathrm{O}$ Rui exige para si próprio mais dias de férias e a Rita também. the R. demands for REFL.PR SELF more days of holiday and the R. too 'Rui demands more days off for himself, and Rita too.'

a. Rita demands more days off for herself.

b. $\quad *_{-}$??Rita demands more days off for him. (him = Rui)

(444) Sp. Juan exige para sí un día extra de vacaciones y Marta también.

J. demands for REFL.PR a day extra of holiday and $\mathrm{M}$. too

'Juan demands an extra day off for himself, and Marta too.'

a. Marta demands a day off for herself.

b. $\quad *$ Marta demands a day off for him. (him = Juan)

As for the interpretation of the non-reflexive pronoun, the judgements are not so clear. Lobo \& Menuzzi (2016:348) mention that a bound variable reading is 'difficult to get' with a non-reflexive pronoun, as shown in the sentence in (445). For Spanish, Baauw (2002) claims in passing that pronouns inside PPs are interpreted as bound variables. His example is given in (446).

(445) EP A Joana confia nela, e o Jorge também. (Lobo \& Menuzzi 2016:348) the J. trusts in.her and the J. too

'Joana trusts in her, and Jorge too.'

a.

??Jorge trusts himself.

b.

Jorge trusts her. (her = Joana)

$(446)$

Sp. María puso una silla detrás de ella y Juana también. (Bauuw 2002:145)

M. put a chair behind of her and $\mathbf{J}$ too

'María put a chair behind her, and Juana too.'

a. Juana put a chair behind her. (her = Juana)

b. Juana put a chair behind her. (her = María)

At first sight, one might be tempted to conclude that Spanish, but not European Portuguese, allows a bound variable interpretation. But the crucial difference between (445) and (446) is that in (445) the subject DP of the elided sentence, o Jorge, and the subject DP of the non-elided sentence, a Joana, do not match in the gender feature, whereas in the Spanish example they do. Both subject DPs have identical phi-features and so do the pronouns in the elided and non-elided VPs. Recall from section 4.1.1 that the phi-features on a bound pronoun are not interpreted, and consequently they should not affect the results. Thus, if the pronoun in (446) were a true bound variable, this reading should be still available even if the subject DPs do not match in phi-features. I presented the same sentence to native 
speakers, but replacing the subject DP of the second conjunct with a non-matching DP. The judgements were contrary to Baauw (2002). As shown in (447), the sloppy/bound reading was not accepted. Thus, the non-reflexive pronoun is not interpreted as a bound variable in this context.

(447) Sp. María puso una silla detrás de ella y los chicos también.

M. put a chair behind of her and the boys too

'María put a chair behind her, and the boys too.'

a.

??The boys put a chair behind themselves.

b. $\quad$ The boys put a chair behind her. (her = María)

Another factor that plays a crucial role is the presence of the intensifier. In (448) and (449), the intensifier is present and the sloppy reading is now easily available; it is even the case that the coreferential reading becomes hardly acceptable. Compare these examples to the judgements of Lobo \& Menuzzi (2016:348) with the bare non-reflexive pronoun in (445) above. With the bare non-reflexive pronoun, the coreferential reading was the preferred reading, and the bound reading was 'difficult to get'. If the intensifier licenses the sloppy reading, then it seems that the sloppy reading is a surface effect of the intensifier, rather than an indication for a true bound variable reading.

(448) EP A Rita confia nela própria e o Rui também. the R. trusts in.her SELF and the R. too

'Rita trusts in herself, and Rui too.'

a. $\quad$ Rui trusts in himself.

b. $\quad$ ??Rui trusts in herself. (herself $=$ Rita)

(449) Sp. Juan confía en él mismo y María también.

J. trusts in him SELF and M. too

'Juan trusts himself, and María too.'

a. María trusts herself.

b. $\quad$ ??María trusts himself. (himself $=$ Juan)

The same effect is also found with PP-adjuncts. The sloppy reading becomes acceptable and the coreferential reading is now no longer available. In (450) and (451), the intensifier is represented in round brackets. The judgements without the intensifiers are given in $(450 \mathrm{a}, \mathrm{b})$ for European Portuguese and then in $(451 \mathrm{a}, \mathrm{b})$ for Spanish. The judgements with the intensifier are given on the right of each example.

(450) EP $\mathrm{O}$ Rui exige para ele (próprio) mais dias de férias e a Rita também. the J. demands for him SELF more days of holiday and the R. too 'Rui demands more days off for him(self), and Rita too.'

b. 
(451) Sp. Juan exige para él (mismo) un día extra de vacaciones y Rita también. J. demands for him SELF a day extra of holiday and R. too 'Juan demands an extra day off for him(self), and Rita too.'

a. ??Rita demands an extra day off for herself.

OK with mismo

b. $\quad$ Rita demands an extra day off for him. (him = Juan)

?? with mismo

The bare non-reflexive pronoun is preferred with a coreferent interpretation in (450) and (451). If the intensifier is present, the sloppy reading becomes available and the coreferent interpretation is clearly degraded.

Again, the conclusion that can be drawn from this section is that only the reflexive pronoun is unambiguously interpreted as a bound variable. The interpretation of the non-reflexive pronoun depends crucially on the presence or absence of the intensifier. If it is absent, the pronoun is more likely to be interpreted as coreferential, disallowing the bound/sloppy variable interpretation. If the intensifier is present, the judgements are reversed: the bound/sloppy reading becomes acceptable and the coreferential reading is degraded.

\subsection{Only-contexts}

The interpretation of the reflexive pronoun in only-contexts comes as no surprise, given the results of the previous sections. As with the other diagnostics that help to differentiate a bound variable interpretation and a coreferential interpretation, the reflexive pronoun allows only for the bound interpretation, as shown in the entailments of the sentences in (452) and (453).

EP Só a Rita confia em si própria.

only the R. trusts in REFL.PR SELF

'Only Rita trusts herself.'

a. $\quad$ Nobody else trusts himself.

b. $\quad *$ Nobody else trusts Rita.

Sp. $\quad$ Solo Juan confia en sí mismo.

only J. trusts in REFL.PR SELF

'Only Juan trusts himself.'

a. Nobody else trusts himself.

b. $\quad *$ Nobody else trusts Juan.

The coreferential interpretation was rejected unanimously. Again, there is no difference between reflexives in PP-complements and in PP-adjuncts, as shown in (454) and (455). 
(454) EP Só o João exige para si próprio mais dias de férias.

only the J. demands for REFL.PR SELF more days of holiday

'Only João demands more days off for himself.'

a. $\quad$ Nobody else demands more days off for himself.

b. $\quad *$ Nobody else demands more days off for João.

Solo Juan exige para sí un día extra de vacaciones.

only J. demands for REFL.PR a day extra of holiday

'Only Juan demands an extra day off for himself.'

a. $\quad$ Nobody else demands an extra day off for himself.

b. $\quad *$ Nobody else demands an extra day off for Juan.

Interestingly, the non-reflexive pronoun easily allows for the bound interpretation even without the intensifier. ${ }^{126}$ As shown in (456) and (457), the non-reflexive pronoun allows for the bound and the coreferential interpretation. Although the intensifier is not needed to license a bound reading, its effect on the coreferential reading remains the same: if it is present, the coreferential interpretation is blocked and the bound reading is clearly the preferred interpretation in Spanish and European Portuguese.

(456) EP Só a Rita confia nela (própria).

only the R. trusts in.her SELF

'Only Rita trusts herself.'

a. $\quad$ Nobody else trusts himself.

b. $\quad$ Nobody else trusts Rita.

* with própria

(457) Sp. Solo Juan confía en él (mismo).

only J. trusts in him SELF

'Only Juan trusts him(self).'

a. $\quad$ Nobody else trust himself.

b. $\quad$ Nobody else trusts Juan.

* with mismo

As for the interpretation of pronouns in PP-adjuncts, the interpretation is identical to the pronouns in PP-complements. The bare non-reflexive pronoun allows for the bound and the coreferential interpretation, and again, the intensifier blocks a coreferential reading and requires the bound reading of the non-reflexive pronoun. The example for European Portuguese is given in (458) and the example for Spanish in (459).

\footnotetext{
126 This result may be related to the interpretation of the focus particle, but a discussion must be left for future research.
} 
EP Só o João exige para ele (próprio) mais dias de férias. only the J. demands for him SELF more days of holiday 'Only João demands more days off for him(self).'

a.

b.

a.

b. Nobody else demands more days off for himself.

Nobody else demands more days off for João.

Solo Juan exige para él (mismo) un día extra de vacaciones.

only J. demands for him SELF a day extra of holiday

'Only Juan demands an extra day off for him.'

Nobody else demands an extra day off for himself.

Nobody else demands an extra day off for Juan.

* with mismo

\subsection{Summary}

The diagnostics presented in this chapter clearly show that the reflexive pronoun is limited to a sentence-internal antecedent and that it is interpreted as a bound variable in Spanish and European Portuguese. The interpretive diagnostics are summarised in (460).

(460) Interpretive diagnostics for reflexive pronouns inside all types of PPs (Sp. and EP)

\section{Diagnostics}

(i) Sentence-external antecedent

(ii) Split antecedent

(iii) Binding by quantifiers

(iv) VP-ellipsis

(v) Only-contexts

\section{Reflexive Pronoun}

$*$

$*$

$\checkmark$

only sloppy

only bound

Differently from the reflexive pronoun, the intensifier has a surprisingly strong impact on the interpretation of the non-reflexive pronoun in both languages, as summarised in the table in (460). The bare non-reflexive pronoun behaves as expected: it allows for a sentence-external antecedent, and it is interpreted as coreferential. But as soon as the intensifier is present, it imposes a bound/sloppy interpretation. In the light of the results about quantifier binding, these bound/sloppy readings seem to be 'fake', rather than true bound variable readings.

(461) Interpretive diagnostics for non-reflexive pronouns inside PPs

\begin{tabular}{|c|c|c|}
\hline \multirow{2}{*}{ Diagnostics } & \multicolumn{2}{|c|}{ Non-reflexive Pronoun } \\
\hline & without intensifier & with intensifier \\
\hline (i) Sentence-external antecedent & $\checkmark$ & $*$ \\
\hline (ii) Split antecedent & $\checkmark$ & $\checkmark$ \\
\hline
\end{tabular}




\section{Diagnostics}

\section{Non-reflexive Pronoun}

without intensifier

with intensifier

(iii) Binding by quantifiers

\begin{tabular}{|c|c|c|}
\hline pronominal QPs & \multicolumn{2}{|c|}{ EP:*, Sp.:\% } \\
\hline complex QPs & \multicolumn{2}{|c|}{ EP: $\checkmark$, Sp.: $\checkmark$} \\
\hline (iv) VP-ellipsis & (nearly) only strict & 'fake' sloppy \\
\hline (v) Only-contexts & bound and coreferential & 'fake' bound \\
\hline
\end{tabular}

The structural diagnostics for the strong reflexive pronoun are summarised in the table in (462). In Spanish, the reflexive pronoun needs to take a clause-internal antecedent, whereas European Portuguese additionally allows for long-distance reflexives in all types of PPs. If there are two clause-internal antecedents, as in sentences with locative or benefactive PPs, Spanish allows for both clause-internal antecedents, but the judgements vary across Spanish speakers: some permit reference to the subject, in addition to reference to the more local DO; others only allow for the most local antecedent. These conflicting judgements are marked with the symbol \%. In European Portuguese, the judgements are uniform, and both the subject and the direct object are possible as the antecedent of the reflexive pronoun. A diagnostic that gave uniform results in both languages was that for c-command. The strong reflexive pronoun needs a c-commanding antecedent in every sentence-internal context: both clauseinternal and clause-external.

(462) Structural diagnostics for reflexive pronouns in Sp. and EP

\section{Diagnostics} without intensifier in complements PPs and locative and benefactive PPs

(i) Clause-external antecedent

a. c-commanding SU

b. non-c-commanding SU

(ii) Clause-internal antecedent

a. c-commanding SU

b. non-c-commanding SU

\section{Reflexive pronoun}

with intensifier

\begin{tabular}{|llc|c}
\hline & \multicolumn{2}{c}{ in locative and benefactive PPs } \\
\hline a. & SU & EP: $\checkmark$, SP.: $\%$ & EP: $\checkmark-? ?$, Sp.: $\%$ \\
\hline b. & DO & $\checkmark$ & $\checkmark$ \\
\hline
\end{tabular}

The structural diagnostics for the non-reflexive pronoun are summarised with special attention to the differences between pronouns in locative PPs and PP-complements. With PP-complements the two 
languages are uniform: the bare non-reflexive pronoun can take a non-c-commanding, clause-internal or clause-external antecedent. The intensifier has the same effect: it restricts the reference to a clause-internal, c-commanding antecedent. Sentences with a locative PP permit two clause-internal antecedents: either the subject or the direct object. The subject can be the antecedent of the bare non-reflexive pronoun in Spanish and European Portuguese, but as soon as the intensifier is present, this interpretation becomes less acceptable in the two languages. With respect to reference to the DO, the bare nonreflexive pronoun is impossible in Spanish and European Portuguese, but if the intensifier is present this interpretation becomes available in the two languages.

(463) Structural and interpretive diagnostics for non-reflexive pronouns in Sp. and EP

\begin{tabular}{|c|c|c|c|c|}
\hline \multirow{3}{*}{ Diagnostics } & \multicolumn{4}{|c|}{ Non-reflexive Pronoun } \\
\hline & \multicolumn{2}{|c|}{ without intensifier } & \multicolumn{2}{|c|}{ with intensifier } \\
\hline & Compl. PP & Loc. PP & Compl. PP & Loc. PP \\
\hline (i) Clause-external antecedent & $\checkmark$ & $\checkmark$ & $*$ & $*$ \\
\hline \multicolumn{5}{|l|}{ (ii) Clause-internal antecedent } \\
\hline a. non-c-commanding SU & $\checkmark$ & $\checkmark$ & $*$ & $*$ \\
\hline b. SU & $\checkmark$ & $\checkmark$ & $\checkmark$ & EP:??, Sp.:* \\
\hline c. $\mathrm{DO}$ & - & EP:??, Sp.:* & - & EP: $\checkmark$, Sp.: $\checkmark$ \\
\hline
\end{tabular}

The effects of the intensifier observed throughout this chapter have not yet been described in a systematic way. Most work concerned with interpretation of pronouns in European Portuguese and Spanish, such as Lobo (2013), Estrela (2006), Lobo \& Menuzzi (2016), Menuzzi (1996), Fernández Soriano (1999), and Bosque \& Gutiérrez-Rexach (2016), focusses on complementary distribution and the attempt to accomodate this fact within a domain-based approach in the spirit of classic Binding Theory. Otero (1999) and Mellado \& Pavón (2002) made occasional reference to the effects of the intensifier, but did not elaborate on its effects in a systematic way. Due to these intriguing results, the next chapter is devoted to the interpretation of the reflexive intensifiers in Spanish and European Portuguese. 



\section{On the interpretation of pronouns and intensifiers}

I want to start this chapter by quoting Hackl (2013), who summarised the goal of the study of the syntax-semantics interface:

The empirical goal of research on the syntax-semantics interface is to determine the extent to which the meaning of an expression depends on its syntactic properties and the extent to which its syntactic properties are a function of its meaning. [emphasis added]

The theoretical goal is to give a principled account of these interactions, [...]. At the current state of research, we do not have such an account nor do we have fail-safe criteria that identify all and only those phenomena that are a product of interactions of syntax and semantics. [emphasis added]

(Hackl 2013:66-67)

On the study of the syntax-semantics interface see also Stechow (1991), Sauerland \& Stechow (2001), and Partee (2014). This chapter aims at contributing to the empirical goal from an Ibero-Romance perspective, in particular with respect to the question as to how the intensifier affects the interpretation of strong pronouns. As observed throughout the previous chapters, the elements mismo ${ }^{127}$ (Sp.) and mesmo/próprio ${ }^{128}$ (EP) affect in particular the interpretation of the non-reflexive pronoun. These elements have been classified according to König \& Siemund (2000) and Gast \& Siemund (2006) as reflexive intensifiers. The effects of the intensifiers observed in chapter 8 have received little attention within the study of Ibero-Romance languages. To my knowledge, no systematic (and formal) study exists on Spanish or European Portuguese intensifiers. Otero (1999) gives an overview of the different uses of mismo as a nominal modifier. Most detailed studies on the elements mismo and mesmo/próprio are concerned with adjectival or adverbial uses. ${ }^{129}$ For example, Bosque (2012) concentrates on the prenominal adjective mismo. The adverbial use of mesmo has been studied for European Portuguese in Moreira (1997) and for Brazilian Portuguese in Guimarães (2010) and Klein (1998).

In order to propose a first analysis to reflexive intensification in Spanish and European Portuguese, I will first review the approaches of König \& Siemund (2000) and Gast \& Siemund (2006), who base their generalisations on broad cross-linguistic data, ${ }^{130}$ and the approach of Reinhart \& Reuland

\footnotetext{
127 According to the NGLE (2009:1191ff), propio was used in Old Spanish as an intensifier with reflexive pronouns, but in contemporary Spanish this use is considered an archaism and will not be taken into account.

${ }^{128}$ In European Portuguese, the two elements have a very similar interpretive effect when used together with the reflexive pronoun or non-reflexive pronoun. As noted in Delille (1970), the use of próprio has been documented since the 16th century and its use is increasing, while the use of mesmo as a reflexive intensifier is decreasing in contemporary European Portuguese. In this book these elements will not be considered separately if they are used as reflexive intensifiers.

129 The adverbial use of mismo has been lost in Modern Spanish, according to NGLE:1193.

${ }^{130}$ Gast \& Siemund (2006) examined 72 languages from 32 different language families, and their study revealed that intensifiers or intensifying strategies are diverse from a morphosyntactic point of view (e.g. grammatical category), but uniform with respect to their relation to reflexive forms.
} 
(1991, 1993) and Reuland (2011), which is based on Germanic data. These accounts will be evaluated with respect to Spanish and European Portuguese. The main insights of these accounts are that reflexive intensifiers are related on the one hand to the interpretation of identity predicates and on the other hand to the interpretation of focus in terms of focus alternatives. In section 9.3, I will argue that Spanish and European Portuguese intensifiers combine aspects of the two notions due to their heritage in Latin IPSE and IDEM. The Ibero-Romance intensifiers will be analysed as operators that restrict the values of the pronominal variable to its co-argument domain.

Before starting with the discussion on the interpretation of the intensifier in sections 9.2 and 9.3, I want to briefly introduce some ideas on the way strong pronouns are translated at the syntax-semantics interface.

\subsection{Pronouns at the syntax-semantics interface}

This section aims at giving a tentative answer to the question how the lexical type (reflexive, non-reflexive) and the morphosyntactic type (clitic, strong) of a pronoun determines its translation at the syntax-semantic interface. Semantic approaches compatible with the Minimalist Program such as Heim \& Kratzer (1998) and Büring (2005) show how a bound reading is computed by application of Quantifier Raising, as in Heim \& Kratzer (1998), and the Binder Index Evaluation rule, as in Büring (2005:91). The interpretive procedures operate on syntactic structures that are already coindexed. They argue that semantic binding (operator-variable binding) is preceded by syntactic binding in the sense of classic BT (antecedent-argument binding). This means that the syntactic structure already contains indicesthe information concerning who is bound by whom-before it translates to the semantic structure. In an index-free syntax such information must come about by different means.

We have seen throughout the previous chapters that clitics are involved in the syntactic encoding of an anaphoric dependency, while strong pronouns inside PPs, including the $a$-marked phrase in a clitic doubling structure, are not subject to this encoding mechanism (cliticisation and upward valuation). In clitic doubling structures, the referent of the strong pronoun is determined by the clitic due to Match$\mathrm{CID}$, but the clitic does not determine the way a pronoun is interpreted at the interfaces. Following the economy hierarchy of Reuland (2011) and Reinhart (2006), an anaphoric relation can be established in the semantic component by means of variable binding or pragmatic corefernce, if it was not established in syntax. Thus, the strong pronouns should be subject to semantic binding and pragmatic coreference. The definition of semantic binding, given in (20), is repeated here as (464).

Semantic Binding/A- binding (logical syntax-based definition)

$\alpha$ binds $\beta$ iff $\alpha$ is the sister of a $\lambda$-predicate whose operator binds $\beta$.

(Reinhart 2006:166/171)

Semantic binding should take place whenever possible, and if semantic binding is impossible, a coreferent reading should not be 'sneaked in'. This is expressed by the Rule I of Reinhart (2006), reproduced in (465). Note that the term covaluation corresponds to what was called coreference throughout this 
book. Rule I excludes a coreferent interpretation of two lexical items if the structural requirements for binding are fulfilled, as stated in Condition (465a); if the item $\beta$ has some lexical property that prevents its translation as a (bound) variable, as stated in condition (465b) states This condition is meant to exclude R-expressions and to account for Principle C effects. Condition (465c) states that coreference or covaluation is excluded if it yields the same interpretative results as semantic binding.

Rule I (an interface rule)

$\alpha$ and $\beta$ cannot be covalued in a derivation $D$, if

a. $\alpha$ is in a configuration to A-bind $\beta$, and

b. $\alpha$ cannot A-bind $\beta$, and

c. the covaluation interpretation is indistinguishable from what would be obtained if $\alpha$ A-binds $\beta$.

(Reinhart 2006:185)

Let us see how the principles of Reinhart (2006) and Reuland (2011) apply to the Spanish and European Portuguese data. I will use European Portuguese examples to illustrate the binding patterns for both languages. Let us start with a quantified antecedent. The diagnostic 'binding by a quantifier' in sections 5.4 and 8.5 showed that the strong reflexive pronoun is always bound by a quantifier in all types of prepositional phrases: an $a$-marked KP, a complement PP, and a locative or benefactive PP, but the strong non-reflexive pronoun resisted a bound variable interpretation.

This is illustrated for clitic doubling structures in (466). An agreement link is established between the clitic and its double by means of Match-CID, and the clitic is associated with the subject QP by means of upward valuation. Thus, the syntactic structure contains the information that the subject QP must be the antecedent of the strong reflexive pronoun. Additionally, I proposed that the null-values on the number and gender feature serve as an instruction to translate the strong reflexive pronoun into a bound variable at the syntax-semantics interface. This is represented by means of identical variable names in (466).

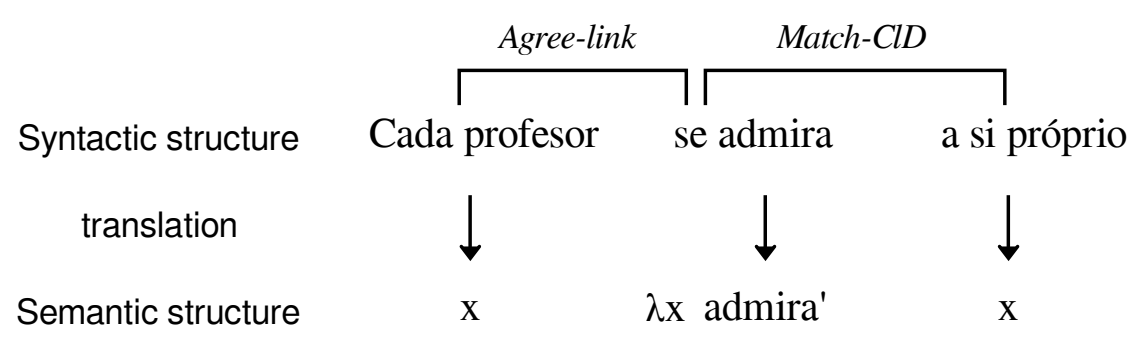

But syntactic binding by means of Agree or Match-CID cannot impose a bound variable reading on the pronoun. The strong non-reflexive pronoun resists a bound variable interpretation as shown in sections 5.4 and 8.5. Thus, the strong non-reflexive pronoun carries some information that makes it translate as a free variable or as an E-type/D-type pronoun. The fact that it cannot be a bound variable is not only due to its lexical type, which has been formalised as a full set of valued phi-features, but also due to its morphosyntactic type, formalised as $\Sigma$ P. Recall from section 5.4, that non-reflexive clitics are 
perfectly acceptable with a QP antecedent. Thus, the morphosyntactic type together with the lexical type count as instruction to translate the strong non-reflexive pronoun as free variable at the syntax-semantics interface. This is illustrated in (467). The non-reflexive double must translate as a free variable despite the fact that the Agree-link between the reflexive clitic and the QP subject determined the referent/binder for the double. This creates a situation with conflicting requirements: the QP needs to bind the pronominal variable, whereas the strong pronoun resists binding. This conflict is the reason for the ungrammaticality of this type of sentence.

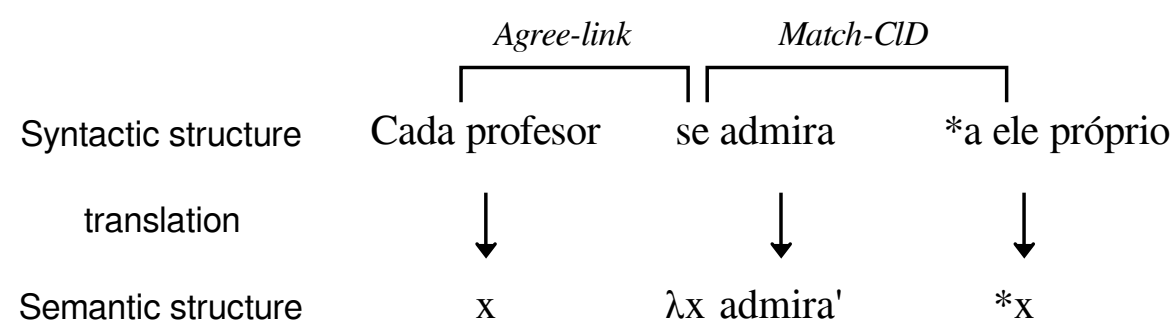

These data perfectly fit the hierarchy of Reinhart (2006) and Reuland (2011) and Rule I. The nonreflexive pronoun cannot be a bound variable due to its feature content, and covaluation is correctly ruled out by condition (465b) of Rule I.

But this is only true for QP antecedents. With a non-quantified DP antecedent, the non-reflexive pronoun is perfectly acceptable, not only in clitic doubling structures, as in (468), but also in other PP contexts to be discussed below. In (468), the subject DP is in a configuration to semantically bind the strong non-reflexive pronoun, but the pronoun cannot translate as a bound variable. Thus, semantic binding is impossible, and according to Rule I, coreference between the subject DP and the pronoun should not be possible, contrary to fact. In (468), the pronoun is a free variable, but it is not 'free' in the sense that reference is determined by discourse-pragmatic factors alone; rather it is the clitic that determines the reference of the double by means of Match-CID.

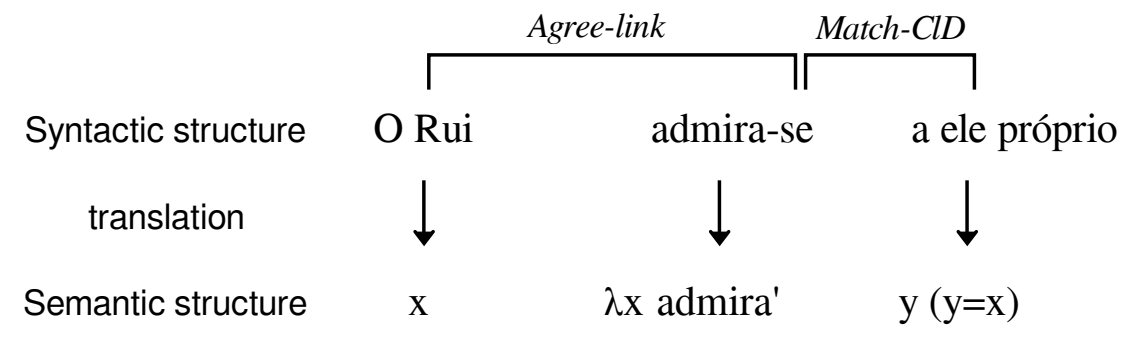

The same is true for non-reflexive clitic doubling structures. As exemplified in (469), it is the clitic that determines that the non-reflexive double must not be coreferent with the subject.

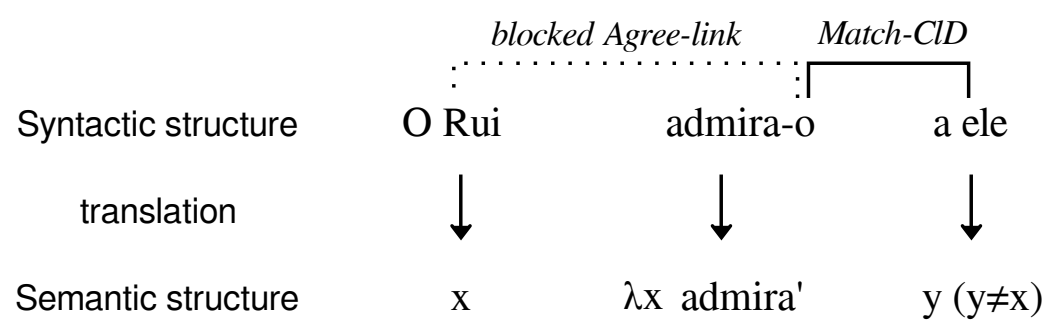


Let us turn now to strong pronouns in complement or adjunct PPs. As a clitic is ungrammatical in these constructions, the reference of the pronoun has to be determined by other means. As for the reflexive pronoun, it is clearly subject to semantic binding. Due to its defective feature content (null-values for number and gender) it translates as a bound variable, as illustrated in (470).

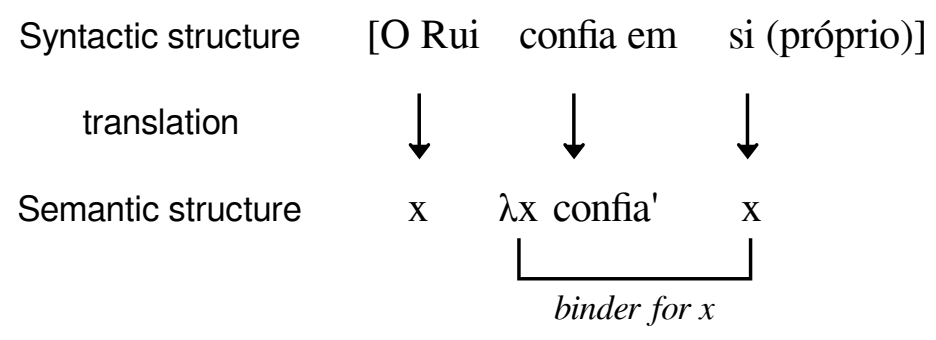

Again, the non-reflexive pronoun can be coreferent with a potential binder, contradicting Rule I. In (471) there is no syntactic or lexical information that helps to determine the referent of the pronoun. Whether it is coreferent with the subject DP or with another salient entity is exclusively determined by the context.

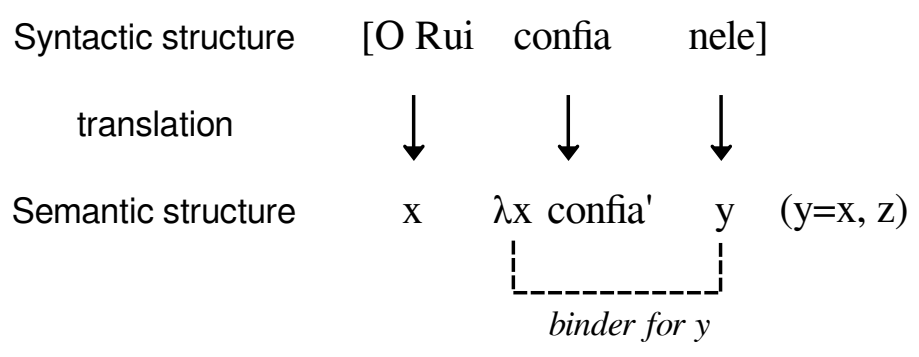

In this situation the effects of the intensifier become clearly visible. In (472), the pronoun is no longer free, but its referent has to be the subject DP.

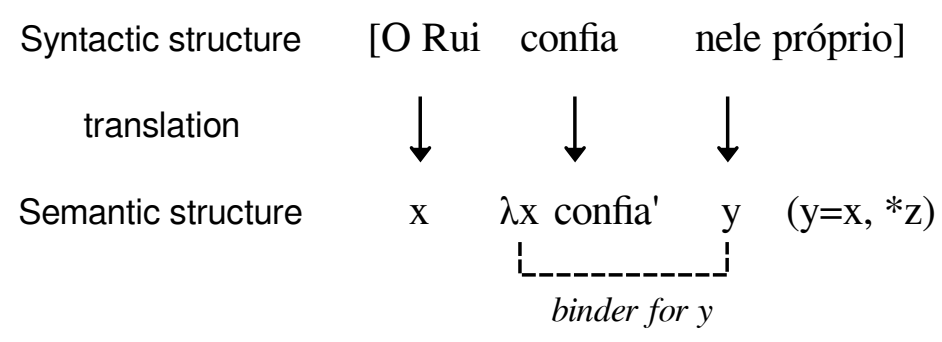

These data showed that the approach of Reinhart (2006) and Reuland (2011), in particular Rule I, makes wrong predictions about the interpretation of non-reflexive strong pronouns in Spanish and European Portuguese. An alternative account is needed, at least for the languages under discussion here. This final chapter aims to provide the first step towards such an account, focussing on the effects of the intensifier on the intepretation of strong non-reflexive pronouns in Spanish and European Portuguese.

\subsection{Interpretation of (SELF-)intensifiers}

This section presents the approach of Reinhart \& Reuland (1991, 1993) and Reuland (2011) in sections 9.2.1 and 9.2.2. The approach of König \& Siemund (2000) and Gast \& Siemund (2006) is discussed in 
section 9.2.3. At first sight, these approaches appear to be quite distinct, but both of them formalise the meaning of intensifiers in terms of a relation/function and give important guidelines for the anaylsis of Romance intensifiers.

\subsubsection{Reflexive marking}

Reinhart \& Reuland (1991, 1993) and Reuland (2011) argue that (Germanic) SELF-elements like English self and Dutch zelf are reflexive markers in the sense that the SELF-element is obligatory for a reflexive interpretation of a transitive verb. For examples, the Dutch SELF-element zelf is obligatory for a reflexive interpretation of the transitive verb bewonderen 'admire' in (473). The simplex anaphor zich alone cannot license a reflexive interpretation (see chapter 1).

$$
\begin{aligned}
& \text { D. Willem bewondert zichzelf / *zich (Reuland 2011:100) } \\
& \text { W. } \quad \text { admires Sx.SELF / sx. } \\
& \text { 'Willem admires himself.' }
\end{aligned}
$$

The SELF-element is conceived as a relational noun with a meaning similar to being-a-SELF-of in Reuland (2011:216). The meaning of the complex anaphor can be paraphrased as $x$ is the self of $x$. The SELF-element provides a relation between an entity and the self of this entity. Syntactically, the SELFelement is a noun and occupies the NP layer inside the pronominal DP. The pronoun is located in the $\mathrm{D}^{\circ}$ position. The schematic structure in (474) represents the internal structure of complex anaphors, as assumed by Reuland (2011:216).

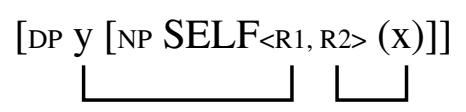

The pronoun in $\mathrm{D}^{\circ}$ position is taken to denote an identity function ${ }^{131} \mathrm{f}(\mathrm{x})$ that maps the entity (x) onto itself. The process of reflexive marking and its interpretation are represented in the tree structures in (475) and (476) below.

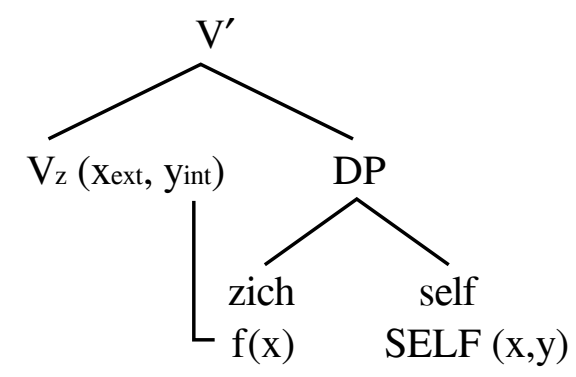

\footnotetext{
131 The assumption that all pronouns denote an identity function is put forward in Jacobson (1999), who elaborates an account of pronominal interpretation based on principles of categorial grammar and a 'variable free' semantics, a semantics that aims to eliminate variable assignment functions. Pronouns are interpreted directly as identity functions of type $<e$, e $>$. A verbal predicate that expects an argument of type $<\mathrm{e}>$ is subjected to the type-lifting rule rule $z$. Applying this rule to a standard transitive predicate of type $<e,<e, t>>$ (the first leftmost argument is the internal argument), the internal argument is lifted from type $<\mathrm{e}>$ to $<\mathrm{e}, \mathrm{e}>$ and can now take the pronoun as an argument.
} 
In (475), the transitive verb V(x,y) of type $<e,<e, t>>$ combines with the SELF-anaphor. The complex anaphor, which is of type $<e, e>$, is meant to satisfy the internal argument, but in order to be compatible with the transitive verb, Reuland assumes Jacobson's (1999) type-lifting rule $z$. This rule is applied to $\mathrm{V}$, indicated by the subscript on $\mathrm{V}_{\mathrm{z}}$, and has the effect that the internal argument is type-lifted from type $<\mathrm{e}>$ to $<\mathrm{e}, \mathrm{e}>$. After type-lifting, the complex anaphor can saturate the internal argument. The central aspect of syntactic reflexive marking is the covert adjunction of the SELF-element to $\mathrm{V}^{\circ}$, as shown in (476).

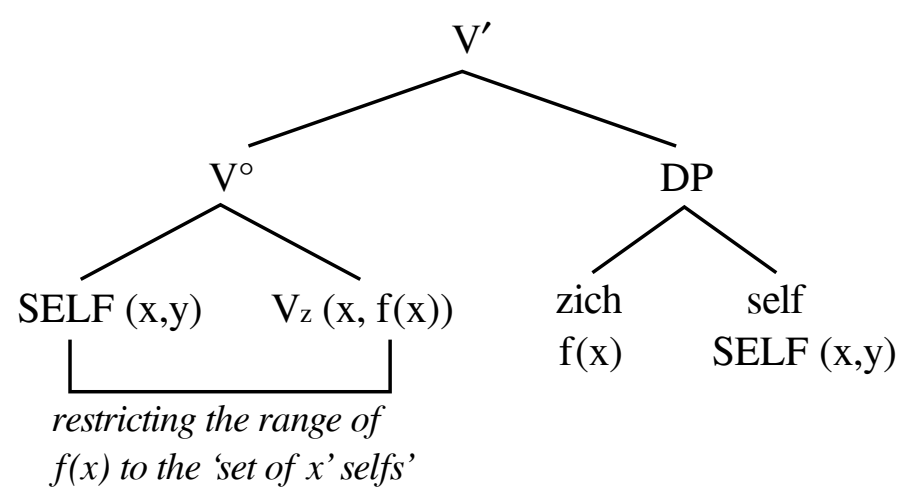

The interpretive effect of the adjoined SELF-element is such that it determines the range of the identity function $\mathrm{f}(\mathrm{x})$ in such a way that $x$, the external argument of $\mathrm{V}_{\mathrm{z}}$, is mapped onto the set of $x$ 's selfs $\left(f_{\text {self }}(x)\right)$. Movement of SELF to the verb assures that only co-arguments of the pronoun will be values for the arguments of $\mathrm{f}_{\text {self }}$. Movement of the SELF-element is motivated by the fact that Germanic SELFelements are also used as suffixes that overtly adjoin to nouns and adjectives, as in self-destruction, selfregarding, or to deverbal nouns like self-hater (see Reuland 2011:231).

An application of SELF-movement and reflexive marking to Spanish and Portuguese is not supported by morphosyntactic facts. In Spanish and European Portuguese, the elements mismo, mesmo/ próprio are not used as derivational affixes. The Romance counterpart of self- in nominal and verbal morphology is auto- as in autodestrucción/autodestruir (Sp.) or autocensuralautocensurar (EP). Furthermore, the intensifiers mismo (Sp.), mesmo/próprio (EP) are not obligatory for a reflexive interpretation of a transitive predicate. As shown throughout this book, it is the reflexive clitic or the strong reflexive pronoun that licenses a reflexive interpretation of transitive predicates. For these reasons, Reuland's (2011) SELF-movement analysis is not feasible for the intensifiers in Spanish and European Portuguese. But the account of Reuland (2011) gives important hints as to how the intensifier influences the interpretation of the pronoun.

\subsubsection{Proxy readings}

Reuland (2011) claims that the presence of a SELF-element is necessary to license a proxy interpretation of the internal argument of reflexive predicates. Recall from section 3.2.3.2 that this is not the case in Spanish and European Portuguese. There it has been shown that a proxy reading is available with the reflexive clitic, irrespective of the presence of the pronominal double or the intensifier. The 
important licensing condition for a proxy reading in Spanish and European Portuguese is thus the availability of a second argument and not the presence of the intensifier. Interestingly, the intensifier is only grammatical if its pronominal host realises an independent argument, as observed with predicates of obligatory reflexivity in section 8.1.1. The examples from chapter 8.1.1 fn. 111 are repeated here as (477). With this type of predicates, the non-reflexive pronoun obligatorily refers to the subject and cannot be replaced by a full DP, as would be the case with true transitive predicates. This fact was taken as an indication that these predicates are not semantically transitive and the pronoun does not realise an independent argument.

(477) a. EP $\mathrm{O}$ João $\mathrm{o}_{\mathrm{i}}$ tem para ele $_{\mathrm{i} / *_{\mathrm{k}}}$ (*próprio) que a Maria está grávida. the J. has to him SELF that the M. is pregnant 'João believes that Maria is pregnant.'

Lobo \& Menuzzi (2016:344)

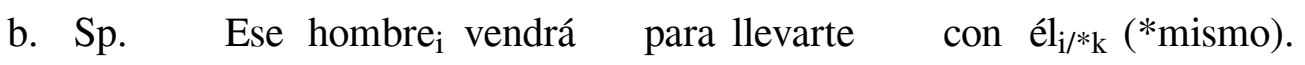

this man will.come to take=you.CL with him SELF

'This man will come and take you with him.'

The intensifier, although not necessary for a proxy interpretation, is linked to the argumental status of its pronominal host, and with pronouns in locative PPs of perception verbs or placement verbs it helps to license a proxy reading, in the appropriate contexts, as in (478) and (479).

(478) a. Sp. Amador lo sentía dentro de sí mismo y, a la vez, lo leía en aquellos ojos que iban ya familiarizándose con los fantasmas. (CREA: Savater, F. 1981. 'Caronte aguarda'.) 'Amador felt it inside himself, and at the same time he read it in those eyes that had already grown accustomed to the ghosts.'

b. $\quad$ El tiempo, por ejemplo, se disfraza primero de delincuente (pág. 18) y viste más tarde de luto (pág. 58); puede situarse por detrás de sí mismo (pág. 55) o competir, con ventaja, con el poeta cuyas palabras va pisoteando (pág. 83). (CREA: ABC Cultural, 13/12/1996.)

'Time, for example, dresses up as criminal (p. 18) and later wears mourning clothes (p. 58); it can place itself behind itself (p. 55) or compete, with an advantage, with the poet over whose words it will walk.'

(479) a. EP Imaginas tu o que é isto de sentir-se um homem infame diante de si mesmo? (CRPC: Branco, C.C. 'O Condemnado / Como os Anjos se Vingam / Entre a Flauta e a Viola'.)

'Do you imagine what it is like for a man to feel contemptible in front of himself?' 
b.

Anda a correr vertiginosamente atrás de si próprio, substituindo sistemáticamente a prática da política pelo fabrico afanoso de cachas de primeira página, [...]. (CRPC, Público, noCOD_1081518.)

'He is running tremendously fast after himself, substituting systematically the political practice by the keen production of front-page headlines.'

For the sake of clear exposition, a proxy reading is illustrated by means of the well-known sentences in (480). The situation described in these sentences is visualised in the pictures in (481) below.

(480) a. Sp. Ella $a_{i}$ vio una serpiente cerca de síi

$a^{\prime}$. EP Ela $a_{i}$ viu uma serpente perto de $\mathrm{si}_{\mathrm{i}}$

b. Sp. Ella $a_{i}$ vio una serpiente cerca de síi misma.

$b^{\prime}$. EP Ela $\quad a_{i}$ viu uma serpente perto de $s i_{i}$ própria.

'She saw a snake near herself.'

The picture in (481a) corresponds to the sentences (480a, $\left.a^{\prime}\right)$ with the bare reflexive pronoun. The locative preposition such as cerca de (Sp.) or perto de (EP) 'near' establishes a spatial relation between two entities: the snake and the reflexive pronoun, or more precisely the antecedent of the reflexive pronoun. The antecdent is the point of reference for locating the snake. As the antecedent is the external argument of the perception verb, the snake is located with respect to the external argument. Thus, the external argument and the location coincide, they are identical and no proxy reading is available. This is important because the location itself is not available as an independent argument; it is completely identical to the subject DP. The picture in (481b) gives an idea how this situation could look like with a proxy reading evoked by the intensifier in the sentences in $\left(480 \mathrm{~b}, \mathrm{~b}^{\prime}\right)$. The agent/experiencer sees a snake near his proxy, which might be a statue or a mirror image. Differently from the use of the bare reflexive, the location realised as the reflexive pronoun is available for interpretation. Using the terminology of Reuland (2011), the intensifier protects the argument variable realised by the reflexive pronoun.

a. No proxy reading

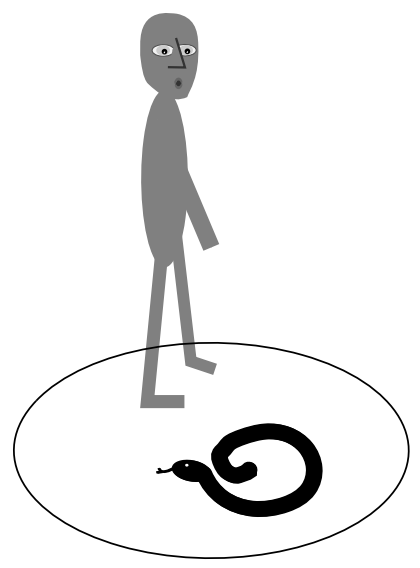

b. Proxy reading

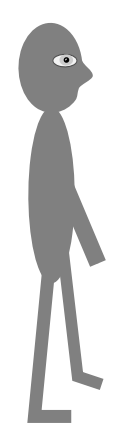

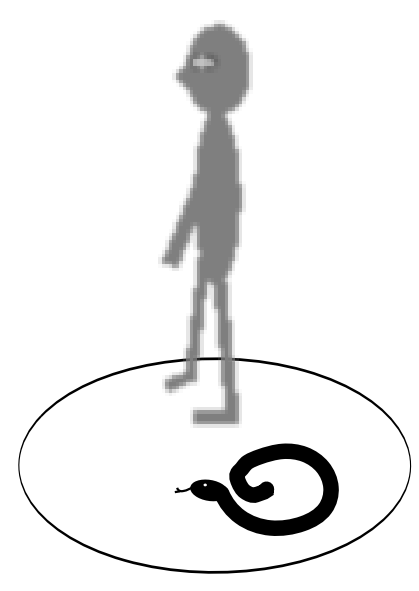


Interestingly, a proxy reading is not available with benefactive PPs, as shown in (482) and (482). The examples in (482a) and in (483a) contain the intensifier, while in the examples in (482b) and (483b) it is absent. What can be observed here is that the intensifier faciliates a contrastive reading that is not available in the examples without it.

(482) a. $\quad$ [...] Andrea, que después de la cueva azul parecía vivir para sí misma y estar en otro mundo, [...]. (CREA: Regás, R. 'Azul'. 1994.)

'[...] Andrea seemed to live for herself and to be in another world after the blue cave $[\ldots]$.

b. Desde 1875 Rimbaud vivirá para sí ignorando que su nomadismo errante acabaría siendo la vida literaria del héroe contemporáneo. (CREA, ABC Cultural, 08/11/1991.)

'After 1875 Rimbaud will live for himself, unaware that his aimless nomadism would become the literary life of the contemporary hero.'

(483) a. As superesquadras são a concepção de uma Polícia longe dos cidadãos, vivendo para si mesma, em grandes unidades onde se cultiva o espírito de corpo e a disciplina de tipo militar e se privilegia a via repressiva. (CRPC, Jornal de Notícias, J82085.)

'The police super-stations are the conception of a police alienated from the citizens, living for themselves, in big units where the esprit de corps and a military-like discipline are cultivated and repressive ways are favoured.'

b. Talvez você tenha razão... Bem vistas as coisas, cada um deve viver para si... e os outros que se arrangem. (CRPC: Braga, M. 1957. 'Quatro Reis'.)

'Maybe you are right... After all, everyone should live for himself... and let other people get along on their own.'

It can be concluded that an analysis of the SELF-intensifer as a licensing element of a proxy reading, as proposed in Reinhart \& Reuland (1991, 1993) and Reuland (2011), cannot be applied to Ibero-Romance. But their main insight that the intensifier is closely linked to the argumenthood of its pronominal host is also relevant for Spanish and European Portuguese. This fact will reappear in the account of König \& Siemund (2000) and Gast \& Siemund (2006).

\subsubsection{Adnominal intensifiers, actor-oriented intensifiers, and focus}

König \& Siemund (2000) and Gast \& Siemund (2006) differentiate between adnominal intensifiers and actor-oriented intensifiers and reflexive intensifiers. In English, the three types of intensifiers are formally non-distinct from the reflexive pronoun, as shown in (484a)-(484c). The adnominal intensifier occurs adjacent to a definite, specific DP. The actor-oriented intensifier is modifiying a VP and may be related to an indefinite, but necessarily animate DP. 
(484) a.

b.

c.
The professor criticised himself.

The professor himself criticised the student.

The professor criticised the student himself. [reflexive pronoun]

[adnominal intensifier]

[actor-oriented intensifier]

König \& Siemund (2000) claim that the meaning of the reflexive intensifier is related to the interpretation of adnominal intensifiers. Later, Gast \& Siemund (2006) revise this assumption and argue that the meaning of these intensifiers should be derived from the interpretation of actor-oriented intensifiers. After introducing both types of intensification by means of English examples, I will show that mismo, mesmo/próprio are used as adnominal and actor-oriented intensifiers. At the end of this section, I will conclude that reflexive intensifiers are related to actor-oriented intensifiers and focus.

König \& Siemund (2000) state that the interpretation of intensifiers is best analysed in terms of Rooth's (1992) alternative semantics for focus, already introduced for the focus particle only in sections $1.2,5.7$, and 4.1.1. Rooth's idea is that focus adds a focus semantic value to the regular semantic value of an expression. For example, the regular semantic value of the sentence in (484b) is that a contextually given professor criticised a certain student. If the DP the professor is focalised, the focus semantic value is the set of all propositions that consist of all contextually given alternatives of the professor as subject of the predicate criticise the student. König \& Siemund (2000) state that intensifiers influence this set of alternatives in the following way. First, the adnominal intensifier evokes alternatives to the DP the professor, but the set of alternatives, instead of containing all possible entities from the discourse domain, is restricted by the broader meaning of the NP, here the meaning of the NP professor. Secondly, the intensifier establishes a relation between the modified NP and the alternative values. The restricted set of alternatives is described as periphery or entourage in König \& Siemund (2000). The periphery of professor in (484b) is the domain of university and teaching, including students and teaching and administrative staff. This interpretation is defined as in (485).

Adnominal intensifiers relate a center $\mathrm{X}$ (referent of the focus) to a periphery of alternative values.

König \& Siemund (2000:45)

König \& Siemund (2000:45) also give different types of relations that can be established between the centre and its periphery, reproduced here in (486).

(486) i. $\quad \mathrm{X}$ has a higher position than $\mathrm{Y}$ in a hierarchy.

ii. $\quad \mathrm{X}$ is more significant than $\mathrm{Y}$ in a specific situation.

iii. $\quad \mathrm{Y}$ is defined in terms of $\mathrm{X}$.

iv. $\mathrm{X}$ is the center of perspective (logophoricity).

In the example (484b) above, the intensifier establishes the relation (486i) or (486ii): the intensified DP the professor evokes alternatives from the domain of universitiy with its roles and ranks, such as researchers, assistants, administrative staff, and students. The effect of the intensifier is to place the 
focussed DP (x) in a relation such as $x$ is more significant than $y$ or $x$ has a higher rank than $y$; with $y$ being the members of the periphery.

The interpretation of actor-oriented intensifiers is also accounted for in terms of alternative semantics and is described in Gast \& Siemund (2006) as in (487).

Actor oriented intensifiers are used to relate a proposition $\pi$ to a set of alternative propositions $\mathrm{R}=\left\{\mathrm{p}_{1}, \mathrm{p}_{2} \ldots \mathrm{p}_{\mathrm{n}}\right\}$ in such a way that:

a. in the alternative propositions $\mathrm{p}_{\mathrm{i}}$, the actor-role is assigned to some individual $\mathrm{y}$ other than the referent of $\mathrm{x}$ of the associated NP, and

b. $\quad x$ has a different thematic role in the alternative propositions, for example that of an external causer or beneficiary.

Gast \& Siemund (2006:358)

The intensifier in (484c) affects the actor role of the focussed predicate in two ways. First, the actor role is assigned to an alternative entity from the discourse domain, and secondly, the former bearer of the actor role is assigned a different thematic role in the alternative proposition. As for the sentences in $(484 \mathrm{c})$, the intensifier evokes alternative values for the external/actor argument of the predicate criticise the student and assigns to the former bearer of the actor role-the professor-another role, as for example the causer role in the sentences The professor made someone else criticise the student or Someone else criticises the student on behalf of the professor.

Both intensifiers are like focus markers evoking alternatives, but adnominal intensifiers relate the centre of the focus to the alternative values and actor-oriented intensifiers evoke alternative thematic roles for the DP bearing the actor role. The next section discusses these uses for Spanish and European Portuguese intensifiers.

\subsubsection{Adnominal intensification in Spanish and European Portuguese}

In Spanish and in European Portuguese, adnominal intensification is possible with mismo, propio (Sp.) and mesmo, próprio (EP). Starting with European Portuguese, the intensifier mesmo occurs nearly exclusively ${ }^{132}$ with common nouns, as in (488). In this example, the behaviour of Alfonso is compared to the expression with the intensifier stating that his behaviour is as highly ranked or as convincing as the properties associated with a encarnação mesma da honra doméstica 'the domestic honour itself'.

EP Afonso ergueu-se diante dele, rígido e inexorável como a encarnação mesma da honra doméstica. (CRPC: Eça de Queiroz, J. M. 1888. 'Os Maias'.)

'Afonso stood up infront of him, severe and unrelentingly as the incarnation of the domestic honour itself.'

\footnotetext{
${ }^{132}$ A query for occurrences of mesmo in prenominal position with proper names returned 22 results, of which only four correspond unambigously to the intensifier. Compared with 26,479 matches for próprio preceding proper names, the use of mesmo seems to be negligible. The results are reproducible with the following query: "\{próprio\} *_PNM".
} 
In Spanish, the intensifier mismo can be combined with common nouns and proper names, as described in Otero (1999). An example for both types of nouns given in (488a) and (488b).

(489) a. Sp. De hecho, las palabras "paz" y "mundo" son homónimas en ruso y se escriben igual a partir de la reforma ortográfica rusa de 1918. Sin embargo, Tolstói mismo tradujo el título al francés como La Guerre et la Paix. (CEA: A_63_737)

"In fact, the words "peace" and "world" are homonyms in Russian and are written identically since the spelling reform of 1918. However, Tolstói himself translated the title into French as La Guerre et la Paix.'

b. El contacto con el enemigo inicia una batalla que ocurre directamente en el mapa mismo en vez de en una pantalla de batalla separada. (CEA: A_63_737)

'The contact with the enemy initiates a battle that takes place directly on the map itself instead of in a separate battle window.'

The alternatives to Tolstoi in (488a) are, for example, translators and researchers. These stand in a relation of type (486i) or (486ii) with the author of the book. The statements of the author are more significant and credible than those of the translators or researchers. In (488b), the intensified DP $e l$ mapa mismo 'the map itself' refers to a main window in a video game in which the relevant actions are displayed. The alternatives to the map evoked by the intensifier are mentioned directly in the linguistic context: a separate window. This alternative is ranked lower because it is technically less advanced or because it makes the game more complicated.

The elements propio (Sp) and próprio (EP) are also interpreted as adnominal intensifiers evoking relations such as (486i) or (486ii), in additon to their interpretation as attributive adjectives with the meaning similar to 'own'. In European Portuguese and in Spanish, the interpretation as adnominal intensifier is possible only in prenominal position with proper names and with definite common nouns. Examples for intensification of proper names are given in (490), along with an example for its use with common nouns in (491).

(490) a. EP O próprio Dalí sempre defendeu que "a única forma de chegar ao universal era ser ultralocal". (CRPC: Público. noCOD_1051882.)

'Dali himself always advocated the idea that "the only way to get to the universal is to be ultra-local".'

b. Sp. También el propio Octavio encontraba satisfactoria la amistad con la pareja. (CREA: Aldecoa, J.R. 1994. 'Mujeres de negro'.)

'Octavio himself also found their friendship with the couple satisfying.' 
(491) a. EP Está a pôr em causa o próprio regime democrático, está a pôr em causa o próprio direito consagrado na Constituição Portuguesa de o País deve ser governado de acordo com as maiorias. (CRPC: Politica. A119639.)

'You are calling into question the democratic order itself, you are calling into question the right itself enshrined in the Portuguese Constitution that the country must be governed in accordance with the majorities.'

b. Sp. Fue el propio miedo el que me ayudó a tomar la urna helada, [...] (CREA: Millás, J. J. 'Dos mujeres en Praga'. 2002.)

'It was the fear itself that helped me take the ice-cold urn [...]'

\subsubsection{Actor-oriented intensification in Spanish and European Portuguese}

In Spanish and European Portuguese, the actor-oriented intensification is realised by means of a combination of a personal pronoun and the intensifier, but not by the intensifier alone, as shown in (492).

(492) a. EP Os meninos pensam pintar a casa eles próprios.

(Lobo 2013:2224) the kids think paint the house them SELF

$a^{\prime}$. Sp. La presidenta les ha dado la enhorabuena ella misma. the president them.CL=has given the congratulation her SELF

(Otero 1999:1453)

b. EP *Os meninos pensam pintar a casa próprios. the kids think paint the house SELF

$\mathrm{b}^{\prime}$. Sp. *La presidenta les ha dado la enhorabuena misma. the president them.CL=has given the congratulation self

The personal pronoun modified by the intensifier is placed to the right of the VP/vP, a designated focus position in Romance (see, e.g., Zubizarreta 1998 for Spanish and Costa 2004 for European Portuguese), and it corefers and agrees with the subject. The interpretation of (492) is captured by the definition in (487) above. The intensifier focusses on the actor role of the event and evokes alternatives in which the referent of the focussed DP is related to the event by means of another thematic role. The examples above do not provide context information, but the following examples from the CREA and the CRPC show that an alternative is not only evoked, but is actually present in the linguisitic context, and this brings intensfication into line with contrastive focus.

(493) a. Sp. El espada pone como ejemplos de su preparación el hecho de que salga a parar a los toros con el capote él mismo y no sus peones. (CREA: El País. 01/06/1987.) 'The torero gives as an example for his preparation the fact that he goes out to stop the bulls with the cape himself and not his assistants.' 
b. EP Sebastião Feyo de Azevedo, professor catedrático da Faculdade de Engenharia, elogiou a capacidade de Cadilhe em controlar a pulso forte a duração das comunicações. [...] O docente não imaginaria que, na sua intervenção final, Miguel Cadilhe ultrapassasse ele próprio os quinze minutos previstos. (CRPC: Público. J102457.) 'Sebastião Feyo de Azevedo, professor in the faculty of Engineering, praised the capacity of Cadilhe to strictly control the duration of the talks. [...] The professor did not imagine that, in his final speech, Miguel Cadilhe, would exceed the scheduled fifteen minutes himself.'

In (493a), the alternative is that the torero sends his assistants (peones) to stop the bull for him. In (493b), the alternative is that Miguel Cadilhe controls the duration of other people's talks.

The actor-oriented intensifier is not restricted to duplication structures, as in (493). In (494) it realises the postverbal subject of a non-finite verb. Personal pronouns realised in this position are interpreted as emphatic pronouns (see Mensching 2000:59ff) even without the element mismo, mesmo/próprio. Thus, a focus-like interpretation is already licensed without the intensifiers enforcing a contrastive interpretation or an interpretation in the sense of König \& Siemund (2000).

(494) a. Sp. Me extrañó que hubiera enviado a Mara a buscarme en vez de hacerlo él mismo, dada la familiaridad con que circulaba por la pensión. (CREA: García Morales, A. 1990. 'La lógica del vampiro'.)

'I was surprised that he had sent Mara to fetch me instead of doing it himself, given the familiarity with which he moved around the guesthouse.'

b. EP Criou então as «Bolsas de Estudo à Volta do Mundo», para permitir aos intelectuais entrarem em contacto com ideias, os sentimentos e as vidas dos diferentes povos. Em 1908 decidiu fazer ele próprio uma volta ao mundo, [...]. (CRPC: Diário de Notícias. J24288.)

'He created the "Scholarships for Studies Around The World", to allow intellectuals to come in contact with the ideas, the feelings, and the lives of other peoples. In 1908 he decided to make a trip around the world himself, [...].'

But the actor-oriented intensifier is also possible in preverbal position, which is typically a topic position in Romance languages. The examples are given in (495). Again, the alternatives in the sense of König $\&$ Siemund (2000) are not only evoked, but are present in the (broader) linguistic context.

(495) a. Sp. Ventura no recordaba haberse enfadado de esa manera nunca. Él mismo se extrañó de esa explosión de ira contenida. (CREA: Madrid, J. 1989. 'Flores, el gitano'.) 'Ventura couldn't remember him ever getting upset like this. He himself was surprised at this outburst of pent-up anger.' 
b. EP Todos os familiares e outros amigos sabiam que o fim se aproximava. Ele próprio tinha a consciência disso. (CRPC: Diário de Notícias. J71801.)

'All his family and other friends knew that the end was near. He himself was aware of that.'

In (495a), the alternatives are the people who are shocked by Ventura's angry outburst. In (495b), the alternative actor/experiencers are mentioned in the previous sentences. The alternatives are the family and friends that understood that the referent of the pronoun was going to die soon. Thus, in preverbal position as well, the contrastive flavour of the intensifier is clearly given.

The following conclusion can be drawn from this section. The Spanish and European Portuguese data seem to corroborate the proposal of König \& Siemund (2000) and Gast \& Siemund (2006) that intensifiers evoke alternatives, in which the DP bearing the actor role switches to another thematic role. The actor-oriented interpretation, with a switch of thematic roles, has also been observed in true reflexives (see section 5.1). The reflexive double in (496) is associated not only with contrastive focus on the object, as mentioned in Lobo (2013), Martins (2013), and Alboiu, Barrie \& Frigeni (2004), but also shows an interpretation similar to that of an actor-oriented intensifier. In (496a), alternatives are evoked on the position of the internal argument and in (496b) on the position of the external argument.

$$
\text { EP Hoje, a Rita maquilha-se a si própria... }
$$

today the R. puts.make-up=SE.REFL OM REFL.PR SELF

'Today, Rita is doing her own make-up...'

a.

... normalmente só maquilha outras pessoas

Maquilhar (Rita, $\mathrm{X}^{\text {Focus }}$ )

'... usually she is doing the make-up of other people.'

b.

... normalmente deixa-se maquilhar pela cabeleireira

Maquilhar ( $\mathrm{X}^{\text {Focus }}$, Rita)

'... usually the stylist is doing her make-up.'

The next section aims to bring these observations together and presents a tentative explanation for the effects of the intensifier on the interpretation of the strong reflexive and non-reflexive pronouns in Spanish and European Portuguese.

\subsection{On the interpretation of the reflexive intensifiers mismo and mesmo/próprio}

Let us bring the results of the previous sections together. The fact that the intensifier operates on the co-arguments of its host has been analysed in the approach of Reinhart \& Reuland (1991, 1993) and Reuland (2011), and in the approach of König \& Siemund (2000) and Gast \& Siemund (2006). The former formalise this link as movement of the SELF-intensifier to the verb. Due to this movement, the possible values of the pronoun hosting the intensifier are restricted to the co-arguments of the verbal predicate. König \& Siemund (2000) and Gast \& Siemund (2006) formalised the connection between argument structure and intensification in terms of focus alternatives. Both properties of intensifica- 
tion—argumenthood of the pronominal host and thematic alternatives—were corroborated for Spanish and European Portuguese.

In the following, I will argue that the intensifier acts like an operator that relates its host to the host's co-arguments. As a first step let us look again into the history of the elements mismo (Sp.) and mesmo/próprio (EP). The fact that mismo and mesmo carry the legacy of Latin IDEM, the Latin identity predicate with a meaning similar to English 'same', inspired a closer look into the meaning of identity predicates. ${ }^{133}$ Before elaborating my proposal, I want to state that I will not assume that the pronominal intensifiers mismo and mesmo/próprio are identity predicates or comparative operators. I will use the meaning of the identity predicate as a kind of springboard for my proposal.

In prenominal position, mismo/mesmo are attributive, relational adjectives with a meaning similar to English 'same', as exemplified in (497a) and (497b).

(497) a. EP As gémeas usam até a mesma escova de dentes.

the twins use even the same toothbrush

'The twins even use the same toothbrush.'

b. Sp. Mi hermana y yo usamos el mismo móvil.

my sister and I use the same mobile.phone

'My sister and me use the same mobile phone.'

The adjectives mismo/mesmo establish an identity relation or a similarity relation between two entities. The identity reading is obtained in (497) if there is one unique toothbrush or a unique mobile phone and both girls are using the unique object. The similarity reading is obtained if there are two objects, which are similar with respect to their properties, such as form, colour, and material. The similarity relation is gradable, and the adjectives mismo/mesmo express a very high or the maximal degree of similarity. Alrenga (2006) formalises the two interpretations as given in (498).

(498) a.

$\llbracket$ (the) same $\rrbracket=\lambda x \cdot \lambda y \cdot x=y$

(identity relation between individuals)

b.

$$
\forall \mathrm{P}[\mathrm{P}(\mathrm{x}) \leftrightarrow \mathrm{P}(\mathrm{y})]
$$

(maximal similarity of properties)

The term in (498a) states that the entities $x$ and $y$ are compared to each other, while in (498b), it is the properties of $x$ and $y$ that are compared to each other. In the sentence in (497) above, the two entities

\footnotetext{
133 Recall from section 6.3 that during the development of Modern Spanish and Modern European Portuguese, the intensifiers took over the meaning of the Latin pronoun IDEM meaning 'same' denoting an identity relation (see Penny 2002). This meaning is also attested for Late Latin IPSE in Manoliu (2011:477). Thus, the source of the modern forms-the combinations of MET+IPSE - carried not only the intensifying function, but also the properties of an identity predicate.
} 
to be compared are supplied by the immediate linguistic context, the so-called internal reading. ${ }^{134}$ The plural DP as gémeas or the conjoined subject DP mi hermana y yo define the entities that are compared. In the Spanish example, it is el móvil de mi hermana 'my sister's mobile phone' that is compared with mi móvil 'my mobile phone'. The second entity can also be supplied by the context of discourse (the external reading), as in (499). The compared entities are two mobile phones, the speaker's mobile phone and another phone that is salient in the extralinguisitic context.

$$
\begin{aligned}
& \text { Sp. Tengo el mismo móvil. } \\
& \text { I have the same mobile.phone } \\
& \text { 'I have the same mobile phone.' }
\end{aligned}
$$

Hardt et al. (2012), following Heim (1985) proposes that same is a symmetrical comparative ${ }^{135}$ operator with the schematic logical structure, as in (500a). The meaning of same consists of the operator (OP), which brings along a set $\mathrm{A}$ and a function $\mathrm{f}$. The members of the set $\mathrm{A}$ are either supplied sentence-internally or by the context of the utterance. The identity relation is constructed as a truth condition (is true iff...). An application of the formula to the sentence in (497) above is shown in (500b). The set A consists of the speaker and the sister. The function is constructed out of the NP modified by mismo: the range of $\mathrm{f}$ is the set of mobile phones. If $\mathrm{f}$ (speaker) and $\mathrm{f}$ (sister of speaker) yield an identical mobile phone, then the sentence is mapped to true.

(500) a.

$$
\text { "same } O P\langle A\rangle \text { " is true iff for all } x, y \text { in } A: f(x)=f(y) \text {. }
$$

b.

$$
\text { "mismo } \mathrm{OP}\langle\text { Yo, mi hermana }\rangle \mathrm{f}_{\text {móvil }} \text { " is true iff } \mathrm{f}_{\text {móvil }}(\mathrm{yo})=\mathrm{f}_{\text {móvil }}(\text { mi hermana) }
$$

What is important here is that the adjective mismo/mesmo is an operator that selects a set of entities from which the arguments of a function are selected. This approach opens a way to account for some interpretative and structural restrictions imposed by the reflexive intensifiers, as will become clear below.

I propose that the intensifiers mismo (Sp.), mesmo/próprio (EP) are such that they select a set of possible referents for the pronoun they modify, and this set is the set of co-arguments of the pronoun.

\footnotetext{
${ }^{134}$ Bosque (2012) observed for the internal reading (I) in Spanish that the antecedent of mismo is subject to similar restrictions as the antecedent of a pronomial anaphor. The antecedent has to be local, as shown in (i), c-commanding, as shown in (ii), and it cannot be a split antecedent, as in (iii).

(i) *Juan y María se conocen desde [que yo iba al mismo colegio].

(ii) El jefe de dos amigos míos vive en la misma (E/*I) calle.

(iii) Juan le hablaba a María de los mismos $\left(\mathrm{E} /{ }^{*} \mathrm{I}\right)$ problemas.

But differently from pronominal anaphors, mismo allows its host to take a sentence-external antecedent-the external reading (E) of mismo. Furthermore, c-command is not a necessary condition. For these reasons, Bosque (2012) dismisses an anaphoric approach to the syntax and interpretation of mismo and proposes that it has properties of an idefinite.

135 Similarity is conceived as 'type comparison', and identity is conceived as a 'token comparison'.
} 
The identity between the referent and the pronoun is established independently from the intensifier. The intensifier just states that whatever value is assigned to the pronominal variable has to be in the set of the pronoun's co-arguments. This is tentatively described as in (501).

(501) a. $\quad \mathrm{OP}_{\mathrm{mismo} / \text { próprio }}\langle\mathrm{A}\rangle$; all $\mathrm{x}, \mathrm{y}$ in $\mathrm{A}: \mathrm{x}$ is co-argument of $\mathrm{y}$.

Operator-like properties are also observed for the intensifier próprio. Just like other operators such as focus, quantifiers, or negation, the element próprio triggers proclisis in prenominal position, as in (502a), or in postnominal position, as in (502b) (Martins 2013:2273). ${ }^{136}$

(502) a. EP Os próprios ruídos se diluíam [...].

(Martins 2013:2273)

the SELF noises SE.ACA= disperse

'The sounds themselves got dispersed.'

b. $\quad$ Eu próprio o viu sair $[\ldots]$.

I SELF him.CL= saw go out [...]

(ibid.)

'I myself saw him go out.'

In the following, I want to show that a restriction to the co-argument domain may explain some interpretative and structural restrictions attested throughout chapter 8.

Co-argumenthood and 'fake' bound readings. The most important test for co-argumenthood is ccommand. The strong non-reflexive pronoun has been shown to be interpreted as a free variable able to corefer with a non-c-commanding antecedent in examples such as in (421), repeated here as (503). The presence of the intensifier causes that relation to become unacceptable. The strong pronoun needs to refer to the external argument realised by the head noun of the complex DP.

(503) a. EP $\quad\left[\mathrm{O}\right.$ pai $\mathrm{d}\left[\mathrm{o} \quad \mathrm{João}_{\mathrm{i}}\right]_{\mathrm{k}}$ confia nele $*_{\mathrm{i} / \mathrm{k}}$ próprio.

the father of.the J. trust in.him SELF

'João's father trusts himself.'

b. Sp. [La madre de $\left.[\text { Luisa }]_{\mathrm{i}}\right]_{\mathrm{k}}$ confía en ella $*_{\mathrm{i} / \mathrm{k}}$ misma.

the mother of $\mathrm{L}$. trust in her SELF

'Luisa's mother trusts herself.'

The notion of co-argumenthood may also explain the effect of the intensifier with respect to the interpretive diagnostics VP ellipsis and only-contexts, discussed in sections 8.6 and 8.7, respectively. In both diagnostics, the intensifier blocks the coreferential/strict interpretation of the strong non-reflexive pronoun and strongly favours a bound/sloppy reading. Starting with only-contexts, the examples (456) and (457) are repeated here as (504) and (505). If the intensifier is absent, both interpretations-

$\overline{136}$ See section 2.2 for the presentation of the proclisis trigger in European Portuguese. 
the bound interpretation and the coreferent interpretation-are possible. However, if the intensifier is present, the coreferent interpretation is blocked and the bound reading is the only acceptable option.

(504) a. EP Só a Rita confia nela.

$\mathrm{a}^{\prime}$. $\quad$ Nobody else trusts himself.

$a^{\prime \prime}$ Nobody else trusts Rita.

(505) a. Sp. Solo Juan confía en él.

$a^{\prime}$.

$a^{\prime \prime}$.
Nobody else trusts himself.

Nobody else trusts Juan. b. Só a Rita confia nela própria.

$b^{\prime}$. Nobody else trusts himself.

b". ??Nobody else trusts Rita.

b. Solo Juan confía en él mismo.

$\mathrm{b}^{\prime}$. $\quad$ Nobody else trusts himself.

b". *Nobody else trusts Juan.

Recall from sections 1.2 and 8.7 that the focus particle only evokes alternatives for the DP in its scope. The intensifier is also part of the alternative propositions, such as the proposition Marta confia nela própria and Marta confía en ella misma. Due to the presence of the intensifier in the alternative proposition, a coreferent reading of the pronoun is blocked for the following reason. The intensifier in the alternative selects the co-arguments of its host for the set of possible referents. As a consequence, the pronoun cannot take a sentence-external antecedent and refer to the subject DP of the initial sentence. The same argument works for VP elipsis contexts, illustrated with examples from European Portuguese. In the examples in (445) and (448), repeated here as (506) and (507), respectively.

(506) EP A Joana confia nela, e o Jorge também. (Lobo \& Menuzzi 2016:348) the J. trusts in.her and the J. too

'Joana trusts in her, and Jorge too.'

a. ??Jorge trusts himself.

b. $\quad$ Jorge trusts her. (her = Rita)

(507) EP A Rita confia nela própria e o Rui também. the R. trusts in.her SELF and the R. too

'Rita trusts in herself, and Rui too.'

a. $\quad$ Rui trusts himself.

b. $\quad$ ??Rui trusts her. (her = Rita)

A bound reading of the non-reflexive pronoun in the elided sentence is unacceptable if the intensifier is absent, as shown in (506). The only possible way to interprete the pronoun is via coreference. But as soon as the intensifier is present, as in (507), the bound reading becomes acceptable and the coreferential reading is degraded. The assumption that the intensifier restricts the referent of its host to a co-argument correctly predicts that reference to a sentence-external DP is no longer possible and, as a consequence, the coreferntial reading becomes unacceptable. The only co-argument available is the external argument of the elided VP. 
Co-argumenthood and locality. With respect to locality, the intensifier restricts the referent of its pronominal host not only to a sentence-internal antecedent, but to the most local clause-internal antecedent. This effect was very clear with non-reflexive pronouns in sentences with complement PPs, as given above in (404) for Spanish and in (401) for European Portuguese. For these examples, the locality restricting effect is schematically represented as in (508).
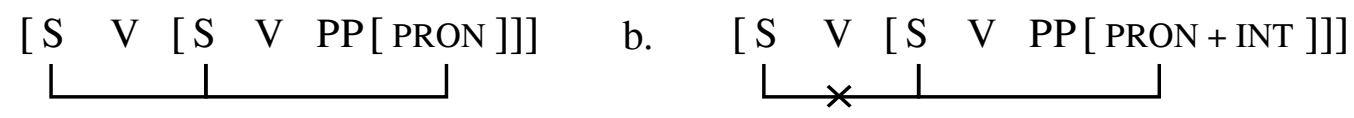

The schema in (508a) represents the long-distance reading of a bare reflexive pronoun in European Portuguese and the interpretation of the bare non-reflexive pronoun in Spanish and European Portuguese. The pronoun can take either a local or a non-local DP as its antecedent, but as soon as the intensifier is present, only is the local reading available, as shown in (508b). Sentences with a PP complement are transitive, and the local subject is the only available co-argument of the pronoun. With locative PPs there are two clause-internal antecedents: the direct object and the subject DP. In these structures, the effect of the intensifier has been visible in particular with the non-reflexive pronoun, as illustrated in (509a) and (509b). The bare non-reflexive pronoun can be associated with the subject DP, but not with the direct object DP. As soon as the the intensifier is present, only reference to the DO is possible, as shown in $(509 b)$.
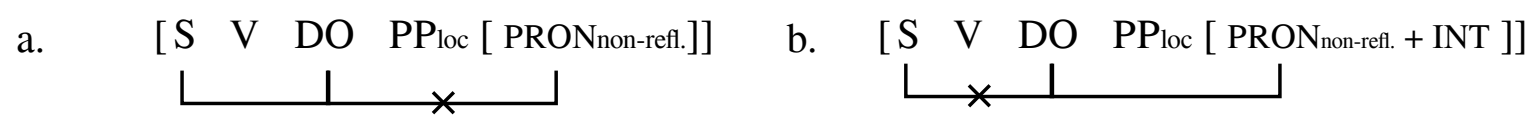

If the analysis in terms of co-argumenthood is on the right track, these data suggest that locative PP forms a predicate, as suggested in Otero (1999). But with the reflexive pronoun, native speaker judgements have been less clear or even contradictory in Spanish and European Portuguese. The subject as antecedent of the reflexive pronoun was accepted both with and without the intensifier. The reasons why the intensifier does not affect the reflexive pronoun in the same way as it affects the non-reflexive pronoun, and the implications for the status of the PP have to be left for future research. In benefactive PPs, the pronouns-reflexive and non-reflexive-cannot refer to the DO, even if the intensifier is present. The sentences in (510) cannot mean that Pedro or Maria hired a clown that performs for himself. The pronouns must take the subject DP as antecedent.

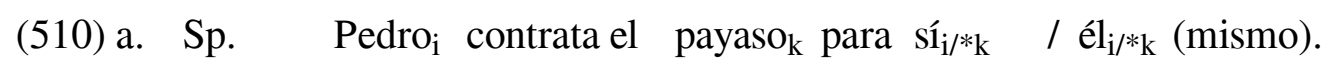

P. hires the clown for REFL.PR / him SELF

'Pedro hires the clown for himself/him.'

b. EP A Maria ${ }_{i}$ contrata a palhaça $a_{k}$ para $\mathrm{si} *_{\mathrm{k} / \mathrm{i}} / \mathrm{ela} *_{\mathrm{k} / \mathrm{i}}$ (própria).

the M. hires the clown for REFL.PR / her SELF

'Maria hires the clown for herself/her.' 
In the light of the assumption that the intensifiers mismo, mesmo/próprio impose a co-argument restriction on the referent of the pronoun, the benefactive PP is correctly predicted to be an adjunct (see Zagona 2002) and accounts for the locality restrictions observed throughout chapter 8. 


\section{Conclusions}

This chapter summarises the results and, in particular, the Minimalist analysis of anaphoric relations in Spanish and European Portuguese put forward in this book.

Apart from the general and well-known problems that we encounter when trying to adapt Binding Theory to the Minimalist Program, I have reported some special problems of Spanish and European Portuguese, which I extensively discussed and supported with novel data in the course of the book, in particular in chapters 5 and 8. Some of these problems can be summarised as follows: 1. Differently from clitic pronouns, reflexive and non-reflexive strong pronouns are not in complementary distribution either in clitic doubling contexts or inside complement or adjunct PPs. 2. Strong pronouns (both reflexive and non-reflexive) are obligatorily doubled with a clitic in transitive structures. 3. Strong pronouns can be complemented by an intensifier, which yields special effects; for example, it imposes locality restrictions and facilitates a sloppy/bound interpretation.

In order to resolve these problems, I had to assess and theoretically interpret theories and data both on anaphoricity/reflexivisation and on areas of grammar that go beyond these issues, but whose analysis was necessary to answer the research questions of this book. With respect to (true) reflexives, I showed in chapters 3 and 4 that reflexivisation in Spanish and European Portuguese amounts to transitive structures, unlike other theories and, possibly, other Romance languages such as Italian and French.

With respect to other phenomena, I reviewed and partially reanalysed the pronominal systems of these languages, the syntax of clitics (including clitic climbing and, in particular, clitic doubling), as well as case marking (in particular differential case marking).

The central finding of this book is that the interpretive and structural properties of reflexive and non-reflexive personal pronouns fall out from their phi-feature content and, in the case of reflexive clitics, from Agree. In chapter 6 I argued that reflexive pronouns (clitic and strong) differ from nonreflexive pronouns (clitic and strong) with respect to phi-feature values. Reflexive pronouns only have a specified value for person, but null-values for number and gender, while non-reflexive pronouns have fully specified values for all three features, in addition to a feature for animacy. Furthermore, I argued that clitics consist soley of phi-features and that no additional syntactic projection or descriptive feature for specificity and animacy are needed for their interpretation, and consequently for cliticisation. Clitic pronouns in Spanish and European Portuguese are conceived as defective goals in the sense of Roberts (2010) and are taken to be $\varphi^{\circ} / \varphi$ P items. Furthermore, following Cardinaletti \& Starke (1999), I proposed that strong pronouns have a more articulated internal syntactic structure. Strong pronouns are taken to be $\Sigma$ Ps instead of DPs.

This definition of reflexive and non-reflexive pronouns is in the spirit of a Minimalist programme for Binding Theory because it replaces the classification of pronouns as anaphors and pronominals with a definition based on phi-features and morphosyntactic structure. In classical Binding Theory, the notions anaphor and pronominal are understood as instructions for the interpretation: an anaphor is bound, and a pronominal is free. These two modes of interpretation are related to structural conditions 
such as a local and c-commanding antecedent. Within the research programme for a Minimalist Binding Theory set out in chapter 1, these interpretive and structural restrictions are an expression of three different ways of encoding an anaphoric dependency: (i) a syntactic encoding mechanism that involves operations of Narrow Syntax, and either (ii) a semantic encoding in terms of variable binding, or (iii) a discourse pragmatic encoding at the interface with the Conceptual-Intentional system.

An anaphoric relation is established by syntactic means if a pronoun must take a local and ccommanding antecedent, and if it is in complementary distribution with other pronouns. Furthermore, the pronoun is obligatorily interpreted as a bound variable. Semantic encoding is at issue if a pronoun has a sentence-internal and c-commanding antecedent. Semantic binding is not subject to sentence-internal locality restrictions. A pronoun subject to semantic binding is interpreted as a bound variable. An anaphoric dependency is established by discourse pragmatic means if the pronoun and its antecedent are not subject to structural conditions such as locality and c-command, and if the pronoun is interpreted as free variable.

I have been able to uncover these properties by means of a set of structural and interpretive diagnostics. these diagnostics have been applied to clitic doubling structures and to strong pronouns inside PP-complements and locative and benefactive PP arguments and adjuncts. The results allowed for the following conclusion: clitic pronouns, but not strong pronouns, are subject to a syntactic encoding mechanism. Strong pronouns must therefore be interpreted at the syntax-semantics interface.

Furthermore, I argued that an anaphoric relation involving reflexive and non-reflexive clitics is encoded syntactically because both types of clitics show the same clitic doubling syntax. This claim needed justification, and in chapters 3 and 4 I showed that reflexive clitics are not case-reducing or valence-reducing elements, but realise the internal argument (cf. Kayne 1988, Marantz 1984, Reinhart \& Siloni 2004, 2005 among many others.). Reflexive predicates therefore have a transitive syntactic structure. This result gave the empirical basis for a unified analysis of reflexive and non-reflexive clitic (doubling) structures.

The main analysis is elaborated in chapter 7. Following Roberts (2010), cliticisation is the result of phi-agreement with a defective goal. The probe on little $\mathrm{v}$, the verbal host of the clitic, enters into Agree with the clitic. After valuation, the defective goal deletes, while the phi-probe remains and now has interpretable and valued features. Agree with null-values is vacuous in the sense that the probe cannot value its features. If the strong reflexive pronoun is involved in Agree, for example with the phiprobe in $\mathrm{T}^{\circ}$, Agree is vacuous and the probe with unvalued and uninterpretable features cannot delete. As a consequence, the derivation will not converge at the interfaces. The assumption that reflexive pronouns have null-values and that Agree with this type of value is vacuous accounts for the Rizzi's (1990) Anaphor Agreement Effect and the ban of reflexive pronouns from subject position. If Agree targets a clitic, cliticisation takes place, with the result that the probe/clitic has unvalued feature for number and gender. This should cause the derivation to crash, but the fact that little v additionally enters into a checking relation with the external argument creates a configuration-the Bjorkman \& Zeijlstra configuration - in which the unvalued features on the probe are valued by upward valuation, namely 
by the features of the external argument. This valuation process establishes an agreement link between the external argument, the reflexive clitic, and its pronominal double. This agreement link translates as a reflexive predicate at the syntax-semantics interface and gives an explanation for the interpretive and structural properties, such as locality, c-command, and a bound variable interpretation.

The non-reflexive clitic undergoes cliticisation in the same way as the reflexive clitic, but due to its fully valued phi-features no upward valuation is possible. An agreement link between the external argument and the clitic cannot be established. The fact that the non-reflexive clitic and the external argument are obligatorily disjoint in reference thus follows from their phi-features and their inability to enter into upward valuation with the external argument. Furthermore, the economy hierarchy of Reuland (2011) and Reinhart (2006) correctly predicts that a relation once blocked in syntax cannot be established by semantic or discourse-pragmatic means. But the economy hierarchy of Reuland (2011) and Reinhart (2006) made wrong predictions for the interpretation of strong pronouns inside PP-complements and locative or benefactive PPs in the languages at issue here. In this environment, reflexive and non-reflexive pronouns are not in complementary distribution, at least in local contexts. The interpretive diagnostics showed that strong reflexive pronouns are interpreted as bound variables, but strong non-reflexive pronouns resist a bound variable interpretation and show features of E-type pronouns.

In chapter 9, I showed that the economy hierarchy of Reuland (2011) and Reinhart (2006) runs into problems for the following reason: if an anaphoric dependency cannot be established by semantic binding, the same relations should not be established by means of pragmatic coreference. But this situation is essentially found with Spanish and European Portuguese non-reflexive pronouns: they cannot be bound by the subject DP, but they can corefer with it. This result calls for an alternative analysis. Chapter 9 is devoted to a first step towards an alternative account for the interpretation of strong pronouns, focussing on the effects of the reflexive intensifiers mismo (Sp.) and mesmo/próprio (EP). I proposed that the intensifier acts like an operator that preselects the referents of its pronominal host from the pronoun's co-argument domain.

Finally, it can be concluded that the research programme of Reinhart \& Reuland (1991, 1993), Reuland (2011), and Reinhart (2006) adopted as a guideline for this book gave important insights for the development of the Minimalist syntactic analysis of the interpretation of reflexive and non-reflexive clitic doubling structures, but the programme needs to be refined with respect to the interpretation of strong reflexive and non-reflexive pronouns in Spanish and European Portuguese and most probably for other languages, a topic left for future research. 



\section{References}

Adger, David and Gilian Ramchand (2005): 'Merge and Move: Wh-dependencies revisited'. Linguistic Inquiry 36(2), 161-193.

Alboiu, Gabriela, Michael Barrie, and Chiara Frigeni (2004): 'SE and the unaccusative-unergative paradox'. In: Martine Ciene, Gretel de Cuyper, and Yves d'Hulst (eds.): Current Studies in Comparative Romance Linguistics. Antwerp Papers in Linguistics 107. Antwerp: University of Antwerp, 109-141.

Alonso-Ovalle, Luis and Francesco D'Introno (2001): 'Full and null pronouns in Spanish: The Zero Pronoun Hypothesis'. In: Héctor Campos (ed.): Hispanic Linguistics at the Turn of the Millennium: Papers from the 3rd Hispanic Linguistics Symposium. Sommerville, Mass.: Cascadilla Press, 89-210.

Alrenga, Peter (2006): 'Scalar (non-)identity and similarity'. In: Donald Baumer, David Montero, and Michael Scanlon (eds.): Proceedings of the 25th West Coast Conference on Formal Linguistics. Somerville: Cascadilla Proceedings Project, 49-57.

Ausín, Adolfo and Marcela Depiante (2000): 'On the syntax of parecer ('to seem') with and without an experiencer'. In: Héctor Campos, Elena Herburger, Alfonso Morales-Front, and Thomas Walsh (eds.): Hispanic Linguistics at the Turn of the Millennium: Papers from the 3rd Hispanic Linguistics Symposium. Summerville, Mass.: Cascadilla Press, 155-170.

Baauw, Sergio (2002): Grammatical Features and the Acquisition of Reference: A Comparative Study of Dutch and Spanish. New York: Routledge.

Baauw, Sergio and Denis Delfitto (2005): 'New views on reflexivity: Delay effects in Romance'. Probus $17,145-184$.

Barbosa, Pilar, Maria da Conceição de Paiva, and Kellen Cozine Martins (2017): 'Clitic climbing in the speech of Braga and Lisbon'. In: Pilar Barbosa, Maria da Conceição de Paiva, and Celeste Rodrigues (eds.): Studies on Variation in Portuguese. Amsterdam: John Benjamins, 200-217.

Barbosa, Pilar and Eduardo Raposo (2013): 'Verbo e sintagma verbal'. In: Eduardo Raposo, Maria Fernanda Bacelar do Nascimento, Maria Antónia Coelho da Mota, Luísa Segura, and Amália Mendes (eds.): Gramática do Português. Coimbra: Gráfica de Coimbra, 1901-1980.

Bassi, Itai and Nicholas Longenbaugh (2017): 'Features on bound pronouns: An argument against syntactic agreement approaches'. Unpublished manuscript, MIT. [https://ling.auf.net/ lingbuzz/004056/current.pdf, accessed on: 24 July 2020]. 
Belletti, Adriana and Luigi Rizzi (1988): 'Psych-verbs and $\theta$-theory'. Natural Language and Linguistic Theory 130, 291-352.

Benveniste, Émile (1966): Problèmes de linguistique générale. Paris: Gallimard.

Bjorkman, Bronwyn and Hedde Zeijlstra (2019): ' Checking up on (Phi-) Agree'. Linguistic Inquiry 50(3), 527-569.

Bjorkman, Bronwyn and Hedde Zeijlstra (2014): 'Upward Agree is superior'. Ms. Universität Göttingen. [https://ling.auf.net/lingbuzz/002350/current.pdf?_s=tkUhu0CniY6eK42Q, accessed on: 24 July 2020].

Bleam, Tonia (2003): 'Properties of the double object construction in Spanish'. In: Rafael NúñezCedeño, Luis López, and Richard Cameron (eds.): A Romance Perspective on Language Knowledge and Use. Amsterdam: John Benjamins, 233-252.

Bleam, Tonia (1999): Leísta Spanish and the Syntax of Clitic Doubling. PhD dissertation. University of Delaware.

Boeckx, Cedric (2003): Islands and chains: Resumption as stranding. Amsterdam: John Benjamins.

Boeckx, Cedric, Norbert Hornstein, and Jairo Nunes (2010): Control as Movement. Cambridge: Cambridge University Press.

Bonet, Eulàlia (2008): 'The Person-Case Constraint and repair strategies'. In: Roberta D'Alessandro, Susann Fischer, and Gunnar Hrafn Hrafnbjargarson (eds.): Agreement Restrictions. Berlin: Mouton de Gruyter, 103-128.

Bonet, Eulàlia (1991): Morphology after Syntax: Pronominal Clitics in Romance. PhD dissertation. Department of Linguistics and Philosophy, Massachusetts Institute of Technology.

Bosque, Ignacio (2012): 'Sobre el adjetivo mismo en las construcciones de dependencia interna'. In: Tomás Jiménez Juliá, Belén López Meirama, Victoria Vázquez Rozas, and Alexandre Veiga Rodríguez (eds.): Cum corde et in nova grammatica: Estudios ofrecidos a Guillermo Rojo. Santiago de Compostela: Universidade de Santiago de Compostela, 93-108.

Bosque, Ignacio and Violeta Demonte (1999): Gramática descriptiva de la lengua española. Madrid: Real Academia Española. Espasa Calpe.

Bosque, Ignacio and Javier Gutiérrez-Rexach (2016): Fundamentos de Sintaxis Formal. Madrid: Ediciones Akal.

Bošković, Željko and Daiko Takahashi (2005): 'Scrambling and last resort'. Linguistic Inquiry 29(3), 347-366. 
Bresnan, Joan, Ash Asudeh, Ida Toivonen, and Stephen Wechsler (2016): Lexical Functional Grammar. Oxford: Wiley Blackwell.

Brito, Ana Maria (2015): 'Two base generated structures for ditransitives in European Portuguese'. In: Alberto Simões, Anabela Barreiro, Diana Santos, Rui Sousa-Silva, and Stella Tagnin (eds.): Linguîstica, Informática e Traduçao: Mundos que se Cruzam. Homenagem a Belinda Maia. Oslo: Oslo Studies in Language, 337-357.

Brito, Ana Maria (2008): 'Grammar variation in the expression of verb arguments: The case of the Portuguese indirect object'. PHRASIS: Studies in Language and Literature 40(2), 31-58.

Brito, Ana Maria (2003): 'Tipologia e Distribução das expressões nominais’. In: Mateus, Maria Helena Mira, Ana Maria Brito, Inês Duarte, Isabel Hub Faria, Sónia Frota, Gabriela Matos, Fátima Oliveira, Marina Vigário, and Alina Villalva (eds.): (2003): Gramática da Língua Portuguesa. Lisboa: Editorial Caminho, 795-826.

Büring, Daniel (2011): 'Pronouns'. In: Klaus von Heusinger, Claudia Maienborn, and Paul Portner (eds.): Semantics: An International Handbook of Natural Language Meaning. Handbücher zur Sprachund Kommunikationswissenschaft / Handbooks of Linguistics and Communication Science. Berlin: Mouton de Gruyter, 971-996.

Büring, Daniel (2005): Binding Theory. Cambridge: Cambridge University Press.

Burzio, Luigi (1986): Italian Syntax. Dordrecht: Reidel.

Camacho, José (2003): The structure of Coordination: Conjunction Agreement Phenomena in Spanish and other Languages. Dodrecht: Kluwer.

Campos, Héctor (1995): 'Reconstruction and picture nouns in Spanish'. In: Héctor Campos and Paula Kempchinsky (eds.): Evolution and Revolution in Syntactic Theory: A Festschrift in Honor of Carlos Otero. London: Society of Genealogists, 155-167.

Cardinaletti, Ana and Michael Starke (1999): 'The typology of structural deficiency: A case study of the three classes of pronouns'. In: Henk van Riemsdijk (ed.): Clitics in the Languages of Europe. Berlin, New York: Mouton de Gruyter, 145-233.

Carrilho, Ernestina (2008): 'Beyond doubling: Overt expletives in European Portuguese dialects'. In: Sjef Barbiers, Olaf Koeneman, Marika Lekakou, and Margreet van der Ham (eds.): Microvariation and Syntactic Doubling. Bingly: Emerald, 301-323.

Carrilho, Ernestina (2005): Expletive Ele in European Portuguese Dialects. PhD dissertation. Faculdade de Letras da Universidade de Lisboa. 
Carrilho, Ernestina and Catarina Magro (2010): ‘A anotação sintáctica do CORDIAL-SIN'. In: Ana Maria Brito, Fátima Silva, João Veloso, and Alexandra Fiéis (eds.): Actas do XXV Encontro Nacional da Associação Portuguesa de Linguística. Porto: APL, 225-241.

CEA = Subirats, Carlos and Marc Ortega (2012): Corpus del Español Actual. [http://spanishfn.org/tools/ cea/english, accessed on: 24 July 2020].

Chierchia, Gennaro (2004): 'A semantics for unaccusatives and its syntactic consequences'. In: Artemis Alexiadou, Elena Anagnostopoulou, and Martin Everaert (eds.): The Unaccusativity Puzzle. Oxford: Oxford University Press, 22-59.

Chierchia, Gennaro (1992): 'Anaphora and dynamic binding'. Linguistics and Philosophy 15(2), 111183.

Chierchia, Gennaro (1989): 'A semantics for unaccusatives and its syntactic consequences'. Manuscript, Cornell University [published 2004, Oxford: Oxford University Press]. [https:// scholar.harvard.edu/files/chierchia/files/chierchia_2004_unaccusatives.pdf, accessed on: 24 July 2020].

Chomsky, Noam (2013): 'Problems of projection'. Lingua 130, 33-49.

Chomsky, Noam (2008): 'On phases’. In: Robert Freidin, Carlos P. Otero, and Maria Luisa Zubizarreta (eds.): Foundational Issues in Linguistic Theory: Essays in Honor of Jean-Roger Vergnaud. Cambridge, Mass.: MIT Press, 133-166.

Chomsky, Noam (2004): 'Beyond explanatory adequacy'. In: Adriana Belletti (ed.): Structures and Beyond: The Cartography of Syntactic Structures. Oxford: Oxford University Press, 104-131.

Chomsky, Noam (2001): 'Derivation by phase'. In: Michael Kenstowicz (ed.): Ken Hale. A Life in Language. Cambridge, Mass.: MIT Press, 1-52.

Chomsky, Noam (2000): 'Minimalist inquiries: The framework'. In: Roger Martins, David Michaels, and Juan Uriagereka (eds.): Step by Step: Essays on Minimalist Syntax in Honor of Howard Lasnik. Cambridge, Mass.: MIT Press, 85-155.

Chomsky, Noam (1995a): The Minimalist Program. Cambridge, Mass.: MIT Press.

Chomsky, Noam (1995b): 'Bare phrase structure'. In: Héctor Campos and Paula Kempchinsky (eds.): Evolution and Revolution in Syntactic Theory: A Festschrift in Honor of Carlos Otero. London: Society of Genealogists, 51-109.

Chomsky, Noam (1986): Knowledge of Language: Its Nature, Origin, and Use. New York: Praeger.

Chomsky, Noam (1981): Lectures on Government and Binding. Dordrecht: Foris. 
Chomsky, Noam (1980): 'On binding'. Linguistic Inquiry 11(1), 1-46.

Chomsky, Noam (1973): 'Conditions on transformations'. In: Stephen Anderson and Paul Kiparski (eds.): A Festschrift for Morris Halle. New York: Holt, Rinehart and Winston, 232-286.

Citko, Barbara (2014): Phase Theory. Cambridge: Cambridge University Press.

Costa, João (2004): Subject Positions and Interfaces: The Case of European Portuguese. Berlin: de Gruyter.

Costa, João and Sandra Pereira (2013): 'A gente: Pronominal status and agreement revisited'. The linguistic Review 30(2), 161-184.

Coutinho de Lima, Ismael (1974): Gramática Histórica. Rio de Janeiro: Livraria Acadêmica.

CREA = Real Academia Española (2008/2014): Corpus de referencia del español actual. CREA, versión 3.2/CREA anotado, versión 0.1. [http://www.rae.es, accessed on: 24 July 2020].

CRPC = Centro de Linguística da Universidade de Lisboa - CLUL (2012): Corpus Referência do Português Contemporâneo. Versão 3.0. [http://alfclul.clul.ul.pt/CQPweb/, accessed on: 24 July 2020].

Cuervo, María Cristina (2003): Datives at Large. PhD dissertation. Massachussets Institute of Technology.

Danon, Gabi (2011): 'Agreement and DP-internal feature distribution'. Syntax 14, 297-317.

Déchaine, Rose-Marie and Martina Wiltschko (2017): 'The heterogeneity of reflexives'. Studia Linguistica 71(1), 60-106.

Déchaine, Rose-Marie and Martina Wiltschko (2012): 'When and why can 1st and 2nd person pronouns be bound variables?'. Proceedings of Pronouns Workshop, MIT [https:// linguistics.sites.olt.ubc.ca/files/2018/03/dechaine_wiltschko.pdf, accessed on: 24 July 2020].

Déchaine, Rose-Marie and Martina Wiltschko (2003): 'On pro-nouns and other "pronouns”. In: Yves D’Hulst and Martine Coene (eds.): From NP to DP. Volume I: The Syntax and Semantics of Noun Phrases. Amsterdam: John Benjamins, 71-89.

Déchaine, Rose-Marie and Martina Wiltschko (2002): 'Decomposing Pronouns'. Linguistic Inquiry 33, 409-422.

Delille, Karl Heinz (1970): Die Geschichte des präpositionalen Akkusatives im Portugiesischen. Bonn: Romanisches Seminar der Universität Bonn.

Demonte, Violetta (1995): 'Dative alternation in Spanish'. Probus 7, 5-30. 
Diesing, Molly (1992): Indefinites. Cambridge, Mass.: MIT Press.

Duarte, Inês (2013): ‘Construções ativas, passivas, incoativas e médias'. In: Eduardo Raposo, Maria Fernanda Bacelar do Nascimento, Maria Antónia Coelho da Mota, Luísa Segura, and Amália Mendes (eds.): Gramática do Português. Coimbra: Gráfica de Coimbra, 429-460.

Duarte, Inês, Gabriela Matos, and Anabel Gonçalves (2005): 'Pronominal clitics in European and Brazilian Portuguese'. Journal of Portuguese Linguistics 4(2), 113-141.

d'Alessandro, Roberta and Diego Pescarini (2016): 'Agreement restrictions and agreement oddities'. In: Susan Fischer and Christoph Gabriel (eds.): Manual of Grammatical Interfaces in Romance. Berlin: Mouton de Gruyter, 267-294.

Epstein, Samuel D. (1999): 'Un-principled syntax: The derivation of syntactic relations'. In: Samuel D. Epstein and Norbert Hornstein (eds.): Working Minimalism. Cambridge, Mass.: MIT Press, 317-345.

Epstein, Samuel David and Seely T. Daniel (2002): 'Rule application as cycles in a level-free syntax'. In: Samuel David Epstein and T. Daniel Seely (eds.): Derivation and Explanation in the Minimalist Program. Oxford: Blackwell, 65-89.

Estrela, Antónia (2006): A teoria da ligação: Dados do português europeu. MA thesis. Facultade de Ciências Socias e Humanas da Universidade Nova de Lisboa.

Evans, Gareth (1977): 'Pronouns, quantifiers, and relative clauses'. Canadian Journal of Philosophy 7(3), 467-536. [https://www.tandfonline.com/loi/rcjp20, accessed on: 24 July 2020].

Fanselow, Gisbert (2001): '[Theta]-roles, and free constituent order'. Linguistic Inquiry 32(3), 405-437.

Fernández Soriano, Olga (1999): 'El pronombre personal. Formas y distribuciones. Pronombres átonos y tónicos'. In: Ignacio Bosque and Violeta Demonte (eds.): Gramática descriptiva de la lengua española. Madrid: Real Academia Española/Espasa Calpe, 1209-1273.

Fodor, Janet and Ivan Sag (1982): 'Referential and quantificational indefinites'. Linguistics and Philosophy 5(3), 355-398.

Forchheimer, Paul (1953): The Category of Person in Language. Berlin: Mouton de Gruyter.

Franco, Jon (1999): ‘Agreement as a Continuum. The case of Spanish pronominal clitics'. In: Fitz Beukema and Marcel Den Dikken (eds.): Clitic Phenomena in European languages. Amsterdam: John Benjamins, 147-190.

Franco, Jon (1994): 'On the absence of Spanish past participal object clitic agreement: The AGRo parameter in Romance'. Anuario del Seminario de Filología Vasca Julio de Urquijo 28, 247- 
262. [http://www.ehu.eus/ojs/index.php/ASJU/article/viewFile/8431/7601, accessed on: 24 July 2020].

Franco, Jon and Alazne Landa (1995): 'An analysis of AGRo projections for Spanish causatives'. International Journal of Basque Linguistics and Philology 29, 199-218.

Galves, Charlotte, Maria Aparecida Torres Morales, and Ilza Ribeiro (2005): 'Syntax and morphology in the placement of clitics in European and Brazilian Portuguese'. Journal of Portuguese Linguistics $4(2), 143-177$.

García García, Marco (2007): 'Differential object marking with inanimate objects'. In: Georg Kaiser and Manuel Leonetti (eds.): Proceedings of the Workshop: Definiteness, Specificity and Animacy in Ibero-Romance Languages. Arbeitspapier 122. Fachbereich Sprachwissenschaft. Konstanz: Universität Konstanz, 63-84. [http://nbn-resolving.de/ urn:nbn:de:bsz:352-opus-32751, accessed on: 24 July 2020].

Gast, Volker and Peter Siemund (2006): 'Rethinking the relationship between self-intensifiers and reflexives'. Linguistics 44(2), 343-381.

Gonçalves, Rita (2015): 'Romance languages do not have double objects: Evidence from European Portuguese and Spanish'. Estudos de Lingüística Galega 7, 53-67.

Gonçalves, Anabel (1999): Predicados Complexos Verbais em Contextos de Infinitivo não Preposicionado do Português Europeu. PhD dissertation. Faculdade de Letras da Universidade de Lisboa.

Gonçalves, Anabela, Ernestina Carrilho, and Sandra Pereira (2016): 'Predicados complexos numa perspetiva comparativa'. In: Ana Maria Martins and Ernestina Carrilho (eds.): Manual de Linguística Portuguesa. Berlin: De Gruyter Mouton, 523-557.

Gonçalves, Anabela and Eduardo Raposo (2013): 'Verbo e sintagma verbal'. In: Eduardo Raposo, Maria Fernanda Bacelar do Nascimento, Maria Antónia Coelho da Mota, Luísa Segura, and Amália Mendes (eds.): Gramática do Português. Coimbra: 1155-1220.

Guimarães, Márico Renato (2010): 'O focalizador mesmo: Verificação por coincidência com um protótipo versus verificação por extensão para instâncias-limite'. Cadernos de Estudos Lingüísticos 52(2), 285-296.

Gutiérrez-Rexach, Javier (2001): 'Interface conditions and the semantics of argument clitics'. In: Javier Gutiérrez-Rexach and Luis Silva-Villar (eds.): Current Issues in Spanish Syntax and Semantics. Berlin, Boston: Mouton de Gruyter, 107-142.

Gutiérrez-Rexach, Javier (1999): 'The formal semantics of clitic doubling'. Journal of Semantics 16, 315-380. 
Hackl, Martin (2013): 'The syntax-semantics interface'. Lingua 130, 66-87.

Halle, Moris and Alec Marantz (1994): 'Some key features of Distributed Morphology'. In: Carnie Andrew and Harley Heidi (eds.): Papers on Phonology and Morphology. MIT working papers in linguistics 21. Cambridge, Mass.: MIT Press, 275-288.

Halle, Moris and Alec Marantz (1993): 'Distributed Morphology and the pieces of inflection'. In: Hale Kenneth and Keyser Jay (eds.): The View from Building 20. Cambridge, Mass.: MIT Press, 111176.

Hardt, Dan, Line Mikkelsen, and Bjarne Ørsnes (2012): 'Sameness, ellipsis, and anaphora'. In: Maria Aloni, Vadim Kimmelman, Floris Roelofsen, Galit Sassoon, Katrin Schulz, and Matthijs Westera (eds.): Logic, Language and Meaning. Lecture Notes in Computer Science, vol 7218. Berlin, Heidelberg: Springer, 341-350. [http://linguistics.berkeley.edu/ mikkelsen/ papers/ac_postproceedings.pdf, accessed on: 24 July 2020].

Harley, Heidi (2008): 'When is a syncretism more than a syncretism?'. In: Daniel Harbour, David Adger, and Susana Béjar (eds.): Phi Theory: Phi-features across Modules and Interfaces. Oxford: Oxford University Press, 251-294.

Harley, Heidi and Ritter Elizabeth (2002): 'Person and number in pronouns: A feature-geometric analysis'. Language 78(3), 482-526.

Heim, Irene (2008): ‘Features on bound pronouns'. In: Daniel Harbour, David Adger, and Susana Béjar (eds.): Phi Theory: Phi-features across Modules and Interfaces. Oxford: Oxford University Press, $35-56$.

Heim, Irene (1990): 'E-type pronouns and donkey anaphora'. Linguistics and Philosophy 13(2), 137-177.

Heim, Irene (1989): The Semantics of Definite and Indefinite Noun Phrases. New York: Garland.

Heim, Irene (1985): 'Notes on comparatives and related matters'. Manuscript, University of Texas. [http://semantics.uchicago.edu/kennedy/classes/f07/comparatives/heim85.pdf, accessed on: 24 July 2020].

Heim, Irene and Angelika Kratzer (1998): Semantics in Generative Grammar. Malden, Mass.: Blackwell.

Heusinger, Klaus von (2002): 'Reference and representation of pronouns'. In: Heike Wiese and Horst Simon (eds.): Pronouns: Grammar and Representation. Amsterdam: John Benjamins, 109-135.

Heusinger, Klaus von and Georg Kaiser (2007): 'Differential object marking and the lexical semantics of verbs in Spanish'. In: Georg Kaiser and Manuel Leonetti (eds.): Proceedings of the 
Workshop: Definiteness, Specificity and Animacy in Ibero-Romance Languages. Arbeitspapier 122. Fachbereich Sprachwissenschaft. Konstanz: Universität Konstanz, 85-110. [http://nbnresolving.de/urn:nbn:de:bsz:352-opus-32751, accessed on: 24 July 2020].

Heusinger, Klaus von and Georg Kaiser (2003): 'The Interaction of Animacy, Definiteness, and Specificity in Spanish'. In: Klaus von Heusinger and Georg Kaiser (eds.): Proceedings of the Workshop: Semantic and Syntactic Aspects of Specificity in Romance Languages . Arbeitspapier 113. Fachbereich Sprachwissenschaft. Konstanz: Universität Konstanz, 41-65. [http://nbnresolving.de/urn:nbn:de:bsz:352-opus-17209, accessed on: 24 July 2020].

Hicks, Glyn (2009): The Derivation of Anaphoric Relations. Amsterdam: John Benjamins.

Horn, Laurence (1969): ‘A presuppositional analysis of only and even'. In: Alice Binnick, Georgia Green, and J. L. Morgan (eds.): Papers form the fifth Regional Meeting of the Chicago Linguistic Society. Chicago: University of Chicago Illinois, 98-107.

Hornstein, Norbert (2009): A Theory of Syntax. Cambridge: Cambridge University Press.

Hornstein, Norbert (2007): 'Pronouns in a Minimalist setting'. In: Norbert Corver and Jairo Nunes (eds.): The Copy Theory of Movement. Amsterdam: John Benjamins, 351-385.

Hornstein, Norbert (2001): Move! A Minimalist Theory of Construal. Cambridge, Mass.: MIT Press.

Iglesias Bango, Manuel (1992): 'Acerca del supuesto estatuto perifrástico de la construcción causativa hacer + infinitivo y otras cuestiones conexas (I y II)'. Contextos X, 87-148. [https:// buleria.unileon.es/handle/10612/1742, accessed on: 24 July 2020].

Jackendoff, Ray (1992): 'Mme Tussaud meets the binding theory'. Natural Language and Linguistic Theory 10, 1-33.

Jacobson, Pauline (2012): 'Direct compositionality and 'uninterpretability': The case of (sometimes) 'uninterpretable' features on pronouns'. Journal of Semantics 29, 305-343.

Jacobson, Pauline (1999): ‘Towards a variable-free semantics'. Linguistics and Philosophy 22(2), 177185.

Jaeggli, Oswaldo (1986): 'Three issues in the theory of clitics: Case, doubled NPs, and extraction'. In: Hagit Borer (ed.): The Syntax of Pronominal clitics. New York: Academic Press, 15-42.

Jaeggli, Oswald (1982): Topics in Romance Syntax. Dordrecht: Foris.

Kaiser, Georg (1992): Die klitischen Personalpronomina im Französischen und Portugiesischen. Frankfurt a.M.: Vervuert. 
Kaplan, David (1989): 'Afterthoughts'. In: Josef Almog, John Perry, and Howard Wettstein (eds.): Themes from Kaplan. Oxford: Oxford University Press, 565-635.

Kayne, Richard (2002): 'Pronouns and their antecedents'. In: Samuel David Epstein and T. Daniel Seely (eds.): Derivation and Explanation in the Minimalist ProgramInternational Encyclopedia of the Social and Behavioural Sciences. Oxford: Blackwell, 133-166.

Kayne, Richard (1994): The Antisymmetry of Syntax. Cambridge: Cambridge University Press.

Kayne, Richard (1988): 'Romance SE/si'. GLOW Newsletter.

Kayne, Richard (1975): French Syntax: The Transformational Cycle. Cambridge, Mass.: MIT Press.

Kayne, Richard (1972): 'Subject inversion in French interrogatives'. In: Jean Casagrande and Bohdan Saciuk (eds.): Generative Studies in Romance Languages. Rowley, Mass.: Newbury House, 70126.

Klein, Susan (1998): 'Mesmo and the NP in Brazilian Portuguese'. Cadernos de Estudos Lingüísticos 34, 93-102.

König, Ekkehard and Peter Siemund (2000): 'Intensifiers and reflexives: A typological perspective'. In: Zygmunt Frajzyngier and Traci Curl (eds.): Reflexives: Forms and Functions. Amsterdam: John Benjamins, 41-74.

Kratzer, Angelika (2009): 'Making a pronoun: Fake indexicals as windows into the properties of pronouns'. Linguistic Inquiry 40(2), 187-237.

Kratzer, Angelika (1998): 'More structural analogies between pronouns and tenses'. In: Devon Strolovitch and Aaron Lawson (eds.): Proceedings of the 8th Semantics and Linguistic Theory Conference. 92-110. [https://journals.linguisticsociety.org/proceedings/ index.php/SALT/article/view/2808/2548, accessed on: 24 July 2020].

Krifka, Manfred (2007): 'Basic notions of information structure'. In: Caroline Fery and Manfred Krifka (eds.): Interdisciplinary Studies of Information Structure 6. Potdam: Universität Potsdam, 13-55. [https://publishup.uni-potsdam.de/opus4-ubp/frontdoor/deliver/index/docId/1430/file/ ISIS06.pdf, accessed on: 24 July 2020].

Kühner, Raphael and Karl Friedrich Stegman (1912): Ausführliche Grammatik der lateinischen Sprache, vol. 1: Elementar-, Formen- und Wortlehre. Second edition revised by Friedrich Holzweissig. Hannover: Hahnsche Buchhandlung.

Kučerová, Ivona (2018): ‘ $\varphi$ features at the syntax-semantic interface: Evidence from nominal inflection'. Linguistic Inquiry 49(4), 813-845. 
Landau, Idan (2016): 'DP-internal semantic agreement: A configurational analysis'. Natural Language and Linguistic Theory 34, 975-1020.

Lasnik, Howard (1976): 'Remarks on co-reference'. Linguistic Analysis 2, 1-22.

Lebeaux, David (1985): 'Locality and anaphoric binding'. The linguistic Review 4(4), 343-363.

Leonetti, Manuel (2008): 'Specificity in clitic doubling and in differential object marking'. Probus 20, 33-66.

Leonetti, Manuel (2007): 'Clitics do not encode specificity'. In: Georg Kaiser and Manuel Leonetti (eds.): Proceedings of the Workshop: Definiteness, Specificity and Animacy in IberoRomance Languages. Arbeitspapier 122. Fachbereich Sprachwissenschaft. Konstanz: Universität Konstanz, 111-139. [http://nbn-resolving.de/urn:nbn:de:bsz:352-opus-32751, accessed on: 24 July 2020].

Leonetti, Manuel (2003): 'Specificity and object marking: The case of Spanish a'. In: Klaus von Heusinger and Georg Kaiser (eds.): Proceedings of the Workshop: Semantic and Syntactic Aspects of Specificity in Romance Languages. Arbeitspapier 113. Fachbereich Sprachwissenschaft. Konstanz: Universität Konstanz, 67-101. [http://nbn-resolving.de/ urn:nbn:de:bsz:352-opus-17209, accessed on: 24 July 2020].

Löbner, Sebastian (2011): ‘Concept types and determination'. Journal of Semantics 28, 279-333.

Lobo, Maria (2013): 'Dependências referenciais'. In: Eduardo Raposo, Maria Fernanda Bacelar do Nascimento, Maria Antónia Coelho da Mota, Luísa Segura, and Amália Mendes (eds.): Gramática do Português. Coimbra: Gráfica de Coimbra, 2177-2230.

Lobo, Maria and Sergio Menuzzi (2016): 'Binding and pronominal forms in Portuguese'. In: W. Leo Wetzels, Sergio Menuzzi, and João Costa (eds.): Handbook of Portuguese Linguistics. Oxford: John Wiley \& Sons, 338-355.

Lohnstein, Horst (2011): Formale Semantik und natürliche Sprache. Berlin: Walter de Gruyter.

Longobardi, Giuseppe (1994): 'Reference and proper names: A theory of N-movement in syntax and logical form'. Linguistic Inquiry 25(4), 609-665.

López, Luis (2012): Indefinite Objects. Scrambling, Choice Functions and Differential Marking. Cambridge, Mass.: MIT Press.

Ludow, Peter (2013): 'Descriptions'. In: Edward Zalta (ed.): The Stanford Encyclopedia of Philosophy. [https://plato.stanford.edu/archives/fall2013/entries/descriptions/, accessed on: 24 July 2020]. 
Luís, Ana and Georg Kaiser (2016): 'Clitic pronouns: phonology, morphology, and syntax'. In: W. Leo Wetzels, Sergio Menuzzi, and João Costa (eds.): Handbook of Portuguese Linguistics. Oxford: John Wiley \& Sons, 234-253.

Magro, Catarina (2019): 'Redobro de clíticos em português europeo'. Estudios de Lingüística Galega $11,29-75$.

Manoliu, Maria (2011): 'Pragmatics and discourse changes'. In: Martin Maiden, John Charles Smith, and Adam Ledgeway (eds.): The Cambridge History of Romance Languages, vol. 1. Cambridge: Cambridge University Press, 472-531.

Marantz, Alec (2007): 'Phases and words'. In: S. H. Choe (ed.): Phases in the theory of grammar. Seoul: Dong-In Publishing Co., 191-222. [https://babel.ucsc.edu/ hank/ mrg.readings/Phases_and_Words_Final.pdf, accessed on: 24 July 2020].

Marantz, Alec (2001): 'Words and Things'. Handout, Massachusetts Institute of Technology. [http:// web.mit.edu/marantz/Public/ALI/Handouts/ALIThird.pdf, accessed on: 24 July 2020].

Marantz, Alec (1984): On the Nature of Grammatical Relations. Cambridge: Cambridge University Press.

Marelj, Marijana and Eric Reuland (2016): 'Clitics and reflexives: Reducing the Lexicon-Syntax Parameter'. In: Martin Everaert, Marijana Marelj, and Eric Reuland (eds.): Concepts, Syntax and their Interfaces. Cambridge, Mass.: MIT Press, 175-252.

Martins, Ana Maria (2016): ‘A colocação dos pronomes clíticos em sincronia e diacronia’. In: Ana Maria Martins and Ernestina Carrilho (eds.): Manual de Linguística Portuguesa. Berlin: De Gruyter Mouton, 401-430.

Martins, Ana Maria (2013): 'Posição dos pronomes pessoais clíticos'. In: Eduardo Raposo, Maria Fernanda Bacelar do Nascimento, Maria Antónia Coelho da Mota, Luísa Segura, and Amália Mendes (eds.): Gramática do Português. Coimbra: Gráfica de Coimbra, 2231-2301.

Martins, Ana Maria (2009): 'Subject doubling in European Portuguese dialects: The role of impersonal se'. In: Enoch O. Aboh, Elisabeth van der Linden, Joseph Quer, and Petra Sleeman (eds.): Romance Languages and Linguistic Theory: Selected papers from 'Going Romance', Amsterdam 2007. Amsterdam: John Benjamins, 179-200.

Martins, Ana Maria (2004): 'Ambiguidade estrutural e mudança linguística: A emergência do infinitivo flexionado nas orações complemento de verbos causativos e perceptivos'. In: Ana Maria Brito, Olívia Figueiredo, and Clara Barros (eds.): Linguística Histórica e História da Língua Portuguesa: Actas do Encontro de Homenagem a Maria Helena Paiva. Porto: FLUP, 197-225. [http:// ler.letras.up.pt/uploads/ficheiros/6290.pdf, accessed on: 24 July 2020]. 
Martins, Ana Maria (2000): 'A Minimalist approach to clitic climbing’. In: João Costa (ed.): Portuguese Syntax: New Comparative Studies. Oxford: Oxford University Press, 169-190.

Martins, Ana Maria (1994): 'Enclisis, VP-deletion and the nature of Sigma'. Probus 6, 173-205.

Martins, Ana Maria (1992): 'Quantifiers and clitics in European Portuguese'. Faculdade de Letras da Universidade de Lisboa.

Martins, Ana Maria and Nunes Jairo (2016): 'Passives and se constructions'. In: W. Leo Wetzels, Sergio Menuzzi, and João Costa (eds.): Handbook of Portuguese Linguistics. Oxford: John Wiley \& Sons, 318-337.

Masullo, Pascual José (1992): ‘Antipassive constructions in Spanish'. In: Paul Hirschbühler and Konrad Koerner (eds.): Romance Languages and Modern Linguistic Theory: Selected Papers from the XX Linguistic Symposium on Romance Languages, University of Ottawa, 10-14 April 1990. Amsterdam: John Benjamins, 175-194.

Mateus, Maria Helena Mira, Ana Maria Brito, Inês Duarte, Isabel Hub Faria, Sónia Frota, Gabriela Matos, Fátima Oliveira, Marina Vigário, and Alina Villalva (2003): Gramática da Língua Portuguesa. Lisboa: Editorial Caminho.

Mellado, Alicia and Pavón, María Victoria (2002): 'Elementos anafóricos en complementos locativos: Restricciones semantico-sintacticas'. In: Alberto Bernabé, José Antonio Berenguer, Margarita Cantarero, and José Carlos Torres (eds.): Presente y Futuro de la Lingüística en España: La Sociedad de Lingüística, 30 años después. Madrid: Sociedad Española de Lingüística, 208-217.

Mendikoetxea, Amaya (1999): 'Construcciones inacusativas y pasivas'. In: Ignacio Bosque and Violeta Demonte (eds.): Gramática Descriptiva de la Lengua Española. Madrid: Real Academia Española/Espasa Calpe, 1574-1629.

Mensching, Guido (2018): 'Romance clitics as probes'. Lecture 'Form-Meaning Mismatches in Natural Language' at the summer school, 2 August 2018, University of Göttingen.

Mensching, Guido (2000): Infinitive Constructions with Specified Subjects: A Syntactic Analysis of the Romance Languages. Oxford and New York: Oxford University Press.

Mensching, Guido and Eva Remberger (2006): 'Probes: Lack of Agreement in Romance'. In: João Costa and Maria Cristina Figueiredo (eds.): Studies on Agreement. Amsterdam: John Benjamins, 173-201.

Mensching, Guido and Anja Weingart (2016): 'The Null Subject Parameter and the lexicon in Minimalist syntax'. In: Amaya Mendikoetxea and Luis Eguren (eds.): Rethinking Parameters. Oxford: Oxford University Press, 292-385. 
Menuzzi, Sergio (1999): Binding Theory and Pronominal Anaphor in Brazilian Portuguese. The Hague: Holland Academic Graphics.

Menuzzi, Sergio (1996): 'Constraint interaction in binding and the feature specification of anaphoric forms'. In: Crit Cremers and Marcel den Dikken (eds.): Linguistics in the Netherlands 1996. Amsterdam: John Benjamins, 183-194.

Montalbetti, Mario (1984): After binding. $\mathrm{PhD}$ dissertation. Massachusetts Institute of Technology. Dept. of Modern Languages and Linguistics. [https://dspace.mit.edu/bitstream/ handle/1721.1/15222/13150148-MIT.pdf, accessed on: 24 July 2020].

Morais, Maria Aparecida (2006): 'Argumentos dativos: Um cenário para o núcleo aplicativo no português europeu'. ABRALIN 5, 239-266.

Moreira, Benjamim (1997): 'Sobre as propriedades de mesmo'. In: Maria Antónia Mota and Rita Marquilhas (eds.): Actas do XIII Encontro Nacional da Associação Portuguesa de Linguística. Lisboa: APL / Colibri, 219-226.

Moro, Andrea (1997): The Raising of Predicates: Predicative Noun Phrases and the Theory of Clause Structure. Cambridge: Cambridge University Press.

Müller, Natascha and Beate Riemer (1998): Generative Syntax der romanischen Sprachen, Französisch, Italienisch, Portugiesisch, Spanisch. Tübingen: Stauffenburg.

Neeleman, Ad and Tanya Reinhart (1998): 'Scrambling and the PF interface'. In: Miriam Butt and Wilhelm Geuder (eds.): The Projection of Arguments. Stanford: CSLI Publications, 309-353.

NGLE = Real Academia Española (2009): Nueva gramática de la lengua española vol. 2: Sintaxis. Madrid: Espasa Libros.

Nicol, Janet and David Swinney (2008): 'The psycholinguistics of anaphora'. In: Andrew Barss (ed.): Anaphora: A Reference Guide.

Nunes, José Joaquim (1930): Compedio de Gramática Histórica Portuguesa. Lisboa: Livraria Clássica Editora.

Ormazabal, Javier and Juan Romero (2007): 'The object agreement constraint'. Natural Language and Linguistic Theory 25, 331-376.

Otero, Carlos Peregrin (1999): 'Pronombres reflexivos y reciprocos'. In: Ignacio Bosque and Violeta Demonte (eds.): Gramática descriptiva de la lengua española. Madrid: Real Academia Española/Espasa Calpe, 1427-1518.

Paiva, Dulce de Faria (1988): História da Língua Portuguesa. São Paulo: Atica. 
Partee, Barbara (2014): 'A brief history of the syntax-semantics interface in Western formal linguistics'. Semantics-Syntax Interface 1, 1-21.

Partee, Barbara (2008): 'Formal Semantics and Current Problems of Semantics, Lecture 6'. KampHeim I. Anaphora with Indefinite Antecedents; Donkey Anaphora.. Lecture notes, University of Massachusetts Amherst. [http://people.umass.edu/partee/720_09/materials/720_09_2Heim1.pdf, accessed on: 24 July 2020].

Patel-Grosz, Pritty and Patrick Grosz (2009): 'On the typology of donkeys: Two types of anaphora resolution'. In: Patrick Grosz, Martin Prinzhorn, and Sarah Zobel (eds.): Proceedings of Sinn und Bedeutung 14. Wien: Universität Wien, 339-355. [https://www.univie.ac.at/sub14/proc/patelgrosz.pdf, accessed on: 24 July 2020].

Penny, Ralph (2002): A History of the Spanish Language. Cambridge: Cambridge University Press.

Perlmutter, David (1971): Deep and surface structure constraints in syntax. New York: Rinehart \& Winston Inc.

Pesetsky, David and Esther Torrego (2004): 'The syntax of valuation and the interpretability of features'. In: Simin Karimi, Vida Samiian, and Wendy Wilkins (eds.): Phrasal and Clausal Architecture Syntactic Derivation and Interpretation. Amsterdam: John Benjamins, 262-294.

Pineda, Anna (2013): 'Romance double object constructions and transitivity alternations'. In: Enrico Boone, Martin Kohlberger, and Maartje Schulpen (eds.): Proceedings of ConSOLE XX. Leiden: Universitet Leiden, 185-211.

Pollard, Carl and Ivan Sag (1992): 'Anaphors in English and the scope of Binding Theory'. Linguistic Inquiry 23(5), 261-303.

Preminger, Omer (2018): 'The Anaphor Agreement Effect: Further evidence against anaphora-asagreement'. Paper presented at the LinG1 workshop 'Anaphora and Agreement', Georg-AugustUniversität Göttingen, 26 September 2018.

Radford, Andrew (2004): Minimalist Syntax. Cambridge: Cambridge University Press.

Raposo, Eduardo (2013a): 'Pronomes'. In: Eduardo Raposo, Maria Fernanda Bacelar do Nascimento, Maria Antónia Coelho da Mota, Luísa Segura, and Amália Mendes (eds.): Gramática do Português. Coimbra: Gráfica de Coimbra, 833-918.

Raposo, Eduardo (2013b): 'Orações copulativas e predicações secundárias’. In: Eduardo Raposo, Maria Fernanda Bacelar do Nascimento, Maria Antónia Coelho da Mota, Luísa Segura, and Amália Mendes (eds.): Gramática do Português. Coimbra: Gráfica de Coimbra, 1285-1359. 
Reimer, Marga and Eliot Michaelson (2017): 'Reference'. In: Edward Zalta (ed.): The Stanford Encyclopedia of Philosophy. [http://plato.stanford.edu/archives/spr2017/entries/reference/, accessed on: 24 July 2020].

Reinhart, Tanya (2016): 'The Theta System: Syntactic realization of verbal concepts'. In: Martin Everaert, Marijana Marelj, and Eric Reuland (eds.): Concepts, Syntax and Their Interface. Cambridge, Mass.: MIT Press, 1-112.

Reinhart, Tanya (2006): Interface Strategies. Cambridge, Mass.: MIT Press.

Reinhart, Tanya (2002): 'The Theta System: An overview'. Theoretical Linguistics 28(3), 391-434.

Reinhart, Tanya and Eric Reuland (1993): 'Reflexivity'. Linguistic Inquiry 24(4), 657-720.

Reinhart, Tanya and Eric Reuland (1991): 'Anaphors and logophors: An argument structure perspective'. In: Jan Koster and Eric Reuland (eds.): Long Distance Anaphora. Cambridge: Cambridge University Press, 283-321.

Reinhart, Tanya and Tal Siloni (2005): 'The Lexicon-Syntax Parameter: Reflexivization and other arity operations'. Linguistic Inquiry 36(4), 439-492.

Reinhart, Tanya and Tal Siloni (2004): 'Against the unaccusative analysis of reflexives'. In: Artemis Alexiadou, Elena Anagnostopoulou, and Martin Everaert (eds.): The Unaccusativity Puzzle. Oxford: Oxford University Press, 288-331.

Reuland, Eric (2011): Anaphora and Language Design. Cambridge, Mass.: MIT Press.

Reuland, Eric (2005): 'Binding conditions: How are they derived?'. In: Stephan Müller (ed.): Proceedings of the 12th International Conference on Head-Driven Phrase Structure Grammar. Standford: CSLI Publications, 578-593.

Reuland, Eric (2001): 'Primitives of binding'. Linguistic Inquiry 32(2), 439-492.

Rezac, Milan (2011): Phi-features and the Modular Architecture of Language. Dodrecht: Springer.

Rizzi, Luigi (2016): 'Labeling, maximality and the head: Phrase distinction'. The Linguistic Review 33(1), $103-127$.

Rizzi, Luigi (1990): ‘On the Anaphor-Agreement Effect'. Rivista di Linguistica 2, 27-42.

Roberts, Ian (2010): Agreement and Head Movement: Clitics, Incorporation and Defective Goals. Cambridge, Mass.: MIT Press.

Roberts, Craige (2003): 'Uniqueness in definite noun phrases'. Linguistics and Philosophy 26(3), 287350. 
Rooth, Mats (1992): ‘A theory of focus interpretation'. Natural Language Semantics 1, 75-116.

Rooth, Mats (1985): Association with Focus. PhD dissertation. Universitiy of Massachussets, Amherst Mass.

Ross, John Robert (1967): Constraints on variables in syntax. PhD dissertation. Massachusetts Institute of Technology. Dept. of Modern Languages and Linguistics. [https://dspace.mit.edu/bitstream/ handle/1721.1/15166/14704247-MIT.pdf, accessed on: 24 July 2020].

Rullmann, Hotze (2004): 'First and second person pronouns as bound variables'. Linguistic Inquiry 35, $159-168$.

Russel, Bertrand (1905): 'On denoting'. Mind 14(4), 479-493. [http://www.jstor.org/stable/2248381, accessed on: 24 July 2020].

Sag, Ivan (1980): Deletion and Logical Form. New York: Garland.

Sánchez, Liliana (2003): Quechua-Spanish Bilingualism: Interference and convergence in functional categories. Amsterdam: John Benjamins.

Sauerland, Uli (2013): 'Presuppositions and the alternative tier'. In: Todd Snider (ed.): Proceedings of the 23rd Semantics and Linguistic Theory Conference. 156-173. [https:// journals.linguisticsociety.org/proceedings/index.php/SALT/article/view/2673/2419, accessed on: 24 July 2020].

Sauerland, Uli (2008): 'On the semantic markedness of phi-features'. In: Daniel Harbour, David Adger, and Susana Béjar (eds.): Phi Theory: Phi-features across Modules and Interfaces. Oxford: Oxford University Press, 57-81.

Sauerland, Uli (2003): 'A new semantics for number'. In: Robert Young and Zhou Yuping (eds.): Proceedings of the 13th Semantics and Linguistic Theory Conference. Washington DC: LSA Publications, 258-275.

Sauerland, Uli and Arnim von Stechow (2001): 'The syntax-semantics interface'. In: Neil Smelser and Paul Baltes (eds.): International Encyclopedia of the Social and Behavioural Sciences. Oxford: Pergamon Press, 15412-15418.

Schäfer, Florian (2007): On the Nature of Anticausative Morphology: External Arguments in Changeof-State Contexts. PhD dissertation. Institut für Linguistik/Anglistik der Universität Stuttgart. [http://dx.doi.org/10.18419/opus-5245, accessed on: 24 July 2020].

Schäfer, Florian and Margot Vivanco (2015): 'Reflexively marked anticausatives are not semantically reflexive'. In: Enoch O. Aboh, Aafke Hulk, Jannette Schaeffer, and Petra Sleeman (eds.): 
Romance Languages and Linguistic Theory: Selected papers from 'Going Romance', Amsterdam 2013. Amsterdam: John Benjamins, 203-220.

Schlenker, Philippe (2003): ‘A plea for monsters’. Linguistics and Philosophy 26(1), 29-120.

Spathas, Giorgos (2009): 'Interpreting gender on bound pronouns'. In: Claire Halpert, Jeremy Hartman, and David Hill (eds.): Proceedings of the 2007 Workshop in Greek Syntax and Semantics at MIT. MIT Working Papers in Linguistics 57. Cambridge, Mass.: MIT Press, 275-290.

Speaks, Jeff (2017): 'Theories of meaning'. In: Edward Zalta (ed.): The Stanford Encyclopedia of Philosophy. [https://plato.stanford.edu/entries/meaning/, accessed on: 24 July 2020].

Speas, Margaret (2004): 'Evidentiality, logophoricity and the syntactic representation of pragmatic features '. Lingua 114, 255-276.

Sportiche, Dominique (2014): 'Assessing unaccusativity and reflexivity: Using focus alternatives to decide what gets which $\theta$-role'. Linguistic Inquiry 45(2), 305-321.

Sportiche, Dominique (1998): Partitions and Atoms of Clause Structure: Subjects, Agreement, Case, and Clitics. London: Routledge.

Sportiche, Dominique (1990): 'Movement, agreement, and case'. Manuscript, UCLA; also published in Sportiche (1998:83-236). [http://ling.auf.net/lingbuzz/000020/current.pdf? _s=mxaHGFosAna1ETxq, accessed on: 24 July 2020].

Stechow, Arnim von (2009): 'Syntax and semantics: An overview'. [http://www.sfs.uni-tuebingen.de/ astechow/Aufsaetze/SySemArt.pdf, accessed on: 24 July 2020].

Stechow, Arnim von (2003): 'Feature deletion under semantic binding'. In: Makoto Kadowaki and Shigeto Kawahara (eds.): Proceedings of North East Linguistic Society (NELS) 33. Amherst, Mass.: GLSA, University of Massachusetts/Amherst, 175-252. [http://www.sfs.unituebingen.de/ astechow/Aufsaetze/vonstech.pdf, accessed on: 24 July 2020].

Stechow, Arnim von (1991): 'Syntax und Semantik'. In: Arnim von Stechow and Dieter Wunderlich (eds.): Semantik/Semantics. Ein internationales Handbuch der zeitgenössischen Forschung. An International Handbook of Contemporary Research. Berlin, Boston: Mouton de Gruyter, 90-147.

Sudo, Yasutada (2012): On the Semantics of Phi Features on Pronouns. PhD dissertation. Massachussets Institute of Technology.

Suñer, Margarita (1988): 'The role of agreement in clitic-doubled constructions'. Natural Language and Linguistic Theory 6, 391-434. 
Torrego, Esther (1998): The Dependencies of Objects. Cambridge, Mass.: MIT Press.

Torrego, Esther (1996): 'Experiencers and raising verbs'. In: Robert Freidin (ed.): Studies in Natural Language and Linguistic Theory 35. Dodrecht: Kluwer, 101-120.

Torrego, Esther (1995): 'From argumental to non-argumental pronouns: Spanish doubled reflexives'. Probus 7, 221-241.

Treviño, Esthela (1992): 'Subjects in Spanish Causative Constructions'. In: Paul Hirschbühler and Ernst Koerner (eds.): Romance Languages and Modern Linguistic Theory: Selected Papers from the XX Linguistic Symposium on Romance Languages, University of Ottawa, 10-14 April 1990. Amsterdam: John Benjamins, 309-324.

Uriagereka, Juan (2012): Spell-Out and the Minimalist Program. Oxford and New York: Oxford University Press.

Uriagereka, Juan (1999): 'Commentary on: “The typology of structural deficiency”. In: Henk van Riemsdijk (ed.): Clitics in the Languages of Europe. Berlin, New York: Mouton de Gruyter, 267272.

Uriagereka, Juan (1995): 'Aspects of the syntax of clitic placement in Western Romance'. Linguistic Inquiry 26(1), 79-123.

Wechsler, Stephen (2011): 'Mixed agreement: The person feature and the index/concord distinction'. Natural Language and Linguistic Theory 29, 999-1033.

Wechsler, Stephen (2004): 'Number as person'. In: Olivier Bonami and Patricia Cabredo Hofherr (eds.): Empirical Issues in Syntax and Semantics 5: Selected Papers from the Colloque de Syntaxe et Sémantique à Paris, 2-5 October 2003. CNRS Paris, 255-274. [http://www.cssp.cnrs.fr/eiss5/, accessed on: 24 July 2020].

Wechsler, Stephen and Larisa Zlatić (2003): The many faces of agreement. Standford: CSLI Publications.

Zagona, Karen (2002): The Syntax of Spanish. Cambridge: Cambridge University Press.

Zribi-Hertz, Anne (1980): 'Coréférences et pronoms réfléchis: Notes sur le contrast lui/lui même’. Linguisticae Investigationes IV, 131-179.

Zubizarreta, María Luisa (1998): Prosody, Focus and Word Order. Cambridge, Mass.: MIT Press.

Zumpt, Karl Gottlieb (1845): A grammar of the Latin language. Translated form German by Leonard Schmitz (Lateinische Grammatik). London: Longman, Brown, Green, and Longmans. 
Zwart, Jan-Wouter (2002): 'Issues relating to a derivational theory of binding'. In: Samuel David Epstein and T. Daniel Seely (eds.): Derivation and Explanation in the Minimalist Program. Oxford: Blackwell, 903-946.

Zwart, Jan-Wouter (1997): Morphosyntax of Verb Movement: A Minimalist Approach to Dutch Syntax. Dordrecht: Kluwer.

Zwicky, Arnold (1977): On clitics. Bloomingtone: Indiana University Linguistic Club. [https:// web.stanford.edu/ Zwicky/on_clitics.pdf, accessed on: 24 July 2020]. 


\section{Appendix}

\section{Doubling the non-reflexive pronoun with a reflexive clitic in Spanish}

\section{A.1 Direct object pronouns}

\section{Type 1.1 : contrast established by repetition of the verb}

- Sin embargo, Miguel es un caso excepcional entre los niños superdotados. Más de la mitad de estos niños sufre en sus carnes la huella del fracaso escolar y falta de integración con sus compañeros. No se comprenden a ellos mismos, con lo que difícilmente puedan comprender a los demás.(CREA: ABC Electrónico, 14/07/1997.)

- Las terapias [...] Se persigue que el agresor tome conciencia que cuando degrada a su pareja se degrada a él mismo, y de que abandonar las conductas violentas es beneficioso para los dos. (CREA: Papeles del Psicólogo, no 88, 05-08/2004.)

- Hay que seguir haciéndolo para acabar enérgicamente con esos atletas que tratan de engañarnos a todos dopándose y que terminan engañándose a ellos mismos. (CREA: El Mundo, 03/10/1994.)

- Decía María Zambrano que hay escritores que han nacido para revelar algo, y para revelarse fundamentalmente a ellos mismos.(CREA: El Mundo, 25/05/1996.)

- Hay bebedores que sólo recurren al alcohol cuando tienen necesidad de establecer relaciones interpersonales, o cuando estas relaciones lo son con personas concretas del mismo o del otro sexo; pero hay también bebedores solitarios, los cuales no soportan la soledad o no se toleran a ellos mismos (inaceptan su self). (CREA: Castilla del Pino, C. 1980. 'Introducción a la psiquiatría')

\section{Type 1.2 : contrast established in the broader context}

- Allí aterriza Claudio con su consumismo y sus vacíos -"la madre adinerada que se dedicó a buscarse a ella misma, un padre que no sabe quién es"-. (CREA: El País, 09/12/2003.)

- [Skip] Arnold disfruta con las caras de sorpresa cuando enseña las fotos de algunas de sus representaciones: Freight en 1993, en la que se embaló a él mismo en una caja gigante y se mandó a una exhibición como objeto de arte; (CREA: La Vanguardia, 24/10/1994.)

- La televisión debería de criticarse a ella misma desde dentro. (CREA: Época, 10/02/1997.)

- Se justifica el posible perdón de los masones que se delaten a ellos mismos, en un plazo máximo de quince días, diciendo literalmente: [...]. (CREA: A Hispania Nova. Revista de Historia Contemporánea, n 3, 2003.)

- Ahora lo que hace falta -añadía- es que HB [coalición Herri Batasuna] se legalice a ella misma acudiendo al Parlamento vasco." (CREA: ABC, 03/06/1986.) 
Type 2: proxy or statue readings in the context of dreams and extraordinary psychological states

- De improviso, todo eran sombras a su alrededor. La pesadilla volvía. Se veía en lo alto, mirándose a él mismo, y muerto. (CREA: Tomás García, J. L. 1984. 'La otra orilla de la droga'.)

- Y siendo el animal una parte que cada cual debe dominar en sí, puede resultar para el niño amenazador y perseguidor. Pero, cuando el niño se sueña a él mismo como cazador, es para equilibrar conceptos como el de justicia. (CREA: Carranza, A. 2003. 'Comprender los sueños de los niños'.)

- Aquella tarde ambos se comportaron como dos jóvenes torpes y presuntuosos; cada uno soñó que se perdía y, mientras, qué sé yo si procuraba desenganchar un pie bajo la sábana o que el gemido tuviera un deje animal compatible, no obstante, con la ternura. Soñaron que se perdían, se contaron a ellos mismos que se perdían. (CREA: Gopegui, B. 2001. 'Lo real'.)

- José Gracia sólo conseguía pronunciar el nombre de Francia pero eso según el viejo ya era importante.- No le dé reparo. Se oía a él mismo y a su grito le faltaba continuidad, no lo reconocía, le parecía que se unía a otros gritos, oyó a Sisamón: déjese ir, eso le hará bien, con toda confianza, no quiera conformarse que no le va a servir, no pretenda ser más hombre, ¡nada de silencio!, ¡nada de silencio!, diga lo que piensa del Adjunto del Habilitado y de mí mismo, pues bien eso y mucho más, [...]. (CREA: García-Badell, G. 1975. 'Funeral por Francia'.)

- El psicólogo Allport mantiene una gran verdad, comprobada en su experiencia: que "el neurótico que aprende a reírse de sí mismo puede estar en el comienzo de gobernarse a él mismo, y tal vez de curarse". (CREA: Miret Magdalena, E. 2002. ¿¿Qué nos falta para ser felices? Un nuevo modo de pensar y de vivir'.)

\section{A.2 Indirect object pronouns}

\section{Type 1.1 : contrast established by repetition of the verb}

- Sólo con Gauss y con Cauchy, las definiciones de "sucesión", "convergencia" y "límite" adquirieron un carácter verdaderamente riguroso, no porque ellos fuesen capaces de hacerlas más intuitivas o de contarlas con más gracia y con más vivacidad, sino porque sólo ellos fueron capaces de explicárselas a ellos mismos y hasta de explicárnoslas a nosotros (incluso a nosotros los tontos) con la suficiente claridad formal. (CREA: Cuaderno de Materiales, no 18, 12/2002.)

- Son ellos los que primero ponen a Zülle en sus apuestas. Después se ponen a ellos mismos, pero en un plano de igualdad. "Espero que nos dé ventaja el haber corrido la Vuelta", dice Mauri. (CREA: El País, 09/10/1997.)

- En una ocasión me confesó que tenía el vicio, aunque bien ves que era una virtud, porque a él de niño nunca le habían regalado nada. Ni un simple caramelo. "Entonces deduje que 
posiblemente lo que le ocurría al Burguete era que veía en el niño al que obsequiaba su propia niñez, la de Burguete, huérfana de los pequeños detalles propios de la ternura. Es decir, que se regalaba a él mismo los dichosos caramelos. (CREA: Zaragoza, C. 1981. 'Y Dios en la última playa'.)

\section{Type 1.2 : contrast established in the broader context}

- Soy yo dice Jeanne pero se lo ha dicho más a ella misma que a ese silencio opuesto en el que bailan, como en un telón de fondo, algunas chispas de sonido. (CREA: Espéculo. Revista de estudios literarios, 06/2003.)

- De cualquier manera, eso no fue lo único que sucedió en la gira de Levante de 1981 y el lector ávido de sensaciones morbosas puede empezar ya a salivar porque entramos a partir de aquí en las primeras olas del torbellino rock que nos arrastro en dos de sus más clásicas vertientes: violencia y sexo. Claro que, tratándose de nuestro caso, la arquitectura de ambos términos es parecida a la historia militar de los españoles en los últimos cuatro siglos, que para salir vencedores de alguna guerra no les quedó más remedio que declarársela a ellos mismos. (CREA: Méndez, S. 2000. 'Corre, rocker. Crónica personal de los ochenta'.)

- La relación de Conde con las sociedades suizas Kaneko Holding, Asni Investment y Jamuna son más que evidentes para los peritos del Banco de España. Tan evidentes, que han afirmado en su informe entregado al juez Manuel García-Castellón, que Mario Conde es el propietario real de esas sociedades, que utilizó para transferirse fondos a él mismo desde el exterior. (CREA: El Mundo, 07/02/1996.)

Type 2: proxy or statue readings in the context of dreams and extraordinary psychological states

- ¿Serás capaz? murmuró Estefanía como si se lo preguntara a ella misma, sintiendo en el vientre el tósigo de una defraudación inconsolable. (CREA: Caballero Bonald, J. M. 1981. 'Toda la noche oyeron pasar pájaros'.) 



\section{Bestätigung}

Hiermit bestätige ich, dass die digitale Version der Dissertation mit dem Titel:

Anaphoric Dependencies in Spanish and European Portuguese: A Minimalist Analysis mit der Papierform übereinstimmt.

Göttingen, den

Unterschrift: 


\section{Erklärung}

Hiermit erkläre ich, dass die schriftliche wissenschaftliche Abhandlung (Dissertation) selbstständig verfasst und keine anderen als die angegebenen Quellen und Hilfsmittel benutzt wurden und dass anderweitig keine entsprechende Promotion beantragt wurde und hierbei die eingereichte Dissertation oder Teile daraus vorgelegt worden sind.

Göttingen, den

Unterschrift: 